\title{
Industria farmacéutica, derecho a la salud y propiedad intelectual: el reto del equilibrio
}

\section{Manuel BECERRA RAMÍREZ Roberto MARTÍNEZ OLIVERA}

Coordinadores

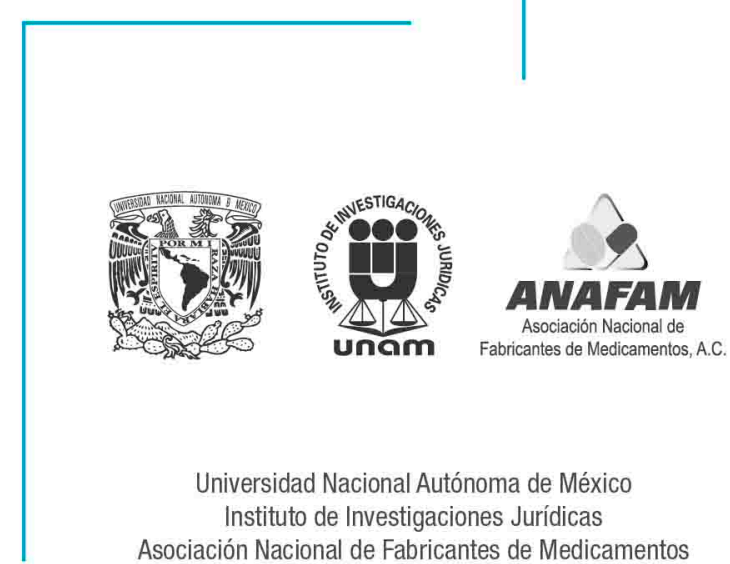


INDUSTRIA FARMAGÉUTICA, DEREGHO A LA SALUD Y PROPIEDAD INTELEGTUAL: EL RETO DEL EQUILIBRIO 


\title{
INSTITUTO DE INVESTIGACIONES JURÍDICAS \\ Serie DOGTRINA JuRÍDICA, núm. 823
}

\section{GOORDINACIÓN EDITORIAL}

\author{
Lic. Raúl Márquez Romero \\ Secretario Técnico
}

Lic. Wendy Vanesa Rocha Cacho

Jefa del Departamento de Publicaciones

Wendy Vanesa Rocha Cacho

Cuidado de la edición

José Antonio Bautista Sánchez

Formación en computadora

Carlos Martín Aguilera Ortiz

Elaboración de portada 


\title{
INDUSTRIA FARMACÉUTICA, DEREGHO A LA SALUD Y PROPIEDAD INTELEGTUAL: EL RETO DEL EQUILIBRIO
}

\author{
MANUEL BEGERRA RAMÍREZ \\ ROBERTO MARTÍNEZ OLIVERA \\ Coordinadores
}
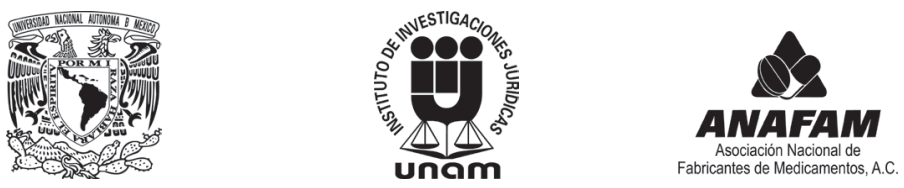

UNIVERSIDAD NACIONAL AUTÓNOMA DE MÉXICO INSTITUTO DE INVESTIGACIONES JURÍDICAS ASOCIACIÓN NACIONAL DE FABRICANTES DE MEDICAMENTOS 
Primera edición: 28 de febrero de 2018

DR (C) 2018. Universidad Nacional Autónoma de México INSTITUTO DE INVESTIGACIONES JURÍDICAS

Circuito Maestro Mario de la Cueva s/n Ciudad de la Investigación en Humanidades

Ciudad Universitaria, 04510 Ciudad de México

$$
\text { Impreso y hecho en México }
$$

ISBN electrónico: 978-607-30-0267-7 


\section{CONTENIDO}

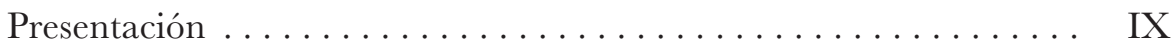

Pedro Salazar Ugarte

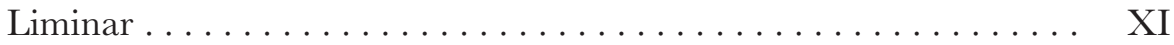

Dagoberto CORTÉs CERvanteS

Introducción $\ldots \ldots \ldots \ldots \ldots \ldots \ldots \ldots \ldots \ldots \ldots \ldots \ldots \ldots \ldots \ldots \ldots$

Manuel BECERRA RAMÍREZ

Roberto MARTÍNEZ OLIVERA

Pautas de patentabilidad y acceso a medicamentos . . . . . . . . 1 Germán VeLÁsQUEZ

La vinculación entre patentes y registros sanitarios en México . . . . 41 Gustavo Alcaraz H.

El proyecto de directiva europea relativa a la protección del saber hacer y los secretos comerciales. Avances y retrocesos . . . . . . . 69 Jorge KORS

La información genética humana ante el derecho . . . . . . . . .

Salvador Darío BERGEL

La excepción de fabricación para la exportación . . . . . . . . . . . 119

Xavier SEUBA

Luis Mariano GeNOVESI

Pedro RofFE

Preguntas relativas a la Asociación Transatlántica de Comercio e Inversión y el acceso a medicamentos . . . . . . . . . . . . . 167 Holger P. Hestermeyer 
La ampliación del concepto de invención, y de la materia patentable. Los segundos usos, los métodos de diagnóstico, terapéuticos y qui-

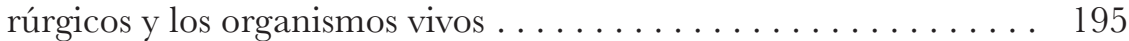
Rafael J. PÉREZ MirANDA

Naturaleza de la difusión del conocimiento tecnológico en el sector biofarmacéutico de Brasil y México. Un análisis de cita de patentes . Alenka GuZMÁN GHÁvez Edgar ACATITLA ROMERO Karina MaLdONADO Garbajal

The Generics Pathway in the USA: The American Experience, a Model for the World? . . . . . . . . . . . . . . . . . . . . . . . . . 253 Frederick M. АввотT

Algunas reflexiones sobre judicialización y acceso a medicamentos: el caso de Brasil y México. . . . . . . . . . . . . . . . . . . . . . 269 José Luis CÁRdenAS T.

El Acuerdo de Asociación TransPacífico (TPP) a la luz de la Convención de Viena sobre el Derecho de los Tratados . . . . . . . . . . . 299 Manuel BECERRA RAMÍREZ

El uso estratégico de las patentes secundarias y otros instrumentos en el sector farmacéutico: la experiencia mexicana . . . . . . . . . 319 Hedwig LINDNER LÓPEZ Manuel MORANTE SORIA 


\section{PRESENTACIÓN}

Uno de los temas más importantes no sólo para la academia sino para las políticas públicas de los Estados es indudablemente el acceso de la población a la salud. Con el cambio de paradigma, en la década de los años noventa, en la protección de la propiedad intelectual que incluye a las patentes farmacéuticas, los Estados, como México, sufrieron un fuerte impacto en varias áreas de su economía. En principio, en el precio de los farmacéuticos y, por supuesto, en el acceso a la salud; después en lo que toca a la industria nacional de farmacéuticos, que tiene que ver también con el tema anterior de acceso a los medicamentos y con el desarrollo de una soberanía de la salud del Estado mexicano.

Por otra parte, es evidente la tendencia en los tratados internacionales en materia de libre comercio que se siguen celebrando, a aumentar la protección de las invenciones farmacéuticas vía el reforzamiento de la normatividad en materia de propiedad intelectual. Con lo cual convergen tres temas fundamentales: industria farmacéutica, derecho a la salud y propiedad intelectual, que se colocan en el centro de la preocupación del Estado contemporáneo.

El Instituto de Investigaciones Jurídicas (IIJ) de la UNAM, atento desde la perspectiva académica a estos temas desde hace ya varios años, ha creado una línea de investigación sobre propiedad intelectual e industria farmacéuticos, como lo atestigua el libro Propiedad intelectual y farmacéutica. Hacia una política de Estado, publicado por este mismo IIJ en coedición con la Asociación Nacional de Medicamentos, A. G. (ANAFAM).

En esta ocasión presentamos un libro que es producto de la reflexión de varios expertos, de gran prestigio, en propiedad intelectual de nuestro continente. También, hay que subrayarlo, significa un ejercicio de vinculación entre academia e industria, en este caso con la industria nacional de fabricantes de medicamentos agrupados en ANAFAM.

Pedro Salazar UgarTe Director del Instituto de Investigaciones furídicas de la UNAM 


\section{LIMINAR}

Equilibrio es la palabra clave del título de este libro que hoy tiene usted en sus manos. Resolver el reto del equilibrio es resolver el acceso a medicamentos eficaces, seguros y de calidad, pero también asequibles.

La relación entre la propiedad intelectual y el derecho a la salud ha generado diversas opiniones y posiciones en los últimos años. La globalización de las patentes farmacéuticas y su impacto en la salud, y el derecho a ésta, repercute directamente en todos los seres humanos.

Recordemos, siempre, que la salud es un derecho humano fundamental. La Organización Mundial de la Salud afirma que "el goce del grado máximo de salud que se pueda lograr es uno de los derechos fundamentales de todo ser humano".

En la Asociación Nacional de Fabricantes de Medicamentos tenemos claridad en cuanto a las responsabilidades que el industrial farmacéutico tiene con el fortalecimiento del derecho a la salud de la población, responsabilidades que asumimos plenamente pero que sabemos compartimos con otras instituciones.

Para fortuna nuestra, hemos celebrado y refrendado un convenio de colaboración con el Instituto de Investigaciones Jurídicas de la Universidad Nacional Autónoma de México. Nos honra este convenio porque nos permite lograr esa vinculación tan necesaria entre academia e industria y en el debate de las ideas con la institución más importante del ramo en México.

Como fruto del convenio referido se han llevado a cabo diversos foros y seminarios, así como la publicación de un libro previo titulado Propiedad intelectual y farmacéutica. Hacia una política de Estado.

Ahora, la Asociación Nacional de Fabricantes de Medicamentos se congratula en publicar, de manera conjunta con el Instituto, los trabajos de reconocidos expertos de talla internacional en la materia a través de este nuevo libro intitulado Industria farmacéutica, derecho a la salud y propiedad intelectual: el reto del equilibrio.

Tengo la seguridad, amigo lector, de que este esfuerzo de la industria y la academia le serán de gran utilidad. 


\section{INTRODUGGIÓN}

Si hay una materia jurídica que está sujeta a una intensa trasformación es indudablemente la de la propiedad intelectual (PI). Y no puede ser de otra manera, si vemos que está ligada a un área tan dinámica como la revolución industrial en curso y, sobre todo, a la industria farmacéutica de gran trascendencia social. De tal manera que siempre es útil y necesaria la doctrina sobre la materia.

Después de 1994, cuando despega la nueva generación de derechos de la PI, con TRIPs a la cabeza, ha habido muchas transformaciones en los tratados de libre comercio y sus respectivas regulaciones en materia de PI, y los cambios se mantienen en las negociaciones de los nuevos tratados comerciales, como por ejemplo en el Acuerdo de Asociación Trans-Pacífico (TPP por sus siglas en inglés: Trans-Pacific Partnership). Si bien sabemos que con la llegada de Donald Trump a la Presidencia, Estados Unidos se retira del TPP, con lo cual frustra su entrada en vigor por disposiciones del mismo tratado, es útil todavía su análisis, pues hay evidencias de que lo que se negoció servirá para las negociaciones de otros tratados internacionales, o bien como modelo para el derecho interno. Su análisis es útil, además, porque las disposiciones en materia de propiedad intelectual del TPP responden a una lógica de los países desarrollados de avanzar en la mayor protección a la propiedad intelectual.

El libro Industria farmacéutica, derecho a la salud y propiedad intelectual: el reto del equilibrio es de gran importancia para la doctrina sobre la materia de PI por dos razones concretas: por los autores, que son sólidos exponentes de la doctrina en nuestro continente, y por los temas que se tocan: el acceso de los ciudadanos a los medicamentos, es decir, el derecho al monopolio de la invención y su relación entre el derecho humano a la salud; la juridificación de los derechos de la PI, sobre todo los relativos a los farmacéuticos; sus aspectos críticos; la difusión del conocimiento tecnológico contenido en la patentes farmacéuticas, entre otros temas de gran repercusión teórica y práctica.

Así, vemos que es sumamente importante el análisis teórico de la figura jurídica denominada linkage para conocer sus limitaciones; sobre todo 
Esta obra forma parte del acervo de la Biblioteca Jurídica Virtual del Instituto de Investigaciones Jurídicas de la UNAM

porque es una figura de carácter administrativo que se ha atado en forma inusitada a las patentes farmacéuticas, y lo que parece adecuado para proteger la salud de los consumidores de productos farmacéuticos, por el otro lado parece un aumento de la protección a los titulares de la patente y un obstáculo para esos mismos consumidores para acceder a los medicamentos en virtud de su elevado precio. Este tema está ligado íntimamente con otro, presente en varios trabajos, que es la relación de patentes farmacéuticas y los derechos humanos; en forma concreta, el derecho de acceso a la salud. Tema que si bien puede ser recurrente en los últimos años en la literatura de la PI, su importancia y trascendencia hacen necesario su enfoque desde diferentes autores y perspectivas.

Por otra parte, con base en la premisa de que los centros industriales del mundo, como Estados Unidos, Japón y la Unión Europea, a través de sus resoluciones, son el punto de referencia en la interpretación de la normatividad en materia de PI, es válido indagar sobre la Directiva europea relativa a la protección del saber hacer y los secretos comerciales, porque su interpretación es un punto de partida para dimensionar lo mismo en nuestro continente.

Asimismo, en la dinámica de la revolución tecnológica en materia de biotecnología, la obtención de datos genéticos hay que analizarla detenidamente, pues al mismo tiempo que presenta indudables beneficios científicos, también una serie de peligros que la doctrina debe indagar y discutir. A propósito de conocimientos científicos, hay un fenómeno bastante interesante y que puede preocupar porque el conocimiento tecnológico (que está protegido precisamente por el derecho de la PI) está siendo cada vez más invasivo del conocimiento científico (que, como sabemos, está libre en el mercado), de tal manera que los límites entre conocimiento científico y conocimiento tecnológico están atenuándose gradualmente. Lo cual no es una mera constatación teórica, sino un preocupación práctica, pues significa una apropiación del conocimiento científico que al final de cuentas encarece los medicamentos y distorsiona el concepto original del derecho de la PI: no protección por la PI del conocimiento científico, ya que éste tiene su propia vía de protección y su lógica de creación.

Además, refiriéndose a ADPIC, podemos ver que los Estados, sobre todo tratándose de patentes farmacéuticas, tienen un catálogo de excepciones a los derechos conferidos en las patentes. La tesis que encontramos en este libro es que ese catálogo sólo tiene como límite la regla de los tres pasos. ${ }^{1}$ Por

1 La regla de los tres pasos está expresada de la siguiente manera: a) deben ser limitadas, b) no deben atentar de manera injustificada contra la explotación normal de la patente, 
Esta obra forma parte del acervo de la Biblioteca Jurídica Virtual del Instituto de Investigaciones Jurídicas de la UNAM

supuesto que el análisis de este tema es de gran importancia no sólo teórica sino práctica, pues los Estados pueden legislar con estos criterios.

Por otra parte, uno de los grandes retos en materia de desarrollo tecnológico es que nuestros países se provean de estrategias de difusión del conocimiento tecnológico y no simplemente se limiten a administrarlo, sin crear estrategias de difusión y de diseminación, elementos claves en el desarrollo tecnológico.

Otro de los grandes problemas, que ya estábamos previendo en otro momento, ${ }^{2}$ es la judicialización de la PI. En efecto, siguiendo el modelo estadounidense, el llevar la problemática o litigios sobre las patentes farmacéuticas a los tribunales podría significar un obstáculo para el acceso a las medicinas. En efecto, el litigio puede ser genuino como una necesidad de aplicar la normatividad en caso de controversia, o puede ser visto también como una estrategia de las grandes empresas para retardar u obstaculizar el acceso a nuevos medicamentos, pues el litigio es costoso y duradero, el cual pueden afrontar las empresas con suficiente capital, pero no algunas empresas farmacéuticas de los países subdesarrollados.

Por último, queremos dejar constancia y nuestro agradecimiento a la estudiante Yazareth A. Sánchez por su invaluable apoyo.

Manuel BEGERRA RAMÍREZ Roberto MARTíNEZ OLIVERA Ciudad de México, diciembre de 2017

y c) ni causar un perjuicio injustificado a los legítimos intereses del titular de la patente, teniendo en cuenta los intereses legítimos de terceros.

2 Véase Becerra Ramírez, Manuel, La propiedad intelectual en transformación, México, Porrúa-UNAM, 2009. 
Esta obra forma parte del acervo de la Biblioteca Jurídica Virtual del Instituto de Investigaciones Jurídicas de la UNAM

\title{
PAUTAS DE PATENTABILIDAD Y ACGESO A MEDICAMENTOS
}

\section{Germán VELÁSQUEZ*}

\begin{abstract}
Sumario: I. Introducción. II. Propiedad intelectual, Organización Mundial de la Salud y medicamentos. III. El sistema de patentes aplicado a los medicamentos. IV. Pautas para el examen de patentes farmacéuticas: una perspectiva desde la salud pública. V. Compatibilidad con el Acuerdo ADPIC de la OMC. VI. Conclusiones. VII. Anexo.
\end{abstract}

\section{INTRODUCGIÓN}

Hasta hace muy pocos años la relación entre el examen de patentes realizado por las oficinas nacionales de patentes y el derecho de los ciudadanos al acceso a los medicamentos no era nada evidente. Dos funciones o responsabilidades del Estado que aparentemente no tenían nada que ver la una con la otra. Examinando la literatura creciente sobre propiedad intelectual y acceso a medicamentos, pareciera que el análisis de un actor se ha escapado: las oficinas de patentes. Y la razón es evidente: las oficinas de patentes son instituciones administrativas. Los estándares de patentamiento no son definidos por las oficinas de patentes, sino con frecuencia por las cortes, los tribunales, las leyes o los negociadores de tratados. ${ }^{1}$ Hoy en día hay mayor entendimiento de que el examen de patentes y el papel de los examinadores de patentes son un elemento clave que puede contribuir o entrabar el acceso a los medicamentos. Debido al impacto de las patentes farmacéuticas en el acceso a los medicamentos, las oficinas de patentes deberán formular políticas públicas y estrategias que respondan a las políticas nacionales de salud y de medicamentos.

* Consejero especial para salud y desarrollo en el Centro Sur, Ginebra, Suiza.

1 Drahos, Peter, Trust Me: Patent Offices in Developing Countries, Centre for Governance of Knowledge and Development, documento de trabajo, noviembre de 2007. 
Esta obra forma parte del acervo de la Biblioteca Jurídica Virtual del Instituto de Investigaciones Jurídicas de la UNAM

En 1994, la creación de la Organización Mundial del Comercio (OMG) supuso el establecimiento de un nuevo tratado, el más amplio sobre derechos de propiedad intelectual: el Acuerdo sobre los Aspectos de los Derechos de Propiedad Intelectual Relacionados con el Comercio (ADPIC). Este Acuerdo relaciona por primera vez cuestiones de propiedad intelectual y comercio, y proporciona un mecanismo multilateral para la solución de diferencias entre los Estados. El Acuerdo sobre los ADPIC exige que todos los Estados miembros de la OMC incorporen en sus legislaciones normas universales mínimas para casi todos los derechos en este campo: los derechos de autor, las patentes y las marcas. ${ }^{2}$ Además, el Acuerdo ha limitado considerablemente la libertad que hasta entonces tenían los países para elaborar y aplicar sus propios sistemas de propiedad intelectual. ${ }^{3}$ Tal obligación no existía en el marco de los anteriores convenios internacionales. En el pasado, se consideraba que cada nación tenía el derecho de legislar a ese respecto. Los convenios internacionales anteriores al Acuerdo sobre los ADPIC no especificaban normas mínimas relativas a derechos de propiedad intelectual. Antes del Acuerdo sobre los ADPIC, el número de países que no proporcionaba protección mediante patente para productos farmacéuticos ascendía a más de 50; muchos otorgaban protección mediante patente a los procesos, pero no a los productos, y en numerosos países la duración era muy inferior a 20 años. ${ }^{4}$

Una patente es un "título expedido por las autoridades públicas que confiere el monopolio temporal de explotación de una invención a aquel que la revele, suministre una descripción suficientemente clara y completa de ella y reclame ese monopolio". ${ }^{5}$ Los monopolios conllevan generalmente altos precios que, en muchos casos, restringen el acceso. El esquema: patente-monopolio-alto precio-acceso restringido no presenta ningún problema cuando se trata de patentar una simple mercancía: un perfume, un aparato de música. El problema se plantea cuando se otorgan monopolios a bienes públicos o productos esenciales para prevenir la enfermedad, recuperar la salud o evitar la muerte.

2 Velásquez, Germán y Boulet, Pascale, "Essential Drugs in the New International Economic Environment”, Boletín de la OMS, Ginebra, vol. 77, núm. 3, 1999.

3 Correa, C., "Health and Intellectual Property Rights", Boletín de la OMS, vol. 79, núm. 5, 2001.

4 Correa, C., Pautas para el examen de patentes farmacéuticas, WHO-ICTSD-UNTAD, marzo, 2008.

5 Velásquez, G. y Boulet, P., Globalización y acceso a los medicamentos: perspectivas sobre el acuerdo ADPIC/OMC, 2a. ed., Ginebra, WHO-DAP-98.9, 1999. 
Esta obra forma parte del acervo de la Biblioteca Jurídica Virtual del Instituto de Investigaciones Jurídicas de la UNAM

En virtud del Acuerdo sobre los ADPIC, los criterios de patentabilidad utilizados por las oficinas nacionales de propiedad intelectual exigen que un producto o proceso de fabricación reúna las condiciones necesarias para recibir protección mediante patente, a saber: novedad, espíritu inventivo y aplicación industrial (utilidad). Estos tres elementos, sin embargo, no están definidos en el Acuerdo sobre los ADPIC y los países miembros de la OMC poseen libertad para definir estos tres elementos de una manera coherente con los objetivos de salud pública definidos por cada país.

Según el informe del Alto Comisario de Naciones Unidas para la Salud:

[Los] requisitos del Acuerdo sobre los ADPIC para otorgar patentes - novedad, espíritu inventivo y aplicación industrial - están abiertos a la interpretación en la legislación nacional y cada país puede decidir de acuerdo a sus condiciones locales. En consecuencia, el Alto Comisario recomienda que se interpreten estos requisitos de manera que no se pierda de vista el interés público y la amplia diseminación del conocimiento... ${ }^{6}$

El mundo nunca había tenido a su disposición un arsenal tan amplio de tratamientos para luchar contra las enfermedades que afligen a la humanidad. Al mismo tiempo, muchísimas personas mueren por falta de ciertos medicamentos y/o vacunas. Esto se refiere a las enfermedades como el SIDA, la malaria, la tuberculosis, el cáncer, la diabetes, la hepatitis $\mathrm{C}$, la meningitis bacteriana y la neumonía, entre muchas otras.

Las crecientes preocupaciones acerca de la manera en que los acuerdos comerciales internacionales, y particularmente el Acuerdo sobre los ADPIC, pudieran limitar el acceso a los medicamentos dieron lugar a la adopción de la Declaración Ministerial de Doha relativa al Acuerdo sobre los ADPIC y la Salud Pública (2001). La Declaración de Doha marcó un hito importante en las discusiones sobre derechos de propiedad intelectual y acceso a los medicamentos, al afirmar que el Acuerdo sobre los ADPIC deberá ser interpretado y aplicado de una manera que apoye el derecho de los miembros de la OMC de proteger la salud pública y, en particular, de promover el acceso a los medicamentos para todos. A ese respecto, la Declaración de Doha consagra los principios que la OMS defendió y promovió desde finales de los años noventa, a saber: la reafirmación del derecho de los miembros de la OMC de aplicar plenamente las disposiciones de salvaguardia previstas en el Acuerdo sobre los ADPIC con el fin de proteger la salud pública y promover el acceso a los medicamentos.

6 The Impact of the Agreement on Trade-Related Aspects of Intellectual Property Rights on Human Rights. Report of the High Commissioner, E/CN.4/Sub.2/2001/13, 27 de junio de 2001, para. 62. 
Esta obra forma parte del acervo de la Biblioteca Jurídica Virtual del Instituto de Investigaciones Jurídicas de la UNAM

En general, se cree que las patentes se conceden normalmente para proteger nuevos medicamentos, pero el número de patentes que se obtienen anualmente para proteger productos farmacéuticos realmente nuevos es muy pequeño y va en descenso. Cada año se otorgan miles de patentes de productos farmacéuticos, aunque sólo unos pocos son nuevas entidades moleculares (NME).

En un conocido y citado artículo de 2002, P. Trouiller y otros encontraron que de todos los productos farmacéuticos que fueron desarrollados en el mundo entre 1975 y 1999, sólo 1.1\% correspondía a enfermedades olvidadas, que más vale llamar ignoradas. El mismo estudio fue repetido recientemente $^{7}$ y los resultados no son significativamente mejores. De los 850 productos puestos en el mercado en el mundo entre 2000 y 2011 , sólo el $4 \%$ (37 exactamente) corresponde a las enfermedades ignoradas, que existen principalmente en los países en desarrollo, tales como el paludismo, la tuberculosis, la enfermedad del sueño, la leishmaniosis o las enfermedades diarreicas.

El carácter acumulativo de las innovaciones, debido a las bajas exigencias en materia de patentabilidad y a las deficiencias en los procedimientos de concesión de patentes, tiene sobre el sistema de patentes importantes repercusiones que limitan la difusión de las innovaciones que el sistema procura promover, y dificultan el acceso a medicamentos vitales. "Por lo general, las patentes basadas en principios científicos amplios son malas porque, en palabras de la Suprema Corte de los Estados Unidos, pueden conferir poder para obstruir completamente ciertas áreas de desarrollo científico, y no proporcionar a cambio ningún beneficio para el público". ${ }^{8}$

Todo lo anterior llevó a la OMS, en colaboración con la UNCTAD, el PNUD y el ICTSD, a elaborar en 2007 unas pautas para el examen de patentes farmacéuticas desde una perspectiva de salud pública.

Estas pautas o directrices fueron concebidas como una contribución para mejorar la transparencia y la eficacia del sistema de patentes en lo que respecta a productos farmacéuticos, para que los países pudieran prestar mayor atención a los procedimientos de examen y concesión de patentes, a fin de evitar los efectos negativos de las patentes de desarrollos no inventivos sobre el acceso a los medicamentos. ${ }^{9}$

El ejercicio de elaboración de pautas para el examen de patentes buscaba la manera de gestionar el sistema de patentes de productos farmacéuticos

7 Pedrique, Belen et al., The Drug and Vaccine Landscape for Neglected Diseases (2000-11): a Systematic Assessment, Lancet, 24 de octubre de 2013.

8 Barton, John H., Boletín de la OMS, vol. 82, núm. 10, octubre de 2004.

9 Correa, C., Pautas..., cit. 
y, más específicamente, el "sistema de patentes reforzado" dimanante del Acuerdo sobre los ADPIC y los actuales acuerdos de comercio y de inversiones regionales y bilaterales. Las patentes representan un contrato social entre el titular de la patente y la sociedad; por este motivo es preciso buscar, identificar y aplicar mecanismos destinados a mejorar el funcionamiento y la transparencia del sistema de patentes en interés de la salud pública.

A fin de elaborar un marco jurídico y normativo para otorgar a los productos farmacéuticos una protección mediante patente que asegure el equilibrio entre los intereses de los productores y los usuarios de conocimientos tecnológicos (conforme al artículo 7o. del Acuerdo sobre los AD$\mathrm{PIC}$ ), algunas cuestiones se deberán examinar y analizar detenidamente en el ámbito nacional, con miras a asegurar el acceso a los medicamentos. En ese contexto, las pautas para el examen de patentes son una contribución para abordar ese importante desafío.

Tres preguntas claves que este documento podría plantearse: 1) cómo llega el tema de la propiedad intelectual a la salud pública y cuáles son las implicaciones, particularmente en lo que se refiere al acceso a medicamentos; 2) cuál es el margen de maniobra o flexibilidad que permiten las nuevas reglas internacionales de comercio y, en particular, el Acuerdo sobre los ADPIC, y 3) punto central de esta reflexión, cuál es el papel y sobretodo la contribución que las oficinas nacionales de patentes pueden aportar para mejorar el acceso a los medicamentos, a través de las pautas para el examen de patentes.

\section{Propiedad INTEleGtual, Organización MUNDIAL DE LA SALUD Y MEDICAMENTOS}

\section{El mandato de la Organización Mundial de la Salud}

El tema de la propiedad intelectual aparece por primera vez en la Organización Mundial de la Salud (OMS) en 1996 y coincide prácticamente con el final de la Ronda de Uruguay y la creación de la Organización Mundial del Comercio. En 1995, la Universidad Carlos III de Madrid, con el Programa de Medicamentos Esenciales de la OMS, organiza una conferencia donde el profesor Carlos Correa ${ }^{10}$ presenta un trabajo intitulado "La Ronda

10 Negociador del Acuerdo de los ADPIC durante la Ronda de Uruguay, en calidad de secretario de Industria del gobierno de Argentina. 
Esta obra forma parte del acervo de la Biblioteca Jurídica Virtual del Instituto de Investigaciones Jurídicas de la UNAM

de Uruguay y los medicamentos". ${ }^{11} \mathrm{El}$ artículo, de unas 40 páginas, analiza las posibles implicaciones del Acuerdo sobre los ADPIC en el acceso a los medicamentos y da a conocer el "margen de maniobra" que tiene el Acuerdo para proteger la salud pública. Dicho artículo es el primer documento que específicamente alerta al sector salud sobre las posibles implicaciones del Acuerdo de los ADPIC en la salud pública y, más concretamente, en el acceso a medicamentos.

Ya durante las negociaciones de la Ronda de Uruguay (1986-1994) algunos negociadores de los países en desarrollo preveían que el Acuerdo de los ADPIC tendría implicaciones importantes en el campo farmacéutico y en el campo de la salud. Poco después de su adopción la UNGTAD publicó un estudio sobre el Acuerdo de los ADPIC y los países en desarrollo. ${ }^{12}$

En la Asamblea Mundial de la Salud, en 1996, se adopta una resolución sobre medicamentos ${ }^{13}$ que constituye el primer mandato dado por los países miembros al secretariado de la OMS para trabajar en el tema de la propiedad intelectual en relación a la salud (Resolución 49.14).

El pedido realizado al director general de la OMS a través de la Resolución 49.14, de 1996, de elaborar un estudio sobre las implicaciones del acuerdo de los ADPIC es confiado al Programa de Acción sobre Medicamentos Esenciales (PAME), quien publicó en noviembre de 1997 un documento con el título: "Mundialización y acceso a los medicamentos: implicaciones del Acuerdo de los ADPIC de la OMC". ${ }^{14}$

El resumen ejecutivo del documento expresa claramente cuál es su objetivo: "El presente documento pretende esclarecer a las personas del sector salud, que carecen de formación jurídica, sobre el impacto de la mundialización en el acceso a los medicamentos, y particularmente sobre las repercusiones del Acuerdo de los ADPIC en el sector farmacéutico". Más adelante, el documento afirma que "los estándares del Acuerdo de los ADPIC se derivan de los países industrializados que no son necesariamente los más apropiados para el nivel de desarrollo de todos los países. Las preocupaciones de salud pública deben por lo tanto ser tenidas en cuenta cuando se implemente el acuerdo". ${ }^{15}$

11 Correa, C., The Uruguay Round and Drugs, Ginebra, WHO-TFHE-97.1, 1997.

12 UNCTAD, The TRIPS Agreement and Developing Countries, prepared for the UNCTAD secretariat by Correa, Carlos et al., U.N. Pub. 96.II.D.10, 1996.

13 WHA 49.14, Estrategia Revisada de Medicamentos, Ginebra, OMS, 1996.

14 Velásquez, G. y Boulet, P., Mundialización y acceso a los medicamentos: implicaciones del Acuerdo de los ADPIC de la OMC, Ginebra, WHO/DAP/98.9, noviembre de 1997.

15 Ibidem, pp. 3 y 4. 
Esta obra forma parte del acervo de la Biblioteca Jurídica Virtual del Instituto de Investigaciones Jurídicas de la UNAM

Esta publicación sobre globalización y acceso a medicamentos "anticipó lo que luego la Declaración de Doha vino a reconocer: el derecho de los miembros de la OMC de explotar al máximo las flexibilidades incorporadas en el Acuerdo a fin de proteger la salud pública". ${ }^{16}$

En el documento de la UNCTAD ya citado, ${ }^{17} \mathrm{C}$. Correa y otros se refieren al "margen de maniobra" que deja el acuerdo ADPIC para formular políticas públicas nacionales. Según una opinión, la expresión "margen de maniobra" era demasiado dura para el ambiente diplomático de Naciones Unidas, y por tal razón la OMS habla de "márgenes de libertad"18 (1997). Posteriormente, en marzo de 2001, la OMS adopta el término de "salvaguardias" en un documento ampliamente distribuido en las seis lenguas oficiales de la OMS. ${ }^{19}$

La Comisión Europea, en junio de 2001, menciona un "margen suficientemente amplio de discreción", ${ }^{20}$ refiriéndose a la implementación del Acuerdo sobre los ADPIC. Unos meses después, en noviembre de 2001, la Declaración de Doha sobre el Acuerdo de los ADPIC y la Salud Pública de la OMC se refiere a "las provisiones del Acuerdo sobre los ADPIC que proveen flexibilidad". ${ }^{21}$ Es en junio de 2002 cuando la OMS, en un documento que analiza las implicaciones de la Declaración de Doha, cuyo autor es Carlos Correa, se refiere a las "flexibilidades" del Acuerdo. ${ }^{22}$

Actualmente, existe un amplio consenso sobre el uso del término "flexibilidades" para citar los mecanismos y provisiones del Acuerdo sobre los ADPIC dirigidos a proteger la salud pública. Flexibilidades que no son, como algunos pretenden sugerirlo, excepciones para los países en desarrollo, sino un derecho obtenido en la negociación que llevó a la adopción del Acuerdo sobre los ADPIC.

A partir de 1999, en sucesivas resoluciones de la Asamblea Mundial de la Salud se pidió a la OMS que asegurara que su estrategia farmacéutica

16 Ibidem, p. 44.

17 UNCTAD, The TRIPS..., cit.

18 Velásquez, G. y Boulet, P., Mundialización..., cit.

19 WHO, "Globalization, TRIPS and Access to Parmaceuticals", Policy Perspectives on Medicines, Ginebra, WHO, núm. 3, marzo de 2001, p. 5.

20 Comisión Europea, A Sufficiently Wide Margin of Discretion, IP-C-W-280, sumisión del 12 de junio de 2001.

21 WTO, Doha Declaration on the TRIPS Agreement and Public Health, WT-MIN(01)-DEGW-2, p. 1.

22 Correa, C., Implications of the Doha Declaration on the TRIPS Agreement and Public Health, Ginebra, WHO-EDM-PAR-2002.3, 2012. Véase el capítulo intitulado: "Flexibilidad de los ADPIC", p. 13. 
Esta obra forma parte del acervo de la Biblioteca Jurídica Virtual del Instituto de Investigaciones Jurídicas de la UNAM

abordara la importante cuestión relativa a los efectos de los acuerdos comerciales internacionales sobre la salud pública y el acceso a los medicamentos. La Asamblea Mundial de la Salud ha pedido a la OMS que cooperara con los Estados miembros y las organizaciones internacionales para vigilar y analizar las consecuencias farmacéuticas y sanitarias de los acuerdos comerciales internacionales, a fin de prestar asistencia a los Estados miembros para evaluar y desarrollar políticas y medidas de reglamentación farmacéuticas y sanitarias que potencien al máximo los efectos positivos de esos acuerdos y atenúen sus efectos negativos. En su conjunto, esas resoluciones han proporcionado a la OMS un mandato que se puede resumir a grandes rasgos de la manera siguiente: 1) analizar y vigilar los efectos sobre la salud pública derivados de la globalización, los derechos de propiedad intelectual y los acuerdos comerciales, e informar al respecto; 2) prestar asistencia a los Estados miembros para que fortalezcan sus políticas y prácticas farmacéuticas, y 3) proporcionar asistencia técnica y apoyo a los Estados miembros para aplicar integralmente las salvaguardias y flexibilidades en materia de salud pública previstas en el Acuerdo sobre los ADPIC.

\section{La Comisión sobre Propiedad Intelectual, Innovación y Salud Pública}

En 2003, por medio de una resolución de la Asamblea Mundial de la Salud, ${ }^{23}$ se crea la Comisión sobre Propiedad Intelectual, Innovación y Salud Pública (CIPIH). Los países miembros de la OMS solicitaban al secretariado de la OMS que se realizara un informe de expertos independientes sobre el tema de la propiedad intelectual, la innovación y la salud pública, un ejercicio que continuara y profundizara los aspectos ya tratados en el Informe de la Comisión Británica de $2002^{24}$ sobre el mismo tema.

En 2006, el informe de la CIPIH de la OMS sobre "La salud pública innovación y derechos de propiedad intelectual" afirma que "el Acuerdo sobre los ADPIC deja a los países bastante libertad en la aplicación de sus leyes sobre patentes... De esta manera, los países en desarrollo pueden establecer, según sus propios métodos, la definición de invención, los criterios de patentabilidad que ésta debe cumplir, los derechos conferidos al titular de la patente y las excepciones a la patentabilidad que se permiten...". ${ }^{25}$

23 WHA 56.26, Intellectual Property Rights, Innovation and Public Health, Ginebra, OMS.

24 Comisión sobre Derechos de Propiedad Intelectual, "Integrando los derechos de propiedad intelectual y la política de desarrollo", Informe, Londres, septiembre de 2002.

25 OMS, Salud pública, la innovación y la propiedad intelectual, Ginebra, OMS, 2006, p. 21. 
Esta obra forma parte del acervo de la Biblioteca Jurídica Virtual del Instituto de Investigaciones Jurídicas de la UNAM

El Informe de la CIPIH incluso sugiere que el problema del acceso a los medicamentos no se limita a los países en desarrollo.

Se trata de una cuestión importante, porque incluso en los países desarrollados, el rápido aumento de los costos de la atención sanitaria, incluido el suministro de medicamentos, es motivo de gran preocupación pública. En los países en desarrollo, e incluso en algunos países desarrollados, el costo de los medicamentos, que a menudo no se pueden conseguir a través de los sistemas públicos de atención sanitaria, puede ser una cuestión de vida o muerte. ${ }^{26}$

El Informe de la CIPIH contiene 60 recomendaciones; la mayoría se refiere a asuntos relacionados con la propiedad intelectual, que fueron retomados por el Plan de Acción de la Estrategia Mundial sobre Salud Pública, innovación y propiedad intelectual, resolución WHA 61.21, aprobada en 2009. Es en el contexto de las recomendaciones de la CIPIH y del mandato dado por las resoluciones de la Asamblea Mundial de la Salud desde 1999 que la OMS elabora las "pautas para el examen de patentes farmacéuticas" a las que se refiere específicamente el apartado IV de este documento.

En las pautas de la OMS se sugieren algunos de los mecanismos que pueden adoptarse para incorporar perspectivas de salud pública en los procedimientos para la concesión de patentes de productos farmacéuticos. También se propone un conjunto de medidas generales para la evaluación de algunas de las modalidades comunes de las reivindicaciones en patentes de productos farmacéuticos y se sugieren elementos para la elaboración de directrices que tengan en cuenta la salud pública para la evaluación y el examen de patentes de productos farmacéuticos a nivel nacional en los países en desarrollo.

En poco más de 10 años, la OMS ha producido importante material en el área de la salud pública y propiedad intelectual. Ya sea en las 17 resoluciones ${ }^{27}$ de la Asamblea Mundial de la Salud, como en las numerosas publicaciones ${ }^{28}$ de análisis y orientación con el fin de proteger el acceso a la salud, frente a las nuevas normas internacionales de comercio, exigidas en el marco de la OMC, y recientemente los acuerdos de libre comercio y los acuerdos bilaterales de inversión que contienen cláusulas y condiciones más

\footnotetext{
26 Ibidem, p. 177.

27 Véase, infra, VII. Anexo.

28 Las publicaciones de la OMS sobre propiedad intelectual y salud pública pueden consultarse en: Velásquez, Germán, Algunas cuestiones clave relacionadas con el acceso a los medicamentos y la propiedad intelectual, Valencia, Centro Sur-Farmamundo, 2014, serie contextos Farmamundo, vol. 5, pp. 42-45.
} 
Esta obra forma parte del acervo de la Biblioteca Jurídica Virtual del Instituto de Investigaciones Jurídicas de la UNAM

exigentes que los estándares del Acuerdo sobre los ADPIC. La publicación "Pautas para el examen de patentes farmacéuticas" es tal vez el documento más importante de orientación elaborado por la OMS para cumplir el mandato de las diversas resoluciones de la Asamblea Mundial de la Salud y de la Declaración de Doha de dar una perspectiva de salud pública al uso del sistema de patentes en el sector farmacéutico.

\section{Estrategia de propiedad intelectual para salud pública}

Durante la Asamblea Mundial de la Salud de la OMS, en mayo de 2008, se aprobó la "Estrategia mundial sobre la salud pública. Innovación y propiedad intelectual" elaborada por el grupo de trabajo intergubernamental conocido con las siglas en inglés IGWG. Dicha estrategia da el mandato a la OMS de "prestar... en colaboración con otras organizaciones internacionales competentes, apoyo técnico... a los países que tengan intención de hacer uso de las disposiciones del Acuerdo sobre los Aspectos de los Derechos de Propiedad Intelectual relacionados con el Comercio, incluidas las flexibilidades reconocidas en la Declaración ministerial de Doha relativa al Acuerdo sobre los ADPIC y la Salud Pública...". ${ }^{29}$

La Resolución de la Asamblea Mundial de la Salud 61.21 sobre "La estrategia mundial y el plan de acción sobre salud pública, innovación y propiedad intelectual" reconoció que los incentivos de propiedad intelectual no respondían a las necesidades de un gran número de personas que viven en los países en desarrollo. La Estrategia mundial declara que es necesario:

[A]lentar y apoyar la aplicación y gestión del régimen de propiedad intelectual de una manera que maximice la innovación relacionada con la salud y promueva el acceso a los productos sanitarios y sea compatible con las disposiciones del Acuerdo sobre los ADPIC y otros instrumentos de la OMC relacionados con ese Acuerdo y satisfaga las necesidades específicas de los países en desarrollo en materia de investigación y desarrollo. ${ }^{30}$

El foco de una estrategia de propiedad intelectual para la salud y para medicamentos en particular debe estar centrado en el acceso a los medicamentos y tecnologías esenciales a todas las personas que las necesiten.

Los principios en los que deberá basarse la estrategia son los siguientes:

29 WHA 61.21, La estrategia mundial y el plan de acción sobre salud pública, innovación y propiedad intelectual, Ginebra, OMS, mayo de 2008, párrafo 5.2, p. 17.

30 Idem. 
1) El derecho a la protección de la salud es un derecho universal e inalienable, y es deber de los gobiernos asegurar los medios para su realización.

2) El derecho a la salud tiene primacía sobre los intereses comerciales.

3) El derecho a la salud implica el acceso equitativo a los medicamentos.

4) La promoción de la innovación y la transferencia de tecnología es el derecho de todos los Estados, y no deberían estar restringidas por los derechos de propiedad intelectual.

5) Los derechos de propiedad intelectual no deben convertirse ni en un obstáculo al acceso a los medicamentos, ni ser un obstáculo para la formulación de políticas que aseguren y protejan la salud pública. Los derechos de propiedad intelectual deben garantizar el bienestar económico y social de una manera equilibrada.

6) Los países tienen el derecho de aplicar todas las flexibilidades contenidas en el Acuerdo sobre los ADPIC y que fueron reafirmadas por la Declaración de Doha y otras resoluciones internacionales, para salvaguardar el acceso a la tecnología y los medicamentos.

7) Las negociaciones internacionales relacionadas a la propiedad intelectual y la salud pública llevadas a cabo en las distintas organizaciones, deben mantener coherencia con las prioridades de la salud pública.

8) El refuerzo de la capacidad innovadora es esencial para responder a los problemas de salud.

9) Los países en desarrollo deben tener la capacidad de cooperar con base en sus intereses comunes y sus necesidades económicas y sociales si ellos se quieren beneficiar de los mercados globales.

10) Los componentes de esta estrategia de propiedad intelectual para la salud y los medicamentos, que deberían estar bien definidos en las leyes y normativas nacionales de propiedad intelectual, serían las llamadas flexibilidades de los ADPIC, es decir:

a) Pre y post oposición al otorgamiento de las patentes.

b) Definición de los criterios de patentabilidad desde una perspectiva de salud pública.

c) Las excepciones para la investigación y el earlyworking (excepción Bolar).

d) Importaciones paralelas.

e) El uso de las licencias obligatorias.

f) Test Data Protection.

g) No a la protección exclusiva de los datos como práctica para extender los monopolios. 
Esta obra forma parte del acervo de la Biblioteca Jurídica Virtual del Instituto de Investigaciones Jurídicas de la UNAM

h) La anuencia previa a las patentes por las autoridades sanitarias (como en el caso de Brasil y otros países).

\section{Políticas farmacéuticas y ADPIC}

Las políticas farmacéuticas nacionales han venido elaborando perspectivas políticas sobre acuerdos comerciales, salud pública y acceso a los medicamentos esenciales. Las perspectivas políticas orientan y aseguran la coherencia de los programas nacionales para asegurar el acceso de toda la población a los medicamentos. Sin embargo, la implementación de estas políticas a nivel nacional se dificulta, con frecuencia, por las tensiones que existen entre los diferentes actores: salud, comercio, industria.

Las perspectivas políticas sobre cuestiones relativas al Acuerdo sobre los ADPIC, derechos de propiedad intelectual y acceso a los medicamentos se pueden resumir de la manera siguiente:

1) Los medicamentos esenciales son un bien público.

2) El acceso a medicamentos esenciales es un derecho humano y, en consecuencia, una prioridad de salud pública.

3) Las patentes se deben gestionar de manera imparcial, protegiendo los intereses del titular de la patente y preservando los principios de salud pública, por lo que resulta esencial hacer uso apropiado de las flexibilidades y salvaguardias previstas en el Acuerdo sobre los ADPIC. ${ }^{31}$ La OMS ha venido poniendo al día una guía para la elaboración e implementación de políticas nacionales de medicamentos. ${ }^{32}$

\section{El examen de patentes y acceso a medicamentos}

El desarrollo de una perspectiva de salud pública para el examen de las patentes de productos farmacéuticos es uno de los aspectos fundamentales en el trabajo por el acceso a los medicamentos. En este contexto, la OMS consideró importante la formación de examinadores de patentes de las oficinas de patentes de países en desarrollo. De este modo, entre 2006 y 2010 se realizaron talleres para las oficinas nacionales de patentes de más cuarenta países.

31 Debido a las tensiones entre los distintos actores nacionales, flexibilidades permitidas por el Acuerdo de los ADPIC no siempre se encuentran correctamente en la legislación y políticas de medicamentos.

32 WHO, How to Develop and Implement a National Drug Policy, 2001. 
Esta obra forma parte del acervo de la Biblioteca Jurídica Virtual del Instituto de Investigaciones Jurídicas de la UNAM

Esta asistencia técnica a las oficinas de patentes ha sido retomada por el organismo intergubernamental Centro Sur, que también continúa analizando las tendencias de la concesión de patentes de productos farmacéuticos para responder a las crecientes preocupaciones por el aumento del número de patentes que protegen variantes de medicamentos o procedimientos existentes mientras, tal como fuera mencionado, el número de patentes de nuevas entidades moleculares es reducido y va disminuyendo. Los encargados de la formulación de políticas en la esfera de la salud y los examinadores de patentes deben ser conscientes de que las decisiones relativas a la concesión de una patente (que generalmente se considera válida hasta que se demuestre lo contrario) pueden afectar directamente la salud y la vida de las personas del país en el que se conceda y haga valer esa patente.

\section{EL SISTEMA DE PATENTES APLICADO}

A LOS MEDICAMENTOS

Un tercio de la población mundial no tiene acceso regular a medicamentos esenciales y esta proporción puede llegar a más de la mitad de la población en algunos países en desarrollo. De los 34 millones de personas que viven con el virus de inmunodeficiencia humana (VIH) que la OMS, la UNICEF y ONUSIDA estiman en su informe de $2012^{33}$ que deberían estar recibiendo tratamiento, solamente 8 millones tenían acceso a la terapia a finales de 2012.34

Esta situación, como lo afirma Eric Goemaere, se debe en gran parte a los altos costos de los medicamentos protegidos por patentes.

Cómo me indigna oír que los derechos de las patentes no constituyen una barrera al tratamiento aquí en Sudáfrica. He visto hombres y mujeres jóvenes morir víctimas de tumores cerebrales asociados al SIDA, tras padecer insoportables dolores de cabeza. He visto niños llenos de cicatrices provocadas por dermatitis asociadas al SIDA, incapaces de dormir por el dolor. Sabía que una terapia antirretroviral podía ayudarles, y que la única barrera que lo impedía era el coste del medicamento patentado. ${ }^{35}$

33 UNAIDS World AIDS Day Report 2012.

34 Velásquez, G., en Seuba, X. (coord.), Salud pública y patentes farmacéuticas, Barcelona, 2008, p. 24.

35 Goemaere, E., Patentes de medicamentos en el punto de mira: compartiendo conocimientos prácticos sobre las patentes farmacéuticas, Madrid, MSF, documento de Médicos Sin Fronteras, mayo de 2003. 
Esta obra forma parte del acervo de la Biblioteca Jurídica Virtual del Instituto de Investigaciones Jurídicas de la UNAM

Las patentes para productos farmacéuticos han sido uno de los temas sobre el acceso a medicamentos esenciales más debatidos desde la creación de la OMC en 1995 y la firma del Acuerdo sobre los ADPIC.

Las patentes no son la única barrera al acceso a medicamentos, pero cada vez más pueden ser un factor determinante, en la medida en que las patentes otorgan un monopolio sobre el medicamento al titular de la patente, que posee libertad para fijar los precios. Esta libertad de fijar los precios de los productos patentados ha llevado a que un gran número de medicamentos no se encuentre disponible para la mayoría de la población mundial que vive en los países en desarrollo.

Es importante recordar que la patente es un derecho territorial y que por lo tanto puede concederse una patente de una invención en un país, pero ésta puede ser legalmente rechazada en otro. Al mismo tiempo, una patente que ha sido emitida en un país puede ser revocada si se demuestra que la oficina de patentes no la debió otorgar.

También es importante señalar que en el campo farmacéutico, la situación no es un producto una patente. Una invención puede estar protegida por varias patentes; así como el proceso de producción del producto puede a su vez estar protegido por una o varias patentes, y en muchos países una combinación o una nueva indicación clínica pueden ser patentadas. Como consecuencia de ello, un solo medicamento puede estar protegido por un gran número de patentes.

El Acuerdo de los ADPIC contiene disposiciones que exigieron la modificación de las legislaciones de patentes de la gran mayoría de los países en desarrollo, en el sentido de introducir, ampliar y fortalecer la protección de la propiedad intelectual de los productos farmacéuticos.

Es importante que en la adaptación de las legislaciones de propiedad intelectual se incluyan todas las disposiciones que puedan proteger la salud pública. En los casos en que el margen de maniobra permitido por los ADPIC no fue utilizado, la legislación nacional siempre puede ser revisada, como lo han hecho países como China e India.

En principio, el sistema de patentes fue concebido para asegurar que el público se beneficiara de las invenciones. Actualmente, un gran número de personas que viven en los países en desarrollo no sólo no se benefician sino que, en muchos países, las patentes representan una barrera para el acceso a medicamentos que pueden salvarles la vida. Simplemente porque la lógica comercial prevalece al derecho de acceso a la salud.

Casi veinte años después de la adopción del Acuerdo sobre los ADPIC, su impacto, por lo menos en lo que se refiere a la salud pública, plantea más interrogantes que soluciones. 
Esta obra forma parte del acervo de la Biblioteca Jurídica Virtual del Instituto de Investigaciones Jurídicas de la UNAM

Pocos meses después de la creación de la Organización Mundial del Comercio, y la entrada en vigor del Acuerdo de los ADPIC, Carlos Correa afirmaba que:

La adopción del Acuerdo ha significado, ciertamente, una concesión mayor por parte de los países que han rehusado hasta ahora otorgar patentes sobre los medicamentos, a fin de evitar las consecuencias de la monopolización del mercado que se derivan de los derechos exclusivos. La evidencia disponible... indica que con la universalización de las patentes farmacéuticas no aumentará la I+D en nuevas drogas por parte de las grandes empresas, ni hay posibilidad de que ello ocurra en alguna escala significativa en los propios países en desarrollo. Tampoco recibirán estos países mayores flujos de inversiones directas extranjeras o de transferencia de tecnología. ${ }^{36}$

Quince años después, como veremos más adelante, se constata que ni la I+D ni la transferencia de tecnología han aumentado; por el contrario, la tendencia ha sido más bien a disminuir.

\section{El problema}

Cuatro problemas mayores pueden ser identificados en el actual sistema de patentes aplicado a los medicamentos: disminución de la innovación farmacéutica; altos precios de los medicamentos; falta de transparencia en los costos de la investigación y desarrollo $(\mathrm{I}+\mathrm{D})$, y proliferación de patentes.

\section{A. Disminución de la innovación farmacéutica}

Un estudio realizado por la revista Prescrire analizó los medicamentos que fueron introducidos en el mercado francés entre 2006 y 2011 (seis años), llegando a la conclusión de que el número de moléculas que aportaron un progreso terapéutico importante disminuyó drásticamente: 22 en 2006; 15, 10, 7 y 4 en los años siguientes, hasta llegar a 2011, año en que la revista Prescrire afirma que sólo un medicamento de interés terapéutico importante fue puesto en el mercado. ${ }^{37} \mathrm{Al}$ ser Francia uno de los mercados farmacéuticos más grandes del mundo, donde además el Estado es el que paga la

36 Correa, C., "The Uruguay Round and Drugs", en Lobo, F. y Velásquez, G. (eds.), Medicines and the New Economic Environement, Madrid, Civitas, 1998.

37 Even, Philippe y Debre, Bernard, Guía de los 4000 medicamentos útiles, inútiles o peligrosos, París, Cherche Midi, septiembre de 2012, p. 82. 
Esta obra forma parte del acervo de la Biblioteca Jurídica Virtual del Instituto de Investigaciones Jurídicas de la UNAM

factura de medicamentos, se supone que la gran mayoría de los medicamentos que entraron al mercado entre 2006 y 2011 fueron introducidos en el mercado francés; en otras palabras, la baja en la innovación constatada en Francia es un buen indicador de la situación mundial.

\section{B. Altos precios de los medicamentos}

Otro estudio reciente demostró que, en promedio, los medicamentos cuestan tres veces más en Francia que en Italia. ${ }^{38}$ Vale la pena recordar que la oferta de medicamentos es bastante similar en los dos países. Los mismos laboratorios, los mismos medicamentos y la mayoría de las veces las mismas dosis.

Oncólogos de una quincena de países denunciaron recientemente los precios excesivos de los tratamientos contra el cáncer, que son necesarios para que estos pacientes preserven sus vidas, e instaron a que prevalezcan las "implicaciones morales". ${ }^{39}$ Según este grupo de oncólogos, de los doce tratamientos contra el cáncer aprobados en 2012 por la Agencia Estadounidense de Medicamentos (FDA), once cuestan más de 100 mil dólares estadounidenses (US\$) por paciente, por año.

En 2010 un grupo de académicos ingleses analizó las drogas de mayor prescripción en el Sistema Nacional de Salud (NHS) y calculó que aproximadamente se despilfarra un billón de libras esterlinas por año debido a la prescripción de me-too drugs patentadas, para las cuales existe un equivalente igualmente efectivo, fuera de patente. ${ }^{40}$ Lo que se considera un despilfarro de los fondos del Estado a causa del consumo de medicamentos patentados en el sistema inglés, en los países en desarrollo esta realidad lleva simplemente a la imposibilidad de acceder al medicamento por una gran parte de la población.

Durante el verano de 2014, varios países europeos como Francia y España pasaron varios meses negociando con la firma Gilead el precio del nuevo medicamento para la hepatitis $\mathrm{C}$ (conocido con el nombre de marca "Sovaldi"). El precio fijado por Gilead era de 56,000 euros por paciente para un tratamiento de doce semanas, es decir, 666 euros por comprimido. Según

38 Le Monde, 11 de noviembre de 2013, disponible en: http://werere.lemonde.fr/culture/article/2013/11/13/le-scandale-du-prix-des-medicaments_3510819_3246.html.

39 Revista estadounidense Blood, publicación de la Sociedad Estadounidense de Hematología (ASH, por sus siglas en inglés), abril de 2013.

40 Goldacre, B., op. cit., p. 243. 
Esta obra forma parte del acervo de la Biblioteca Jurídica Virtual del Instituto de Investigaciones Jurídicas de la UNAM

el periódico Le Monde, el precio de cada comprimido era de 280 veces más que el costo de producción. ${ }^{41}$ En Francia se calcula que 250,000 pacientes deberían recibir este nuevo medicamento, cuyo costo representaría el 7\% del presupuesto anual del Estado para medicamentos.

\section{Falta de transparencia en los costos de la investigación y desarrollo $(I+D)$}

Desde los años cincuenta se pueden encontrar algunas referencias sobre los costos de la I+D para productos farmacéuticos. Según algunas fuentes (véase tabla siguiente) estas cifras habrían aumentado de 1 a 1,300 millones de US\$ para el desarrollo de un solo producto. Mientras no exista claridad y transparencia en este campo, el problema que pueden ocasionar los altos precios de los medicamentos seguirá sin resolver.

Otorgar patentes sobre la base de que el inventor debe recuperar los costos de su invención, cuando no existe claridad sobre los costos reales, es algo que los Estados y la sociedad en general deberían cuestionarse. La duración de las patentes, por ejemplo, por un periodo de 20 años, exigido arbitrariamente por el Acuerdo de los ADPIC, debería estar en función de los costos de la $\mathrm{I}+\mathrm{D}$ de los productos.

\section{Coste medio de la investigación de un nuevo producto farmacéutico*}

1950

1970 y 1980

1991

2000

2002

2008

2012

2014

\section{1 millón de US\$}

Entre 48 y 54 millones de US\$

Tufts Center (Boston): 231 millones de US\$

El mismo Tufts Center: 473 millones de US\$

802 millones de US\$ (¡dobla el costo en dos años!)

IFPMA: 900 millones de US\$

IFPMA: 1300 millones de US\$

Tufts Center (Boston): 2.56 billones de US\$

* Elaboración propia basada en fuentes diversas.

41 Santi, P., "Hépatite C: le Nouveau Hold-up des Labos", Le Monde, 8 de julio de 2014. 
Esta obra forma parte del acervo de la Biblioteca Jurídica Virtual del Instituto de Investigaciones Jurídicas de la UNAM

Un artículo del diario BioSocieties, ${ }^{42}$ publicación de la London School of Economics, argumenta que el costo real de la I+D es, de hecho, una fracción de las comúnmente citadas estimaciones. De acuerdo con Light y Warburton, el costo medio de la I+D para desarrollar un medicamento varía entre 13 y 204 millones de US\$, dependiendo del tipo de producto. Los autores estiman un costo medio de 43.4 millones de US\$ para la $\mathrm{I}+\mathrm{D}$ de cada nueva droga. Y concluyen: "esto está muy lejos de US\$ 802 millones o US\$ 1.3 billones reclamados por la industria".

La iniciativa para las enfermedades ignoradas - DNDi (Drugs for Neglected Diseasesinitiative) - , fundada por la ONG Médicos Sin Fronteras (MSF) en 2004, publicó recientemente sus costos de investigación después de diez años de experiencia. ${ }^{43}$ Sus cifras son las siguientes:

1) De 6 a 20 millones de euros para mejorar un tratamiento.

2) De 30 a 40 millones de euros para una nueva entidad química.

Si esta cifra se reajusta de la manera usual en la I+D farmacéutica para enfermedades infecciosas, para cubrir los riesgos de fracaso las cifras serían las siguientes:

1) De 10 a 40 millones de euros para mejorar un tratamiento

2) De 100 a 150 millones de euros para una nueva entidad química.

Resulta incomprensible que después de 15 o más años de debate no exista todavía un consenso sobre cuál es el costo real de la I+D de medicamentos. Mientras este problema no se resuelva será muy difícil avanzar en una reflexión constructiva que pueda elucidar el futuro del acceso a los medicamentos. Las diferencias de datos entre la academia o las iniciativas sin ánimo de lucro como DNDi, y la industria van del uno al diez. La OMS no se pronuncia sobre el asunto, a causa, probablemente, de la influencia creciente de la industria farmacéutica en la elaboración de políticas y toma de decisiones en esta agencia.

Es así como los monopolios otorgados por las patentes permitirán, por un lado, la obtención de beneficios desproporcionados y, por otro lado, bloquearán el acceso de un gran número de personas a medicamentos, en muchos casos vitales.

El problema de los costos de la $\mathrm{I}+\mathrm{D}$ es que no existe transparencia en cuáles son los costos verdaderos de la $\mathrm{I}+\mathrm{D}$ ni una lógica de los precios de los

42 Light, Donald W. y Warburton, Rebecca, "Demythologizing the High Costs of Pharmaceutical Research", BioSocieties, The London School of Economics and Political Science, 1745-8552, 2011, pp. 1-17, puede consultarse en: wrere.palgrave-journals.com/biosoc/.

43 DNDi, An Innovative Approach to RED for Neglected Patients: Ten Years of Experience and Lessons Learned by DNDi, Ginebra, 2013. 
Esta obra forma parte del acervo de la Biblioteca Jurídica Virtual del Instituto de Investigaciones Jurídicas de la UNAM

medicamentos, sólo aquella de que los precios corresponden al máximo de lo que cada mercado puede asumir o pagar.

\section{Proliferación de patentes}

Una investigación realizada por la Unión Europea (UE) sobre la conducta y prácticas de la industria farmacéutica entre 2000 y 2007 encontró que un solo medicamento puede estar protegido hasta por 1,300 patentes o aplicaciones de patente pendientes. ${ }^{44} \mathrm{El}$ número de litigios entre el original y el genérico se ha multiplicado por cuatro en la UE. Estos litigios demoran la entrada del producto genérico entre 6 meses y 6 años. El estudio estima que las economías debidas a la entrada de genéricos hubieran podido ser de aproximadamente 3 billones de euros, si la entrada hubiera sido inmediatamente después de la pérdida de la exclusividad. ${ }^{45}$

Un cambio de política y de estrategia en la oficina de patentes puede llevar a cambios significativos. En Argentina, por ejemplo, después de la introducción al inicio de 2012 de nuevas pautas para el examen de patentes farmacéuticas, el número de patentes otorgadas fue de 54, mientras que en México, un mercado de tamaño similar al de Argentina, las patentes otorgadas en 2012 para productos farmacéuticos fue de 2,500.

\section{El contexto internacional}

En general, se reconoce actualmente que el régimen vigente de protección mediante patentes, "globalizado" por el Acuerdo sobre los ADPIC, tiene importantes repercusiones sobre el sector farmacéutico. Además, existe la preocupación de que las normas especificadas en el Acuerdo sobre los ADPIC no sean necesariamente apropiadas para los países que están luchando por satisfacer sus necesidades de salud y desarrollo. Desde 2002 la Comisión de Derechos de Propiedad Intelectual (CIPR) del Reino Unido publicó un informe recomendando a los países que velaran porque sus regímenes de protección de la propiedad intelectual no menoscabaran sus políticas de salud pública y fueran coherentes con esas políticas.

La investigación y desarrollo (I+D) farmacéutica basada en el sistema de patentes, como principal fuente de financiamiento, no ha logrado que los

44 Investigación de la Unión Europea, puede consultarse en: http://ec.europa.eu/competi tion/sectors/pharmaceuticals/inquiry/index.html.

45 Idem. 
Esta obra forma parte del acervo de la Biblioteca Jurídica Virtual del Instituto de Investigaciones Jurídicas de la UNAM

medicamentos sean accesibles para un gran número de personas, especialmente las que viven en países en desarrollo. Por un lado, hay poca inversión en I+D para las enfermedades prevalentes en dichos países, ya que las grandes empresas se concentran en el desarrollo de productos destinados a satisfacer la demanda de mercados ricos. Por otro lado, los productos sujetos a patentes y otras modalidades de derechos de exclusividad son normalmente comercializados a precios inalcanzables para gran parte de la población. Varios informes y estudios, así como la Estrategia Mundial y Plan de Acción sobre Salud Pública, Innovación y Propiedad Intelectual (EMPA), adoptado por los Estados miembros de la OMS (2003-2008), ${ }^{46}$ han reconocido estos problemas.

En abril de 2012, el Grupo Consultivo de Expertos en Investigación y Desarrollo de la OMS (CEWG por sus siglas en inglés) recomendó el inicio de negociaciones internacionales para un tratado sobre la $\mathrm{I}+\mathrm{D}$ de productos farmacéuticos, en el marco del artículo 19 de la Constitución de la OMS, que señala:

La Asamblea de la Salud tendrá autoridad para adoptar convenciones o acuerdos respecto a todo asunto que esté dentro de la competencia de la Organización. Para la adopción de convenciones y acuerdos se requiere el voto de aprobación de las dos terceras partes de la Asamblea de la Salud; las convenciones y acuerdos entrarán en vigor para cada miembro al ser aceptados por éste de acuerdo con sus procedimientos constitucionales.

El único precedente en la historia de la OMS sobre el uso de este artículo en un ámbito sustantivo fue la Convención Marco de Lucha contra el Tabaco. Se necesitan nuevos mecanismos ${ }^{47}$ que de forma simultánea y eficaz promuevan la innovación y el acceso a los medicamentos, en particular para las enfermedades que afectan mayoritariamente a los países en desarrollo. Un instrumento internacional vinculante o tratado internacional sobre la I+D que se negocie bajo los auspicios de la OMS puede proporcionar el marco adecuado para garantizar el establecimiento de prioridades, la coordinación y la financiación sostenible de los medicamentos a precios asequibles para los países en desarrollo.

Recientemente, en octubre de 2014, en su discurso de apertura de la sexta conferencia de las partes del Convenio Marco de la OMS para el Control del Tabaco (COP6 de la FCTG), realizada en Moscú, la directora general de la OMS afirmó que:

\footnotetext{
46 WHA $61.21 \ldots$, cit.

47 Asamblea Mundial de la Salud, EMPA, punto 13.
} 
Esta obra forma parte del acervo de la Biblioteca Jurídica Virtual del Instituto de Investigaciones Jurídicas de la UNAM

Tenemos pruebas abundantes de múltiples fuentes de que la aplicación del Convenio Marco trae aparejadas mejoras inmediatas y a largo plazo de la salud... Como el tiempo se ha encargado de demostrar, el tratado sobre el tabaco es importante por una segunda razón. Es un modelo de cómo múltiples sectores de gobierno, y múltiples organismos del sistema de las Naciones Unidas, pueden trabajar juntos, sin fisuras y en colaboración, unidos en torno a un objetivo compartido de gran valor. La importancia de este modelo sigue aumentando cuando se advierte que son cada vez más las grandes amenazas actuales para la salud... ${ }^{48}$

\section{Derechos humanos y propiedad intelectual}

$\mathrm{Al}$ hablar de reglas internacionales de comercio o de cuestiones relacionadas con la salud pública, estamos hablando de dos regímenes diferentes y que no están al mismo nivel. En el primer caso se trata de normas y reglas de comercio o de la economía, y en el segundo caso nos referimos al derecho a la salud como parte de los derechos humanos.

Los medicamentos son una herramienta fundamental que posee la sociedad para prevenir, aliviar o curar las enfermedades, y el acceso a ellos es un derecho fundamental de los ciudadanos, parte integrante del derecho a la salud tal como lo establecen algunos tratados internacionales o la misma Constitución de numerosos países. ${ }^{49}$

$\mathrm{El}$ acceso a los medicamentos tiene que abordarse desde la consideración de derecho humano fundamental, con pleno reconocimiento internacional y constitucional. La Declaración Universal de los Derechos Humanos (1948) así lo cita en su artículo 25: "toda persona tiene derecho a un nivel de vida adecuado que le asegure, así como a su familia, la salud y el bienestar, y en especial la alimentación, el vestido, la vivienda, la asistencia médica y los servicios sociales necesarios...".

Los ámbitos de interacción entre la patentabilidad de productos farmacéuticos y los derechos humanos son numerosos, dado que las normas que un país adopta sobre la patentabilidad de invenciones se relacionan con regímenes normativos que protegen bienes jurídicos especialmente tutelados. En efecto, el impacto sobre la vida, sobre la ciencia y sobre el acceso a productos vitales que se produce al aplicar unas u otras normas sobre patentabilidad, incluidos

48 Discurso de Margaret Chan, directora de la OMS, apertura de la COP6 de la FCTC, Moscú, FCTC-COP6-DIV-4, 13 de octubre de 2014.

49 Seuba, X., La protección de la salud ante la regulación internacional de los productos farmacéuticos, tesis de doctorado, Barcelona, 2008, pp. 92 y ss. 
Esta obra forma parte del acervo de la Biblioteca Jurídica Virtual del Instituto de Investigaciones Jurídicas de la UNAM

los criterios de patentabilidad, se traduce en su interacción con un amplio abanico de derechos fundamentales, como el derecho a acceder a los avances de la ciencia y tecnología, el derecho a la salud o el propio derecho a la vida. Esta es precisamente la razón por la que tribunales, órganos administrativos y ministerios de salud, entre otros, prestan creciente atención a la relación entre los criterios de patentabilidad que un país adopta y su régimen de protección de los derechos humanos, en particular el derecho a la salud. ${ }^{50}$

Si bien, tal como afirma P. Drahos, el problema es que las oficinas de patentes han funcionado y muchas funcionan aún como instituciones administrativas, el examen de la solicitudes de patentes "es mucho más que una tarea administrativa. La base sobre la que se conduce tal actividad, y ésta misma, guarda estrecha relación con la protección del dominio público y los derechos fundamentales". ${ }^{51}$

En el contexto de las Naciones Unidas, la gran mayoría de los países ha adoptado tratados internacionales como el Pacto Internacional de Derechos Económicos, Sociales y Culturales (PIDESC); el Convenio sobre los Derechos del Niño o la Convención para la Eliminación de Todas las Formas de Discriminación Racial, que ratifican, de diferentes maneras, el derecho a la salud. El PIDESC ha afirmado que "el derecho a la salud abarca una amplia gama de factores socioeconómicos que promueven las condiciones merced a las cuales las personas pueden llevar una vida sana". ${ }^{52}$ Es dentro de esta "amplia gama de factores socioeconómicos" que están relacionados con la salud, que los estándares de patentabilidad podrían estar ligados al derecho de acceso a la salud.

En el comentario general 14, de mayo de $2000^{53}$ del PIDESC, el Comité declaró que los servicios médicos referidos en el artículo 12.2.(d) incluyen el acceso a medicamentos esenciales, tal como los define la OMS. Es así como el Comité de Derechos Económicos, Sociales y Culturales de las Naciones Unidas ha desembocado en la inclusión del acceso a los medicamentos esenciales entre los componentes centrales del derecho a la salud.

La concepción del acceso a medicamentos como un derecho de los ciudadanos cambiaría el debate y dejaría clara la primacía de la salud por encima de las reglas internacionales de comercio. Esta perspectiva de dere-

50 Seuba, X., Derecho a la salud, política faramacéutica nacional y pautas de patentabilidad, trabajo no publicado, 2012.

51 Op. cit.

52 Comité sobre Derechos Económicos, Sociales y Culturales, Derecho al máximo nivel de salud posible. Observación general 14, E-C.12-2000-4, 2000, paras. 4 y 9.

53 Ibidem, para. 12(a). 
Esta obra forma parte del acervo de la Biblioteca Jurídica Virtual del Instituto de Investigaciones Jurídicas de la UNAM

cho, como lo indica Seuba, "ofrece simultáneamente las herramientas para reportar violaciones y un marco para guiar las políticas nacionales de medicamentos en esta dirección". ${ }^{54}$

\section{PAUtas PARA EL EXAMEN DE PATENTES FARMaCÉUticas: UNA PERSPECTIVA DESDE LA SALUD PÚBLICA ${ }^{55}$}

\section{Historia sobre las pautas}

Como ya fue mencionado, el hecho de que el Acuerdo sobre los ADPIC no defina qué es novedad, espíritu inventivo y aplicación industrial (utilidad) deja un gran margen de maniobra a los países, y en este sentido, los criterios de patentabilidad representan la principal y más importante flexibilidad permitida por el Acuerdo para proteger la salud pública y el acceso a los medicamentos. "Los políticos y legisladores tienen amplio margen de maniobra para dar efecto jurídico a dichas flexibilidades". ${ }^{56}$

Los artículos 7o. y 8o. del Acuerdo sobre los ADPIC (1995) estipulan claramente que todas las disposiciones deben interpretarse a la luz de sus objetivos y principios, los cuales establecen:

Artículo 7o. Objetivos. La protección y la observancia de los derechos de propiedad intelectual deberán contribuir a la promoción de la innovación tecnológica y a la transferencia y difusión de la tecnología, en beneficio recíproco de los productores y de los usuarios de conocimientos tecnológicos y de modo que favorezcan el bienestar social y económico, y el equilibrio de derechos y obligaciones.

Artículo 8o. Principios.1. Los miembros, al formular o modificar sus leyes y reglamentos, podrán adoptar las medidas necesarias para proteger la salud pública y la nutrición de la población, o para promover el interés público en sectores de importancia vital para su desarrollo socioeconómico y tecnológico, siempre que esas medidas sean compatibles con lo dispuesto en el presente Acuerdo.

La perspectiva de los artículos 7o. y 8o. del Acuerdo sobre los ADPIC fue de nuevo ratificada por la Declaración de Doha (2001), que:

54 Seuba, X., "A Human Rights Approach to the WHO Model List of Essential Medicines", Bulletin World Health Organization, Ginebra, vol. 84, núm. 5, mayo de 2006.

55 Correa, C., Pautas para el examen de patentes farmacéuticas: una perspectiva de salud pública, Ginebra, WHO-ICTSD, UNCTAD, marzo de 2008.

56 Arias, Eduardo, Pautas para el examen de patentabilidad de invenciones quimico-farmacéuticas, Argentina, INPI, presentación PPT, 2014. 
Esta obra forma parte del acervo de la Biblioteca Jurídica Virtual del Instituto de Investigaciones Jurídicas de la UNAM

1) Reconoce la gravedad de los problemas de la salud pública que afligen a muchos países en desarrollo y menos adelantados...

2) Recalca la necesidad de que el ADPIC forme parte de la acción nacional e internacional más amplia encaminada a hacer frente a estos problemas. 3) ...

4) Conviene que el Acuerdo sobre los ADPIC no impide ni deberá impedir que los Miembros adopten medidas para proteger la salud pública... afirma que dicho Acuerdo puede y deberá ser interpretado y aplicado de manera que apoye el derecho de los miembros de la OMC de proteger la salud pública y, en particular, de promover el acceso a los medicamentos para todos... reafirmamos el derecho de los miembros de la OMC de utilizar al máximo las disposiciones del Acuerdo sobre los ADPIC, que prevén flexibilidad a este efecto...

En 2005, con el mandato dado por la Asamblea Mundial de la Salud en diferentes resoluciones, el Programa de Medicamentos de la OMS decide elaborar una propuesta de pautas para el examen de patentes farmacéuticas desde una perspectiva de salud pública. Con base en un primer documento de trabajo elaborado por el profesor Carlos Correa se inicia una serie de consultas internacionales, regionales y nacionales, entre las que vale la pena señalar:

1) Octubre de 2005, en Bangkok, Tailandia. Consulta organizada por la Thai Food and DrugAdministration (THAI FDA) y la OMS, incluyó representantes de las autoridades reguladoras de medicamentos y de las oficinas nacionales de patentes de la China, Indonesia, Malasia, Tailandia, representantes de facultades de derecho, medicina y farmacia de Tailandia y de la industria farmacéutica.

2) En junio de 2006 se solicitaron comentarios y contribuciones a expertos en salud pública y patentes de Australia, Reino Unido y de la OMS.

3) Julio de 2006, en Buenos Aires, Argentina. Esta consulta contó con representantes de Argentina, Paraguay y Brasil, provenientes de las oficinas de patentes, ministerios de salud, facultades de derecho y farmacia de los tres países.

4) El 14 de septiembre de 2006, en Ginebra. Esta consulta incluyó representantes de la oficina suiza de patentes, el Centro Sur, la OMS, la UNCTAD, el ICTSD, la Escuela Politécnica de Lausanne, OMPI, OMC, MSF y TWN.

5) Diciembre de 2006, en Beijing, China. El proyecto de pautas fue discutido y analizado con los 50 examinadores de patentes farmacéuticas de la oficina nacional de patentes de China. 
Esta obra forma parte del acervo de la Biblioteca Jurídica Virtual del Instituto de Investigaciones Jurídicas de la UNAM

6) Julio de 2007, en Panamá. Esta consulta incluyó representantes de Costa Rica, Colombia, Cuba, Nicaragua, El Salvador, Guatemala, Honduras y Panamá.

7) Octubre de 2007, en El Cairo, Egipto. Consulta con los examinadores de patentes de la oficina nacional de propiedad intelectual de Egipto.

8) Diciembre de 2007, en Nueva Delhi, India. Revisión y discusión del proyecto de pautas con la oficina de patentes de la India, con la participación de representantes de Tailandia y de las ONG de la India vinculadas a este tema.

Además de las consultas mencionadas, numerosos comentarios fueron dirigidos a la directora general de la OMS y al Programa de Medicamentos de la OMS, entre los que se pueden citar, por ejemplo, la carta del ministro de Salud de Argentina del 25 de octubre de 2007, que cita:

SRA. DiREGTORA General, ORGanización Mundial DE la SALUd, DRA. MARgaret Chan. Por medio de la presente, deseo transmitirle mi gratitud y mis reconocimientos por el documento "Guidelines for the examination of pharmaceutical patents: developing a public health perspective", recientemente publicado por OMS, ICTSD y UNGTAD, ya que considero posee una importancia crucial para los países en desarrollo que, como Argentina, se encuentran compelidos de evitar que la aplicación de los derechos de propiedad intelectual en el área de medicamentos ejerza un impacto negativo sobre la salud de nuestra sociedad.

Desde mi lugar como autoridad sanitaria de Argentina, reconozco la ardua labor de la OMS de acompañar y fortalecer las medidas adoptadas por los países para proteger la salud pública tal como se ha establecido en la Declaración ministerial de Doha, y considero que el documento es fuertemente consistente con las recomendaciones que, al respecto, ha realizado oportunamente la Comisión de Derechos de Propiedad Intelectual, Innovación y Salud Pública (CIPIH).

O la carta del secretario General de la FDA de Tailandia, del 10 de septiembre de 2007:

Su Excelencia Dra. Margaret Chan: La Administración de Alimentos y Medicamentos, Tailandia (FDA), tiene el honor de escribir esta carta para felicitar a la OMS por la exitosa contribución y compromiso con la reciente elaboración y publicación de un documento de gran utilidad titulado Las pautas para el examen de patentes farmacéuticas: el desarrollo de una perspectiva de salud pública...

El documento aborda la importante necesidad de tener en consideración los aspectos de salud pública en el examen de patentes farmacéuticas con 
Esta obra forma parte del acervo de la Biblioteca Jurídica Virtual del Instituto de Investigaciones Jurídicas de la UNAM www.juridicas.unam. $m x$

el fin de garantizar que se concedan sólo las patentes de alta calidad para recompensar una invención genuinamente creativa... La situación de la concesión de patentes de baja calidad agrava el problema del acceso de la población a los medicamentos esenciales en los países en desarrollo. Por lo tanto, las directrices han llegado en el momento adecuado para ayudar a desarrollar una perspectiva de salud pública en el examen de patentes farmacéuticas... La publicación de este documento por parte la OMS representa un verdadero y visionario liderazgo.

En la carta del Ministro de Salud del Brasil, del 27 de octubre del mismo año, dirigida también a la directora general de la OMS, puede leerse:

En nombre del gobierno brasileño me gustaría felicitarla por la iniciativa de la OMS de publicar el documento titulado "Pautas para el examen de patentes farmacéuticas: una perspectiva desde la salud pública", cuyo autor es el profesor Carlos Correa.

El gobierno brasileño cree... que el documento es una herramienta indispensable para evitar los abusos relacionados con los derechos de propiedad intelectual, garantizando que sólo los productos farmacéuticos o procesos que cumplan los criterios de novedad, actividad inventiva y utilidad tendrán sus solicitudes de patentes concedidas.

En los comentarios de la oficina de patentes de Suiza, transmitidos por el representante de Suiza ante la OMC el 14 de septiembre de 2006, puede leerse en el primer párrafo: "I think, the guidelines are carefull y drawn up, very comprehensive and well-balanced in a lot of their points". ${ }^{57}$

Finalmente, conviene señalar que cerca de diez años después de la publicación del documento, ningún cuestionamiento de fondo ha tenido lugar en la Organización Mundial del Comercio. ${ }^{58}$

\section{2. ¿Qué son las pautas para el examen de patentes farmacéuticas?}

Las Pautas para el examen de patentes farmacéuticas elaboradas por la OMS son una guía para la elaboración de los manuales de procedimiento interno de las oficinas nacionales de propiedad intelectual, sobre el examen de patentabilidad de invenciones químico-farmacéuticas.

57 Traducción del autor: "Creo que las directrices se elaboraron cuidadosamente, en forma muy completa y bien equilibrada en muchos de sus puntos".

58 Las preguntas de algunos países, cuando la Ley de Propiedad Intelectual de Argentina fue revisada en la OMC (marzo de 2013), piden información pero no cuestionan la consistencia de las mismas con el Acuerdo sobre los ADPIC. 
Esta obra forma parte del acervo de la Biblioteca Jurídica Virtual del Instituto de Investigaciones Jurídicas de la UNAM

Es una práctica habitual de todas las oficinas de patentes del mundo instruir a sus examinadores sobre la forma de realizar el examen de patentabilidad a través de las llamadas directrices o Guidelines de patentabilidad que describen en detalle la aplicación del derecho de patentes a circunstancias particulares... Estas directrices incluyen por lo general, un capítulo sobre patentes en el sector químico-farmacéutico. ${ }^{59}$

Es también una práctica habitual de todas las oficinas de patentes del mundo fijar el nivel de los estándares de patentabilidad que los examinadores utilizarán para el examen de patentes, a través de las llamadas directrices o pautas de patentabilidad, que describen en detalle la aplicación del derecho de patentes a circunstancias particulares.

En la introducción de las pautas se señala que el sector farmacéutico es un usuario de fundamental importancia dentro del sistema de patentes. Mientras que cada año sólo un número pequeño - y decreciente - de entidades químicas nuevas obtiene su aprobación, miles de solicitudes se presentan para proteger variantes de productos existentes, procedimientos de manufactura o, cuando se permiten, segundas indicaciones de productos farmacéuticos conocidos.

Dado que las patentes confieren derechos exclusivos sobre la producción, venta y uso de la materia patentada, se pueden utilizar para limitar la competencia y fijar precios más elevados que los que existirían de contarse con productos competitivos o medicamentos genéricos.

Teniendo en cuenta que los efectos de fondo que las patentes pueden surtir sobre la competencia y, por consiguiente, sobre los precios y el acceso a las medicinas, los criterios que se aplican para examinar y otorgar patentes farmacéuticas resultan de extrema importancia para las políticas de salud pública.

El propósito de las guías para el examen de patentes farmacéuticas es brindar una serie de pautas generales para la evaluación de algunos de los tipos comunes de reivindicaciones de patentes farmacéuticas. Responde a la creciente inquietud emergente en diferentes círculos ${ }^{60}$ sobre la proliferación de patentes que protegen variantes menores, y en algunos casos obvios, de medicamentos o procesos existentes (por ejemplo, cambios en la formulación de la droga, sales, ésteres, éteres, isómeros, polimorfos de moléculas existentes, combinaciones de una droga conocida con otras drogas conocidas), mientras que el número de entidades químicas nuevas de uso far-

\footnotetext{
59 Arias, Eduardo, Pautas..., cit.

60 Véase, por ejemplo, Comisión Federal de Comercio (FTC), 2003; Jaffe and Lerner, 2004; Correa, 2001 a.
} 
Esta obra forma parte del acervo de la Biblioteca Jurídica Virtual del Instituto de Investigaciones Jurídicas de la UNAM

macéutico es pequeño y decreciente. ${ }^{61}$ Si bien dichas patentes pueden ser débiles o, si se las somete a un estricto escrutinio, inválidas, en muchos casos se las puede utilizar para evitar la competencia genérica y reducir, de tal manera, el acceso a los medicamentos.

Si bien estas pautas reconocen la importancia de las innovaciones farmacéuticas subsiguientes en ciertos casos, ${ }^{62}$ su objetivo es ampliar la capacidad de las oficinas de patentes, de las autoridades reguladoras de medicamentos y de salud pública, como también de la sociedad civil, para evaluar y adoptar las medidas necesarias, acordes a su legislación nacional, para proteger la salud pública en aquellos casos en que las solicitudes u otorgamientos de patentes cubren una materia que no merece la recompensa monopólica que otorga una patente. Estas pautas tienen el propósito de brindar apoyo a las oficinas de patentes nacionales y pretenden contribuir con un análisis razonable de las patentes farmacéuticas, sobre la base de una aplicación racional de los estándares de patentabilidad.

Las pautas no sugieren la aplicación de un nuevo requisito de patentabilidad, sino el tener en cuenta consideraciones específicas relativas a la innovación en los productos farmacéuticos cuando se aplican los requisitos comunes de novedad, paso inventivo y aplicación industrial (utilidad).

\section{Contenido de las pautas}

Las pautas para el examen de patentes analizan y discuten los tipos de reivindicaciones más comunes en el sector farmacéutico. Se incluyen observaciones sobre las prácticas en algunos países y se analizan 41 ejemplos de casos concretos de las distintas reivindicaciones analizadas. A continuación se transcriben, a título de ilustración, sólo las recomendaciones para cada tipo de reivindicación, a la luz de una perspectiva de salud pública que promueva el acceso a los medicamentos.

61 El número de nuevas entidades moleculares (NEM) aprobadas por la Administración de Drogas y Alimentos de los Estados Unidos (FDA) disminuyó de manera drástica desde mediados de la década de los años noventa (de 53 en 1996 a un mínimo de 17 en 2002). Véase CDER, NDAs Approved in Calendar Years 1990-2004 by Therapeutic Potential and Chemical Type, United States Food and Drug Administration, 22 de marzo de 2005, puede consultarse en: http://wrwrefda.gov/cder/rdmt/pstable.htm (fecha de consulta: 14 de noviembre de 2005).

62 CIPIH, p. 17. Sin embargo, en algunos casos, las patentes pueden impedir innovaciones subsiguientes, en particular cuando se patenta materia resultante de la ciencia fundamental. Véase, por ejemplo, Commission on Intellectual Property Rights, 2002; Sampath, 2005, p. 29. 
Esta obra forma parte del acervo de la Biblioteca Jurídica Virtual del Instituto de Investigaciones Jurídicas de la UNAM

\section{A. Formulaciones y composiciones}

Recomendación: las formulaciones y composiciones nuevas, como también los procesos para su preparación, se deberían considerar obvias teniendo en cuenta el arte previo, en particular cuando se reivindica un único principio activo junto con vehículos o excipientes conocidos o no especificados. Como excepción, las reivindicaciones de este tipo podrían ser patentables si se obtiene un efecto realmente inesperado o sorpresivo; por ejemplo, cuando se resuelve, de manera no obvia, un problema verdaderamente difícil o una necesidad de larga data, tal como una disminución considerable de los efectos colaterales, o cuando la solución que se encuentra al problema origina una enorme ventaja en comparación con el estado de la técnica.

\section{B. Combinaciones}

Recomendación: las combinaciones de principios activos conocidos se deben considerar carentes de actividad inventiva. No obstante, si un nuevo efecto sinérgico no obvio se considera como base para la patentabilidad, éste deberá quedar adecuadamente demostrado mediante pruebas biológicas, y divulgado de manera apropiada en la memoria descriptiva de la patente.

\section{Dosificación/dosis}

Recomendación: las nuevas dosis para la misma indicación o para una diferente no constituyen invenciones, en particular - si bien no exclusivamente - en países en los que los métodos de tratamiento médico no son patentables como tal.

\section{Sales, éteres y ésteres}

Recomendación: las nuevas sales, ésteres y otras formas de productos farmacéuticos conocidos se pueden obtener generalmente mediante procedimientos comunes, y no son patentables. Esto puede no ser así si se demuestra, mediante pruebas llevadas a cabo y descritas de manera adecuada en la memoria descriptiva, la existencia de ventajas inesperadas (por ejemplo, un importante aumento en la eficacia) con respecto al arte previo. 
Esta obra forma parte del acervo de la Biblioteca Jurídica Virtual del Instituto de Investigaciones Jurídicas de la UNAM

\section{E. Polimorfos}

Recomendación: el polimorfismo es una propiedad inherente a la materia en su estado sólido. Los polimorfos no se crean, sino que se descubren. Las oficinas de patentes deben tomar conciencia de la posible ampliación injustificada del periodo de protección que surge del patentamiento sucesivo del principio activo y sus polimorfos, incluyendo hidratos/solvatos. Los procedimientos para obtener polimorfos pueden ser patentables en algunos casos, si demuestran ser novedosos y cumplen con el requisito de altura inventiva.

\section{F. Reivindicaciones tipo Markush}

Recomendación: las reivindicaciones que cubren un gran número de compuestos no se deberían permitir. Las oficinas de patentes deberían requerir a los solicitantes que brinden información suficiente acerca de las formas de realización de la invención para las que procuran obtener protección mediante parámetros tales como punto de fusión, espectro de absorción infrarroja (ir) y de resonancia magnética nuclear (NMR), los que deberían ser obtenidos con base en experimentaciones reales, para posibilitar su reproducción mediante el procedimiento divulgado. Se podrían otorgar reivindicaciones de alcance limitado si se comprueba fehacientemente que al realizar la sustitución de cualquier miembro de la familia por otro de su misma clase se obtiene un resultado igual al revelado en la memoria. El alcance de la patente estaría limitada a aquello que efectivamente se puede reproducir mediante lo divulgado en la memoria descriptiva.

\section{G. Patentes de selección}

Recomendación: como regla general, no se deben otorgar patentes de selección si los componentes seleccionados ya han sido revelados y, por lo tanto, carecen de novedad. Si se consideraran patentables las ventajas inesperadas de productos conocidos bajo el derecho vigente, se podría considerar la patentabilidad de una selección cuando esté presente un paso inventivo. 
Esta obra forma parte del acervo de la Biblioteca Jurídica Virtual del Instituto de Investigaciones Jurídicas de la UNAM

\section{H. Procedimientos análogos}

Recomendación: los procedimientos farmacéuticos no novedosos u obvios se deben considerar no patentables como tales, más allá de que los materiales de partida, los intermedios o el producto final sean novedosos o inventivos.

\section{Enantiómeros}

Recomendación: los enantiómeros individuales no deben considerarse patentables cuando la mezcla racémica se encuentra revelada. No obstante, podrán ser patentables los procesos para la obtención de enantiómeros individuales, si son novedosos y poseen actividad inventiva.

\section{J. Metabolitos activos y prodrogas}

Recomendación: en términos generales, los metabolitos activos de medicamentos no deben considerarse patentables en forma separada del principio activo del que derivan.

Las patentes sobre prodrogas, si se conceden, deben excluir de la reivindicación al principio activo como tal, si éste ya fue divulgado o si es no patentable. Como todo objeto reivindicado en una patente, una prodroga debe estar respaldada de manera suficiente por la información provista en la memoria descriptiva. Además, se podrá requerir evidencia de que la prodroga es inactiva o menos activa que el compuesto que será liberado, que la generación del compuesto activo (en el organismo) asegura un nivel eficaz de la droga que minimice el metabolismo directo de la prodroga, así como la gradual inactividad de la droga.

\section{K. Métodos de tratamiento}

Recomendación: los métodos de tratamiento, incluso los de prevención, diagnóstico o profilaxis, no deben considerarse patentables cuando la aplicación industrial es necesaria como requisito de patentabilidad (incluso en los casos en que la patentabilidad de dichos métodos no esté excluida de manera expresa). 
Esta obra forma parte del acervo de la Biblioteca Jurídica Virtual del Instituto de Investigaciones Jurídicas de la UNAM

\section{Reivindicaciones de uso, con inclusión de segundas indicaciones}

Recomendación: las reivindicaciones de uso, incluyendo la segunda indicación de un producto farmacéutico conocido, pueden ser denegadas, entre otras razones, por falta de novedad y aplicación industrial.

La OMS ha suspendido los talleres para examinadores de patentes probablemente porque muchos países han ya adoptado formalmente estas pautas, como es el caso de los países del Mercosur, o informalmente, como es el caso de Egipto, o se han inspirado en ellas para la elaboración de sus propias pautas, como fue el caso de la India, Ecuador y algunos otros. Actualmente el Centro Sur continúa prestando este tipo de apoyo a los países; el caso más reciente fue a través de la realización de seminarios en las cuatro oficinas de patentes de la India en Mumbai, Chennai, Kolkata y Nueva Delhi, en agosto de 2014.

\section{El caso de la India}

El 4 de abril de 2005, el presidente de la India dio su consentimiento a la enmienda de la Ley de Patentes. Esto puso en vigor la ley que debía llevar a la India al cumplimiento del Acuerdo sobre los ADPIC. India fue uno de los pocos países en desarrollo miembros de la OMC que habían optado por hacer uso de un periodo de transición de diez años (1995-2005) en virtud del Acuerdo sobre los ADPIC, para retrasar la introducción de las patentes de productos farmacéuticos.

Como el Acuerdo sobre los ADPIC no define los tres criterios de patentabilidad — novedad, actividad inventiva y aplicación industrial—, dejando un margen de flexibilidad para que los países definan e interpreten el significado de estos criterios, la nueva Ley de Patentes de la India contiene una serie de disposiciones que tratan de definir los criterios de patentabilidad, como sigue:

En primer lugar, una definición de "actividad inventiva" se proporciona como algo que "implica avance técnico en comparación con el conocimiento existente o tenga importancia económica o ambos, y que hace que la invención no es evidente para un experto en la materia". En segundo lugar, hay una disposición destinada a impedir la "perpetuación" de las patentes al no permitir que los simples descubrimientos de una nueva forma de una sustancia conocida que no resulte en la mejora de la eficacia conocida de esa sustancia, o el mero descubrimiento de una nueva propiedad o una nue- 
Esta obra forma parte del acervo de la Biblioteca Jurídica Virtual del Instituto de Investigaciones Jurídicas de la UNAM

va utilización de una sustancia conocida, o la mera utilización de un proceso conocido para ser patentable.

India, considerada la "farmacia del tercer mundo", tiene desde 2005 una legislación sobre la propiedad intelectual que, desde el punto de vista de la salud pública puede ser considerada como un modelo para otros países en desarrollo. Por primera vez, el 12 de marzo de 2012, la oficina de patentes de la India emitió una licencia obligatoria para la empresa local NactoPharma para un medicamento contra el cáncer: "Sorafenibtosylate" (nombre comercial "Nexabar") patentado por Bayer, creando así la posibilidad de obtener este producto a un menor costo con el fin de aumentar el acceso a las personas que necesitan este medicamento. Con el fin de justificar el alto precio de este medicamento (5,600 USD por paciente, por mes) Bayer intentó argumentar con el alto costo del desarrollo, aunque se negó a presentar cifras de la $\mathrm{I}+\mathrm{D}$ de este producto. ${ }^{63}$

Después de siete años de litigio, el gigante farmacéutico suizo Novartis perdió el caso ante el Tribunal Supremo de la India. El lunes 1o. de abril de 2013, el Tribunal rechazó la petición de patente para un costoso producto contra el cáncer con el nombre de marca Gleevec (o Glivec, dependiendo del país). Desde 2006, Novartis venía luchando en diferentes instancias jurídicas de la India para obtener la patente para el Gleevec. En 2006, y luego en 2009, India había rechazado la patente sobre la base de que no se trataba, según su Ley de Propiedad Intelectual, de un nuevo medicamento sino de una simple modificación de una molécula ya conocida. El medicamento simplemente no cumple con uno de los requisitos de patentabilidad, el de la novedad. No contento con el fallo, Novartis llevó el caso al Tribunal Supremo para combatir el artículo de la Ley de Propiedad Intelectual de la India conocido como la sección 3(d), artículo perfectamente consistente con las exigencias del Acuerdo sobre los ADPIC de la OMC.

Con cierto cinismo la firma suiza, dado que no le convenía la ley de la India, intentó cambiarla. Según MSF, citado por Le Monde del 1o. de abril de 2013, el precio del Glivec en la India es de 4,000 dólares por persona por mes (3,122 euros), cuando el de la versión genérica, el Imantinib, es de 73 dólares por persona por mes (57 euros). Ello en un país donde el $40 \%$ de la población vive con menos de 1.25 dólares ( 0.97 euros) al día.

Desde que el caso entró en el Tribunal Supremo para denunciar la Ley de Propiedad Intelectual, dejó de ser un litigio de Glivec contra la India y se

63 Velásquez, G., "India Compulsory License for Anti-Cancer Medicine", South Bulletin, núm. 62, mayo de 2012. 
Esta obra forma parte del acervo de la Biblioteca Jurídica Virtual del Instituto de Investigaciones Jurídicas de la UNAM

convirtió en el caso de la salud pública contra la gran industria farmacéutica. La India seguirá negándose a patentar pequeñas modificaciones (conocido con la expresión inglesa evergreening) y muchos países podrán seguir su ejemplo para permitir el acceso a medicamentos de las poblaciones sin recursos. El Glivec de Novartis está patentado en más de 40 países, incluidos los Estados Unidos, Rusia y China. El artículo ya citado del periódico Le Monde menciona que se trata del medicamento más vendido de Novartis, con ventas en 2012 por un valor de 4,600 millones de dólares (3,590 millones de euros).

La industria de genéricos de la India podrá seguir fabricando y exportando éste y muchos otros medicamentos a precios a los que las personas o los sistemas de salud de muchos países podrán tener acceso. ${ }^{64}$

Actualmente, en septiembre de 2014, la oficina de patentes de la India está concluyendo el proceso de revisión de las pautas para el examen de productos farmacéuticos, que se espera serán aprobadas antes del final de 2014. Como ya se mencionó, existen varios elementos en común o similares entre las pautas propuestas por la OMS y las pautas que la India está finalizando actualmente.

\section{Experiencias en la implementación de pautas para el examen} de patentes farmacéuticas

\section{A. Argentina}

Haciendo uso del margen de maniobra existente en el Acuerdo de los ADPIC en cuanto a la definición de los criterios de patentabilidad, el ministro de Salud, la ministra de Industria y el presidente del INPI dictaron el 2 de mayo de 2012 la resolución conjunta MI 118/2012, MS 546/2012, e INPI 107/2012, mediante la cual aprobaron las Pautas para el Examen de Patentabilidad de las Solicitudes de Patentes sobre Invenciones Químico-Farmacéuticas. Las Pautas se aplican a todas las solicitudes de patentes en trámite a la fecha de su entrada en vigor.

Las Pautas no agregan nuevos requisitos de patentabilidad. Las patentes se conceden o deniegan sobre la base de aplicar a cada solicitud los requisitos de patentabilidad previstos en la ley de patentes: novedad, actividad inventiva y

64 Velásquez, G., "David contra Goliat", El País, España, visible en: http://sociedad.elpais. com/sociedad/2013/04/01/actualidad/1364824227_627519.html. 
Esta obra forma parte del acervo de la Biblioteca Jurídica Virtual del Instituto de Investigaciones Jurídicas de la UNAM

aplicación industrial; como así también las normas atinentes a qué son consideradas invenciones y cuáles invenciones está excluidas de la patentabilidad de acuerdo a aquella ley. ${ }^{65}$

\section{B. Mercosur}

En la misma línea, los ministros de salud del Mercado Común del Sur (Mercosur) señalaron, en ocasión de la XXVII Reunión de Ministros celebrada en la ciudad de Montevideo, el 4 de diciembre de 2009, que la coincidencia de objetivos entre las políticas públicas y el sistema de propiedad intelectual, en particular del cumplimiento y aplicación de los criterios de patentabilidad en la región, despierta preocupación debido a la proliferación de solicitudes de patentes sobre materias que no constituyen propiamente una invención o son desarrollos marginales.

En consecuencia, los ministros acordaron en dicha oportunidad promover en el Mercosur la adopción de criterios que protejan la salud pública en las pautas o guías de patentabilidad.

\section{GOMPatibilidad GON EL AGUERdo ADPIC DE LA OMG}

Durante el IV Examen de Políticas Comerciales de Argentina en la Organización Mundial del Comercio (OMC) relativo al periodo 2006-2011, realizado en marzo de 2013, varios países hicieron preguntas en relación con las Pautas para el examen de patentes farmacéuticas adoptadas en Argentina en 2012.

Durante el examen de políticas comerciales mencionado, Japón, Estados Unidos, Suiza, Canadá y la Unión Europea hicieron preguntas y cuestionamientos muy detallados sobre si las nuevas pautas permitían el patentamiento de composiciones, dosis, ésteres y éteres, polimorfos, procesos análogos, metabolitos activos y pro fármacos, enantiomeros, patentes de selección y reivindicaciones tipo Markush. Los Estados Unidos preguntaron específicamente si la nueva regulación añadía nuevos criterios de patentabilidad más allá de la novedad, la actividad inventiva y la aplicación industrial.

Es evidente que las pautas no añaden nuevos criterios de patentabilidad y sólo hacen uso del margen dejado por el Acuerdo sobre los ADPIC en la definición e interpretación de los criterios de patentabilidad.

65 Arias, Eduardo, Pautas..., cit. 
Esta obra forma parte del acervo de la Biblioteca Jurídica Virtual del Instituto de Investigaciones Jurídicas de la UNAM

Dos países en desarrollo, Chile y Costa Rica, expresaron interés por el establecimiento por parte de Argentina de pautas en esta materia.

Basada en lo estipulado en el Acuerdo de los ADPIC, la respuesta de Argentina a las largas y detalladas preguntas de los países mencionados se limitó a afirmar que las interrogantes relacionadas con las Pautas para el examen de productos farmacéuticos no eran objeto del examen de políticas comerciales de Argentina, por no ser éstas una exigencia del Acuerdo sobre los ADPIC.

\section{CONCLUSIONES}

Las políticas nacionales de medicamentos, incluídos los asuntos relacionados con la propiedad intelectual, son elementos fundamentales de una política nacional de salud que pretenda proteger el derecho de acceso de todos los ciudadanos a la atención sanitaria.

Para desarrollar nuevos medicamentos se deben establecer mecanismos que promuevan la innovación y el desarrollo de productos, y al mismo tiempo asegurar que los pacientes puedan acceder rápidamente a los frutos de esa investigación. En el contexto de los medicamentos esenciales, la innovación debe estar estructuralmente ligada al acceso. Esto quiere decir que el costo de la investigación y el precio final del producto deben estar desligados.

Los efectos de la introducción de patentes farmacéuticas en el acceso a medicamentos dependen, en gran parte, de la forma en que se interprete e implemente el Acuerdo sobre los ADPIC. Es por ello de particular importancia que al incorporar las exigencias del Acuerdo de los ADPIC los países consideren, entre otras, las siguientes medidas:

a) La incorporación de las exigencias del Acuerdo de los ADPIC en la legislación nacional de propiedad intelectual deberá tener en cuenta los principios de los artículos 7o. y 8o., de modo de regular la propiedad intelectual de forma compatible con los intereses de la salud pública y minimizando los costos económicos y sociales que los cambios pueden acarrear sobre la producción, comercio y acceso a los medicamentos. Estos principios fueron ratificados por la Declaración de Doha (2001) sobre la Propiedad Intelectual y la Salud Pública.

b) Definir los tres criterios de patentabilidad - novedad, espíritu inventivo y aplicación industrial (utilidad) - de una manera coherente con los objetivos de salud pública. 
c) Instrumentar en la legislación nacional los mecanismos para otorgar licencias obligatorias permitidas por el Acuerdo.

d) Asegurar la importación de productos puestos en el mercado legítimamente, bajo el principio de agotamiento internacional.

e) Excluir de la patentabilidad (por no reunir los requisitos constitutivos de una "invención") las sustancias existentes en la naturaleza.

f) Limitar la inversión de la carga de la prueba a patentes de procesos relativos a entidades químicas nuevas.

Las oficinas nacionales de propiedad intelectual, a través del examen de patentes, juegan un papel importante en el acceso a los medicamentos. Los criterios y estándares para el patentamiento de bienes públicos deben ser diferentes al de simples mercancías o artículos de lujo. Con este fin, el primero y más importante paso es el de utilizar la libertad permitida por el Acuerdo sobre los ADPIC para definir los criterios de patentabilidad: novedad, espíritu inventivo y aplicación industrial — utilidad-, de manera que no se pierda de vista el interés público y la amplia diseminación del conocimiento. 66

Los países pueden interpretar los criterios para evaluar las solicitudes de patentes de manera concordante con sus políticas públicas. Los regímenes de dotación de patentes son, por lo general, parte de las estrategias tecnológicas e industriales nacionales, pero también es fundamental que se diseñen de manera congruente con las estrategias de salud pública. En particular, es importante que el alcance de la patentabilidad guarde coherencia con las políticas de salud pública, y que los gobiernos tengan conciencia de que la indebida expansión de la patentabilidad puede distorsionar la competencia y reducir el acceso a los medicamentos. Las patentes sobre desarrollos menores se pueden utilizar, efectivamente, para desalentar u obstaculizar la competencia, dado que los productores de genéricos, los agentes de compra y los consumidores, particularmente en los países en desarrollo, por lo general carecen de recursos financieros y técnicos esenciales para oponerse a patentes otorgadas incorrectamente o para defenderse frente a reclamos por infracciones.

El análisis y los criterios manifestados en las Pautas para el examen de patentes $^{67}$ tienen el propósito de brindar una orientación general para las oficinas de patentes y otros organismos que participan en el examen de patentes farmacéuticas, de manera tal que dicho examen sea concordante con

66 The Impact..., cit., para. 62.

67 Correa, C., Pautas..., cit. 
Esta obra forma parte del acervo de la Biblioteca Jurídica Virtual del Instituto de Investigaciones Jurídicas de la UNAM

la legislación de patentes y a la vez congruente con los objetivos de salud pública, en particular, con el derecho de todos de acceder a los medicamentos. Dichas pautas deben ser posteriormente perfeccionadas y ajustadas a la legislación nacional, según corresponda.

Como se ha analizado anteriormente, si se implementan dichas Pautas, es improbable que los siguientes tipos de solicitudes de patentes de producto sean admisibles por una oficina de patente nacional:

a) Una nueva sal, éster, éter o polimorfo, incluyendo hidratos y solvatos, de una entidad química existente.

b) Un enantiómero individual de una entidad química existente.

c) Una nueva combinación de dos o más principios activos que ya están disponibles como entidades individuales.

d) Una nueva forma de administración que permita una nueva ruta de administración (por ejemplo, una forma inyectable cuando ya existe un comprimido oral).

e) Una forma de administración de liberación controlada cuando ya existe una forma de administración de liberación no controlada.

f) Una nueva ruta de una forma de administración existente (por ejemplo, la administración por vía intravenosa de un fármaco cuando ya está aprobada su administración por vía subcutánea).

g) Un cambio en la formulación.

Un requisito indispensable para abordar el tema de las solicitudes de patentes desde una perspectiva de salud pública es, necesariamente, capacitar de forma adecuada y retener en las oficinas de patentes a los examinadores calificados. La capacitación suministrada por las oficinas de patentes de países desarrollados puede aumentar los conocimientos técnicos de los examinadores, pero también puede transmitir estándares de evaluación que conduzcan a una indebida expansión del alcance de la patentabilidad de los productos farmacéuticos.

Finalmente, los examinadores de patentes deben ser conscientes de que las decisiones que toman, aunque parezcan de naturaleza técnica, pueden tener consecuencias muy concretas sobre la vida y salud de la gente, ya que patentes otorgadas de manera incorrecta pueden ser utilizadas para limitar indebidamente la competencia y restringir el acceso a medicamentos necesarios. 
Esta obra forma parte del acervo de la Biblioteca Jurídica Virtual del Instituto de Investigaciones Jurídicas de la UNAM

\section{ANEXO \\ Resoluciones de la Asamblea Mundial de la Salud que se refieren a la propiedad intelectual 68}

1996 WHA49.14: Revised drug strategy.

1999 WHA52.19: Revised drug strategy.

2000 WHA53.14: HIV/AIDS: confronting the epidemic.

2001 WHA54.10: Scaling up the response to HIV/AIDS.

2001 WHA54.11: WHO medicines strategy.

2002 WHA55.14: Ensuring accessibility of essential medicines.

2003 WHA56.27: Intellectual property rights, innovation and public health. 2003 WHA56.30: Global health sector strategy for HIV/AIDS.

2004 WHA57.14: Scaling up treatment and care within a coordinated and comprehensive response to HIV/AIDS.

2006 WHA59.24: Public health, innovation, essential health research and intellectual property rights: towards a global strategy and plan of action. 2006 WHA59.26: International trade and health.

2007 WHA60.30: Public health, innovation and intellectual property.

2008 WHA61.21: Global strategy and plan of action on public health, innovation and intellectual property.

2009 WHA62.16: Global strategy and plan of action on public health, innovation and intellectual property.

2011 WHA64.5: Pandemic influenza preparedness: sharing of influenza viruses and access to vaccines and other benefits.

2011 WHA64.14: Global health sector strategy on HIV/AIDS, 2011-2015. 2012 WHA65.22: Follow up of the report of the Consultative Expert Working Group on Research and Development: Financing and Coordination.

68 Las publicaciones de la OMS sobre propiedad intelectual y salud pública pueden consultarse en: Velásquez, Germán, Algunas cuestiones clave relacionadas con el acceso a los medicamentos y la propiedad intelectual, Valencia, Centro Sur-Farmamundo, 2014, serie Contextos Farmamundo, vol. 5, pp. 42-45. 
Esta obra forma parte del acervo de la Biblioteca Jurídica Virtual del Instituto de Investigaciones Jurídicas de la UNAM

\title{
LA VINGULAGIÓN ENTRE PATENTES Y REGISTROS SANITARIOS EN MÉXICO
}

\author{
Gustavo Alcaraz H.
}

SUMARIO: I. Introducción al tema y planteamiento del problema. II. El procedimiento. III. El origen de la figura de la vinculación y su relación con la Gaceta de medicamentos en la experiencia mexicana. IV. Conclusiones. V. Propuestas. VI. Fuentes.

\section{INTRODUCGIÓN AL TEMA Y PLANTEAMIENTO DEL PROBLEMA}

El trámite de registro sanitario ${ }^{1}$ de un medicamento alopático ${ }^{2}$ es el acto administrativo por medio del cual un solicitante se presenta ante la Comisión Federal para la Protección contra Riesgos Sanitarios (en adelante Cofepris) ${ }^{3}$

1 Los medicamentos requieren de este registro sanitario de conformidad con el artículo 376 de la Ley General de Salud, que establece: "Requieren registro sanitario los medicamentos...".

2 "Medicamento alopático, [es] toda sustancia o mezcla de sustancias de origen natural o sintético que tenga efecto terapéutico, preventivo o rehabilitatorio, que se presente en forma farmacéutica y se identifique como tal por su actividad farmacológica, características físicas, químicas y biológicas, y se encuentre registrado en la Farmacopea de los Estados Unidos Mexicanos para medicamentos alopáticos", de conformidad con la Norma Oficial Mexicana NOM-072-SSA1-2012, Etiquetado de medicamentos y remedios herbolarios, fracción 4.1 Definiciones, punto 21, publicado en el Diario Oficial de la Federación el 21 de noviembre de 2012.

3 Autoridad sanitaria facultada para expedir tales autorizaciones de conformidad con los artículos 3o. fracciones I y VII, del Reglamento de la Comisión Federal para la Protección contra Riesgos Sanitarios y 1o. del Reglamento de la Comisión Federal para la Protección contra Riesgos Sanitarios, que establece que:

“...la Comisión Federal para la Protección contra Riesgos Sanitarios, como órgano administrativo desconcentrado de la Secretaría de Salud, con autonomía técnica, administrativa y operativa que tiene a su cargo el ejercicio de las atribuciones en materia de regulación, 
Esta obra forma parte del acervo de la Biblioteca Jurídica Virtual del Instituto de Investigaciones Jurídicas de la UNAM

con un formato oficial que es acompañado de toda la información ${ }^{4}$ relativa al producto (medicamento) sobre el cual se desea obtener dicho registro. ${ }^{5}$ Solamente obteniendo el referido registro sanitario, el solicitante podrá comercializar su producto en el territorio nacional.

Así, la labor de la Cofepris con respecto a la expedición de registros sanitarios de medicamentos alopáticos se torna fundamental para el derecho a la salud, pues Cofepris es la autoridad facultada para verificar que los medicamentos que se comercializarán en el mercado mexicano sean seguros para el tratamiento de los padecimientos o enfermedades que aquejan a la población mexicana, garantizando su eficacia y verificando que no pongan en riesgo ni la integridad física ni la salud de los consumidores.

Es importante comprender desde ahora la naturaleza y atribuciones jurídicas de la Cofepris, autoridad ante la cual el particular realiza la solicitud de registro sanitario de medicamento alopático, para posteriormente analizar la trascendencia de la vinculación entre los registros sanitarios otorgados por esta autoridad y las patentes farmacéuticas otorgadas a otros particulares por otra autoridad, que es el Instituto Mexicano de la Propiedad Industrial (en adelante IMPI), relación conocida como vinculación o también como linkage.

En México, el derecho a la salud se encuentra consagrado en el artículo 4o., párrafo cuarto, de la Constitución Política de los Estados Unidos Mexicanos, que señala que:

Toda persona tiene derecho a la protección de la salud. La ley definirá las bases y modalidades para el acceso a los servicios de salud y establecerá la concurrencia de la Federación y las entidades federativas en materia de salubridad general, conforme a lo que dispone la fracción XVI del artículo 73 de esta Constitución (Adicionado mediante decreto publicado en el Diario Oficial de la Federación el 3 de febrero de 1983). ${ }^{6}$

control y fomento sanitarios en los términos de la Ley General de Salud y demás disposiciones aplicables".

4 Aparte de la solicitud, se presenta el pago de derechos, copia simple de licencia sanitaria, información sobre el acondicionador (en su caso), copia simple de responsable sanitario, copia de aviso de responsable sanitario, copia simple de contrato de maquila (en su caso), proyecto de membretes, proyecto de prescripción en forma amplia y reducida, certificado de buenas prácticas de fabricación del medicamento original de la patente en hoja membretada (en su caso), información del fármaco, sobre su fabricación, calidad y estabilidad, documentación sobre biodisponibilidad y bioequivalencia del mismo, por citar algunos ejemplos.

5 Ley General de Salud: "Artículo 368. Las autorizaciones sanitarias tendrán el carácter de... registros...".

6 Artículo 4o. constitucional recuperado de http://info4.juridicas.unam.mx/ijure/fed/9/5. htm?'s (última fecha de consulta: 8 de noviembre de 2014). Las cursivas fueron añadidas. 
Esta obra forma parte del acervo de la Biblioteca Jurídica Virtual del Instituto de Investigaciones Jurídicas de la UNAM

La fracción XVI del artículo 73, mencionado en el artículo 4o. constitucional, establece que: el Congreso de la Unión es el facultado para dictar leyes en materia de salubridad. ${ }^{7}$

En este orden de ideas y en el ámbito de la administración pública del Poder Ejecutivo Federal, se establece por medio del artículo 26 de la Ley Orgánica de la Administración Pública Federal que el despacho de los asuntos en materia de salud compete a la Secretaría de Salud. ${ }^{8}$ Así, el Congreso de la Unión, de conformidad con el artículo 73, fracción XVI antes referida, decretó la Ley General de Salud, que es la norma específica reglamentaria del artículo 4o. constitucional ${ }^{9}$ por medio de la cual la Secretaría de Salud adquirió sus facultades.

En virtud de la Ley General de Salud (artículo 17 bis, primer párrafo), la Secretaría de Salud encarga a su vez el ejercicio de las atribuciones de regulación, control y fomento sanitario a la Cofepris. ${ }^{10}$

De acuerdo con el mismo artículo 17 bis, párrafo segundo, de la Ley General de Salud, compete a la Cofepris, entre otras cosas: ${ }^{11}$

IV. Evaluar, expedir o revocar autorizaciones que en las materias de su competencia se requieren, así como aquellos actos de autoridad que para la regulación, control y el fomento sanitario se establecen o deriven de esta Ley; sus reglamentos, las normas oficiales mexicanas y demás ordenamientos aplicables. ${ }^{12}$

7 El artículo 73 establece las facultades del Congreso, y su fracción XVI señala: "XVI. Para dictar leyes sobre nacionalidad, condición jurídica de los extranjeros, ciudadanía, naturalización, colonización, emigración e inmigración y salubridad general de la República". Recuperado de la Constitución Política de los Estados Unidos Mexicanos en línea en la página oficial del Instituto de Investigaciones Jurídicas de la UNAM, disponible en: http://info 4 . juridicas.unam.mx/juslab/leylab/250/74.htm (última fecha de consulta: 7 de noviembre de 2014).

8 Véase el artículo 26 de la Ley Orgánica de la Administración Pública Federal.

9 Véase el artículo 1o. de Ley General de Salud.

10 Artículo 17 bis de la Ley General de Salud: "La Secretaría de Salud ejercerá las atribuciones de regulación, control y fomento sanitarios que conforme a la presente Ley, a la Ley Orgánica de la Administración Pública Federal, y los demás ordenamientos aplicables le corresponden a dicha dependencia en las materias a que se refiere el artículo 3o. de esta Ley en sus fracciones I, en lo relativo al control y vigilancia de los establecimientos de salud a los que se refieren los artículos 34 y 35 de esta Ley; XIII, XIV, XXII, XXIV, XXV, XXVI, ésta salvo por lo que se refiere a cadáveres y XXVII, esta última salvo por lo que se refiere a personas, a través de un órgano desconcentrado que se denominará Comisión Federal para la Protección contra Riesgos Sanitarios".

11 Atribuciones, funciones y características de la Cofepris, recuperado de la página oficial de la Cofepris, visible en: http://wrwre.cofepris.gob.mx/cofepris/Paginas/AtribucionesFuncionesYCaracteristicas.aspx (última fecha de consulta: 9 de noviembre de 2014).

12 Artículo 17 bis de la Ley General de Salud. Las cursivas fueron añadidas. 
Esta obra forma parte del acervo de la Biblioteca Jurídica Virtual del Instituto de Investigaciones Jurídicas de la UNAM

Para cumplir cabalmente con su encargo, el 13 de abril de 2004 se publicó en el Diario Oficial de la Federación el Reglamento de la Cofepris, en cuyo artículo 3o., fracción VII, se replican casi íntegramente las competencias asignadas a Cofepris en materia de autorizaciones sanitaras establecidas en el artículo 17 bis, párrafo segundo, de la Ley General de Salud:

VII. Emitir, prorrogar o revocar las autorizaciones sanitarias en las materias de su competencia, así como ejercer aquellos actos de autoridad para la regulación, control y fomento sanitarios que se establecen o deriven de la Ley y sus reglamentos, las normas oficiales mexicanas, el presente Reglamento y las demás disposiciones aplicables. ${ }^{13}$

Así, por medio de su Reglamento, la Cofepris es la única autoridad administrativa facultada para verificar la aplicación de medidas de seguridad y mejora continua de las condiciones sanitarias de procesos, productos, métodos, instalaciones, servicios y actividades que pudieran representar un riesgo a la salud de la población mexicana, ${ }^{14}$ es decir, responsable del fomento sanitario.

Dentro del denominado "fomento sanitario" a cargo de la Cofepris se encuentra en específico el control sanitario de los insumos, entendiéndose por éstos a los medicamentos, además de las materias primas y aditivos que intervengan para su elaboración de acuerdo con la propia Ley General de Salud, artículo 194 bis. ${ }^{15}$

Por su parte, el "control sanitario", de conformidad con el Reglamento de la misma Cofepris, se define como "[e]l conjunto de acciones de orientación, educación, muestreo, verificación y, en su caso, aplicación de medidas de seguridad y sanciones que ejerce la Secretaría de Salud con la participación de los productores, comercializadores y consumidores". ${ }^{16}$ Dentro de las actividades de control sanitario a cargo de la Cofepris se encuentra la verifica-

13 Artículo 3o., fracción VII, del Reglamento de la Comisión Federal para la Protección contra Riesgos Sanitarios, Diario Oficial de la Federación, 13 de abril de 2004. Las cursivas fueron añadidas.

14 Véanse los artículos 1o. a 3o. del Reglamento de la Comisión Federal para la Protección contra Riesgos Sanitarios.

15 "Para los efectos de esta ley se consideran insumos para la salud: los medicamentos, substancias psicotrópicas, estupefacientes y las materias primas y aditivos que intervengan para su elaboración; así como os equipos médicos, prótesis, órtesis, ayudas funcionales, agentes de diagnóstico, insumos de uso odontológico, material quirúrgico, de curación, y productos higiénicos, estos últimos en los términos de la fracción VI del artículo 262 de esta ley".

16 Artículo 2o., fracción II, del Reglamento de la Comisión Federal para la Protección contra Riesgos Sanitarios. Las cursivas fueron añadidas. 
Esta obra forma parte del acervo de la Biblioteca Jurídica Virtual del Instituto de Investigaciones Jurídicas de la UNAM

ción de las medidas de seguridad en la fabricación y comercialización de los medicamentos, materias primas y aditivos.

A su vez, el Reglamento de Insumos para la Salud (en adelante RIS) es el ordenamiento jurídico que establece de forma detallada, en su capítulo III, lo relativo al trámite de los registros sanitarios de medicamentos alopáticos que expide la Secretaría de Salud a través de la Cofepris. De conformidad con su artículo 167, se solicita al particular que desee tramitar el registro sanitario a fin de comercializar algún medicamento alopático en el mercado mexicano, que presente:

I. Información técnica y científica que demuestre:

a. La identidad y pureza de sus componentes de acuerdo con lo que establece la Farmacopea de los Estados Unidos Mexicanos y sus suplementos.

b. La estabilidad del producto terminado conforme a las normas correspondientes.

c. La eficacia terapéutica y seguridad de acuerdo con la información científica que corresponda.

II. La información para prescribir, en sus versiones amplia y reducida.

III. El proyecto de etiqueta.

IV. Lo señalado en el artículo 167-bis de este Reglamento.

V. Para medicamentos genéricos, en lugar de lo indicado en el inciso $c$ de la fracción I, el informe de pruebas de intercambiabilidad de acuerdo a las normas correspondientes y demás disposiciones aplicables, y

VI. Identificación del origen y certificado de buenas prácticas de fabricación del fármaco expedido por la Secretaría o por la autoridad competente del país de origen.

Como se puede observar, se ha resaltado en cursivas la fracción IV, atendiendo a que el 19 de septiembre de 2003 el entonces presidente Vicente Fox Quesada publicó un decreto mediante el cual se modificó el capítulo III, "Registros", del RIS, para añadir la fracción IV al artículo 167.17

El artículo 167-bis del RIS textualmente señala:

Artículo 167-bis. El solicitante del registro de un medicamento alopático deberá anexar a la solicitud la documentación que demuestre que es el titular de la patente de la sustancia o ingrediente activo o que cuenta con la licencia correspondiente, ambas inscritas en el Instituto Mexicano de la Propiedad Industrial.

17 Véase el Decreto por el que se reforma el Reglamento de Insumos para la Salud y el Reglamento de la Ley de la Propiedad Industrial, publicado en el Diario Oficial de la Federación el 19 de septiembre de 2003. Las cursivas son propias. 
Esta obra forma parte del acervo de la Biblioteca Jurídica Virtual del Instituto de Investigaciones Jurídicas de la UNAM

Alternativamente, y de acuerdo con el listado de productos establecidos en el artículo 47 bis del Reglamento de la Ley de Propiedad Industrial, ${ }^{18}$ podrá manifestar, bajo protesta de decir verdad, que cumple con las disposiciones aplicables en materia de patentes respecto a la sustancia o ingrediente activo objeto de la solicitud. En este supuesto, la Secretaría pedirá de inmediato la cooperación técnica del Instituto Mexicano de la Propiedad Industrial para que dentro de su ámbito de competencia, éste determine a más tardar dentro de los diez días hábiles posteriores a la recepción de la petición, si se invaden derechos de patente vigentes. ${ }^{19}$

De esta manera se incluyó como "atribución"20 de Cofepris verificar que al realizar sus funciones y otorgar algún registro sanitario de medicamento alopático al solicitante, éste no vulneraría algún derecho otorgado con anterioridad por el IMPI, el cual tiene por objeto el fomento y protección de los derechos de propiedad industrial, en particular para el caso que se estudia: la protección a patentes vigentes de medicamentos.

A partir de ese momento la autoridad sanitaria se vio obligada a solicitar la ayuda técnica del IMPI para cerciorarse de que el registro sanitario de medicamento alopático que le fuera solicitado por un particular, no invadiera los derechos concedidos a otro que fuera el titular de una patente vigente,,$^{21} \mathrm{O}$

18 "Artículo 47 bis. Tratándose de patentes otorgadas a medicamentos alopáticos, el Instituto publicará en la Gaceta, y pondrá a disposición del público un listado de productos que deban ser objeto de protección industrial de acuerdo con la sustancia o ingrediente activo, el cual precisará la vigencia de la patente respectiva.

Este listado contendrá la correspondencia entre la denominación genérica e identidad farmacéutica de la sustancia o ingrediente activo y su nomenclatura o forma de identificación en la patente, la cual deberá realizarse conforme al nombre reconocido internacionalmente.

El listado a que se refiere este artículo no contendrá patentes que protejan procesos de producción o de formulación de medicamentos.

En caso de existir controversia respecto de la titularidad de la patente de la sustancia o principio activo, los interesados podrán someterse, de común acuerdo, a un arbitraje, en los términos de la legislación mercantil".

Artículo adicionado al Reglamento de Propiedad Industrial, Diario Oficial de la Federación del 19 de noviembre de 2003. Las cursivas son propias.

19 Decreto por el que se reforma el Reglamento de Insumos para la Salud y el Reglamento de la Ley de la Propiedad Industrial. Las cursivas fueron añadidas.

20 En realidad, el Decreto por el que se reforma el Reglamento de Insumos para la Salud y el Reglamento de la Ley de la Propiedad Industrial, publicado en el Diario Oficial de la Federación el 19 de septiembre de 2003, no especifica si esta comunicación entre autoridades administrativas es una facultad, una obligación, un derecho o un simple deber de consulta técnica a cargo de la Cofepris.

21 "Dado que las patentes confieren derechos exclusivos sobre la producción, venta y uso de la materia patentada, se pueden utilizar para limitar la competencia y fijar precios más elevados que los que existirían, de contarse con productos competitivos. Éste es el verdadero 
Esta obra forma parte del acervo de la Biblioteca Jurídica Virtual del Instituto de Investigaciones Jurídicas de la UNAM

bien, beneficiario de una licencia de explotación de alguna patente relacionada con el registro sanitario que se estuviera tramitando, según fuera el caso.

La reforma del 19 de septiembre de 2003, que modificó el capítulo III, "Registros", del RIS, añadiéndole la fracción IV al artículo 167 y el consecuente artículo 167-bis, causó polémica desde un principio, pues se consideró por parte de algunos fabricantes nacionales de medicamentos que desnaturalizaba el trámite de registro sanitario, ya que se estaba introduciendo una figura en la normatividad reglamentaria, en franca violación al artículo 89 constitucional, ${ }^{22}$ que establece que las facultades y obligaciones del presidente son entre otras "promulgar y ejecutar las leyes que expida el Congreso de la Unión, proveyendo en la esfera administrativa a su exacta observancia". ${ }^{23}$ Es decir que el decreto presidencial excedió las facultades otorgadas al presidente en materia de salud, ya que para que se pudieran incluir nuevas facultades a la Cofepris se debieron de incorporar a la Ley General de Salud por medio de la labor legislativa a cargo del Congreso de la Unión, que de acuerdo con el artículo 4o. constitucional y la fracción XVI del artículo 73 de la misma Constitución, es el único facultado para dictar leyes en materia de salubridad.

De este modo y por medio de un decreto presidencial se inició desde entonces la vinculación o linkage entre registros sanitarios otorgados por la Cofepris y las patentes otorgadas por el IMPI. Se diseñó un formato de consulta ex professo para que la autoridad patentaria auxiliara a la autoridad sanitaria para identificar si un registro sanitario solicitado por un tercero debiera ser negado cuando el principio activo del medicamento se encontrara patentado y la patente correspondiente se encontrara vigente.

Es importante resaltar que el artículo 167-bis del RIS menciona específicamente la vinculación o linkage entre el registro sanitario y las patentes de sustancia o ingrediente activo y no deja abierta la posibilidad de tomar en consideración otras patentes, como podrían ser las de uso, proceso o de compuesto, por mencionar algunas otras.

La normatividad complementaria de este proceso la constituyó la inclusión en 2003 del artículo 47 bis al Reglamento de la Ley de Propiedad Industrial, en el que se dispuso que tratándose de patentes otorgadas a me-

propósito del sistema de patentes, cuya existencia usualmente se justifica como necesaria para incentivar las inversiones en el desarrollo de nuevos productos y procedimientos". Correa, Carlos, Pautas para el examen de patentes farmacéuticas. Una perspectiva desde la salud pública, Ginebra, International Centre for Trade and Sustainabke Development (ICTSD), 2006, p. 1.

22 Vinculación de los artículos 167 y 167-bis del Reglamento de Insumos para la Salud, y 47 del Reglamento de la Propiedad Industrial en México, julio de 2007.

23 Constitución Política de los Estados Unidos Mexicanos. Las cursivas fueron añadidas. 
Esta obra forma parte del acervo de la Biblioteca Jurídica Virtual del Instituto de Investigaciones Jurídicas de la UNAM

dicamentos alopáticos, el IMPI publicaría una Gaceta de medicamentos que se pondría a disposición del público. De esta manera, los solicitantes de registros de medicamentos alopáticos podrían consultar el listado de productos que eran susceptibles de protección de acuerdo a la sustancia o ingrediente activo; habría la precisión respecto a la vigencia de la patente respectiva, y sería más sencillo establecer la vinculación a los registros sanitarios solicitados. En esta Gaceta se dejarían fuera las patentes de procesos de producción o de formulación de medicamentos y todo ello aportaría certeza jurídica a las partes involucradas. ${ }^{24}$

Así surgió la publicación de patentes vigentes de medicamentos que ha resultado en la práctica un intento insuficiente de consulta para la Cofepris a efecto de constatar si una solicitud de medicamento se encuentra protegido por patente de principio activo, en virtud de que dicha gaceta súbitamente tuvo que incluir por resoluciones judiciales no solamente patentes de principio activo, sino también aquellas de formulación o composición farmacéutica; combinaciones; dosificación/dosis; sales, éteres y ésteres; polimorfos; reivindicaciones tipo Markush; de selección de un segmento o grupo de elementos; de proceso o procedimientos; metabolitos activos y prodrogas; métodos de tratamiento, y reivindicaciones de uso, e inclusive de dispositivos médicos para la aplicación de medicamentos.

Uno de los principales problemas que presenta la vinculación es que si bien el artículo 167-bis del RIS establece que el solicitante de un registro sanitario debe anexar a la solicitud la documentación que demuestre que es el titular de la "patente de la sustancia o ingrediente activo o que cuenta con la licencia correspondiente", esto ha sido interpretado de distintas maneras, lo cual ha ocasionado retrasos en el otorgamiento, e incluso la negación, de los registros sanitarios a los particulares al no reparar en la pluralidad de reivindicaciones de patentes de medicamentos existentes y que no todas las reivindicaciones de patentes deben ser consideradas para establecer el linkage o vinculación.

Por su parte, el particular que desea conocer la protección patentaria de medicamentos se encontrará en graves problemas, toda vez que hallará que el IMPI las publica en dos gacetas, la primera de ellas en la publicación de solicitudes de patentes, que tiene su fundamento en la LPI y se edita mensualmente respecto a solicitudes de patentes sin importar la materia, y la segunda con fundamento en el artículo 47-bis del Reglamento de la Ley de Propiedad Industrial, que se circunscribe a "medicamentos" y se publica semestralmente sin sustento alguno en la LPI, y que no lista solamente medicamentos.

\footnotetext{
24 Véase el artículo 47 bis del Reglamento de la Ley de Propiedad Industrial.
} 
Esta obra forma parte del acervo de la Biblioteca Jurídica Virtual del Instituto de Investigaciones Jurídicas de la UNAM

\section{EL PROCEDIMIENTO}

La vinculación, como se ha venido mencionando, es la relación que existe entre el registro sanitario que pudiera obtener un solicitante que pretende incorporar un medicamento alopático al mercado y la posible colisión de este registro con los derechos del titular de una patente de medicamento vigente (distinto al solicitante del registro) que hubiera obtenido la patente otorgada por el IMPI.

Así, una vez que el solicitante somete la información sobre el medicamento alopático del cual se solicita el registro a la autoridad sanitaria, ésta realiza la consulta técnica al IMPI para que realice el análisis sobre el estado de las patentes en torno al medicamento sobre el cual se pretende obtener el registro sanitario en la Cofepris. El particular desconoce la fecha de solicitud de información y si entre las citadas autoridades existe un diálogo posterior que permita a la autoridad patentaria ahondar y conocer más información sobre el producto que se le somete a consulta, además de aquellos datos que se plasman en el formato de consulta.

Es de resaltar la exclusión de los particulares en el referido procedimiento de vinculación, participación que por el contrario debiera ser un papel preponderante en dicha consulta, toda vez que la resolución que derive de la misma les podrá causar perjuicio a los particulares, ya se trate del solicitante de registro sanitario, ya se trate del titular de patente, y en tal caso, los gobernados se encuentran ante la imposibilidad jurídica de manifestar lo que a su derecho corresponda, colocándolos en total estado de indefensión, lo que resulta ilegal.

En efecto, el Formato de consulta intragubernamental sobre patentes de medicamentos alopáticos Cofepris-IMPI25 que se utiliza entre autoridades es base para que la autoridad patentaria determine la posible vulneración o no de alguna patente y el consecuente otorgamiento o negación del registro sanitario por parte de la Cofepris a los particulares que lo han solicitado.

Sin embargo, el solicitante del registro sanitario de medicamento alopático no participa ni valida o emite opinión o comentario alguno respecto

25 Véase el formato referido en http://wwre.impi.gob.mx/TemasInteres/Documents/acuerdo_ IMPI_COFEPRIS.pdf (última fecha de consulta: 2 de noviembre 2014). Consúltese el Diario Oficial de la Federación del 17 de abril de 2013: "Instituto Mexicano de la Propiedad Industrial: Acuerdo que modifica el diverso por el que se dan a conocer las disposiciones relativas a la integración, funcionamiento y actualización del listado a que se refiere el artículo 47-bis del Reglamento de la Ley de Propiedad Industrial, así como el formato de consulta sobre patentes de medicamentos alopáticos, Cofepris-IMPI". Es importante señalar que el formato ha sufrido diversos cambios a los que nos referiremos más adelante. 
Esta obra forma parte del acervo de la Biblioteca Jurídica Virtual del Instituto de Investigaciones Jurídicas de la UNAM

al llenado del Formato de consulta intragubernamental sobre patentes de medicamentos alopáticos Cofepris-IMPI, sino que es el propio personal de la Cofepris quien realiza el llenado del mismo, seleccionando parte de la información proporcionada por el solicitante del registro sanitario respectivo.

Así se inicia el procedimiento de consulta entre autoridades administrativas, donde el solicitante del registro sanitario y dueño de la información, motivo de la consulta técnica, no puede emitir observación o comentario alguno respecto al medicamento alopático a registrar, quedándose al margen de la consulta técnica y de las comunicaciones que pudieran existir entre las autoridades, expectante de la respuesta que emita el IMPI; respuesta a la cual no tendrá acceso ni podrá consultar, ni aun cuando la Cofepris niegue el registro sanitario de medicamento alopático solicitado.

La información relativa a las comunicaciones que pudieran surgir entre autoridades administrativas se ha estado reservando, por lo que es menester observar quién y cómo clasifica esta información, pues atendiendo a los principios de máxima publicidad, universalidad y transparencia de la información, indudablemente se están vulnerando derechos fundamentales del solicitante del registro sanitario de medicamento. No se debe pasar por alto que la información sobre la que versa la consulta es proporcionada por el solicitante del registro sanitario y por ende le pertenece a éste, así que no es legalmente válido que se omita proporcionarle un reporte pormenorizado de la consulta técnica elaborada por el IMPI; sólo de esta manera se puede hablar de transparencia en la forma en que el IMPI evalúa la información de las solicitudes de registro sanitario y se puede tener la certeza jurídica de la forma en que sus especialistas y técnicos llegan a la conclusión sobre la invasión o no de un derecho de patente farmacéutica.

El IMPI tiene la obligación de responder a la consulta de la Cofepris dentro del lapso de 10 días hábiles, ${ }^{26}$ aclarando si la información proporcionada por el solicitante del registro sanitario de medicamento alopático y sometida a su consulta técnica por parte de la Cofepris a través del Formato de consulta intragubernamental sobre patentes de medicamentos alopáticos Cofepris-IMPI, podría o no invadir derechos de alguna patente, sea de sustancia activa o cualquier otra, pero que se encuentre vigente.

En los hechos, el formato que se somete a la consideración de la autoridad patentaria es poco claro e insuficiente, pues no aporta los elementos mínimos necesarios para que dicha autoridad pueda pronunciarse sobre la posible invasión de patentes vigentes, ya que en el formato de consulta que se presenta ex professo no se contemplan todas y cada una de las carac-

26 De conformidad con el artículo 167-bis del RIS. 
Esta obra forma parte del acervo de la Biblioteca Jurídica Virtual del Instituto de Investigaciones Jurídicas de la UNAM

terísticas del producto que se pretende registrar y, por ende, la autoridad patentaria se encuentra imposibilitada para referir posibles invasiones de reivindicaciones ${ }^{27}$ de patentes vigentes.

Así las cosas, el IMPI da respuesta a la consulta técnica de la Cofepris con los insuficientes elementos que le fueron proporcionados, y esta última informa al solicitante si procede o no que se le otorgue el registro sanitario en trámite, o bien lo previene sobre alguna posible invasión de patentes identificadas por las autoridades patentarias para que acredite el solicitante ser titular de la patente o licenciatario del mismo.

En la respuesta que emite la Cofepris se proporciona un "resumen", normalmente contenido en un párrafo, de la información sobre el resultado de la consulta técnica, mas no la respuesta fundada y motivada de las autoridades patentarias y el estudio elaborado por los especialistas del IMPI concretamente, por lo que el solicitante del registro sanitario básicamente sólo conoce el número de la patente de referencia y por esta razón no hay elementos suficientes para que el solicitante pueda conocer los argumentos de la respuesta del IMPI en los que se señale con claridad la reivindicación de la patente que se invade, quedando en total estado de indefensión, pues, como ha sucedido en los hechos, la respuesta no considera las particularidades de las composiciones, procesos de fabricación, número de excipientes, uso de aglutinantes en la preparación o incluso el estado de la técnica del principio o sustancia activa, que en ocasiones puede ni siquiera estar protegida en México. Evidentemente, la Cofepris no cuenta con los conocimientos técnicos suficientes para evaluar las reivindicaciones, por no ser parte de sus funciones; sin embargo, previene y puede incluso negar al solicitante el registro sanitario, situación a todas luces adversa para los particulares y la sociedad en su conjunto al no poder incorporar medicamentos genéricos al mercado mexicano. Por la manera en que se realiza la consulta técnica, se deja al solicitante ciego e ignorante, al margen de la consulta,

27 "Las reivindicaciones de las patentes definen los derechos del inventor. El alcance de las reivindicaciones determina hasta dónde llega la protección del monopolio del inventor, y por lo tanto es un aspecto importante que hay que considerar a la hora de diseñar y aplicar las leyes de patentes nacionales. Esta cuestión es particularmente pertinente en el caso de las invenciones relacionadas con la salud, debido a las prácticas de concesión de patentes que prevalecen en este ámbito... Recientemente los expertos han advertido que patentes demasiado amplias en el campo de la biotecnología podrían excluir importantes herramientas de investigación del dominio público y cerrar áreas enteras a ulteriores investigaciones. También se ha cuestionado la protección amplia que a veces se otorga a invenciones relacionadas con productos farmacéuticos". Correa, Carlos, Integrando la salud pública en la legislación sobre patentes de los paises en desarrollo, Ginebra, South Centre, 2001, p. 34. 
Esta obra forma parte del acervo de la Biblioteca Jurídica Virtual del Instituto de Investigaciones Jurídicas de la UNAM

aun cuando es él quien al final se verá afectado o beneficiado de este procedimiento entre autoridades administrativas.

La normatividad es clara cuando indica que el solicitante que recibe la respuesta negativa a su solicitud de registro sanitario por invadir derechos de patentes o licencias vigentes debe, en el transcurso de a más tardar cinco días, acreditar que es el titular de la patente o que tiene una licencia o consentimiento del titular para usar o explotar la patente asociada a la sustancia o ingrediente activo, ${ }^{28}$ situación que se antoja un tanto ilógica pues probablemente el solicitante, al desconocer los fundamentos y motivos de la negación del registro, vuelva a presentar la documentación que ya entregó al inicio de la solicitud o, al desconocer qué elementos tiene que solventar o justificar ante la supuesta invasión de patente, simplemente quede en pasiva espera del desechamiento de su trámite.

Desafortunadamente se desconocen los motivos que tuvo el Ejecutivo Federal para que el procedimiento en comento fuera implementado en nuestra legislación, constituyendo innecesariamente a sus autoridades de salud y propiedad intelectual como intermediarios en asuntos que son única y exclusivamente del interés de los particulares, y considerándose el hecho de que los particulares siempre han contado con un medio de solución de controversias contemplado en el artículo 47-bis del Reglamento de la Ley de Propiedad Industrial (arbitraje de común acuerdo entre las partes), además, la Ley de Propiedad Industrial, en su artículo 221 bis, establece la reparación de daños sufridos por la violación a un titular de una patente.

Aunado a lo anterior, el procedimiento referido no está contemplado ni en el Acuerdo sobre los Aspectos de los Derechos de Propiedad Intelectual relacionados con el Comercio (ADPIC) ni en el Tratado de Libre Comercio para América del Norte (TLCAN); por lo tanto, México no está obligado bajo ningún tratado a implementarlo. De acuerdo con la experiencia de otros países, la figura incluso se considera contraria al derecho (como es el caso de la Unión Europea).

28 “...En caso de que el Instituto Mexicano de la Propiedad Industrial concluya que existen patentes vigentes sobre la sustancia o ingrediente activo de las que el solicitante no sea titular o licenciatario, lo informará a la Secretaría para que ésta prevenga al solicitante con el objeto de que demuestre que es titular de la patente o que cuenta con la licencia respectiva, dentro del plazo que determine la Secretaría y que no podrá ser menor a cinco días hábiles contados a partir de que haya surtido efectos la notificación. En el supuesto de que el solicitante no subsane la omisión, la Secretaría desechará la solicitud e informará al solicitante los motivos de esta determinación para que, en su caso, los dirima ante la autoridad competente. La falta de respuesta del Instituto Mexicano de la Propiedad Industrial dentro del plazo señalado se entenderá en sentido favorable al solicitante”. Decreto por el que se reforma el Reglamento de Insumos para la Salud y el Reglamento de la Ley de la Propiedad Industrial, publicado en el Diario Oficial de la Federación el 19 de septiembre de 2003. 
Esta obra forma parte del acervo de la Biblioteca Jurídica Virtual del Instituto de Investigaciones Jurídicas de la UNAM

En consecuencia, la vinculación o linkage de las patentes a los registros sanitarios en nuestro país es trascendente, pues no debería perderse de vista que mientras las patentes y sus reivindicaciones son competencia de la autoridad patentaria, en México el IMPI, los registros sanitarios son actos administrativos que tienen por objeto verificar que un medicamento es eficaz y seguro. Su trámite y otorgamiento corresponde a la Cofepris, autoridad administrativa diferente al IMPI y dependiente de la Secretaría de Salud, es decir, que aunque en ambos casos los particulares están frente a actos de autoridad, la finalidad con la que estos actos administrativos fueron creados es diametralmente distinta, y al vincularlos, más que obtener un beneficio, en la práctica se observa una afectación al retardar la entrada de medicamentos genéricos al mercado mexicano, una franca afectación a la economía del Estado y a los consumidores finales.

\section{EL ORIGEN DE LA FIGURA DE LA VINCULACIÓN Y SU RELAGIÓN CON LA GACETA DE MEDICAMENTOS EN LA EXPERIENCIA MEXICANA}

El procedimiento de vinculación o linkage no es una figura jurídica que se haya gestado en México. Tiene sus orígenes en los Estados Unidos.

Para comprender la vinculación o linkage que se hace de una patente de medicamento vigente (que tiene como objetivo la protección de los derechos de propiedad industrial de un particular) con un permiso sanitario para la comercialización de un medicamento alopático (que tiene como finalidad verificar la calidad, seguridad y eficacia terapéutica de los medicamentos que otro particular pondrá en el mercado) hace falta conocer su génesis.

Surge en 1984 en el seno del Congreso de los Estados Unidos con la Ley de Competencia en Precio de Medicamentos y de Restauración del Plazo de las Patentes ${ }^{29}$ (Drug Price Competition and Patent Term Restoration Act, en adelante DPGPTRA), conocida también bajo el nombre de Enmienda Hatch-Waxman por los apellidos del senador republicano de Utah, Orrin Hatch, y el diputado demócrata de California, Henry Waxman. Dicha enmienda tenía por objeto alentar la entrada de medicamentos genéricos al mercado norteamericano pero sin debilitar el sistema de patentes existente en aquel país. ${ }^{30}$

29 Drug Price Competition and Patent Term Restoration Act of 1984 (Hatch-Waxman Amendments), puede consultarse en: http://wrere.fda.gov/newevevents/testimony/ucm115033.htm (última fecha de consulta: 29 de diciembre de 2014).

30 Véase González Luna M., Santiago, Los medicamentos genéricos: un acierto patente. Innovación y libre competencia en la industria farmacéutica nacional, México, Porrúa, 2004, p. 27. 
Esta obra forma parte del acervo de la Biblioteca Jurídica Virtual del Instituto de Investigaciones Jurídicas de la UNAM

La DPGPTRA consistía en dos títulos. El primero de ellos autorizaba a los fabricantes de medicamentos genéricos a comercializar las versiones genéricas de medicamentos que ya habían sido aprobados por la Agencia Federal de Alimentos y Drogas (Food and Drug Adminstration, en adelante FDA) de los Estados Unidos.

En un inicio, el fabricante de la versión genérica del medicamento era requerido de realizar un procedimiento denominado "solicitud de nuevo medicamento" (New Drug Application). Esta solicitud demandaba que el fabricante de medicamento genérico presentara nuevamente ante la FDA los estudios clínicos que avalaran la eficacia y seguridad de su medicamento. Esta situación fue modificada tras aprobarse con posterioridad la solicitud abreviada de nuevo medicamento (Abbreviated New Drug Application, ANDA en adelante). Así, el fabricante de medicamento genérico podía apoyar su solicitud en los estudios clínicos que ya habían sido presentados por el fabricante del producto original del medicamento y aprobados por la FDA. Con esta modificación a la solicitud, los productores de medicamentos genéricos no tenían que hacer estudios largos y costosos sobre una sustancia que ya había sido previamente aprobada por la agencia en la primera solicitud y elaborada por el fabricante del producto original. ${ }^{31}$

Los solicitantes del registro para medicamentos genéricos debían llevar a cabo el procedimiento denominado ANDA, comprobando que el medicamento era bioequivalente al medicamento original, es decir, que contenía un ingrediente activo químicamente idéntico al del medicamento original y que era absorbido por el cuerpo humano en la misma cantidad y con la misma rapidez.

Para ello, el fabricante de medicamentos genéricos podía realizar las pruebas que fueran necesarias sin que vulnerara los derechos de patente de los titulares del producto original. ${ }^{32}$

El título I de esta Ley también exigía a los solicitantes y titulares de nuevos fármacos, proporcionar información sobre las patentes que abarcara el producto del medicamento que se pretendía copiar.

Una vez aprobado un medicamento, la FDA publica la información sobre el mismo y enlista las patentes que el solicitante mencionó en su solicitud de ANDA bajo el supuesto de que el medicamento innovador se fabrica en los términos de las patentes referidas. El listado se hace en una publicación titulada Productos medicinales aprobados con evaluaciones de equivalencia terapéutica (Approved Drugs Products with Therapeutic Equivalent Evaluation), conocido

\footnotetext{
31 Op. cit.

32 Idem.
} 
Esta obra forma parte del acervo de la Biblioteca Jurídica Virtual del Instituto de Investigaciones Jurídicas de la UNAM

como el Orange Book (Libro Naranja), pero a diferencia de la vinculación que se realiza en México, la FDA no analiza si la patente que menciona el solicitante del registro sanitario se encuentra vigente o no, ni hace consulta alguna a la oficina de patentes (USPTO) respecto a cuál es el alcance de sus reivindicaciones para determinar si otorga o no un registro sanitario al particular fabricante de medicamentos genéricos. ${ }^{33}$

En la experiencia estadunidense, el Libro Naranja cumple con una función práctica: listar las patentes que se ven involucradas en una solicitud de nuevo medicamento permite que los titulares de las patentes mencionadas en la producción del medicamento innovador, puedan oponerse al otorgamiento del registro sanitario genérico solicitado por el particular, que está utilizando sin su consentimiento la patente de la cual es titular. Es decir que permite que los titulares de patentes incluso puedan acudir a los tribunales al identificar alguna violación a su patente.

La Enmienda Hatch-Waxman buscó un equilibrio porque alentaba a la industria de medicamentos genéricos sin debilitar el sistema de patentes y, por ello, en el título II de la Ley en comento se autorizaba la extensión de la vigencia de una patente de productos médicos originales previamente aprobados (incluyendo antibióticos y medicamentos biológicos) si se añadían algunos dispositivos médicos, aditivos alimenticios y aditivos de color. ${ }^{34}$

33 Véase Price, Drug, Competition..., cit. En el original se puede leer: "Title I also amends Section 505 of the FFD\&C Act (21 U.S.C. 355) by requiring all New Drug Application (NDA) applicants and holders to provide certain patent information, requiring ANDA applicants to certify as to the status of patents claiming the drug product they intend to copy, providing for the submission and approval of applications for which the investigations relied on by the applicant to satisfy the «full reports» of safety and effectiveness requirements were not conducted by the applicant or for which the applicant had not obtained a right of reference or use from the person who conducted the investigations, establishing rules for disclosure of safety and effectiveness data submitted as part of an NDA, and providing specific time periods during which an NDA or an ANDA cannot be submitted or approved. The DPCPTRA also required the Food and Drug Administration (FDA) to promulgate new regulations implementing the statute". Visible en: http://wwre.mlmlaw.com/library/guides/fda/reg_proc/rchap2. html\#DRUGPRICECOMPETITIONANPA TENTTERM RESTORATIO ACTOF1984DPCPTR.

34 Véase el Manual de Procedimientos Regulatorios (Regulatory Procedures Manual), que puede consultarse en: http://wwremlmlaw.com/library/guides/fda/reg_proc/rchap2.html\#DRUGPRICE COMPETITIONAN PATENTTERM RESTORATIO ACTOF1984DPCPTR.

En el original se lee: "On September 24, 1984, the Drug Price Competition and Patent Term Restoration Act of 1984 (Public Law [P.L.] 98-417) was enacted. The DPCPTRA consists of two different titles. Title I authorizes the approval of duplicate versions of approved drug products (other than those reviewed and approved under Section 507 of the FFD\&C Act (21 United States Code [U.S.C.] 357) under an Abbreviated New Drug Application (ANDA) procedure. Title II authorizes the extension of patent terms for approved new drug products (including antibiotics and biological drug products), some medical devices, food 
Esta obra forma parte del acervo de la Biblioteca Jurídica Virtual del Instituto de Investigaciones Jurídicas de la UNAM www.juridicas.unam. $m x$

De este modo, cuando un fabricante de genéricos en Estados Unidos presenta su ANDA, tiene que hacer alguna de las siguientes declaraciones:

1) Que para ese medicamento no hay patente listada en el Libro Naranja.

2) Que aunque hay patente, la misma ya expiró.

3) Que aunque existe una patente vigente listada en el Libro Naranja, la solicitud es para vender el genérico una vez que la patente haya expirado.

4) Que aunque hay una patente vigente listada en el Libro Naranja, la misma es inválida o no es infringida por el medicamento cuya aprobación se solicita. ${ }^{35}$

La última fracción se conoce en Estados Unidos como la "certificación bajo el párrafo IV" (en inglés, paragraph IV certification) o también como ANDA IV. ${ }^{36}$ Como explica Santiago González Luna:

El solicitante de una ANDA IV debe notificar al titular de la patente involucrada. Éste puede oponerse a la solicitud de registro sanitario del medicamento genérico, y su sola oposición le otorga una suspensión del trámite del genérico por 30 meses o la duración del juicio por infracción de patente, lo que sea menor, circunstancia que dependerá de lo expedita que pueda ser la administración de la justicia. Sin embargo, no basta la pura oposición ante la FDA para obtener esta suspensión. Además se requiere que dentro de los 45 días siguientes a la fecha en que se le notificó la ANDA IV el titular de la patente demande ante los tribunales al solicitante de la ANDA IV, por violación de su patente. Esta demanda es admitida a pesar de que no ha habido producción o venta del producto patentado. Si no se presenta la demanda dentro del plazo mencionado, el titular de la patente no tiene derecho a la suspensión de 30 meses. ${ }^{37}$

additives, and color additives. Congress intends these provisions to provide a careful balance between promoting competition among brand-name and duplicate or generic drugs and encouraging research and innovation".

35 Véase Drug Price Competition and Patent Term Restoration Act of 1984 (Hatch-Waxman Amendments): "(I) that the required patent information relating to such patent has not been filed; (II) that such patent has expired; (III) that the patent will expire on a particular date; or (IV) that such patent is invalid or will not be infringed by the drug, for which approval is being sought".

36 Véase González Luna M., Santiago, Los medicamentos..., cit., p. 28.

37 Ibidem, p. 31. 
Esta obra forma parte del acervo de la Biblioteca Jurídica Virtual del Instituto de Investigaciones Jurídicas de la UNAM

Así, la función del listado de patentes que se hace en el Orange Book o Libro Naranja de los Estados Unidos cumple una función muy distinta a la que se le ha pretendido dar a la Gaceta de medicamentos en México.

Por otra parte, en la experiencia de los Estados Unidos se reportó que los dueños de las patentes hicieron uso de las suspensiones permitidas en la Ley de los 30 meses para impedir indebidamente el acceso de los medicamentos genéricos al mercado. Así, los titulares de las patentes las podían prolongar al agregar a los productos cosas como: nuevos empaques, reivindicaciones de proceso, metabolitos o productos intermedios.

Debido a esto, fue necesario que la FDA se pronunciara respecto a las múltiples ocasiones en que los titulares de patentes podían prolongar su patente por 30 meses, dejando solamente el derecho a una sola suspensión respecto a cada solicitud ANDA IV, sin importar si posteriormente hubiera nuevas patentes registradas en relación con el medicamento en cuestión, es decir, sólo se otorgaría el derecho a primeras patentes registradas y no a las posteriores sobre el mismo medicamento. También se prohibió que se pudieran listar en el Libro Naranja aquellas patentes que no fueran de moléculas patentadas y atendieran a reivindicaciones nuevas como las de empaque, procedimientos, metabolitos, etcétera. ${ }^{38}$

Asimismo, bajo esta reglamentación se permite a las empresas de genéricos solicitar el permiso sanitario en cualquier momento del periodo de la patente, es decir durante los 20 años de la patente, y no se limita a sólo los tres últimos años, como en el caso mexicano, y esto es con el objeto de tener en el mercado versiones genéricas al día siguiente de la fecha de expiración de la patente. De existir patente el titular es notificado, y si éste considera invadidos sus derechos puede - durante un lapso no mayor a 45 días - demandar a la empresa de genéricos; si no lo hiciera, la autoridad sanitaria continúa con el procedimiento para la emisión del registro sanitario.

Ahora bien, en el caso estadounidense, la vinculación o linkage delimita en un tiempo determinado las patentes que se contienen en el ya mencionado Orange Book, con lo cual se cierra la puerta a listar patentes que son comúnmente conocidas como evergreening, que suelen tener mínimas modificaciones respecto de la patente inicial y las cuales sólo buscan ampliar el monopolio.

En el caso mexicano, luego de la incorporación de la figura de la vinculación o linkage, se ha observado que no hay una claridad respecto a la relevancia, trascendencia e idoneidad de una adecuada valoración de las reivindicaciones de las patentes de medicamentos.

38 Idem. 
Esta obra forma parte del acervo de la Biblioteca Jurídica Virtual del Instituto de Investigaciones Jurídicas de la UNAM www.juridicas.unam.mx

Esto se ha hecho aún más evidente tras el diseño que guarda el Formato de consulta intragubernamental sobre patentes de medicamentos alopáticos, CofeprisIMPI (en adelante, Formato de consulta), pues tal y como se encuentra en la actualidad, no permite a la autoridad patentaria tener los elementos suficientes para que identifique la invasión o no de alguna patente.

El Formato de consulta no toma en consideración la pluralidad de reivindicaciones que existen respecto de las patentes de medicamentos, ${ }^{39}$ lo que se ha traducido en retrasos y en la obstaculización de la obtención de las solicitudes de registros sanitarios de medicamentos genéricos, aun cuando no se vulnere ninguna patente.

También, como ya se apuntó en la experiencia estadounidense del linkage, la FDA no se pronuncia sobre la validez de las patentes, tampoco detiene el trámite de una solicitud abreviada de un registro genérico (ANDA), pero en caso de que existan patentes listadas en el Orange Book, el solicitante del genérico debe avisar al titular de las patentes; a pesar de esta situación, la FDA no niega los registros sanitarios que se le solicitan, como equivocadamente se ha implementado para la Cofepris en el caso mexicano.

En México esta situación es a todas luces contraria a derecho, pues pese a que el solicitante del registro sanitario se vea afectado por la vinculación o linkage, no tiene derecho a participar en un juicio porque no tiene personalidad jurídica para ello. ${ }^{40}$ Tampoco puede exponer a la autoridad sanitaria los argumentos que demuestran que no requiere ser titular ni licenciatario para obtener un registro sanitario.

Éstas son algunas de las diferencias que existen entre la vinculación o linkage, figura que surge de las necesidades del mercado estadounidense para impulsar a los medicamentos genéricos sin afectar los medicamentos protegidos por patentes, que permite solicitar el registro de un genérico desde el día siguiente en que se autoriza el registro de un medicamento innovador o de referencia, mientras que en México no se permite iniciar los trámites con

39 Como las patentes de formulaciones y composiciones; combinaciones; dosificaciones o dosis; sales, éteres y ésteres; polimorfos; reivindicaciones tipo Markush; patentes de selección; procedimientos análogos; enanotiómeros; metabolitos activos y prodrogas; métodos de tratamiento; reivindicaciones de uso, con inclusión de segundas indicaciones, que no necesariamente cumplen con los requisitos de novedad, innovación o utilidad industrial, como se explica en el apartado anterior.

40 El interés jurídico exige, como uno de sus elementos torales, que la persona que inicie un procedimiento sufra un menoscabo o afectación por la existencia, en este caso, de la patente cuya nulidad se demande. En consencuencia, únicamente tendrá interés jurídico para demandar la nulidad de una patente aquella persona física o moral que fabrique, importe o comercialice el producto patentado, y en el caso de los solicitantes no aplica ninguna de estas tres. 
Esta obra forma parte del acervo de la Biblioteca Jurídica Virtual del Instituto de Investigaciones Jurídicas de la UNAM

el fin de obtener un registro genérico sino hasta que sólo queden tres años de vigencia de la patente, que tendría que ser de principio activo.

\section{La Gaceta de medicamentos en México}

Como ya se mencionaba, en 2003 se publicaron en el Diario Oficial de la Federación las reformas al RIS y a la LPI. En ese momento se incorporó el artículo 47 bis al Reglamento de la Ley de Propiedad Industrial para hacer referencia a la Gaceta de medicamentos, en un intento de utilizar una versión mexicanizada del Libro Naranja de los Estados Unidos. El artículo 47 bis se transcribe a continuación:

Artículo 47 bis. Tratándose de patentes otorgadas a medicamentos alopáticos, el Instituto publicará en la Gaceta y pondrá a disposición del público un listado de productos que deban ser objeto de protección industrial de acuerdo con la sustancia o ingrediente activo, el cual precisará la vigencia de la patente respectiva.

El listado contendrá la correspondencia entre la denominación genérica e identidad farmacéutica de la sustancia o ingrediente activo y su nomenclatura o forma de identificación de la patente, la cual deberá realizarse conforme al nombre reconocido internacionalmente.

El listado a que se refiere este artículo no contendrá patentes que protejan procesos de producción o de formulación de medicamentos.

En caso de existir controversia respecto de la titularidad de la patente de la sustancia o principio activo, los interesados podrán someterse, de común acuerdo, a un arbitraje, en los términos de la legislación mercantil.41

Como se resalta en cursivas, en la Gaceta de medicamentos se listarían los productos susceptibles de protección industrial de acuerdo con la sustancia o ingrediente activo, y señala expresamente que no contendrá patentes que protejan procesos de producción o de formulación de medicamentos.

No obstante lo anterior, en la Gaceta de medicamentos se han incluido múltiples patentes que no se refieren a principios activos. El espíritu sobre el que versaron las negociaciones para la inclusión del sistema de vinculación pretendió claramente ligar la autorización o negativa de un registro de un tercero exclusivamente a la patente que ampare el principio activo (sustancia con efectos terapéuticos) del medicamento que se pretendiera registrar.

Esta definición es de fundamental importancia, ya que existe una clara tendencia (desde hace más de una década) de los titulares de patentes a cen-

41 Las cursivas son propias. 
Esta obra forma parte del acervo de la Biblioteca Jurídica Virtual del Instituto de Investigaciones Jurídicas de la UNAM

trar sus desarrollos en modificaciones a un mismo principio activo, como nuevas formulaciones, combinaciones de principios activos conocidos, nuevos usos, dosificaciones, empaques, formas de presentación, etcétera. Estos desarrollos, a pesar de carecer del mérito inventivo que sí posee el descubrimiento de una nueva molécula, también son patentados, y las patentes correspondientes ("patentes periféricas") también gozan del mismo periodo de exclusividad de veinte años.

De esta manera, la denominada Gaceta de medicamentos ni siquiera debería llamarse de esa manera, pues no contiene un listado de medicamentos, ya que el concepto de "medicamento" es utilizado para referirse a un producto que se encuentra en el mercado. Tampoco podría denominarse "gaceta de principios activos", dado que se han listado dentro de la Gaceta patentes distintas a las de sustancia activa.

Si bien el espíritu primigenio de la vinculación únicamente permitiría negar el registro sanitario de un tercero que pretendiera registrar el medicamento que contuviera el principio activo patentado, en la práctica se niegan registros sanitarios aun cuando la patente del principio activo hubiera expirado.

En sus orígenes parecía un gran acierto publicar una lista de patentes para que los particulares conocieran, al igual que en el Libro Naranja de los Estados Unidos, cuáles patentes podrían ser susceptibles de vinculación en las solicitudes de registro sanitario de los medicamentos genéricos.

Sin embargo, en la Gaceta de medicamentos de México, a diferencia de la lista que se publica en los Estados Unidos, se han incorporado tanto patentes de sustancia activa como de composición farmacéutica, de uso, incluso de sales o polimorfos, y hasta de empaques, sin atender a la diferencia que existe entre estas reivindicaciones y los principios o sustancias activas. Asimismo, se incorporan patentes que no corresponden a ningún medicamento innovador o de referencia.

Los datos contenidos en la Gaceta de medicamentos publicada por el IMPI son:

1) Nombre genérico del medicamento.

2) Descripción especifica del medicamento.

3) Nombre químico del medicamento.

4) Patente.

5) Vigencia de la patente.

6) Pago de anualidades al momento de la publicación de la Gaceta.

7) Titular de la patente. 
Esta obra forma parte del acervo de la Biblioteca Jurídica Virtual del Instituto de Investigaciones Jurídicas de la UNAM

8) Reivindicación principal.

9) Observaciones. ${ }^{42}$

Sin embargo, en algunos casos la descripción específica del medicamento se omite atendiendo a la interpretación de la responsabilidad de la autoridad para preservar la protección de datos. Esto demuestra el desconocimiento de la necesidad de la descripción específica para poder establecer la correcta vinculación con la solicitud del registro sanitario que se tramita ante Cofepris.

Con este sistema de vinculación, y lo técnica que resulta la materia de patentes, se ha bloqueado en gran medida la salida de versiones genéricas de un principio activo que ya no tiene patente, lo que deriva en un alto impacto económico que deben pagar las instituciones de seguridad social y los pacientes, siendo injustificable este sobreprecio.

En la práctica, en la Gaceta de medicamentos que publica el IMPI se presentan varias situaciones en las que es necesario profundizar, pues se han incluido múltiples patentes que no se refieren a principios activos. Esta definición es de fundamental importancia, ya que existe una clara tendencia de los titulares de patentes a centrar sus desarrollos en modificaciones mínimas a un mismo principio activo (nuevas formulaciones, usos, combinaciones de principios activos conocidos, dosificaciones, empaques, formas de presentación, etcétera). La posición de la industria mexicana es de respeto a la propiedad industrial cuando esta innovación merezca por su aportación a la sociedad mantener el monopolio del mercado, y no mediante un artificio técnico-legal para que sobre un mismo principio activo existan múltiples patentes, con modificaciones en muchos casos irrelevantes, con lo cual se amplía el monopolio por hasta once años adicionales a los veinte años de la primera patente del mismo principio activo.

Las empresas de investigación suelen contar con un principio activo patentado y con otras tantas patentes de las denominadas periféricas, marginales o espurias, las cuales se diferencian respecto de la primera por ser una nueva presentación, en cristal, de formulación o simplemente agregan un nuevo radical y con ello efectivamente no se extiende técnicamente la patente, pero sí el monopolio a través de otras tantas patentes de un mismo principio; se trata de las reivindicaciones de patentes que no aportan realmente innovación, novedad o uso industrial, las cuales se han explicado en el apartado anterior de este trabajo.

42 Acuerdo por el que se dan a conocer las disposiciones relativas a la integración, funcionamiento y actualización del listado a que se refiere el artículo 47 bis del Reglamento de la Ley de Propiedad Industrial, así como el Formato de consulta sobre patentes de medicamentos alopáticos Cofepris-IMPI, Diario Oficial de la Federación del 4 de febrero de 2005. 
Esta obra forma parte del acervo de la Biblioteca Jurídica Virtual del Instituto de Investigaciones Jurídicas de la UNAM

La versión "mexicana" del Libro Naranja dista mucho de ser útil para la identificación de patentes para poder establecer la vinculación, pues a diferencia del Libro Naranja no sólo se enlista la primera patente que ha agotado las pruebas clínicas. Esto no abona para dotar de certeza jurídica a los solicitantes de registros sanitarios, pues ya no sólo se incluyen las patentes de principio activo como se estableció en el decreto que le dio origen a dicha Gaceta, sino que se han incorporado patentes de distintas reivindicaciones.

Este tipo de errores se han venido cometiendo desde 1991, año en el que México decidió considerar en su legislación a las patentes de medicamentos, pues inclusive se han reconocido patentes que ya eran de dominio público; también ha provocado extensiones de vigencia de patentes con base en extensiones otorgadas a patentes extranjeras, sustentadas en legislaciones extranjeras y otorgadas por autoridades también extranjeras.

Para colmo, regularmente el IMPI otorga patentes sobre nuevos usos o patentes de implicaciones terapéuticas que están prohibidas en México, disfrazadas como kits de tratamiento. Sin embargo, aunque cualquier patente que se otorgue contra la ley es nula y esa nulidad es absoluta, ésta no opera automáticamente. Es necesario iniciar un procedimiento contencioso en el que tal nulidad sea declarada. El procedimiento contencioso, al final del día, resulta tardado y no resarce los daños o perjuicios causados a terceros por el ejercicio de una patente nula, pues el titular de la patente siempre podrá cobijarse bajo el argumento de que el Estado mexicano le otorgó la patente.

Esto obedece a que los titulares de patentes litigan la inclusión de patentes periféricas en la Gaceta de medicamentos con el único objeto de lograr que éstas se constituyan en barreras para la obtención de registros sanitarios de terceros y en monopolizaciones de ventas al sector salud, que ante la posibilidad de que se infrinja una patente (sin analizar si se trata de la patente que protege el principio activo o una periférica) obvian licitaciones y optan por el procedimiento de adjudicación directa en favor del titular de la patente en cuestión (o a sus distribuidores). No sobra resaltar el impacto presupuestal que esto supone, por los altos precios que resultan de un mercado en el que "no puede haber" competencia.

A diferencia de la experiencia estadounidense del linkage, los particulares en la vinculación en México no pueden enfrentarse en un litigio para resolver la vulneración de las patentes, como se ha dejado de manifiesto, pues no se les reconoce a los solicitantes del registro sanitario la personalidad jurídica necesaria para ello. En los litigios no han participado los terceros cuyos intereses afectan las inclusiones, ya que al no contar con el registro sanitario correspondiente no se demuestra el interés jurídico ante el Poder 
Esta obra forma parte del acervo de la Biblioteca Jurídica Virtual del Instituto de Investigaciones Jurídicas de la UNAM

Judicial, lo que ha proporcionado un terreno fértil a favor de los titulares de las patentes periféricas para lograr inclusiones indebidas o cuando menos cuestionables.

Aunado a esto, existe la particularidad respecto a las patentes vigentes de medicamentos, para las cuales no se pueden otorgar registros sanitarios porque las patentes se prolongan a sus dueños no por el proceso natural de una patente, que sería la inventiva, sino que se encuentran en litigio ${ }^{43} \mathrm{y}$ mientras el mismo no se resuelva no se pueden liberar.

Por su parte, en el caso de los productores de medicamentos originales que en ocasiones solicitan la extensión ("corrección") de la vigencia de su patente al IMPI, ante la negativa pueden impugnar esa resolución ante el Tribunal Federal de Justicia Fiscal y Administrativa. Mientras esto sucede, los fabricantes de genéricos, con base en la publicación de la patente con la vigencia original, inician con toda oportunidad el desarrollo de la tecnología y tramitan el registro sanitario respectivo, para fabricar y comercializar el producto tan pronto venza la vigencia publicada de la patente y en muchas ocasiones obtienen el registro respectivo.

Lamentablemente, esos terceros que se ven afectados por tales decisiones nunca son llamados a juicio y se enteran de las extensiones cuando los litigios ya quedaron definitivamente resueltos y las extensiones "por mandato judicial" son publicadas en la Gaceta de medicamentos.

Desafortunadamente, los obstáculos que enfrentan los fabricantes de medicamentos genéricos no se detienen ante este panorama, pues aun cuando conocieran los casos de las impugnaciones a las negativas del IMPI promovidas por los titulares de las patentes de medicamentos originales, su situación es totalmente inequitativa, porque no tienen a su alcance los mecanismos para conocer en qué sala del Tribunal Federal de Justicia Fiscal y Administrativa se está suscitando el juicio de nulidad que habrá de afectarlos y en los que deberían participar como terceros, lo que los obliga a promover "a ciegas" su participación en los litigios que se detecten, con el riesgo de que no se trate en concreto de la patente de su interés. Suponiendo que la promoción haya sido certera, el siguiente obstáculo se presenta con las "suspensiones" que dicho Tribunal concede, mismas que en ocasiones

43 Véase Coronel, Maribel R., "Patentes periféricas y las reformas que vienen”, El Economista, México, sección Salud y Negocios, 1o. de julio de 2009, disponible en: http://eleconomista.com.mx/notas-impreso/columnas/columna-invitada-empresas/2009/07/01/patentes-perifericas-lasreformas-que-vi (última fecha de consulta: 7 de octubre de 2014).

Véase, también, "Disputan farmacéuticas ampliación de patentes en México", disponible en: http://bitacorafarmaceutica.wordpress.com/2009/09/22/disputan-farmaceuticas-ampliacion-de-pa tentes-mexico/ (última fecha de consulta: 7 de octubre de 2014). 
Esta obra forma parte del acervo de la Biblioteca Jurídica Virtual del Instituto de Investigaciones Jurídicas de la UNAM

tienen efectos restitutorios, pues poseen el alcance de revivir las patentes, no obstante que "el estado que guardan las cosas" en el momento en que se otorgan es justamente el de una patente caduca cuya extensión fue negada.

La intervención de los tribunales jurisdiccionales en lo que respecta a la inclusión de patentes de medicamentos que no son de sustancia activa, relacionado directamente con la vinculación para negar u otorgar registros sanitarios, ha producido diversas resoluciones contradictorias, situación que fue denunciada por el magistrado presidente del Segundo Tribunal Colegiado de Circuito del Centro Auxiliar de la Segunda Región, quien sostuvo, al igual que el Cuarto Tribunal Colegiado en Materia Administrativa del Primer Circuito, una tesis diferente de la sustentada por el Segundo Tribunal Colegiado en Materia Administrativa del Primer Circuito.

Los dos primeros sostuvieron la tesis de que las patentes de medicamentos alopáticos que deben publicarse en la Gaceta relativa son únicamente aquellas que protegen una sustancia, ingrediente o principio activo; en tanto que el último de ellos sostuvo que el artículo 47 bis del Reglamento de la Ley de Propiedad Industrial, en su primer párrafo, no sólo se refiere a las patentes que protegen una sola sustancia, sino también a las que protegen una mezcla de sustancias y que como composición farmacéutica se presenta como remedio de enfermedades o para conservar la salud, realizándose el listado de los productos de acuerdo con la sustancia, si es el caso de las primeras, o bien, de acuerdo con el ingrediente activo, en tratándose de las segundas, lo que provocó que la Segunda Sala de la Suprema Corte de Justicia de la Nación (SCJN) emitiera una resolución por contradicción de tesis respecto de los alcances de la multicitada Gaceta. ${ }^{44}$

En el caso de la contradicción de tesis 386/2009, "la resolución se basa en la definición del medicamento alopático que se encuentra contenida en la Ley General de Salud, en el sentido de que también un medicamento de este tipo puede ser una mezcla de sustancias para entonces considerar que las patentes de formulación deben incluirse en la Gaceta al proteger medicamentos". ${ }^{45}$

Actualmente el IMPI, a pesar de no estar obligado a aplicar la jurisprudencia por contradicción de tesis en virtud de ser una autoridad dependiente del Ejecutivo Federal y no del Poder Judicial, y por lo tanto no le es aplicable, ha hecho suyo el criterio de la SCJN e incluye en la Gaceta de medicamentos

44 El sistema de vinculación y la resolución que, por contradicción de tesis, pronuncia la Segunda Sala de la Suprema Corte de Justicia de la Nación, en relación al alcance que debe darse al artículo 47 bis del Reglamento de la Ley de Propiedad Industrial, p. 3.

45 Ibidem, p. 4. 
cualquier patente, sin considerar su propia naturaleza y a simple solicitud que realicen los titulares de la misma, constituyéndose ahora en juez de facto y apartándose de su obligación de estricta observancia de la ley.

Aunado a lo anterior, la Gaceta de medicamentos ha dejado de ser el documento idóneo para la vinculación administrativa a la que me he referido, toda vez que el IMPI informa a la Cofepris respecto de la existencia de cualquier patente registrada en México, forme parte o no de dicho instrumento de información.

Por otra parte, la expedición inmediata de registros sanitarios una vez vencida las patentes tampoco opera, ya que la Cofepris retarda la entrada al mercado de los productos genéricos al aglutinar, para efectos de difusión mediática, la entrega de las autorizaciones sanitarias respecto de moléculas que han caído al dominio público, operando de facto una extensión al monopolio comercial que deriva del patentamiento, en perjuicio del acceso a la salud de amplios sectores de la población mexicana.

\section{Gonclusiones}

Las distorsiones de que ha sido objeto el sistema de vinculación han creado un ambiente de gran inseguridad jurídica que ha favorecido el abuso de patentes, en directo detrimento de la entrada al mercado de medicamentos genéricos, en perjuicio del acceso a la salud de amplios sectores de nuestra población.

La vinculación, como se ha ejercido e interpretado en nuestro país, impide por largos periodos el registro de medicamentos cuyo principio activo ya está en el dominio público.

La vinculación patente-registro sanitario en México es un ejemplo de inequidad jurídica para las partes involucradas y sobrepasa los estándares aplicados en los pocos países desarrollados que la han adoptado. En Europa, por ejemplo, se han opuesto a la vinculación porque correctamente distinguen entre los fines de la aprobación sanitaria y el ejercicio de los derechos de los titulares de patentes, que deberán defender sus derechos por sí mismos en el caso de existir violación ante las autoridades competentes que tienen los conocimientos y facultades para analizar una supuesta violación de derechos de patente.

La Gaceta de medicamentos, que debería ser la gaceta de principios activos con patentes vigentes, se ha convertido en la gaceta de patentes de formulaciones farmacéuticas (composiciones farmacéuticas), procesos y nuevos usos, lo que ha generado barreras inaceptables para el trámite y obtención 
Esta obra forma parte del acervo de la Biblioteca Jurídica Virtual del Instituto de Investigaciones Jurídicas de la UNAM

de registros sanitarios de productos competidores, así como demandas en contra de la autoridad sanitaria y de propiedad intelectual.

\section{Propuestas}

Como una consecuencia, la propuesta inicial e idónea sería eliminar el linkage a través de la derogación del decreto del 19 de septiembre de 2003 o, en su defecto, buscar una modificación a la normatividad actual que con base en la experiencia internacional y la participación conjunta de los fabricantes de medicamentos, armonice y dé equilibrio al sistema en México, impidiendo que se coloque a las autoridades administrativas en posibilidad de ser demandadas por los particulares por arrogarse facultades o derechos que en origen les corresponden a los gobernados, estableciéndose un procedimiento transparente que permita a los particulares involucrados contar con garantía de audiencia y capacidad de acceder a la justicia.

En este sentido, la Cofepris debería hacer públicos los registros sanitarios de medicamentos innovadores o de referencia vigentes, en tanto que, el IMPI debería incluir únicamente en su Gaceta de medicamentos aquellos cuya patente haya estado vigente cuando se autorizó el registro sanitario y que se encuentren identificados por la Cofepris como medicamentos de referencia, para que en efecto los particulares tengan certeza plena de los medicamentos que cuentan con protección patentaria.

Finalmente, no se pueden desligar los aspectos referidos como parte de una política farmacéutica nacional integral que impulse un marco regulatorio eficiente, robusteciendo su labor a través de la creación de una base científica y tecnológica en el país que incluya la participación de centros públicos de investigación y universidades; eficientando el comercio exterior; la transparencia en compras, precios de medicamentos, y los costos de investigación; combatiendo la entrada de productos apócrifos y la piratería y, sobre todo, una mejor farmacovigilancia para prevenir los riesgos sanitarios.

\section{FUENTES}

Coronel, Maribel R., "Historia de una patente estirada", El Economista, México, 23 de enero de 2011, disponible en: http://eleconomista.com.mx/ columnas/salud-negocios/2011/01/23/historia-patente-estirada.

Coronel, Maribel R., "Patentes periféricas y las reformas que vienen", $E l$ Economista, México, sección Salud y Negocios, 1o. de julio de 2009, dispo- 
nible en: http://eleconomista.com.mx/notas-impreso/columnas/columna-invitadaempresas/2009/07/01/patentes-perifericas-las-reformas-que-vi.

Correa, Carlos, Pautas para el examen de patentes farmacéuticas, Ginebra, International Centre for Trade and Sustainable Development, 2006.

"Disputan farmacéuticas ampliación de patentes en México", Bitácora farmacéutica, 22 de septiembre de 2009, disponible en: http://bitacorafarmaceutica. wordpress.com/2009/09/22/disputan-farmaceuticas-ampliacion-de-patentes-mexico/.

GONZÁlEz LunA M., Santiago, Los medicamentos genéricos: un acierto patente. Innovación y libre competencia en la industria farmacéutica nacional, México, Porrúa, 2004. 
Esta obra forma parte del acervo de la Biblioteca Jurídica Virtual del Instituto de Investigaciones Jurídicas de la UNAM

\title{
EL PROYEGTO DE DIREGTIVA EUROPEA RELATIVA A LA PROTEGGIÓN DEL SABER HACER Y LOS SEGRETOS COMERCIALES. AVANGES Y RETROGESOS
}

Jorge KORS

\begin{abstract}
SumARIO: I. Introducción. II. Antecedentes del proyecto de Directiva europea. III. Consideraciones sobre la categoría jurídica de los secretos comerciales e industriales. Secreto industrial y patentes de invención. IV. La información confidencial y el Acuerdo de los ADPIC. V. Contenido del proyecto. VI. Las disposiciones respecto de las medidas de forma y de fondo en la protección del secreto comercial e industrial. VII. Las medidas cautelares y el exceso sobre la protección del secreto. VIII. Comparación entre la protección de la información confidencial y las patentes de invención. IX. El incidente de explotación del artículo 9.2. X. Conclusiones.
\end{abstract}

\section{INTRODUCGIÓN}

Las decisiones referidas a la propiedad intelectual y a los conocimientos técnicos emanados de Japón, de los Estados Unidos y de la Unión Europea son de alto impacto en el resto de los países, ya que son centros de referencia que imponen las agendas tanto para las naciones desarrolladas como para las que se encuentran en vías de desarrollo.

Dado que esta materia está regida por el Acuerdo de los ADPIC, las leyes y directivas de estos países operan de alguna manera como correo para modificaciones del Acuerdo o mediante las negociaciones bilaterales, como son los tratados de libre comercio, en las que se reclaman estándares superiores a los previstos en el Acuerdo, lo que en doctrina se conoce como ADPIC Plus.

Este trabajo analiza el proyecto de nueva directiva europea para la protección de los secretos comerciales e industriales, que abarcará a todos los estados miembros de la Unión, quienes deberán adecuar sus legislacio- 
Esta obra forma parte del acervo de la Biblioteca Jurídica Virtual del Instituto de Investigaciones Jurídicas de la UNAM

nes una vez aprobada esta directriz. Representará una mayor protección de los secretos y de la información confidencial, pues la norma prevé un sistema de garantías por medio de acciones y medidas provisionales que en algunos aspectos los coloca a nivel de las patentes de invención; preocupante decisión tratándose de un aspecto tan sensible como el desarrollo tecnológico.

Los secretos industriales son una herramienta que por su carácter ambiguo pueden ser utilizados como un instrumento para realzar la competencia tanto como para frenarla. Es cierto que todo desarrollo tecnológico exige un grado de confidencialidad muy alto hasta la puesta en marcha del invento - sea éste patentable o no-y que las mejoras incrementales desarrolladas por la práctica productiva deben ser protegidas frente a la competencia desleal. Pero de allí a darle un exagerado marco regulatorio es un paso muy largo y peligroso que es necesario revisar y debatir.

En la industria farmacéutica, donde se juegan valores tales como la salud pública y el acceso a los medicamentos, y en aquellas otras ramas de la industria en donde se aplican tecnologías de rápida obsolescencia, como la electrónica, la información digital, la telefonía celular, etcétera, el uso de la información confidencial es una práctica habitual y es necesario ofrecer a este mecanismo legítimo un cerco de protección eficaz "intra muros" para evitar el espionaje industrial o cualquier otro acto calificado como prácticas anticompetitivas o de competencia desleal, contrarias al honesto obrar en el comercio y la industria. Pero, al mismo tiempo, cuando se trata de obtener ventajas de dudoso carácter concurrencial - v. gr., ocultar pasos indispensables en algunos logros en la investigación científica, especialmente en el campo de la biología y de la biotecnología - se abre una gran interrogante respecto de estas estrategias que importan una obstrucción deliberada de la competencia y, por ende, sobre la necesidad de establecer mayores herramientas legales.

Es necesario comprender que la existencia de iguales disposiciones normativas en países de desigual desarrollo no siempre resultan tener la misma eficacia. Normalmente traen consigo un desbalance que favorece a los países tenedores de tecnología respecto de aquellos que no la poseen.

Así, es una constante que a través de los contratos de transferencia de tecnología las empresas multinacionales ingresan tecnología protegida por patentes mientras éstas están en vigencia, y bajo secreto industrial cuando han ingresado en el dominio público. Las empresas dominantes exigen estas cláusulas abusivas a las empresas que adquieren o licencian estas tecnologías, que por necesidad se ven obligadas a aceptar tales condiciones. 
Esta obra forma parte del acervo de la Biblioteca Jurídica Virtual del Instituto de Investigaciones Jurídicas de la UNAM

\section{ANTECEDENTES DEL PROYECTO} DE DIREGTIVA EUROPEA

Se ha elevado para su tratamiento en el Parlamento Europeo y en el Consejo Europeo, un proyecto de Directiva relativo "a la protección del saber hacer y la información empresarial no divulgados (secretos comerciales) contra su obtención, utilización y divulgación ilícitas". Es probable que antes de que finalice el 2015 la misma sea aprobada y rija en todos los Estados miembros de la Unión Europea, dado que se estima que existe consenso entre los parlamentarios sobre su aprobación. Por lo tanto, este trabajo, que ha sido escrito antes de esa fecha, debe leerse en relación con el proyecto como tal, que puede o no resultar la última versión aprobada de la misma.

Se trata de una disposición muy completa destinada a unificar y perfeccionar de manera consistente las legislaciones de los países que integran la región, elaborada tras evaluar que existe una gran dispersión legislativa que conspira contra el desarrollo de la innovación tecnológica, según las afirmaciones emanadas de la exposición de motivos que precede a la propuesta.

Resulta muy interesante analizar algunos conceptos de dicha exposición, ya que señala objetivos para lograr una "unión para la innovación"; es decir, que en una Europa en donde valga la pena innovar conviene mejorar las condiciones que favorezcan la actividad empresarial innovadora. Una inversión empresaria en investigación y desarrollo (I+D) por debajo del nivel óptimo - dice- afecta negativamente la introducción de nuevos productos, procesos, servicios y saber hacer (know how).

En ciertos casos, en función del modelo empresarial del innovador, la confidencialidad puede ser la base necesaria sobre la cual puede cultivarse la propiedad intelectual para que su explotación pueda traducirse en innovación y en una mayor competitividad.

Según el proyecto, se destaca el sector de servicios, en el que el secreto industrial se utiliza para crear y explotar comercialmente los conocimientos con fines de competitividad; a esto se lo denomina innovación "blanda".

Se señala que el poseedor de un secreto comercial no tiene derechos exclusivos sobre la información amparada por dicho secreto; no obstante, para proteger un proceso competitivo y eficiente, las restricciones a la utilización de un secreto están justificadas cuando ese saber hacer haya sido obtenido por terceros contra su voluntad, utilizando medios deshonestos.

La diversidad del marco jurídico transfronterizo mina la capacidad de las empresas europeas para responder a los ataques deshonestos contra su 
Esta obra forma parte del acervo de la Biblioteca Jurídica Virtual del Instituto de Investigaciones Jurídicas de la UNAM

saber hacer. La idea entonces es crear un mercado único de la propiedad intelectual. Se responde con esto a la decisión tomada por la Comisión Europea en mayo de 2011 (COM [2011] 287).

Las nuevas disposiciones se han fundado en los resultados de dos consultas que se han realizado: por un lado, a las partes interesadas y, por el otro, la evaluación de impacto. Los estudios fueron efectuados en enero y mayo de 2013 y confirmaron la fragmentación y el carácter heterogéneo de la protección existente en los países de la Unión; se concluyó que la armonización mejorará las condiciones de elaboración, intercambio y utilización de conocimiento innovadores por parte de las empresas.

De lo que se puede colegir, y se refleja en la exposición de motivos, que las dos consultas han llegado a conclusiones que son a mi entender superficiales, y creo que han sido sólo una justificación formal como paso necesario para la presentación de este proyecto, sin que hayan pasado evaluaciones y opiniones técnicas de mayor envergadura.

Una de las cuestiones que se ha evaluado sin mayor análisis y que es una de las constataciones más fuertes de estos estudios ha sido que la industria química europea, que depende en gran medida de la innovación de los procesos sustentada en secretos comerciales, estima que la apreciación indebida de un secreto comercial podría conllevar en muchos casos una reducción del volumen de negocios de hasta un 30\%.

Justamente esta rama de la industria europea es una de las más potentes - y la que más cuestionamientos ha tenido por abuso de posición dominante - que constantemente apela al uso del secreto industrial como manera de proteger sus avances tecnológicos, y que más presiona para obtener protecciones desmedidas a la información confidencial. Es, junto con la industria farmacéutica, de los mayores lobbies en el mundo.

Se advierte en el proyecto que con las debidas salvaguardas, la competencia entre empresas no se vería restringida, pues no se otorgarían derechos exclusivos y cualquier competidor sería libre de obtener de forma independiente (incluso con ingeniería inversa) los conocimientos protegidos por el secreto comercial. Del mismo modo, no debería afectar la libre movilidad de la mano de obra altamente cualificada, que son quienes tienen acceso a los secretos comerciales.

Se habla, en fin, de promover el derecho de propiedad y la libertad de empresa y que esta iniciativa es compatible con las obligaciones internacionales, especialmente con el Acuerdo sobre los ADPIC. 
Esta obra forma parte del acervo de la Biblioteca Jurídica Virtual del Instituto de Investigaciones Jurídicas de la UNAM

\section{CONSIDERACIONES SOBRE LA GATEGORÍA JURÍDICA DE LOS SEGRETOS COMERCIALES E INDUSTRIALES. SECRETO INDUSTRIAL Y PATENTES DE INVENCIÓN}

Los secretos de empresa pueden ser clasificados, a grandes rasgos, en secretos comerciales y secretos industriales. En el primer caso, se trata de información altamente cualificada y confidencial basada en los métodos administrativos utilizados, sus programas de computación, la preparación y entrenamiento de funcionarios y empleados, la clientela, los métodos de venta, la agenda de sus clientes y proveedores con sus datos de identificación y vinculación, etcétera. Estrategias, en fin, que hacen a la comercialización de los productos pero no a la calidad e identidad técnica de los mismos.

En el segundo caso, se trata de información de carácter técnico, científico, de investigación y desarrollo (I+D). No obstante la importancia que revisten los secretos comerciales, no alcanzan el relieve que registran los denominados conocimientos técnicos, que en muchos casos son verdaderas invenciones, y que por razones de estrategia se decide mantener en secreto por distintos factores que hacen a la competencia en el mercado.

Señalo como dato complementario que la utilización del concepto "secretos comerciales" en la versión en castellano de esta disposición está basada en una traducción directa de la expresión trade secrets de la versión oficial en lengua inglesa, que abarca ambos conceptos - secretos comerciales y secretos industriales - en una sola idea, configurada por esas dos palabras. Por mi parte, sólo como una cuestión técnica, prefiero distinguir los secretos comerciales de los industriales no sólo por su valor económico, sino porque en el segundo caso se trata de una forma de protección de la tecnología que básicamente se rige por el sistema de patentes de invención y que se sujeta a reglas mucho más rigurosas. La versión en idioma francés, secrets d'affaires es más amplia gracias a una conjunción de palabras que mejor lo expresan.

Los secretos industriales pueden ser definidos como "los conocimientos técnicos no patentados sobre los cuales se ha tenido la debida precaución de no difundirlos". Tal como se señala en la exposición de motivos de este proyecto, sobre los secretos industriales no se ejerce ningún derecho de propiedad o derecho de exclusiva, pudiendo llegarse al mismo evento técnico en forma lícita por cualquier otro medio, inclusive el mismo que usa otro poseedor, si esa información está configurada en forma lícita por un tercero que la ha obtenido por medios propios. 
Esta obra forma parte del acervo de la Biblioteca Jurídica Virtual del Instituto de Investigaciones Jurídicas de la UNAM

Lo mismo puede decirse de los secretos comerciales cuando han llegado al alcance de una empresa, sin perjuicio de que terceros hayan llegado al mismo resultado sin recurrir a medios deshonestos y desleales.

El régimen de patentes de invención otorga la propiedad temporal sobre un invento, cumpliendo con los requisitos legales exigidos por un organismo del Estado, las oficinas de patentes, que son las encargadas de conceder la patente y constituir un monopolio de derecho que permite su explotación exclusiva durante un tiempo limitado, que normalmente es de veinte años.

El secreto industrial, en cambio, se protege sólo mientras exista el secreto, y aunque sea una banalidad decirlo, una vez que el secreto se revela pasa al dominio público y cualquiera podría usarlo, siempre y cuando esto sea lícito. Aun teniendo el acto originario un carácter ilícito, el hecho de su difusión pública exime de responsabilidad a cualquier tercero que no haya participado en el acto antijurídico e ilícito. Vale decir que este secreto es un "monopolio de hecho". Es necesario protegerlo pero dentro del margen que su naturaleza jurídica exige.

Que se haya otorgado una protección por patente a las invenciones implica una excepción al principio de libre circulación de las ideas, norma de carácter general dentro del marco de los bienes inmateriales.

La competencia aparece afectada por el monopolio, pero el precio que paga la sociedad por este contrato social implica un convenio implícito destinado a generar un estímulo económico a los investigadores y creadores con la condición de que den a publicidad al contenido de su invento. Por lo tanto, si bien durante ese lapso nadie lo puede comercializar, producir o industrializar, sí puede informarse respecto de su contenido y aprovecharlo para iniciativas futuras y hacer real el principio de que en investigaciones científicas alguien parte de lo que otro dejó.

La decisión de mantener un secreto industrial implica un riesgo empresario, y es el hecho de que otro pueda llegar a este avance tecnológico por medios lícitos al mismo resultado, y en ese caso no hay daño qué reclamar ni acto que afecte el derecho a la libre competencia. Mucho más teniendo en cuenta la facilidad que otorgan las comunicaciones digitales y el acceso a múltiples bancos de datos extremadamente informados, que con rapidez distribuyen los conocimientos abiertamente.

La protección de la ley a las invenciones patentadas es firme y rigurosa, mientras que las normas que protegen el secreto industrial deben necesariamente estar limitadas a la sanción de las conductas ilícitas basadas en la violación de la competencia leal y contrarias al accionar honesto y la buena fe comercial. No pueden igualarse los remedios legales para protegerlos por- 
Esta obra forma parte del acervo de la Biblioteca Jurídica Virtual del Instituto de Investigaciones Jurídicas de la UNAM

que ambas instituciones jurídicas responden a distinta naturaleza jurídica y la afectación al derecho de la competencia es diferente.

Por lo tanto, una mayor protección de los secretos no significa una mejor legislación. El avance de la legislación respecto del secreto hace que se parezca mucho a las patentes de invención; en consecuencia, va a resultar más conveniente mantener un secreto industrial, que no tiene fecha de vencimiento, que patentar un invento, que sí debe darse a conocer públicamente y tiene plazo de vigencia.

\section{LA INFORMAGIÓN CONFIDENGIAL Y EL ACUERDO DE LOS ADPIC}

La exposición de motivos del proyecto resalta la necesidad de compatibilizar las legislaciones nacionales de los miembros de la región con el Acuerdo de los ADPIC, por lo que esta Directiva está dirigida a ese objetivo.

Teniendo en cuenta este lineamiento, es interesante revisar las disposiciones de dicho Acuerdo para establecer la consistencia técnica de esta norma con el tratado.

La inclusión de la protección de la información confidencial en la Ronda Uruguay del GATT, antecedente del Acuerdo sobre los Aspectos de los Derechos de Propiedad Intelectual relacionados con el Comercio (Acuerdo sobre los ADPIC), se produjo en enero de 1990, es decir, casi cuatro años después del comienzo de las negociaciones que se iniciaron en 1986.

Si polémica fue la incorporación en esa Ronda de los derechos intelectuales en general, bajo el rubro "nuevos temas", más conflictivo aún resultó imponer la cuestión sobre la protección de la información confidencial.

En efecto, el GATT es un tratado multilateral regulador del comercio mundial basado en la libertad de comercio y sustentado en los principios de trato nacional, no discriminación y de nación más favorecida, que, desde su nacimiento en 1954 y hasta la sanción del Acta de Marrakech en 1994, no se ocupó de la propiedad intelectual.

Los países industrializados presionaron para utilizar el marco de este tratado incluyendo la propiedad intelectual, por la capacidad sancionatoria de este convenio que cuenta en su estructura con un sistema de solución de controversias con capacidad de imponer sanciones a los países miembros que no adecuan sus legislaciones a los principios y estándares que se formulan.

Esto no ocurre con el Convenio de París, que tradicionalmente ha sido el tratado bajo el cual se regulaban internacionalmente la propiedad indus- 
Esta obra forma parte del acervo de la Biblioteca Jurídica Virtual del Instituto de Investigaciones Jurídicas de la UNAM

trial y el derecho de la competencia, convenio que no contempla ninguna sanción efectiva contra sus miembros por la falta de cumplimiento de sus reglas.

El GATT gana en eficacia regulatoria sin duda. De él nació la Organización Mundial del Comercio (OMG) y, como anexo, el Acuerdo de los ADPIC.

Admitida en la Ronda Uruguay la incorporación de los temas de propiedad intelectual, se planteó de inmediato un primer problema, cual fue el papel que debía jugar la Organización Mundial de la Propiedad Intelectual (OMPI). Los países en desarrollo defendieron la competencia de la OMPI en cuanto agencia de las Naciones Unidas encargada de administrar los Convenios de París y de Berna, ambos referidos a la propiedad intelectual, entendiendo que dicha materia debía ser tratada con exclusividad en ese organismo. Por el contrario, los países desarrollados propugnaron que al seno del GATT debían incorporarse los temas vinculados a la propiedad intelectual.

Más allá de analizar los tropiezos, las presiones y los debates que se originaron por la inclusión de la protección de la información confidencial, cabe señalar finalmente que el Acuerdo de los ADPIC regula la "Protección de la información no divulgada" en la sección 7, artículo 39, cuya redacción está dividida en tres apartados: el primero establece que la protección será dada sobre la base del artículo 10 bis del Convenio de París (versión de 1967), es decir, la competencia desleal. El segundo apartado desarrolla este concepto, definiendo la conducta antijurídica como "la utilización por terceros sin su consentimiento, de manera contraria a los usos comerciales honestos".

Por último, el tercer apartado se refiere a la protección de los datos de prueba cuando los miembros exijan como condición para aprobar la comercialización de productos farmacéuticos o químicos y agroquímicos que utilizan nuevas entidades químicas, la presentación de datos de prueba u otros no divulgados. Esta compleja sección está regulada en Europa por el reglamento sobre los ensayos clínicos de la European Medicines Agency New Clinical Trials Regulations de enero de 2015, por lo que no está comprendida en este proyecto.

Es bueno recordar que la posición adoptada en los debates del artículo 39 del ADPIC en forma conjunta por la delegación europea y un frente constituido por los países en desarrollo, permitió que la protección del secreto se regulara bajo el amparo del artículo 10 bis del Convenio de París, contra la línea sostenida por los Estados Unidos de América, que era la de otorgar a la información confidencial una protección con base en un derecho exclusivo. 
Esta obra forma parte del acervo de la Biblioteca Jurídica Virtual del Instituto de Investigaciones Jurídicas de la UNAM

Ésta era la doctrina sostenida por la corporación de negocios, expuesta en un documento denominado Brussels Draft, que proponía la creación de un derecho exclusivo respecto de la protección de datos para los productos farmacéuticos y agroquímicos, por un plazo de cinco años. En el debate de los ADPIC y en el texto final esta posición no tuvo éxito.

Tiempo después, la Unión Europea modificaría su posición en lo referido al tercer apartado del artículo 39, siguiendo los pasos de los Estados Unidos de América, por lo que la protección de los datos de prueba pasó a ser un tema central de su política comercial internacional, instrumentada no ya a través de los ADPIC sino en los tratados bilaterales de libre comercio, en los que se ha fijado como requisito específico el otorgamiento de un derecho exclusivo de cinco o diez años según cada uno de los acuerdos.

La consecuencia de este plan político es que ha obligado a los cofirmantes de los tratados a incorporar esa protección en sus respectivas legislaciones nacionales a cambio de ventajas relacionadas con la apertura de sus mercados al ingreso de materia prima, o al levantamiento de medidas arancelarias para determinado tipo de productos, sumando una cantidad considerable de países que han modificado su legislación en lo que representa una protección extra a la prevista en el Acuerdo de los ADPIC.

Dado que este capítulo no ha sido incluido en el proyecto, no está en consideración en el presente trabajo.

\section{CONTENIDO DEL PROYECTO}

La propuesta de Directiva consta de cuatro capítulos; el tercero dividido a su vez en tres secciones. El primer capítulo se refiere al objeto y ámbito de aplicación; el segundo a la obtención, utilización y divulgación ilícitas de secretos comerciales, y el tercero a las medidas, procedimientos y remedios, cuya sección primera se refiere a las disposiciones generales; la segunda a las medidas provisionales y cautelares, y la tercera a las medidas resultantes de una resolución sobre el fondo. Finalmente, el capítulo IV se ocupa de sanciones, informes y disposiciones finales.

Es de señalar que el proyecto sólo tiende a la reparación civil en caso de obtención, utilización y divulgación de secretos comerciales. No se ocupa de las sanciones penales que cada país pueda regular ni tampoco las promueve.

El capítulo I define los objetivos de la norma relacionados con lo que atañe a la obtención, divulgación y utilización ilícitas de secretos comerciales, y a las medidas, procedimientos y remedios que deberían estar disponibles a efectos de reparación civil en la materia. 
Esta obra forma parte del acervo de la Biblioteca Jurídica Virtual del Instituto de Investigaciones Jurídicas de la UNAM

Se caracteriza el secreto comercial en función de tres elementos: 1) la información es confidencial; 2) debe tener un valor comercial por el hecho de ser confidencial, y 3 ) el poseedor del secreto debe haber tomado medidas razonables para mantenerla en secreto.

El poseedor del secreto debe estar legitimado. El secreto comercial puede ser defendido tanto por el poseedor original como por los licenciatarios.

El bien infractor es aquel que ha sido diseñado, fabricado o comercializado mediante un comportamiento ilícito. Cualquier medida que se contemple que afecte directamente a los bienes fabricados o comercializados debe ser evaluada en forma proporcional a las características de este bien infractor.

En el capítulo II, la Directiva establece algunas definiciones para precisar el alcance y contenido de esta disposición. Especifica que el elemento sustancial para que los actos sean considerados ilícitos es la ausencia de consentimiento por parte del poseedor del secreto.

Igualmente resulta ilícita la utilización de un secreto por un tercero que no haya participado directamente en la obtención, utilización o divulgación ilícita original, pero que tenga o haya debido tener conocimiento del acto ilícito original.

En el marco de la naturaleza jurídica de la información confidencial se establece correctamente que es posible y legítimo llegar al conocimiento en forma independiente o recurriendo a la ingeniería inversa. Ambos mecanismos son legales y no están alcanzados por la sanción de la Directiva.

\section{LAS DISPOSICIONES RESPECTO DE LAS MEDIDAS DE FORMA Y DE FONDO EN LA PROTECGIÓN DEL SEGRETO COMERGIAL E INDUSTRIAL}

El capítulo III se ocupa de las medidas, procedimientos y remedios que deben estar a disposición del titular del secreto en caso de que se produzca la obtención, utilización o divulgación ilícitas de dicho secreto por un tercero no autorizado.

El artículo 5.2 establece que las medidas, procedimientos y remedios: a) serán justos y equitativos; b) no serán innecesariamente complicados o gravosos ni comportarán plazos irrazonables o retrasos injustificados, y c) serán efectivos y disuasorios.

Este capítulo es el de mayor relevancia en la Directiva, ya que establece los instrumentos de que se puede valer el tenedor de un secreto en defensa y protección de esa información. 
Esta obra forma parte del acervo de la Biblioteca Jurídica Virtual del Instituto de Investigaciones Jurídicas de la UNAM

Los principios generales expuestos se basan - dice el proyecto- en establecer medidas eficaces, equitativas y proporcionales. Al mismo tiempo, estas medidas deben estar controladas por salvaguardas que eviten acciones judiciales abusivas.

Una de las novedades de la Directiva es que exige a los Estados miembros dotar a las autoridades judiciales de mecanismos que permitan preservar la confidencialidad en los tribunales en el marco de las acciones judiciales. Propone para ello restringir el acceso a la totalidad o parte de la documentación presentada en juicio; la restricción de acceso a las audiencias y a las actas correspondientes; la obligación a las partes o terceros intervinientes de redactar las versiones no confidenciales de los documentos que contienen secretos comerciales, y la redacción de versiones no confidenciales de las resoluciones judiciales.

Estas medidas se aplicarán durante el proceso judicial, sin perjudicar el derecho de defensa, y también después de concluido el mismo, en el tiempo durante el cual la información siga siendo secreta.

La Directiva ha hecho un interesante aporte en relación a cómo cubrir los riesgos que se corren durante la tramitación de un juicio y después de él. En este tipo de acciones judiciales resulta difícil el mantenimiento del secreto, por lo que la preocupación por su vigencia ha llevado a una regulación tendente a que no sea vulnerado tanto durante como después del juicio, mientras la información permanezca en secreto.

\section{LAS MEDIDAS CAUTELARES Y EL EXCESO SOBRE LA PROTECGIÓN DEL SECRETO}

La sección 2 es la más controversial y la que más afecta a la caracterización del secreto, y por derivación a los principios que rigen el derecho de patentes. Es aquí donde advierto un serio retroceso no sólo en la legislación que se busca plasmar, sino principalmente en los fundamentos que llevan a imponer este tipo de medidas.

La mirada no está puesta en el interés público sino en el aprovechamiento de las ventajas que le corresponden a las empresas precursoras que ponen nuevos productos en los mercados, otorgando herramientas de defensa que ni siquiera poseen los titulares de patentes de invención.

Se prevén en esta sección las medidas provisionales y cautelares de forma, es decir, los recursos procesales para asegurar los resultados de una sentencia. Se regulan también las medidas de salvaguarda a fin de cumplir con los fines de equidad y proporcionalidad. 
Esta obra forma parte del acervo de la Biblioteca Jurídica Virtual del Instituto de Investigaciones Jurídicas de la UNAM

En el considerando 15 del proyecto se puede encontrar la matriz de la imposición de estas medidas. Allí se dice:

Es esencial pues prever medidas provisionales rápidas y accesibles para poner fin inmediatamente a la obtención, utilización o divulgación ilícitas de un secreto comercial. Estas medidas deben estar disponibles sin tener que esperar una decisión sobre el fondo del asunto, con el debido respeto de los derechos de defensa y el principio de proporcionalidad y habida cuenta de las peculiaridades de cada caso.

Veamos ahora cómo se llevan a la práctica los principios enunciados. $\mathrm{El}$ artículo 9o. (medidas provisionales y cautelares) dice:

1. Los Estados miembros garantizarán que las autoridades judiciales competentes puedan, a instancia del poseedor del secreto comercial, ordenar cualquiera de las siguientes medidas provisionales y cautelares contra el presunto infractor:

a) El cese o, en su caso, la prohibición de la utilización o divulgación del secreto comercial con carácter provisional.

b) La prohibición de producir, ofrecer, comercializar o utilizar bienes infractores o de importar, exportar o almacenar bienes infractores a tales fines.

c) La incautación o la entrega de los presuntos bienes infractores, incluidos los bienes importados, a fin de impedir su introducción o su circulación en el mercado.

Como se puede observar, mediante el recurso de una medida cautelar el poseedor de un secreto puede sin más obtener el cese o la prohibición de utilizar o divulgar el secreto a quien no se ha determinado aún si es infractor o no, si ha llegado o no por medios lícitos a los mismos resultados que el precursor. También la prohibición de producir, ofrecer, comercializar o utilizar bienes infractores.

Es decir, el accionante, quien deberá acreditar en forma fehaciente la titularidad del secreto, obtiene como medida formal y provisoria lo que sólo le puede dar una sentencia definitiva. Por la vía procesal se obtiene rápidamente un anticipo de jurisdicción, puesto que se decreta antes del fin del proceso una medida similar a la de la sentencia pretendida al iniciar la acción.

Si dificil resulta conocer para un juez el contenido de una patente y su probable infracción, mayor aún será el esfuerzo probatorio para justificar el contenido de un secreto industrial, incluyendo su carácter novedoso y económicamente valioso. 
Esta obra forma parte del acervo de la Biblioteca Jurídica Virtual del Instituto de Investigaciones Jurídicas de la UNAM

No es suficiente fijar una fianza importante para el caso de que la medida sea injusta o que la sentencia sea contraria al accionante, ya que finalizado el juicio - que seguramente no será en forma inmediata- el demandado que no ha infringido ningún secreto ni alguna información confidencial seguramente ya estará fuera del mercado.

El otorgamiento de protecciones en forma desmedida insta al supuesto titular de un secreto, que puede ser novedoso o no, a litigar para expulsar a los legítimos competidores, porque no le resultará difícil jugar la carta de una medida cautelar anticipada.

El exceso que esto implica queda puesto en evidencia en las disposiciones del artículo 11.1 incluido en la sección 3, "Medidas resultantes de una resolución sobre el fondo", que establece:

1. Los Estados miembros garantizarán que, cuando se haya dictado una resolución judicial por la que se constate la obtención, utilización o divulgación ilícitas de un secreto comercial, las autoridades judiciales competentes pueden, a instancia de la parte demandante, ordenar contra el infractor:

a) El cese o, en su caso, la prohibición de la utilización o divulgación del secreto comercial.

b) La prohibición de producir, ofrecer, comercializar o utilizar mercancías infractoras o de importar, exportar o almacenar mercancías infractoras a tales fines.

Si se compara el artículo 9.1, que se refiere a las medidas de forma de carácter provisorio, con el artículo 11.1, que se refiere a las medidas de fondo que deberán tomarse una vez dictada la sentencia, se observará que los apartados 1.a) y 1.b) son idénticos, con la salvedad de que en el artículo 11 se les ha quitado el carácter de provisorias.

Una Directiva de esta naturaleza no es equitativa ni proporcionada. Una medida de cese o prohibición de utilizar una información tecnológica sólo puede tener razón de ser frente a una sentencia firme, no como medida anticipada.

Si las medidas de forma son iguales a las medidas de fondo que se ponen en funcionamiento sólo cuando existe una sentencia definitiva, justifica la crítica al excesivo rol que se le ha dado a las medidas cautelares.

Creemos que se da un paso en la dirección incorrecta, estableciendo una sobreprotección legal con las características mencionadas de normas ADPIC plus. 
Esta obra forma parte del acervo de la Biblioteca Jurídica Virtual del Instituto de Investigaciones Jurídicas de la UNAM

\section{COMPARAGIÓN ENTRE LA PROTECGIÓN DE LA INFORMACIÓN CONFIDENGIAL Y LAS PATENTES DE INVENCIÓN}

Como se ha señalado, la característica de los secretos es que son efectivamente eso, informaciones comerciales o técnicas que se encuentran en conocimiento de una o pocas personas y su beneficio económico y su protección duran mientras se mantiene el secreto. La información no llega a la comunidad, se constituye en un monopolio de hecho; es decir, no validado por un derecho de propiedad ni una exclusividad.

En cambio, la invención patentada es un monopolio de derecho mediante el cual la ley permite obtener un beneficio exclusivo durante un plazo no menor de veinte años mediante el jus prohibendi, es decir, la facultad de excluir a un tercero no autorizado a que produzca, venda, importe, exporte, utilice ese producto o proceso resultante de una patente otorgada, luego de cumplir los requisitos exigidos.

Reiteramos que esta excepción al principio de la libre utilización de la información es una concesión que la sociedad acepta y tiene como objeto promover las invenciones y el desarrollo tecnológico. La contrapartida es la obligación de hacer de conocimiento público el invento, formando parte del estado de la técnica, para colaborar de esta manera con el mejor vivir de toda la sociedad.

No es el secreto lo que promueve la ley sino la información pública debidamente protegida. El secreto es un límite al conocimiento público. No está prohibido pero tampoco debe ser estimulado. Es una decisión riesgosa que todo empresario puede tomar, porque no es ilegítimo tener información en secreto, pero debe aceptarse como un riesgo.

Desde ya, todo acto ilícito destinado a la sustracción de un secreto debe ser sancionado, y de ahí las disposiciones del artículo 39 del Acuerdo de los ADPIC que condena todo acto de competencia desleal y deshonesto en el marco de la actividad comercial. Pero esto no significa que se le adjudiquen beneficios mayores que a la tecnología patentada.

Si agregamos a estos beneficios el hecho de que el secreto no tiene límite temporal ni requiere mérito inventivo, la comparación entre las patentes y los secretos pasaría a tener un saldo a favor de estos últimos. En efecto, las invenciones son protegidas por la ley una vez que las oficinas de patente les han concedido el brevet. En el tiempo que va desde la solicitud hasta el otorgamiento, carecen de protección por tratarse de un derecho en expectativa, tal el caso de la legislación argentina. En algunas legislaciones, entre ellas la española, se prevén para este periodo medidas provisionales mínimas que 
Esta obra forma parte del acervo de la Biblioteca Jurídica Virtual del Instituto de Investigaciones Jurídicas de la UNAM

sólo pueden ser ratificadas una vez que la patente se otorga. En ningún caso se prevé el cese de explotación o sanciones similares.

Además, una vez otorgadas las patentes de invención, la facultad de hacer cesar judicialmente la explotación, el uso o la producción de la tecnología que infrinja el campo de la patente, por medio de una medida cautelar, es de carácter excepcional y luego de tramitar ciertos requisitos, como por ejemplo la designación de un perito ad-hoc que le justifique al juez, que usualmente no es un experto en materias técnicas que se debaten en los litigios de patentes, que no está cometiendo un error o un abuso. Las exigencias que debe sortear un accionante en un juicio de patentes en los Estados Unidos de América o en Japón son altamente complicadas y no son concedidas habitualmente.

\section{EL INCIDENTE DE EXPLOTAGIÓN DEL ARTÍCULO 9.2}

Así como resulta criticable el artículo 9.1, que a mi entender debe ser suprimido de acuerdo con los fundamentos que he expuesto, considero un acierto las disposiciones y las facultades emergentes del artículo 9.2 del proyecto de Directiva.

El artículo dice: "Los Estados miembros garantizarán que las autoridades judiciales pueden supeditar la continuación de la obtención, utilización o divulgación presuntamente ilícitas de un secreto comercial a la constitución de garantías que puedan servir para indemnizar al poseedor del secreto comercial".

Se trata de lo que en la doctrina se denomina "incidente de explotación", que tiene una larga trayectoria en la legislación argentina tanto en el derecho de marcas como en el de patentes.

Es un mecanismo mediante el cual el juez puede reclamar al que presuntamente está infringiendo el secreto, que manifieste su intención de seguir explotándolo. En caso afirmativo le deberá exigir una fianza a modo de contracautela que sirva para indemnizar al poseedor del secreto por los daños y perjuicios que pueda llegar a sufrir. De no aceptar el pago de la fianza o negarse a continuar con la explotación, deberá inmediatamente cesar en el uso, explotación o divulgación del secreto.

Las condiciones de aplicación y las medidas de salvaguarda están bien diseñadas en el artículo 10.1, que dice:

Los Estados miembros garantizarán que las autoridades judiciales competentes estén habilitadas, en lo que concierne a las medidas contempladas en el 
Esta obra forma parte del acervo de la Biblioteca Jurídica Virtual del Instituto de Investigaciones Jurídicas de la UNAM

artículo 9o., para exigir a la parte demandante que aporte pruebas que puedan razonablemente considerarse disponibles para asegurarse de que existe un secreto comercial, de que la parte demandante es su poseedor legítimo y de que el secreto comercial ha sido obtenido de forma ilícita, de que el secreto comercial está siendo utilizado o divulgado de forma ilícita o de que es inminente la obtención, utilización o divulgación ilícitas del secreto comercial.

Aquí el proyecto es perfectamente compatible con su considerando 18, que sostiene que "estas medidas deben estar disponibles sin tener que esperar una decisión sobre el fondo del asunto, con el debido respeto de los derechos de defensa y el principio de proporcionalidad, y habida cuenta de las peculiaridades de cada caso".

\section{Conclusiones}

Llegado a esta instancia, cabe hacer un balance respecto de las disposiciones de esta Directiva. No hay duda de que las normativas respecto de los secretos comerciales e industriales deben tener un tratamiento uniforme en el marco regional de la Unión Europea, ya que éstos constituyen un instrumento complementario esencial para la protección de los activos intelectuales. Al mismo tiempo, esa legislación debe ser consistente con el Acuerdo de los ADPIC.

En ese sentido, la Directiva en análisis cumple con un papel ordenador respecto de los miembros de la Unión y rescata los principios expuestos en el artículo 39, apartados 1 y 2, del Acuerdo.

Esto no autoriza, sin embargo, a asemejar su tratamiento al de las invenciones patentadas ni a ningún otro derecho industrial cuya característica es que son derechos exclusivos y, como tales, sus titulares ejercen el jus prohibendi en toda su amplitud en tanto impiden que los terceros sin su autorización puedan explotarlos comercialmente en todo el circuito productivo.

De las virtudes y defectos que hemos puesto en consideración en el curso de este trabajo podemos señalar a modo de síntesis cuáles han sido los principales aspectos en los que coincidimos y cuáles son nuestros desacuerdos.

Como parte de los acuerdos, cabe señalar que la Directiva señala claramente que la protección de los secretos no otorga derechos exclusivos, por lo que cualquier tercero puede llegar al mismo conocimiento si lo hace en forma lícita y por sus propios medios, permitiéndose el uso de la ingeniería inversa. La protección del secreto opera esencialmente contra todo acto contrario a los usos comerciales honestos, tal como lo enuncia el artículo 10 bis del Convenio de París. 
Esta obra forma parte del acervo de la Biblioteca Jurídica Virtual del Instituto de Investigaciones Jurídicas de la UNAM

Acordamos también con que la apreciación del carácter necesario y proporcionado de las restricciones al derecho de los terceros está sujeta caso por caso al control judicial. No hay posibilidades de establecer en general y a priori cuáles son los conocimientos vulnerados, ya que se trata de secretos y por ende no está preestablecido un campo preciso de la técnica que debe protegerse, tal como sucede con las invenciones patentadas.

Incluye la norma un aspecto novedoso, no regulado con anterioridad en otras disposiciones conocidas, relativo a garantizar la confidencialidad de los documentos en los procedimientos judiciales y aun después de finalizados los mismos si el secreto continúa. Es una adecuada previsión legislativa, ya que si bien se da por sobreentendida la necesidad de preservar el secreto en todas las instancias del proceso, se regula de manera cuidadosa el accionar judicial para que esto ocurra tanto de las partes como de los funcionarios intervinientes en el juicio.

Por otra parte, se señala que los procesos judiciales no serán abusivos y la norma debe ser aplicada por las autoridades judiciales competentes en forma proporcionada, evitando la creación de obstáculos al comercio legítimo en el mercado interior, estableciendo medidas de salvaguarda contra los abusos y sancionando la iniciación y prosecución de todo proceso judicial incoado de mala fe. Se establecen además medidas destinadas a garantizar la libertad de expresión y de información, y la defensa de los derechos. Las disposiciones establecidas en el artículo 10 relacionadas con las condiciones de aplicación y medidas de salvaguarda están ampliamente desarrolladas con adecuada técnica legislativa.

En cambio, considero un retroceso las disposiciones atinentes a las medidas cautelares y provisionales establecidas en el artículo 9.1, norma que entiendo debe directamente derogarse en virtud de que el dispositivo que autoriza a requerir el cese completo y desde el inicio del juicio de todo tipo de producción, utilización y comercialización de un conocimiento técnico que aún no se ha comprobado mediante sentencia firme que haya infringido un secreto, además de la incautación de todos los bienes producidos o importados, es excesivo.

Téngase en cuenta que estas medidas son de carácter provisorio y sin embargo el accionante puede lograr desde el inicio, lo que pretende en la sentencia. Se trata de una norma ciertamente peligrosa, ya que establece de manera provisoria las mismas sanciones que se prevén para el caso de ganar el caso.

Resulta ser una medida desproporcionada que permite potencialmente que bajo un manto de legalidad se oculten conductas anticompetitivas y se 
Esta obra forma parte del acervo de la Biblioteca Jurídica Virtual del Instituto de Investigaciones Jurídicas de la UNAM

logre por esa vía desplazar a cualquier competidor mediante una jugada audaz que, siendo de mala fe, va a ser sancionada cuando la sentencia esté firme, es decir que en cualquier ordenamiento jurídico, aun el más eficaz, se garantiza un tiempo de exclusión del mercado, que se cuenta en años. Con esa regla a mano se puede desnaturalizar cualquiera de las disposiciones que con la mejor técnica legislativa se promulguen. La práctica judicial es rica en este tipo de jugadas.

Esa disposición puede ser modificada por el establecimiento de medidas de carácter conservativo o anticipadas para preservar las pruebas existentes utilizando estas medidas que sí son proporcionales a las reglas de observancia que corresponden a los secretos, ya que en este caso son mayores incluso que las que tienen los titulares de patentes.

Es de aplicación en los sistemas procesales más avanzados, autorizar por ejemplo, el inventario de las mercaderías producidas, secuestrar uno o más ejemplares para preservar pruebas, requerir documentación respecto de la comercialización y determinar los procedimientos utilizados en la producción mediante la presencia de peritos, etcétera.

Por su parte, el apartado 2 del artículo 9o. debe mantenerse, pues se trata de una razonable alternativa procesal denominada incidente de explotación, que permite garantizar el resultado del pleito ya sea por la decisión de continuar con la explotación del conocimiento técnico o desistir de ella. En todos los casos, mediante el establecimiento de una garantía fijada por el juez en cabeza del demandado, en el primer caso, o en la del actor, en el segundo. 
Esta obra forma parte del acervo de la Biblioteca Jurídica Virtual del Instituto de Investigaciones Jurídicas de la UNAM

\title{
LA INFORMAGIÓN GENÉTICA HUMANA ANTE EL DERECHO
}

\author{
Salvador Darío BERGEL
}

\begin{abstract}
SUMARIO: I. Introducción. II. Información y datos genéticos. III. Particularidades que exhiben los datos genéticos. IV. Fuentes de los datos genéticos. V. Datos que puede aportar un análisis genético. VI. Datos personales y datos de carácter personal. VII. El derecho a la protección de los datos genéticos. VIII. El derecho a la autodeterminación genética. IX. La intimidad, la privacidad y la confidencialidad en relación con los datos genéticos. X. Conflictos relativos a la confidencialidad de los datos. XI. Los momentos de la protección de los datos genéticos. XII. La utilización indebida de datos genéticos.
\end{abstract}

\section{INTRODUCGIÓN}

El tema de la protección de los datos genéticos debe considerarse un ejemplo notable de cómo el progreso de la investigación científica desafía al derecho, obligándolo a introducir nuevos objetos de protección. Hasta el advenimiento de la genética molecular en el estudio científico del genoma humano, el tema de la información genética era prácticamente inexistente. ${ }^{1}$ Ahora, Romeo Casabona nos habla de la información genética como nuevo y peculiar objeto material de tutela jurídica. ${ }^{2}$

Recién en 1944 Avery identificó al ADN como base molecular de la herencia, y en 1953 Watson y Crick propusieron su modelo estructural de la doble hélice. A partir de ese entonces el progreso de la genética ha sido continuo y acelerado, pasando de los abstractos factores hereditarios mendelianos a los genes tangibles y manipulables. Con posterioridad, a partir de 1975 se desarrolló la secuenciación del genoma humano, aventura que

Auffray, C. H. y Jacquard, A., Dictionaire de la Biologie, París, Flamarionn, 1998, p. 117.

2 Romeo Casabona, C. M., Genética y derecho, Buenos Aires, Astrea, 2003, p. 67. 
Esta obra forma parte del acervo de la Biblioteca Jurídica Virtual del Instituto de Investigaciones Jurídicas de la UNAM

desembarcó en el Proyecto Genoma Humano, cuyas investigaciones no sólo fueron de interés científico sino comercial. ${ }^{3}$

Paralelamente se entró a estudiar y vincular la información genética con aspectos centrales del fenotipo y del genotipo, lo que generó un marcado interés por hacer de la misma un objeto de protección especial, dadas las consecuencias que genera su difusión indebida.

Esta evolución científica se vio potenciada por la informática, que contribuyó a una difusión incontrolada de todo tipo de datos, entre ellos los genéticos. Hoy, el tema de la información genética y su circulación no es sólo un tema de dimensiones biológicas, sino - y en forma preponderante- un problema jurídico y social.

Nuestro genoma es una fuente de informaciones de alcances monumentales, un reto para los analistas y para los decodificadores. No es el grial ni la solución a todos nuestros males, pero nos ayuda a comprender infinidad de aspectos de nosotros mismos y de la naturaleza. ${ }^{4}$

Una de las características destacables de los tiempos que transitamos es la facilidad con que circulan los datos genéticos vinculados con seres humanos determinados o determinables. Un verdadero arsenal de medios técnicos, que se van perfeccionando con gran rapidez, está al servicio de ello.

El conocimiento que los terceros pueden adquirir de tales datos es motivo de creciente preocupación, ya que se ven invadidas esferas íntimas reservadas al sujeto. Junto a la circulación, se agrega el problema del entrecruzamiento de tales informaciones, lo que permite a los terceros tener el dominio de las esferas reservadas a los privados.

Para Rodotà el conocimiento de la información genética se transforma en un condicionante absoluto para el futuro de una persona. Está en juego la libertad existencial, no como expresión abstracta sino por los concretos vínculos con la formación y el desarrollo de la persona. ${ }^{5}$

En los hechos, la informática y la genética tienen puntos de contacto destacables. El abuso de la utilización de los datos personales existió desde antes de la aparición de la informática; pero ahora el riesgo ha crecido considerablemente. La informática permite la elaboración y manipulación de los datos, su agregación o desagregación en un reducido espacio de tiempo, con lo cual ha cambiado la calidad del peligro. ${ }^{6} \mathrm{El}$ tema de mayor relevancia no estriba tanto en la cantidad de información, la diversificación de

3 Lacadena, J. R., Genética y bioética, Madrid, Comillas, 2012, p. 17.

4 Purroy, J., La era del genoma, Madrid, Salvat Ciencia, 2001, p. 49.

5 Rodotà, S., Tecnologia e Diritti, Bolonia, Il Mulino, 1995, p. 207.

6 Losano, C. M., en Fundesco 128, abril de 1992, p. 6. 
Esta obra forma parte del acervo de la Biblioteca Jurídica Virtual del Instituto de Investigaciones Jurídicas de la UNAM

su contenido, sino en la posibilidad de vincularla y obtener de ella nuevos datos. ${ }^{7}$ Cuando se trata de datos genéticos humanos el tema adquiere una dimensión mayor en atención a los valores en juego, sin dejar de considerar los efectos que tiene la utilización de los recursos informáticos en cuanto a la difusión del daño.

La reacción del derecho a los abusos de tal utilización ha sido oportuna. Hace tiempo que las habeas data se han convertido en un derecho fundamental, asegurando al ciudadano el control de las informaciones que le conciernen en diversos campos (salud, economía, trabajo, etcétera).

Dentro de los datos personales existe una categoría que se agrupa bajo la denominación de "datos sensibles" por cuanto tocan aspectos muy reservados de la vida del individuo (sanitarios, sexuales, políticos, etcétera), cuya difusión indebida tiene entidad para generar daños relevantes. Entre estos datos sensibles que se pretende tutelar se han incorporado - como una subcategoría - los denominados "datos genéticos", capaces de afectar no sólo al individuo al cual se refieren, sino a su familia y al grupo étnico del cual forma parte, lo cual torna necesaria una tutela más estricta. La particular relevancia de la información genética deriva de su carácter estructural y permanente. ${ }^{8}$

Rodotà nos habla de un estatuto general de las informaciones genéticas. Considera que al ser fuente de comunicación entre esferas subjetivas diferentes, trasciende la materialidad de los cuerpos y define una dimensión que ya no puede quedar reducida a la dimensión amplísima de la protección a la salud. 9

Hay que reconocer que resulta muy dificultosa la protección de los datos genéticos, ya que las posibilidades de su acceso son ilimitadas y, de común, cuando actúan los mecanismos acuñados al efecto, el perjuicio ya se ha producido. Pero ello, lejos de hacernos renunciar a la protección, debe inducirnos a extremar los mecanismos jurídicos, sobre todo en el campo de la prevención.

Estas circunstancias movieron tempranamente a la Unesco, al tiempo de acrecentarse la investigación biomédica en el campo de la genética, a la elaboración de la Declaración Internacional sobre Datos Genéticos Humanos. ${ }^{10}$ "Conscientes — según expresa en sus considerandos - que la recolec-

7 Frosini, J., "La protección de la intimidad: de la informática al bien jurídico informático”, Derecho y Tecnología Informática, Bogotá, núm. 3, 1990, p. 19.

8 Rodotà, S., Tecnologia..., cit., p. 207.

9 Rodotà, S., La vida y las reglas. Entre el derecho y el no derecho, Madrid, Trotta, 2010, p. 218.

10 Aprobada por unanimidad y aclamación en la 32a. reunión de la Conferencia General de la Unesco el 16 de octubre de 2003. 
Esta obra forma parte del acervo de la Biblioteca Jurídica Virtual del Instituto de Investigaciones Jurídicas de la UNAM www.juridicas.unam.mx

ción, el tratamiento, la utilización y la conservación de los datos genéticos humanos pueden entrañar riesgos para el ejercicio y la observancia de los derechos humanos y las libertades fundamentales y para el respeto de la dignidad humana". He aquí expresada la razón última de la protección privilegiada de la información genética.

Nuevos instrumentos - tales como la informática - o nuevas creaciones impuestas por la investigación científica - tal es el caso de los biobancos - deben merecer una respuesta adecuada del derecho para no convertir la vida de los ciudadanos en un verdadero calvario.

\section{INFORMACIÓN Y DATOS GENÉTICOS}

Hemos abordado el tema en anterior oportunidad destacando que si bien el término información genética se emplea indistintamente con el de dato genético, cabe establecer una distinción conceptual. ${ }^{11}$

La información se refiere primordialmente a lo biológico. La información - se ha señalado - es tan fundamental y única a la vida como el metabolismo o la reproducción. Mensajes codificados ocurren en una miríada de formas y se transmiten entre una multitud de distintos tipos de emisores y receptores. En el mundo viviente la información fluye como el agua a partir de un hidrante roto. ${ }^{12}$

Destacamos allí que pese al hecho que todos los seres vivos responden a un mismo código genético, ${ }^{13}$ cada especie posee una información genética que le es propia, distintiva en el mundo natural, lo que permite la reproducción dentro de la misma especie e imposibilita a la vez la invasión de las especies por otras, manteniendo las barreras naturales, y dentro de cada especie, los individuos poseen una información genética única y diferenciada del resto.

La información biológica se utiliza tanto para replicar la misma estructura de la célula como para contribuir a generar un nuevo individuo en la especie. ${ }^{14}$ La expresión "información genética” permite que un organismo

11 Bergel, S. D., "Información genética y derecho", en Casado, M. y Guillén, M., ADN forense: problemas éticos y jurídicos, Barcelona, Universidad de Barcelona, 2014, p. 25.

12 Zweiger, G., El genoma humano, México, McGraw-Hill, 2000, p. 22.

13 Correspondencia que relaciona diferentes combinaciones de tres bases nitrogenadas con sus aminoácidos equivalentes (Purroy, J., La era..., cit., p. 253).

14 El genoma contiene la información específica de las características hereditarias que se transmiten a su turno a sus descendientes. Para hacerlo, dispone en el seno de las células de un mecanismo de lectura y de transformación de esa información que le posibilita producir 
Esta obra forma parte del acervo de la Biblioteca Jurídica Virtual del Instituto de Investigaciones Jurídicas de la UNAM

pueda replicarse dentro de unos cánones preestablecidos. En las células, la información necesaria para ello se encuentra codificada en una molécula conocida como ADN (ácido desoxirribonucleico). ${ }^{15}$

El dato genético es, conforme a la definición dada por la mencionada Declaración, la información sobre las características hereditarias de las personas obtenidas por análisis de los ácidos nucleicos u otros análisis científicos. El más relevante de los ácidos nucleicos es el ADN. ${ }^{16}$

Lo que circula, lo que se archiva en un banco o registro, es el resultado del análisis sobre esa información. Es la versión legible de la estructura de la información genética. La información de naturaleza genética - afirma Guy - no es la persona ni la prolongación de la persona. Ella configura más bien un mensaje que da el perfil de una persona, que le confiere una posibilidad de vida y de riesgo. ${ }^{17}$

Si bien estos datos pueden ser en algunas circunstancias equiparables a los fines de su tratamiento jurídico con los datos médicos, no siempre lo son, tal como veremos más abajo.

Los datos genéticos - en opinión de Troncoso Reigada - reflejan la individualidad de la persona y aportan información de su salud pasada, presente y futura, siendo el máximo exponente de la medicina predictiva y preventiva. $^{18}$

\section{PARTIGUlaRIDADES QUE EXHIBEN LOS DATOS GENÉTICOS}

Los datos genéticos tienen características que los singularizan respecto de los datos médicos en general. La importancia de la definición de datos genéticos para el derecho radica en que para esa categoría de datos se ha construido un

de forma rigurosa las proteínas, que son los componentes más importantes de su organismo (Auffray, G. H. y Jacquard, A., Dictionnaire..., cit., p. 149).

15 Blázquez Fernández, E., "El concepto de información genética. Ácidos nucleicos. Estructura del ADN", en Tresguerras, J. A. et al., Biología aplicada a la medicina, Madrid, Díaz de Santos, 2003, p. 1.

16 El término "dato genético" se suele referir más en concreto al "dato genético de carácter personal", como aquel que se puede relacionar con la identidad de un individuo de manera directa o indirecta (como por ejemplo a través de un código). Nicolás Giménez, P., "Datos genéticos", en Romeo Casabona, C. M. (dir.), Enciclopedia de bioderecho y bioética, t. I, p. 525 .

17 Guy, H., en Knoppers, B. et al., La Génétique Humaine, de L'information a L'informatisation, París, Litec, 1992, p. 43.

18 Troncoso Reigada, A., "Prólogo", en Sánchez Caro, J. y Abellán, F., Datos de salud y datos genéticos. Su protección en la Unión Europea y en España, Granada, Comares, 2004. 
Esta obra forma parte del acervo de la Biblioteca Jurídica Virtual del Instituto de Investigaciones Jurídicas de la UNAM

régimen particular diferente en algunos aspectos al que se aplica a otros datos sensibles, en concreto los datos de la salud, dentro de los que se encuadra. ${ }^{19}$

Estos datos caracterizan a la información genética como "polimórfica" en relación con los otros datos.

Esta naturaleza deriva de tres niveles de información. Un primer nivel de "identidad genética" se corresponde con la constitución genética de la persona singular; un segundo nivel, con la capacidad de inferir la expresión fenotípica de una persona a partir de su familia, como condición hereditaria normalmente de carácter recesivo, y un tercer nivel destinado a reconocer una esfera social en la genética humana. ${ }^{20}$

Dentro de las características que les son propias a los datos genéticos cabe destacar:

a) Son datos que pueden revelar la identidad del sujeto y algunas de sus características fenotípicas. Si se los extrae de vestigios inicialmente innominados, un análisis genético puede llegar a determinar su vinculación con un sujeto determinado, dato que en materia criminal - tal como veremos - puede resultar muy valioso, tanto para incriminarlo como para desincriminarlo.

b) Pueden tener para la familia, comprendida la descendencia, y a veces para todo el grupo al que pertenezca la persona en cuestión, consecuencias importantes que se perpetúan durante generaciones (artículo 4.a.ii de la Declaración).

Tal como lo enseña Carlos de Sola, desde el punto de vista biológico el sujeto de los datos genéticos no es el individuo, sino la familia (o si se quiere cada uno de los miembros de una familia).21

c) Están reiterados en todas las células del organismo (a excepción de los hematíes), lo cual nos habla de la extrema facilidad de su acceso.

d) Son indestructibles. Acompañan al hombre durante toda su vida y después de muerto durante un largo periodo de tiempo. A menudo sirven para análisis genéticos que permiten hallazgos importantes $(v$. gr. el hallazgo de los restos de la familia Romanov, o los recientes estudios sobre los restos de Cristóbal Colón).22

19 Nicolás Giménez, P., "Datos genéticos", op. cit., p. 527.

20 Corcoy Bidasolo, M., "Protección penal de la información genética", en Casado, M. y Guillén, M. (coords.), ADN forense: problemas éticos y jurídicos, cit., p. 93.

21 De Sola, C., "Intimidad y datos genéticos. Situaciones de conflicto", Revista de Derecho y Genoma Humano, núm. 1, enero-julio de 1994, p. 186.

22 Alzogaray, R. A., Una tumba para los Romanov, Buenos Aires, Siglo XXI, 2006, p. 93. 
Esta obra forma parte del acervo de la Biblioteca Jurídica Virtual del Instituto de Investigaciones Jurídicas de la UNAM

e) Los datos pueden surgir de análisis a los que voluntariamente se presta el sujeto, o bien de materiales respecto de los cuales el sujeto no dio el consentimiento para su análisis (sobre células extraídas de la ropa, de las tazas o vasos usados, de la saliva, etcétera). Esto nos muestra que todos los individuos nos hallamos permanentemente expuestos a suministrar de forma involuntaria materiales a partir de los cuales se pueden realizar análisis genéticos y obtener la información deseada.

f) Pueden servir para análisis que denuncian la existencia de una enfermedad actual (enfermedad monogénica) o la predisposición actual o futura de padecer una enfermedad determinada.

g) La evolución de las técnicas empleadas puede llevar al extremo de que mediante análisis genéticos se puedan conocer otros datos del sujeto fuente (origen biogeográfico, estatura, color de los ojos, color de piel, etcétera). ${ }^{23}$

h) Pueden contener información cuya relevancia no se conozca necesariamente al momento de extraer las muestras biológicas (artículo 4.a. iii de la Declaración). La información genética afecta aspectos tales como la autonomía privada y la propia imagen. En determinadas circunstancias podría inclinar al individuo a cambiar su proyecto vital. ${ }^{24}$

i) Su conocimiento por terceros tiene entidad suficiente para perturbar al sujeto fuente.

j) Cruzados con otros datos genéticos pueden constituir una prueba decisiva en los procesos penales y de filiación.

Gómez Sánchez considera que la singularidad de la información genética se enmarca en el contexto de la emergencia de nuevos derechos que vienen a dar respuesta a situaciones derivadas de la aparición y progresiva implantación de novedosas biotecnologías. ${ }^{25}$

23 Huidobro, V. L., "Nuevos polimorfismos de ADN: predicción de origen biogeográfico y características físicas", en Casado, M. y Guillén, M. (coords.), ADN forense: problemas éticos y jurídicos, cit., p. 157.

24 Luján, J. L., "Genética, gestión del riesgo y contrato social”, en Borillo, D. (ed.), Genes en el estrado, Madrid, Consejo Superior de Investigaciones Científicas, 1993, p. 3.

25 Gómez Sánchez, Y., "La protección de los datos genéticos: el derecho a la autodeterminación informativa", ResearchGate, disponible en: http://wrere.researchgate.net/publication $/ 43125810$. 
Esta obra forma parte del acervo de la Biblioteca Jurídica Virtual del Instituto de Investigaciones Jurídicas de la UNAM

\section{FUENTES DE LOS DATOS GENÉTICOS}

Los datos genéticos surgen de los pertinentes análisis que pueden realizarse con base en diversas muestras orgánicas. ${ }^{26}$

Su fuente es variada. Así, tenemos:

\section{Muestras extraídas mediando el consentimiento informado para la realización de un análisis genético como fruto de una decisión médica o al margen de ella}

El consentimiento informado, instrumento central de la bioética que ha sido incorporado en la reciente reforma del Código Civil y Comercial (artículo 59), es un instituto que ha llegado a legitimar todo tipo de intervención médica, sea en el plano clínico o en el de investigación. Expresa la vigencia plena del principio de autonomía del sujeto y se lo define como una manifestación libre, inequívoca, específica e informada, surgida de un diálogo previo en el cual el sujeto consiente la utilización de su cuerpo o partes del mismo para fines médicos.

En esta materia, el consentimiento informado apunta a la autorización de ingreso a sus datos genómicos. En un simple análisis clínico el consentimiento es correlativo a la extracción de la muestra, lo cual no ofrece mayores problemas.

La forma más común de obtención de los datos genéticos es la del examen del genoma mediante el denominado "análisis genético", que consiste en el procedimiento destinado a la identificación del estado de afectado, de no afectado, o de portador de una variante genética que puede predisponer al desarrollo de una enfermedad específica de un individuo o condicionar su respuesta a un tratamiento concreto a través de la detección de la presencia, ausencia o variantes de uno o varios segmentos de material genético humano, o en su caso a la identificación del sujeto. ${ }^{27}$

\footnotetext{
26 Existe una serie de situaciones en las que se puede plantear un análisis genético: a) cuando existe el riesgo de una determinada enfermedad dentro de un procedimiento de reproducción asistida; b) en la confirmación o no de un diagnóstico o enfermedad genética hecha previamente con base en la sintomatología clínica; c) en el diagnóstico del estatus genético de un individuo, generalmente adulto, con respecto a una enfermedad de comienzo tardío; d) en la determinación de riesgo de una enfermedad compleja, y e) en caso de identificación de un gen candidato a una enfermedad (Sudbery, P., Genética molecular humana, 2a. ed., Madrid, Pearson-Prentice Hall, 2004, p. 255).

27 Baiget Bastus, M., "Análisis genético", en Romeo Casabona, C. M. (dir.), Enciclopedia de bioderecho y bioética, t. I, p. 29.
} 
Esta obra forma parte del acervo de la Biblioteca Jurídica Virtual del Instituto de Investigaciones Jurídicas de la UNAM

En el ámbito médico, los análisis genéticos pueden llevarse a cabo con el propósito, entre otros, de investigar ciertas enfermedades relacionadas con el ADN (análisis de investigación), así como de diagnóstico de carácter asistencial (análisis clínicos). Dejamos por ahora los análisis destinados a establecer la identidad del sujeto portador de la muestra o su relación con otro u otros sujetos.

Los análisis clínicos son principalmente prescritos por un genetista con base en ciertas circunstancias que hacen presumir la existencia de una anomalía vinculada con la genética. Dado el nivel de la información que puede suministrar el análisis es conveniente que sea un especialista quien lo encomiende y, en definitiva, quien lo interprete y aconseje los pasos a seguir. ${ }^{28}$

En la actualidad, la genética ha sido invadida por los intereses del mercado y asistimos a un proceso en el cual los individuos contratan test genéticos simplemente por capricho o para indagar el conocimiento de su genoma, tal como si encerrara la piedra filosofal.

Estos test genéticos, denominados direct-to-consumer genetic test se ofrecen por Internet, son amplios y variados, y así tenemos, por ejemplo, que se ofrecen test de riesgo de sufrir cáncer de mama, Alzheimer u otras dolencias.

Marfany considera que estos test pertenecen a un ámbito ambiguo y difuso, casi sin legislación y de regulación laxa, denominada "ciencia recreacional". ${ }^{29}$

Sequeiros expresa sobre este particular que a la gran utilidad de muchas pruebas genéticas fundamentales para el diagnóstico de enfermedades hereditarias y el asesoramiento genético a las familias afectadas, se suman otras pruebas sin ningún tipo de validez o utilidad clínica, que no son más que "horóscopos genéticos", que ignoran y pasan por alto a los médicos y convierten a los pacientes en meros consumidores. ${ }^{30}$

Pueden observarse aquí objetivos comerciales de diverso tipo bajo una apariencia seudocientífica.

Francis Collins, destacado científico norteamericano que presidiera uno de los grupos de investigación del Proyecto Genoma Humano en su última

28 El artículo 12 del Convenio Europeo de Biomedicina (Convenio de Oviedo) establece que sólo podrán hacerse pruebas predictivas de enfermedades genéticas o que permitan identificar al sujeto como portador de un gen responsable de una enfermedad, o detectar una predisposición o una susceptibilidad genética a una enfermedad, con fines médicos o de investigación médica, y con un asesoramiento médico apropiado.

29 Marfany, G., "Test genético y protección de datos personales", en Buisan, L. y Sánchez Urrutia, A. (coords.), Intimidad, confidencialidad y protección de datos de salud, Madrid, Thomson Reuters, 2011, p. 123.

30 Sequeiros, J., "La genética y los derechos humanos" (prólogo), en Penchaszadeh, V. (comp.), Genética y derechos humanos, Buenos Aires, Paidós, 2012. 
Esta obra forma parte del acervo de la Biblioteca Jurídica Virtual del Instituto de Investigaciones Jurídicas de la UNAM

fase, en una obra reciente enuncia en un anexo los servicios proporcionados por compañías de análisis genéticos directos al consumidor. Entre ellos menciona rendimiento muscular, dependencia a la nicotina, tipo de cera de los oídos, intolerancia a la lactosa, esclerosis múltiple, etcétera. ${ }^{31}$

Todo esto es muy poco serio y tiende a banalizar un tema que compromete la esencia de lo humano. El Colegio Americano de Genética Médica, la principal organización profesional de medicina especializada en este campo, recomienda que no se realicen análisis genéticos DAC (análisis genéticos directos al consumidor, en sus siglas en inglés) bajo ningún concepto, sino que se hagan únicamente por petición de un profesional de la salud. A la gran utilidad de muchas pruebas genéticas fundamentales para el diagnóstico de enfermedades hereditarias y el asesoramiento genético a las familias afectadas, se suman otras pruebas sin ningún tipo de validez o utilidad clínica que ignoran y pasan por alto a los médicos especialistas. ${ }^{32}$

Por otra parte, la garantía de privacidad de la información genética - tema central de este trabajo - queda destruida al circular sin mayor control las muestras que servirán para la realización de estos test genéticos.

\section{Muestras obrantes en biobancos}

Se considera, en líneas generales, que un biobanco es una colección de material biológico, junto con los datos y la información asociados al mismo, almacenada en una forma organizada para una población o un subconjunto de la población. ${ }^{33}$

Los biobancos pueden variar en términos de tamaño, escala, alcances y tipo, pero en cualquier caso comparten una serie de características típicas que incluyen: ser una combinación de datos fenotípicos y genotípicos, constituir un foco de interés público e incorporar un organismo de gobernanza que permita el acceso a los mismos para investigaciones futuras, aunque con ciertas condiciones. ${ }^{34}$

Existe una tendencia cada vez más generalizada a tener biobancos con varias vías de entrada y salida de las muestras de la información genética (datos genéticos) y de la información media, de estilo de vida y genealógica,

31 Collins, F., El lenguaje de la vida, Barcelona, Crítica, 2011, p. 113.

32 Idem.

33 OCDE, "Biobank, Definition", Glossary of Statical Terms.

34 Kosseim, P. y Jope, D., "La puesta en práctica del consentimiento en el contexto de los biobancos”, en Buisan, L. y Sánchez Urrutia, A. (coords.), Intimidad, confidencialidad y protección de datos de salud, cit., p. 138. 
Esta obra forma parte del acervo de la Biblioteca Jurídica Virtual del Instituto de Investigaciones Jurídicas de la UNAM

además de la información biométrica de identificación civil de los individuos. La posibilidad de cruzar información entre los distintos repositorios de datos, de acceder a ellos desde servidores remotos o de ceder esa información a terceros no requiere sino de passwords, una autorización del curador de la base de datos o un trámite apenas engorroso para poder tener acceso a estas vías de entrada y salida de la información existente en los biobancos. ${ }^{35}$

Las muestras biológicas que se incorporan a los biobancos son en su inmensa mayoría nominativas, lo que no excluye que en ciertos casos ingresen muestras innominadas, respecto de las cuales no son de aplicación las normas sobre el resguardo y protección de la información genética.

El consentimiento informado contemporáneo a la incorporación de la muestra al biobanco debe contener el máximo de recaudos necesarios a los fines de resguardar los datos genéticos que porta la muestra (cuidado en la gestión, circulación y destino). Asimismo, pueden determinarse los límites de su utilización (para una investigación determinada o para investigaciones varias, etcétera) como, asimismo, la comunicación de los resultados obtenidos, el tiempo en el cual la muestra permanecerá en el biobanco, su destino final de destrucción, etcétera.

En principio, el consentimiento se refiere o debe referirse - en estos casos - a una concreta investigación, determinando los fines perseguidos, el deber de guardar el secreto en relación con los datos que se obtengan, y el término temporal en el que se desarrollará la investigación.

La dificultad, a veces insalvable, es que la información obtenida se utilice para otro tipo de investigación distinto al inicialmente previsto.

En una apreciación estricta, la nueva investigación se efectuaría al margen de los términos en que se otorgara el consentimiento, lo cual, para no generar una infracción, debería llevar al otorgamiento de un nuevo consentimiento.

Con conocimiento de ello, existe un movimiento enderezado al otorgamiento de un consentimiento ampliado, lo que equivale a decir que sirva

35 Keyeux, G., "Bancos de datos genéticos humanos: el equilibrio vacilante entre ciencia y derechos humanos", en Penchaszadeh, V. (comp.), Genética y derechos humanos, Buenos Aires, Paidós, 2012, p. 237. En esta situación, anota Ruth Macklin, no es sólo la información escrita sino los materiales biológicos los que proporcionan información que potencialmente pueden identificar las fuentes. Las muestras genómicas de estos bancos biológicos pueden reidentificarse, dado que las bases de datos disponibles al público hacen posible que se vincule un grupo concreto de muestras con otro grupo (Mackin, R., "Privacidad y confidencialidad en la investigación médica y del comportamiento", en Buisan, L. y Sánchez Urrutia, A. (coords.), Intimidad, confidencialidad y protección de datos de salud, cit., p. 33). 
Esta obra forma parte del acervo de la Biblioteca Jurídica Virtual del Instituto de Investigaciones Jurídicas de la UNAM

a los fines inicialmente previstos o a otros fines (siempre dentro de la idea de investigación) que no pudieran haber sido previstos al momento de su otorgamiento. ${ }^{36}$

En tales casos, este consentimiento ampliado sólo es permitido si el anonimato puede ser garantizado y no existe riesgo de que resultados inesperados puedan afectar a los sujetos participantes.

Si esta garantía no es posible o si la vinculación de datos es necesaria para la investigación, se debe obtener el consentimiento específico para una investigación específica. El uso de cláusulas de caducidad, según las cuales el consentimiento sólo sería válido por un periodo determinado de tiempo, puede considerarse un medio para garantizar una protección adecuada a los intereses de los sujetos participantes. ${ }^{37}$

Un principio clave de protección de los datos relacionados con el consentimiento informado requiere honestidad y transparencia en las disposiciones, procesos y procedimientos para garantizar una gestión adecuada de los datos personales que se recogen, almacenan, utilizan y se diseminan por una organización. ${ }^{38}$

La privacidad es perfectamente compatible con un modelo de consentimiento informado específico de acuerdo con el cual se debe contactar nuevamente a los participantes, caso por caso, y que les ofrece la oportunidad de decidir si desean o no permitir el acceso a los investigadores en función de cada investigación. La privacidad, entendida de esta forma, no sería incompatible necesariamente con un modelo de consentimiento ampliado, siempre dentro de ciertos parámetros. ${ }^{39}$

Los recientes avances en genómica, el uso de biobancos y la bioinformática, que han convertido en obsoletas las tradicionales pertenencias de la confidencialidad, exigen un replanteo en el consentimiento informado. Se necesitan nuevos mecanismos para mantener el ritmo de los avances rápidos en la genética y la creciente cantidad de bus biológicos existentes a fin de asegurar que la protección de la confidencialidad mejore y sea éticamente sólida. ${ }^{40}$

36 Un consentimiento ampliado es una forma más general de consentimiento mediante la cual los individuos aceptan que sus muestras biológicas y datos personales sean recogidos y ampliados en el biobanco y que se utilicen para investigaciones futuras inespecíficas (Kosseim, P. y Jope, D., op. cit., p. 140).

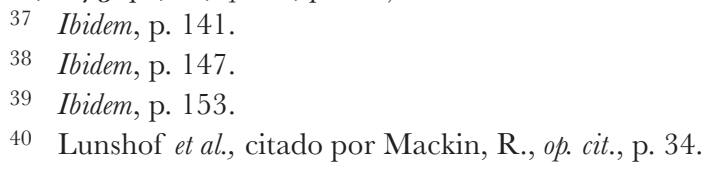


Esta obra forma parte del acervo de la Biblioteca Jurídica Virtual del Instituto de Investigaciones Jurídicas de la UNAM

3. Análisis realizados sobre vestigios abandonados, que normalmente se practican en los procedimientos penales para determinar la relación entre la muestra y un sujeto determinado

$\mathrm{El}$ avance de la investigación biológica, ${ }^{41}$ que posibilita el análisis sobre muestras minúsculas (restos epiteliales o una taza de café, por ejemplo), ha incorporado una nueva fuente que se puede denominar "muestras atribuidas" (normalmente abandonadas y que suelen ser tomadas de una manera subrepticia, ignorando el afectado que está facilitando una evidencia biológica susceptible de ser recogida y luego analizada). ${ }^{42}$

4. Análisis que se practican en contra de la voluntad del sujeto, en el caso de un proceso penal o para integrar un registro creado por ley

Los datos que surgen del análisis practicado pueden quedar contenidos en soporte papel o en otro tipo de soporte que permita su conocimiento.

En los hechos, pueden constar en:

a) Protocolos de análisis clínicos.

b) Historias clínicas.

c) Archivos de hospitales o establecimientos de salud, biobancos, etcétera.

d) Archivos policiales o de registros criminales.

\section{DATOS QUE PUEDE APORTAR UN ANÁLISIS GENÉTICO}

Nuestro genoma se conforma básicamente de dos partes: una codificante ${ }^{43} \mathrm{y}$ otra no codificante.

41 Un aporte fundamental en esta materia es la incorporación del PCR (polimerace chain reaction - reacción en cadena de la polimerasa), por medio del cual pequeños fragmentos de ADN se amplifican, y a partir de una cadena única se pueden hacer millones de copias, de modo tal que el producto amplificado se pueda analizar fácilmente (Mora Sánchez, J. M., Aspectos sustanciales y procesales de la terminología del ADN, Granada, Comares, 2001, p. 23).

42 García Fernández, O. y Yurebaso, E., "Recogida de vestigios biológicos y su introducción en base de datos. Las muestras abandonadas", en Casado, M. y Guillén, M., ADN forense: problemas éticos y jurídicos, cit., p. 219.

43 La cadena codificante de un gen es la cadena que no es transcrita. La región codificante de un gen es la porción transcrita en ARN mensajero y subsiguientemente producida en proteínas (componente central del organismo). 
Esta obra forma parte del acervo de la Biblioteca Jurídica Virtual del Instituto de Investigaciones Jurídicas de la UNAM www.juridicas.unam.mx

Dado que la mayor parte de nuestro genoma no codifica directamente para ninguna instrucción, muchas mutaciones ${ }^{44} \mathrm{o}$ "cambios" en el seno del ADN no tienen por qué reflejarse en el fenotipo (características internas o externas), sino que pueden pasar desapercibidos, llamados mutaciones o polimorfismos neutros. Se asume que la selección natural no actúa en favor ni en contra de estos polimorfismos neutros y por eso se encuentran distribuidos en la población humana. ${ }^{45}$

Entre los polimorfismos existen dos variables:

a) Las secuencias reproducidas en tándem (micro satélites y mini satélites) cuyas variables o alelos ${ }^{46}$ se diferencian en el número de repeticiones.

En estas variables se ubican los marcadores genéticos ${ }^{47}$ que se utilizan tanto en pruebas de identificación genética como de paternidad.

b) Otro tipo de variables se refiere a cambios en un único nucleótido (conocido con la expresión inglesa single nucleotide polymorfism, o por sus siglas SNP's).

Aun cuando los SNP's pueden ser neutros, pueden relacionarse con enfermedades genéticas (mutaciones patogénicas), así como con variantes de riesgo o de susceptibilidad de diferentes enfermedades o condiciones. ${ }^{48}$

Hasta no hace mucho tiempo dominaban en genética - sin mayor base científica pero con gran adhesión - los criterios basados en un firme determinismo: el fenotipo, las características definitorias de un individuo (inteligencia, capacidad de adaptación, capacidad para incorporar conocimientos, sentimientos, etcétera) estaban determinados por sus genes. El individuo no podía sustraerse a los designios de un camino ya marcado, que debía recorrer sin atisbos de mayores cambios. ${ }^{49}$

44 Mutación: cambio de la secuencia de bases de ADN que no modifica la actividad del producto de un gen (Purroy, J., La era del genoma..., cit., p. 255).

45 Marfany, G., "Test genético y protección de datos personales", op. cit., p. 119.

46 Alelo: una de las formas de variantes de un gen en un locus de un marcador particular en el cromosoma (Collins, F., El lenguaje..., cit., p. 302).

47 Marcadores genéticos: segmentos de ADN con una ubicación física identificable en un cromosoma y cuya herencia se puede rastrear. Un marcador puede ser un gen o puede ser alguna sección del gen sin función conocida (ibidem, p. 307).

48 Marfany, G., "Bancos de datos genéticos o ¿qué dice mi ADN de mí? Regulación y privacidad", en Casado, M. y Guillén, M. (coord.), ADN forense: problemas éticos y jurídicos, cit., p. 199.

49 Penchaszadeh, V., "Introducción”, en Penchaszadeh, V. (comp.), Genética..., cit., p. 32. 
Esta obra forma parte del acervo de la Biblioteca Jurídica Virtual del Instituto de Investigaciones Jurídicas de la UNAM

En lo relativo a la salud se consideraba que los genes eran determinantes de las enfermedades presentes y futuras. Para el determinismo genético los factores "hereditarios" son los que determinan los rasgos humanos, las enfermedades, así como la propensión a sufrirlas. ${ }^{50}$

$\mathrm{El}$ avance de las investigaciones llevó a poner las cosas en su justo lugar. Los condicionantes externos (ambiente, educación, alimentación, observancia de reglas higiénicas, etcétera) se mostraron tanto o más importantes que los aportes genéticos. La vida humana - señala Sequeiros - es el producto complejo de genes y ambientes, de proteínas y vivencias, de moléculas y probabilidades, de culturas diversas y experiencias significantes, y de las infinitas interacciones entre todos éstos, y como si no fuera suficiente, de la interacción incluso de otros factores (muchos aún desconocidos), entre ellos el azar. ${ }^{51}$

Hoy sabemos que en materia de enfermedades y de características fenotípicas la información genética no realiza aportes definitivos e irrefutables. Salvo las enfermedades monogenéticas provocadas por la disfunción de un gen, en los demás casos lo que podía aportar la información genética surgida de la combinatoria de un número creciente de genes, llegaría a mostrar tendencias que al tiempo podrían confirmarse o dejarse de confirmar. Algunas enfermedades como la fibrosis quística, la anemia falciforme o la enfermedad de Huntington son el resultado predecible de un gen concreto y se agrupan por ello bajo el calificativo de enfermedades mendelianas, o de un solo gen. ${ }^{52}$

En cambio, la herencia de las enfermedades multifactoriales ${ }^{53}$ no es tan simple. En la mayoría de los casos un gen defectuoso provoca una predisposición a la enfermedad y no una predeterminación. Los genetistas suelen referirse a este fenómeno con la expresión "penetrancia incompleta", lo que significa que una persona poseedora de un gen que puede conferir riesgos de una enfermedad no siempre sufre sus consecuencias. ${ }^{54}$

50 Esta deslumbrante luz biológica - apunta Rodotà - tiene un riesgo: la irrupción en las relaciones sociales del reduccionismo biológico que borra la legitimidad de cualquier otra relación que no esté basada en lo que solíamos llamar "el vínculo de sangre". La biología pretende anular la biografía con una peligrosa regresión cultural y social (Rodotà, S., La vida y las reglas..., cit., p. 206).

51 Sequeiros, J., "Prólogo", en Penchaszadeh, V. (comp.), Genética..., cit.

52 Collins, F., El lenguaje..., cit., p. 48.

53 Multifactorial: enfermedad causada por la interacción del ambiente y de varios genes. Sudbery, P., Genética molecular..., cit., p. 353.

54 Collins, F., El lenguaje..., cit., p. 50; Cooper, David N. et al., "Where Genotype is not Predictive of Phenotype: Towards an Understanding of the Molecular Basis of Reduced Penetrance in Human Inherited Disease", Human Genetics, núm. 132, 2013, pp. 1077-1130. 
Esta obra forma parte del acervo de la Biblioteca Jurídica Virtual del Instituto de Investigaciones Jurídicas de la UNAM

Rodotà plantea el riesgo de predicciones equívocas: los datos genéticos - expresa- proporcionan un conjunto de informaciones no sólo sobre lo que la persona es, sino sobre lo que la persona puede llegar a ser. Así se amplían y se transforman cualitativamente las posibilidades de clasificación, introduciendo conceptos como "predicción", "predisposición", "persona en riesgo". Pero estas categorías interpretativas, de las que se recomienda un prudente uso en el ámbito de la medicina predictiva, pueden generar equívocos peligrosos que se intentan "exportar" del ámbito de la genética clínica al de las políticas sociales. ${ }^{55}$

Aunque prácticamente todas las enfermedades comunes, como la diabetes, las dolencias cardíacas, el cáncer, tienen componentes hereditarios, existen factores de riesgo genético múltiple que contribuyen al riesgo de desarrollar estas afecciones (enfermedades poligénicas).

El valor predictivo de cada uno de estos factores de riesgo genético es bastante bajo, de modo que lo más probable es que la enfermedad se manifieste sólo cuando coincidan varios factores de riesgo en un entorno que inspirara los estimulantes ambientales apropiados. ${ }^{56}$

No obstante ello, el conocimiento de una predisposición a alguna minusvalía resulta suficiente para exponer al sujeto a ser discriminado. Cuando en 2005 el gobierno británico propuso crear las cédulas genéticas, portadoras de datos genéticos (gene ID cards), la Royal Society se pronunció en contra advirtiendo acerca de los potenciales peligros de crear una infra-clase genética (gene under class) con base en las características genéticas de susceptibilidad o predisposición a enfermedades. ${ }^{57}$

Tal como lo grafica Penchaszadeh, hemos aprendido que los genes no son "buenos" ni "malos", que no tienen ningún áurea mágica ni poder para determinar rasgos, que no tienen "vida propia" ni otra función que la de transmitir en cada célula del organismo la información para producir proteínas específicas, lo que sí tiene funciones biológicas. También sabemos que la actividad de los genes de transmitir información es influenciada profundamente por señales del medioambiente que "activan" y "desactivan" genes, y que los resultados de la transmisión de la información genética a las células no siempre son predecibles, pues dependen de las circunstancias del ambiente. ${ }^{58}$

55 Rodotà, S., La vida y las reglas..., cit., p. 204.

56 Collins, F., El lenguaje..., cit., p. 52.

57 Keyeux, G., "Bancos de datos genéticos...", op. cit., p. 237.

58 Penchaszadeh, V., "Genética, reduccionismo y derecho a la salud", en Penchaszadeh, V. (comp.), Genética..., cit., p. 177. 
Esta obra forma parte del acervo de la Biblioteca Jurídica Virtual del Instituto de Investigaciones Jurídicas de la UNAM

Los descubrimientos más recientes nos permiten enunciar varios aportes significativos:

a) Que para cada enfermedad existen factores de riesgo genético y ambientales específicos.

b) Que estos descubrimientos proporcionan ideas nuevas y de gran potencial para su tratamiento y prevención. ${ }^{59}$

c) Que cuanto más conocimiento tenga uno de todas estas circunstancias, mejor podrá modificar su estilo de vida y ajustar las revisiones médicas para prevenir enfermedades o detectarlas en estadios iniciales de fácil tratamiento.

Sabemos, por ejemplo, que la diabetes es altamente hereditaria; sin embargo, los análisis genéticos no han descubierto por el momento ni siquiera el $10 \%$ de ese componente hereditario.

Como conclusión de lo hasta aquí dicho podemos anotar:

a) Que en el estado actual de los conocimientos, un análisis genético puede mostrar la existencia de una enfermedad monogenética o la predisposición a enfermedades multifactoriales.

b) Que esta predisposición puede o no constituirse en el tiempo en una enfermedad, tomando siempre en cuenta la contribución de los factores ambientales. ${ }^{60}$

A los fines de la actuación médica el análisis genético en la gran mayoría de los casos será un elemento más a tomar en consideración para el diagnóstico y tratamiento del paciente. Si los antecedentes familiares muestran una mayor prevalencia de la enfermedad, se deberán tomar las medidas del caso.

59 Relacionado con la regulación de los genes ha surgido un nuevo campo de investigación: la epigenética, término que hace referencia al hecho que la función de una molécula de ADN derivaría no sólo de las secuencias de base, sino también del modo en que el ADN es modificado por otras fuerzas. Por ello, el estudio de la epigenética ha cobrado tanto interés para quienes intentan entender de qué manera las interacciones entre la herencia y el medioambiente afectan la salud o la enfermedad (Collins, F., El lenguaje..., cit., p. 314).

60 Sulston, uno de los actores centrales en la secuenciación del genoma humano, señala que es importante que no prejuzguemos la salud o la habilidad de una persona sobre la base de su genotipo y que tratemos de ver qué es lo que realmente puede conseguir. Aunque la correlación entre características genéticas y resultados físicos y mentales sería en la mayoría de los casos de naturaleza estadística, existiría la tentación - y existe- de utilizar aquéllas en las predicciones actuariales muy probablemente en detrimento de las oportunidades de algunos individuos. Debemos oponernos a ello (Sulston, J. y Ferry, G., El hilo común de la humanidad, Madrid, Siglo XXI, 2003, p. 247). 
Esta obra forma parte del acervo de la Biblioteca Jurídica Virtual del Instituto de Investigaciones Jurídicas de la UNAM www.juridicas.unam.mx

Ahora bien, si estos datos llegan a conocimiento de algún interesado (v. gr. dador de trabajo, empresa de medicina prepaga, empresa de seguros, etcétera) podrán ser interpretados en forma totalmente interesada para discriminar al individuo, provocando los consabidos efectos negativos. ${ }^{61}$

A esta altura de los tiempos, el riesgo de obtener datos genéticos fuera de los conductos usuales puede constituirse en un factor negativo. Los progresos de las ciencias médicas, que sin duda son notables, en lugar de volcarse en beneficio de los sujetos para ayudarlos a prevenir o, en su caso, a disminuir los efectos negativos de una dolencia, se convertirían así en una poderosa arma discriminatoria con un claro potencial negativo (pérdida de oportunidad de obtener un empleo, pérdida del empleo efectivo, negativa de ingreso a un seguro de salud, etcétera), a más de la pérdida de autoestima y la seguridad personal en el sujeto.

He aquí expresadas en pocas líneas las razones que justifican en el caso de los datos genéticos un tratamiento especial, aun por encima de los datos de salud en general.

\section{DATOS PERSONALES Y DATOS DE GARÁGTER PERSONAL}

Hay que hacer una diferenciación, que si bien es de aplicación a los datos genéticos no se refiere con exclusividad a éstos, entre los datos personales y los datos de carácter personal.

Los datos de carácter personal - conforme lo define la legislación española - se refieren a toda información numérica, alfabética, gráfica, fotográfica, acústica o de cualquier otro tipo, susceptible de recogida, registro, tratamiento o transmisión concerniente a una persona física identificada o identificable. ${ }^{62}$

Los datos personales son datos que genéricamente se refieren a una persona determinada o indeterminada, no susceptible de ser identificada. El dato anonimizado es el que, siendo de carácter personal, se desprende

61 Uno de los mayores riesgos que puede derivarse del conocimiento de los datos genéticos de una persona, se haya accedido a ellos legítimamente o no, es el de ser objeto de prácticas discriminatorias, las cuales son más proclives en determinados sectores productivos, económicos, o relacionados con la participación social. Riesgo que puede verse agravado por no basarse en hechos ciertos, sino en simples conjeturas - e incluso prejuicios-. El reduccionismo y el determinismo serían, en este sentido, ejemplos de los perjuicios y peligros que puede generar un uso inadecuado de la información genética (Azofra, M. J., Análisis genéticos en el ámbito asistencial. Reflexión ético-jurídica, Granada, Comares, 2010, p. 215).

62 Real decreto 1332/94 del 20 de junio de 1994. 
Esta obra forma parte del acervo de la Biblioteca Jurídica Virtual del Instituto de Investigaciones Jurídicas de la UNAM

absolutamente de toda vinculación con un sujeto, sin que exista la posibilidad de personalizarlo, por haber sido eliminado cualquier nexo con toda información que identifique a quien la suministró. ${ }^{63}$

El elemento clave y distintivo para singularizar los datos de carácter personal es la identificación o identificabilidad; éste es el reconocimiento de la posibilidad de reconocer la identidad de una persona a partir de ciertos datos.

En un fichero, en una historia clínica, pueden recolectarse datos de una persona anónima o de una persona identificable (datos de carácter personal, tales como edad, peso, altura, color de piel, etcétera) que están vinculados claramente a una persona determinada; pueden existir datos referidos a una persona que sólo esté determinada por un código impersonal o pueden existir datos referidos a una persona incierta o indeterminada. ${ }^{64}$

Mientras que la persona identificada o identificable es sujeto de la protección legal, la persona no identificada ni identificable se encuentra fuera del ámbito de la protección legal.

La cuestión más controvertida es la que se da con respecto a la persona que no tiene signos claros de identificación, pero puede ser identificada rastreando los datos contenidos en el registro.

Conforme a la Directiva europea 95/46/CE se considerará identificable a toda persona cuya identidad pueda determinarse directa o indirectamente, en particular mediante un número de identificación o uno o varios elementos específicos, características de su identidad física, fisiológica, psíquica, económica, cultural o social.

La ausencia de relación o vinculación de los datos con una persona identificada o identificable determina que tales datos sean considerados como anónimos.

Así, si una muestra humana ingresa a un biobanco sin ningún tipo de elemento identificatorio, debería ser considerada anónima.

\section{EL DEREGHO A LA PROTECGIÓN DE LOS DATOS GENÉTICOS}

En la doctrina, cuando se hace referencia a la problemática de la informática y las libertades se utilizan con frecuencia expresiones tales como "protección de datos" o "protección de datos personales". La expresión - tal como

63 Declaración de la Unesco, artículo 2(xi).

64 Nicolás Jiménez, P., "Datos genéticos"..., op. cit., p. 525. 
Esta obra forma parte del acervo de la Biblioteca Jurídica Virtual del Instituto de Investigaciones Jurídicas de la UNAM

lo hemos expresado en anterior oportunidad -65 nos aproxima al tema en estudio, pero es de un contenido equívoco. En realidad, todos los esfuerzos relativos aportan a la protección del individuo ante el abuso del poder informático. Esto claramente lo expresó en su momento el Consejo de Europa en el Convenio de 1971, al enunciar que "el presente Convenio tiene por objeto reforzar la protección de datos, es decir, la protección jurídica de los individuos con relación al tratamiento automatizado de los datos de carácter personal que le conciernen".

En la sociedad de la información, el individuo se encuentra permanentemente asediado por múltiples actores que pugnan por obtener y catalogar informaciones relativas a su persona. Existe la convicción de que información equivale a poder y que la posesión de informes del tipo mencionado asegura a un sujeto un mayor poder sobre otro u otros, sea económico, político, social.

Refiriéndose a este tema, Rodotà señala que existe una dificultad social difusa y persistente de metabolizar las innovaciones científicas y tecnológicas cuando éstas inciden en el ciclo vital. Es la antropología profunda del género humano la que de golpe, en el transcurso de unos pocos años, ha sido puesta en discusión. Se manifiestan angustias, fantasmas, y el derecho aparece como la única terapia social con una demanda intensa de normas, límites y prohibiciones. ${ }^{66}$

Las informaciones personales provienen de las vías más extrañas y se procesan con gran rapidez, dejando paralelamente al sujeto fuente en una situación de extrema vulnerabilidad. El Estado en sus más diversas agencias, las empresas, el mercado, en una dimensión ampliada, los empleadores, las aseguradoras, pugnan por obtener informaciones y datos en una vorágine cada vez más acelerada.

El conocimiento de los datos personales, en especial de los datos sensibles, tiene entidad suficiente para causar perjuicios considerables al individuo, lo que torna necesaria una protección privilegiada.

El sistema jurídico ha reaccionado para proteger al individuo. Junto al derecho a la autodeterminación informática y genética nació el derecho autónomo de protección de los datos personales, como un derecho fundamental.

Este derecho - al decir de Seoane Rodríguez - no restringe su objeto a la esfera de aplicación de los tratamientos informatizados o derivados del

65 Bergel, S. D., "El habeas data, instrumento protector de la privacidad", Revista de Derecho Privado y Comunitario, núm. 7, p. 189.

66 Rodotà, S., "Usos del derecho y regulación de la vida", en Sánchez, A. et al. (eds.), Tecnología, intimidad y sociedad democrática, Barcelona, Icaria, 2003, p. 157. 
Esta obra forma parte del acervo de la Biblioteca Jurídica Virtual del Instituto de Investigaciones Jurídicas de la UNAM

uso de la informática, sino que se aplica a todo tipo de tratamiento, automatizado o no. Su contenido fundamental consiste en un poder de disposición y control sobre los derechos personales que facilita al sujeto para decidir cuáles son los datos a proporcionar a terceros, y que también permite al individuo saber quién posee esos datos personales y para qué, pudiendo oponerse a esa posesión o uso. ${ }^{67}$

Este derecho a la protección de los datos personales, si bien tiene un objetivo común con el derecho a la intimidad, se diferencia en cuanto a su función, objeto y contenido.

La función del derecho a la intimidad es eminentemente defensiva; en cambio, el derecho de protección de datos personales desempeña una función eminentemente activa, al garantizar al sujeto un poder de control sobre los datos, su uso y su destino.

El objeto de protección de los datos personales no se reduce a los datos íntimos sino a cualquier tipo de dato personal cuyo conocimiento o empleo por terceros puede afectar sus derechos.

Finalmente, en cuanto al contenido, el derecho a la intimidad confiere el poder jurídico de imponer a los terceros el abstenerse de toda intromisión en la esfera íntima de la persona y la prohibición de hacer uso de lo conocido. Por su parte, el derecho a la protección de los datos personales atribuye a su titular un haz de facultades consistentes en diversos poderes jurisdiccionales y cuyo ejercicio impone a terceros deberes jurídicos que no se contienen en el derecho fundamental a la intimidad: tales como el previo consentimiento a su recogida y uso, y el derecho a saber y ser informado sobre el destino y uso de dichos datos. ${ }^{68}$

Las protecciones especiales buscadas y obtenidas para la información genética llegan a conocerse como "excepcionalismo genético", es decir que se requiere una protección más estricta que para cualquier otra información médica. ${ }^{69}$

\section{EL DEREGHO A LA AUTODETERMINAGIÓN GENÉTICA}

Los constantes avances de las ciencias y de las técnicas que caracterizan el estadio actual de la civilización ha conducido al establecimiento de nuevos

67 Seoane Rodríguez, A., "De la identidad genética al derecho de la protección de los datos genéticos en el derecho español”, Revista de Derecho y Genoma Humano, núm. 16, p. 97.

68 Ibidem, p. 101.

69 Mackin, R., op. cit., p. 31. 
Esta obra forma parte del acervo de la Biblioteca Jurídica Virtual del Instituto de Investigaciones Jurídicas de la UNAM www.juridicas.unam.mx

derechos como vallas de contención, ya que estos avances no sólo han posibilitado un mayor y mejor nivel de vida de la población, sino que - paralelamente - han creado nuevos problemas derivados de una utilización desviada de los medios creados.

Uno de los casos más reconocidos - tal como lo señalamos - es el de la informática. La velocidad con que se pueden difundir los datos almacenados y la infinita posibilidad de vincularlos con muy poco esfuerzo han contribuido a crear un nuevo derecho: el derecho a la autodeterminación informativa.

Al pronunciarse el Tribunal Constitucional de la entonces Alemania Federal el 15 de diciembre de 1983 acerca de la constitucionalidad de la Ley de Censo de la Población, tomando como base la Ley Fundamental de Bonn en lo referente al derecho al libre desarrollo de la personalidad y a la dignidad del ser humano, afirmó que:

...el derecho general de la personalidad, resultante de ambos preceptos, a la vista de la evolución moderna y de las nuevas amenazas que lleva aparejadas para la personalidad, cobra significación especial. Su contenido abarca la facultad del individuo, derivada de la idea de autodeterminación, de decidir básicamente por sí mismo cuándo y dentro de qué límites procede revelar situaciones referentes a la propia vida.

La autodeterminación del individuo - agregó - presupone también en las condiciones de las técnicas modernas de tratamiento de la información, que se conceda al individuo la libertad de decisión sobre las acciones que vaya a realizar, o en su caso a omitir, incluyendo la posibilidad de obrar de hecho en forma consecuente con la decisión adoptada.

Las ideas que presiden el concepto de autodeterminación informativa son enteramente aplicables a la información genética.

La facilidad con la cual se puede obtener, la multiplicidad de sujetos que - con diversa finalidad - tienen acceso a los datos genéticos, la facilidad con la cual puede circular - potenciada por los medios informáticos- y los perjuicios de todo orden que pueden ocasionar al sujeto el acceso y la circulación indebida de tal información, torna aplicable al caso la doctrina jurisprudencial de la "autodeterminación informativa". ${ }^{70}$

Tal como lo sostiene Seoane Rodríguez, el derecho a la autodeterminación informativa surge a partir de análisis de un tratamiento automatizado

70 Uno de los principales argumentos sobre el que se sustentan quienes defienden el reconocimiento de un nuevo derecho fundamental a la autodeterminación informativa se basa en la insuficiencia protectora de los mecanismos propios del derecho a la intimidad (Azofra, M. J., Análisis genéticos..., cit., p. 194). 
Esta obra forma parte del acervo de la Biblioteca Jurídica Virtual del Instituto de Investigaciones Jurídicas de la UNAM

de datos de carácter personal. Con todo, cabe aplicar el derecho a la autodeterminación informativa, igualmente, a los tratamientos no automatizados, en la medida en que el énfasis no se sitúa en la naturaleza de las acciones susceptibles de amenazar el derecho general de la personalidad, sino a las restricciones que tales conductas originan en el ejercicio del mencionado derecho y sus repercusiones, tanto individuales o subjetivas como institucionales u objetivas.

Sería contrario a dicha facultad de autodeterminación un orden social y un orden jurídico que hiciese posible que el ciudadano ya no pudiera saber quién, qué, cuándo y con qué motivo se sabe algo sobre él. Esto no sólo menoscabaría las oportunidades del desarrollo de la personal individual, sino también al bien público, porque la autodeterminación constituye una condición elemental de funcionamiento de toda comunidad fundada en la capacidad de obrar y de cooperación de sus ciudadanos. ${ }^{71}$

Pocos años después de la citada sentencia, Stefano Rodotá utilizó la expresión "autodeterminación" con especial referencia a los datos genéticos, y a partir de ella se difundió su empleo. ${ }^{72}$

\section{LA INTIMIDAD, LA PRIVACIDAD Y LA CONFIDENGIALIDAD EN RELACIÓN CON LOS DATOS GENÉTICOS}

La privacidad se define como el ámbito de la vida privada que se tiene derecho a proteger de cualquier intromisión, mientras la privacidad de la persona constituye un conjunto más amplio y global de facetas de su personalidad, que aisladamente pueden carecer de significación intrínseca pero que coherentemente enlazados entre sí arrojan como precipitado un retrato de la personalidad del individuo que éste tiene derecho a mantener reservado. ${ }^{73}$

El significado actual del derecho a la privacidad debe buscarse en la idea más general de autodeterminación informativa frente a los demás, con respecto a datos e informaciones concernientes a la persona. El derecho a la intimidad sugiere una noción inicial al reconocimiento de la esfera de vida personal exclusiva y excluyente de un sector de la persona y que puede excluir del acceso a los terceros. ${ }^{74}$

71 Seoane Rodríguez, A., "De la identidad genética...", op. cit., p. 105.

72 Rodotà, S., Tecnologia..., cit., p. 207.

73 Solá Rocha, E., "Derecho a la intimidad", en Romeo Casabona, C. M. (dir.), Enciclopedia de bioderecho y bioética, t. I, p. 560.

74 Tobías, J. W., Derecho de las personas, Buenos Aires, La Ley, 2009, p. 657. 
Esta obra forma parte del acervo de la Biblioteca Jurídica Virtual del Instituto de Investigaciones Jurídicas de la UNAM www.juridicas.unam.mx

Modernamente se habla de su transformación en un habeas data proyectando sus informaciones de diversa índole o naturaleza, y que aunque no necesariamente íntimas, su conocimiento combinado puede desbordar la construcción legítimamente deseada por su titular, siendo éste un riesgo que se ve incentivado por la potencialidad que ofrecen las nuevas tecnologías de la información. ${ }^{75}$

El derecho a la intimidad decae con la difusión por el individuo de los hechos que le conciernen, aunque obviamente hay que pensar sobre lo que es objeto de prohibición. El ordenamiento jurídico - se ha señalado- no puede ser llamado a suplir las deficiencias de la autoprotección de la intimidad. ${ }^{76}$

Clarizia entiende que en una sociedad informatizada la misma noción de intimidad resulta insuficiente, ${ }^{77}$ y Rodotà afirma que el concepto tradicional de "derecho a ser dejado solo" ha sido sustituido por el derecho a "controlar el uso que otros hagan de informaciones concernientes a un determinado sujeto". ${ }^{78}$

La finalidad última de la tutela del derecho a la privacidad no consiste en limitar la circulación de los datos, sino más bien de hacer transparente su circulación evitando todo abuso. Pero esto no implica limitar sus alcances a un conjunto de datos comúnmente denominados sensibles. En este sentido, Frozini advierte que el problema de la protección de la intimidad no debe ceñirse a establecer límites a los datos nominativos y sensibles. Esta protección debe extenderse, como por lo común se ha advertido, incluso a la intimidad en el ámbito familiar, a la intimidad vinculada con el propio trabajo profesional o con el secreto de los datos que en cualquier forma tengan un valor de intimidad. ${ }^{79}$

De un modo genérico la confidencialidad se puede definir como el derecho que asiste a las personas para que se mantenga a reserva sobre lo que confesó a otros, quienes de manera correlativa adquieren la obligación de guardar secreto. La confidencialidad incluye tres elementos fundamentales: quien hace la confidencia; quien es portador de la confianza de mantener el

75 Solá Rocha, E., "Derecho a la intimidad...", op. cit., p. 561.

76 Ibidem, p. 564.

77 Clarizia, R., La Proposta del Progetto Mirabelli per la Tutela della Reservanza di Datti e Diritti della Persona, Padua, CEDAM, 1985, p. 129.

78 Rodotà, S., citado por Carrascosa López, V., "Derecho a la intimidad informática", Informática y Derecho, núm. 1, p. 12.

79 Frozini, V., "La protección de la intimidad: de la informática a bien jurídico informático", Derecho y Tecnología Informática, Bogotá, núm. 3, 1990, p. 19. 
Esta obra forma parte del acervo de la Biblioteca Jurídica Virtual del Instituto de Investigaciones Jurídicas de la UNAM

secreto, y la comunidad que reconoce y protege esta relación confidencial como un bien social. ${ }^{80}$

En los hechos, en la práctica médica compete al profesional la confidencialidad de los datos proporcionados por el paciente o extraídos de la actuación clínica o de los análisis particulares, sin necesidad de un acuerdo previo. El secreto profesional es inherente al ejercicio de la profesión médica.

La confidencialidad es una garantía para la esfera de privacidad que las personas necesitan en el desarrollo de su vida afectiva. Al personal de la salud se le permite entrar y sólo en la justa medida en que sea necesario para el cuidado de la salud del paciente.

Nicolás Jiménez - citando a Knoppers - considera que el enfoque global de la intimidad genética justifica una reformulación de este derecho que armonice los nuevos intereses en juego, y que las normas tradicionales de la confidencialidad y acceso, y las obligaciones - exenciones intrafamiliaresrequieren una nueva formulación. ${ }^{81}$

\section{CONFLICTOS RELATIVOS A LA CONFIDENCIALIDAD DE LOS DATOS}

Los datos genéticos constituyen un bien respecto del cual prevalece - como norma de carácter general- la autodeterminación del sujeto. Los que bajo cualquier circunstancia obran en poder de un facultativo o de una institución sanitaria sólo pueden ser suministrados a terceros en la medida en la cual el sujeto fuente otorgue el correspondiente consentimiento.

No obstante ello, se pueden presentar situaciones en las cuales entren en conflicto los referidos derechos del sujeto con otros derechos de igual o mayor protección.

Ya la Declaración de la Unesco había contemplado la existencia de este tipo de conflictos. El artículo 14.b establece que los datos genéticos humanos y las muestras biológicas asociadas con una persona identificable no deben ser dadas a conocer ni puestas a disposición de terceros, de empleadores, compañías de seguros o establecimientos de enseñanza y familiares de la persona en cuestión, sino sólo por una cuestión importante de interés público en los restringidos casos previstos en el derecho interno compatible con el derecho internacional relativo a los derechos humanos, o cuando se

80 Altisent Trota, R., "Confidencialidad", en Romeo Casabona, C. M. (dir.), Enciclopedia de bioderecho y bioética, t. I, p. 425.

81 Nicolás Giménez, P., "Datos genéticos", op. cit., p. 530. 
Esta obra forma parte del acervo de la Biblioteca Jurídica Virtual del Instituto de Investigaciones Jurídicas de la UNAM

haya obtenido el consentimiento previo, libre, informado y expreso de esa persona, siempre que éste sea conforme al derecho interno y al derecho internacional relativo a los derechos humanos.

Un tema relevante en este supuesto es el que plantea el conflicto entre la protección de la intimidad del paciente y la salvaguardia de la salud de los familiares al ocultárseles el conocimiento de datos que les permitirían prevenir determinados efectos sometiéndose a tratamientos adecuados o cambiando hábitos de vida.

Existen sobre esto dos modalidades de solución que otorgan prevalencia, respectivamente, a los derechos de intimidad o autodeterminación, o a la preservación de la salud.

La Recomendación R(90) del Consejo de Europa, en el principio 13, establece que el derecho de acceso a datos de carácter personal recogidos durante la realización de cribados genéticos prenatales y pruebas de diagnóstico genético prenatal únicamente deberán suministrarse al sujeto de los datos en el modo normal exigido para los datos sanitarios de carácter personal, de conformidad con el derecho nacional y la práctica. Los datos genéticos que se refieren a la pareja no deberán ser comunicados al otro miembro de la misma sin el consentimiento libre e informado del primero de ellos. A su vez, el artículo 9o. establece que en el caso de un grave riesgo genético para otros miembros de la familia deberá considerarse, de acuerdo con la legislación nacional y las normas deontológicas, el informar a los familiares sobre los extremos pertinentes a su salud o a la de sus hijos.

La Ley francesa 2004-800 contempla expresamente el tema, estableciendo un original método de comunicación de las informaciones genéticas.

El paciente revela al facultativo los datos de ubicación de los miembros de su familia y el grado de parentesco, el médico transmite sus datos a la agencia de biomedicina para que - a través de otro facultativo- haga saber a su familia que existe una información médica de carácter familiar que le concierne y los medios de acceso a la misma. Pero lo cierto es que el paciente sigue teniendo el poder de informar o no a sus familiares, y la negativa del mismo a permitirlo no le genera responsabilidades.

Knoppers considera que los datos genéticos son de "titularidad familiar" y que el principio de reciprocidad en el flujo de información entre médico y paciente incluye que el primero debe comunicar el riesgo de ser portador o de padecer una enfermedad genética a los familiares, del segundo en determinadas circunstancias.

La autora se muestra partidaria de una posición intermedia entre la protección total de la intimidad del paciente, que se plasma en el deber absoluto de confidencialidad del profesional, y la posibilidad de develar datos 
Esta obra forma parte del acervo de la Biblioteca Jurídica Virtual del Instituto de Investigaciones Jurídicas de la UNAM

sobre la salud sin limitaciones. De otro modo se quebrarían los principios de mutualidad familiar y solidaridad familiar y social, y el individuo quedaría desamparado. Se impone, por tanto, a su juicio, lograr un adecuado equilibrio entre estas dos concepciones. ${ }^{82}$

Los genetistas aconsejan extremar los procedimientos tendentes a posibilitar la transmisión de datos que sean de utilidad a sus familiares, pero ante la negativa del titular a comunicarlos debe prevalecer su determinación.

\section{LOS MOMENTOS DE LA PROTEGCIÓN \\ DE LOS DATOS GENÉTICOS}

Los datos genéticos y las muestras de las cuales ellos derivan - que en los hechos conforman un dúo inseparable - reconocen tres fases vinculadas con su protección.

El primer momento se refiere a la protección al tiempo de obtenerse la muestra biológica, ya sea para la realización de un análisis genético o para su ingreso a un biobanco o establecimiento sanitario.

El consentimiento libre e informado constituye en este caso el medio protector por excelencia que reafirma el derecho a la autodeterminación genética atribuido al sujeto fuente. En él deben constar todas las previsiones en cuanto a su utilización y destino final.

En un segundo momento, una vez obtenida la muestra nacen los cuidados correspondientes a su conservación, protección de la intimidad del sujeto fuente, observando que su utilización responda a lo que se expresara en el consentimiento informado o, en defecto de ello, a los deberes de conducta que genera la utilización de datos sensibles. ${ }^{83}$

En un tercer momento, realizado el análisis correspondiente, los datos que se obtengan, volcados en soporte papel u otro soporte, quedan sujetos a los derechos de protección que son comunes. Tanto debe protegerse al material que contiene los datos genéticos como a los propios datos obtenidos. Estos deberes corresponden al facultativo que realizó el análisis, al responsable del biobanco o al que recibió los datos obtenidos del análisis. El material empleado puede, según lo establecido en el consentimiento, ser destruido o

82 Knoppers, B., citado por Nicolás Giménez, P., "Datos genéticos", op. cit., p. 525.

83 El artículo 14.e de la Declaración de la Unesco establece que los datos genéticos humanos y los datos proteómicos no deberán conservarse de manera que sea posible identificar a la persona a quien correspondan por más tiempo del necesario para cumplir los fines con los que fueron recolectados o ulteriormente tratados. 
Esta obra forma parte del acervo de la Biblioteca Jurídica Virtual del Instituto de Investigaciones Jurídicas de la UNAM

- en el caso de los biobancos - ser conservado para otras investigaciones, con las salvedades expuestas.

Como principio general, cabe destacar que el consentimiento informado recabado al momento de extraerse la muestra debe presidir todos los pasos siguientes, y a falta de estipulaciones, quien tenga bajo su gobierno el material o el dato producido debe proceder en todo momento respetando y haciendo respetar los derechos de autodeterminación genética, de privacidad y en su caso de confidencialidad.

\section{LA UTILIZACIÓN INDEBIDA DE DATOS GENÉTICOS}

Cuando los datos genéticos son empleados de forma correcta son de gran utilidad, ya que pueden orientar a los facultativos al diagnóstico y tratamiento de diversas dolencias y pueden constituir un instrumento al servicio de la investigación científica.

En una dirección opuesta pueden contribuir a discriminaciones indebidas. Se ha enfatizado particularmente en las consecuencias que pueden ocurrir en las relaciones laborales y en las de seguro.

Una ilustre filósofa mexicana - Juliana González Valenzuela- ha descrito magistralmente lo que significa la utilización desviada de la información genética:

El individuo - señala- deja de ser ese "desconocido" al hacerse transparente su interior biológico. $\mathrm{Y}$ es aquí donde cae todo el peso de la visión determinista: el otro queda etiquetado y marcado. Las consecuencias de ello pueden ser el rechazo, la discriminación y la segregación de unos hacia otros, particularmente cuando la información es negativa y cae en manos de quienes tienen el poder sobre los que no lo tienen o que son vulnerables, ahondándose gravemente las desigualdades. En efecto, además del impacto que para sí mismo ocasiona el saber sobre el propio genoma, están los efectos que la información genética produce para los otros que se hallan en relación con cada persona y que pueden - y en ocasiones hasta deben - tener acceso a dicha información. ${ }^{84}$

En las relaciones laborales, uno de los temas que inicialmente preocupó en la materia de datos genéticos es el abuso que podrían hacer los empleadores en detrimento de los legítimos derechos del empleado, al exigir

84 González Valenzuela, J., Genoma humano y dignidad humana, Barcelona, Anthropos, 2005, p. 133. 
Esta obra forma parte del acervo de la Biblioteca Jurídica Virtual del Instituto de Investigaciones Jurídicas de la UNAM

análisis genéticos o al obtener información genética con base en un análisis clínico común, para el cual el sujeto no dio su consentimiento.

Si se eleva a un primer plano de interés el propósito de prevención de riesgos laborales, podrían tener efectos positivos tales análisis; mas si el ejercicio de prospectiva se aplica en beneficio de menesteres selectivos de personal, se advierten efectos bastante perniciosos.

La Declaración de la Unesco hace especial hincapié en el suministro de datos genéticos dentro de la esfera laboral. El artículo 14.b establece que:

...los datos no deberán ser dados a conocer ni puestos a disposición de terceros, en particular de empleadores, compañías de seguro, establecimientos de enseñanza... salvo por una razón importante de interés público en los restringidos casos previstos en el derecho interno compatibles con el derecho internacional relativo a los derechos humanos, o cuando se haya obtenido el consentimiento previo de esa persona.

Igualmente, el artículo 14 de la Convención de Asturias (Convenio Europeo sobre Biomedicina), en su informe preliminar, se pronuncia a favor de que se prohíba realizar pruebas genéticas predictivas como parte de los exámenes médicos previos al empleo.

Una selección basada en la información genética puede dar lugar a una discriminación intolerable, puesto que puede producir el efecto insidioso de excluir del mercado de trabajo a los que presentan una predisposición o susceptibilidad a enfermedades hereditarias.

El Grupo Europeo de Ética de las Ciencias y las Nuevas Tecnologías, en julio de 2003, emitió un dictamen sobre la realización de test genéticos en el lugar de trabajo, el cual se opone como principio general al recurso de este tipo de pruebas predictivas para la selección de personal o respecto de empleados ya incorporados a la empresa, y ello además para evitar cualquier tipo de discriminación, por razón de la falta de evidencia científica sobre la relevancia de estas pruebas en un ámbito laboral y en definitiva sobre su valor predictivo. ${ }^{85}$

Excepcionalmente pueden realizarse análisis genéticos a dependientes cuando la propensión o susceptibilidad a determinadas enfermedades represente un peligro para sus compañeros. Esto cuando no haya otro procedimiento de diagnóstico con igual grado de validez que proporcione un resultado de confiabilidad similar.

85 Goñi Sein, J. L., "Análisis genéticos en el ámbito laboral”, en Romeo Casabona, C. M. (dir.), Enciclopedia de bioderecho y bioética, t. I, p. 72. 
Esta obra forma parte del acervo de la Biblioteca Jurídica Virtual del Instituto de Investigaciones Jurídicas de la UNAM

En principio, la negativa a someterse a análisis genéticos por parte de los trabajadores no debe acarrearle ninguna consecuencia negativa, dada la invalidez radical de dicha prueba.

En el campo de seguros se presenta una ecuación de difícil tratamiento.

Por una parte el reconocido derecho a la intimidad genética, que se traduce en la prohibición de exigir al futuro asegurado el suministro de datos genéticos, conforme a los principios que hemos desarrollado, y por otra parte la caracterización propia del contrato, que depende en ciertos tipos de la predicción de los riesgos de salud a fin de establecer la prima con base en ello.

En líneas generales la normativa internacional y las normativas nacionales se han mostrado contrarias a la exigencia de análisis genéticos en estos casos.

En este sentido, el Parlamento de la Unión Europea aprobó el 26 de marzo de 1989 una declaración que establece que las compañías de seguros carecen del derecho a exigir que se realicen análisis genéticos antes o después de la firma de un contrato de seguro o a obtener información sobre los datos genéticos que el asegurado conoce.

Posteriormente, la Recomendación 9 (2002) del 18 de septiembre de 2002 enfatiza que el derecho a la intimidad debe ser resguardado en la recogida y tratamiento de datos personales para fines relacionados con seguros, siendo necesario que estos datos sean adecuados, relevantes y no excesivos en relación con la finalidad para la cual son recabados o serán tratados en el futuro (principios 1 y 4.1 ).

La Declaración Internacional de la Unesco reconoce igualmente que los datos genéticos humanos, los datos proteómicos asociados con una persona identificable, no deberán ser dados a conocer ni puestos a disposición de terceros, en particular empleadores y compañías de seguros.

Diversos países europeos han establecido normas prohibitivas de la exigencia de recabar los datos genéticos o someterse a análisis genéticos en esta materia. Así, Austria, Bélgica, Francia, Portugal, Suiza y Suecia. ${ }^{86}$

De igual forma en los Estados Unidos se han dictado leyes estatales que receptan estas prohibiciones. Así, Oregon dispone que una aseguradora no puede hacer referencia a un test genético favorable para promover un contrato; la norma del Health and Safety Code de California prohíbe a los aseguradores el establecimiento o la inserción de condiciones o modalidades

86 Azofra, M. J., Análisis genéticos..., cit., p. 58. 
Esta obra forma parte del acervo de la Biblioteca Jurídica Virtual del Instituto de Investigaciones Jurídicas de la UNAM

contractuales diferentes sobre la base de las características genéticas de las personas. ${ }^{87}$

El tema de las exigencias de análisis genéticos por parte de las compañías aseguradoras asume una dimensión mayor cuando se trata de contratos de seguro de asistencia sanitaria. Si el país cuenta con un sistema de atención pública, o si no contara con él, los efectos son sustancialmente distintos.

Si el individuo tiene como única protección de los infortunios de su salud un seguro privado, las exigencias de las compañías pueden determinar la privación de derechos fundamentales. En este sentido, Rodotà señala que un contrato de seguro cada vez más personalizado, de acuerdo con la misma lógica que lleva a la despersonalización de los tratamientos, cortado a la medida de cada individuo, concentraría el riesgo en el interesado y dejaría de distribuirlo en el conjunto más amplio de sujetos, como quiere la lógica típica del seguro. ${ }^{88}$

En igual dirección, Roscam Abbing entiende que si una compañía privada de seguros de asistencia sanitaria utiliza la tecnología genética como instrumento de discriminación genética, ello sería contrario al derecho a la atención sanitaria universalmente aceptado y al principio de solidaridad internacionalmente reconocido. En caso de que el acceso a la atención sanitaria dependa en los principal de seguros privados, la aseguradora deberá soportar una responsabilidad social, ya que entonces el seguro de asistencia sanitaria desempeñará una función social. ${ }^{89}$

El tema planteado es sumamente preocupante. Haciendo eco de estas implicancias, Rodotà expresa que si no se logra establecer un marco institucional que pueda evitar el abuso de la utilización de datos genéticos, existe la concreta posibilidad de que podamos asistir al nacimiento de una "competencia genética" y una "eugenesia de mercado". Los sujetos que estén en posesión, individual o colectivamente, de una dotación genética de excelencia podrán solicitar a los aseguradores que les proporcionen condiciones particularmente beneficiosas o una "discriminación positiva" conforme a una lógica opuesta, pero simétrica, respecto a la que se aplica a los sujetos "genéticamente negativos". ${ }^{90}$

87 Rodotà, S., La vida y las reglas..., cit., p. 221.

88 Ibidem, p. 219.

89 Roscam Abbing, H. D., "La información genética y los derechos de terceros, ¿cómo encontrar el adecuado equilibrio?", Revista de Derecho y Genoma Humano, núm. 2, p. 35.

90 Rodotà, S., La vida y las reglas..., cit., p. 221. 


\title{
LA EXCEPGIÓN DE FABRICACIÓN PARA LA EXPORTAGIÓN
}

\author{
Xavier SEUBA \\ Luis Mariano GenOvesi \\ Pedro ROFFE
}

\begin{abstract}
SUMARIO: I. Introducción. II. Las excepciones al derecho de patente. III. El artículo 30 del Acuerdo sobre los ADPIC. IV. Precedentes de la excepción de fabricación para la exportación. V. Análisis del cumplimiento de la excepción de fabricación para la exportación de las tres condiciones del artículo 30 del ADPIC. VI. Conclusiones.
\end{abstract}

\section{INTRODUCGIÓN}

Este trabajo tiene por objeto demostrar la compatibilidad con el artículo 30 del Acuerdo sobre los ADPIC (en adelante ADPIC) de la excepción a los derechos del titular de una patente que habilita a terceros a fabricar y exportar bienes protegidos por una o más patentes a países donde la o las invenciones no son objeto de protección, es decir, a países donde las invenciones se encuentran en el dominio público. Esta excepción es denominada en este estudio como "excepción de fabricación para la exportación".

El ADPIC no contiene un numerus clausus o catálogo de excepciones a los derechos conferidos por una patente. Por el contrario, su artículo 30 establece un numerus appertus de excepciones, en la medida en que serán admisibles todas aquellas que cumplan con tres requisitos: 1) deben ser limitadas; 2) no deben atentar de manera injustificable contra la explotación normal de la patente, y 3) no causar un perjuicio injustificado a los legítimos intereses del titular de la patente, teniendo en cuenta los intereses legítimos de terceros. Cualquier excepción legislada por los miembros de la Organización Mundial del Comercio (OMC) debe, en consecuencia, ser compatible con los requisitos del artículo 30, conocida como "regla de los tres pasos" (threestep test). 
Esta obra forma parte del acervo de la Biblioteca Jurídica Virtual del Instituto de Investigaciones Jurídicas de la UNAM

A fin de probar la hipótesis de este artículo, en la primera sección (II) se examina brevemente la noción y características de las excepciones al derecho de patente, su evolución histórica y el catálogo de excepciones admitidas en el derecho comparado.

La segunda sección (III) contiene un análisis del artículo 30 del ADPIC. Se comenta la interpretación restrictiva que hizo de esa norma el Grupo Especial Canadá-Genéricos. ${ }^{1}$ También se aborda la interpretación más liberal y contemporánea del artículo 30 del ADPIC presente en estudios del Comité de Patentes de la OMPI y en la Declaración sobre Protección Mediante Patente $^{2}$ auspiciada por el Instituto Max Planck.

La sección tercera (IV) revela los precedentes de la excepción de fabricación para la exportación en el derecho comparado. Si bien no hemos logrado identificar en el derecho positivo la excepción bajo análisis, sí se han individualizado estudios e iniciativas legislativas que consideran esa excepción, como así también la previsión de una excepción similar en materia de certificados complementarios de protección.

Por último, la cuarta sección (V) — que es el núcleo del artículo- contiene un pormenorizado análisis y justificación de por qué la excepción de fabricación para la exportación cumple con la regla de los tres pasos del artículo 30 del ADPIC.

\section{LAS EXCEPGIONES AL DERECHO DE PATENTE}

\section{Noción y características de las excepciones}

Todos los ordenamientos prevén limitaciones a los derechos del titular de una patente. Ésta es, en líneas generales, la definición de "excepción", término que en función del ordenamiento jurídico puede mutar por el de "limitaciones", "eximentes", "actos autorizados" o, entre otros, "restricciones". Se trata, como se verá, de excepciones que responden a distintos fundamentos, si bien tienen como nexo común que los usos previstos en las mismas eximen al autor de responsabilidad de infracción de patente, por más que los actos llevados a cabo caigan dentro del ius prohibendi del titular.

1 Organización Mundial del Comercio, Informe del Grupo Especial Canadá-Protección mediante patente de los productos farmacéuticos-Reclamación de las comunidades europeas y de sus Estados miembros, OMC, 17 de marzo de 2000, WT/DS114/R (en adelante, Grupo Especial Canadá-Genéricos).

2 Declaration on Patent Protection, Regulatory Sovereignty under TRIPS, disponible en: wrere.ip.mpg.de/en/pub/news/patentdeclaration.cfm. 
Esta obra forma parte del acervo de la Biblioteca Jurídica Virtual del Instituto de Investigaciones Jurídicas de la UNAM

En este trabajo utilizaremos el término "excepciones" en sentido estricto, es decir, aquellas reguladas por el artículo 30 del ADPIC y que se caracterizan por operar en forma automática. Las "excepciones" en sentido restringido se caracterizan por no estar sujetas a una autorización o comprobación previa por parte de una autoridad gubernamental o corte judicial y usualmente son invocadas como defensa frente a una demanda por infracción de patentes. ${ }^{3}$ Por el contrario, no utilizaremos el término "excepciones" en un sentido más amplio, que abarca también a los institutos del agotamiento de derecho, las licencias obligatorias y el uso gubernamental, que son objeto de tratamiento por otras normas del ADPIC y que están sujetos a regímenes jurídicos diferentes.

Las excepciones no han sido extensamente reguladas en el plano internacional, en el que las normas existentes se limitan a las condiciones generales que deben cumplir las excepciones, sin establecer un régimen estricto ni, sobre todo, un listado numerus clausus de excepciones admisibles. En buena lógica, el estudio de las excepciones que se han previsto en derecho comparado permite constatar que tanto en lo que se refiere al listado de excepciones como al régimen jurídico de cada excepción, existen notables diferencias de país a país.

Si bien desde la óptica del titular o del solicitante de la patente tanto las excepciones como las exclusiones a la patentabilidad representan un impedimento a sus objetivos, las excepciones lo son en menor medida. En efecto, mientras las exclusiones impiden el nacimiento del derecho del titular ab initio, puesto que la patente nunca va a ser concedida, en el caso de las excepciones la patente existe y es plenamente vigente, si bien para determinados usos la misma no permite al titular exigir el respeto a los usos típicamente prohibidos. Si bien en términos generales las diferencias entre excepciones y exclusiones son más que notables, tanto en términos de fundamentos como de aplicación, en algunos casos lo que en un país se ha considerado no patentable en otros países se aborda como una excepción a los derechos del titular. Seguramente el caso paradigmático, en este sentido, sea el de los métodos de diagnóstico y de tratamiento.

En comparación con las exclusiones al derecho de patente, las excepciones son más nuevas, son más flexibles que las exclusiones a la patentabilidad y existen menos normas en el plano internacional que las delimiten estrictamente. ${ }^{4}$ Un análisis histórico demuestra un proceso de normalización y

3 Roffe, P. y Spennemann, C., Resource Book on TRIPS and Development, UNCTADUCTSD, Nueva York, Cambridge University Press, 2005, p. 431.

4 Bentley, L., "Introducción", Estudio de expertos sobre exclusiones de la materia patentable y excepciones y limitaciones a los derechos conferidos por las patentes, Ginebra, OMPI, Comité Perma- 
Esta obra forma parte del acervo de la Biblioteca Jurídica Virtual del Instituto de Investigaciones Jurídicas de la UNAM

limitación significativas de las exclusiones, en particular como resultado del ADPIC y los acuerdos regionales de concesión de patentes, así como una expansión del uso de excepciones, en buena medida gracias a la flexibilidad de la legislación internacional relacionada con las mismas.

Además, mientras los tribunales y las oficinas de patentes han encontrado dificultades concretas para aplicar exclusiones, académicos y expertos piden que se preste más atención a las excepciones, desarrollándose en los últimos tiempos excepciones que pretenden responder a nuevos problemas. ${ }^{5}$

Como ha sido señalado, no existe ningún tratado multilateral de alcance universal que recoja en un listado las excepciones tasadas, ni tan siquiera una enumeración de las mismas. Existen, eso sí, ejercicios del tipo descrito en contextos regionales, si bien incluso en el plano regional los mismos son raros. En el contexto europeo, y hasta que empiece a operar el Tribunal Unificado de Patentes, el texto que más se ha acercado a dicha función ha sido el Convenio de Luxemburgo sobre la Patente Comunitaria, si bien el mismo nunca llegó a entrar en vigor.

El desarrollo de las excepciones es fruto de respuestas normativas y jurisprudenciales que han tenido lugar en el contexto de jurisdicciones nacionales. En efecto, no ha sido a través de tratados internacionales sino de avances, en gran medida independientes, en diferentes países que el corpus de excepciones se ha ampliado. Este aumento se explica principalmente por tres causas: ${ }^{6}$ a) la evolución de la ciencia, la tecnología y la sociedad; b) la existencia de nueva materia patentable, y c) la necesidad de dar respuesta a la existencia de nuevas prácticas y nuevas materias. ${ }^{7}$

\section{Evolución histórica de las excepciones}

El Convenio de París en su versión original (1883) no contemplaba principios ni referencias a las excepciones. Es sólo en la conferencia de revisión del Convenio de La Haya de 1925, a propuesta de Francia, que el artículo 5-ter introduce la excepción relativa a navíos extranjeros y material de

nente de Derecho de Patentes, SCP-15-3, decimoquinta sesión, 11 a 15 de octubre de 2010, $\S \S 3$ y 5 .

5 En círculos académicos se ha propuesto una serie de posibles excepciones: la excepción al "uso leal"; la excepción por motivos de "interoperabilidad", y la excepción en razón de la "necesidad". Ibidem, p. 67.

6 Idem.

7 Éste sería el origen de la excepción Bolar. 
Esta obra forma parte del acervo de la Biblioteca Jurídica Virtual del Instituto de Investigaciones Jurídicas de la UNAM

aviación. ${ }^{8}$ En la época del Convenio de París, los ordenamientos nacionales reconocían por norma general solamente dos de las excepciones que hoy caerían bajo el artículo 30 del ADPIC: la excepción relativa al uso anterior ${ }^{9}$ y el uso personal. ${ }^{10}$

Desde 1883 hasta el periodo que precede al ADPIC se agregaron la excepción relativa al uso con fines experimentales; la excepción relativa a los actos realizados sin fines comerciales o los actos meramente privados; el uso de farmacia para la preparación de recetas individuales; la llamada excepción de Chicago en cuanto a la libertad de movimiento y mantención de aviones extranjeros, y la excepción regulatoria o Bolar. ${ }^{11}$

En la actualidad pueden identificarse más de 35 excepciones de distinta naturaleza reconocidas en diferentes jurisdicciones. ${ }^{12}$ El número es sensiblemente inferior si el concepto de excepción se delimita de manera afín al ADPIC y no incluye ni las licencias obligatorias ni el agotamiento de derechos. En cualquier caso, incluso de este modo el número de excepciones sigue superando la veintena. Ciertamente, su grado de reconocimiento difiere según las jurisdicciones. Por ejemplo, un gran número de ordenamientos jurídicos, más de 80, prevén excepciones tales como la de uso con fines experimentales o de educación, uso anterior y actos relativos a medios de transporte extranjeros que ingresan en el territorio nacional en forma transitoria o accidental (navíos, aviones). Por el contrario, un número importante de excepciones se encuentran reconocidas tan sólo en una única jurisdicción, como sería el caso de "objetos que se lancen al espacio desde el territorio nacional francés" o el "uso de material biológico ya existente en la naturaleza que no resulte necesario para la aplicación industrial especificada en la patente".

8 "This Article concerns patents only. It was introduced into the Convention by the Revision Conference of The Hague in 1925 and has not been changed since, except for some minor modifications as to form". Bodenhausen, G. H. C., Guide to the Application of the Paris Convention for the Protection of Industrial Property, BIRPI, 1968, p. 82. Las licencias obligatorias son también introducidas en la misma Conferencia de revisión de La Haya.

9 Pouillet, E., Traité Théorique et Pratique des Brevets D'Invention et de la Contrefaçon, 13a. ed., París, Marchal et Billard, 1889, p. 821, § 891.

10 Ibidem, p. 631, §§ 676 y 678.

11 Garrison, C., Exception to Patent Rights in Developing Countries, UNCTAD-ICTSD, Issue Paper 17, 2006.

12 Bentley, L., Estudio de expertos sobre exclusiones de la materia patentable y excepciones y limitaciones a los derechos conferidos por las patentes, Ginebra, OMPI, Comité Permanente de Derecho de Patentes, decimoquinta sesión, 11 a 15 de octubre de 2010, SCP-15-3, 2 de septiembre de 2010, pp. 28-30. 
Esta obra forma parte del acervo de la Biblioteca Jurídica Virtual del Instituto de Investigaciones Jurídicas de la UNAM

3. Catálogo numerus appertus de excepciones

La flexibilidad para con los fundamentos y justificación última de las excepciones ha dado lugar a una rica diversidad de excepciones en derecho comparado. Pueden enumerarse, sin carácter exhaustivo, las siguientes:

1) Uso con fines experimentales.

2) Actos realizados a título particular sin fines de lucro.

3) Preparación ex professo de medicamentos para casos individuales efectuada en una farmacia en virtud de una receta médica.

4) Uso anterior.

5) Uso no comercial de material vivo como fuente inicial de variación o propagación.

6) Uso de material de reproducción por los agricultores en su propia explotación.

7) Usos indirectos de procedimientos de producción para obtener otros productos.

8) Importación o entrada de pequeñas cantidades de mercancías no comerciales en los efectos personales de pasajeros o enviadas en paquetes pequeños.

9) Excepción regulatoria o Bolar.

10) Uso privado.

11) Usos de minimis.

12) Usos en la enseñanza.

13) Uso de determinados métodos de tratamiento.

14) Empleo de la invención patentada a bordo de buques, medios de locomoción aérea o terrestre o de cualesquiera otros medios de transporte.

15) Uso por un agricultor o ganadero de animales protegidos con fines agrícolas.

16) Actos relacionados con la descompilación e interoperabilidad.

\section{Fundamentos de las excepciones}

Una aproximación sistemática a las excepciones consiste en clasificarlas en función de los fundamentos sobre los que se basan. Ello permite agrupar las excepciones en tres grandes categorías, a saber: a) excepciones que reflejan el análisis de costos y beneficios del derecho de patentes; $b$ ) excepciones destinadas a facilitar el funcionamiento del derecho de patentes, y $c$ ) excep- 
Esta obra forma parte del acervo de la Biblioteca Jurídica Virtual del Instituto de Investigaciones Jurídicas de la UNAM

ciones que permiten resolver los conflictos entre el monopolio asociado a una patente y otros objetivos o valores de carácter social. Se trata de una categorización flexible, en el sentido de que varias de las excepciones pueden encontrar su justificación en más de una de estas categorías.

\section{A. Excepciones cuyo fundamento refleja el análisis de los costos} y beneficios del derecho de patente

Algunas excepciones se explican por referencia al fundamento mismo de la concesión de patentes, esto es, incentivar la inversión en investigación y la divulgación mediante la concesión de derechos. ${ }^{13}$ En efecto, las patentes deben concederse en la medida en que el monopolio sea necesario para corregir una ineficiencia del mercado para generar ciertos bienes, mientras que no deberán concederse si su aplicación puede restringir el desarrollo de nuevas invenciones. ${ }^{14}$

En esta categoría caben excepciones tales como el uso para fines de investigación o científicos, los usos no comerciales, el uso anterior, el uso privado y los usos de minimis. Algunas construcciones en derecho comparado han ido más allá en términos de laxitud y flexibilidad, al prever excepciones del tono "actos que no son perjudiciales para la explotación normal de la patente, o para los intereses del propietario de la patente y de otras partes". ${ }^{15}$

\section{B. Excepciones destinadas a facilitar el funcionamiento del derecho de patentes}

Existen excepciones que se basan en la propia lógica del sistema y que son necesarias para mantener el funcionamiento del propio sistema de patentes. ${ }^{16}$ Éste es el caso de la excepción por usos experimentales, que permite implementar la invención divulgada y comprobar también las propiedades de la misma. Ello dentro de la lógica que los sistemas modernos de patentes establecen, la condición general de divulgación pública de la invención, de suerte que terceros puedan experimentar con la invención a fin de comprobar si efectivamente funciona ( $y$ si se ha divulgado suficiente información sobre la misma).

\footnotetext{
13 Ibidem, p. 55.

14 Idem

15 Éste es el caso de Egipto. Idem.

16 Ibidem, p. 57.
} 
Esta obra forma parte del acervo de la Biblioteca Jurídica Virtual del Instituto de Investigaciones Jurídicas de la UNAM www.juridicas.unam.mx

\section{Excepciones que permiten resolver los conflictos entre el monopolio asociado a una patente y otros objetivos o valores de carácter social e intereses compensatorios públicos y privados}

En esta categoría de excepciones están aquellas que reflejan el hecho de que el incentivo de la innovación, aun siendo un importante objetivo social, entra a veces en conflicto con otros objetivos sociales o intereses privados, y se considera a estos últimos prioritarios o más importantes. En este contexto, y de acuerdo con este tercer fundamento, pueden citarse los usos en la enseñanza de los derechos de titulares de patentes, el privilegio de los agricultores o el uso de determinados métodos de tratamiento.

En este grupo también se pueden incluir las excepciones que responden a la necesidad de una protección eficaz y que las medidas de observancia no constituyan obstáculos al comercio, en línea con lo que disponen el preámbulo y el artículo 41.1 del ADPIC. En este subconjunto puede identificarse la importación o entrada de pequeñas cantidades de mercancías no comerciales en los efectos personales de pasajeros o enviadas en paquetes pequeños, o puede encontrarse de nuevo la excepción Bolar.

\section{Las excepciones en derecho europeo}

No existe un texto único de alcance europeo que regule la concesión, el régimen jurídico y la observancia del derecho de patentes. Éste no es solamente el caso de la Unión Europea, ${ }^{17}$ sino también de Europa en un concepto más amplio, esto es, incluidos todos los países de la Organización Europea de Patentes. A efectos introductorios debe mencionarse en cualquier caso la tríada compuesta por el Convenio de Estrasburgo del Consejo de Europa, la Convención de Múnich vinculado a la Organización Europea de Patentes y el Convenio de Luxemburgo, desarrollado en el marco de la

17 La Unión Europea carece tanto de una regulación específica uniformadora de los principios que deben regir la normativa nacional, como de un título único comunitario en materia de patentes. Ello ha llevado a que el Tribunal de Justicia haya declinado pronunciarse sobre la excepción de uso experimental en el marco de la controversia suscitada en un asunto planteado ante los tribunales holandeses, al entender que se trataba de una materia sometida a un derecho exclusivamente nacional. Sentencia del 9 de julio de 1997 en el asunto C-316/95, Generics BV contra Smith Kline \& French Laboratories Ltd. Véase, al respecto, Vidal-Quadras Trias de Bes, M., "La recepción de la cláusula Bolar en Europa", en Seuba, X., Propiedad intelectual, competencia y aspectos regulatorios del medicamento, Bogotá, PUJ-ICTSD, 2013, p. 295. 
Esta obra forma parte del acervo de la Biblioteca Jurídica Virtual del Instituto de Investigaciones Jurídicas de la UNAM

Comunidad Económica Europea y que, si bien nunca llegó a entrar en vigor, ejerció una gran influencia sobre las leyes nacionales de patentes.

El Convenio de Estrasburgo sobre la Unificación de Determinados Elementos del Derecho Sustantivo de Patentes de 1963 y el Convenio de Múnich sobre la Concesión de Patentes Europeas de 1972 abordaron las cuestiones relacionadas con los estándares de patentabilidad, validez, legitimación, el proceso para obtener una patente, el rol de las reivindicaciones en la definición del alcance de la patente y el método para interpretar las reivindicaciones de patente. No trataron, sin embargo, asuntos capitales como los derechos conferidos por la patente o las limitaciones a estos derechos, $\operatorname{erg}$, las excepciones.

El Convenio de Múnich dejó en manos de los países miembros la cuestión de los derechos conferidos por una patente europea, al establecer que tales derechos serían los mismos que los que establezca el derecho nacional con respecto a patentes nacionales, ${ }^{18}$ y que su violación debería ser tratada de acuerdo con lo dispuesto en la legislación nacional. ${ }^{19}$ El Convenio de Luxemburgo de 1975 sobre la Patente Comunitaria se adentró en estos aspectos, y si bien nunca llegó a entrar en vigor, ejerció una gran influencia en diversas leyes nacionales de patentes. Entre otras, también en materia de excepciones.

Efectivamente, en la parte relativa a los efectos de la patente comunitaria, los artículos 25 y 26 del Convenio de Luxemburgo definen los actos de explotación directa e indirecta que abarca el ius prohibendi del titular. Acto seguido, en materia de excepciones el artículo 27 recoge un catálogo ${ }^{20}$

18 Artículo 64.1.

19 Artículo 64.3.

20 En el que se incluyen: a) los actos realizados en la esfera privada y con fines no comerciales; b) los actos realizados con carácter experimental que se refieran al objeto de la invención patentada; c) la preparación extemporánea de medicamentos para casos individuales efectuada en una farmacia y con receta médica, ni a los actos relativos a los medicamentos así preparados; d) el empleo de la invención patentada a bordo de buques de los países de la Unión de París para la protección de la propiedad industrial distintos de los Estados contratantes, en el casco, máquinas, pertrechos, aparejos y otros accesorios, cuando estos navíos entren temporal o accidentalmente en las aguas de los Estados contratantes, siempre que la invención patentada se utilice exclusivamente para las necesidades del buque; e) el empleo de la invención patentada en la construcción o funcionamiento de aparatos de locomoción aérea o terrestre de los países de la Unión de París para la protección de la propiedad industrial distintos de los Estados contratantes, o de accesorios de estos aparatos, cuando penetren temporal o accidentalmente en el territorio de los Estados contratantes; f) los actos previstos por el artículo 27 del Convenio relativo a la aviación civil internacional, de 7 de diciembre de 1944, cuando estos actos afecten a aeronaves de un Estado, distinto de los Estados contratantes, que se beneficie de las disposiciones de este artículo. 
Esta obra forma parte del acervo de la Biblioteca Jurídica Virtual del Instituto de Investigaciones Jurídicas de la UNAM

que ha sido copiado en distintas leyes nacionales y luego retomado también en el texto del Acuerdo por el que se establece el Tribunal Unificado de Patentes. Dado que hasta la fecha este último es el texto más completo en materia de excepciones y recoge todas las previstas en el Convenio de Luxemburgo, se enumeran a continuación las excepciones previstas en el mismo. Se trata, como puede comprobarse, de la adición al contenido en el Convenio de Luxemburgo de otras excepciones desarrolladas en el transcurso de los años por la Unión Europea, como las relativas a las invenciones agrobiotecnológicas, ${ }^{21} \mathrm{o}$ a la excepción regulatoria. ${ }^{22}$ Así, según el Acuerdo por el que se establece el Tribunal Unificado de Patentes, los derechos del titular no se extienden a:

a) los actos efectuados a título particular y sin fines comerciales;

b) los actos realizados con fines experimentales que se refieran al objeto de la invención patentada;

c) el uso de material biológico con fines de cultivo o descubrimiento y desarrollo de otras variedades vegetales;

d) los actos permitidos por el artículo 13, apartado 6, de la Directiva 2001/82/CE o el artículo 10, apartado 6, de la Directiva 2001/83/CE, respecto de cualquier patente relativa al producto que se define en cualquiera de esas directivas;

e) la preparación ex profeso de medicamentos para casos individuales efectuada en una farmacia en virtud de una receta médica, ni a los actos relativos a los medicamentos así preparados;

f) el empleo de la invención patentada a bordo de buques de los países de la Unión Internacional para la Protección de la Propiedad Industrial (Unión de París) o de los miembros de la Organización Mundial del Comercio, distintos de aquellos Estados miembros contratantes en que esa patente tenga efecto, en el casco, las máquinas, los pertrechos, aparejos y demás accesorios,

21 La Unión Europea ha regulado el derecho del agricultor a utilizar el producto de su cosecha para la ulterior reproducción o multiplicación, cuando ésta es realizada por el mismo agricultor en su propia explotación (véase la Directiva 98/44/CE del Parlamento Europeo y del Consejo, del 6 de julio, relativa a la protección jurídica de las invenciones biotecnológicas). Todo ello en congruencia con el alcance y modalidades previstos en la legislación sobre obtenciones vegetales. En este contexto, los agricultores podrán utilizar la cantidad de material patentado que precisen para los fines de su propia explotación, y podrán también llevar a cabo las operaciones de tratamiento necesarias para la plantación del material.

22 El 30 de abril de 2004 se aprobaron las directivas: 2004/27/CE del Parlamento Europeo y del Consejo, del 31 de marzo de 2004, que modifica la Directiva 2001/83/CE por la que se establece un código comunitario sobre medicamentos de uso humano, y 2004/28/CE del Parlamento Europeo y del Consejo, del 31 de marzo de 2004, que modifica la Directiva 2001/82/CE por la que se establece un código comunitario sobre medicamentos veterinarios. En ambas se incluía la cláusula conocida como Bolar. 
Esta obra forma parte del acervo de la Biblioteca Jurídica Virtual del Instituto de Investigaciones Jurídicas de la UNAM

cuando esos buques penetren temporal o accidentalmente en las aguas de un Estado miembro contratante en el que esa patente tenga efecto, siempre que la invención se emplee exclusivamente para las necesidades del buque;

g) el empleo de la invención patentada en la construcción o el funcionamiento de medios de locomoción aérea o terrestre o de cualesquiera otros medios de transporte de los países de la Unión Internacional para la Protección de la Propiedad Industrial (Unión de París) o de los miembros de la Organización Mundial del Comercio, distintos de aquellos Estados miembros contratantes en que esa patente tenga efecto, o de los accesorios de los mismos, cuando dichos medios de locomoción o transporte penetren temporal o accidentalmente en el territorio de un Estado miembro contratante en el que esa patente tenga efecto;

h) los actos previstos por el artículo 27 del Convenio sobre Aviación Civil Internacional de 7 de diciembre de 1944, cuando esos actos afecten a aeronaves de un Estado parte en dicho Convenio distinto de un Estado miembro contratante en el que esa patente tenga efecto;

i) la utilización por un agricultor del producto de su cosecha para la reproducción o multiplicación por él mismo en su propia explotación, siempre que el material de reproducción vegetal haya sido vendido o comercializado de cualquier otra forma por el titular de la patente o con su consentimiento al agricultor, con fines agrícolas. El alcance y las condiciones de dicha utilización serán los establecidos en el artículo 14 del Reglamento (CE) nº 2100/94;

j) la utilización, por un agricultor o ganadero, de animales protegidos con fines agrícolas, siempre que los animales de cría o cualquier otro material de reproducción animal hayan sido vendidos o comercializados de cualquier otra forma al agricultor o ganadero por el titular de la patente o con su consentimiento. Dicha utilización incluye la puesta a disposición del animal o de otro material de reproducción animal, para la actividad agrícola del agricultor o ganadero, pero no su venta para una actividad reproductiva con fines comerciales;

k) los actos y la utilización de la información obtenida que se autorizan en virtud de los artículos 5 y 6 de la Directiva 2009/24/CE, en particular, sus disposiciones relativas a la descompilación y la interoperabilidad, y

l) los actos autorizados en virtud del artículo 10 de la Directiva 98/44/CE.

Además de los casos mencionados en la lista, tanto el Convenio de Luxemburgo ${ }^{23}$ como el Acuerdo por el que se establece el Tribunal Unificado de Patentes ${ }^{24}$ se refieren a los "usuarios anteriores", que tienen la facultad de conservar derechos:

23 Artículo 37 del Acuerdo sobre Patentes Comunitarias, Luxemburgo, 15 de diciembre de 1989 (89/695/CEE).

24 Ibidem, artículo 28. 
Esta obra forma parte del acervo de la Biblioteca Jurídica Virtual del Instituto de Investigaciones Jurídicas de la UNAM

1) Quien, en caso de que se hubiera expedido una patente nacional para una invención, hubiera adquirido, en alguno de los Estados contratantes, un derecho fundado en una utilización anterior de esta invención o un derecho de posesión personal de la misma disfrutará en este Estado del mismo derecho respecto de una patente comunitaria para la misma invención.

2) Los derechos conferidos por una patente comunitaria no se ampliarán a los actos relativos a un producto cubierto por esta patente y realizados en territorio del Estado afectado después de que la persona que goce del derecho contemplado en el apartado 1 haya comercializado este producto en dicho Estado, en la medida en que el derecho interno de tal Estado regule este efecto respecto a las patentes nacionales.

\section{Las excepciones a los derechos conferidos por las patentes en los Estados Unidos}

En el derecho de patentes estadounidense se denominan "limitaciones" (limitations) a las excepciones a los derechos conferidos por las patentes. Algunas son de origen legal, es decir, se encuentran incorporadas a la ley de patentes o a otras leyes, mientras que otras tienen su fuente en el common law, es decir, son creaciones jurisprudenciales, a veces codificadas a posteriori.

Entre las excepciones de origen legal encontramos a la excepción Bolar o excepción regulatoria, la defensa del primer inventor y la presencia temporaria de la invención patentada en vehículos, buques y aviones. Por su parte, entre las excepciones de fuente jurisprudencial se pueden incluir la excepción de experimentación sin fines de lucro, la doctrina de la licencia implícita y el derecho de hacer reparaciones respecto a un producto patentado.

\section{El ARTÍCUlo 30 DEL ACUERdo sObRE lOS ADPIC}

\section{La norma global sobre las excepciones al derecho de patente}

El ADPIC establece la regla general que deben cumplir las excepciones al ius excluendi del titular. El artículo 30 del Acuerdo prescribe que:

Los miembros podrán prever excepciones limitadas de los derechos exclusivos conferidos por una patente, a condición de que tales excepciones no atenten de manera injustificable contra la explotación normal de la patente ni causen un perjuicio injustificado a los legítimos intereses del titular de la patente, teniendo en cuenta los intereses legítimos de terceros. 
Esta obra forma parte del acervo de la Biblioteca Jurídica Virtual del Instituto de Investigaciones Jurídicas de la UNAM

Se trata, en efecto, de la traslación al ámbito de las patentes de la regla de los tres pasos o etapas originaria en el Convenio de Berna para la Protección de las Obras Literarias y Artísticas. Según el artículo 30 transcrito, la excepción a los derechos del titular: 1) debe ser limitada; 2) no ha de atentar "de manera injustificable contra la explotación normal de la patente", y 3) no debe causar "un perjuicio injustificado a los legítimos intereses del titular de la patente, teniendo en cuenta los intereses legítimos de terceros".

En efecto, durante la negociación del ADPIC algunos países intentaron especificar las excepciones concretas que pudieran ser objeto del artículo 30 del ADPIC, ${ }^{25}$ sin llegar a ningún acuerdo al respecto, lo que llevó al texto abierto del artículo. Precisamente, la Unión Europea fue uno de los miembros que trató de enumerar y restringir las excepciones. ${ }^{26}$

Tal como destacáramos en la introducción, el artículo 30 refleja el consenso internacional respecto de que: 1) las excepciones son abiertas; 2) los criterios ahí tasados se interpretan de acuerdo con el derecho nacional; 3) las excepciones pueden perseguir fines económicos, ${ }^{27}$ y 4) puede existir cierto

25 Véase: a) Declaración formulada por Tailandia en la reunión celebrada del 12 a 14 de septiembre de 1988, MTN.GNG/NG11/W/27, p. 2; b) Directrices y objetivos propuestos por la Comunidad Europea para las negociaciones sobre los aspectos de las normas sustantivas de los derechos de propiedad intelectual relacionados con el comercio, 7 de julio de 1988, MTN.GNG/NG11/W/26, pp. 6 y 7; c) Existencia, alcance y forma de las normas y los criterios internacionales generalmente aceptados y aplicados para la protección de la propiedad intelectual, nota preparada por la Oficina Internacional de la OMPI, 15 de septiembre de 1988, MTN.GNG/NG11/W/24/Rev.1, pp. 7 y 8; d) Compilación de comunicaciones escritas y declaraciones orales preparada por la Secretaría, 5 de febrero de 1988, MTN.GNG/ NG11/W/12/Rev.1, p. 17; e) Propuesta de los países nórdicos para las negociaciones sobre las normas y principios relativos a los aspectos de los derechos de propiedad intelectual relacionados con el comercio, 10 de julio de 1989, MTN.GNG/NG11/W/36, p. 2; f) Normas y principios relativos a la existencia, alcance y ejercicio de los derechos de propiedad intelectual relacionados con el comercio, comunicación de la India, 10 de julio de 1989, MTN. GNG/NG11/W/37, pp. 6, 7 y 17;g) Aspectos de los derechos de propiedad intelectual relacionados con el comercio, comunicación de las comunidades europeas, 14 de noviembre de 1989, MTN.GNG/NG11/W/49, p. 8; h) Normas relativas a los derechos de propiedad intelectual relacionados con el comercio, comunicación de Hong Kong, 29 de noviembre de 1989, MTN.GNG/NG11/W/51, p. 6; i) Proyecto de acuerdo sobre los aspectos de los derechos de propiedad intelectual relacionados con el comercio (de la delegación de las CE), 29 de marzo de 1990, MTN.GNG/NG11/W/68, pp. 10 y 11; j) Comunicación de Argentina, Brasil, Chile, China, Colombia, Cuba, Egipto, India, Nigeria, Perú, Tanzania y Uruguay, 14 de mayo de 1990, MTN.GNG/NG11/W/71, p. 10, y k) Comunicación de Brasil, 31 de octubre de 1988, MTN.GNG/NG11/W/30.

26 MTN.GNG/NG11/W/26, 7 de julio de 1998 (sección D.a. [i]).

27 Es interesante retomar el hecho de que la propuesta europea de que las excepciones se limiten a aquellas que no tienen fines comerciales, fue rechazada. En su propuesta de proyecto de ADPIC, del 29 de marzo de 1990, una disposición establecía que: "Se podrán 
Esta obra forma parte del acervo de la Biblioteca Jurídica Virtual del Instituto de Investigaciones Jurídicas de la UNAM www.juridicas.unam.mx

grado de conflicto entre la explotación de la patente y las excepciones, habida cuenta de los intereses de terceros.

En efecto, los negociadores del ADPIC optaron por redactar un texto amplio que no se limita a ninguna circunstancia particular, no se supedita a un fin u objetivo concreto, no se circunscribe a un tipo específico de excepción ni está limitado por una enumeración numerus clausus. No sólo eso, sino que, como se verá, las condiciones que se establecen en el artículo 30 tampoco son, a juicio de una importante corriente doctrinal, cumulativas. De este modo, el artículo 30 se diferencia notablemente de las excepciones previstas en el GATT, mucho más limitadas, y también de las excepciones referidas a derecho de autor ${ }^{28}$ y marcas ${ }^{29}$ previstas en el ADPIC. A diferencia de estos casos, el artículo 30 del ADPIC, sin lugar a dudas, contempla una aplicación limitada o especial. ${ }^{30}$

La excepción para la fabricación destinada a la exportación se relaciona con varios de los principios y objetivos anunciados en el ADPIC, en el preámbulo y en los artículos 7o., 8o. y 41. Como se verá al analizar la satisfacción de cada uno de los requisitos de la excepción, el componente teleológico es importante al justificar la necesaria consideración de los intereses de terceros, así como el hecho de que con dicha excepción no se produce una limitación injustificada sobre los derechos del titular.

\section{El artículo 30 según la diferencia Canadá-Genéricos}

El artículo 30 del ADPIC ha sido objeto de un conocido caso en el marco del sistema de solución de diferencias de la OMC. Nuestro objetivo no es analizar el informe del Grupo Especial Canadá-Genéricos en profundidad, sino extraer las opiniones del Grupo Especial que sirven a los efectos de de-

admitir excepciones limitadas de los derechos exclusivos conferidos por una patente para ciertos actos, como los derechos basados en el uso anterior, actos de carácter privado y sin fines comerciales y los actos realizados con fines experimentales, a condición de que tomen en cuenta los intereses legítimos del titular de la patente y de terceros".

28 El artículo 13 del ADPIC, referido al derecho de autor, dispone que "los miembros circunscribirán las limitaciones o excepciones impuestas a los derechos exclusivos a determinados casos especiales que no atenten contra la explotación normal de la obra ni causen un perjuicio injustificado a los intereses legítimos del titular de los derechos".

$29 \mathrm{El}$ artículo 17 del ADPIC, referido a marcas, dispone que "los miembros podrán establecer excepciones limitadas de los derechos conferidos por una marca de fábrica o de comercio, por ejemplo el uso leal de términos descriptivos, a condición de que en ellas se tengan en cuenta los intereses legítimos del titular de la marca y de terceros".

30 Canadá-Genéricos, p. 26. 
Esta obra forma parte del acervo de la Biblioteca Jurídica Virtual del Instituto de Investigaciones Jurídicas de la UNAM

sarrollar una aproximación más a fondo acerca del significado del artículo 30 , y que se desarrollan y ponen en contexto con mayor profundidad en la sección IV, cuando en detalle se examina la excepción de fabricación para la exportación.

El Grupo Especial Canadá-Genéricos tenía por delante la tarea de analizar dos excepciones recogidas en la Ley de Patentes de Canadá. Se trataba de la excepción basada en el "examen reglamentario" y de la excepción que permitía el "almacenamiento de mercancía".

La excepción basada en el "examen reglamentario" consistía en una redacción amplia de la excepción Bolar, en virtud de la cual los competidores genéricos podían avanzar sus trámites ante la administración a fin de poder, al expirar la protección mediante patente, competir en el mercado con el originador. Y ello con el objetivo de evitar una extensión de facto del periodo de exclusividad, puesto que de no existir tal excepción el competidor solamente podría empezar a preparar y presentar la información a partir de ese momento, con los consiguientes efectos sobre la competencia y precios de medicamentos.

La segunda excepción habilitada por la Ley de Patentes de Canadá permitía a los competidores genéricos, durante el periodo de protección de la patente, fabricar y almacenar existencias de sus productos, de modo que a partir del primer día del vencimiento de la patente el producto estuviera listo para satisfacer el mercado. No se trataba de todo el periodo de protección de la patente, sino durante el "periodo establecido en la reglamentación".

El Reglamento sobre la Fabricación y el Almacenamiento de Medicamentos Patentados, de 1993, estipulaba un plazo de seis meses en lo que respecta a los medicamentos patentados. Todo competidor podía así fabricar por anticipado un medicamento antes de que expirara el plazo de la patente, y explotar el producto en el mercado una vez expirada la misma.

Para responder a la conformidad de estas excepciones con el derecho de la OMC, el Grupo Especial realizó la que por ahora es la única interpretación de un grupo especial sobre el artículo 30 del ADPIC. Se trata de una interpretación estricta, realizada por un Grupo Especial en el cual ninguno de sus componentes era experto en derecho de patentes, ${ }^{31}$ y que ha sido calificada como restrictiva en la Declaración patrocinada por el Instituto

31 El Grupo Especial, integrado por los académicos Robert Hudec, especialista en derecho del GATT, fundamentalmente en solución de diferencias y la relación entre medio ambiente y derecho del comercio; Mihaly Ficsor, especialista en derecho de autor, y Jaime Sepúlveda, un salubrista mexicano. 
Esta obra forma parte del acervo de la Biblioteca Jurídica Virtual del Instituto de Investigaciones Jurídicas de la UNAM

Max Planck de 2014. ${ }^{32}$ No obstante ello, como tendrá ocasión de detallarse, inclusive a la luz de esta interpretación restrictiva se justifica la excepción de fabricación para la exportación.

El Grupo Especial constató que la palabra "limitada" debe interpretarse en sentido estricto. Para el panel, dicho adjetivo califica la palabra "excepción", que en sí misma tiene la connotación de "derogación limitada". Por consiguiente, la expresión "limitada" ha de interpretarse en el sentido de que entraña una excepción estricta, que conlleva una pequeña disminución de los derechos en cuestión. ${ }^{33}$

Además, para el Grupo Especial, determinar si una excepción es "limitada" no se trata de evaluar el "impacto económico", sino el impacto que puede tener dicha excepción en los "derechos" del titular. ${ }^{34}$ Tampoco se trata de contabilizar, al realizar la valoración, cuántos derechos (de fabricación, venta, importación) se ven afectados. ${ }^{35}$ Tras aplicar ese razonamiento, el Grupo Especial llega a la conclusión de que la "excepción basada en la acumulación de existencias" abrogaba los derechos del titular de la patente a fabricar y utilizar la invención en su totalidad en los seis meses anteriores a la expiración de la patente, sin límites de volumen y de mercados, y por consiguiente no podía calificarse de "limitada". ${ }^{36}$ Por el contrario, la excepción Bolar se entendió que se refería a actos cuyo alcance "será pequeño y circunscrito", ${ }^{37}$ por lo que la misma sí era aceptable a la luz del requisito de que se esté ante una excepción "limitada".

En relación con el requisito de no interferir con la explotación normal de la patente, para el Grupo Especial la "explotación" es la "actividad comercial por la que los titulares de patentes utilizan sus derechos exclusivos de patente para obtener un valor económico de su patente". ${ }^{38}$ Por otro lado, consideró que la noción de "normalidad" se refería, bien a una "conclusión empírica sobre lo que es corriente dentro de una colectividad dada, bien a un criterio que permite determinar aquello a lo que se tiene derecho". ${ }^{39}$ Se trata de un juicio orientado, pero en último término subjetivo, que llevó al panel a sostener que la "explotación normal” sí incluye el plazo de exclu-

\footnotetext{
32 Véase infra, apartado 3.B. de este mismo epígrafe.

33 Bentley, L., Estudio de expertos..., cit., p. 36; Canadá-Genéricos, $§ 7.48$.

34 Canadá-Genéricos $\$ 7.32$.

35 Idem.

36 Ibidem, $\$ 7.35$.

37 Ibidem, § 7.45.

38 Ibidem, $\$ 7.54$.

39 Ibidem, $\$ 7.56$.
} 
Esta obra forma parte del acervo de la Biblioteca Jurídica Virtual del Instituto de Investigaciones Jurídicas de la UNAM

sividad de facto tras la expiración, derivado de la necesidad de fabricar el producto, pero no la exclusividad que resulta de la necesidad para los competidores de obtener aprobación reglamentaria.

En relación con el tercer requisito, centrado en los "intereses legítimos" del titular y de terceros, el Grupo Especial analizó también cuáles son tales "intereses legítimos" tanto del titular como de terceros. En este contexto, distinguió entre "intereses legítimos" e "intereses jurídicos", y señaló que los primeros tienen un significado propio, el de "justificables", en el sentido de que están apoyados por políticas públicas u otras normas sociales pertinentes. Desde esta óptica se planteaba la cuestión de si los beneficios posteriores al plazo de la patente, que obtenía el titular habida cuenta del retraso que entrañaba para los competidores tener que obtener aprobación reglamentaria, eran "justificables". El Grupo Especial distinguió esta situación de la que se planteaba con respecto al retraso de los fabricantes de genéricos motivado por la necesidad de producir los medicamentos una vez expirada la patente. Mientras este último se consideró que era razonable, el Grupo Especial adujo que "el interés declarado en nombre de los titulares de patentes cuyo periodo efectivo de exclusividad en el mercado se veía reducido por las demoras habidas en la aprobación de la autorización para la comercialización no era tan perentorio ni estaba reconocido tan ampliamente como para que pudiera considerarse como un «legítimo interés»". Por ello, el Grupo Especial consideró que la excepción Bolar no afectaba la explotación normal de la patente, ni tampoco causaba un perjuicio injustificado a los intereses legítimos de los terceros, razón por la cual cumplía con las condiciones de admisibilidad del artículo 30.

\section{La visión contemporánea del artículo 30 del Acuerdo sobre los $A D P I C$}

Tanto la base normativa internacional como diversas opiniones influyentes permiten una lectura abierta del artículo 30 del ADPIC, más flexible que la que hizo el panel del asunto Canadá-Genéricos. Se trata de una lectura que encuentra apoyo tanto en el trabajo en materia de excepciones desarrollado en el seno del Comité de Patentes de la OMPI, como en la opinión de un buen número de respetados académicos y expertos internacionales que en 2014 consensuaron la Declaración sobre Protección Mediante Patente auspiciada por el Instituto Max Planck. 
Esta obra forma parte del acervo de la Biblioteca Jurídica Virtual del Instituto de Investigaciones Jurídicas de la UNAM www.juridicas.unam.mx

\section{A. Los trabajos del Comité de Patentes de la OMPI}

El Comité de Derecho de Patentes de la OMPI ha prestado especial atención a las excepciones al derecho de patentes en los últimos diez años. Entre otras iniciativas, ha encargado una cantidad importante de estudios sobre la temática a expertos internacionalmente reconocidos. ${ }^{40}$

En uno de estos estudios se afirma que "conviene considerar detenidamente hacer un uso más amplio de las excepciones", por lo que se aconseja, en relación con las excepciones, "velar por que las normas internacionales no repriman el uso de este medio tan importante para ajustar debidamente la política nacional en materia de patentes". ${ }^{41}$ Esta amplitud de miras con respecto al uso de excepciones responde a que las mismas excepciones permiten garantizar que "se llegue a un compromiso conveniente dentro del sistema de patentes", ${ }^{42}$ y se erigen en una suerte de "regulador de intensidad luminosa" que permite reducir la intensidad sin apagar, ello no obstante, la luz. ${ }^{43}$

La flexibilidad en torno a las excepciones resulta también del hecho que no existe apenas armonización internacional de las excepciones permitidas ni existe aparentemente voluntad para llevar a cabo tal armonización. Al contrario, como fuera subrayado, la interpretación del artículo 30 del ADPIC es abierta y flexible.

40 Véase Organización Mundial de la Propiedad Intelectual, Comité Permanente sobre el Derecho de Patentes: a) Exclusiones de la materia patentable y excepciones y limitaciones a los derechos conferidos por las patentes, Ginebra, SCP/13/3, 23 al 27 de marzo de 2009; b) Estudio de expertos sobre exclusiones de la materia patentable y excepciones y limitaciones a los derechos conferidos por las patentes, Ginebra, SCP/15/3, decimoquinta sesión, 11 a 15 de octubre de 2010; c) Reseña general de las respuestas al cuestionario sobre excepciones y limitaciones a los derechos conferidos por las patentes, Ginebra, SCP/18/3, 21 a 25 de mayo de 2012; d) Excepciones y limitaciones a los derechos conferidos por las patentes: uso privado y no comercial, Ginebra, SCP/20/3, 27 a 31 de enero de 2014; e) Excepciones y limitaciones a los derechos conferidos por las patentes: uso con fines experimentales o de investigación científica, Ginebra, SCP/20/427, 31 de enero de 2014; f) Excepciones y limitaciones a los derechos conferidos por las patentes: preparación extemporánea de fármacos, Ginebra, SCP/20/527, 31 de enero de 2014; g) Excepciones y limitaciones a los derechos conferidos por las patentes: uso anterior, Ginebra, SCP/20/627, 31 de enero de 2014, y h) Excepciones y limitaciones a los derechos conferidos por las patentes: uso de artículos en navios, aeronaves y vehículos terrestres extranjeros, Ginebra, SCP/20/7, 27 a 31 de enero de 2014 .

41 Comité Permanente sobre Derecho de Patentes, Estudio de expertos sobre exclusiones de la materia patentable y excepciones y limitaciones a los derechos conferidos por las patentes, Ginebra, SCP15-3, decimoquinta sesión, 11 a 15 de octubre de 2010, Anexo I (Preparado por Lionel Bentley), 2 de septiembre de 2010, p. 4.

42 Ibidem, p. 63.

43 Idem. 
Esta obra forma parte del acervo de la Biblioteca Jurídica Virtual del Instituto de Investigaciones Jurídicas de la UNAM

En lo sustantivo, el tratamiento de la regla de los tres pasos realizado por el Grupo Especial Canadá-Genéricos también ha sido criticado. Así, en la propia OMPI se ha considerado que algunas nociones del informe del asunto Canadá-Genéricos son excesivamente restrictivas. Éste es particularmente el caso del requisito de que se esté ante una excepción "limitada", que se entiende que puede articularse "para privar a los países miembros del verdadero potencial que alberga el uso de excepciones" ${ }^{44}$ Como se verá, se trata de una crítica compartida en la Declaración patrocinada por el Instituto Max Planck.

Las excepciones están adquiriendo una creciente relevancia. Por un lado, como alternativa a las exclusiones a la patentabilidad, puesto que estas últimas son delimitadas de forma cada vez más estricta en textos internacionales. Por otro lado, las excepciones se entienden también como un cauce adecuado para dar respuesta a necesidades que se manifiestan en diversos campos de la tecnología. Esto explica la aparición de nuevas excepciones en derecho comparado y en la diversidad de la interpretación de la misma excepción en distintos países (véase supra, apartado II).

\section{B. La Declaración sobre Protección Mediante Patente}

En la Declaración sobre Protección Mediante Patente, patrocinada por el Instituto Max Planck y redactada por un grupo de influyentes profesores y expertos en el plano internacional, ${ }^{45}$ se abordaron los aspectos centrales del derecho de patentes, a fin de presentar una aproximación a los mismos que permita al sistema de patentes cumplir con su función instrumental e incentivadora de la innovación.

En relación con las excepciones a los derechos del titular, la Declaración sostiene que, de forma contraria a lo que podría deducirse del informe del panel del asunto Canadá-Genéricos, las tres condiciones que se encuentran en el artículo 30 no tienen carácter cumulativo. El análisis de la satisfacción del artículo 30 requiere, en cambio, una aproximación global a la medida, distinta al examen excluyente e independiente de cada uno de los requisitos. Más explícitamente, de acuerdo con los redactores de la Declaración,

44 Ibidem, $\S 69$.

45 Declaration on Patent Protection, Regulatory Sovereignty under TRIPS, disponible en: wrwr.ip.mpg.de/en/pub/news/patentdeclaration.cfm. Para la lista completa de los redactores de la Declaración véase la p. 19 del documento, visible en: wrere.ip.mpg.de/files/pdf3/Patent_Declaration_en.pdf (fecha de consulta: 2 de octubre de 2014). 
Esta obra forma parte del acervo de la Biblioteca Jurídica Virtual del Instituto de Investigaciones Jurídicas de la UNAM

"no cumplir con una de las tres condiciones no tiene por qué resultar en el rechazo de la excepción". ${ }^{46}$

Resulta oportuno en este contexto describir el significado de cada uno de los tres requisitos según se recoge en la Declaración auspiciada por el Instituto Max Planck.

Así, para considerarse "limitada" la excepción no tiene por qué tener efectos restringidos, como señalara el panel del asunto Canadá-Genéricos. Al contrario, se entenderá que se está ante una excepción limitada si el alcance de la misma es proporcionado conforme a su objetivo y propósito. La excepción debe perseguir un objetivo legítimo, ser adecuada para lograr dicho objetivo y no exceder lo que resulta necesario y suficiente para conseguirlo. ${ }^{47}$

En segundo lugar, una excepción entra en conflicto de forma irrazonable con la explotación normal de la patente si la misma perjudica la eficiencia de la patente como mecanismo de regulación del precio. Éste, según la Declaración, es el caso si la excepción injustificadamente mengua los incentivos a la innovación que provee el mercado. ${ }^{48}$

En tercer lugar, una excepción no perjudica de manera injustificada los intereses legítimos del titular si la misma es proporcional y razonable. En este contexto deben considerarse todos los intereses relevantes, incluyendo los del titular y posibles licenciatarios; los innovadores - que se apoyan en la invención en un momento posterior-, competidores y otros actores que necesitan operar en el mercado bajo condiciones de competencia real; científicos e investigadores que requieren acceso a los hallazgos resultantes de la investigación básica; consumidores, que disfrutan de los beneficios del avance tecnológico, así como el público en general, en una mejoría social, cultural y de bienestar económico. ${ }^{49}$

Según los redactores de la Declaración, lo fundamental a la hora de implementar el artículo 30 es el respeto del principio de proporcionalidad y tener en cuenta los intereses de los distintos interesados en la medida. Es desde este punto de vista que la Declaración critica el informe del asunto Canadá-Genéricos, y señala la posibilidad de que existan otras excepciones, incluida la relativa a la fabricación para el almacenamiento durante la vigencia de la patente. ${ }^{50}$

\footnotetext{
46 Ibidem, punto 22, p. 8.

47 Ibidem, punto 23.

48 Ibidem, punto 24.

49 Ibidem, punto 25.

50 Ibidem, punto 26, p. 9.
} 
Esta obra forma parte del acervo de la Biblioteca Jurídica Virtual del Instituto de Investigaciones Jurídicas de la UNAM

\section{PRECEDENTES DE LA EXCEPCIÓN DE FABRICACIÓN PARA LA EXPORTAGIÓN}

\section{Referencias a la exportación en el marco del Código de Medicamentos para Uso Humano}

En 2002, y con el fin de "garantizar que la industria genérica europea pueda ser competitiva en el mercado mundial", ${ }^{51}$ el Parlamento Europeo propuso una enmienda al articulado del Código de Medicamentos para Uso Humano en virtud de la cual la concesión de la autorización para la exportación de un genérico no se consideraría contraria al derecho relativo a las patentes y al relativo a los certificados complementarios de protección.

La mencionada propuesta y los intentos posteriores en la misma línea ${ }^{52}$ fueron desatendidos. En efecto, en la Posición Común del Consejo, del 29 de septiembre de 2003, se rechazó la parte referente a los medicamentos destinados a la exportación que se podía encontrar en la anterior redacción. A este respecto, el Consejo consideraba que "tales excepciones quedan al margen del ámbito que debe regular una directiva sobre medicamentos destinados a comercializarse en los Estados miembros", ${ }^{53}$ si bien no adujo cuáles podían ser las razones jurídicas que podían llevar a rechazar dicha excepción.

\section{La excepción para exportación en el marco del Acuerdo Económico y Comercial Global entre la Unión Europea y Canadá}

Otro antecedente, esta vez de plena actualidad y con consecuencias normativas directas, es el Acuerdo Económico y Comercial Global entre

51 Informe sobre la propuesta de directiva del Parlamento Europeo y del Consejo que modifica la Directiva 2001/83/CE, por la que se establece un código comunitario sobre medicamentos para uso humano (COM [2001]) 404, C5-0592/2001, 2001/0253(COD), p. 27.

52 Un año más tarde, en el mismo proceso de enmienda normativa, el Parlamento volvió a insistir en la mención a la exportación en el contexto de actos que no se consideraban contrarios a los derechos del titular de una patente o certificado complementario de protección. Recomendación para la segunda lectura, respecto de la Posición Común del Consejo con vistas a la adopción de la Directiva del Parlamento Europeo y del Consejo que modifica la Directiva 2001/83/CE por la que se establece un código comunitario sobre medicamentos para uso humano (10950/03/2003 - C5-0464/2003 - 2001/0253[COD]), p. 14.

53 Posición Común (CE) No. 61/2003, de 29 de septiembre de 2003, aprobada por el Consejo de conformidad con el procedimiento establecido en el artículo 251 del Tratado Constitutivo de la Comunidad Europea, con vistas a la adopción de una Directiva del Parlamento Europeo y del Consejo que modifica la Directiva 2001/83/CE por la que se establece un Código Comunitario sobre Medicamentos de Uso Humano. 
Esta obra forma parte del acervo de la Biblioteca Jurídica Virtual del Instituto de Investigaciones Jurídicas de la UNAM

la Unión Europea y Canadá (CETA, por sus siglas en inglés), ${ }^{54}$ en el que el artículo 9o. del capítulo sobre propiedad intelectual recoge la que denomina "protección sui generis de la propiedad intelectual".

Bajo este término, CETA regula los que en Europa son los certificados complementarios de protección. En efecto, en un extenso artículo que se ha propuesto copiar en otros acuerdos que la Unión Europea negocia actualmente, en particular con los Estados Unidos ${ }^{55}$ CETA regula prácticamente todos los aspectos de los certificados complementarios de protección, sin utilizar, no obstante, esta denominación. Extremadamente interesante a los efectos de la excepción de fabricación para la exportación es el apartado 5 del mismo artículo, en el que se establece que: "A pesar de lo dispuesto en los parágrafos 1 a 4, cada parte puede limitar el alcance de la protección a través de la concesión de excepciones para fabricar, usar, ofrecer para la venta, vender o importar productos para el propósito de exportar durante el periodo de protección".

Si bien la redacción de la disposición es satisfactoria, la misma presenta una limitante importante al no obligar a su implementación. En efecto, según CETA se está ante una autorización, por lo que queda a criterio de las partes hacer uso de la facultad.

\section{La excepción para exportación en el marco de los certificados complementarios de protección-dimensión interna}

En el plano interno europeo, y en consonancia con lo previsto en CETA, se ha propuesto la adopción de una excepción que permita la exportación de productos genéricos y biosimilares de otros protegidos en Europa por certificados complementarios de protección, allí donde no exista protección de patente. ${ }^{56}$

Se trata de una previsión importante, puesto que al día de hoy los productores de genéricos y biosimilares europeos compiten en condiciones desiguales con los fabricantes de los países que no han adoptado certificados complementarios de protección, o figuras similares como la extensión de la patente. Es decir, casi todos los países, entre los que se encuentran potencias

54 Puede consultarse en: http://wrerr.tagesschau.de/wirtschaft/ceta-dokument-101.pdf.

55 EGA, EU-US Transatlantic Trade and Investment Partnership, Bruselas, EGA, 6 de mayo de 2013 .

56 EGA, An EU Advanced Manufacturing Provision for Export of Generic and Biosimilar Medicines to Third Countries, Bruselas, EGA, septiembre de 2013. 
Esta obra forma parte del acervo de la Biblioteca Jurídica Virtual del Instituto de Investigaciones Jurídicas de la UNAM

con importantes industrias de genéricos y biosimilares, como India, China o Brasil.

Los argumentos son en buena medida idénticos a los que permiten sustentar la excepción para la fabricación y exportación durante el periodo de vigencia de la patente a países sin protección. Una de las ideas centrales es que permitir la fabricación y exportación durante el periodo de vigencia del certificado complementario de protección no perjudica al titular del derecho, en tanto en cuanto dichas actividades tienen lugar en mercados donde el certificado no existe y, sobre todo, la producción y exportación se realizan para satisfacer un mercado donde no existe protección.

La nueva excepción se introduciría a través de la adopción de un nuevo reglamento que complementaría el Reglamento 1768/92 de 18 junio de 1992 del Consejo, con un texto que dijera:

La fabricación en un país miembro de la Unión Europea durante el periodo de vigencia de un certificado complementario de protección para productos farmacéuticos con fines de exportación a otros países miembros de la Unión Europea o terceros países en los que a) el periodo de exclusividad de la patente o extensión de la patente ha expirado, caducado o dejado de existir de cualquier otra forma, y/o b) en respuesta a una licencia obligatoria, no deberá ser considerado contrario a los certificados suplementarios de protección para productos farmacéuticos. ${ }^{57}$

La Unión Europea está analizando la implantación de esta cláusula en el marco de su competencia sobre certificados complementarios de protección. En el Informe del Parlamento Europeo sobre la Reindustrialización de Europa para Promover la Competitividad y la Sostenibilidad ${ }^{58}$ se pide a la Comisión que:

...proponga legislación que permita a las empresas europeas fabricar medicamentos genéricos y biosimilares en la UE para la exportación a países en los que no existe patente ni certificado complementario de protección; considera que dichas disposiciones podrían ayudar a evitar la externalización de la producción y a fomentar la creación de empleo en la UE, así como a generar la igualdad de condiciones para las empresas europeas y sus competidores de terceros países. ${ }^{59}$

57 EGA, An EU Advanced Manufacturing Provision for Export of Generic and Biosimilar Medicines to Third Countries, Bruselas, EGA, septiembre de 2013, p. 3 (traducción y adaptación propias).

58 Informe del Parlamento Europeo sobre la Reindustrialización de Europa para Promover la Competitividad y la Sostenibilidad (2013/2006[INI]), ponente Reinhard Bütikofer, ref. A7-00464/2013, 18 de diciembre de 2013.

59 Ibidem, p. 21. 
Esta obra forma parte del acervo de la Biblioteca Jurídica Virtual del Instituto de Investigaciones Jurídicas de la UNAM www.juridicas.unam.mx

\section{La excepción para la exportación en Australia}

La excepción para fabricación y exportación fue examinada por el Comité encargado de la revisión de la ley de patentes australiana en lo que se refiere a las patentes farmacéuticas. ${ }^{60} \mathrm{El}$ Comité acogió positivamente los argumentos en favor de la excepción, en particular los relacionados con el desarrollo industrial y con la falta de afectación de los intereses del titular de la patente. De acuerdo con el Comité:

...de forma perversa, si la patente aplicable no ha expirado en Australia, parecería que los fabricantes de genéricos australianos deben establecer plantas de manufacturación en el extranjero para servir aquellos mercados y evitar de este modo infringir los derechos de patente australianos. Se trata de un resultado que no ofrece ventaja obvia alguna para los titulares de derechos, puesto que los fármacos sería producidos para el mercado de exportación, pero priva a las empresas y trabajadores australianos de producirlos. ${ }^{61}$

El mismo Comité señaló, sin embargo, que en su opinión dicha excepción podía contradecir las normas internacionales que obligan a Australia, fundamentalmente el ADPIG y el Acuerdo de Libre Comercio con los Estados Unidos. Con un argumento bastante deficitario y atribuyendo afirmaciones al informe del Grupo Especial Canadá-Genéricos que no se encuentran en el mismo, el Comité señaló que era preferible evitar el litigio que supondría la enmienda de la ley para incorporar la excepción para la exportación, y propuso en cambio que Australia lidere un proceso internacional que permita la enmienda de las obligaciones existentes a fin de que se admita la excepción para la exportación. Entre tanto, propuso la conclusión de acuerdos voluntarios en virtud de los cuales los titulares de patentes no denunciarían a los fabricantes de genéricos que manufacturaran a los fines exportar la producción a países donde no exista protección. ${ }^{62}$

60 El denominado "The Pharmaceutical Patents Review Panel", véase Review of Pharmaceutical Patents in Australia, disponible en: http://wrore.ipaustralia.gov.au/about-us/ip-legislationchanges/review-pharmaceutical-patents/(fecha de consulta: 28 de septiembre de 2014).

61 Harris, T. D. y Gruen, Nicol N., Pharmaceutical Patents Review Report, Canberra, 2013, p. VI.

62 Ibidem, p. XV. 
Esta obra forma parte del acervo de la Biblioteca Jurídica Virtual del Instituto de Investigaciones Jurídicas de la UNAM

\section{ANÁLISIS DEL GUMPLIMIENTO DE LA EXCEPGIÓN \\ DE FABRICACIÓN PARA LA EXPORTACIÓN DE LAS TRES GONDICIONES DEL ARTÍCULO 30 DEL ADPIC}

La compatibilidad de la excepción de fabricación para la exportación con el artículo 30 del ADPIC reconoce dos caminos diferentes, pero complementarios. Por un lado, se puede demostrar que la excepción es compatible con el artículo 30, aun aplicando la restrictiva interpretación que realizó el Grupo Especial Canadá-Genéricos. Por el otro, se puede articular una interpretación más extensiva del artículo 30 del ADPIC en línea con los cánones propuestos por la Declaración sobre Protección Mediante Patente patrocinada por el Instituto Max Planck y los últimos trabajos del Comité de Patentes de la OMPI.

Con este norte, demostraremos a continuación que la excepción de fabricación para la exportación es una excepción limitada, que no atenta de manera injustificada contra la explotación normal de la patente ni causa un perjuicio injustificado a los legítimos intereses de sus titulares, teniendo en cuenta los intereses legítimos de los terceros.

\section{Es una excepción limitada}

\section{A. Aplicación de los criterios del Grupo Especial Canadá-Genéricos}

La aplicación de los principios que llevaron al Grupo Especial CanadáGenéricos a constatar que la excepción basada en el almacenamiento de existencias no era una "excepción limitada" no lleva necesariamente a concluir que la excepción de fabricación para la exportación es inconsistente con el estándar del artículo 30 del ADPIC.

En forma preliminar, debe destacarse que si la expresión "excepción limitada" equivaliera a la imposibilidad de limitar el ius excluendi, la cláusula de excepción del artículo 30 no tendría sentido ya que ninguna excepción sería admisible, por lo que una interpretación de tales características violentaría el principio de efecto útil de interpretación de los tratados. ${ }^{63}$ Por lo tanto, si una "excepción limitada" significa evidentemente algo menos que el

63 El principio ut res magis valeat quam pereat, tal como lo señalara el Tribunal Internacional de Justicia, "sería contrario a las reglas de interpretación generalmente reconocidas al considerar que una disposición, insertada en un compromiso, sea una disposición sin sentido y sin efecto". Asunto del Estrecho de Corfú, CIf Rec 1949, 24. 
Esta obra forma parte del acervo de la Biblioteca Jurídica Virtual del Instituto de Investigaciones Jurídicas de la UNAM

pleno uso del derecho de excluir, entonces el tema a dilucidar es cómo configurar una excepción que restrinja el derecho de excluir, pero lo haga con una intensidad tal que pueda ser considerada "limitada" en el contexto de la interpretación dada al artículo 30 por el Grupo Especial Canadá-Genéricos.

En tal sentido, debe destacarse que el Grupo Especial descartó que la evaluación de la primera condición estuviera concebida para abordar directamente la cuestión de las repercusiones económicas de la excepción, sino que tales repercusiones debían ser analizadas en el contexto del segundo y del tercer requisito. ${ }^{64}$ Por lo tanto, no es el impacto económico de la excepción lo que importa a los fines de evaluar si una excepción es limitada, sino el nivel de menoscabo de los derechos de exclusión que otorga el artículo 28 del ADPIC.

Una primera dificultad es que el propio Grupo Especial Canadá-Genéricos evitó definir con exactitud qué nivel de reducción del derecho de impedir actos de fabricación, uso, oferta para la venta, venta o importación del producto patentado sería descalificador de una excepción en general. Simplemente, el Grupo Especial se limitó a constatar que la excepción basada en la acumulación de existencias presentaba una reducción sustancial del ius excluendi y que, por tanto, no podría considerarse una "excepción limitada" ${ }^{65}$ Para llegar a esa conclusión, el Grupo Especial expuso dos razones.

La primera razón fue que la acumulación de existencias coartaba los derechos del titular de patente a impedir la "fabricación" y el "uso" del producto patentado. Según el Grupo Especial, el derecho a impedir la "fabricación" y el "uso" es, durante la totalidad de la vigencia de la patente, una protección complementaria de la constituida por el derecho a impedir la venta, al cortar el suministro de productos competidores en la fuente e impedir así la utilización de tales productos, sea cualquiera la forma en que se obtengan.

Para el Grupo Especial, la inexistencia de alguna limitación al volumen de producción durante los últimos seis meses del término de duración de la patente, al margen de cualesquiera otras consecuencias posteriores que pudiera tener, fue determinante para constatar que la excepción suprimía, por ese sólo efecto, enteramente los derechos de impedir la fabricación y el uso. ${ }^{66}$

La segunda razón del Grupo Especial estuvo destinada a refutar los argumentos expuestos por Canadá de que la excepción era limitada porque

\footnotetext{
64 Canadá-Genéricos, § 49.

65 Ibidem, $\S 7.36$.

66 Ibidem, $§ 7.34$.
} 
Esta obra forma parte del acervo de la Biblioteca Jurídica Virtual del Instituto de Investigaciones Jurídicas de la UNAM

preservaba los beneficios comerciales antes de la expiración de la patente, ya que no existían ventas a los consumidores en el territorio de Canadá durante su vigencia. Sin embargo, el Grupo Especial llegó a la conclusión de que, tanto en teoría como en la práctica, las ventajas comerciales obtenidas por el titular de la patente durante los meses siguientes a la expiración del término de protección de la patente eran ventajas comerciales adicionales que estaban comprendidas por el derecho de impedir actos de "fabricación" y de "uso" antes del vencimiento de la patente. ${ }^{67}$

Esta constatación llevó al Grupo Especial a afirmar que los derechos del titular de la patente se consideran en general como un derecho a impedir las actividades comerciales competitivas de otros y que la fabricación para la venta comercial es la quintaesencia de las actividades comerciales competitivas, cuyo carácter no se altera por un mero retraso en la obtención de una recompensa comercial.

Cabe destacar que el Grupo Especial no consideró que la excepción de acumulación de existencias fuera incompatible per se con el artículo 30 del ADPIC, y no descartó que, bajo otras circunstancias, una excepción de similares características pudiera superar la prueba de compatibilidad con aquella norma. En efecto, el Grupo Especial afirmó que las limitaciones a la excepción de acumulación de existencias previstas en la legislación canadiense eran insuficientes para considerarla una "excepción limitada".

En tal sentido, Canadá había realizado importantes esfuerzos argumentativos para sostener que la excepción era limitada, señalando que: a) sólo podían invocarla las personas que hubieran sido beneficiada de la excepción Bolar; b) la excepción cubría únicamente los productos comprendidos por aquella excepción, y c) la excepción tenía una duración de tan sólo seis meses. Sin embargo, el Grupo Especial concluyó que tales limitaciones eran insuficientes porque, como ya expusiéramos supra, un plazo de seis meses era un periodo de tiempo comercialmente sustancial, en especial porque no había absolutamente ninguna limitación del volumen autorizado de producción ni de los mercados a los que se destinaba tal producción. ${ }^{68}$

Una interpretación a contrario sensu de esta constatación del Grupo Especial permite afirmar, en consecuencia, que si la excepción canadiense hubiera tenido límites respecto al volumen autorizado o en relación con los mercados a los que se destinaba la producción, no estaríamos frente a una excepción no limitada y fuera del estándar del artículo 30, sino en presencia

67 Ibidem, $\S 7.35$.

68 Ibidem, $§ 7.38$. 
Esta obra forma parte del acervo de la Biblioteca Jurídica Virtual del Instituto de Investigaciones Jurídicas de la UNAM

de una excepción que podría ser limitada y consistente con esta primera condición del artículo 30.

Generalizada esta conclusión, se puede afirmar entonces que la afectación del derecho de impedir la fabricación de un producto patentado sería congruente con los principios del artículo 30 si tuviera, al menos, limitaciones en cuanto al volumen autorizado de producción o respecto a los mercados a los que se destina. La presencia de otras limitaciones, no enumeradas por cierto por el Grupo Especial, coadyuvaría a distinguir una excepción admisible de una que no lo es.

Y precisamente la excepción de fabricación para la exportación tiene limitaciones que le son inherentes y que le permiten superar satisfactoriamente el riguroso test de "excepción limitada" del Grupo Especial en el caso Canadá-Genéricos.

Primero, no limita significativamente el ius excluendi respecto de los actos que el titular de la patente puede impedir realizar a terceros, sino que lo hace únicamente en relación con objetos destinados a la exportación. El titular conserva intacto todo el poder para excluir la realización de cualquier acto que esté conectado con la comercialización en el mercado interno.

Segundo, a diferencia del caso Canadá-Genéricos, la excepción de fabricación para exportación no limita la posibilidad de ejercer el ius excluendi en el tiempo respecto de las ventas destinadas al mercado interno. Este derecho puede ser ejercido hasta el último día del término de vigencia de la patente y, aún más, se preservan las ventajas comerciales que, eventualmente, puede obtener el titular de la patente durante el tiempo posterior a la expiración de la patente y hasta la entrada de un competidor en el mercado. Este competidor bien puede ser el mismo beneficiario de la excepción en la medida en que los productos hayan sido fabricados después del vencimiento de la patente.

Tercero, la excepción de fabricación para la exportación tiene, por definición, una limitación en el volumen de producción. A diferencia del caso Canadá-Genéricos, donde el beneficiario de la excepción podía fabricar y almacenar el producto patentado en un volumen ilimitado, la excepción de fabricación para la exportación no admitiría una fabricación ilimitada del producto patentado, sino únicamente de aquellas unidades destinadas a la exportación a mercados sin protección de patente. Cualquier fabricación que excediera las necesidades de exportación infringiría entonces los derechos del titular, de allí que no se afecta el volumen de productos que el titular de la patente puede destinar al mercado nacional.

Cuarto, la excepción tiene una clara limitación respecto a los mercados a los cuales se destina la producción. La excepción no afecta en modo al- 
Esta obra forma parte del acervo de la Biblioteca Jurídica Virtual del Instituto de Investigaciones Jurídicas de la UNAM

guno la posibilidad de oponer el ius excluendi respecto a las ventas en el mercado interno que, en palabras del Grupo Especial, es la quintaesencia de las actividades comerciales competitivas. ${ }^{69}$ Por el contrario, la excepción no permite otra alternativa que la comercialización en un mercado extranjero, sin afectar el mercado nacional.

En síntesis, la excepción de fabricación para la exportación tiene un efecto mucho más restringido sobre los derechos del titular de patente que la excepción canadiense de acumulación de existencias, motivo por el cual la excepción estaría en armonía con el primer requisito o condición del artículo 30 del ADPIC de ser una "excepción limitada".

\section{B. Interpretación del artículo 30 a la luz de criterios más amplios que los del Grupo Especial Canadá-Genéricos}

Una interpretación más amplia del artículo 30 que la desarrollada en los párrafos precedentes, en línea con los trabajos del Comité de Patentes de la OMPI y la Declaración sobre Protección Mediante Patente patrocinada por el Instituto Max Planck, ratifica la compatibilidad de la excepción de fabricación para exportación con el ADPIC.

La mencionada Declaración afirma que para considerarse "limitada" una excepción no tiene por qué tener efectos restringidos, como señalara el panel del asunto Canadá-Genéricos. Al contrario, se entenderá que se está ante una excepción limitada si el alcance de la misma es proporcionado conforme a su objetivo y propósito. Por lo tanto, la excepción debe perseguir un objetivo legítimo, ser adecuada para lograr dicho objetivo y no exceder lo que resulta necesario y suficiente para conseguir tal objetivo. ${ }^{70}$

En este orden de ideas, para resolver la cuestión de si la excepción propuesta es una "excepción limitada" en el sentido del artículo 30 del ADPIC, la redacción de este artículo 30 debe interpretarse con arreglo a las reglas consuetudinarias de interpretación de los tratados internacionales que se recogen en la Convención de Viena sobre el Derecho de los Tratados (GVDT).

El artículo 31 de la CVDT establece que "[u]n tratado deberá interpretarse de buena fe conforme al sentido corriente que haya de atribuirse a los términos del tratado en el contexto de éstos y teniendo en cuenta su objeto y fin”. En su segundo párrafo, el mismo artículo 31 se refiere al contexto en

69 Ibidem, $\S 7.35$.

70 Declaration on Patent Protection..., cit., punto 23, p. 8. 
Esta obra forma parte del acervo de la Biblioteca Jurídica Virtual del Instituto de Investigaciones Jurídicas de la UNAM

el que deben interpretarse los términos del tratado, y que comprende, entre otros elementos, el preámbulo del tratado.

El primer párrafo del preámbulo del ADPIC afirma que los miembros están "[d] eseosos de reducir las distorsiones del comercio internacional y los obstáculos al mismo, y teniendo en cuenta la necesidad de fomentar una protección eficaz y adecuada de los derechos de propiedad intelectual y de asegurarse de que las medidas y procedimientos destinados a hacer respetar dichos derechos no se conviertan a su vez en obstáculos al comercio legítimo".

La referencia al comercio legítimo en el preámbulo permite subrayar lo que ha sido ya indicado en otros puntos de este trabajo, que se está ante una situación en la que no puede satisfacerse una demanda comercial en un país distinto al que tiene reconocidos los derechos del titular, y se crea por tanto una barrera al comercio internacional. A nuestro juicio, por tanto, se está yendo más allá de la "protección eficaz y adecuada" a la que alude el preámbulo.

En el artículo 7o. del ADPIC se enuncian los objetivos del Acuerdo. El artículo 7o. deja claro que los derechos de propiedad intelectual no se confieren en el vacío y que, por consiguiente, el ADPIC no tiene por finalidad conseguir un grado de protección de esos derechos que indebidamente vayan en detrimento de los intereses públicos vitales en el bienestar social y económico o de los derechos de terceros.

El artículo 7o. refleja precisamente la concepción instrumental de la propiedad intelectual que caracteriza al ADPIC, al establecer que "la protección y la observancia de los derechos de propiedad intelectual deberán contribuir a la promoción de la innovación tecnológica y a la transferencia y difusión de la tecnología, en beneficio recíproco de los productores y de los usuarios de conocimientos tecnológicos y de modo que favorezcan el bienestar social y económico y el equilibrio de derechos y obligaciones".

A la luz del contexto de los objetivos anunciados en el preámbulo del ADPIC y en el artículo 7o., la existencia del artículo 30 sobre las excepciones a los derechos del titular, llama la atención sobre el hecho de que una aplicación inflexible y absoluta de los derechos del titular puede resultar efectivamente contraria a los objetivos de ese Acuerdo. El artículo 30 permite, en efecto, limitar la plena aplicación de los derechos de patente en función de las circunstancias particulares de los países cuando se requiera un equilibrio y cuando haya que considerar el bienestar social y económico. ${ }^{71}$ En este contexto, conviene recordar también que la libertad a la que hace referencia

71 Ibidem, punto 24, p. 8. 
Esta obra forma parte del acervo de la Biblioteca Jurídica Virtual del Instituto de Investigaciones Jurídicas de la UNAM

el artículo 1o. del ADPIC, para establecer libremente el método adecuado para aplicar las disposiciones del ADPIC, cubre igualmente el artículo 30.

Limitado, se dice, de aquello ajustado dentro de límites definidos, de alcance restringido. La excepción para la exportación está circunscrita estrictamente al caso de que un tercero fabrique y exporte una invención patentada exclusivamente a países en los que la invención no sea objeto de protección. No afecta por ello las ventas del titular en dicho país efectuadas por el titular de la patente durante el plazo de vigencia de ésta. Más en general, los derechos exclusivos de los que disfrutaba el titular de la patente continúan vigentes durante la totalidad del plazo de protección. Así, el titular tiene el derecho a iniciar actuaciones por infracción para impedir que otros realicen cualquier acto de fabricación, uso, oferta para la venta, venta o importación de la materia patentada fuera del ámbito restringido de la excepción.

En síntesis, la excepción de fabricación para la exportación cumple con la primera condición del artículo 30 de ser una "excepción limitada", tanto en la interpretación de la primera condición realizada por el Grupo Especial Canadá-Genéricos, como una más amplia según la Declaración patrocinada por el Instituto Max Planck.

\section{No afecta a la explotación normal de la patente}

La segunda condición que impone el artículo 30 del ADPIC es que una excepción no atente "de manera injustificable contra la explotación normal de la patente". Esta condición fue objeto de interpretación por el Grupo Especial Canadá-Genéricos al analizar si la excepción Bolar era compatible con el artículo citado. ${ }^{72}$ Tanto siguiendo la interpretación sentada por el Grupo Especial como la más liberal promovida por la Declaración impulsada por el Instituto Max Planck, puede sostenerse que la excepción de fabricación para la exportación cumple con la segunda condición que impone el artículo 30 del ADPIC.

\section{A. Aplicación de los criterios del Grupo Especial Canadá-Genéricos}

La condición bajo comentario impone, en primer término, interpretar qué significa "explotación normal" de la patente y determinar si la excepción interfiere o no con esa explotación normal. Si no existe ningún con-

72 Por el contario, el Grupo Especial declinó analizar la segunda condición respecto de la excepción de acumulación de existencias, ya que no cumplía con la primera condición de ser una "excepción limitada". Véase $\$ 7.38$. 
Esta obra forma parte del acervo de la Biblioteca Jurídica Virtual del Instituto de Investigaciones Jurídicas de la UNAM

flicto con la "explotación normal de la patente", entonces no es necesario continuar el análisis, y la excepción cumpliría con la segunda condición del artículo $30 .{ }^{73}$ En cambio, si existiera un conflicto con la explotación normal, entonces debe evaluarse si ese conflicto es justificable. Si existen razones que permitan justificar la excepción, aun cuando se interfiera con la "explotación normal" de la patente, entonces la excepción también cumpliría con la segunda condición. ${ }^{74}$

Según el Grupo Especial Canadá-Genéricos, determinar si una excepción atenta contra la explotación normal de una patente es una cuestión que guarda relación con las repercusiones económicas de la excepción. ${ }^{75}$ Así, el Grupo Especial interpretó que la palabra "explotación" se refiere "a la actividad comercial por la que los titulares de la patente utilizan sus derechos exclusivos de patente para obtener un valor económico de su patente". ${ }^{76}$

Asimismo, el mismo Grupo Especial interpretó que "normal" define al tipo de actividad que se trata de proteger con el artículo 30, asignándole el sentido corriente dado por los diccionarios de "regular, usual, typical, ordinary, conventional (corriente, usual, típico, ordinario y convencional)". ${ }^{77}$ Por lo tanto, el Grupo Especial afirmó que la palabra "normal" tiene dos connotaciones diferentes, una empírica y otra normativa, ${ }^{78}$ y que refieren tanto a una conclusión empirica sobre lo que es corriente dentro de una colectividad dada, como a un criterio que permite determinar aquello a lo que se tiene derecho. En definitiva, el Grupo Especial concluyó que en el contexto del artículo 30, el término "normal" se utiliza en un sentido que combina esas dos acepciones.

Luego de delimitar el significado de las palabras "explotación" y "normal" por separado, el Grupo Especial interpretó el alcance de ambas palabras ensambladas. Según el Grupo Especial,

...la práctica normal seguida por los titulares de patentes en lo que se refiere a la explotación, al igual que ocurre con los titulares de cualquier otro derecho de propiedad intelectual, consiste en impedir todas las formas de competencia que puedan detraer considerablemente de las ventajas económicas previstas como resultado de la exclusividad en el mercado otorgada por la patente. ${ }^{79}$

73 Canadá-Genéricos, $\$ 7.59$.

74 Idem.

75 Ibidem, $§ 7.49$.

76 Ibidem, $§ 7.54$.

77 Idem.

78 Senftleben, M., "Towards a Horizontal Standard for Limiting Intellectual Property Rights?-WTO Panel Reports Shed Light on the Three-Step Test in Copyright Law and Related Tests in Patent and Trademark Law", IIC, vol. 37, núm. 4, 2006, p. 428.

79 Canadá-Genéricos, $\$ 7.55$. 
Esta obra forma parte del acervo de la Biblioteca Jurídica Virtual del Instituto de Investigaciones Jurídicas de la UNAM

En este contexto, el Grupo Especial puntualizó que la protección de todas las prácticas de explotación normales es un elemento clave de la política que se refleja en todas las legislaciones de patentes. Estas legislaciones establecen, al efecto, un periodo cuidadosamente definido de exclusividad en el mercado como incentivo para la innovación, y que la política de esas legislaciones no puede convertirse en realidad a menos que los titulares de patentes puedan aprovechar efectivamente ese incentivo una vez definido tal periodo. ${ }^{80}$

Tanto la Unión Europea como Canadá coincidieron en que la "explotación" de la patente entraña la extracción de su valor comercial mediante tres formas de "aprovechamiento": a) vendiendo el producto en un mercado del que están excluidos los competidores; $b$ ) concediendo a otros la licencia para hacerlo, y c) transfiriendo directamente los derechos conferidos por la patente. ${ }^{81}$

El Grupo Especial consideró entonces si la exclusividad en el mercado luego de la expiración del plazo de vigencia de la patente podía ser considerada como parte de la "explotación normal". Según el Grupo Especial, algunos de los derechos básicos concedidos a todos los titulares de las patentes y ejercidos corrientemente por todos los titulares suelen llevar cierto periodo de exclusividad en el mercado después de la expiración de la patente.

Por ejemplo, según el Grupo Especial, sería normal el periodo de explotación en exclusividad posterior al vencimiento de la patente, que es consecuencia del ejercicio del derecho de impedir la fabricación del producto patentado a los competidores para acumular existencias durante la vigencia de la patente. ${ }^{82}$ Por el contrario, el Grupo Especial consideró anormal el periodo adicional de exclusividad de facto creada por la utilización de los derechos conferidos por la patente para impedir las presentaciones necesarias para obtener las autorizaciones regulatorias, como es el caso de los medicamentos, que es consecuencia de la combinación de los derechos de patentes con las leyes que regulan la aprobación de medicamentos. ${ }^{83}$

Uno de los argumentos que expuso el Grupo Especial para considerar que este último modo de explotación era anormal fue que la inmensa mayoría de los productos patentados no tienen reglamentaciones similares a los de los medicamentos, razón por la cual la mayoría de los titulares no recurre a este tipo de explotación. ${ }^{84}$

\footnotetext{
80 Idem.

81 Ibidem, $\$ 7.51$.

82 Ibidem, $\S 7.56$.

83 Ibidem, $§ 7.57$.

84 Idem.
} 
Esta obra forma parte del acervo de la Biblioteca Jurídica Virtual del Instituto de Investigaciones Jurídicas de la UNAM

Según el Grupo Especial, la Unión Europea no había logrado acreditar ni había desarrollado argumentos respecto a los diversos significados de la palabra "normal". No había probado que la mayoría de los titulares de los derechos obtenía el valor de las patentes impidiendo que los competidores fabriquen, vendan o usen productos patentados a fin de obtener la autorización regulatoria para comercializarlos. Tampoco había probado que el ejercicio del ius excluendi en tales circunstancias fuera "normal" en el sentido de ser esencial para la consecución de los objetivos de la política en materia de patentes.

Aplicando estos principios, se puede sostener fundadamente que la excepción de fabricación para la exportación a países donde la invención se encuentra en el dominio público no afecta la "explotación normal" de la patente, porque no detrae ninguna de las ventajas económicas previstas como resultado de la exclusividad en el mercado nacional otorgada por la patente.

En efecto, los derechos exclusivos conferidos por una patente se implementan mediante la explotación de la invención patentada a fin de obtener beneficios comerciales. Ello suele implicar la utilización de la patente por parte del propio titular para fabricar y vender el producto, la cesión a otras personas mediante licencia del derecho a utilizar la invención, o bien, la venta de su derecho de propiedad en la invención y su patente.

La excepción de fabricación para la exportación no impide que el titular de patente conserve el derecho pleno y exclusivo de impedir la explotación económica de la invención patentada en el ámbito espacial o territorio para la que tiene concedida la protección exclusiva, y así obtener de este modo un provecho económico durante el plazo de vigencia de la protección.

\section{B. Interpretación del artículo 30 a la luz de criterios más amplios que los del Grupo Especial Canadá-Genéricos}

Una interpretación más amplia de la segunda condición del artículo 30, conforme a la Declaración sobre Protección Mediante Patente, también confirma la compatibilidad de la excepción de fabricación para la exportación. De acuerdo con la Declaración, una excepción entra en conflicto de forma irrazonable con la explotación normal de la patente si la misma perjudica la eficiencia de la patente como mecanismo de regulación de los precios. Este, según la Declaración, es el caso si la excepción injustificadamente mengua los incentivos a la innovación que provee el mercado. ${ }^{85}$

85 Declaration on Patent Protection..., cit., punto 24, p. 8. 
Esta obra forma parte del acervo de la Biblioteca Jurídica Virtual del Instituto de Investigaciones Jurídicas de la UNAM

La explotación económica de los objetos fabricados bajo la excepción de fabricación para la exportación se produce en mercados extranjeros en los cuales la invención se encuentra en el dominio público. La patente no le permite a su titular ejercer poder de mercado en el extranjero, particularmente para usar la patente como mecanismo regulador de precios. Por lo tanto, el titular de la patente no recibe de mercados extranjeros - donde no está patentada la invención - ningún incentivo para innovar, porque al no tener derecho alguno en él, la invención se encuentra sometida a la competencia, la que en definitiva fijará los precios en esos mercados.

En síntesis, al igual que en la primera condición, tanto la interpretación del Grupo Especial como la de la Declaración patrocinada por el Instituto Max Planck confirman que la excepción de fabricación para la exportación no interfiere de manera injustificable con la explotación normal de las patentes.

3. No causa un perjuicio injustificado a los legítimos intereses del titular de la patente, teniendo en cuenta los intereses legítimos de terceros

La tercera y última condición del artículo 30 del ADPIC es que las excepciones no causen "un perjuicio injustificado a los legítimos intereses del titular de la patente, teniendo en cuenta los intereses legítimos de terceros". La misma también fue interpretada y aplicada por el Grupo Especial Canadá-Genéricos respecto a la excepción Bolar. A fin de facilitar el análisis de este requisito, se tratará por separado la interpretación de los subrequisitos de: 1) "intereses legítimos del titular de la patente"; 2) "perjuicio injustificado", y 3) "intereses legítimos de terceros".

\section{A. Intereses legítimos del titular de la patente}

$\mathrm{Al}$ interpretar el alcance de la condición de no atentar contra los "intereses legítimos del titular de la patente", la Unión Europea afirmó que esta expresión "era equivalente a «intereses jurídicos»". Desde esta perspectiva, los "intereses legítimos" del titular de la patente no podían consistir más que en el pleno disfrute de sus derechos de patente - es decir, los derechos enumerados en el artículo 28 del ADPIC- durante el plazo de vigencia de la patente. ${ }^{86}$

86 Canadá-Genéricos, $\$ 7.62$. 
Esta obra forma parte del acervo de la Biblioteca Jurídica Virtual del Instituto de Investigaciones Jurídicas de la UNAM

Asimismo, la Unión Europea argumentó que la expresión “intereses legítimos de terceros" aplicado al caso comprendía únicamente a los derechos de los competidores del titular de la patente para fabricar, usar o vender el producto patentado al día siguiente a la fecha de expiración de la patente. ${ }^{87}$ Por el contrario, el término "terceros" no comprendería los intereses de otras personas distintos a los de los competidores o de la sociedad en su conjunto.

En consecuencia, según la Unión Europea, la excepción Bolar no cumplía con la tercera condición del artículo 30 porque: 1) afectaba los "intereses legítimos" de los titulares de las patentes al impedir el ejercicio del ius excluendi que otorga el artículo 28.1 del ADPIC; 2) no había ningún "interés legítimo" de los competidores al sopesar la excepción, ya que los derechos para fabricar, usar y vender nacían luego de expirada la patente, y 3) la excepción era lo suficientemente sustancial como para ser calificada de "injustificada". ${ }^{88}$

Un segundo argumento expuesto por la Unión Europea fue que los titulares de las patentes tenían un "interés legítimo" respecto a los beneficios posteriores al plazo de la patente, que obtenían habida cuenta del retraso que entrañaba para los competidores tener que obtener la aprobación reglamentaria. La justificación de ese "interés legítimo" era que tales beneficios compensaban la pérdida que sufría el titular de la patente al no poder beneficiarse de la patente por la prescriptiva realización de ensayos y espera de los resultados del examen reglamentario. Es decir, como había un retraso inicial para entrar en el mercado, debía haber también un periodo posterior a la expiración de la patente para recuperarse de tal retraso. A juicio de la Unión Europea, un plazo compensaba el otro de modo "justificable". ${ }^{89}$

No obstante, la postura de la Unión Europea no fue la que se impuso. El Grupo Especial interpretó que la expresión "legítimos intereses" debe definirse - tanto en relación con el titular de la patente como con los terceros - de la forma en que frecuentemente se utiliza en los textos jurídicos, es decir, como concepto normativo que exige la protección de intereses que son "justificables" en el sentido de que están apoyados por políticas públicas y otras normas sociales pertinentes. ${ }^{90}$

En este contexto interpretativo, el Grupo Especial concluyó, por un lado, que el argumento de la Unión Europea basado solamente en que la

\footnotetext{
87 Idem.

88 Ibidem, $§ 7.64$.

89 Ibidem, $\$ \S 7.74$ y 7.75 .

90 Ibidem, $§ 7.69$.
} 
Esta obra forma parte del acervo de la Biblioteca Jurídica Virtual del Instituto de Investigaciones Jurídicas de la UNAM

excepción afectaba los derechos del titular para impedir la fabricación, uso, oferta para la venta, venta o importación consagrados por el artículo 28.1 del ADPIC, sin referencia a ninguna declaración de interés normativa más particular, no era una alegación de incumplimiento que hubiera de tenerse en cuenta. ${ }^{91}$

Por el otro lado, el Grupo Especial consideró que tampoco los titulares de las patentes tenían un "interés legítimo" respecto a los beneficios posteriores al plazo de la patente, que obtenían habida cuenta del retraso que entrañaba para los competidores tener que obtener aprobación reglamentaria, porque ese argumento no era tan perentorio ni se basaba en una norma de política ampliamente reconocida entre los miembros de la $\mathrm{OMC},{ }^{92}$ por lo que la idea de los "intereses legítimos" del artículo 30 no debía utilizarse para dirimir, por decisión arbitral, una cuestión de política normativa que todavía era evidentemente objeto de un debate político no resuelto". ${ }^{93}$

\section{B. Perjuicio injustificado}

Ante la inexistencia de un "legítimo interés" por parte de los titulares de las patentes - y en la perspectiva cumulativa de la regla de los tres pasos-, el Grupo Especial Canadá-Genéricos no continuó con el análisis del resto de la tercera condición del artículo 30, por considerarlo innecesario. En consecuencia, ese Grupo Especial — ni algún otro que se haya constituido hasta la fecha- no interpretó el alcance y significado de la expresión "perjuicio injustificado" en el contexto del artículo 30.

No obstante, puede ser de utilidad la interpretación de la expresión "perjuicio injustificado" que realizó el Grupo Especial Estados Unidos-Derecho de Autor en el contexto del artículo 13 del ADPIC. Los artículos 13 y 30 del ADPIC regulan el régimen de excepciones en derecho de autor y patentes de invención, respectivamente. Se trata, por así decirlo, de disposiciones hermanas: ambas aplican la regla de los tres pasos, tienen una redacción similar y reconocen su fuente en el artículo 9(b) del Convenio de Berna. ${ }^{94}$

El artículo 13 del ADPIC establece que: "Los miembros circunscribirán las limitaciones o excepciones impuestas a los derechos exclusivos a determinados casos especiales que no atenten contra la explotación normal de la

\footnotetext{
91 Ibidem, $\S 7.73$.

92 Ibidem, $\S 7.77$.

93 Ibidem, § 7.82.

94 Roffe, P. y Spennemann, C., Resource Book..., cit., p. 431.
} 
Esta obra forma parte del acervo de la Biblioteca Jurídica Virtual del Instituto de Investigaciones Jurídicas de la UNAM

obra ni causen un perjuicio injustificado a los intereses legítimos del titular de los derechos" (el resaltado nos pertenece).

Como se observa, la tercera condición del artículo 13 no indica que deben tenerse en cuenta los "intereses legítimos de los terceros", como hace el artículo 30 respecto de las patentes, pero sí contiene la expresión idéntica "perjuicio injustificado". Por tal motivo, aunque no es vinculante la interpretación que realizó el Grupo Especial, además de resolver una excepción de derecho de autor, el precedente puede ser de utilidad con fines hermenéuticos, sin descartarse que en el futuro quizás esta interpretación se extienda mutatis mutandis a la tercera condición del artículo 30.

Según el Grupo Especial, el sentido corriente de la palabra "perjuicio" connota daño, detrimento o lesión. Por su parte, la expresión "no injustificado" supone, a criterio del Grupo Especial, un umbral ligeramente más estricto que "justificado". Este último término significa "proporcionado", "dentro de los límites de la razón, ni mucho menor ni mucho mayor de lo que podía considerarse probable o apropiado", o "de un monto o tamaño justo, promedio o considerable". ${ }^{95}$

El Grupo Especial estimó que la cuestión decisiva era saber cuál era el grado o nivel de "perjuicio" que podía considerarse como "injustificado", en vista de que, con arreglo a la tercera condición, podía considerarse que un cierto "perjuicio" es "no injustificado". Como corolario de ello, para el Grupo Especial el perjuicio de los intereses legítimos de los titulares de derechos llega a un nivel injustificado si una excepción o limitación causa o puede causar una pérdida de ingresos injustificada al titular del derecho de autor. ${ }^{96}$

\section{Teniendo en cuenta los intereses legítimos de terceros}

El Grupo Especial Canadá-Genéricos tampoco tuvo necesidad de embarcase en la tarea de elaborar una técnica para dirimir eventuales conflictos entre los "legítimos intereses del titular de la patente" con los "legítimos intereses de terceros", pues, como ya indicáramos en la sección V.3.A, al no identificarse ningún "interés legítimo" de la Unión Europea afectado por la excepción Bolar, no fue necesario continuar con el análisis de la tercera condición. Sin perjuicio de ello, tanto las expresiones "terceros" como "intereses legítimos" sí fueron interpretadas por el Grupo Especial.

95 US-Copyright, $\S 6.225$.

96 Ibidem, $\$ 6.229$. 
Esta obra forma parte del acervo de la Biblioteca Jurídica Virtual del Instituto de Investigaciones Jurídicas de la UNAM

El Grupo Especial constató que en el contexto del artículo 30, "terceros" son, por definición, partes que no tienen ningún derecho legal a desempeñar las funciones excluidas por los derechos de patente conferidos por el artículo 28 del ADPIC. ${ }^{97}$ Por lo tanto, por "terceros" debe entenderse quienes tienen intereses diferentes al titular de la patente. Esto incluye todos aquellos que tienen algún interés en relación con la disponibilidad, el consumo, el costo o la producción de productos reglamentados que estaban sujetos a protección mediante patente. "Terceros" tiene, por tanto, un sentido amplio, e incluye la sociedad en su conjunto, los consumidores de otros países y los posibles competidores.

Respecto a la expresión "intereses legítimos”, el Grupo Especial interpretó que debe definirse como un concepto normativo que exige la protección de intereses que son "justificables" en el sentido de que están apoyados por políticas públicas y otras normas sociales pertinentes. ${ }^{98}$

Queda entonces por determinar cómo debe realizarse el balance entre los "intereses legítimos" de los titulares de la patente con los intereses legítimos de los terceros. En tal sentido, se ha propuesto la aplicación del principio de proporcionalidad. Es el caso, por ejemplo, de la Declaración patrocinada por el Instituto Max Planck, la que considera que una excepción no perjudica de manera injustificada los intereses legítimos del titular si la misma es proporcional y razonable, ${ }^{99}$ tomándose en cuenta todos los intereses afectados. ${ }^{100}$

El principio de proporcionalidad exige, en la jurisprudencia del Tribunal de Justicia de la Unión Europea, evaluar si la restricción de un derecho cumple con tres requisitos: idoneidad, necesidad y proporcionalidad en sentido estricto. El requisito de idoneidad exige que el medio utilizado se revele apto para conseguir el cumplimiento del objetivo deseado; el requisito de necesidad impone que no haya otro modo efectivo de lograr ese objetivo, y, finalmente, el requisito de proporcionalidad en sentido estricto requiere que la carga impuesta no sea excesiva o desproporcionada comparada con los beneficios. ${ }^{101}$

97 Ibidem, $§ 7.68$.

98 Ibidem, $§ 7.69$.

99 Declaration on Patent Protection..., cit., puntos 25 y 26, pp. 8-9.

100 Senftleben, M., "Towards a Horizontal Standard...", op. cit., p. 151.

101 Respecto al principio de proporcionalidad en el derecho comunitario véase, entre otras, la sentencia del Tribunal de Justicia de la Unión Europea de los casos Internationale Handelsgesellschaft mbH v. Einfuhr- und Vorratsstelle für Getreide und Futtermittel v. Einfuhr- und Vora, caso 11/70 [1970], ECR 1161. 
Esta obra forma parte del acervo de la Biblioteca Jurídica Virtual del Instituto de Investigaciones Jurídicas de la UNAM

En consecuencia, la aplicación del principio de proporcionalidad en el balance de los intereses legítimos de los titulares de las patentes y de los intereses legítimos de terceros requiere: 1) que la excepción sea un medio efectivo para la protección de los intereses legítimos de terceros que forman parte de los objetivos de política pública subyacentes a la excepción; 2) que la excepción sea idónea para lograr el cumplimiento de tales objetivos, y 3) que el perjuicio causado al titular de los derechos no sea excesivo ni desproporcionado comparado con los beneficios que produce la excepción a los terceros.

En este contexto deben considerarse, tal como señala la Declaración patrocinada por el Instituto Max Planck, todos los intereses relevantes, incluyendo los del titular de la patente y posibles licenciatarios; los innovadores, que se apoyan en la invención en un momento posterior, los competidores y otros actores del mercado que necesitan operar bajo condiciones de competencia real; científicos e investigadores que requieren acceso a los hallazgos resultantes de la investigación básica; consumidores que disfrutan de los beneficios del avance tecnológico, así como el público en general en una mejoría social, cultural y de bienestar económico. ${ }^{102}$

\section{El pago de una remuneración equitativa como variable de ajuste de la excepción}

El análisis de la tercera condición del artículo 30 no finaliza aquí. Más allá de la interpretación del texto, parte de la doctrina ha señalado que esa condición puede ser utilizada como una herramienta para realizar un ajuste final en la aplicación de la regla de los tres pasos. ${ }^{103}$

En efecto - si se adopta una interpretación cumulativa de las condiciones del artículo 30-, si una excepción supera la primera condición (la excepción es limitada) y también la segunda (no interfiere con la explotación normal de la patente), pero falla respecto a la tercera condición (porque causa un perjuicio injustificado a los intereses legítimos del titular de la patente teniendo en cuenta los intereses de terceros), entonces el pago de una remuneración equitativa puede servir de variable de ajuste para reequilibrar la excepción. Así, el perjuicio injustificado a los derechos del titular de la patente que causa una excepción puede ser reducido a un nivel razonable mediante el pago de una remuneración equitativa. ${ }^{104}$

\footnotetext{
102 Declaration on Patent Protection..., cit., punto 25, p. 8.

103 Senftleben, M., “Towards a Horizontal Standard...", op. cit., p. 436.

104 Idem.
} 
Esta obra forma parte del acervo de la Biblioteca Jurídica Virtual del Instituto de Investigaciones Jurídicas de la UNAM

Este modo de atenuar o mitigar el "perjuicio injustificado" fue previsto para el artículo 9(2) del Convenio de Berna. Como ya fuera expresado, el artículo 9(2) del Convenio de Berna fue introducido en la Conferencia de Estocolmo de 1967 y consagró por primera vez la regla de los tres pasos. Ese artículo es la fuente de los artículos 13, 17 y 30 del ADPIC. ${ }^{105}$

En el informe sobre los trabajos del Comité Principal (disposiciones sustantivas del Convenio de Berna: artículos 1o. a 20), al explicarse el alcance y sentido del artículo 9(b), se expresa que una excepción puede no causar un perjuicio injustificado a los legítimos intereses del autor a condición de que, conforme a la legislación nacional, una remuneración equitativa sea pagada. ${ }^{106}$ Por lo tanto, un perjuicio injustificado a los intereses legítimos de un autor puede potencialmente ser reducido a un nivel admisible bajo el cristal del artículo 9(2) mediante el pago de una remuneración equitativa. ${ }^{107}$

Este principio puede ser extendido, mutatis mutandis, al artículo 30 del Acuerdo de los ADPIC. ${ }^{108} \mathrm{Si}$ una excepción supera las condiciones de ser "limitada" y de no interferir con la normal explotación de la patente, pero no cumple la tercera condición de no causar un perjuicio injustificado a los intereses legítimos del titular de la patente, teniendo en cuenta los intereses legítimos de terceros, entonces el pago de una remuneración equitativa podría amortiguar el impacto negativo del perjuicio injustificado.

\section{E. Fustificación del cumplimiento del tercer requisito}

En el marco interpretativo desarrollado en las secciones 3.A a 3.D supra, debe determinarse entonces la consistencia de la excepción de fabricación para la exportación con la tercera condición del artículo 30 del ADPIC.

Según el Grupo Especial Canadá-Genéricos, no basta argumentar que se están afectando los derechos de excluir, previstos en el artículo 28.1 del ADPIC, para configurar la afectación de los "legítimos intereses" del titular de la patente. A tal efecto, debería identificarse un interés legítimo tutelado por una norma de política ampliamente reconocida entre los

105 Roffe, P. y Spennemann, C., Resource Book..., cit., p. 431.

106 World Intellectual Property Organization, Records of the Intellectual Property Conference of Stockholm, Ginebra, 1971, vol. II, p. 1146. El Grupo Especial Canadá-Genéricos reconoció que la interpretación del ADPIC puede basarse también en los trabajos preparatorios de los instrumentos internacionales de la propiedad intelectual incorporados en ese Acuerdo.

107 Senftleben, M., “Towards a Horizontal Standard...", op. cit., p. 435.

108 Canadá-Genéricos, $\$ 7.60$. 
Esta obra forma parte del acervo de la Biblioteca Jurídica Virtual del Instituto de Investigaciones Jurídicas de la UNAM

miembros de la OMC, cuya carga de la prueba corresponde a quien invoca su existencia. ${ }^{109}$

En este contexto, no hemos podido identificar ningún interés legítimo afectado por la excepción de fabricación para la exportación y que sea una política ampliamente reconocida por los miembros de la OMC.

Ahora bien, si por hipótesis se asumiera que el Grupo Especial se equivocó al delimitar el contenido de los "legítimos intereses" del titular de la patente y que la expresión intereses legítimos se refiere, en relación con el titular de la patente, a la facultad de ejercer en plenitud el ius excluendi previsto por el artículo 28.1 del ADPIC, ${ }^{110}$ tampoco se observa menoscabo alguno para tales derechos.

Parafraseando la constatación del Grupo Especial Canadá-Genéricos, ${ }^{111}$ la cuestión es si los titulares de las patentes pueden alegar un "interés legítimo" en las ventajas económicas que podría reportarles usar el ius excluendi para impedir la fabricación de productos patentados para su exportación.

En una primera aproximación, podría afirmarse que a cambio de divulgar una invención al público y obtener la concesión de una patente, el titular de la patente tiene un "interés legítimo" en la explotación y ejercicio durante el plazo de vigencia de la protección del derecho exclusivo a "aprovechar" la patente como "monopolista" y obtener los beneficios económicos que recompensaban la actividad y las inversiones relacionadas con la invención.

Sin embargo, la excepción para la exportación a países en los que no existe protección no perjudica ningún "interés legítimo" del titular de la patente, simplemente en lo que respecta al derecho de explotación de la patente con respecto a un mercado para el cual no existe exclusividad.

En efecto, al no menoscabarse el derecho del titular de la patente a entablar, en cualquier momento del plazo de vigencia de la protección, un procedimiento por infracción para impedir a otros la venta comercial de la invención patentada en el país donde ha sido concedida la protección, no perjudica los intereses legítimos del titular de la patente en lo que respecta a la prohibición de la explotación comercial durante el plazo de vigencia de la protección.

109 El contexto para interpretar el ADPIC no se limita a su texto, preámbulo y anexos, sino también a las disposiciones de instrumentos internacionales incorporados al ADPIC. Véase el caso Canadá-Genéricos, §§ 7.14 y 7.15. El artículo 9(b) del Convenio de Berna se encuentra incorporado por referencia en virtud de lo dispuesto por el artículo 2.1.

110 Véase, por ejemplo, Senftleben, M., "Towards a Horizontal Standard...”, op. cit., p. 437.

111 Canadá-Genéricos, § 7.61. 
Esta obra forma parte del acervo de la Biblioteca Jurídica Virtual del Instituto de Investigaciones Jurídicas de la UNAM

El análisis del cumplimiento de la tercera condición podría detenerse aquí, ya que al no estar afectado ningún interés legítimo del titular de la patente, entonces se cumpliría la condición. No obstante, a efectos de confirmar la adecuación de la excepción al tercer requisito, se analizará si se causa un "perjuicio injustificado", teniendo en cuenta los intereses legítimos de terceros.

Recordemos que el Grupo Especial Canadá-Genéricos no estableció ningún criterio respecto a la interpretación de "perjuicio irrazonable", razón por la cual se puede acudir, mutatis mutandis, al desarrollo del Grupo Especial Estados Unidos-Derecho de Autor. Según este Grupo Especial, la cuestión decisiva es saber cuál es el grado o nivel de "perjuicio" que puede considerarse como "injustificado", en vista de que, con arreglo a la tercera condición, podría considerarse que un cierto "perjuicio" es "no injustificado".

De tal forma, para el Grupo Especial Estados Unidos-Derecho de Autor, ${ }^{112}$ el perjuicio a los intereses legítimos de los titulares de derechos de propiedad intelectual llegaría a un nivel injustificado si una excepción o limitación causa o puede causar una pérdida de ingresos injustificada a esos titulares.

La excepción de fabricación para la exportación no causa ninguna pérdida de ingresos al titular de la patente. En efecto, el titular de una patente no puede esperar o tener garantizado ningún ingreso en un mercado extranjero donde la invención no está patentada. Ello por aplicación del principio de territorialidad de las patentes. La causa de la pérdida de eventuales ingresos del exterior no será consecuencia de la excepción de la fabricación para la exportación, sino que la causa es que la invención patentada se encuentra en el dominio público en el país de exportación y, por tanto, sujeta a las reglas de la competencia económica. La pérdida de ingresos del titular de la patente podría ser causada tanto por la comercialización de productos fabricados en el país de exportación como por la importación desde otros países distintos.

Por último, aun cuando se identificaran "intereses legítimos" de los titulares de los derechos amparados por una política ampliamente reconocida por los miembros de la OMC, y que estos "intereses legítimos" fueran afectados por la excepción de modo de causar o poder causar una pérdida de ingresos injustificada a esos titulares, todavía deben balancearse esos intereses con los intereses legítimos de terceros.

Como señalara Canadá en sus alegaciones ante el Grupo Especial Canadá-Genéricos, la estructura del ADPIC responde al propósito de conseguir un equilibrio entre intereses contrapuestos y garantizar que la reivindicación

112 Véase sección V.3.B, supra. 
Esta obra forma parte del acervo de la Biblioteca Jurídica Virtual del Instituto de Investigaciones Jurídicas de la UNAM

de los derechos de patente no impida el logro de otros objetivos sociales. Como declara el primer párrafo del preámbulo y en los objetivos recogidos en el artículo 7o., el ADPIC no pretende promover los derechos de patente a expensas del comercio legítimo, el bienestar social y económico y los derechos de terceros. Es en este contexto que, con el objetivo de lograr el equilibrio buscado con la referencia a "terceros" del artículo 30, se reconocen los intereses de estos últimos.

Los "intereses legítimos" de terceros subyacen también en los principios consagrados por el artículo 8o. del ADPIC, en la medida que faculta a los miembros, al implementar las obligaciones dimanantes del Acuerdo, a adoptar las medidas necesarias para proteger la salud pública y la nutrición de la población, o para promover el interés público en sectores de importancia vital para su desarrollo socioeconómico y tecnológico.

Identificados estos "intereses legítimos" de terceros que están soportados por normas de política ampliamente reconocidas por los miembros de la $\mathrm{OMC}$, debe resolverse entonces, aplicando el principio de proporcionalidad, si la excepción de fabricación para la exportación causa un perjuicio injustificado a los intereses legítimos de los titulares de las patentes, teniendo en cuenta los intereses legítimos de los terceros.

Aplicando los principios desarrollados en la sección V.3.C supra, sobre el principio de proporcionalidad respecto a la excepción de fabricación para la exportación, se concluye que la excepción cumple con la tercera condición del artículo 30 del ADPIG porque:

1) La excepción es un medio efectivo para la protección de los intereses legítimos de desarrollo económico, social y tecnológico de los competidores de los titulares de las patentes y de la sociedad en su conjunto.

2) La excepción es idónea para lograr el cumplimiento de tales objetivos, pues posibilita el desarrollo de inversiones, la investigación científico-tecnológica, la creación de puestos de trabajo, la concreción de exportaciones, etcétera, objetivos que, en ausencia de la excepción, los competidores ni siquiera podrían intentar satisfacer.

3) No se causa un perjuicio al titular de las patentes, ya que éste no tiene derecho alguno en el mercado de exportación y, por el contrario, los beneficios en términos económicos y de desarrollo que produce la excepción a favor de los competidores-exportadores termina por inclinar el test de proporcionalidad a favor de la excepción.

Finalmente, aun cuando se verificara el incumplimiento de la tercera condición, siempre quedará disponible el recurso de establecer que el uso de la excepción estará sujeta al pago de una remuneración equitativa, lo que 
Esta obra forma parte del acervo de la Biblioteca Jurídica Virtual del Instituto de Investigaciones Jurídicas de la UNAM

reequilibraría favorablemente la excepción al disminuir el perjuicio irrazonable sufrido por el titular de la patente.

\section{CONCLUSIONES}

El derecho de patentes reconoce que en ciertas circunstancias es preciso el uso de excepciones para satisfacer objetivos de política pública, entre otros, el fomento de la innovación, el desarrollo industrial o la competencia, así como para proteger bienes jurídicos de primer orden, como la salud o la educación. Se trata de excepciones que se encuentran en todas las legislaciones nacionales y sobre las cuales existe una gran diversidad.

Las excepciones tienen como nexo común el hecho de que los usos previstos en las mismas eximen al autor de responsabilidad por infracción de patente, por más que los actos llevados a cabo caigan dentro del ius prohibendi del titular. Existe un estado de opinión, identificable tanto en foros multilaterales como en la academia, favorable a la expansión del uso de excepciones para responder a nuevas situaciones.

El artículo 30 del ADPIC regula las condiciones bajo las cuales los miembros de la OMC pueden legislar sobre excepciones en los derechos nacionales. A tal efecto, establece tres condiciones o regla de los tres pasos: 1) las excepciones deben ser limitadas; 2) no deben atentar de manera injustificable contra la explotación normal de la patente, y 3) no pueden causar un perjuicio injustificado a los legítimos intereses del titular de la patente, teniendo en cuenta los intereses de terceros

El artículo 30 del ADPIC refleja el consenso internacional respecto de que: a) las excepciones son abiertas y no están sujetas a numerus clausus; b) establece las condiciones generales que deben cumplir las excepciones; c) las condiciones establecidas en dicho artículo se interpretan de acuerdo con el derecho nacional; d) las excepciones pueden perseguir fines económico, y e) puede existir conflicto entre la explotación de la patente y las excepciones, habida cuenta de los intereses de terceros. No existe consenso, sin embargo, con respecto a si las condiciones mencionadas son cumulativas.

Debe subrayarse que no existe en el plano internacional ninguna interpretación que siente de manera concreta y coercitiva el significado de los requisitos del artículo 30. Existe, no obstante, una muy limitada experiencia cuasi-jurisprudencial en el seno de la OMC, y existe también una fuerte corriente doctrinal expresada en la Declaración sobre Protección Mediante Patente patrocinada por el Instituto Max Planck y en los trabajos del Comité de Derecho de Patentes de la OMPI. 
Esta obra forma parte del acervo de la Biblioteca Jurídica Virtual del Instituto de Investigaciones Jurídicas de la UNAM

Si bien representa en ciertos aspectos polos opuestos, en tanto en cuanto el Grupo Especial Canadá-Genéricos adoptó una interpretación restrictiva de las excepciones mientras la mencionada corriente doctrinal es favorable a una postura más abierta y expansiva, la excepción de fabricación para la exportación encuentra acomodo tanto en el primero como en el segundo contexto interpretativo del artículo 30 del ADPIC.

La excepción de fabricación para la exportación es una excepción que cumple con las tres condiciones que impone el artículo 30 del ADPIC. Es una excepción limitada, no afecta la normal explotación de la patente por parte de su titular y tampoco causa un perjuicio injustificado a los legítimos intereses del titular de la patente, teniendo en cuenta los intereses legítimos de terceros.

La excepción de fabricación para la exportación es "limitada" porque no restringe totalmente el ius excluendi del titular de la patente, sino mínimamente respecto a aquellos objetos fabricados para la exportación. El titular conserva intacto todo el poder de excluir cualquier acto relacionado con la comercialización en el mercado interno. Este derecho a excluir puede ser ejercido hasta el último día de vigencia de la patente y, aún más, se preservan las ventajas comerciales que, eventualmente, puede obtener el titular durante el tiempo posterior a la expiración de la patente y hasta la entrada de un competidor en el mercado, impidiendo la reimportación en el país de exportación.

Por otra parte, la excepción también es limitada porque, por definición, tiene una restricción en el volumen de producción. Cualquier fabricación que exceda las necesidades de exportación infringiría los derechos del titular, de ahí que no afecta el volumen de productos que el titular de la patente puede destinar al mercado nacional. Asimismo, la excepción tiene una clara limitación respecto a los mercados a los cuales se destina la producción, ya que sólo puede abastecer mercados extranjeros.

La excepción de fabricación para la exportación no afecta la "explotación normal" de la patente porque no detrae ninguna de las ventajas económicas previstas como resultado de la exclusividad en el mercado donde está concedida la patente. La excepción no le impide al titular conservar el derecho pleno y exclusivo de impedir la explotación económica de la invención patentada en el ámbito espacial o territorio para la que tiene concedida la protección, y así obtener de este modo un provecho económico durante el plazo de vigencia de la protección.

A igual conclusión se llega aplicando los principios de la Declaración sobre Protección Mediante Patente auspiciada por el Instituto Max Planck, 
Esta obra forma parte del acervo de la Biblioteca Jurídica Virtual del Instituto de Investigaciones Jurídicas de la UNAM

ya que la excepción no perjudica la "explotación normal" de la patente porque no afecta la eficiencia de la patente como mecanismo de regulación del precio en el mercado.

La excepción también cumple con la tercera condición de no causar "un perjuicio injustificado a los legítimos intereses del titular de la patente, teniendo en cuenta los intereses legítimos de terceros". No se ha podido identificar ningún interés legítimo - distinto a los derechos conferidos por el artículo 28.1 del ADPIC - que constituya una norma de política ampliamente reconocida por los miembros de la OMG y que esté afectado por la excepción.

Si por hipótesis se asumiera que la expresión intereses legítimos se refiere a la facultad de ejercer en plenitud el ius excluendi, tampoco se observa menoscabo alguno a tales derechos. En efecto, los titulares de las patentes no pueden alegar un "interés legítimo" en las ventajas económicas que podría reportarles usar el ius excluendi para impedir la fabricación de productos patentados para su exportación porque respecto de los mercados extranjeros no poseen ninguna exclusividad.

Asimismo, aun cuando existieran "intereses legítimos" de los titulares afectados por la excepción, ésta no causa ni puede causar una pérdida de ingresos injustificada. El titular de la patente no puede esperar o tener garantizado ningún ingreso en un mercado extranjero. El perjuicio causado por la pérdida de eventuales ingresos del exterior no será consecuencia de la excepción de fabricación para la exportación, sino que será del hecho de que la invención patentada en el país de fabricación no se encuentra protegida en el país de exportación y por tanto está sujeta a las reglas de la competencia económica.

Aun cuando la excepción cause un perjuicio injustificado a los intereses legítimos de los titulares de las patentes, la balanza se inclina - por aplicación del principio de proporcionalidad - a favor de los intereses legítimos de los terceros beneficiados por la excepción. Estos intereses legítimos son, entre otros, los intereses nacionales en términos de desarrollo industrial, balanza comercial y empleo, lo que remite al bienestar social, a la consecución de un equilibrio entre derechos y obligaciones, y al desarrollo socioeconómico, objetivos reconocidos por los artículos 7o. y 8o. del ADPIC y por otras normas de política de los miembros de la OMC.

Finalmente, queda la posibilidad de interpretar el artículo 30 del ADPIC en una forma más liberal, como lo hace la Declaración patrocinada por el Instituto Max Planck. Bajo esta mirada, los tres requisitos no son cumulativos. Por el contrario, el análisis de la satisfacción del artículo 30 requiere 
una aproximación global a la medida, distinta al examen excluyente e independiente de cada uno de los requisitos, como el realizado en los párrafos precedentes.

Desde esta perspectiva, cualquier duda que pudiera suscitarse al interpretar la excepción de fabricación para la exportación de acuerdo con los criterios sentados por el Grupo Especial Canadá-Genéricos queda disipada. 
Esta obra forma parte del acervo de la Biblioteca Jurídica Virtual del Instituto de Investigaciones Jurídicas de la UNAM

\title{
PREGUNTAS RELATIVAS A LA ASOCIACIÓN TRANSATLÁNTICA DE COMERGIO E INVERSIÓN Y EL ACGESO A MEDICAMENTOS
}

\author{
Holger P. HESTERMEYER*
}

\begin{abstract}
Sumario: I. Alcance de este trabajo. II. Estatus de la ATCI. III. El contenido de la ATCI. IV. Cooperación reglamentaria. V. Propiedad intelectual (incluyendo datos de análisis y transparencia). VI. Resolución de controversias entre inversionistas y Estados (ISDS). VII. Impacto en países en desarrollo. VIII. Recomendación.
\end{abstract}

\section{AlGance DE ESTE Trabajo}

El mundo del derecho del comercio internacional está cambiando rápidamente. Empezó, ahora, el tiempo de los tratados "mega-regionales": el Acuerdo Transpacífico de Cooperación Económica (TPP) entre doce países de la región Asia-Pacífico, incluyendo Chile, Canadá, Estados Unidos (EEUU), México y Japón, se selló en 2015. Un acuerdo por un mercado aún más grande está en el proceso de negociaciones: la Asociación Transatlántica de Comercio e Inversión (ATCI) entre la Unión Europea (UE) y EEUU. El impacto de estos tratados sobre el derecho nacional de las partes es enorme y no queda de ninguna manera limitado a preguntas tarifarias. ATCI, por ejemplo, tendría 24 capítulos con normativas, por ejemplo, sobre comercio de bienes, servicios, normas de origen, contratación pública, coherencia reguladora, seguridad alimentaria, propiedad intelectual e inversiones.

\footnotetext{
* Shell Reader in International Dispute Resolution, King's College, London, holger.hes termeyer@kcl.ac.uk. El texto está basado en un reporte informal escrito por una ONG. Las opiniones expresadas son de exclusiva responsabilidad del autor. El presente trabajo fue escrito en abril de 2015 y solamente se actualizó con respecto al acuerdo TPP. No se analiza a detalle la nueva propuesta de la UE en materia de derecho de inversiones. El autor agradece la traducción a Roberto Martínez.
} 
Esta obra forma parte del acervo de la Biblioteca Jurídica Virtual del Instituto de Investigaciones Jurídicas de la UNAM

El cabildeo tiene un gran impacto en los tratados de libre comercio y algunos grupos industriales - como el sector farmacéutico, tradicionalmente llamado "innovador" - tienen una importante experiencia en este trabajo de cabildeo. El alcance de las negociaciones de la ATCI implica que las normativas negociadas en el acuerdo serán de interés para muchos sectores de la sociedad. Si sólo las industrias tradicionalmente involucradas en el cabildeo para los tratados de libre comercio tienen un impacto sobre las negociaciones, el resultado será un acuerdo sin equilibrio, que omita los intereses de los consumidores y la industria genérica. En un acuerdo de la importancia de la ATCI, todas las entidades interesadas deben asegurar que sus intereses se estén tomando en cuenta en las negociaciones. De hecho, se podría decir que una amplia presión por parte de todas las entidades interesadas sería deseable para lograr un desenlace equilibrado de la negociación.

$\mathrm{El}$ presente trabajo intenta responder varias preguntas que surgen con respecto a la ATCI y su probable impacto en el derecho de la propiedad intelectual, el acceso a medicamentos y los precios de los medicamentos para la comunidad interesada en este tema, pero tradicionalmente poco representada en las negociaciones, con la esperanza de motivar a esta comunidad a insistir en que su voz sea representada. Responder a estas preguntas plantea un problema conceptual: las negociaciones de la ATCI no están aún terminadas. No existe entonces el texto definitivo del tratado - y tampoco un texto preliminar publicado de la parte del acuerdo sobre propiedad intelectual, que sea de interés particular para esta temática- Pero ello no significa que este informe se publique prematuramente. La comunidad tiene que actuar ahora para proteger sus intereses, para argumentar a favor o en contra de lo que podría ser el contenido del tratado. Esperar hasta que el tratado esté concluso no es una opción viable: ningunos cambios serán posibles en ese momento. Entonces, hay que actuar y hacer valer sus argumentos ahora.

El presente trabajo iniciará con una explicación del estatus de la ATCI (II) y su contenido (III), mencionando en particular, aunque brevemente, la cooperación regulatoria (IV). Posteriormente abordará, a su vez, los temas de la propiedad intelectual (incluyendo exclusividad de datos de análisis y datos de estudios clínicos y transparencia) (V), la fijación de precios de medicamentos (VI), la resolución de controversias entre inversionistas y Estados (ISDS - Investor-State Dispute Settlement-, por sus siglas en inglés) (VII), y el impacto de ATCI en los países en desarrollo (VIII). El reporte estará redactado como un reporte informal; es decir, tiene como objetivo resaltar varias áreas de interés particular, más que explicar todos los posibles impactos relevantes de ATCI. 
Esta obra forma parte del acervo de la Biblioteca Jurídica Virtual del Instituto de Investigaciones Jurídicas de la UNAM

\section{ESTATUS DE LA ATCI}

Siempre y cuando la ATCI entre en efecto, toda la legislación de EEUU, la UE y los Estados miembros de la UE tendrá que cumplir con la normativa de este tratado. En los casos en que una ley no cumpla con el tratado, ésta se tendrá que modificar.

\section{Explicación}

Un convenio internacional que entra en vigor se torna vinculante para las partes. Desde el punto de vista de la UE, la ATCI constituye un "acuerdo mixto", ${ }^{1}$ un convenio en el que tanto la UE como los Estados miembros de la UE serán partes, ya que la ATGI abarca áreas de la competencia de los Estados miembros y competencia de la UE. ${ }^{2}$ Entonces la ATGI será vinculante para EEUU, la UE y sus Estados miembros.

El hecho de que el convenio sea vinculante significa que todas las partes están obligadas a cumplir con él. La forma en la que se logre este cumplimiento depende de la legislación nacional de la parte del convenio. En algunos países, los tratados se aplican como ley nacional ("sistemas monistas"); otros permiten la aplicación de tratados en el sistema interno sólo después de que el tratado ha sido implementado en la legislación nacional mediante la aprobación de una ley por el Parlamento nacional ("sistemas dualistas"). Algunos países aplicarán ciertas disposiciones de un tratado sin que se requiera la implementación, si éstas son suficientemente claras y no requieren medidas de implementación ("efecto directo"). ${ }^{3}$

Dentro del sistema de la UE, no es probable que la ATCI tenga un efecto directo, ${ }^{4}$ es decir, la UE tendrá que modificar su legislación para cumplir

1 Sobre los acuerdos mixtos véase Hillion, C. y Koutrakos, P., Mixed Agreements Revisited, Hart, 2010; EGJ, Opinión 1/94, WTO.

2 La UE tiene amplias competencias en el área de política comercial. El artículo 207 TFUE permite a la Unión negociar convenios con respecto a aranceles, comercio en bienes y servicios, aspectos comerciales de la propiedad intelectual, inversiones extranjeras directas, la uniformización de las medidas de liberalización, la política de exportación y medidas de protección comercial. Los problemas involucrados en las nuevas competencias más amplias después del Tratado de Lisboa son ilustrados por ECJ, Case C-414/11, Daïchi.

3 Véase, por ejemplo, Jennings, R. y Watts, A., Oppenheim's International Law, 9a. ed., OUP, 1996, pp. 52 y ss.

4 Es probable que los nuevos tratados de libre comercio de la UE estipulen explícitamente la falta de aplicabilidad directa (véase el artículo 14.16 CETA). Con respecto al GATT/WTO, fue la jurisprudencia que desarrolló esta norma: ECJ, Joined Cases 21-24/72, 
Esta obra forma parte del acervo de la Biblioteca Jurídica Virtual del Instituto de Investigaciones Jurídicas de la UNAM www.juridicas.unam.mx

con la ATCI. Lo mismo vale para los EEUU. De ahí que en ninguno de los países el tratado automáticamente, y sin nada más, sustituirá las leyes nacionales anteriores. Sin embargo, todas las partes de la ATCI tendrán la obligación de cumplir con el tratado y modificar sus leyes nacionales si éstas no están en conformidad. Si no lo hacen, será en violación del tratado.

\section{EL CONTENIDO DE LA ATCI}

Conforme a la información publicada por la UE, la ATCI comprendería 24 capítulos, agrupados en tres partes. La UE intenta negociar el acuerdo de la manera más abierta posible y publicó fichas informativas sobre aspectos del tratado, por ejemplo, sobre productos farmacéuticos, inversiones, derechos de propiedad intelectual e indicaciones geográficas, así como documentos de posición de la UE sobre derechos de propiedad intelectual, productos farmacéuticos y, en algunos (pocos) casos, propuestas de redacción, como, por ejemplo, sobre cooperación reglamentaria e inversiones. Sin embargo, se desconoce el contenido exacto del ATGI. Este trabajo se basará en tratados de libre comercio estadounidenses anteriores y el anteproyecto de ley sobre la Autoridad de Promoción Comercial de los EEUU, así como las declaraciones de PhRMA para identificar posibles propuestas y demandas por los EEUU, las cuales tradicionalmente exigen un estándar de protección de la propiedad intelectual más alto.

\section{Explicación}

No conocemos el contenido exacto de la ATCI. Las negociaciones comerciales nunca han sido totalmente transparentes y es difícil ver cómo se podría lograr una transparencia completa, dada la dificultad de negociar con éxito y lograr obtener concesiones de la contraparte si la posición de negociación es pública. ${ }^{5}$ La negociación de la ATCI es particularmente compleja y difícil por dos consideraciones: primero, la ATCI establecerá normas para la UE y los EEUU y, por consiguiente, constituye el acuerdo comercial

International Fruit Company, y EGJ, Case C-149/96, Portugal v. Council. Sin embargo, su alcance no siempre fue claro, la norma no fue aplicada a la Cuarta Convención de Lomé: EGJ, Case C-469/13, Amministrazione delle Finanze dello Stato v. Chiquite Italia SpA, para. 35.

5 Cartas tanto por USTR como por la UE sobre normas que protegen los documentos de negociación se han puesto a la disposición del público en: http://keionline.org/node/2021, y http://keionline.org/node/2033. 
Esta obra forma parte del acervo de la Biblioteca Jurídica Virtual del Instituto de Investigaciones Jurídicas de la UNAM

más grande que se haya celebrado. Segundo, más allá de las particularidades de los enormes mercados de los EEUU y la UE, los negociadores desean que la ATCI constituya un "estándar de oro": debido al tamaño de los mercados de la UE y los EEUU combinados, es probable que la ATCI establezca estándares que serán copiados en otros convenios. ${ }^{6}$

Aunque no conocemos el texto del acuerdo o de las propuestas que se hacen, varias fuentes nos permiten imaginarnos cómo se vería un posible convenio y lo que cada parte considerará importante en las negociaciones. En primer lugar, la $\mathrm{UE}^{7}$ ha publicado una variedad de documentos relativos al ATCI, como el mandato de negociación de la UE, fichas informativas, documentos de posición y, en algunos casos, propuestas de redacción. ${ }^{8}$ Con respecto a las posibles demandas de los EEUU, dos fuentes son particularmente importantes. Antes que todo, el gobierno de los EEUU negocia tradicionalmente los tratados de libre comercio (sujetos a aprobación por el Congreso) bajo una autoridad particular otorgada a él por el Congreso. Esta autoridad, ahora denominada "Autoridad de Promoción Comercial", define también los objetivos de negociación de los EEUU. ${ }^{9}$ La Autoridad de Promoción Comercial del presidente venció en 2007, pero la nueva autoridad fue propuesta en la Ley de Prioridades Comerciales Bipartidistas del Congreso de 2014. ${ }^{10}$

Otra fuente importante son los tratados de libre comercio anteriormente negociados por los EEUU, ya que éstos indican la forma legal concreta que podrán adoptar las propuestas estadounidenses. Entre ellos se destaca el Acuerdo Transpacífico de Cooperación Económica (TPP), que aún no entra en vigor pero que se selló en octubre de 2015 entre doce países, incluyendo Australia, Canadá, Chile, EEUU, Japón, México y Vietnam, negociado recientemente y el cual puede ayudar a hacer una estimación bien fundada acerca de posibles demandas. El texto del Acuerdo se publicó hace poco, ${ }^{11}$

6 El argumento del "estándar de oro" se cita periódicamente con respecto a InvestorState Dispute Settlement (ISDS): si no hay ISDS en el ATCI, se señala, será difícil de incluir en un convenio con China.

7 Consejo de la UE, Doc. $11103 / 13$ del 9 de octubre de 2014, disponible en: http://data. consilium.europa.eu/doc/document/ST-11103-2013-DCL-1/en/pdf.

8 Véanse http://ec.europa.eu/trade/policy/in-focus/ATCI/documents-and-events/y http://trade. ec.europa.eu/doclib/press/index.cfm. id $=1230$.

9 Véase https://ustr.gov/trade-topics/trade-promotion-authority.

10 Fergusson, Trade Promotion Authority and the Role of Congress in Trade Policy, Congressional Research Service 2015.

11 Véase https://medium.com/the-trans-pacific-partnership. 
Esta obra forma parte del acervo de la Biblioteca Jurídica Virtual del Instituto de Investigaciones Jurídicas de la UNAM

pero ya antes se había divulgado vía Wikileaks un capítulo (preliminar) sobre propiedad intelectual de este convenio. ${ }^{12}$

Finalmente, cabe resaltar que la falta de transparencia de las negociaciones comerciales incrementa las posibilidades de cabildeo. La industria farmacéutica ha desempeñado tradicionalmente un papel importante en el cabildeo de los tratados de libre comercio. ${ }^{13}$ El testimonio ante el House Energy \& Commerce Subcommittee on Commerce, Manufacturing \& Trade de la Cámara de Representantes de los EEUU, en una audiencia en 2013, provisto por el presidente y director general de Investigación y Productores Farmacéuticos de América (PhRMA, por sus siglas en inglés) permite tener detalles de la "lista de deseos" de PhRMA con respecto a la ATCI. ${ }^{14}$

\section{COOPERAGiÓn REgLAMENTARIA}

La ATCI pone énfasis particular en la cooperación y coherencia reglamentaria. Parece que hay común acuerdo en que se puede lograr un acercamiento de los respectivos requisitos para productos no relacionados con el nivel de protección, por ejemplo, del medio ambiente y la salud, así como para reducir los trámites burocráticos a través de la colaboración estrecha de reguladores estadounidenses y europeos. Los ejemplos en el campo de la medicina incluyen la introducción de identificadores únicos para dispositivos médicos; el reconocimiento de las buenas prácticas de fabricación para evitar la duplicación de trabajo, como las inspecciones de plantas de fabricación; permitir el intercambio de información confidencial para respaldar la evaluación conjunta de nuevos medicamentos; la armonización de requerimientos para aprobar los biosimilares; la agilización de sistemas para autorizar los medicamentos genéricos; la actualización de lineamientos internacionales sobre el análisis de medicamentos. ${ }^{15}$ Sin embargo, aquí, como en muchos otros campos, el problema está en el detalle: permitir el intercambio de información confidencial para respaldar la evaluación de nuevos medicamentos sería solamente posible propiciando la protección de la confidencialidad de la

12 Véase https://wikileaks.org/tpp-ip2/tpp-ip2-chapter.pdf.

13 Sell, S., Private Power, Public Law, CUP, 2003.

14 Disponible en: http://docs.house.gov/meetings/IF/IF17/20130724/101197/HHRG-113IF17-Wstate-Castellanif-20130724.pdf. Una respuesta de PhRMA a una solicitud por comentarios con respecto a ATCI puede verse en: http://wrew.plos.org/wp-content/uploads/2014/05/ PhRMA_Comentarios_to_USTR_on_ATCI.pdf, pero no puede verificarse su veracidad.

15 Véase http://trade.ec.europa.eu/doclib/docs/2015/february/tradoc_153121.pdf. 
Esta obra forma parte del acervo de la Biblioteca Jurídica Virtual del Instituto de Investigaciones Jurídicas de la UNAM

información relacionada. Esto podría oponerse a los principios de la transparencia de datos de estudios, como fueron desarrollados en la UE. ${ }^{16}$

\section{PROPIEDAD INTELECTUAL (INCLUYENDO \\ DATOS DE ANÁLISIS Y TRANSPARENCIA)}

Tradicionalmente, los tratados de libre comercio pos-OMC han propiciado la protección de los derechos de propiedad intelectual que van más allá del estándar en el Acuerdo sobre los Aspectos de los Derechos de Propiedad Intelectual relacionados con el Comercio (ADPIC o TRIPS, por sus siglas en inglés), un convenio sobre las normas de propiedad intelectual que es parte de los convenios de la OMC. Esta protección más fuerte de la propiedad intelectual se denomina a menudo "TRIPS-plus". EEUU, entre otros, ha incrementado el nivel de protección de patentes en sus tratados de libre comercio y exigido normas más fuertes de protección de datos de pruebas, explícitamente con el objetivo de lograr estándares de protección similares a aquellos que se encuentran en la legislación de EEUU. La UE está consciente de los problemas que esto implica, pero la participación de las entidades interesadas es esencial para resaltar las consecuencias negativas de cada propuesta a tiempo.

\section{Explicación}

La protección de la propiedad intelectual (IP, por sus siglas en inglés) se ha incluido en los tratados de libre comercio desde la negociación del Acuerdo ADPIC en el contexto de la OMC. Ese convenio se concibe explícitamente para establecer estándares "mínimos". Los miembros de la OMG pueden estipular una mayor protección de la propiedad intelectual que aquella prevista en el Acuerdo ADPIC (denominado "TRIPS-plus"), pero nunca quedarse por debajo de los estándares en ADPIC. ${ }^{17}$ Los países han aprovechado ampliamente la posibilidad para negociar estándares TRIPS-plus en los tratados de libre comercio: la tendencia general consiste

16 Maier-Rigaud, R., Between Transparency and Secrecy: How Does TTIP Impact the Publication Policy of Clinical Studies in the Pharmaceuticals Field, WISO Direkt, enero de 2015, disponible en: http://library:fes.de/pdf-files/wiso/11151.pdf.

17 Artículo 1(1) ADPIC. Para explicaciones minuciosas del Acuerdo ADPIC véase Correa, C., Trade Related Aspects of Intellectual Property Rights: A Commentary on the TRIPS Agreement, OUP, 2007; Stoll, P-T. et al., WTO: Trade-Related Aspects of Intellectual Property Rights, BRILL, 2009 . 
Esta obra forma parte del acervo de la Biblioteca Jurídica Virtual del Instituto de Investigaciones Jurídicas de la UNAM www.juridicas.unam.mx

en establecer estándares cada vez más altos de protección de la propiedad intelectual en los tratados de libre comercio. ${ }^{18}$ Los objetivos de negociación de los EEUU respecto a la propiedad intelectual se pueden encontrar en la Ley de Prioridades Comerciales Bipartidistas del Congreso de 2014. ${ }^{19}$ Esa autoridad afirma explícitamente que uno de los objetivos de negociación de los EEUU es asegurar "que las disposiciones de cualquier tratado de libre comercio sobre los derechos de propiedad intelectual celebrado por Estados Unidos refleje un estándar de protección similar a aquel que se halla en la legislación de Estados Unidos". ${ }^{20}$ Estándares de propiedad intelectual más altos son de importancia considerable para los productos farmacéuticos en varios aspectos, algunos de los cuales se mencionarán a continuación.

\section{Patentes}

Muchos productos farmacéuticos importantes ya no están protegidos por patentes. ${ }^{21}$ Sin embargo, varios productos farmacéuticos nuevos se encuentran bajo el amparo de patentes. Las patentes confieren a sus titulares la autoridad legal para "impedir que terceros, sin su consentimiento, realicen actos de: fabricación, uso, oferta para la venta, venta o importación para estos fines del producto objeto de la patente"..22 Por lo tanto, los titulares de las patentes pueden cobrar precios más elevados, lo cual es parte de la misma justificación de las patentes: sus titulares deben ser capaces de recuperar su inversión en la innovación. ${ }^{23}$

A pesar de que ADPIC establece reglas estrictas para las leyes de patentes nacionales de los miembros de la OMC, sí deja un "espacio de maniobra"

18 Véase, también, Grosse Ruse-Kahn, H. et al., "Principles for IP Provisions in Bilateral and Regional Agreements", 44 IIC, 2013, pp. 873 y ss.; Ho, C., Access to Medicine in the Global Economy, OUP, 2011; Musungu, S. F. y Dutfield, G., Multilateral Agreements and a TRIPS-Plus World, QUNO, 2003.

19 Fergusson, Trade Promotion Authority and the Role of Congress in Trade Policy, cit.

20 Sección 2 (b)(5)(A)(i)(II) de la Ley de Prioridades Comerciales Bipartidistas del Congreso de 2014 (no vigente).

21 Véanse, en este contexto, las Listas Modelo de la OMS de Medicamentos Esenciales (la actualización más reciente es la 18a. ed. - de abril de 2013 - para adultos y la 4a. ed. — de abril de 2013 - para niños, ambas revisadas en octubre de 2013). Muchos de estos medicamentos no se encuentran patentados. Véase Attaran, A., "How Do Patents and Economic Policies Affect Access to Essential Medicines in Developing Countries", 23 Health Aff, 2004, pp. 155 y ss.

22 En el caso de una patente de producto. Artículo 28 (1)(a) ADPCI (se omitieron las notas al pie internas).

23 Sobre este tema véase Hestermeyer, H., Human Rights and the WTO, OUP, 2007. 
Esta obra forma parte del acervo de la Biblioteca Jurídica Virtual del Instituto de Investigaciones Jurídicas de la UNAM

en algunos aspectos. Este espacio de maniobra se ha reducido significativamente en varios tratados de libre comercio, y PhRMA cabildea para una reducción todavía más significativa del espacio de maniobra en la ATCI. ${ }^{24}$

- Por ejemplo, la revisión regulatoria de productos farmacéuticos limita el plazo real por el cual un titular puede disfrutar de una patente: la protección conferida por una patente expira cuando haya transcurrido un periodo de 20 años contados desde la fecha de presentación de la solicitud ${ }^{25}$ - el periodo entre la presentación de la solicitud y la admisión regulatoria del producto no permite al titular sacar provecho del producto- - Una prórroga del plazo de la patente, otorgada en los EEUU bajo la Ley de Hatch-Waxman, y en la UE bajo certificados complementarios de protección (SPC, por sus siglas en inglés), compensa en parte el plazo perdido debido a la revisión regulatoria. PhRMA parece cabildear para una mayor compensación en el ATCI. ${ }^{26}$

- No queda totalmente claro si el ADPIC requiere el otorgamiento de patentes para nuevos usos de sustancias conocidas. Este tipo de requerimiento se incluyó explícitamente en varios tratados de libre comercio de los EEUU. ${ }^{27}$

- El régimen de agotamiento internacional ha sido otro concepto controvertido en el ADPIC. "Agotamiento" significa que el titular de la patente sólo puede controlar la primera venta del producto patentado. Después de la primera venta autorizada, no restringida, se "agotan" sus derechos, por lo que no tiene control sobre la reventa de los productos. ${ }^{28}$ Sin embargo, tradicionalmente hay diferencias entre los países con respecto a si consideran que la doctrina deba

24 No todas las formas para reducir este espacio en los tratados de libre comercio serán tratadas a continuación. Una lista más completa de lo que quiere PhRMA se incluye en este sometimiento de PhRMA, cuya veracidad no puede verificarse: $h t t p: / / w w r w . p l o s . o r g / w p-$ content/uploads/2014/05/PhRMA_Comments_to_USTR_on_TTIP.pdf. Solicita aclaraciones de elegibilidad para la protección de patentes, novedad, paso inventivo, normas sobre patentado de compuestos/moléculas específicas, revelación, periodos de gracia, restablecimiento del plazo de una patente, estándares de cumplimiento de patentes.

25 Artículo 33 ADPIC.

26 Véase http://docs.house.gov/meetings/IF/IF17/20130724/101197/HHRG-113-IF17-Ws tate-Castellanif-20130724.pdf, p. 5.

27 Véanse, por ejemplo, los artículos 15.8, para. 1, literal b, US-Oman FTA; 17.9, para. 1, US-Australia FTA; 15.9, para. 2, US-Morocco FTA.

28 Véase en detalle Rinehart, A., "Contracting Patents: A Modern Patent Exhaustion Doctrine", 23 Harvard f of L \& Tech, 2010, p. 483. 
Esta obra forma parte del acervo de la Biblioteca Jurídica Virtual del Instituto de Investigaciones Jurídicas de la UNAM

aplicar internacionalmente, es decir, si el titular de la patente puede bloquear las importaciones de un producto que él mismo colocó en un mercado extranjero. ${ }^{29}$ La cuestión es de suma importancia para el abastecimiento y los precios de medicamentos. Los EEUU no están a favor de una doctrina de agotamiento internacional. El Tratado de Libre Comercio entre EEUU y Marruecos señala explícitamente que cada "parte debe estipular que el derecho exclusivo del titular de la patente para prevenir la importación de un producto patentado... sin el consentimiento del titular de la patente no debe estar limitado por la venta o la distribución de ese producto fuera de su territorio". ${ }^{30}$ Curiosamente, Chile y otros países en desarrollo han propuesto, según el texto de negociación del capítulo de propiedad intelectual de TPP publicado, una disposición que constata que "se exhorta a las partes a establecer un agotamiento internacional de derechos" en el TPP. ${ }^{31}$ EEUU, Australia, Japón y México se opusieron a esta disposición y la versión final estipula que "[n]ada en este Acuerdo impide a una parte determinar, en su caso, bajo qué condiciones aplica el agotamiento de los derechos de propiedad intelectual, de conformidad con su sistema jurídico", clarificando, para mayor certeza, que "este artículo aplica sin perjuicio de cualquier disposición relativa al agotamiento de los derechos de propiedad intelectual prevista en acuerdos internacionales de los que una parte sea parte".

- Los remedios que se otorgan en caso de una infracción a un derecho de propiedad intelectual y los procedimientos relativos a la observancia de estos derechos pueden ser diferentes según el país. El capítulo sobre la propiedad intelectual del TPP contiene una sección detallada sobre la observancia de los derechos de propiedad intelectual, incluyendo procedimientos relativos a la de observancia y normas sobre los remedios, incluso, por ejemplo, sobre el cálculo de daños. ${ }^{32}$ Este tipo de medidas puede reforzar la protección de la propiedad intelectual de manera considerable. En la ATCI, PhRMA

29 Wasserman Rajec, S. R., "Free Trade in Patented Goods: International Exhaustion for Patents", 29 BTLf, 2014, p. 317; Poget, C. J., Parallel Imports of Pharmaceuticals, Birkhäuser, 2008; Valletti, T. y Szymanski, S., Parallel Trade, International Exhaustion and Intellectual Property Rights, Centre for Economic Policy Research, 2005.

30 Artículo 15.9, para. 4, US-Morocco FTA.

31 Artículo QQ.A.12.

32 Artículos 18.74 (4) y ss., TPP. 
Esta obra forma parte del acervo de la Biblioteca Jurídica Virtual del Instituto de Investigaciones Jurídicas de la UNAM

cabildea para un sistema de observancia, incluyendo medidas para la pronta resolución de disputas de patentes farmacéuticas antes de que un producto en infracción se lance al mercado. ${ }^{33}$

- Es importante observar que los tratados de libre comercio entran ocasionalmente en detalles que hasta ahora no se consideraba adecuado para los convenios internacionales. Nuevamente, el texto divulgado por Wikileaks del capítulo de propiedad intelectual del TPP nos proporciona un ejemplo. Según este documento, EEUU y Japón han propuesto la siguiente disposición: "una parte no podrá denegar una patente exclusivamente sobre la base de que el producto no resulte en eficacia mejorada de un producto conocido cuando el solicitante ha expuesto características distintivas estableciendo que la invención es nueva, que involucra un paso inventivo, y es capás (sic) de aplicación industrial". ${ }^{34}$ La propuesta debe entenderse en el contexto de la Ley de Patentes de la India. Esta ley constata que "el mero descubrimiento de una nueva forma de una sustancia conocida que no produce un incremento de la eficacia conocida de esa sustancia ..." no constituye una invención patentable (sección 3 (d) de la Ley de Patentes, de 1970, y sus enmiendas). La disposición dificulta la patentabilidad con respecto a algunos productos farmacéuticos para los cuales las patentes se otorgarían solamente cuando se pudiera demostrar una mayor eficacia, lo cual frecuentemente no es el caso. ${ }^{35}$ La propuesta estadounidense/japonesa en el TPP prevendría explícitamente que las partes del TPP sigan el ejemplo de la India con respecto a esta disposición. La negociación del TPP también demuestra la importancia de defender sus intereses: los otros diez países se opusieron a la propuesta y el texto final del TPP no la incluye. ${ }^{36}$

33 Véase http://docs.house.gov/meetings/IF/IF17/20130724/101197/HHRG-113-IF17-Ws tate-Castellanif-20130724.pdf, p. 5.

34 Artículo QQ.E.1 (a).

35 Véase Kapczynski, A., "Engineered in India - Patent Law 2.0", N. Engl. 7. Med., 2013, p. 497.

36 El texto final sí incluye la siguiente normativa en el artículo 18.37 (2): "Sujeto a los párrafos 3 y 4 de conformidad con el párrafo 1, cada parte confirma que las patentes están disponibles para invenciones que se reivindiquen con al menos uno de los siguientes: nuevos usos de un producto conocido, nuevos métodos de usar un producto conocido, o nuevos procesos de uso de un producto conocido. Una parte puede limitar dichos procesos a aquellos que no reivindiquen el uso del producto como tal". 
Esta obra forma parte del acervo de la Biblioteca Jurídica Virtual del Instituto de Investigaciones Jurídicas de la UNAM

\section{Protección de datos de pruebas y transparencia}

Tanto los EEUU como la UE proveen una protección de datos de pruebas. La Comisión Europea define a la exclusividad de datos como "el periodo durante el cual los datos del titular de la autorización de comercialización original, relativos a los análisis (pre-) clínicos, están protegidos". ${ }^{37} \mathrm{La}$ regulación de la exclusividad de datos es compleja y multifacética; describirla iría más allá del alcance de este trabajo. Sin embargo, basta decir que los tratados de libre comercio estadounidenses sirven y han servido como un vehículo para impulsar estándares más elevados en la protección de datos de pruebas..$^{38}$ Las negociaciones del TPP enfrentaron un fuerte esfuerzo de cabildeo en este sentido, sobre todo en relación con los nuevos productos biológicos. En EEUU, los productos biológicos se benefician por 12 años de protección de datos regulatorios bajo la Ley de Competencia de Precios de Productos Biológicos e Innovación de 2009, que se aprobó como parte del paquete de reformas. PhRMA argumentó con mucha fuerza a favor de incluir esta norma de los EEUU en el TPP ${ }^{39}$ y la ATCI. ${ }^{40} \mathrm{Al}$ final, en el TPP se encontró un compromiso que protege los datos por 8 años. ${ }^{41}$

Una cuestión relacionada con la protección de datos de pruebas es la transparencia de datos clínicos. El acceso público a datos clínicos ha sido una preocupación de la UE, que ha desarrollado un principio de publicación y de acceso a datos clínicos, ${ }^{42}$ convencida de que la transparencia de datos clínicos es esencial para mejorar la salud pública. PhRMA ha criticado esta política en una declaración al Congreso sobre la ATCI:

...la revelación de datos no públicos de compañías, presentados en dossiers clínicos y pre-clínicos... pone en riesgo la salud pública y el bienestar de los pacientes. La PhRMA y sus miembros instan al gobierno estadounidense a

37 Preliminary Report, Pharmaceutical Sector Inquiry of DG Comp, 28 de noviembre de 2008.

38 Véanse, por ejemplo, los artículos 15.10, para. 2, US-Morocco FTA; 17.10, para. 1, US-Chile FTA; 15.10, para. 1, CAFTA-DR.

39 Véase http://wrew.phrma.org/note-media-elected-officials-support-12-years-data-protection-tpp.

40 Véase http://docs.house.gov/meetings/IF/IF17/20130724/101197/HHRG--113-IF17-W state-Castellanif-20130724.pdf, p. 5.

41 Artículo 18.52 ("Un país puede lograr la protección de 8 años de varias maneras..."). Véase el texto del artículo para mayores detalles.

42 Véase la regulación de la UE 536/2014 y la política definitiva de EMA sobre el acceso público a datos clínicos. La declaración de la UE se incluye en el documento "Pharmaceuticals in TTIP", disponible en: http://trade.ec.europa.eu/doclib/docs/2015/january/tradoc_ 153010.4.7\%20Pharmaceuticals.pdf. 
Esta obra forma parte del acervo de la Biblioteca Jurídica Virtual del Instituto de Investigaciones Jurídicas de la UNAM

negociar con la UE en cada fórum disponible para asegurar que [los] datos se compartan de manera responsable para proteger la privacidad de pacientes, mantener la integridad del proceso de revisión regulatoria y conservar los incentivos para la investigación biomédica al proteger adecuadamente la información comercial confidencial de la revelación inapropiada. Las políticas de revelación de datos actuales y propuestas de la EMA ponen en riesgo estos principios. ${ }^{43}$

Se pueden concebir diferentes maneras en las que la transparencia de datos de pruebas podría ser impugnada en las negociaciones del ATCI: la industria farmacéutica podría alegar que esta transparencia constituye una protección insuficiente de secretos comerciales, una violación a los derechos de autor (incluso de derechos ya protegidos en convenios previos, como ADPIC) o el tema puede surgir en el curso de las discusiones sobre la cooperación regulatoria en las cuales EEUU podría insistir en la protección de la confidencialidad de datos de pruebas como requerimiento previo para el intercambio de información entre las agencias estadounidenses y europeas. ${ }^{44}$

\section{ATCI, productos farmacéuticos y protección de la propiedad intelectual}

No queda claro cómo las cuestiones que se mencionan con anterioridad o algunas otras, incluyendo la protección de marcas comerciales, serán abordadas en las negociaciones de la ATGI. La UE está consciente de que la protección de la propiedad intelectual con respecto a productos farmacéuticos es controvertida, y afirma que ya cuenta con reglas eficaces para la protección de la propiedad intelectual, logrando un delicado equilibrio entre los beneficios concedidos a las compañías y los beneficios que los pacientes deberían obtener de nuevos medicamentos. No "negociará nada en la ATCI que alterara este delicado equilibrio o aumentara los costos para los sistemas nacionales de salud de los países europeos que ya se encuentran extendidos". ${ }^{45}$ Con respecto a la transparencia de datos de estudios clínicos, la UE ha afirmado explícitamente que no negociaría las reglas que afecten el derecho desarrollado en su directiva y la política de la EMA con respecto

43 Véase http://docs.house.gov/meetings/IF/IF17/20130724/101197/HHRG-113-IF17-Ws tate-Castellanif-20130724.pdf, pp. 3 y 4.

44 Santos, A., "HAI Europe, ATCI \& Access to Clinical Trial Data", disponible en: http://haieurope.org/wp-content/uploads/2015/01/HAI-Europe-ATCIaccess-CTD.pdf.

45 La declaración de la UE se incluye en el documento "Pharmaceuticals in TTIP", cit. 
Esta obra forma parte del acervo de la Biblioteca Jurídica Virtual del Instituto de Investigaciones Jurídicas de la UNAM

al acceso público a datos clínicos. ${ }^{46}$ Es decir, la UE está consciente de las implicaciones del tema.

Sin embargo, es poco realista confiar en que las declaraciones de la UE impliquen que las reglas actuales de la UE no cambiarán con motivo de la ATCI. En primer lugar, las negociaciones requieren reciprocidad, y no se puede descartar categóricamente que los negociadores abandonen una convicción arraigada para obtener beneficios que la otra parte no otorgaría sin esta concesión. Segundo, el ATCI será un convenio inmensamente complejo. Es poco probable que los negociadores en todas las áreas siempre estén conscientes de los posibles efectos negativos de cada una de las propuestas de negociación. En consecuencia, es fundamental que las instituciones interesadas que representan los intereses de salud pública se involucren y estén conscientes de las propuestas de negociación para señalar los posibles efectos negativos en la salud pública de cualquier propuesta presentada.

\section{Fïación de precios de medicamentos}

Es un objetivo declarado del gobierno de los EEUU el lograr la eliminación de medidas gubernamentales como controles de precios y el uso de precios de referencia, ya que EEUU considera este tipo de medidas como una negación del acceso total al mercado para productos estadounidenses. Una propuesta probable en este sentido se refiere al acceso al mercado, la transparencia y el debido proceso en la fijación de precios y el proceso de reembolso, como es estipulado en el Tratado de Libre Comercio entre Corea del Sur y Estados Unidos.

\section{Explicación}

La fijación de precios de medicamentos y las políticas que tienen un efecto en dichos precios son un campo complejo. Numerosas políticas afectan los precios de medicamentos, desde los requerimientos de aprobación hasta las reglas sobre las importaciones de medicamentos y esquemas de seguros. Los modos en que los precios se determinan varían considerablemente entre un Estado y otro. Los temas ya discutidos tienen un impacto en los precios de medicamentos: la cooperación regulatoria llevará probablemente

46 Véase la regulación de la UE 536/2014 y la política definitiva de EMA sobre el acceso público a datos clínicos. La declaración de la UE se incluye en el documento "Pharmaceuticals in TTIP", cit. 
Esta obra forma parte del acervo de la Biblioteca Jurídica Virtual del Instituto de Investigaciones Jurídicas de la UNAM

a precios más bajos; la protección de la propiedad intelectual probablemente los aumentará. Esta sección no puede describir todas las formas en que la ATCI afectará los precios de medicamentos. En su lugar, se centrará en un posible impacto directo en las decisiones acerca de la fijación de precios de medicamentos y sistemas de salud pública.

El Proyecto de Ley de la Autoridad de Promoción Comercial de los EEUU afirma explícitamente que los tratados de libre comercio de EEUU deberían lograr "la eliminación de las medidas gubernamentales como los controles de precios y uso de precios de referencia que niegan el acceso total al mercado de productos estadounidenses" ${ }^{47}$ La PhRMA cabildea explícitamente contra "medidas cortoplacistas de contención de costos, supuestamente propuestas en respuesta a la crisis financiera, pero con demasiada frecuencia implementadas sin procesos predecibles, transparentes y consultativos", y propone disposiciones de los tratados de libre comercio entre Corea del Sur y Estados Unidos y entre Corea del Sur y la Unión Europea como ejemplos. ${ }^{48} \mathrm{La}$ UE ha publicado el siguiente comentario con respecto a la ATCI y la fijación de precios de medicamentos: "Ni la ATCI ni ningún otro tratado de libre comercio europeo afectaría el derecho de los gobiernos europeos a decidir cuánto debe pagar la gente o de qué manera serán reembolsados. Lo único que la legislación europea requiere de los gobiernos es que tomen sus decisiones de una manera clara y abierta". ${ }^{49}$

Dadas estas declaraciones, ¿qué estipularía un acuerdo comercial? Una posible indicación es el artículo 5o. del capítulo 5 del Tratado de Libre Comercio entre Corea del Sur y Estados Unidos..$^{50}$ El artículo 5.2 del Tratado contiene ciertas condiciones para reglas relativas a los procedimientos para enlistar productos farmacéuticos para el reembolso o establecer la cantidad del reembolso. Bajo estas disposiciones, las partes no sólo deben garantizar procedimientos justos, razonables y no discriminatorios, sino también que el monto del reembolso se base en precios competitivos derivados del mercado o al menos reconozca "apropiadamente" el valor del producto farmacéutico patentado, y las partes deben permitir que fabricantes soliciten un reembol-

\footnotetext{
47 Sección 2 (b)(7)(F) Bipartisan Congressional Trade Priorities Bill.

48 Véase http://docs.house.gov/meetings/IF/IF17/20130724/101197/HHRG-113-IF17-Ws tate-Castellanif-20130724.pdf, pp. 3 y 4.

49 Véase http://trade.ec.europa.eu/doclib/docs/2015/january/tradoc_153010.4.7\%20Pharmace uticals.pdf.

50 Disposiciones similares se incluyeron en el Anexo 2-G del Tratado de Libre Comercio entre Australia y EEUU, disponible en: http://wrwre.dfat.gov.au/about-us/publications/trade-invest ment/australia-united-states-free-trade-agreement/Documents/Final_text_ausfta.pdf.
} 
Esta obra forma parte del acervo de la Biblioteca Jurídica Virtual del Instituto de Investigaciones Jurídicas de la UNAM

so mayor bajo circunstancias específicas. Bajo el título de "Transparencia", el artículo 5.3 estipula condiciones adicionales:

1. Cada parte garantizará que sus leyes, regulaciones y procedimientos de aplicación general que se refieran a cualquier asunto relacionado con la fijación de precios, el reembolso o la regulación de productos farmacéuticos o dispositivos médicos se publiquen sin demora o se pongan a disposición de manera tal de permitir que las personas interesadas y la otra parte tengan conocimiento de ellos.

2. En la medida de lo posible, cada parte:

(a) Publicará por adelantado cualquier medida que se proponga adoptar; y

(b) Brindará a las personas interesadas y a la otra parte oportunidad razonable para comentar sobre las medidas propuestas.

3. Con respecto a las regulaciones de aplicación general propuestas de su nivel central de gobierno que se refieran a cualquier asunto relacionado con fijación de precios, el reembolso o la regulación de productos farmacéuticos o dispositivos médicos que se publiquen de conformidad con el párrafo 2(a), cada parte:

(a) Publicará las regulaciones propuestas, incluyendo una explicación del propósito de esas regulaciones, en un solo diario oficial de circulación nacional y alentará su distribución a través de medios adicionales;

(b) Deberá publicar, en la mayoría de los casos, las regulaciones propuestas no menos de 60 días antes de la fecha en la que deben presentarse los comentarios públicos; y

(c) Abordará, en el momento de adoptar las regulaciones finales, por escrito los comentarios sustantivos significativos recibidos de personas interesadas durante el periodo de comentarios y explicará cualquier revisión sustantiva que haya aplicado a las regulaciones propuestas.

4. En la medida de lo posible, cada parte deberá permitir que haya un tiempo razonable entre la publicación de regulaciones finales de aplicación general de su nivel central de gobierno, que se refiera a cualquier asunto relacionado con la fijación de precios, el reembolso o la regulación de productos farmacéuticos o dispositivos médicos, y la fecha de entrada en vigor.

5. Al grado en que autoridades del servicio de salud a nivel central de gobierno de una parte opere o mantenga procedimientos para enlistar productos farmacéuticos, dispositivos médicos o indicaciones para el reembolso o el establecimiento de montos de reembolso para productos farmacéuticos o dispositivos médicos, bajo los programas de servicio de salud operados por su nivel central de gobierno, una parte:

(a) Asegurará que la consideración de todas las solicitudes formales para la fijación de precios o aprobación de productos farmacéuticos o dispositivos médicos para el reembolso se finalice dentro de un periodo razonable especificado; 
Esta obra forma parte del acervo de la Biblioteca Jurídica Virtual del Instituto de Investigaciones Jurídicas de la UNAM

(b) Revelará a los solicitantes, dentro de un periodo razonable especificado, todas las normas de procedimiento, metodologías, principios, criterios (incluyendo aquellos utilizados, en su caso, para determinar productos comparadores) y los lineamientos utilizados para determinar la fijación de precios y el reembolso de productos farmacéuticos o dispositivos médicos;

(c) Brindará a los solicitantes oportunidades significativas, sin demora, para proporcionar comentarios en puntos relevantes en los procesos de toma de decisiones acerca de la fijación de precios y el reembolso para productos farmacéuticos o dispositivos médicos;

(d) Dentro de un periodo razonable especificado, ofrecerá a los solicitantes información significativa, detallada y por escrito con respecto al fundamento para las recomendaciones o determinaciones de la fijación de precios y el reembolso de productos farmacéuticos o dispositivos médicos, incluyendo citas a opiniones de expertos o estudios académicos que se utilizaron como base de estas recomendaciones o determinaciones;

(e) Pondrá a la disposición un proceso de revisión independiente que puede ser invocado a petición de un solicitante directamente afectado por una recomendación o determinación;

(f) Abrirá todos los órganos que toman decisiones sobre el reembolso a todas las partes interesadas, incluyendo compañías innovadoras y genéricas; y

(g) Pondrá a disposición del público la lista de miembros de todos los comités relacionados con la fijación de precios o el reembolso de productos farmacéuticos o dispositivos médicos.

6. Cada parte debe asegurar que todas las medidas de aplicación general que se refieran a cualquier asunto relacionado con la fijación de precios, el reembolso o la regulación de productos farmacéuticos o dispositivos médicos se administren de una manera razonable, objetiva e imparcial.

Los sindicatos en la UE han expresado su preocupación de que las disposiciones de transparencia del Tratado de Libre Comercio entre Corea del Sur y Estados Unidos permiten que los fabricantes tengan demasiada influencia en las decisiones sobre la fijación de precios. ${ }^{51} \mathrm{~A}$ pesar de que el contenido de la disposición se encuentra elaborado totalmente en el lenguaje de la transparencia, brinda, sin duda, a los fabricantes la oportunidad de que se escuche su voz. Esto es seguramente deseable en cierta medida, pero se debe tomar en cuenta que ofrecerá oportunidades adicionales de cabildeo para un grupo de presión que tiene bastante fuerza. El alcance de este trabajo no permite un análisis detallado del grado al que las disposiciones se desvíen de las prácticas actuales.

51 Véase http://infojustice.org/wp-content/uploads/2013/12/ATCI-TPP-drug-pricing-letter.pdf. 
Esta obra forma parte del acervo de la Biblioteca Jurídica Virtual del Instituto de Investigaciones Jurídicas de la UNAM

\section{RESOLUCIÓN DE CONTROVERSIAS ENTRE INVERSIONISTAS Y ESTADOS (ISDS)}

ISDS en la ATCI permitirá a los inversionistas de los EEUU, por ejemplo compañías estadounidenses que poseen patentes en la UE o que han adquirido instalaciones, interponer demandas contra la UE o un Estado miembro ante un tribunal internacional, sosteniendo que la UE o el Estado miembro ha violado la protección de la inversión otorgada en el Convenio (por ejemplo, al tratar al inversionista de manera injusta e inequitativa). Tal infracción puede ser cometida también por la legislación de un Estado miembro. Se deben distinguir dos aspectos con respecto a la protección de la inversión.

Antes que todo, la ATCI comprenderá normas sustantivas acerca de la protección de inversiones. Estas normas no sólo protegerán a los inversionistas de expropiaciones directas de su propiedad sin compensación inmediata, adecuada y efectiva, sino también, por ejemplo, de la expropiación indirecta (es decir, de medidas que sustancialmente privan al inversionista de la inversión, pero que formalmente no toman posesión de la propiedad del inversionista), de un tratamiento injusto e inequitativo y de la violación de su plena protección y seguridad. Sobre todo los conceptos de "tratamiento justo y equitativo" y "expropiación indirecta" han suscitado preocupaciones, porque tienen el potencial de limitar sustancialmente la libertad de los Estados de aprobar regulaciones. Particular conciencia en el sector de salud ha sido creada por la demanda de Philip Morris en contra de la legislación del empaquetado genérico del tabaco en Australia en un tribunal de arbitraje internacional, basada en un tratado bilateral de inversión entre Hong Kong y Australia, desestimada en diciembre de 2015 por razones procesales, así como la demanda de Eli Lilly (todavía pendiente) de que Canadá violó el capítulo de protección a la inversión del NAFTA cuando sus tribunales invalidaron dos de sus patentes por no cumplir con los requerimientos de utilidad. Un capítulo sobre inversiones de la ATCI muy probablemente comprendería extensas definiciones de la protección otorgada a los inversionistas (incluyendo definiciones de conceptos como "tratamiento justo y equitativo" y "expropiación indirecta") y un "derecho a regular" de los Estados. Aunque un derecho explícito de los Estados a regular a favor de la salud pública puede aliviar las preocupaciones que surgieron con respecto a los límites impuestos a esta posibilidad de regulación, se debe tomar en cuenta que en cierta medida es la meta en sí de la protección a la inversión impedir que los Estados tomen medidas que violen los derechos de los inversionistas. En donde un derecho a regular permitiría que los estados tomen 
Esta obra forma parte del acervo de la Biblioteca Jurídica Virtual del Instituto de Investigaciones Jurídicas de la UNAM

tales medidas, esto parece oponerse a la idea de la protección a la inversión, y no está claro cuál consideración será favorecida.

Segundo, ATCI comprenderá un mecanismo que permite a inversionistas que son nacionales de un Estado parte del tratado e invirtieron en otro Estado parte la posibilidad de recurrir a una jurisdicción internacional contra el Estado anfitrión de la inversión (ISDS). Tradicionalmente, los tratados bilaterales de inversión confiaron esta tarea al arbitraje internacional, sin posibilidad de apelación. ATGI podría ser diferente: ISDS se volvió el aspecto más controvertido de la ATCI. El mecanismo ha estado justificado por ser un incentivo necesario para la inversión y garantizar juicios eficientes, justos e imparciales en situaciones en las cuales no siempre se pueda confiar en que los tribunales nacionales - en muchos Estados, ineficientes y parciales - provean este tipo de juicios. Es muy dudoso que estas justificaciones se apliquen también al caso del tratado de libre comercio entre EEUU y la UE: ¿hasta qué grado rechazaría un inversionista invertir en EEUU y la UE sin los beneficios del arbitraje de inversión? Mientras que es probable que los tribunales de inversión tengan un menor sesgo hacia los intereses nacionales que los tribunales nacionales, ¿en qué medida se podrá esperar que un panel de arbitraje con tres miembros, sin derecho de apelar, haga un mejor trabajo manteniendo el principio de derecho que el sistema judicial de EEUU y la UE, incluyendo la protección de los derechos de propiedad, pero también de los intereses públicos? Después de mucha presión pública, la Comisión de la UE organizó una consulta pública y como resultado propuso, por primera vez, una corte internacional de inversiones. La corte propuesta sería un largo paso en dirección de un sistema con menos incentivos económicos para los árbitros, aunque ambos —un sistema de ISDS "tradicional" o una corte- proporcionarían un derecho de recurrir a una jurisdicción a los inversionistas estadounidenses en Europa y a los inversionistas europeos en los EEUU. No está claro si EEUU estará dispuesto a aceptar esta corte, y será difícil para la UE volver al sistema de arbitraje que a los ojos de su población está desacreditado.

\section{Explicación}

El tratamiento de extranjeros, en particular con respecto a la expropiación de extranjeros, ha sido tradicionalmente un asunto difícil bajo el derecho internacional. Esta área sólo puede comprenderse en el contexto de las diferencias de interés de los Estados exportadores de capital y los Estados de importación de capital. Sustancialmente, no estaba claro qué estándar de 
Esta obra forma parte del acervo de la Biblioteca Jurídica Virtual del Instituto de Investigaciones Jurídicas de la UNAM

protección debía un Estado anfitrión a un extranjero: podría un extranjero esperar un estándar de tratamiento mínimo, es decir, la expropiación sólo por el "pago adecuado, efectivo y sin demora por la propiedad expropiada", según fue afirmado por la denominada "Regla de Hull"52 preferida por los países exportadores de capital, o podría esperar solamente no ser tratado de manera diferente que los nacionales del Estado anfitrión, como lo afirma la Doctrina Calvo, preferida por los Estados importadores de capital. ${ }^{53}$ Procesalmente, en caso de violación de los derechos de los extranjeros, el derecho internacional sólo estipuló un recurso incómodo: el Estado de nacionalidad del extranjero podía ejercer el derecho de protección diplomática para sus ciudadanos (sin tener la obligación de hacerlo) e invocar una demanda en contra de ese Estado en su propio nombre, pero el extranjero debía agotar primero los recursos locales; es decir, tenía que ir a los tribunales nacionales del Estado anfitrión, los cuales con frecuencia no eran tan efectivos como hubiera sido deseable. ${ }^{54}$ La situación era particularmente difícil para las sociedades anónimas, ya que la ley internacional limitó la posibilidad de una protección diplomática de los accionistas. ${ }^{55} \mathrm{El}$ resultado fue, en primer lugar, que los inversionistas se quedaron a menudo sin recursos; segundo, que los Estados de nacionalidad de los inversionistas enfrentaron la difícil elección entre ejercer la protección diplomática y arriesgar sus relaciones con el Estado anfitrión, o dejar a sus ciudadanos a su suerte; tercero y último, que los Estados de nacionalidad de los inversionistas que eligieron ejercer la protección diplomática, ocasionalmente utilizaron la fuerza y amenazas de fuerza para respaldar sus demandas. ${ }^{56}$ En pocas palabras, el sistema no era satisfactorio. ${ }^{57}$

El derecho cambió significativamente con la aparición de los tratados bilaterales de inversión (BIT). El primero de estos tratados se firmó entre

52 Secretario de Estado de los EEUU, Cordell Hull, al embajador mexicano, 22 de agosto de 1938, reproducido en "Mexico-United States: Expropriation by Mexico of Agrarian Properties Owned by American Citizens", 33 AJIL Supp, 1938, pp. 191-201.

53 Calvo, G., Le droit international théorique et pratique, 5a. ed., 1896, vol. VI, p. 231.

54 La Comisión de Derecho Internacional ha tratado de codificar las normas sobre la protección diplomática en los Draft Articles on Diplomatic Protection, Official Records of the GA, Sixty-first Session, Supplement No. 10 (A/61/10), 2006.

55 ICJ, Case Concerning the Barcelona Traction, Light y Power Company, Limited, New Application, 1962 (second phase), Judgment of 5 February 1970, ICJ Reports 1970, p. 3. Véase, también, ICJ, Case Concerning Ahmadou Sadio Diallo (Republic of Guinea v. Democratic Republic of the Congo), Preliminary Objections, Judgment, ICJ Reports 2007, p. 582.

56 Se suele denominar "diplomacia de cañonero".

57 Con mayor detalle, Newcombe, A. y Paradell, L., Law and Practice of Investment Treaties, Kluwer Law, 2009, pp. 1-18. 
Esta obra forma parte del acervo de la Biblioteca Jurídica Virtual del Instituto de Investigaciones Jurídicas de la UNAM

Alemania y Pakistán el 25 de noviembre de $1959^{58}$ y estableció un precedente que, hasta ahora, condujo al desarrollo de una red de 2,228 BITs en vigor alrededor del mundo, ${ }^{59}$ a pesar de un reciente rechazo en Latinoamérica. ${ }^{60}$ Dos aspectos del derecho de inversión se deberían mencionar: las normas sustantivas y el mecanismo de resolución de controversias entre inversionistas y Estados (ISDS).

Sustancialmente, los tratados bilaterales de inversión brindan varias garantías a los inversionistas de una de las partes del tratado que invierten en la otra parte del tratado. La Comisión de la UE se refiere a las siguientes cuatro garantías como "garantías clave":

- Protección contra la discriminación.

- Protección contra la expropiación directa o indirecta de la inversión que no sea para un propósito de política pública y no se encuentre compensado de manera justa (usualmente en su totalidad).

- Protección contra el tratamiento injusto e inequitativo.

- Protección de la posibilidad de transferir capital. ${ }^{61}$

Las garantías pueden ser violadas no sólo por medidas administrativas del Estado, sino, también, por ejemplo, por la legislación de un Estado.

Los tratados determinan habitualmente cuándo un inversionista tiene la nacionalidad de una de las partes (que es de particular importancia para las sociedades) y lo que exactamente constituye una inversión protegida. La definición de esta última es generalmente amplia. El Tratado de Libre Comercio entre Canadá y la UE (CETA), por ejemplo, define la inversión como

Cada tipo de activo que un inversionista posee o controla, directamente o indirectamente, que tiene las características de una inversión, lo que incluye una cierta duración y otras características, como el compromiso de capital u otros recursos, la expectativa de una ganancia o un beneficio, o la asunción de riesgo. Las formas que puede adoptar una inversión incluyen:

Una empresa; acciones, y otras formas de participación en el capital en una empresa; bonos, obligaciones y otros instrumentos de deuda de una em-

58 BGBl II, 1961, 793.

59 El Centro de Políticas de Inversión de UNCTAD da seguimiento a los desarrollos en el campo. Véase http://investmentpolicyhub.unctad.org/IIA.

60 Gus van Harten, "Five Justification for Investment Treaties: A Critical Discussion", Trade L. E̊ Dev., vol. 2, núm. 1, 2010.

61 Véase http://trade.ec.europa.eu/doclib/docs/2013/november/tradoc_151916.pdf. 
Esta obra forma parte del acervo de la Biblioteca Jurídica Virtual del Instituto de Investigaciones Jurídicas de la UNAM

presa; un préstamo a una empresa; cualquier otro tipo de participación en una empresa; un interés que surja de: una concesión conferida de conformidad con las leyes nacionales o bajo un contrato, incluyendo la búsqueda, el cultivo, la extracción o explotación de recursos naturales, un contrato de llave en mano, construcción, producción o coparticipación de ingresos u otros contratos similares; derechos de propiedad intelectual; cualquier otra propiedad movible, tangible o intangible, o propiedad inmueble y derechos relacionados; demandas por dinero o demandas por la ejecución bajo un contrato.

Para mayor certeza, 'demandas por dinero' no incluye demandas por dinero que surgen únicamente de contratos comerciales para la venta de artículos o servicios por una persona física o empresa en el territorio de una parte a una persona física o empresa en el territorio de la otra parte, el financiamiento nacional de tales contratos, o cualquier orden, sentencia o laudo arbitral relacionados.

Las ganancias que son invertidas deben tratarse como inversiones. Cualquier alteración de la forma en la que los activos se inviertan o se reinviertan no afectan su calificación como inversión. ${ }^{62}$

La innovación más grande del régimen de inversiones fue procesal. Bajo un mecanismo de resolución de controversias entre inversionistas y Estados (ISDS), un inversionista, quien es ciudadano de un Estado parte de un tratado bilateral de inversión, puede interponer demandas directamente contra el Estado anfitrión de la inversión, el otro Estado parte, ante un tribunal de arbitraje internacional. La demanda de un inversionista debe alegar una violación de una de las disposiciones del capítulo de las inversiones por el Estado anfitrión (según sea estipulado en el tratado de inversión bilateral). El tribunal emite un laudo que es definitivo. Ningún tratado ha establecido hasta ahora un mecanismo de apelación para ISDS y los laudos sólo pueden ser anulados (a través de un panel de anulación) en un número limitado de circunstancias. Los laudos no derogan la legislación de un Estado, pero asignan una compensación monetaria en donde una medida viola la protección a la inversión. ${ }^{63}$

Este sistema de protección a la inversión proporcionó una solución para algunas de las desventajas del sistema legal internacional tradicional: cuando los inversionistas pudieran ampararse en un tratado de inversión, no tendrían que pasar más por los tribunales nacionales del Estado anfitrión, tradicionalmente sesgados a favor de ese Estado (o, en algunos países, in-

62 Artículo X.3 CETA, disponible en: http://trade.ec.europa.eu/doclib/docs/2014/september/ tradoc_152806.pdf.

63 Para un tratamiento detallado véase, por ejemplo, Muchlinski, P. et al., The Oxford Handbook of International Investment Law, OUP, 2008. 
Esta obra forma parte del acervo de la Biblioteca Jurídica Virtual del Instituto de Investigaciones Jurídicas de la UNAM

efectivos), o depender de la protección diplomática por sus Estados de nacionalidad. Podrían esperar una protección de su inversión por un tribunal de arbitraje internacional. Los Estados anfitriones estaban dispuestos a firmar tratados bilaterales de inversión y transferir a los inversionistas el derecho de recurrir al ISDS debido a que esperaron que la protección adicional provista por el tratado atrajera inversionistas que tenían dudas acerca de invertir por la preocupación de que los tribunales del Estado anfitrión no protegieran su inversión de manera suficiente. ${ }^{64}$

Tuvieron que transcurrir varias décadas para que el sistema de inversión entrara en vigor y se desarrollara la jurisprudencia. ${ }^{65}$ Con el tiempo, el sistema se convirtió también en el blanco de muchas críticas. Ellas se referían en parte a las normas sustantivas imprecisas: los conceptos del tratamiento justo y equitativo y la expropiación indirecta no se definieron de manera suficiente, dejando mucho trabajo pesado a los tribunales, que protegieron frecuentemente las expectativas legítimas de los inversionistas. ${ }^{66}$ Bajo estos estándares, los tribunales tienen que decidir si un acto realizado por el Estado anfitrión, ya sea administrativo o legislativo, constituye un tratamiento injusto e inequitativo o una expropiación indirecta del inversionista. Eso significa que los cambios de la regulación están potencialmente sujetos a desafíos, una situación que es considerada por los críticos como una grave restricción del derecho a regular de los Estados. ${ }^{67}$ Para dar sólo un ejemplo: muchos países introdujeron tarifas reguladas (una tarifa fija prometida a productores de energía alternativa) para respaldar la producción de energía a través de energía renovable. Con el tiempo, el gasto por esas tarifas puede convertirse en una carga significante para el Estado y puede considerarse como exagerada o no justificada. De hecho, algunos Estados las han reducido, por ejemplo España, República Checa e Italia. Estas medidas regulatorias se han desafiado ahora en el arbitraje de inversión. ${ }^{68}$ En la UE puede surgir un problema regulatorio adicional para los Estados: en el caso

64 Respecto a las críticas de las justificaciones de los tratados de inversión véase Gus van Harten, "Five Justification for Investment Treaties: A Critical Discussion", op. cit., p. 4.

65 Acerca de la naturaleza sistémica de la ley de inversión véase Schill, S., The Multilateralization of International Investment Law, CUP, 2009.

66 Orrego Vicuña, F., From Preston to Prescott: Globalizing Legitimate Expectations, disponible en: http://wrerr.arbitration-icca.org/media/0/12224288324420/from_preston_to_prescott.pdf; Potestà, M., "Legitimate Expectations in Investment Treaty Law", ICSID Review, núm. 28, 2013, p. 88.

67 Titi, C., The Right to Regulate in International Investment Law, Hart, 2014.

68 Al menos dieciséis arbitrajes bajo tratados están pendientes contra España y la República Checa, y al menos uno contra Italia. Véase http://wrwre.chadbourne.com/renewable_energy_ policy_changes_june2014_projectfinancel. 
Esta obra forma parte del acervo de la Biblioteca Jurídica Virtual del Instituto de Investigaciones Jurídicas de la UNAM www.juridicas.unam.mx

Micula v. Romania, la Comisión de la UE considera que el pago de un laudo de inversión en sí podría constituir un subsidio ilegal. ${ }^{69}$ En algunos casos, la mera amenaza de un litigio costoso llevó a los Estados a reconsiderar la regulación que inicialmente querían aprobar (por ejemplo, una regulación de empaquetado genérico) (el hecho de que un Estado se abstenga de una regulación por miedo a un proceso de arbitraje internacional es descrito como regulatory chill).

Las normas procesales, a saber, el ISDS, también fueron atacadas. Debido a que el ISDS copió normas del arbitraje comercial internacional fue desafiado como poco transparente, costoso y sin lograr la esperada imparcialidad. ${ }^{70}$ Los árbitros en un proceso ad hoc pueden ser los abogados en el próximo. Con los años, también resultó claro que los procesos del ISDS son de larga duración y no cuestan menos que procesos en cortes. También se puede preguntar si el ISDS realmente resulta equitativo: sólo los inversionistas y ningún otro grupo de interés tiene acceso al ISDS. Utilizado con frecuencia por compañías multilaterales, el ISDS podría ser un arma adicional para compañías que ya son muy difíciles de regular. Esas compañías ahora pueden atacar la regulación estatal, pero sigue siendo difícil para los individuos lesionados, en países no desarrollados, invocar la responsabilidad de esas compañías.

El sector de la salud no ha sido inmune a demandas alegando que las medidas gubernamentales violaron la protección de inversionistas. Por lo tanto, la legislación del empaquetado genérico del tabaco de Australia y Uruguay ha sido atacada por Philip Morris, ${ }^{71}$ alegando una violación del tratado bilateral de inversión entre Australia y Hong Kong. La demanda contra Australia se desestimó en diciembre de 2015 por razones procesales, una decisión que no puede asegurar a los gobiernos que similares demandas no serán repetidas por demandantes con una posición procesal mejor. Eli Lilly demandó a Canadá bajo el capítulo sobre inversiones del Tratado de Libre Comercio de América del Norte (TLCAN), alegando que el hecho

69 La Comisión determinó explícitamente que "cualquier ejecución del laudo... equivaldría al otorgamiento de una 'nueva ayuda' incompatible". C (2014) 6848 final, 1o. de octubre de 2014, para. 71 .

70 Las discusiones del arbitraje de inversión han llegado a ser un elemento básico. Un debate más fundamentado se ha realizado, por ejemplo, en wreweverfassungsblog.de.

71 En el caso de Uruguay, la demanda se entabló bajo el TBI Uruguay-Suiza y se refiere a los derechos de propiedad intelectual de Abal Hermanos, la subsidiaria de Philip Morris en Uruguay. En el caso de Australia, la demanda se entabló por Philip Morris Asia Ltd., con sede en Hong-Kong, que posee el afiliado australiano. Véase, por ejemplo, la discusión por M. Hunter y J. García Olmedo en: http://kluwerarbitrationblog.com/blog/2012/01/29/investorstate-arbitration-and-plain-packaging-the-new-'anti-tobacco-movement'-has-begun/. 
Esta obra forma parte del acervo de la Biblioteca Jurídica Virtual del Instituto de Investigaciones Jurídicas de la UNAM

de que los tribunales de Canadá declararon dos de las patentes de Eli Lilly inválidas constituye una expropiación ilícita y una violación de estándares mínimos de tratamiento por Canadá. ${ }^{72} \mathrm{El}$ caso sigue pendiente.

Los EEUU y la UE desean incluir la protección a la inversión y el ISDS en la ATCI. Conforme a las declaraciones públicas de la Comisión de la UE, un capítulo sobre las inversiones en la ATCI comprenderá probablemente, similar al Tratado de Libre Comercio de la UE con Canadá, aclaraciones significativas de varios conceptos de protección a la inversión. Sustancialmente, comprendería un derecho a regular, es decir, el derecho de las partes a regular para alcanzar objetivos de política pública legítimos y definir aún más la expropiación indirecta y el tratamiento justo y equitativo. ${ }^{73}$

¿Qué efecto tendrá la protección de las inversiones en la ATCI para el sector de salud? La comisionada de Comercio de la UE, Cecilia Malmström, no percibe una amenaza grande al sector de servicios de salud por el ISDS. En una carta a Lord Livingston, ella expuso que, por ejemplo, los Estados miembros de la UE continuarán teniendo la libertad de cambiar las políticas y devolver servicios que el sector público de la salud subcontrató a una empresa privada al sector público, protegiendo los derechos de propiedad y sin compensación, debido a que este tipo de compensación "sólo estaría disponible si la devolución de un servicio al sector público involucrara la nacionalización de la propiedad en posesión de inversionistas extranjeros". ${ }^{74}$ No está, por lo tanto, claro si esa declaración describe correctamente cómo se vería un capítulo final sobre inversiones de la ATCI. Evidentemente, definiciones del estándar de tratamiento justo y equitativo, del concepto de la expropiación y de un derecho a regular pueden brindar claridad con respecto a qué conducta estatal se permite y cuáles medidas no se permiten.

Analizando solamente el derecho a regular, el artículo 2(1) de la más reciente propuesta de la UE en materia de inversiones por la ATGI sí parece preferir el derecho del Estado a regular sobre la protección de inversiones y sujeta la regulación solamente a un examen de necesidad para un objeto legítimo:

Las normas de esta sección no afectarán el derecho de las partes a regular en sus territorios a través de medidas necesarias para conseguir objetos políticos legítimos, como por ejemplo la protección de la salud pública, de la seguri-

72 La presentación está disponible en: http://infojustice.org/wp-content/uploads/2013/09/ Eli-Lilly-Notice-of-Arbitration-September-12-2013.pdf.

73 Véase http://trade.ec.europa.eu/doclib/docs/2013/november/tradoc_151916.pdf.

74 Véase https://wrwre.gov.uk/government/publications/nhs-and-ATCI-letter-from-eu-trade-commi ssioner-cecilia-malmstrom/nhs-and-ATCI-letter-from-eu-trade-commissioner-cecilia-malmstrom. 
Esta obra forma parte del acervo de la Biblioteca Jurídica Virtual del Instituto de Investigaciones Jurídicas de la UNAM

dad, del medio ambiente o de las morales públicas, de la protección social o de los consumidores, o la promoción y protección de la diversidad cultural.

No está claro si EEUU aceptará esta formulación, ya que en el TPP dio preferencia a la protección de inversiones: "Nada en este capítulo se interpretará como impedimento para que una parte adopte... cualquier medida, consistente con este capítulo, que considere apropiada para asegurar que las inversiones en su territorio se realizan de una manera sensible al medio ambiente, la salud u otro tipo de objetivos regulatorios". ${ }^{75} \mathrm{Si}$ una medida tiene que ser consistente con todo el capítulo de inversiones, el derecho a regular no constituye una excepción y no tiene ningún valor.

La Alianza Europea para la Salud Pública, en sus comentarios a la Consulta de la UE sobre el ISDS, ha expresado su preocupación de que las compañías farmacéuticas estadounidenses podrían desafiar medidas de los Estados miembros de la UE relativas a concesiones de patentes, decisiones sobre la autorización de comercialización, fijación de precios, reembolso y transparencia de datos, como violatorias de sus inversiones en la forma de propiedad intelectual. ${ }^{76}$ Dependiendo de las formulaciones concretas de los estándares en el convenio definitivo, tales desafíos, de hecho, no pueden descartarse y no deberían descartarse categóricamente, si la meta es una protección eficaz del inversionista a través del derecho de inversión, ya que estas medidas pueden efectivamente tratar a los inversionistas de manera injusta e inequitativa.

Respecto a las normas procesales, el ISDS, la Comisión originalmente quiso introducir solamente algunas innovaciones mejorando el sistema tradicional de arbitraje internacional, por ejemplo, disposiciones sobre transparencia, un código de conducta vinculante para árbitros y protecciones adicionales para las partes. ${ }^{77}$ Pero la reacción del público fue inesperada: el ISDS se volvió en el aspecto más controvertido de la ATCI. Es muy dudoso que las justificaciones tradicionales del ISDS valgan también para un tratado de libre comercio entre EEUU y la UE: ¿hasta qué grado rechazaría un inversionista invertir en EEUU y la UE sin los beneficios del arbitraje de inversión? Mientras que es probable que los tribunales de inversión tengan un menor sesgo hacia los intereses nacionales que los tribunales nacionales, $\dot{c}$ en qué medida se podrá esperar que un panel de arbitraje con tres miembros, sin derecho de apelar, haga un mejor trabajo manteniendo el principio de

\footnotetext{
75 Artículo 9.15 TPP.

76 Véase http://wrwre.epha.org/IMG/pdf/ISDS_Consultation_Response_-_Final_version.pdf.

77 Véase http://trade.ec.europa.eu/doclib/docs/2013/november/tradoc_151916.pdf.
} 
Esta obra forma parte del acervo de la Biblioteca Jurídica Virtual del Instituto de Investigaciones Jurídicas de la UNAM

derecho que el sistema judicial de EEUU y la UE, incluyendo la protección de los derechos de propiedad, pero también de los intereses públicos? Después de mucha presión pública, la Comisión de la UE organizó una consulta pública a la que se ha hecho referencia con anterioridad.

\section{IMPACTO EN PAÍSES EN DESARROLLO}

Como un tratado entre los EEUU, la UE y sus Estados miembros, la ATCI no puede tener efectos legales directos para países en desarrollo (ningún tratado puede vincular a terceros, el denominado principio pacta tertiis). Sin embargo, los países en desarrollo estarán expuestos a efectos significativos del convenio en los siguientes aspectos:

- ATCI simplificará el comercio entre EEUU y la UE. Por lo tanto, las exportaciones de EEUU se tornarán más atractivas en la UE y las exportaciones de la UE en EEUU, ya que se reducen las barreras al comercio. Por consiguiente, algunas exportaciones de países en desarrollo a los EEUU o la EU serán sustituidas por exportaciones de EEUU o la UE ("desviación del comercio").

- ATGI creará un nuevo estándar para los tratados de libre comercio internacionales, incluyendo disposiciones regulatorias, disposiciones sobre la propiedad intelectual y el derecho de inversión. Estos estándares serán incluidos en la siguiente generación de tratados de libre comercio (o los países intentarán adoptarlos), incluyendo convenios con países en desarrollo.

- ATCI llevará, a través de la cooperación regulatoria de la UE y los EEUU, a regulaciones que definen estándares para productos y servicios que pueden ser comercializados en la UE y EEUU. Dado el tamaño de los mercados combinados, muchos productos terminarán fabricándose conforme a esos estándares. Se podría aducir que esto es una desventaja para los países en desarrollo, ya que los productores en estos países no pueden cumplir con los estándares. Sin embargo, esto parece ser un análisis erróneo. La UE y los EEUU ya cuentan con estándares de producto. Para productores que no pueden cumplir con ellos, nada cambia. Sin embargo, los productores en países en desarrollo que pueden cumplir con estos estándares obtienen un acceso simplificado a un mercado adicional.

- Finalmente, los países en desarrollo también se benefician de la cooperación regulatoria de la UE y los EEUU en cuanto a que sus 
Esta obra forma parte del acervo de la Biblioteca Jurídica Virtual del Instituto de Investigaciones Jurídicas de la UNAM

fabricantes (por ejemplo, fabricantes farmacéuticos) están sujetos a inspecciones por agencias de la UE y los EEUU, y la cooperación de estas agencias reducirá la carga impuesta sobre ellos.

\section{RECOMENDACIÓN}

El ATGI será un tratado de libre comercio complejo, de múltiples facetas. Siempre y cuando entre en efecto, EEUU, la UE y sus Estados miembros tendrán que cumplir con él a través de sus reglamentos. Mientras que parte de su probable contenido promete ventajas para el acceso a medicamentos, a saber, la cooperación regulatoria, es probable que otras regulaciones que son objeto de las negociaciones obstaculicen el acceso a medicamentos o suban los precios de medicamentos. Actores en la salud pública deberían asegurar que los intereses sanitarios tengan una voz en la mesa y que los negociadores estén siempre conscientes del impacto de las propuestas presentadas. 
Esta obra forma parte del acervo de la Biblioteca Jurídica Virtual del Instituto de Investigaciones Jurídicas de la UNAM

\title{
LA AMPLIAGIÓN DEL CONGEPTO DE INVENGIÓN, Y DE LA MATERIA PATENTABLE. LOS SEGUNDOS USOS, LOS MÉTODOS DE DIAGNÓSTICO, TERAPÉUTICOS Y QUIRÚRGIGOS Y LOS ORGANISMOS VIVOS
}

\author{
Rafael J. PÉREZ MiRANDA \\ SumARIO: I. Presentación. II. Invenciones y materia patentable. III. Los \\ métodos de diagnóstico, terapéuticos y quirúrgicos. IV. Qué se patenta en la \\ patente de segundos usos. V. Algunas conclusiones.
}

\section{PRESENTAGión}

Los tratados internacionales contemplan la posibilidad de que se considere que no son patentables los métodos de diagnóstico, terapéuticos y quirúrgicos; en los derechos positivos nacionales se suele establecer que no son invenciones o que no son invenciones patentables. Es diferente el caso de los segundos usos de un producto conocido, ya que careciendo de novedad su no patentabilidad es un sobreentendido; para que se puedan patentar se requiere una disposición que lo autorice de manera expresa. Estas exclusiones se encuentra actualmente sometidas a un intenso debate en la doctrina y en los tribunales, en especial en los Estados Unidos (EUA) y en las propuestas de este país en las negociaciones de tratados internacionales, impulsado por las grandes corporaciones farmacéuticas. Los dos temas se encuentran estrechamente vinculados por cuanto el patentamiento de segundos usos de productos conocidos puede ser identificado, en la mayoría de los casos, con los métodos terapéuticos y, en otros, con métodos de diagnóstico. ${ }^{1}$ La importancia del tema que se analiza la podemos ejemplificar con el valor del

1 Correa, Carlos M., Derechos de propiedad intelectual, competencia y protección del interés público, Buenos Aires, B de F, 2009, p. 215. 
Esta obra forma parte del acervo de la Biblioteca Jurídica Virtual del Instituto de Investigaciones Jurídicas de la UNAM

mercado de diagnóstico molecular en EUA, que se estima cercano a los 3 mil millones de dólares. ${ }^{2}$

El debate se presenta en diferentes áreas, en tanto se cuestiona si los métodos de diagnóstico, terapéuticos y quirúrgicos son invenciones; si se justifica eximir del requisito de novedad a los segundos usos; también si otorgar estas patentes viola la moral y el orden público, por un lado, y si no afecta directamente el derecho humano de acceso a la salud, por el otro. En este trabajo, por necesidades de extensión, nos circunscribiremos a un enfoque estrictamente jurídico.

\section{INVENCIONES Y MATERIA PATENTABLE}

El Convenio de París de 1883 no definía la invención ni establecía un marco preciso respecto a la materia patentable, lo que permitió que los países partes establecieran durante más de cien años diversos conceptos de invención y ejemplos sobre lo que no se debía considerar una invención, así como aquellos casos en los cuales una innovación creativa era considerada una invención, pero se prohibía su patentamiento. Esta prohibición podía responder a diferentes causales, como la afectación de la moral, las buenas costumbres y el orden público, o que la posible invención estuviera protegida por otras disposiciones relacionadas con la propiedad intelectual, o que afectara la seguridad nacional, las políticas de desarrollo del país en cuestión, o que violentara los derechos humanos (hasta la década de los años noventa del siglo $\mathrm{XX}$, múltiples países prohibían el patentamiento de productos farmacéuticos y algunos, inclusive, de los procesos).

Es recién en la negociación del Tratado de Marrakech que se incluye en el Acuerdo sobre Propiedad Intelectual vinculada al Comercio (ADPIC) un principio revolucionario, cuya importancia no fue suficientemente valorada en un inicio: el compromiso de los países partes de incorporar en su derecho positivo el principio de que todo tipo de invención, en todos los campos de la tecnología, es considerado materia patentable y que, por tanto, los países partes sólo podrían excluir aquellas invenciones que fueran enumeradas taxativamente en el Acuerdo:

Artículo 27. [Materia patentable1] Sin perjuicio de lo dispuesto en los párrafos 2 y 3 , las patentes podrán obtenerse por todas las invenciones, sean de

2 Driehaus, Johanna, "Patent Landscape in Molecular Diagnostics", en Storz, Ulrich et al., Intellectual Property Issues. Therapeutics, Vaccines and Molecular Diagnostics, Londres, Springer, 2012, p. 73. 
Esta obra forma parte del acervo de la Biblioteca Jurídica Virtual del Instituto de Investigaciones Jurídicas de la UNAM

productos o de procedimientos, en todos los campos de la tecnología, siempre que sean nuevas, entrañen una actividad inventiva y sean susceptibles de aplicación industrial.

Por otra parte, el mismo ADPIC genera un importante incremento de la materia de las creaciones y tecnologías susceptibles de ser protegidas por el sistema de propiedad intelectual; sin embargo, es conveniente destacar que una importancia similar reviste la ampliación en el Acuerdo y también en la teoría y en la jurisprudencia del concepto de invención, o en un sentido estricto, la protección por el sistema de propiedad intelectual de productos y procesos que no son invenciones. Esta tendencia se concreta y amplía en los tratados de libre comercio (TLC), en especial los suscritos por la Unión Europea (en adelante UE) y los EUA, que incluyen capítulos sobre propiedad intelectual. ${ }^{3}$

Como complemento de estas ambigüedades conceptuales, se suele confundir el requisito de invención: sólo las invenciones son patentables, con la materia patentable: tipos de invenciones que no se pueden patentar o invenciones de productos y procesos en áreas que se excluyen de la patentabilidad.

Estas confusiones se agregan a la tendencia a fortalecer con exceso los sistemas de represión al plagio, a la invasión de patentes, y la ampliación directa o indirecta de los plazos de protección; fenómenos que han desvirtuado los fundamentos y objetivos del sistema de propiedad intelectual sin beneficios para los autores e inventores y en perjuicio de la sociedad.

Quizá merezcan también atención disposiciones relevantes sobre temas, materias, que no hacen al sistema de la propiedad intelectual, ya que su relación es muy indirecta, pero que están reguladas y protegidas por los principios del sistema de propiedad intelectual en el acuerdo ADPIC, como el secreto industrial, que no compete al derecho de propiedad intelectual sino al régimen de la competencia desleal, o la prohibición de fabricar decodificadores de señales de satélite, un vulgar fraude que podría o no relacionarse con los derechos de autor, y la protección de los datos de prueba. ${ }^{4}$

3 Véase una síntesis sobre sus características en: Seuba, Xavier, "Intellectual Property in Preferential Trade Agreements: What Treaties, What Content", The Fournal of Word Intellectual Property, vol. 16, núm. 5-6, 2013, pp. 1-22; Drexl, Josef, "Intellectual Property and Implementation of Recent Bilateral Trade Agreements in the EU" y Seuba, Xavier, "Implementation Issues Arising from Intellectual Property Chapters Contained in Trade Agreements Between the EU and Developing Countries", ambos en Drexl, Josef et al. (eds.), EU Bilateral Trade Agreements and Intellectual Property: For Better or Worse?, Londres, Springer, 2014, pp. 265 y ss.

4 Esta secrecía se debe imponer por actividades relacionadas con una patente que ya se otorgó y cuando los requisitos son impuestos por una unidad administrativa que no es la 
Esta obra forma parte del acervo de la Biblioteca Jurídica Virtual del Instituto de Investigaciones Jurídicas de la UNAM

Esta prohibición no sólo no tiene por qué estar en un sistema de propiedad intelectual, sino que contradice claramente aspectos esenciales del sistema de patentes; en efecto, si se trata de información demostrativa de la actividad inventiva o de elementos sustantivos de la invención, es un requisito que se presenten en la misma solicitud de la patente; si sólo se trata de una exigencia para la comercialización del producto, corresponde a los aspectos de seguridad químico farmacéutica, de inocuidad y eficiencia para la salud que pueden ser protegidos por las normas acerca de la competencia desleal, pero no hace a la invención y por tanto no tiene nada que ver con el derecho de propiedad intelectual.

Los tratados internacionales exigen que los países partes se comprometan a otorgar patentes a todas las invenciones de productos o procesos, si bien en la mayoría de ellos no se define a la invención; es un aspecto conceptual que se deja al derecho positivo nacional y a la doctrina. México define a la invención como "toda creación humana que permita transformar la materia o la energía que existe en la naturaleza, para su aprovechamiento por el hombre y satisfacer sus necesidades concretas", un concepto clásico del derecho comparado. ${ }^{5}$ Esta definición permite distinguir a las invenciones de otras creaciones humanas, como pueden ser los descubrimientos de leyes de la naturaleza o la creación de obras estéticas. Discrepo en este punto con Jalife Daher, que en parte restringe el concepto a la utilidad de la creación intelectual respecto de la cual se solicita una patente; considero que la interpretación del concepto de invención debe ser rigurosa por cuanto es el núcleo de un sistema que permite excepcionalmente el ejercicio de un monopolio, por lo cual no considero conveniente una interpretación laxa. ${ }^{6}$

de propiedad industrial y para una actividad que por su naturaleza debe ser supervisada. Véase el artículo de Seuba, Xavier y Genovesi, Luis M., "Implementación del régimen de protección de los datos de prueba presentados al registro farmacéutico", Revista furídica de Buenos Aires-2013, 2014, pp. 67 y ss. Considero conveniente destacar, por otra parte, que un tratado internacional no puede crear categorías con tanta liviandad: la propiedad intelectual se refiere a las invenciones y a las obras, no a actividades simples de verificación por costosas que éstas sean; por tanto, lo dispuesto en los artículos 1o., fración II, y 39 no hacen referencia a una institución del derecho de propiedad intelectual y sería inconstitucional autorizar en razón de ello una ampliación de un privilegio monopólico. Véase el artículo 39.3 del Acuerdo ADPIC.

5 Ley de Propiedad Industrial de México, 1991-1994. En igual sentido, la Ley de Patentes de Invención y Modelos de Utilidad de la República Argentina, artículo 4.a (Ley 24.481 modificada por la Ley 24.572, texto ordenado en 1996, Boletín Oficial del 22 de marzo de 1996). Modificada por la Ley 25.859.

6 Jalife Daher, Mauricio, Derecho mexicano de la propiedad industrial, México, Tirant lo Blanch, 2014, pp. 123 y ss. 
Esta obra forma parte del acervo de la Biblioteca Jurídica Virtual del Instituto de Investigaciones Jurídicas de la UNAM

\section{Ampliación legal del concepto de invención}

Con múltiples argumentos, los tratados internacionales, la doctrina, la jurisprudencia y, finalmente, el derecho positivo de múltiples países, incorporaron a la protección del sistema de propiedad intelectual creaciones intelectuales que no se pueden considerar invenciones ni obras estéticas en sentido estricto. En la mayoría se hacía referencia a la necesidad de realizar investigaciones muy costosas, y de resultado imprevisible, para el desarrollo científico y tecnológico en áreas económicas estratégicas. Se plantea que a efectos de estimular la inversión riesgosa en investigación y desarrollo es conveniente ofrecer el privilegio de la explotación exclusiva, ampliando el concepto de "invención" de "obra estética" o generando sistemas de protección sui generis. En efecto, a la doctrina y a los jueces les resultaba difícil calificar a las nuevas variedades vegetales, a los microprocesadores y a la topografía de semiconductores, invenciones u obras estéticas, tampoco a los programas de cómputo ni a las bases de datos.

En el caso de las nuevas variedades vegetales obtenidas por fitomejoramiento, que cobraron especial importancia a partir de la revolución verde, y cuyo resultado final derivaba de un proceso esencialmente biológico, se decidió crear un esquema de protección sui generis dentro del sistema de propiedad intelectual, pero fuera de los instrumentos tradicionales conocidos como la propiedad industrial y los derechos de autor. Se otorga a quien ha obtenido la mejora vegetal un derecho de explotación exclusiva de la nueva variedad diferente al derecho que otorga la patente. La protección de los microprocesadores y las topografias de semiconductores, que tampoco se podían considerar una invención, se realizó mediante su incorporación como un capítulo especial de las normas sobre propiedad industrial, otorgando el privilegio monopólico con ciertas limitaciones en la exclusividad y en el tiempo. Los programas de cómputo y las bases de datos ofrecían una especial dificultad y se recurrió a la ficción de considerarlos como obras literarias protegibles por el derecho de autor; se les otorgó el derecho de exclusiva en el Acuerdo ADPIC y en el Convenio de Berna, pero la especificad de la creación intelectual motivó que se debieran realizar, en la mayoría de las legislaciones nacionales, modificaciones significativas a su derecho positivo sujetas a diferentes interpretaciones jurisprudenciales; en muchos fallos, los jueces interpretaron, con mayores o menores exigencias, que cuando un programa de cómputo era parte de una máquina susceptible de ser patentada, o mejoraba el funcionamiento de una máquina, podía ser patentado. ${ }^{7}$

7 Powles, Julia, "Alice v. CLS Bank: el Tribunal Supremo...", op. cit. 
Esta obra forma parte del acervo de la Biblioteca Jurídica Virtual del Instituto de Investigaciones Jurídicas de la UNAM

\section{Ampliación legal de la materia patentable}

Los organismos vivos presentaron un desafío al sistema de propiedad intelectual: por una parte, era muy difícil demostrar que los nuevos productos no fueran resultado de un proceso esencialmente biológico; por otra, resultaba difícil saltar la valla de la afectación a la moral, el orden público y las buenas costumbres. La sentencia de la Suprema Corte de EUA en el caso Diamond v. Chakrabarty, que otorgó una patente a un organismo vivo, un microorganismo modificado genéticamente, tuvo un efecto inmediato en el derecho positivo de muchos países y, a posteriori, en el Acuerdo ADPIC, haciendo que se reconozca de manera expresa la patentabilidad de los microorganismos, sin aclarar el significado de una denominación que no tiene su origen en el vocabulario científico. Podemos decir que éste fue uno de los primeros casos de ampliación de la materia patentable, ya que en términos generales y en el caso de la patente otorgada se podría aceptar que la acción humana fue preponderante respecto al proceso biológico. Sin embargo, la afirmación de la Corte Suprema de EUA respecto a que cualquier invento que se realice "bajo el sol" es patentable generó confusión y encendidos debates en la doctrina.

Una nueva ampliación de la materia patentable se relacionó con el debate en las oficinas administrativas y en la justicia de EUA sobre el patentamiento de secuencias totales o parciales de genes; así, se incorporó en el derecho positivo de la mayoría de los países la exclusión del patentamiento de genes o fragmentos de genes, tal cual se encuentran en la naturaleza, dejando a las oficinas de registro y a la jurisprudencia la posibilidad de reconocer como patentable, a contrario sensu, el mero aislamiento del gen o fragmento a patentar, o de exigir que se pruebe la función de los genes o que además se les realice una modificación sustantiva. Al igual que en los microorganismos, esta ampliación de la materia patentable se vinculó directamente con la definición de invención. La aceptación generalizada del patentamiento de genes aislados fue cuestionada seriamente por la Suprema Corte de EUA en el caso Myriad. ${ }^{8}$ Es interesante esta ampliación de la materia patentable en muchos países, incluidos México, Argentina, Brasil, Canadá, Japón, Australia y la Unión Europea, entre otros, basada en el registro masivo que se realizara en EUA. Ahora, a partir del caso Myriad, que derivó en instrucciones a la oficina norteamericana de patentes de que no

8 Association for Molecular Pathology et al. v. Myriad Genetics, Inc. et al., certiorari to the United States Court of Appeals for the Federal Circuit 12-398, argued April 15, 2013, decided June 13, 2013. 
Esta obra forma parte del acervo de la Biblioteca Jurídica Virtual del Instituto de Investigaciones Jurídicas de la UNAM

registre patentes sobre genes aislados, pasan a diferenciarse, por su mayor amplitud y carencia de criterios científicos, de la jurisprudencia norteamericana. ${ }^{9} \mathrm{El}$ tema no sólo resulta relevante por sus repercusiones crematísticas, sino también por sus posibles efectos negativos en el desarrollo de la ciencia, como el caso del genetista de la Universidad de California, en Los Ángeles, James Grody, citado por el Premio Nobel Laughlin, que "tuvo que dejar de realizar su investigación en sordera congénita ligada al gen para la proteína conexina 26 porque Athena Diagnostics, titular de la patente del gen, le exigió el pago de una regalía excesiva". ${ }^{10}$

\section{El orden público, la moral y las buenas costumbres, y la seguridad nacional, como causales de exclusión}

La posibilidad de excluir el patentamiento de un invento por cuanto el mismo afecta la moral, el orden público o las buenas costumbres es una disposición muy antigua, común al derecho positivo de la mayoría de los países y que fue recogida expresamente por el Acuerdo ADPIC, agregando la condición de que la exclusión no se sustente en la prohibición de comercialización del proceso o producto. Esta condición había sido acordada ya en el Convenio de París, y si bien no se relacionaba directamente con la exclusión por motivos de moral u orden público, la doctrina interpretó que se refería especialmente a estos casos. Es éste quizás el caso más claro de exclusión en lo que se refiere a inventos patentables, es decir, nuevos, útiles y no manifiestos, pero que no se podrán patentar.

Pese a la casi unánime inclusión en el derecho comparado, esta causal de exclusión ha sido cuestionada por la doctrina por cuanto no contempla la esencia de los derechos de propiedad intelectual. En efecto, la patente otorga al titular el derecho de explotación exclusiva del producto o proceso, y de oponerse a que terceros los exploten, pero no autoriza la explotación del producto, lo cual resulta claro en el caso del patentamiento de productos farmacéuticos que a posteriori son sometidos a rigurosas pruebas antes de

9 La legislación mexicana excluye el patentamiento del material biológico y genético "tal cual se encuentra en la naturaleza" (artículo 16, inciso II); es más clara la legislación argentina, que en un texto similar agrega "o su réplica" (artículo 7o., inciso b). La Directiva Europea sobre Patentes Biotecnológicas acepta el patentamiento de una secuencia o de una secuencia parcial de un gen aun en el caso de que sea idéntica a un elemento de la naturaleza, si bien exige que tenga una aplicación industrial (artículo 5o., incisos 2 y 3).

10 Laughin, Robert B., Crímenes de la razón. El fin de la mentalidad científica, Madrid, Katz, 2010, p. 63. 
Esta obra forma parte del acervo de la Biblioteca Jurídica Virtual del Instituto de Investigaciones Jurídicas de la UNAM www.juridicas.unam.mx

autorizar su comercialización. ${ }^{11}$ Estas consideraciones motivaron que fueran muy pocos los casos conocidos de exclusión del patentamiento por estas causales. ${ }^{12}$

Sin embargo, a partir del primer caso de patentamiento de un organismo vivo esta argumentación fue utilizada de manera reiterada, en especial en relación con el patentamiento de plantas, animales y partes del cuerpo humano. Los intentos de aclarar esta causal de exclusión fueron relativamente exitosos en la Directiva de la Unión Europea sobre Patentamiento Biotecnológico, y a partir de su reglamentación y de los casos resueltos se ha generado cierta guía al respecto, si bien en lo esencial subsisten los cuestionamientos. La argumentación moral ha sido utilizada por países influenciados por diversos cultos religiosos para tratar de impedir investigaciones que utilizan embriones humanos y para impedir en la Asamblea de Naciones Unidas la prohibición de la clonación reproductiva, alegando que ello implicaba autorizar a contrario sensu la clonación terapéutica.

Otra causal de exclusión prevista de manera confusa en ADPIC se relaciona con la seguridad nacional; establece la posibilidad de adoptar medidas especiales relacionadas con la energía nuclear, el tráfico de armas, así como la facultad para que los países partes otorguen patentes secretas si lo consideran necesario. ${ }^{13}$

\section{Importancia de la invención como presupuesto del derecho de patente}

Parte de la doctrina y de los jueces suelen analizar en diverso orden los requisitos necesarios para que una creación humana se considere una invención; si se trata además de una invención patentable y, en este caso, si no está afectada por una causal de exclusión. ${ }^{14}$ Quizás un buen ejemplo surge

11 Pérez Miranda, Rafael J., Tratado de derecho de la propiedad industrial, México, Porrúa, 2011, pp. 119 y ss.

12 Las patentes obtenidas por Alfred Nobel, que lo ayudaron a acumular una gran fortuna, eran para proteger productos bélicos que se podían considerar inmorales, pero podían tener usos industriales; un fármaco, como la morfina, puede ser beneficioso para la salud, inocuo o muy nocivo, según la dosis, el tiempo en que se aplique o la consecuencia más nociva de no aplicarlo.

13 ADPIC, artículo 73, excepciones relativas a la seguridad. Una disposición similar se establece en el Tratado sobre Derecho de Patentes de la OMPI, artículo 4o., excepción relativa a la seguridad.

14 Véase un excelente desarrollo del tema en Bergel, Salvador Darío, "La invención y los requisitos objetivos de patentabilidad", en Correa, Carlos et al., Régimen legal de las patentes de invención, Buenos Aires, La Ley, 2013, t. I, pp. 220 y ss. 
Esta obra forma parte del acervo de la Biblioteca Jurídica Virtual del Instituto de Investigaciones Jurídicas de la UNAM

del inicio de un artículo de Julia Powles: "Toda patente debe cumplir el requisito de materia patentable, o las condiciones de patentabilidad, como a veces se la denomina, o bien la exigencia de que exista una invención" ${ }^{15} \mathrm{La}$ autora presenta los requisitos como si bastara con cumplir con uno de ellos, cuando se requiere la suma de todos ellos para una "invención patentable".

En muchos casos, incluso se excluye el análisis sobre el requisito de que se trate de una invención; consideramos, sin embargo, que esta distinción es fundamental en la interpretación y aplicación del derecho internacional.

En efecto, la disposición del Acuerdo ADPIC impone a los países partes la obligación de otorgar patentes a "todas las invenciones", salvo las expresamente exceptuadas, y define qué se debe entender como "invención patentable"; es decir, primero se debe aceptar, probar, que se trata de una invención, y luego evaluar si, además de ello, esa invención reúne los requisitos de novedad, nivel inventivo y aplicación industrial. Pero ADPIC no define a la "invención"; deja a la doctrina y a la legislación de cada país parte la distinción entre descubrimiento e invención y, con base en ella, la definición sobre "qué es una invención" y, por tanto, los requisitos que debe cumplir; es éste un tema de especial interés para evitar, entre otros problemas, que se patenten descubrimientos que, si bien pueden ser producto de investigaciones rigurosas y de alto nivel, no son invenciones. ${ }^{16}$

Otro aspecto que se debe tener en cuenta es que la invención haya culminado, que no se trate de un resultado de una investigación que puede llegar a ser una invención, pero que todavía se trata de un conocimiento básico; la cercanía entre los conocimientos básicos y los productos tecnológicos en la biología molecular y la biotecnología hacen más necesaria esta distinción, para no afectar la evolución y progreso de la investigación científica. ${ }^{17}$

Es decir, se deben respetar pasos excluyentes en la sede administrativa y, si hubiera impugnaciones, en el análisis judicial:

a) Primero se debe analizar si se trata de una invención conforme a la definición de invención, teniendo en cuenta los casos en que la ley considera que ciertos procesos o productos no son invenciones.

b) Luego se debe investigar si la invención es nueva, no manifiesta y aplicable industrialmente.

15 Powles, Julia, "Alice v. CLS Bank: el Tribunal Supremo...”, op. cit.

16 En especial, para el tema que analizamos, aquellos conocimientos básicos que pueden bloquear el desarrollo de nuevas tecnologías relacionadas con el campo de la salud.

17 Bergel, Salvador Darío, "Investigación científica y patentes: análisis ético-jurídico de sus relaciones”, Revista Bioética, Brasil, vol. 22, núm. 3, 2014, p. 419. 
Esta obra forma parte del acervo de la Biblioteca Jurídica Virtual del Instituto de Investigaciones Jurídicas de la UNAM

c) Por último, verificar si, aun reuniendo todos estos requisitos, no le es aplicable alguna de las exclusiones previstas por los tratados o las leyes.

Parte del debate consiste en la calificación de la enumeración que realiza el legislador de las creaciones que no son invenciones; en tanto algunos autores consideran que si se trata de una causal, más de no patentabilidad, la enumeración es iuris tantum, en tanto que si se trata de un ejemplo claro de qué no se considera una invención, la enumeración no admite prueba en contrario, es iuris et de iure. ${ }^{18}$

Ahora bien, si se verifica que una determinada creación humana es una invención, y ésta es nueva, tiene nivel inventivo y aplicación industrial, a posteriori se debe analizar si se la puede considerar materia patentable, y en este campo la exclusión de patentabilidad debe estar contemplada, autorizada, en el Acuerdo ADPIC y en los tratados internacionales de libre comercio con capítulos sobre propiedad intelectual; estos capítulos pueden reducir las causales de exclusión, en tanto los estándares establecidos por ADPIC son estándares mínimos. La reducción normativa, expresa o indirecta, de las causales de exclusión es quizás una de las secciones que lleva a debates más intensos.

Una limitación de las causales de exclusión de patentabilidad se puede verificar en los capítulos sobre propiedad intelectual de los tratados de libre comercio que EUA ha suscrito con Chile, con Colombia y con Centroamérica y República Dominicana, en los cuales las partes expresan que ninguna disposición del TLC afectará el derecho de los países a hacer uso de las exclusiones autorizadas por el artículo 27 del ADPIC, pero luego contraen compromisos de promover en la medida de lo posible el patentamiento de plantas y animales, y se comprometen a que si más adelante se otorgara ese derecho, no se derogará en el futuro. ${ }^{19}$ En la propuesta de EUA para el acuerdo TPP se elimina la referencia al artículo 27 del ADPIC.

18 Véase este debate en Bergel, Salvador Darío, "Exclusiones de patentabilidad", op. cit. $\mathrm{El}$ autor critica lo expuesto en la obra de Bensandón, M., Ley de patentes comentada y concordada con el ADPIC y el Convenio de París, Buenos Aires, Lexis-Nexis, 2007. Esta afirmación de Martín Bensandón, magníficamente rebatida por Bergel, es reiterada en su libro Derecho de patentes, Buenos Aires, Abeledo-Perrot, 2012, pp. 102 y ss.

19 Véase TLC Estados Unidos de América-Chile, artículo 17.9.2; TLC EUA-Colombia, artículo 16.9.2; TLC EUA-República Dominicana y Centroamérica (RD-CAFTA), artículo 15.9.2. 
Esta obra forma parte del acervo de la Biblioteca Jurídica Virtual del Instituto de Investigaciones Jurídicas de la UNAM

\section{La ampliación del concepto de invención y de la materia patentable en las políticas públicas}

El privilegio de exclusiva que otorga el derecho de propiedad intelectual, administrado por los particulares, limita a veces en extremo las facultades de los Estados para ejercer su soberanía en la implementación de políticas públicas en áreas sensibles, como la salud pública, la producción y consumo de alimentos, el acceso a la educación y la cultura y la defensa nacional. Por otra parte, los instrumentos diseñados por el derecho internacional, y en especial por las legislaciones nacionales, no otorgan a los gobiernos instrumentos ágiles para impedir el abuso del ejercicio del privilegio monopólico y/o la inserción en los contratos de licencia de cláusulas consideradas prácticas monopólicas. Son claros ejemplos de ello los elevados precios de los fármacos patentados, que motivan que muchos de ellos se encuentren fuera del cuadro básico de los sistemas públicos de salud, aun en países desarrollados, y el control de todos los niveles de los sectores estratégicos del mercado agrícola de Argentina, Brasil, Canadá y EUA por parte de las corporaciones que detentan los derechos de propiedad intelectual sobre las semillas transgénicas.

La tendencia a flexibilizar el concepto de invención y a ampliar la materia patentable se da en paralelo con la tendencia a ampliar el campo de los derechos humanos, otorgando a los tratados internacionales que los regulan una jerarquía superior en la estructura jurídica. Estas dos tendencias han generado importantes tensiones que se traducen en sólidas argumentaciones doctrinales que impugnan que se utilicen instrumentos de promoción de las inversiones que simultáneamente marginan a vastos sectores de la población del acceso a la salud, la educación y la cultura, entre otros servicios necesarios. Sin embargo, estos debates han tenido poca repercusión legislativa.

\section{LOS MÉTODOS DE DIAGNÓSTICO, TERAPÉUTICOS Y QUIRÚRGICOS}

\section{El concepto de métodos de diagnóstico, terapéuticos y quirúrgicos ${ }^{20}$}

Todas las palabras utilizadas en las exclusiones en estudio son susceptibles de múltiples acepciones. En tanto la disposición hace referencia a la materia

20 Para un análisis detallado de los conceptos de diagnóstico, terapéutico y quirúrgico véase Sterckx, Sigrid y Cockbain, Julian, Exclusions from Patentability. How Far Has the European Patent Office Eroded Boundaries?, Cambridge, Cambridge University Press, 2012, pp. 135 y ss. 
Esta obra forma parte del acervo de la Biblioteca Jurídica Virtual del Instituto de Investigaciones Jurídicas de la UNAM www.juridicas.unam.mx

patentable, y ésta sólo se puede referir a "procesos o productos", se debe interpretar que "método", en este caso, es sinónimo de "proceso"; a contrario sensu, no se excluyen de la patentabilidad los productos, instrumentos y materiales que se puedan considerar una invención nueva, útil y susceptible de aplicación industrial y que son necesarias para el proceso.

a) En términos generales, nos referimos al diagnóstico como el conjunto de estudios y análisis que le permiten a un profesional de la medicina conocer la existencia de una enfermedad o defecto de un cuerpo humano o animal, y en su caso proponer las acciones para curarla, demorar sus efectos nocivos o manifestar la inutilidad de cualquier acción al respecto. En principio, consta de cuatro pasos: 1) examen: recopilación de datos (establecimiento de la historia clínica); 2) comparación de los datos con los valores normales; 3) identificación de cualquier desviación significativa de la norma (por ejemplo, síntoma), y 4) diagnóstico propiamente dicho: la decisión deductiva del médico o veterinario. ${ }^{21}$ Algunos autores consideran que es necesario que se den estos cuatro pasos para que se considere que es un método de diagnóstico y por tanto no patentable. Por el contrario, parte de la doctrina y de la jurisprudencia considera que basta con que se trate de mediciones o registros de condiciones del cuerpo humano con objetivos de conocer su estado de salud o de métodos de preparación para el diagnóstico para que se lo considere "métodos de diagnóstico". ${ }^{22}$

b) Entendemos por métodos terapéuticos el proceso que un médico propone para evitar que se adquiera una enfermedad (terapia preventiva), intentar la cura de una enfermedad, paliar sus efectos o solucionar una carencia del cuerpo humano o animal (terapias curativas). Los métodos terapéuticos se diseñan a partir de un diagnóstico, pero no necesariamente a partir de un diagnóstico se concluye en un método terapéutico, y la utilización de uno u otro dependerá de la deci-

21 Borges Barbosa, Denis y Grau-Kuntz, Karin, 3. Exclusiones de la materia patentable y excepciones y limitaciones a los derechos de los titulares de patentes. Biotecnología, Ginebra, OMPI, 2010, p. 51. Este concepto fue tomado por los autores de una interpretación de los tribunales europeos sobre el artículo 53 de la Ley Europea de Patentes, véase infra.

22 Martínez Barrabés, Mireia, "El ADPIC y la excepción a la patentabilidad de los métodos de diagnóstico, terapéuticos y quirúrgicos para el tratamiento de personas o animales", Revista de Estudios Internacionales, 2014, pp. 12 y ss. Se adhiere a la posición de la Oficina Europea de Patentes respecto a la exigencia de las cuatro etapas o procesos. Por otra parte, en un documento de la OMPI se hace referencia a si se considera posible una mayor flexibilidad; véase el estudio de expertos: Borges Barbosa, Denis y Grau-Kuntz, Karin, 3. Exclusiones de la materia patentable..., cit., pp.14 y ss. 
Esta obra forma parte del acervo de la Biblioteca Jurídica Virtual del Instituto de Investigaciones Jurídicas de la UNAM

sión de un profesional de la medicina. Pueden implicar métodos de tratamiento de los pacientes que no requieren el uso de productos médicos patentados, métodos para usar un medicamento patentado o un dispositivo, o técnicas para el aislamiento de compuestos químicos o para la construcción de dispositivos. ${ }^{23}$

c) Estos métodos de tratamiento se consideran quirúrgicos cuando se requiere la operación de un profesional de la medicina sobre el cuerpo humano o animal, cuando se lo invade mediante cirugía. ${ }^{24}$

\section{Los métodos de diagnóstico, terapéuticos y quirúrgicos como invenciones}

Los métodos de diagnóstico, terapéuticos y quirúrgicos para seres humanos y animales (en adelante, los métodos de diagnóstico) no se consideraron históricamente invenciones en el derecho positivo de casi todos los países, y al no ser considerados una invención, no correspondía analizar si se los podía calificar como una "invención patentable". EUA era y es, relativamente, una excepción, si bien a partir de una reforma a su Ley de Patentes en 1996, propuesta al Congreso por el presidente William Clinton, conocida como Ganske Compromise Law, no se puede sancionar por una infracción a un derecho de patente a un médico que la utiliza en el ejercicio de sus funciones, o a una institución relacionada con la salud por tal actividad médica. Por lo cual, la patente que se pudiera obtener sobre métodos de diagnóstico, terapéuticos o quirúrgicos casi carece de entidad; también han relativizado esta posibilidad sentencias de la Suprema Corte norteamericana que se analizan infra. ${ }^{25}$ Ahora bien, la excepción se limita a casos específicos que ha estudiado detalladamente la doctrina norteamericana. ${ }^{26}$

En efecto, si analizamos cualquiera de las definiciones que hemos presentado sobre método de diagnóstico, podemos ver que son simples métodos científicos que permiten descubrir y luego aplicar leyes de la naturaleza.

23 Brougher, Joanna T., Intellectual Property and Health Technologies. Balancing Innovation and the Public's Health, Nueva York, Springer, 2014, p. 67.

24 Sterckx, Sigrid y Cockbain, Julian, Exclusions from..., cit.

25 United States Code, Title 35, Patents... 35 U.S.G. 287. Limitation on damages and other remedies; marking and notice... (c)(1) With respect to a medical practitioner's performance of a medical activity that constitutes an infringement under section 271 (a) or (b) of this title, the provisions of sections 281, 283, 284, and 285 of this title shall not apply against the medical practitioner or against a related health care entity with respect to such medical activity...

26 Brougher, Joanna T., Intellectual..., cit., pp. 71 y ss.; Sterckx, Sigrid y Cockbain, Julian, Exclusions from..., cit. 
Esta obra forma parte del acervo de la Biblioteca Jurídica Virtual del Instituto de Investigaciones Jurídicas de la UNAM

Sin embargo, a partir de fines del siglo XX se comenzó a cuestionar esta concepción y se introdujo una modificación importante en el artículo 27 del Acuerdo ADPIC, que establece que: "Artículo 27.3. Los miembros podrán excluir asimismo de la patentabilidad: a) los métodos de diagnóstico, terapéuticos y quirúrgicos para el tratamiento de personas o de animales; b) ...".

$\mathrm{Al}$ establecer que los países podrán excluir estos métodos de la patentabilidad, se parte del supuesto de que se trata de invenciones patentables, que está muy lejos de ser aceptada pacíficamente por la doctrina y por el derecho comparado.

Esta recategorización se compagina en cierta medida con la nota agregada al concepto de invención patentable, en la cual se dispone que los países partes podrán considerar que el concepto "susceptible de aplicación industrial" es sinónimo de "útil" (ADPIC, nota aclaratoria 5); se establecen como sinónimos conceptos susceptibles de interpretación muy diferente. ${ }^{27}$ En efecto, como lo expresaba la doctrina y la legislación española (véase infra), en el caso en que se pudiera demostrar que algún método de diagnóstico, terapéutico o quirúrgico fuera una invención, sin duda que carecería de aplicación industrial, pero podría considerárselo útil.

\section{Los métodos de diagnóstico como materia que se puede excluir de la patentabilidad}

El reconocimiento acerca de la posibilidad de declarar a los métodos de diagnóstico, terapéuticos y quirúrgicos "invenciones no patentables" repercutió en el derecho positivo internacional y de inmediato se trasladó al Tratado de Libre Comercio para América del Norte (TLCAN), que se negoció en paralelo al Tratado de Marrakech. ${ }^{28}$ Cabe aclarar que en el capítulo sobre propiedad intelectual del TLGAN se incluyó un texto similar al transcrito por el ADPIC respecto al compromiso de los países partes de otorgar una patente a toda invención en todos los ramos de la tecnología, con la posibilidad de las partes de excluir exclusivamente a las enumeradas taxativamente en el mismo Tratado. ${ }^{29}$

27 ADPIC, nota 5. Las notas del Acuerdo ADPIC no se incluyen en el texto del tratado sometido a ratificación por los países, por lo cual su valor es meramente interpretativo.

28 Artículo 1709, primer párrafo.

29 TLCAN, artículo 1709. Patentes. Sujeto a lo dispuesto en los párrafos 2 y 3, las partes dispondrán el otorgamiento de patentes para cualquier invención, ya se trate de productos o de procesos, en todos los campos de la tecnología, siempre que tales invenciones sean nuevas, 
Esta obra forma parte del acervo de la Biblioteca Jurídica Virtual del Instituto de Investigaciones Jurídicas de la UNAM

Originalmente, la Convención Europea sobre Patentes (CEP) establecía en su artículo 53 que estos métodos carecían de aplicación industrial, por lo cual no se los consideraba invenciones, y al no ser invenciones no eran patentables; a posteriori se adecuó la redacción de la Convención al ADPIC y quedó como una invención no patentable. Similares conclusiones se pueden deducir de la decisión 344 del Pacto Andino, que decía: "Artículo 6o. No se considerarán invenciones: ...f) Los métodos terapéuticos o quirúrgicos para el tratamiento humano o animal, así como los métodos de diagnóstico”.

Ésta fue sustituida por la decisión 486 de 2000 para adecuarla al Acuerdo; en razón de esta decisión se la considera una invención, pero se la excluye de patentabilidad: "Artículo 20. No serán patentables: ...d) los métodos terapéuticos o quirúrgicos para el tratamiento humano o animal, así como los métodos de diagnóstico aplicados a los seres humanos o a animales". ${ }^{30}$

El derecho positivo de México, como expusiéramos, define la invención como una creación humana y a posteriori enumera casos que pudieran considerarse dudosos, aclarando expresamente que no son invenciones. La mayor parte de los casos que no considera invenciones son efectivamente descubrimientos, y por tanto no gozan de ninguna protección, entre ellos: "Artículo 19... V. Las formas de presentación de información; VII. Los métodos de tratamiento quirúrgico, terapéutico o de diagnóstico aplicables al cuerpo humano y los relativos a animales...".

Es decir, si bien sostenemos que las leyes no deben contener definiciones que corresponden a la doctrina, la incorporación de la definición de invención puede ser considerada en este caso un acierto, al menos en relación al tema en estudio, al igual que la enumeración ejemplificativa de casos, presentaciones, que no se consideran invenciones, y por separado precisar qué invenciones no son patentables (se trata de dos enumeraciones que tienen naturaleza jurídica diferente, la primera ejemplificativa y la otra taxativa); sin embargo, como se detalló, el legislador no pudo evitar caer en cierta confusión.

Igual metodología adopta el legislador argentino, que define a la invención, y a título ejemplificativo enumera casos que no son invenciones: "Artículo 6o. No se considerarán invenciones para los efectos de esta ley: e) Los

resulten de una actividad inventiva y sean susceptibles de aplicación industrial... Asimismo, cada una de las partes podrá excluir de la patentabilidad: (a) los métodos de diagnóstico, terapéuticos y quirúrgicos, para el tratamiento de seres humanos y animales...

30 Decisión 486 del Pacto Andino, Convenio de Cartagena; comenzó a regir el 1o. de diciembre de 2000 . 
Esta obra forma parte del acervo de la Biblioteca Jurídica Virtual del Instituto de Investigaciones Jurídicas de la UNAM

métodos de tratamiento quirúrgico, terapéutico o de diagnóstico aplicables al cuerpo humano y los relativos a animales...".

Así como la legislación de Brasil: "Artículo 10. No se considera invención ni modelo de utilidad: VIII. Técnicas y métodos operatorios, bien como métodos terapeúticos o de diagnóstico, para aplicación en el cuerpo humano o animal...".31

\section{Justificaciones para la exclusión como materia patentable de los métodos de diagnóstico, terapéuticos y quirúrgicos}

Como se expresa supra, a partir del ADPIC se comienza a incluir en los instrumentos internacionales, en los estudios de la Organización Mundial de la Propiedad Intelectual (OMPI) y en gran parte de la doctrina, a los métodos de diagnóstico como un ámbito de la tecnología que se puede excluir de la patentabilidad; ahora bien, la interpretación de la doctrina diverge respecto a las causas de su posible exclusión, en tanto se puede deber a que no reúne los requisitos para ser considerada una invención, o puede ser una invención no patentable por carecer de aplicación industrial o una invención patentable que se excluye de la patentabilidad haciendo uso de la posibilidad que le brinda el artículo 27 del ADPIC para proteger el acceso ciudadano al derecho humano a la salud. Las caracterizaciones diversas de los métodos de diagnóstico han influido en las causales alegadas para explicar por qué, aunque se pudiera tratar de una invención, se justifica su exclusión.

La Suprema Corte de México justificó la exclusión considerando que el legislador pretendía, con ella, evitar posibles concesiones discriminatorias que restringieran su utilización y el incremento injustificado de precios; aclara el máximo tribunal que adopta el concepto usual de método de diagnóstico, evitando interpretaciones semánticas bizantinas que pudieran impedir que el precepto cumpliera con sus objetivos. ${ }^{32}$ Se trató de una

31 Argentina: Ley de Patentes de Invención y Modelos de Utilidad (Ley 24.481, modificada por la Ley 24.572, texto ordenado en 1996, Boletín Oficial del 22 de marzo de 1996). Modificada por la Ley 25.859. Brasil: Ley de la Propiedad Industrial 9.279 del 14 de mayo de 1996.

32 "Lo que trata de evitar el legislador es que se eleve el costo de la medicina con el pago de regalías por parte de los laboratorios de diagnóstico, entre otras cosas, y que mediante el sistema de concesiones discriminatorias de métodos patentados, resulte prohibido en algunas instituciones utilizar determinado método o procedimiento para efectuar diagnósticos". Primer Tribunal Colegiado en Materia Administrativa del Primer Circuito, amparo en revi- 
Esta obra forma parte del acervo de la Biblioteca Jurídica Virtual del Instituto de Investigaciones Jurídicas de la UNAM

interpretación de la ley de 1976, cuyo texto era idéntico al actual. ${ }^{33}$ Esta concepción de la exclusión por motivos humanitarios es recogida por un documento de la OMPI, en el cual, sin embargo, se cae en una interpretación equívoca, ya que el requisito de "aplicación industrial" es aplicable a las invenciones, y una invención es tal aun cuando no tenga aplicación industrial; en ese caso, lo que sucede es que "no es patentable". Dice el documento: "Conviene señalar que en numerosos países las invenciones relativas a los métodos de diagnóstico, quirúrgicos y terapéuticos para el tratamiento de seres humanos o animales no son patentables, porque no se consideran invenciones que cumplen el requisito de la aplicabilidad industrial". ${ }^{34}$

\section{La ampliación de la materia patentable a los segundos usos}

Expusimos en un inicio que los debates sobre el patentamiento de los segundos usos y de los métodos terapéuticos tenían el mismo contenido; es conveniente aclarar este punto por la relevancia del tema en el Acuerdo TPP. En este caso, el enfoque de ampliación de la materia patentable se realiza eliminando en determinados casos el requisito de "novedad", es decir, se permite "repatentar", volver a patentar un producto conocido. Para aclarar el tema quizá convenga transcribir dos textos que consideramos relevantes, por un lado el correspondiente a la Convención Europea sobre Patentes:

Artículo 53. Excepciones a la patentabilidad. No se concederán las patentes europeas para: ...c) los métodos de tratamiento quirúrgico o terapéutico del cuerpo humano o animal y los métodos de diagnóstico aplicados al cuerpo humano o animal, no aplicándose esta disposición a los productos, en particular las sustancias o composiciones, para la aplicación de uno de estos métodos.

Artículo 54. Novedad. 1. Se considera que una invención es nueva cuando no está comprendida en el estado actual de la técnica... 4. Lo dispuesto en los párrafos 2 y 3 no excluirá la patentabilidad de cualquier sustancia o composición comprendida en el estado actual de la técnica para la utilización en uno de los métodos indicados en el artículo 53, apartado c), a condición de que su utilización para cualquiera de esos métodos no esté comprendida en

sión 1047/79 del 26 de marzo de 1980, unanimidad de votos, ponente: Guillermo Guzmán Orozco.

33 Ley de Invenciones y Marcas, Diario Oficial de la Federación del 10 de febrero de 1976, artículo 9o., fracción V.

34 Borges Barbosa, Denis y Grau-Kuntz, Karin, 3. Exclusiones de la materia patentable..., cit., p. 4 . 
Esta obra forma parte del acervo de la Biblioteca Jurídica Virtual del Instituto de Investigaciones Jurídicas de la UNAM

el estado actual de la técnica. 5. Los párrafos 2 y 3 no excluirán la patentabilidad de una sustancia o un compuesto de los señalados en el párrafo 4 para toda utilización específica en todo método de los señalados en el artículo 53, apartado c), a condición de que esta utilización no esté comprendida en el estado actual de la técnica. ${ }^{35}$

Y de especial importancia para México, lo dispuesto al respecto en el TPP:

Artículo 18.37. Materia patentable... 2. Sujeto a los párrafos 3 y 4 y de conformidad con el párrafo 1, cada parte confirma que las patentes están disponibles para invenciones que se reivindiquen como (para) al menos uno de los siguientes: nuevos usos de un producto conocido, nuevos métodos de usar un producto conocido, o nuevos procesos de uso de un producto conocido. Una parte puede limitar dichos procesos a aquellos que no reivindiquen el uso del producto como tal.

3. ...Una parte puede excluir también de patentabilidad: (a) métodos de diagnóstico, terapéuticos o quirúrgicos para el tratamiento de humanos o animales... ${ }^{36}$

\section{QUÉ SE PATENTA EN LA PATENTE DE SEGUNDOS USOS}

En los segundos usos no se patenta un producto, ya que por definición las palabras "segundo uso" indican que la cosa, el producto, ya existe; tampoco un proceso, por cuanto en ese caso no se necesitaría incluirlo como una excepción. Surge entonces la duda sobre la materia patentable, que es lo que se patenta, ya que desde sus inicios - en el siglo XV - el objeto de las patentes fueron productos; en el siglo XIX se incorpora de manera expresa la patente de proceso, es decir, se protege no sólo a los productos, sino también los procesos diferentes y más útiles, más competitivos, para elaborar un producto patentado. Por ello debemos ser muy claros en esta tercera opción.

La Convención de Múnich establece con claridad que la autorización para patentar los segundos usos es una excepción a la prohibición de patentar métodos de diagnóstico, terapéuticos y quirúrgicos. No lo hace así el TPP, en tanto entre sus países miembros los hay que autorizan el paten-

35 Convenio de Múnich sobre Concesión de Patentes Europeas, del 5 de octubre de 1973 (versión consolidada tras la entrada en vigor del Acta de revisión del 29 de noviembre de 2000).

36 Secretaría de Economía, México, Tratado de Asociación Transpacífico, 2015. 
Esta obra forma parte del acervo de la Biblioteca Jurídica Virtual del Instituto de Investigaciones Jurídicas de la UNAM

tamiento de métodos de diagnóstico, terapéuticos y quirúrgicos, dado lo cual no requieren de la excepción, habiendo otros que aún lo prohíben. Sin realizar aclaraciones, se expresa que se legislará incorporando a la materia patentable los segundos usos y se mantiene la posibilidad de que los países partes sostengan como causal de exclusión el patentamiento de métodos de diagnóstico, terapéuticos y quirúrgicos. Las redacciones de ambos textos son diferentes, y si bien tienen el mismo esquema conceptual, esa diferencia puede generar confusiones en las reformas legislativas que se generen en los derechos positivos nacionales. ${ }^{37}$

Es conveniente aclarar que pese a que esta exigencia del TPP se inserta en el capítulo de "materia patentable", conceptualmente debiera incorporarse al capítulo del sistema de propiedad industrial que denominamos "invenciones patentables".

a) En el segundo uso propiamente dicho se describe la eficiencia de un producto para producir determinados efectos cuando se lo suministra o aplica a un organismo vivo según determinadas instrucciones; la sustancia en sí carece de novedad y puede estar patentada, puede haber estado patentada o puede ser de uso público; no es una sustancia lo que se patenta sino la reivindicación de que la misma sustancia que carece de novedad puede ser eficiente para generar efectos positivos en la atención de un problema, de una enfermedad, diferente del problema o enfermedad para la cual hasta la actualidad se la utilizaba.

b) También comprende el segundo uso la posibilidad de patentar un producto conocido que, aplicado mediante métodos o procesos no conocidos, es más eficiente para solucionar el mismo problema o enfermedad, para el cual se utilizaba hasta ese momento; en el caso de una sustancia patentada, vigente o no, que se aplica para la misma enfermedad descrita en la reivindicación de la patente original.

c) Estos nuevos usos pueden o no estar insertos en un sistema más complejo que los vinculen a métodos de diagnóstico general o individualizados que permitan definir con mayor precisión el nuevo método o proceso de aplicación del producto conocido.

37 Con una redacción diferente encontramos también la autorización del patentamiento de segundos usos en el Tratado de Libre Comercio de EUA con Australia, cuyo artículo 17.9.1.a se refiere expresamente a la posibilidad de patentar el nuevo uso de un producto conocido, si bien a continuación en el mismo artículo 17.9.1.b dice que los países pueden excluir el patentamiento de métodos de diagnóstico, terapéuticos y quirúrgicos. United StatesAustralia, Free Trade Agreement, 2005. 
Esta obra forma parte del acervo de la Biblioteca Jurídica Virtual del Instituto de Investigaciones Jurídicas de la UNAM

Si bien el TPP no explicita las vías para otorgar patentes a los segundos usos, en tanto se trata de productos o procesos que ya fueron patentados, no cabe otra posibilidad que legislar excluyendo el requisito de "novedad"; es allí cuando el legislador tiene que definir con precisión los casos en los cuales no se exigirá esta elemento constitutivo, y en principio indispensable, para que una "invención" pueda ser considerada "patentable".

\section{Segundos usos y métodos de diagnóstico y terapéuticos}

En efecto, no cualquier segundo uso es patentable; además, se debe prever que es probable que si se otorga una patente a una sustancia conocida alegando un segundo uso, un tercero que es afectado puede solicitar la nulidad por considerar que se trata de un método terapéutico y, por tanto, no es una invención, o no es una invención patentable por estar excluida, según el régimen jurídico concernido. Es por ello que se requiere precisar la distinción entre lo autorizado de manera expresa y aquello que está expresamente prohibido.

La Convención Europea hace referencia a los métodos de diagnóstico, terapéuticos y quirúrgicos; su redacción indica que si bien el patentamiento de estos métodos está prohibido, se puede patentar una "sustancia conocida" cuando se reivindique un método nuevo de aplicación específica o la utilidad de un nuevo método que no esté comprendido en el "nivel actual de la técnica". Es decir, se autoriza el patentamiento del producto, pero la novedad, i.e. el requisito de que no se encuentre en el nivel actual de la técnica, se exige al método; se trata, en consecuencia, de una ficción que permite repatentar una sustancia patentando un método de diagnóstico, terapéutico o quirúrgico, protegiendo la sustancia conocida. ${ }^{38}$

Se pueden presentar las siguientes situaciones:

a) Se trata de una sustancia que se utilizaba para una enfermedad X, cuya patente estaba vencida y se han incorporado al mercado los productos denominados genéricos; en este caso, al patentarse "la sustancia" a la que se le descubrió un segundo uso para atender una enfermedad Y, se deberán sacar del mercado los productos genéricos que se iban a utilizar para atender la enfermedad $\mathrm{X}$, en razón de la cual las personas que padecían la enfermedad X verán cómo se vuelven a encarecer sus fármacos por el otorgamiento de un derecho monopólico a la sustancia.

38 Sterckx, Sigrid y Cockbain, Julian, Exclusions from..., cit. 
Esta obra forma parte del acervo de la Biblioteca Jurídica Virtual del Instituto de Investigaciones Jurídicas de la UNAM

b) Se trata de una sustancia $\mathrm{X}$ con la patente vigente otorgada a un inventor A, y una persona jurídica B descubre un nuevo uso de la sustancia. ¿Debe compartir A el monopolio con B? Porque es claro que en la Convención Europea se patenta la sustancia.

El TPP ofrece una mayor complejidad; en efecto, al no vincular los nuevos usos con los métodos de diagnóstico, terapéuticos y quirúrgicos, deja abierta la posibilidad de patentar segundos usos a todos los productos patentables, no sólo a los farmacéuticos. Por otra parte, no hace referencia expresa a que se otorga patente a la sustancia, como lo hace la Convención Europea, si bien así pareciera sugerir el texto.

Establece el TPP, además, un elemento diferenciador muy elástico: el país parte que, cumpliendo con el compromiso contraído, autorice el patentamiento de segundos usos podrá excluir aquellos casos en que sólo se revindica la utilización de la sustancia conocida como tal. Esta redacción se puede interpretar en el sentido de que la sustancia para la que se reivindica un segundo uso debe tener una diferente presentación, gramaje, forma, como lo exige, por ejemplo, la legislación chilena, país miembro del TPP, o que debe integrar un compuesto nuevo; o bien, lo que parece más razonable, que debe ir acompañada de un método de diagnóstico o terapéutico específico, diferente al anterior, o todos estos cambios integrados.

El requisito de patentabilidad, con una redacción distinta, es que "los usos", "los métodos" o "los procesos" sean nuevos, es decir, que no estén en el nivel de la técnica actual; subsiste, sin embargo, la duda sobre si estos "nuevos usos" permiten patentar la sustancia conocida o sólo los "nuevos usos".

Como se puede ver, la redacción del TPP genera problemas serios al legislador, que tiene que trasladar sus decisiones al derecho positivo nacional; por un lado, debe decidir si se patenta la sustancia, y en este caso brindar solución a las situaciones complejas referidas precedentemente. Si decide limitar la patente a los "nuevos métodos o procesos" para un nuevo uso, distinguir esta patente con la prohibición del patentamiento de métodos de diagnóstico, terapéuticos o quirúrgicos. Si permite patentar la sustancia ya conocida, deberá incorporar una nueva causal de licencia compulsiva para el caso de que quien solicite la patente de la sustancia conocida sea diferente al titular de una patente aún vigente sobre la misma sustancia. Se deberá definir también si se puede autorizar la fabricación de genéricos con la presentación anterior para atender las necesidades que previamente satisfacía para el caso en el cual la sustancia conocida no estuviera protegida por una patente. 
Esta obra forma parte del acervo de la Biblioteca Jurídica Virtual del Instituto de Investigaciones Jurídicas de la UNAM

Por otra parte, se puede interpretar que tratándose de una patente que se refiere directa o indirectamente a una sustancia conocida, el plazo por el cual se otorgue la patente no necesariamente debe ser de veinte años.

\section{El concepto de materia patentable en los tribunales estadounidenses}

Consideramos conveniente hacer una breve referencia al desarrollo del tema en análisis en el derecho estadounidense, por la importancia de este mercado como productor y consumidor de fármacos patentados y de servicios de salud, y por cuanto este tema está en el centro de discusión de dos de los tratados de libre comercio más relevantes, cuyas disposiciones repercutirán en todo el mundo: los citados TLC Transpacífico y TLG Trasatlántico, en los cuales los Estados Unidos de América ocupan una posición relevante.

Un primer precedente en el cual se aclara que las leyes de la naturaleza, los fenómenos naturales y las ideas abstractas no son patentables en EUA, lo definió con claridad la Corte Suprema en el fallo Diamond v. Diehr (1981). Una serie de sentencias del Poder Judicial norteamericano comenzó a llamar la atención sobre el aspecto metodológico; así, en el fallo Alice v. CLS Bank, relativo a un método comercial asistido por computadora, la Corte consideró que antes de definir la patentabilidad se debía analizar si se trataba de una invención y no de un descubrimiento, es decir, si no se realizaba una mera aplicación de leyes de la naturaleza. Ahora bien, todas las invenciones se basan en la aplicación de leyes de la naturaleza, de teorías, de ideas abstractas, por lo cual un segundo paso necesario consistiría en determinar si la utilización de las leyes de la naturaleza derivaba en algo más, en actos que tuvieran la entidad suficiente como para calificar al producto como una invención; en el caso en cuestión se decidió que no se trataba de una invención. ${ }^{39}$

Un nuevo fallo, Mayo v. Prometheus, se refirió a los métodos de diagnóstico en específico, con una decisión similar. ${ }^{40}$ Prometheus Laboratories, Inc., como único licenciatario de dos patentes que se referían al uso de drogas thiopurine (thioguanine) para tratar una enfermedad gastrointestinal autoinmu-

39 Powles, Julia, “Alice v. CLS Bank: el Tribunal Supremo...”, op. cit. La autora utiliza como sinónimos "requisitos de invención" y "materia patentable", lo que la lleva a conclusiones erráticas; es por ello que considera que estos pasos previos son superfluos, innecesarios y que son dañinos para el sistema de propiedad industrial.

40 Supreme Court of the United States, Mayo Collaborative Services, dba Mayo Medical Laboratories et al. v. Prometheus Laboratories, Inc., certiorari to the United States Court of Appeals for the Federal Circuit, No. 10-1150, argued December 7, 201 1, decided March 20, 2012. 
Esta obra forma parte del acervo de la Biblioteca Jurídica Virtual del Instituto de Investigaciones Jurídicas de la UNAM

ne, demandó a Mayo Collaborative Services y otros, por infringir sus derechos. Las patentes protegían un método para administrar las dosis justas del fármaco thiopurine; consistía en: a) administrar una dosis del fármaco; b) medir los niveles de metabolitos del medicamento en los glóbulos rojos del receptor, $\mathrm{y} c$ ) comparar estos niveles con los que se predeterminaron que correspondían, resultado del cual se aumenta o disminuye la dosis. En primera instancia, la Corte de Distrito rechazó la demanda de Prometheus por considerar que se trataba de patentar leyes de la naturaleza; la decisión fue apelada y el tribunal federal revocó la sentencia con un argumento interesante: el cuerpo humano es transformado por las dosis de la droga aplicada y se requiere una intervención para la extracción de la sangre y determinar los diferentes efectos de diferentes dosis. La litis fue elevada a la Corte Suprema, que consideró que los métodos descritos no eran patentables por cuanto se trataba de la utilización de las leyes de la naturaleza. El análisis de la Corte Suprema expresa que en tanto la reivindicación de Prometheus se base en que las relaciones entre las concentraciones de ciertos metabolitos en la sangre determinan la probabilidad de que una dosis del tiopurina (o thiopurina) resulte ineficaz o cause daños, los procesos reivindicados no son patentables a menos que tengan características adicionales. Desarrolla que, si bien los tres pasos reivindicados no son en sí mismos leyes naturales, tampoco son suficientes para transformar la naturaleza de las reivindicaciones. Luego de realizar un cotejo con sentencias anteriores que podrían ser consideradas contradictorias con este fallo, la Corte Suprema realiza una aclaración de sumo interés en materia de políticas públicas. Dice que el argumento de Prometheus de que si se rechaza la patente el fallo repercutirá en rechazos mucho más amplios en el futuro, y que ello desalentaría la inversión en descubrimientos de nuevos instrumentos de diagnóstico, no conduce a una conclusión diferente. ${ }^{41}$ En razón de ello devolvió la sentencia a la Cámara para que reconsiderara el caso conforme a la doctrina establecida en el caso Bilski v. Kappos (2010). En consecuencia, se decidió que el método de diagnóstico de Prometheus no era patentable.

La argumentación de la Corte Suprema es clara en el sentido de negar el carácter de invención a procesos, métodos, que sólo se refieren a las leyes de la naturaleza, que no son invenciones. Por otra parte, indirectamente expresa que los argumentos económicos a favor de ampliar el concepto de invención y de materia patentable, como estímulo a la inversión en investigación, no puede alterar lo dispuesto por el derecho positivo y el objetivo

41 Idem. 
Esta obra forma parte del acervo de la Biblioteca Jurídica Virtual del Instituto de Investigaciones Jurídicas de la UNAM www.juridicas.unam.mx

fundamental, constitucional, del sistema de propiedad intelectual, que es estimular las invenciones.

Quizás el caso más importante para el tema que abordamos en este trabajo es Association for Molecular Phatology v. Myriad Genetics. ${ }^{42}$ En esta sentencia, la Corte Suprema de EUA dictamina sobre tres puntos de sumo interés: a) sobre la patentabilidad de genes o fragmentos de genes aislados; $b$ ) sobre la patentabilidad de métodos de diagnóstico, y c) sobre la patentabilidad de genes o fragmentos de genes tal cual se encuentran en la naturaleza, pero a los que se los ha "limpiado" de material no funcional (ADNc), si bien el mayor impacto de la sentencia lo generó el relativo al primer punto.

En efecto, como dijéramos supra, la oficina de patentes de EUA (USTPO) había otorgado miles de patentes en los últimos años interpretando que el aislamiento de un fragmento de ADN significaba que era diferente a los que se encontraban en un cuerpo vivo, y en la mayoría de los países se había adoptado esta interpretación al considerar que un gen aislado era diferente a un gen tal cual se encontraba en la naturaleza. A partir de esta interpretación de la Corte, algunos países (entre otros, México, Argentina y Brasil en América Latina y, como se expusiera, Canadá, Japón, la Unión Europea, Australia) tienen un régimen jurídico distinto al de EUA, diferencia que surge de haber querido tener coincidencias.

Aparentemente, la Corte de EUA quiso morigerar el impacto de su decisión, que llevará a la posible nulidad de miles de patentes y al rechazo de otro tanto de solicitudes por parte de la USTPO, y sin que fuera parte de la litis aclaró que, por el contrario, el ADNc sí sería patentable; no argumentó al respecto y resulta contradictorio y difícil de explicar por qué la mera eliminación de la parte del genoma que no codifica para una proteína hace que un elemento de la naturaleza sin modificación alguna sea patentable. ${ }^{43}$

Respecto a los métodos de diagnóstico reivindicados por Myriad, la Corte dictaminó en el mismo sentido del caso Mayo v. Prometheus; es decir, la mera comparación de un fragmento de gen de una persona sana con el fragmento del paciente para identificar diferencias que pudieran indicar una tendencia a contraer un cáncer de mama o de útero, no es patentable.

42 Association for Molecular Pathology et al. v. Myriad Genetics, Inc. et al., certiorari to the United States Court of Appeals for the Federal Circuit, No. 12-398, argued April 15, 2013, decided June 13, 2013.

43 Véase el análisis detallado de este fallo relevante pero contradictorio en Bergel, Salvador Darío, "Enfoque ético-jurídico de la sentencia de la Corte Suprema de los Estados Unidos sobre patentabilidad de genes humanos", Revista Bioética, Brasil, vol. 22, núm. 1, 2014, pp. 18 y ss. 
Esta obra forma parte del acervo de la Biblioteca Jurídica Virtual del Instituto de Investigaciones Jurídicas de la UNAM

\section{Algunas CONCLUSIONES}

La evolución de la biología molecular y de la biotecnología vinculadas a las ciencias médicas presionan al sistema de propiedad intelectual en múltiples temas: el patentamiento de genes y fragmentos de genes aislados, purificados, modificados genéticamente; semillas modificadas genéticamente; partes del cuerpo humano, así como de los métodos de diagnóstico, terapéuticos y quirúrgicos, y los segundos usos de sustancias conocidas. Estos métodos están estrechamente vinculados a la terapia génica individualizada que reviste un gran interés científico y económico. Un primer obstáculo que no han podido vencer las corporaciones interesadas en el tema es que se puedan calificar como invención los procesos que utilizan sólo las leyes de la naturaleza para diagnosticar un problema patológico o para indicar las dosis adecuadas para la administración de fármacos, sugerir dosis individualizadas en ciertos casos o aconsejar métodos o enfoques en las intervenciones quirúrgicas.

Los rechazos de la Corte Suprema de EUA a la patentabilidad de los métodos de diagnóstico y terapéuticos en los fallos comentados deja abiertas ciertas puertas sobre las que podrán intentar avanzar las corporaciones vinculadas a estas ramas económicas. Pero una de las estrategias más difíciles, pero también más efectivas, ha sido la de intentar incluir la patentabilidad de los métodos de diagnóstico, terapéuticos y quirúrgicos y de los segundos usos en los capítulos sobre propiedad intelectual de los tratados de libre comercio relevantes que se encuentran en negociación.

Esta estrategia ya fue utilizada, como se expusiera, en la negociación del Acuerdo ADPIC de la OMC, en virtud del cual se declararon invenciones creaciones intelectuales que no lo eran, como los programas de cómputo y las bases de datos, o crear categorías sui generis como la protección de los microcircuitos y las nuevas obtenciones vegetales. En el TPP obtuvo EUA un éxito relativo al comprometerse los países partes a patentar los segundos usos, si bien se deja abierta la posibilidad de excluir los métodos de diagnóstico, terapéuticos y quirúrgicos. Ahora bien, conforme al fast track otorgado al Poder Ejecutivo estadounidense, que obliga al Congreso estadounidense a aprobar o rechazar el tratado a libro cerrado, sin poder hacer modificaciones, no sólo se comprometen los países firmantes a ampliar la materia patentable en estas áreas, sino que obligaría al Congreso estadounidense a modificar de inmediato su legislación sobre patentes. En lo que a México se refiere, de aprobarse el TPP, como todo pareciera indicar, no sólo se deberá analizar bajo qué formas, características y plazos se 
incorpora el patentamiento de los segundos usos, según se analizó en este trabajo, sino que además se deberán reformar disposiciones que otorguen eficiencia a esta nueva materia patentable sin afectar las posibilidades de autorizar genéricos en plazos razonables y de proteger el derecho humano de acceso a la salud. 
Esta obra forma parte del acervo de la Biblioteca Jurídica Virtual del Instituto de Investigaciones Jurídicas de la UNAM

\title{
NATURALEZA DE LA DIFUSIÓN DEL GONOGIMIENTO TEGNOLÓGICO EN EL SEGTOR BIOFARMACÉUTICO DE BRASIL Y MÉXICO. UN ANÁLISIS DE GITA DE PATENTES
}

\author{
Alenka GuZMán CHÁvez \\ Edgar ACATITLA ROMERO \\ Karina MALDONADO GARBAJAL
}

\begin{abstract}
SUMARIO: I. Introducción. II. Antecedentes teóricos y empíricos. III. Modelo de difusión. IV. Análisis de los resultados. V. Conclusiones. VI. Referencias bibliográficas. VII. Anexo.
\end{abstract}

\section{INTRODUCGIÓN}

Los diferentes patrones de difusión del conocimiento tecnológico que adoptan los países han sido identificados como factor clave para explicar las diferentes dinámicas de crecimiento económico entre países. ${ }^{1}$ Los historiadores económicos identifican el papel clave de la absorción y la difusión del conocimiento tecnológico en el crecimiento económico. ${ }^{2}$

El propósito de este capítulo es analizar la naturaleza de la difusión de los nuevos conocimientos tecnológicos generados en el sector biofarmacéutico de Brasil y México de 1980 a 2013 hacia otros países, con base en el análisis de cita de patentes hacia adelante. En particular, nos interesa responder las siguientes interrogantes: ¿cuál es la probabilidad de que las patentes concedidas en el sector biofarmacéutico en la Oficina de Patentes y Marcas de Estados Unidos (USPTO por sus siglas en inglés) a Brasil y México sean difundidas (citadas por otras patentes)?, ¿cuáles son los factores que

1 Rogers, M., Knowledge, Technological Catch-Up and Economic Growth, CheltenhamNorthampton, Edward Elgar, 2003.

2 Rosenberg, N., Inside the Black Box: Technology and Economics, Cambridge University Press, 1982. 
Esta obra forma parte del acervo de la Biblioteca Jurídica Virtual del Instituto de Investigaciones Jurídicas de la UNAM

explican la probabilidad de que las patentes de Brasil y México en el área biofarmacéutica sean difundidas (citadas por otras patentes)?

En un sentido amplio, la difusión del conocimiento permite propagar en tiempo y en espacio: ideas, patrones de cultura, prácticas y modelos institucionales, métodos de producción y nuevos productos y servicios, entre otros. La difusión de cada uno de estos aspectos es analizada desde diferentes campos del conocimiento científico y tecnológico con metodologías específicas. Sin embargo, todas las disciplinas científicas comparten preocupaciones comunes: conocer cuáles son los factores que influyen en la propagación de estos aspectos, cómo interactúan los factores y su efecto en la tasa de difusión. Esto involucra un esfuerzo por construir propuestas teóricas y empíricas para medir estas cuestiones de la difusión. ${ }^{3}$

En el proceso de innovación tecnológica, la difusión adquiere una relevancia fundamental porque en la medida en que se propaga espacialmente el uso de nuevos productos (en regiones, países, habitantes) y se adoptan nuevas técnicas de producción (en sectores productivos), en esa medida, el progreso tecnológico empieza a instalarse en las diferentes regiones y países. Su extensión internacional va destruyendo paulatinamente las viejas tecnologías, tal como lo refiere la idea schumpeteriana de la destrucción creadora. ${ }^{4}$

La industria farmacéutica tiene una particular relevancia para el bienestar de la población de todos los países. El descubrimiento y el desarrollo de nuevas moléculas terapéuticas, su producción industrial y su disponibilidad en el mercado de los diferentes países es crucial para la cura de diferentes enfermedades y la reducción de las tasas de mortalidad en los países, lo cual implica la difusión y la adopción de las novedades médicas. Sin embargo, en los países menos desarrollados económicamente se registran altas tasas de mortalidad y el consumo de medicamentos es notablemente inferior al de países desarrollados. Además, existen algunas enfermedades locales, para las cuales aún no han sido desarrollados medicamentos terapéuticos o existen restricciones al acceso de los nuevos medicamentos. En algunos casos, aquellos países que no han desarrollado una industria farmacéutica local dependen totalmente de la importación de medicamentos. Así, los precios monopólicos u oligopólicos impiden a la población enferma acceder a los medicamentos. En tal caso, la difusión y la utilización de las novedades es limitada. En otros casos, los países tienen una industria local con relativas capacidades de producción de medicamentos al menudeo pero son aun de-

3 Gomulka, S., The Theory of Technological Change and Economic Growth, Londres, Routledge, 1990.

4 Aghion, P. y Howitt, P., A Model of Growth through Creative Destruction, National Bureau of Economic Research, documento núm. 3223, 1990. 
Esta obra forma parte del acervo de la Biblioteca Jurídica Virtual del Instituto de Investigaciones Jurídicas de la UNAM

pendientes de la importación de moléculas, o también de los medicamentos finales, al carecer de capacidades de investigación y desarrollo de moléculas. Finalmente, algunos países, como Brasil y México, han desarrollado capacidades tecnológicas y de innovación, aunque todavía con enormes brechas con respecto a los países industrializados, cuyas industrias farmacéuticas poseen fuertes capacidades de innovación, de producción y de oferta de sus novedades terapéuticas. ${ }^{5}$

No obstante que la actividad inventiva en la industria biofarmacéutica de los dos países latinoamericanos es reducida, hay capacidades inventivas y algunas de ellas de relevancia. En tal sentido, nos interesa estimar la probabilidad de que las patentes, fruto de la investigación y el desarrollo de firmas, instituciones o individuos, sean difundidas y analizar cuáles son los probables factores que estarían explicando su difusión.

Aunque existen estudios sobre la innovación local en la industria farmacéutica de Brasil y México, poco se ha abordado sobre la naturaleza de su difusión. El análisis de este fenómeno nos daría cuenta de cómo las novedades en el campo biofarmacéutico tienen impacto en otras latitudes y cómo se explicaría la velocidad de su difusión. Esto tendría un impacto de retorno en la medida en que los agentes que innovan estarían interactuando con aquellos agentes nacionales e internacionales que reconocen la importancia de la invención y la citan cuando generan otra invención.

Este trabajo se fundamenta en diversas contribuciones teóricas y empíricas sobre la innovación y la difusión del conocimiento tecnológico de innovación. Particularmente, se retoman los estudios que han reconocido la importancia de las patentes como fuente sistematizada y completa de la información tecnológica para estudiar la trayectoria de las innovaciones; ${ }^{6}$ la naturaleza de las mismas; $;^{7}$ los flujos de conocimiento tecnológico; ${ }^{8} \mathrm{y}$, en específico, los flujos de países desarrollados a países en desarrollo; ${ }^{9}$ la impor-

5 Guzmán, A., Propiedad intelectual y capacidades de innovación en la industria farmacéutica de Argentina, Brasil y México, México, Gedisa-UAM, 2014.

6 Schmookler, J., "Economic Sources of Inventive Activity", The Fournal of Economic History, vol. 22, núm. 1, 1962.

7 Griliches, Z., REDD, Patents, and Productivity, Chicago-Londres, The University of Chicago Press, 1984; Jaffe, A. y Trajtenberg, M., Patent, Citations and Innovations, CambridgeLondres, The MIT Press, 2002.

8 Jaffe, A. y Trajtenberg, M., Patent..., cit.

9 Hall, B. et al., NBER Patent Citations Data File: Lessons, Insights and Methodological Tools, National Bureau of Economic Research, documento núm. 8498, 2001; Hu, A. G. Z. y Jaffe, A., "Patent Citations and International Knowledge Flow: The Cases of Korea and Taiwan", International fournal of Industrial Organization, vol. 21, núm. 6, 2003. 
Esta obra forma parte del acervo de la Biblioteca Jurídica Virtual del Instituto de Investigaciones Jurídicas de la UNAM

tancia de las invenciones y su valor comercial, ${ }^{10}$ entre otros. Reconociendo el potencial que ofrecen los datos de las patentes para estudiar diferentes problemas de investigación relativos al proceso de innovación, y la difusión como parte de ese proceso, esta investigación propone un modelo econométrico de tipo Poisson para analizar los factores que influyen en la difusión de las invenciones generadas por Brasil y México de 1980 a 2013 mediante la cita de patentes, con base en la información de las patentes concedidas por la USPTO a agentes de estos dos países.

Se suscribe como hipótesis inicial que considerando a la cita de patentes hacia adelante (forward patent citation) como una variable proxy de la difusión de las innovaciones de mayor valor tecnológico, se espera que esta mayor difusión en el área biofarmacéutica de Brasil y México se asocie positivamente con las siguientes variables: innovación radical, número de reivindicaciones (claims), invenciones patentadas en varias oficinas (patentes PGT), la cooperación tecnológica (co-patentes), el tamaño del equipo de los inventores, la movilidad de los inventores (presencia de inventores extranjeros), la relación con el sector académico (número de citas de artículos científicos), el esfuerzo del sector estatal (institucional) en la innovación en el campo biofarmacéutico (número de patentes por universidades e institutos de investigación en biopharma), la participación de empresas (patentes de empresas), el menor tiempo con el que las patentes de América Latina son citadas (forward patent citation).

Así también, sostenemos que el menor rezago de difusión depende de un mayor esfuerzo en investigación y desarrollo $(\mathrm{I}+\mathrm{D})$, de la capacidad de absorción del nuevo conocimiento tecnológico, la eficiencia de los sistemas nacionales de investigación (SNI), el capital humano especializado y la cooperación tecnológica entre agentes de cada país. Sin embargo, esta hipótesis no será probada en esta investigación.

Este estudio tiene cuatro secciones. En la segunda se exponen los principales conceptos de la difusión tecnológica y la forma en cómo ha sido estudiada y los trabajos empíricos que anteceden a la investigación. En la tercera se expone el modelo propuesto. En la cuarta se da cuenta de los resultados y se analizan. Finalmente se presentan las conclusiones.

10 Criscuolo, P. et al., Measuring Knowledge Flows Among European and American Multinationals: A Patent Citation Analysis, Países Bajos, Eindhoven University of Technology, documento presentado en The Future of Innovation Studies Conference, septiembre de 2001; Hall, B. et al., Market Value and Patent Citations: A First Look, Berkeley, University of California, Department of Economics, documento de trabajo, núm. E01-304, 2001. 
Esta obra forma parte del acervo de la Biblioteca Jurídica Virtual del Instituto de Investigaciones Jurídicas de la UNAM

\section{ANTECEDENTES TEÓRICOS Y EMPÍRICOS}

De acuerdo con la definición de la OCDE, "la difusión de la tecnología es el proceso en el que los conocimientos y las competencias técnicas se expanden y se asimilan en el conjunto de la economía, y ella cubre todas las acciones a nivel de la empresa o de la organización para explotar las ventajas económicas de una innovación". ${ }^{11}$ Se distinguen dos tipos de difusión de la tecnología: a) la difusión de la tecnología incorporada en los equipos, y b) la difusión de la tecnología no incorporada. La primera "describe cómo el proceso de difusión de las innovaciones se difunde en el seno de la economía mediante la compra de maquinaria, componentes y otros equipos de alta intensidad tecnológica". ${ }^{2}$ La segunda se refiere a las vías de difusión de la tecnología de y del conocimiento tácito, el cual difiere de la adquisición de máquinas y equipos.

La difusión del conocimiento científico y tecnológico está estrechamente ligado a su naturaleza. El conocimiento, en tanto bien económico producido por el sector de investigación y desarrollo $(\mathrm{I}+\mathrm{D})$, posee características diferentes a otros bienes económicos. El conocimiento tiene por característica de ser un bien no rival, exclusivo y acumulativo. ${ }^{13}$ La no rivalidad se expresa por el hecho de que el conocimiento puede ser utilizado al mismo tiempo por varios individuos. Pero al mismo tiempo es exclusivo porque el propietario del nuevo conocimiento puede limitar su acceso mediante los derechos de propiedad intelectual. Así también, es acumulativo porque el valor del conocimiento no disminuye cuando se utiliza, por el contrario, se incrementa; ciertos conocimientos pueden ser fácilmente transferidos hacia los distintos agentes económicos, mientras que los otros son tácitos y se expresan a través de los agentes individuales y colectivos. ${ }^{14}$ Por esta razón, una cadena de innovaciones precede a cada innovación. La no-rivalidad y la exclusividad implican un doble carácter, contradictorio de los conocimientos: el carácter público y el carácter privado, cuestión que tiene una influencia en la manera en que los nuevos conocimientos se derraman.

Los conocimientos científicos, producto de la investigación de las ciencias puras realizada por las universidades y las instituciones de estudios su-

11 OCDE, La Mondialisation de l'industrie, París, 1996, p. 18.

12 OCDE, La Mondialisation Industrielle. Quatre Études de Cas: Pièces Automobiles, Produits Chimiques, Construction y Semi-Conducteurs, París, 1992, p. 52.

13 Romer, P., "Endogenous Technological Change", fournal of Political Economy, núm. 98, 1990

14 Lundvall, B. A., National Systems of Innovation: An Analytical Framework, Londres, Pinter, 1992, p. 18. 
Esta obra forma parte del acervo de la Biblioteca Jurídica Virtual del Instituto de Investigaciones Jurídicas de la UNAM

periores son bienes del orden público, constituyen un patrimonio de dominio público y, por tanto, el beneficio se ubica en el ámbito social. Pero la difusión de los nuevos conocimientos, productos o procesos generados en los laboratorios de $\mathrm{I}+\mathrm{D}$ de las empresas, pueden ser protegidos o limitados en su uso por la vía de la legislación de propiedad intelectual vigente.

La sociedad obtiene cuatro clases de beneficios derivados de la concesión temporal de los derechos monopólicos, a través de las patentes: los estímulos para la innovación privada, el uso del nuevo conocimiento para la actividad productiva, la diseminación del nuevo conocimiento y los estímulos de innovación a otras empresas. ${ }^{15}$

Conforme a esta lógica, el grado y el ritmo de difusión están ligados a los márgenes y al monto de beneficio esperado por el empresario y, en añadidura, al marco institucional (legislaciones, reglamentaciones gubernamentales, etcétera) que favorece u obstaculiza a su desarrollo.

Entre los canales de difusión de la tecnología no incorporada están: las licencias de patentes de productos o procesos industriales, servicios de consultoría y capacitación para el uso de tecnologías, subcontratación de I+D (transmisión del conocimiento tácito), que permiten el desarrollo de habilidades técnicas y tecnológicas. ${ }^{16}$

En este proceso de difusión de los nuevos hallazgos científicos y tecnológicos, los investigadores (ingenieros, técnicos, etcétera) de $\mathrm{I}+\mathrm{D}$ desempeñan un papel muy importante, dependiendo de sus capacidades de absorción ${ }^{17}$ y de las redes de conocimiento que se establecen mediante diversos medios (movilidad laboral, asistencias a congresos). La derrama del conocimiento tecnológico hace posible que los investigadores puedan efectuar la ingeniería a la inversa, la estrategia imitativa, para desarrollar la innovación. En tal sentido, la información publicada en las patentes puede ser una fuente importante de difusión tecnológica tanto para una estrategia imitativa como para una de innovación radical

15 Scherer, F. M., Patents, Economics, Policy and Measurement, Cheltenham-Northampton, Edward Elgar, 2005.

16 Veugelers, Reinhilde y Cassiman, Bruno, "Make and Buy in Innovation Strategies: Evidence from Belgian Manufacturing Firms", Research Policy, vol. 28, núm. 1, 1999; Grandstrand, Ove et al., Technology Management and International Business, Wiley \& Sons, 1992; Henderson, Rebecca et al., "Universities as a Source of Commercial Technology: A Detailed Analysis of University Patenting, 1965-1988", Review of Economics and Statistics, vol. 80, núm. 1, 1998; Cockburn, Iain y Henderson, Rebecca, "Scale and Scope in Drug Development: Unpacking the Advantages of Size in Pharmaceutical Research", Fournal of Health Economics, vol. XX, núm. 6, 2001.

17 Levin, Richard et al., "Appropriating the Returns from Industrial Research and Development", Brookings Papers on Economic Activity, vol. 3, 1987. 
Esta obra forma parte del acervo de la Biblioteca Jurídica Virtual del Instituto de Investigaciones Jurídicas de la UNAM

\section{MODELO DE DIFUSIÓN}

\section{Fuente de datos}

Se consultaron 199 patentes concedidas por la Oficina de Patentes y Marcas de Estados Unidos (USPTO, por sus siglas en inglés) a Brasil y México durante el periodo 1980-2013 en las clases 514 y/o 424 y también 800 y/o 435. De las cuales 127 corresponden a Brasil, iniciando en 1985, y 72 a México.

Las variables del modelo propuesto se obtuvieron a partir de los datos contenidos en las patentes concedidas por USPTO: número de la patente, año de la solicitud, año de la concesión, resumen de la patente, reivindicaciones de novedad, nombre y nacionalidad de la patente, nombre y nacionalidad de los inventores, citas que hace la patente, citas hechas por otra patente o patentes, referencias bibliográficas, clases tecnológicas en las que se reconoce la novedad. También se consultaron los datos de las patentes que citan a las patentes de Brasil y México para identificar a los titulares, sus nacionalidades, fechas de concesión de las patentes y clase tecnológica de la patente.

En términos generales, la tasa de difusión tecnológica de un país, teniendo como variable a las patentes, se define como el cociente entre el número de las patentes locales concedidas en la oficina de patentes del país y el número de patentes de este país concedidas en oficinas de propiedad intelectual de otro país en calidad de no residente (USPTO, EPO, WIPO). En especial para países emergentes o en desarrollo este coeficiente es generalmente bajo, lo cual indicaría una baja tasa de difusión de las innovaciones a nivel internacional. No obstante lo anterior, nos interesa estudiar cómo aquellas patentes que han sido otorgadas en otras oficinas internacionales, como la USPTO, logran tener una difusión mayor al reconocerse el valor de la invención por otras patentes, mediante la cita hacia adelante. Elegimos la USPTO debido a las siguientes razones: a) porque Estados Unidos es el mercado tecnológico más importante, y b) por la importancia que tiene el mercado biofarmacéutico de Estados Unidos y el liderazgo de este país en la innovación. Además de que homogeneizamos para los dos países el marco institucional del patentamiento al reconocer una sola oficina de patentes, es decir la USPTO. 
Esta obra forma parte del acervo de la Biblioteca Jurídica Virtual del Instituto de Investigaciones Jurídicas de la UNAM www.juridicas.unam.mx

2. La actividad inventiva en Brasily México 1980-2013

Durante el periodo de análisis, 1980-2013, se registran 199 patentes concedidas de los dos países. En el caso de Brasil, fueron 127 las patentes concedidas. A su vez, México obtuvo 72 patentes. De 1980 a 1994, Brasil prácticamente tiene un nulo patenteamiento en USPTO, pero a partir de 1995 el número de patentes creció, muy probablemente debido al fortalecimiento del sistema de patentes con la adopción del ADPIG en 1996. En el caso de México, la actividad inventiva reconocida como patentes de USPTO fue errática durante la década de 1980, y en los años noventa el número de patentes se incrementó ligeramente hasta lograr un aumento significativo a partir de 2010. No obstante que México adoptó el ADPIC en 1991, antes que Brasil, estimamos la tasa de crecimiento promedio anual de los dos países de 1996 a 2013, con la finalidad de tener un indicador comparativo; el crecimiento de Brasil durante este subperiodo fue de 27.8\% y el de México de $18.3 \%$. Aunque con una tendencia creciente, los dos países están lejos de registrar el número de patentes concedidas en el área de biofarmaceútica que poseen países industrializados o emergentes de Asia.

\section{GRÁFICO 1}

PATENTES GONGEDIDAS A BRASIL Y MÉXICO POR USPTO

EN EL ÁREA BIOFARMACÉUTICA, 1983-2013

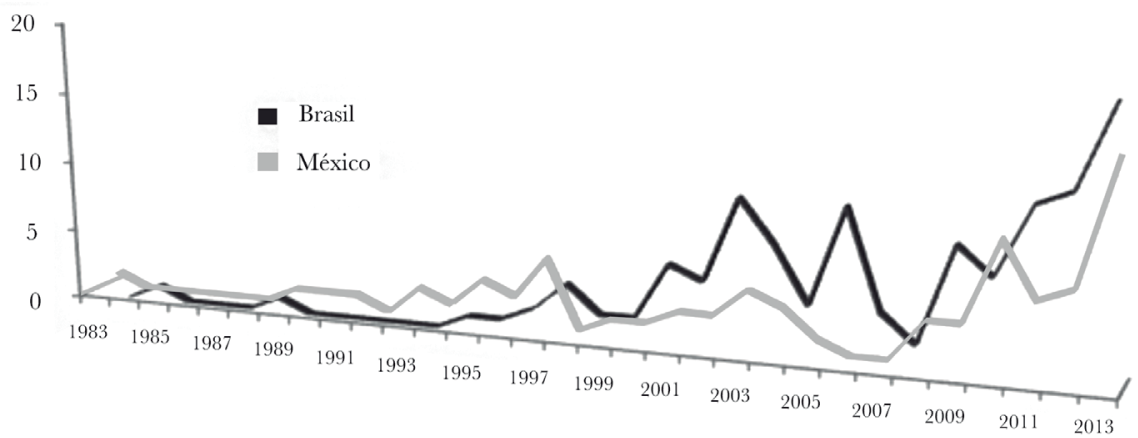

FUENTE: USPTO, clases 514 y/o 424, y 800 y/o 435. 
De acuerdo con la información proporcionada en el resumen y en las reivindicaciones de novedad, clasificamos las invenciones por producto, por proceso o ambos. En México y Brasil tienen mayor importancia las innovaciones de producto. En el periodo de análisis Brasil tiene 30 patentes de producto que representan el 65\% del total, y México 30 patentes que corresponden al 42\%. En ambos países las innovaciones de proceso tienen similar porcentaje de participación, $23 \%$ y $26 \%$, respectivamente. México aventaja a Brasil en las innovaciones que incluyen producto y proceso $(32 \%$ frente a $12 \%$ ).

\author{
GRÁFICO 2 \\ PATENTES GONCEDIDAS A BRASIL Y MÉXICO EN EL ÁREA \\ BIOFARMACÉUTICA POR PRODUCTO, PROCESO O AMBOS, \\ 1983-2013 (NÚMERO DE PATENTES)
}

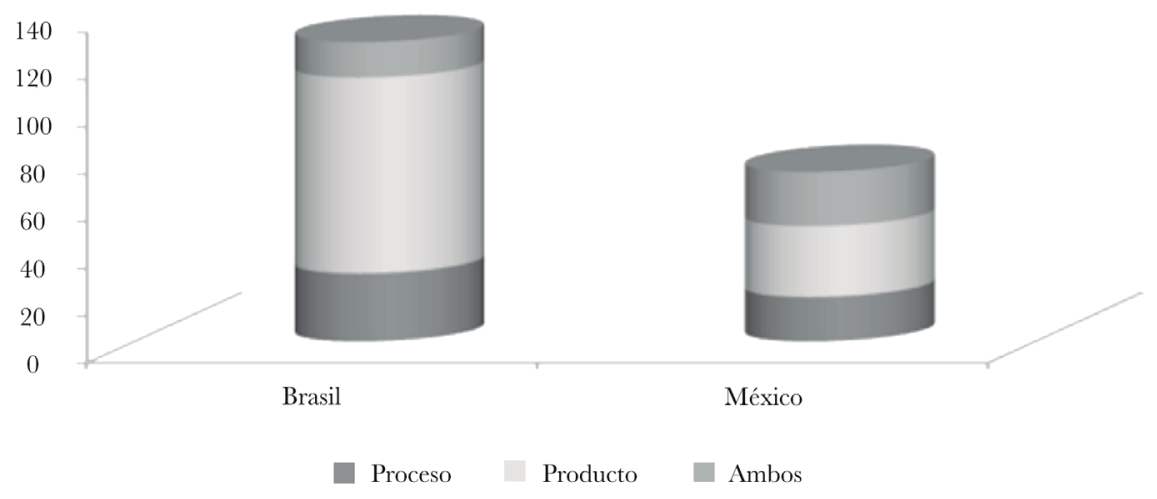

FUENTE: USPTO, clases 514 y/o 424, y 800 y/o 435.

En relación con las invenciones radicales o incrementales, detectamos que las invenciones de ambos países son mayormente incrementales, lo cual se vincula a estrategias imitativas de la industria farmacéutica local. En México, el 90\% (65 patentes) de las innovaciones podrían considerarse incrementales y sólo 10\% radicales (7 patentes). A su vez, en Brasil, 76\% (97 patentes) de las innovaciones se caracterizarían como incrementales y $24 \%$ radicales (30 patentes). Esta característica tiene una gran relevancia porque nos permite identificar la naturaleza de la innovación que se realiza en cada país en esta área tecnológica. 
Esta obra forma parte del acervo de la Biblioteca Jurídica Virtual del Instituto de Investigaciones Jurídicas de la UNAM

\author{
GRÁFICO 3 \\ PATENTES CONGEDIDAS A BRASIL Y MÉXICO \\ DE BIOFARMACÉUTICA POR TIPO DE INNOVAGIÓN RADICAL \\ O INCREMENTAL, 1980-2013 (NÚMERO DE PATENTES)
}

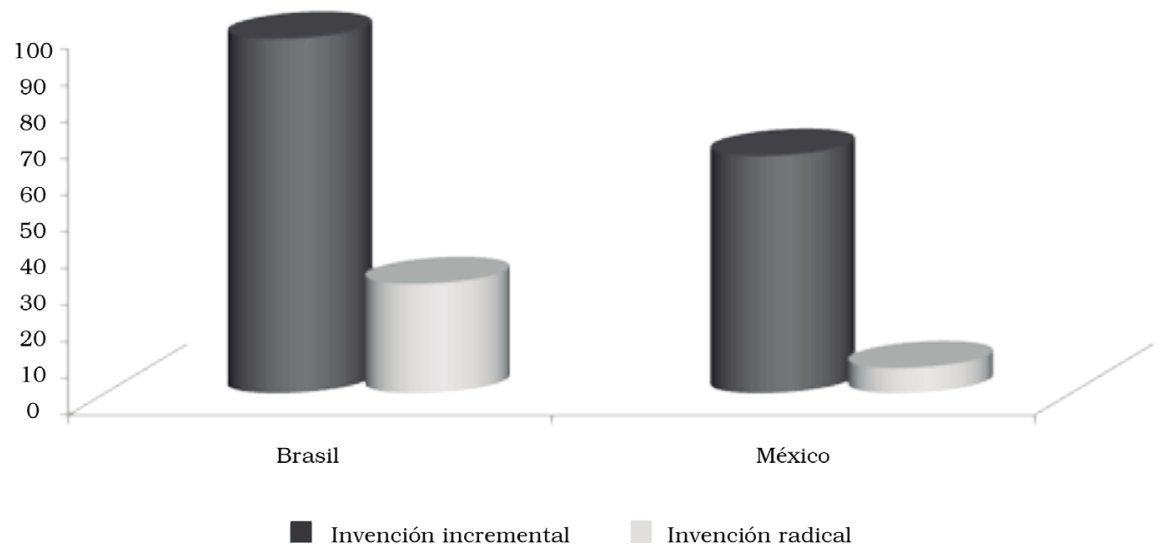

FUENTE: USPTO, clases 514 y/o 424, y 800 y/o 435.

La información de la titularidad de la patente nos permite identificar el tipo de propietario y, con ello, caracterizar a la actividad inventiva en el sector biofarmacéutico. En los países industrializados, las empresas tienen una mayor injerencia en el patentamiento porque son éstas las que escalan a nivel industrial las invenciones. En países emergentes, las instituciones tienen un papel muy importante en la actividad inventiva, sin embargo, no siempre existen vínculos exitosos con las empresas para llevar las invenciones al ámbito productivo mediante transferencia tecnológica. El grado de participación de las empresas es un indicador de qué tan activo es el sector empresarial en desarrollar nuevos productos o procesos. Así, se observa que en Brasil las empresas contribuyen con el $58 \%$ de las patentes, en tanto que en México es de 37\%. No obstante que en Brasil un catalizador de la actividad inventiva han sido las instituciones/universidades, sólo un tercio de las patentes corresponden a éstas; en México, la importancia de las instituciones/universidades es de 50\%. La colaboración empresa-universidad es aún débil en Brasil y México (7\% y 3\%, respectivamente). Las patentes pertenecientes a individuos en México alcanza 10\% y en Brasil 2\%. En ocasiones se patenta a nombre de individuos, aunque detrás hay una empresa o se trata de académicos de universidades, donde no se ha regulado lo suficiente para que se patente a nombre de la institución. 
Esta obra forma parte del acervo de la Biblioteca Jurídica Virtual del Instituto de Investigaciones Jurídicas de la UNAM

\author{
GRÁFICO 4 \\ PATENTES CONGEDIDAS A BRASIL Y MÉXICO \\ POR USPTO EN EL ÁREA DE BIOFARMACÉUTICA \\ POR TIPO DE TITULAR, 1980-2013 (NÚMERO DE PATENTES)
}

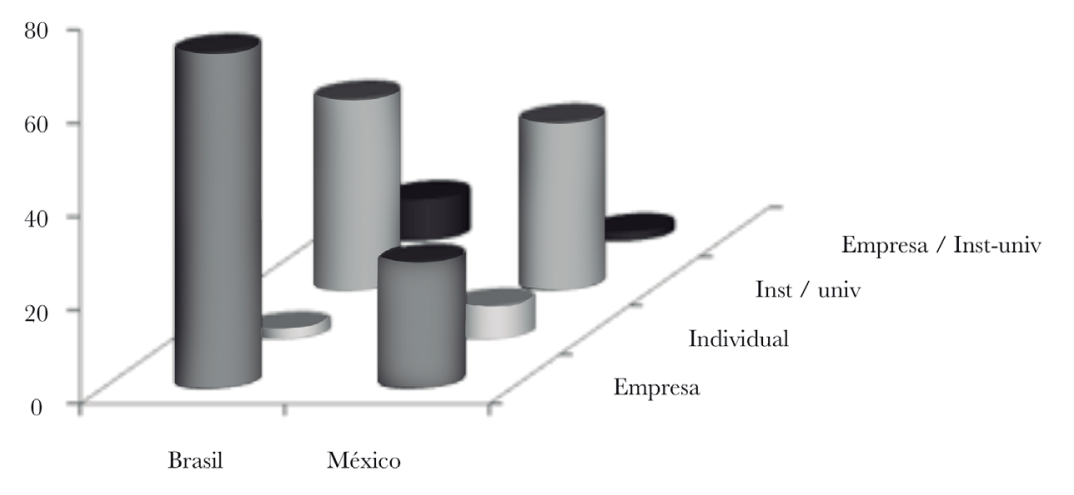

Empresa $\square$ Individual Inst/univ $\square \quad$ Empresa / Inst-univ

FUENTE: USPTO, clases 514 y/o 424, y 800 y/o 435.

El tamaño de los equipos es un indicador clave en las actividades inventivas porque nos sugiere la fortaleza de los grupos de investigación o lo contrario. Generalmente, en los países industrializados líderes, los equipos de investigación son grandes a fin de retroalimentar el proceso de investigación y las ideas novedosas. Tanto en Brasil como en México hay una mayor participación de equipos de inventores conformados por 2 a 4 inventores, lo que dista de lo que ocurre en los países con elevadas capacidades tecnológicas. Brasil tiene 66 patentes y México 44 patentes resultado de la actividad inventiva de 2 a 4 investigadores, lo cual representa $52 \%$ y $61 \%$, respectivamente. Casi un tercio de las patentes de Brasil se dio con la participación de 5 a 11 inventores; en México sólo 22\%. La contribución individual en las patentes es la menor, Brasil 16\% y México 17\%, pero aun resulta mayor a la de otros países, donde ésta es marginal o nula. 
Esta obra forma parte del acervo de la Biblioteca Jurídica Virtual del Instituto de Investigaciones Jurídicas de la UNAM www.juridicas.unam.mx

\section{GRÁFICO 5 \\ PATENTES CONCEDIDAS POR USPTO A BRASIL Y MÉXICO \\ EN EL ÁREA BIOFARMACÉUTICA POR TAMAÑO DEL EQUIPO \\ DE INVENTORES, 1980-2013 (NÚMERO DE PATENTES)}

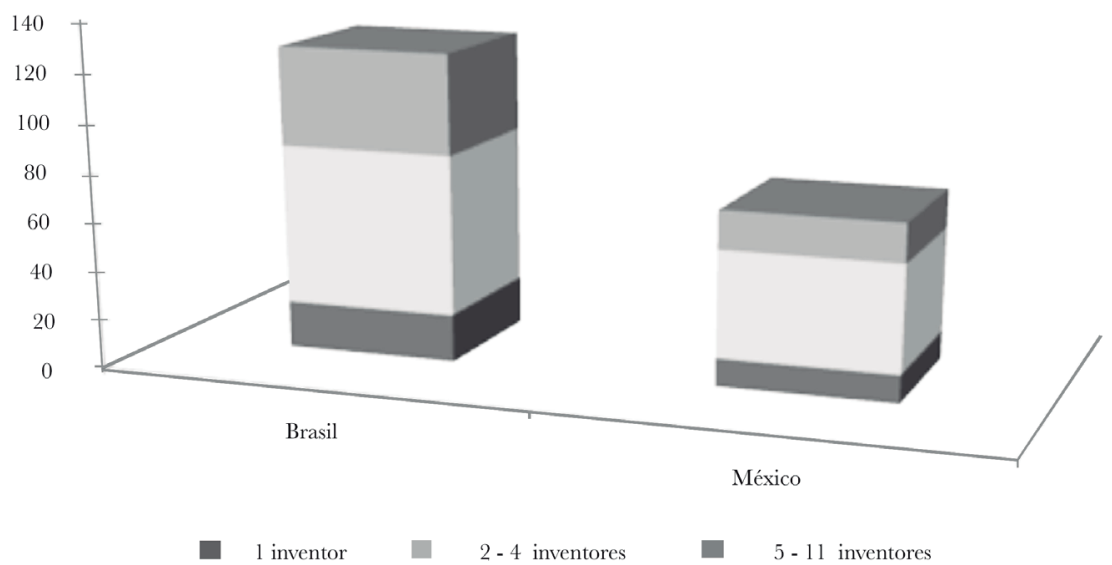

FUENTE: USPTO, clases 514 y/o 424, y 800 y/o 435.

Con respecto a la nacionalidad de los inventores, se advierte que en las patentes de Brasil y México fundamentalmente hay inventores locales (85\% y $83 \%$, respectivamente), y en un porcentaje menor de patentes hay presencia de inventores extranjeros. Este indicador también tiene relevancia para la actividad inventiva porque la movilidad de los inventores se asocia no sólo a derramas de conocimiento tecnológico codificado sino también al conocimiento tácito. Se ha encontrado evidencia de que la productividad de la innovación se incrementa cuando en los equipos hay participación de investigadores extranjeros. 
Esta obra forma parte del acervo de la Biblioteca Jurídica Virtual del Instituto de Investigaciones Jurídicas de la UNAM

\author{
GRÁFico 6 \\ PATENTES CONCEDIDAS A BRASIL Y MÉXICO POR USPTO \\ EN EL ÁREA BIOFARMACÉUTICA POR NAGIONALIDAD \\ DE LOS INVENTORES, 1980-2013 (NÚMERO DE PATENTES)
}

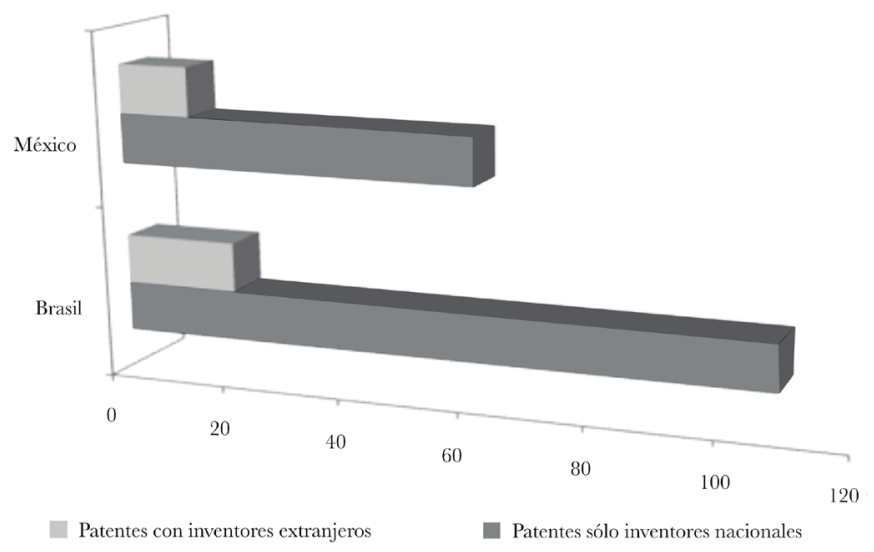

FUENTE: USPTO, clases 514 y/o 424, y 800 y/o 435.

Las citas a patentes previas (citas hacia atrás) es un indicador proxy de los flujos de conocimientos tecnológicos, el cual permite estimar las derramas de conocimiento tecnológico, la proximidad geográfica y la tecnológica de los países frente a los países líderes. Las fortalezas que tienen los países en términos de capital humano, capacidades de absorción y movilidad internacional de los investigadores son factores que contribuyen a explicar la propensión a citar las novedades previas. ${ }^{18}$ Brasil y México cuentan entre 1983 y 2013 con un número similar de citas de patentes previas, 873 y 825 respectivamente, aunque el promedio de cita por patente es de 6.9 y 11.5 citas por patente.

Las citas de patente que reciben las patentes (citas hacia adelante) han sido consideradas un indicador proxy del valor comercial de las invenciones. A mayor número de citas recibidas mayor la importancia de la invención y, por tanto, las expectativas de comercialización también. En este estudio, nosotros consideramos la cita de patentes hacia adelante como un indicador de difusión de las invenciones patentadas por Brasil y México en USPTO en el área biofarmacéutica. Las citas promedio recibidas por las patentes de titulares brasileños y mexicanos han sido durante el periodo de estudio de 1.9

18 Guzmán, A. y Gómez, H., "Patterns of Knowledge Flows from Industrialized to Emerging Countries. The Evidence of the Pharmaceutical Industry's Use of Patent Citation”, Contaduría y Administración, vol. 60, 2015. 
Esta obra forma parte del acervo de la Biblioteca Jurídica Virtual del Instituto de Investigaciones Jurídicas de la UNAM www.juridicas.unam.mx

para Brasil y 4.0 para México. Sin embargo, en el gráfico 7 se advierte que la tendencia ha sido errática para ambos países.

\section{GRÁFICO 7}

CITAS POR PATENTE PROMEDIO RECIBIDAS A LAS PATENTES DE BRASIL Y MÉXICO CONCEDIDAS POR USPTO EN EL ÁREA BIOFARMACÉUTICA, 1983-2013

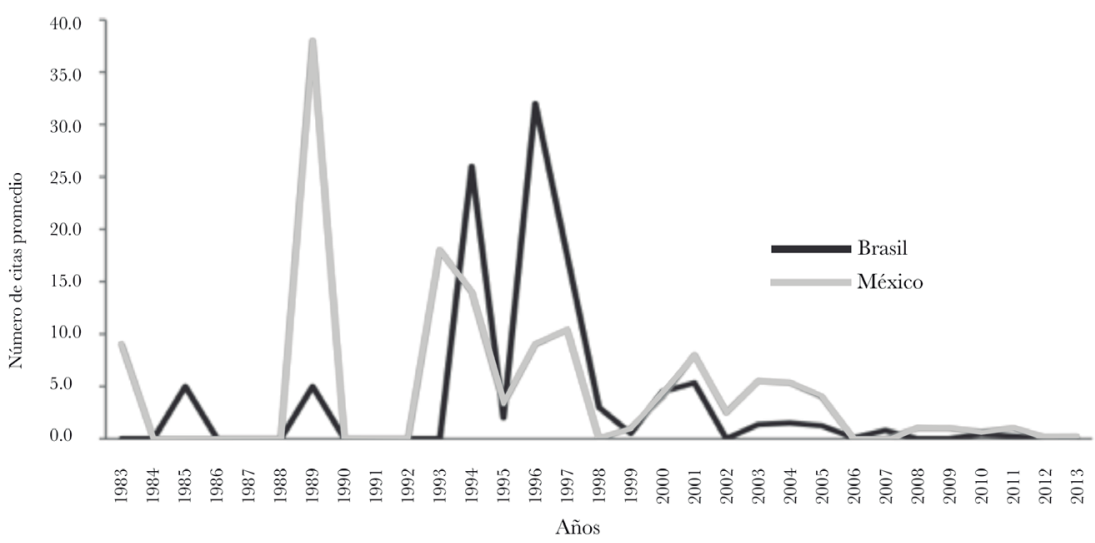

FUENTE: elaboración propia con base en USPTO, clases 514 y/o 424 y 800 y/o 435.

Entre las cinco patentes de Brasil con mayores citas recibidas de titulares destacan dos (5623067 y 5589615), que comparten la titularidad con la empresa Plant Genetic Systems de Bélgica, orientadas a investigación agrícola (por lo que hay inventores de las dos nacionalidades), las cuales acumulan 33 citas cada una. A su vez, la patente 5368867 de la empresa Peroxidos de Brasil registra 27 citas recibidas. En un nivel menor, la patente 6323006 de la Universidad Federal de Minas Gerais obtuvo 16 citas a su patente. Asimismo, la empresa Industria Villares, S. A., ha recibido 15 citas a su invención en el proceso de obtención del etanol.

De las cinco patentes mexicanas con mayores citas, sobresale laboratorios Biochemie de México, empresa trasnacional, con 40 citas a su patente 4828832 sobre un tratamiento terapéutico a la piel. Enseguida, la empresa Grupo Cydsa, S. A. de C. V., obtuvo 27 citas a su patente 5236677; finalmente, la empresa Aplicaciones Farmacéuticas, S. A. de C. V., registró 26, 24 y 17 citas en invenciones de soluciones farmacéuticas inyectables a tres de sus patentes.

Si comparamos este número de citas con las que reciben las patentes de países industrializados, es magro. 
Esta obra forma parte del acervo de la Biblioteca Jurídica Virtual del Instituto de Investigaciones Jurídicas de la UNAM

TABLA 1

PATENTES DE BRASIL Y MÉXICO CONCEDIDAS EN USPTO CON MAYOR NÚMERO DE CITAS RECIBIDAS

\begin{tabular}{|c|c|c|c|c|c|c|}
\hline \multicolumn{7}{|c|}{ Brasil } \\
\hline $\begin{array}{c}\text { Número de } \\
\text { patente }\end{array}$ & Año & $\begin{array}{c}\text { FwPat } \\
\text { Cit }\end{array}$ & Título & Titular & Inventor/es & Nacionalidad \\
\hline 5623067 & 1997 & 33 & $\begin{array}{l}\text { Seed-specific } \\
\text { promoter } \\
\text { region }\end{array}$ & $\begin{array}{l}\text { Plant Genetic } \\
\text { Systems, N.V. } \\
\text { (Ghent, BE) } \\
\text { Brazilian } \\
\text { Agricultural } \\
\text { Research } \\
\text { Organization- } \\
\text { Embrapa/ } \\
\text { Cenargen } \\
\text { (Brasilia, BR) }\end{array}$ & $\begin{array}{l}\text { Vandekerckhove, } \\
\text { Joel S. } \\
\text { (Loppem, BE), } \\
\text { Krebbers, Enno } \\
\text { (Alhambra, CA), } \\
\text { Botterman, } \\
\text { John (Zevergem- } \\
\text { de Pinte, BE), } \\
\text { Leemans, Jan } \\
\text { (Deurle, BE) }\end{array}$ & $\mathrm{BE}, \mathrm{CA}$ \\
\hline 5589615 & 1996 & 33 & $\begin{array}{l}\text { Process for the } \\
\text { production } \\
\text { of transgenic } \\
\text { plants with } \\
\text { increased } \\
\text { nutritional } \\
\text { value via the } \\
\text { expression } \\
\text { of modified } \\
2 \text { S storage } \\
\text { albumins }\end{array}$ & $\begin{array}{l}\text { Plant Genetic } \\
\text { Systems N.V. } \\
\text { (Ghent, BE) } \\
\text { Brazilian } \\
\text { Agricultural } \\
\text { Research } \\
\text { Organization- } \\
\text { Embrapa/ } \\
\text { Cenargen } \\
\text { (Brasilia, BR) }\end{array}$ & $\begin{array}{l}\text { De Clercq, Ann } \\
\text { (Harelbeke, BE), } \\
\text { Krebbers, Enno } \\
\text { (Alhambra, CA), } \\
\text { Vandekerckhove, } \\
\text { Joel (Loppem, } \\
\text { BE), Barreto } \\
\text { de Castro, Luiz } \\
\text { (Brasileia, BR), } \\
\text { Gander, Eugen } \\
\text { (Brasileia, BR), } \\
\text { Van Montagu, } \\
\text { Marc (Brussels, } \\
\text { BE) }\end{array}$ & $\begin{array}{c}\mathrm{CA}, \mathrm{BE}, \\
\mathrm{BR}\end{array}$ \\
\hline 5368867 & 1994 & 27 & $\begin{array}{l}\text { Process for the } \\
\text { accelerated } \\
\text { production of } \\
\text { stable solutions, } \\
\text { in equilibrium, } \\
\text { of peracetic } \\
\text { acid in low } \\
\text { concentrations }\end{array}$ & $\begin{array}{l}\text { Peroxidos Do } \\
\text { Brasil (São } \\
\text { Paulo, BR) }\end{array}$ & $\begin{array}{l}\text { Da Silva, Alcides } \\
\text { B. (São Paulo, } \\
\text { BR), Tognetti; } \\
\text { Joao B. (São } \\
\text { Paulo, BR), } \\
\text { Dadabhoy, Jal R. } \\
\text { (São Paulo, BR) }\end{array}$ & $\mathrm{BR}$ \\
\hline
\end{tabular}


Esta obra forma parte del acervo de la Biblioteca Jurídica Virtual del Instituto de Investigaciones Jurídicas de la UNAM www.juridicas.unam.mx

GUZMÁN / ACATITLA / MALDONADO

\begin{tabular}{|c|c|c|c|c|c|c|}
\hline $\begin{array}{c}\text { Número de } \\
\text { patente }\end{array}$ & Año & $\begin{array}{c}\text { FwPat } \\
\text { Cit }\end{array}$ & Titulo & Titular & Inventor/es & Nacionalidad \\
\hline 6323006 & 2001 & 16 & $\begin{array}{l}\text { Recombinant } \\
\text { human beta- } \\
\text { CIS interferon }\end{array}$ & $\begin{array}{l}\text { Universidad } \\
\text { Federal } \\
\text { de Minas } \\
\text { Gerais (Belo } \\
\text { Horizonte, BR) }\end{array}$ & $\begin{array}{l}\text { Peregrino } \\
\text { Ferreira, Paulo } \\
\text { Cesar (Belo } \\
\text { Horizonte, } \\
\text { BR), Geessien } \\
\text { Kroon, Erna } \\
\text { (Belo Horizonte, } \\
\text { BR), Golgher, } \\
\text { Romain Rolland } \\
\text { (Belo Horizonte, } \\
\text { BR), Bonjardim, } \\
\text { Claudio Antonio } \\
\text { (Belo Horizonte, } \\
\text { BR), De } \\
\text { Carvalho, Alex } \\
\text { Fiorini (Belo } \\
\text { Horizonte, BR) }\end{array}$ & $\mathrm{BR}$ \\
\hline 4529699 & 1985 & 15 & $\begin{array}{l}\text { Process and } \\
\text { installation } \\
\text { for obtaining } \\
\text { ethanol by the } \\
\text { continuous } \\
\text { acid hydrolysis } \\
\text { of cellulosic } \\
\text { materials }\end{array}$ & $\begin{array}{l}\text { Industrias } \\
\text { Villares, S. A. } \\
\text { (BR) }\end{array}$ & $\begin{array}{l}\text { Gerez, Jose C. } \\
\text { G. (Campinas, } \\
\text { BR), Gerez, } \\
\text { Maria D. C. A. } \\
\text { (Campinas, BR), } \\
\text { Miller, Joseph } \\
\text { (Campinas, BR) }\end{array}$ & BR \\
\hline \multicolumn{7}{|c|}{ México } \\
\hline 4828832 & 1989 & 40 & $\begin{array}{l}\text { Method of } \\
\text { manufacturing } \\
\text { a composition } \\
\text { for treating skin } \\
\text { lesions }\end{array}$ & $\begin{array}{l}\text { Laboratorios } \\
\text { Biochemie de } \\
\text { México }(\text { Col. } \\
\text { Granada, MX) }\end{array}$ & $\begin{array}{l}\text { De Cuéllar, } \\
\text { Blanca Rosa A. } \\
\text { (Mexico City, } \\
\text { MX), Bello, Luis } \\
\text { Armando L. } \\
\text { (Ciudad Satélite, } \\
\text { MX) }\end{array}$ & MX \\
\hline
\end{tabular}


Esta obra forma parte del acervo de la Biblioteca Jurídica Virtual del Instituto de Investigaciones Jurídicas de la UNAM www.juridicas.unam.mx

NATURALEZA DE LA DIFUSIÓN DEL CONOGIMIENTO TEGNOLÓGICO...

\begin{tabular}{|c|c|c|c|c|c|c|}
\hline $\begin{array}{l}\text { Número de } \\
\text { patente }\end{array}$ & Año & $\begin{array}{c}\text { FwPat } \\
\text { Cit }\end{array}$ & Titulo & Titular & Inventor/es & Nacionalidad \\
\hline 5236677 & 1993 & 35 & $\begin{array}{l}\text { Biological } \\
\text { process for the } \\
\text { elimination } \\
\text { of sulphur } \\
\text { compounds } \\
\text { present in gas } \\
\text { mixtures }\end{array}$ & $\begin{array}{l}\text { Grupo Cydsa, } \\
\text { S. A. de C. V. } \\
\text { (Garza García, } \\
\text { MX) }\end{array}$ & $\begin{array}{l}\text { Torres-Cardona, } \\
\text { Mario D. (Nuevo } \\
\text { León, MX), } \\
\text { Revah-Moiseev, } \\
\text { Sergio (Virreyes, } \\
\text { MX), Hinojosa- } \\
\text { Martínez, } \\
\text { Antonio (Nuevo } \\
\text { León, MX), } \\
\text { Páez-Moreno, } \\
\text { Fernando J. } \\
\text { (Nuevo León, } \\
\text { MX), Morales- } \\
\text { Baca, Víctor M. } \\
\text { (Nuevo León, } \\
\text { MX) }\end{array}$ & MX \\
\hline 5643604 & 1997 & 26 & $\begin{array}{l}\text { Parenteral } \\
\text { dosage form }\end{array}$ & $\begin{array}{l}\text { Aplicaciones } \\
\text { Farmacéuticas, } \\
\text { S. A. de C. V. } \\
(\text { MX) }\end{array}$ & $\begin{array}{l}\text { Ángeles Uribe, } \\
\text { Juan (México, } \\
\text { MX), Garza } \\
\text { Flores, Josué } \\
\text { (México, MX) }\end{array}$ & MX \\
\hline 5360616 & 1994 & 24 & $\begin{array}{l}\text { Injectable } \\
\text { pharmaceutical } \\
\text { composition }\end{array}$ & $\begin{array}{l}\text { Aplicaciones } \\
\text { Farmacéuticas, } \\
\text { S. A. de C. V. } \\
\text { (Mexico City, } \\
\text { MX) }\end{array}$ & $\begin{array}{l}\text { Garza Flores, } \\
\text { Josué (Mexico } \\
\text { City, MX), } \\
\text { Laiseca Soto, } \\
\text { Laura P. (Mexico } \\
\text { City, MX), } \\
\text { Guillén Pichardo, } \\
\text { José (Sto. } \\
\text { Domingo, DO), } \\
\text { Ángeles Uribe, } \\
\text { Juan (Mexico } \\
\text { City, MX) }\end{array}$ & MX \\
\hline 5512303 & 1996 & 17 & $\begin{array}{l}\text { Injectable } \\
\text { pharmaceutical } \\
\text { composition }\end{array}$ & $\begin{array}{l}\text { Aplicaciones } \\
\text { Farmacéuticas } \\
\text { S. A. de C. } \\
\text { V. (Mexico } \\
\text { City, MX) }\end{array}$ & $\begin{array}{l}\text { Garza Flores, } \\
\text { Josué (Mexico } \\
\text { City, MX), } \\
\text { Laiseca Soto, } \\
\text { Laura P. (Mexico } \\
\text { City, MX), } \\
\text { Guillén Pichardo, } \\
\text { José (Sto. } \\
\text { Domingo, DO), } \\
\text { Ángeles Uribe, } \\
\text { Juan (Mexico } \\
\text { City, MX) }\end{array}$ & MX \\
\hline
\end{tabular}


Esta obra forma parte del acervo de la Biblioteca Jurídica Virtual del Instituto de Investigaciones Jurídicas de la UNAM www.juridicas.unam.mx

Los gráficos 8 y 9 ilustran el destino geográfico de la difusión de la novedad patentada con mayor número de citas recibidas de Brasil y México. En el caso de la patente 4828832 de México, las patentes que citan son fundamentalmente de titulares de Estados Unidos. En relación con la patente 5623067 de Brasil, se advierte una mayor diversificación geográfica en la difusión (Estados Unidos y países de la Unión Europea).

\section{GRÁFICO 8 \\ PATENTE DE MÉXICO CONCEDIDA POR USPTO MAYOR CITADA POR PAÍSES Y NÚMERO DE LAS PATENTES QUE CITAN}

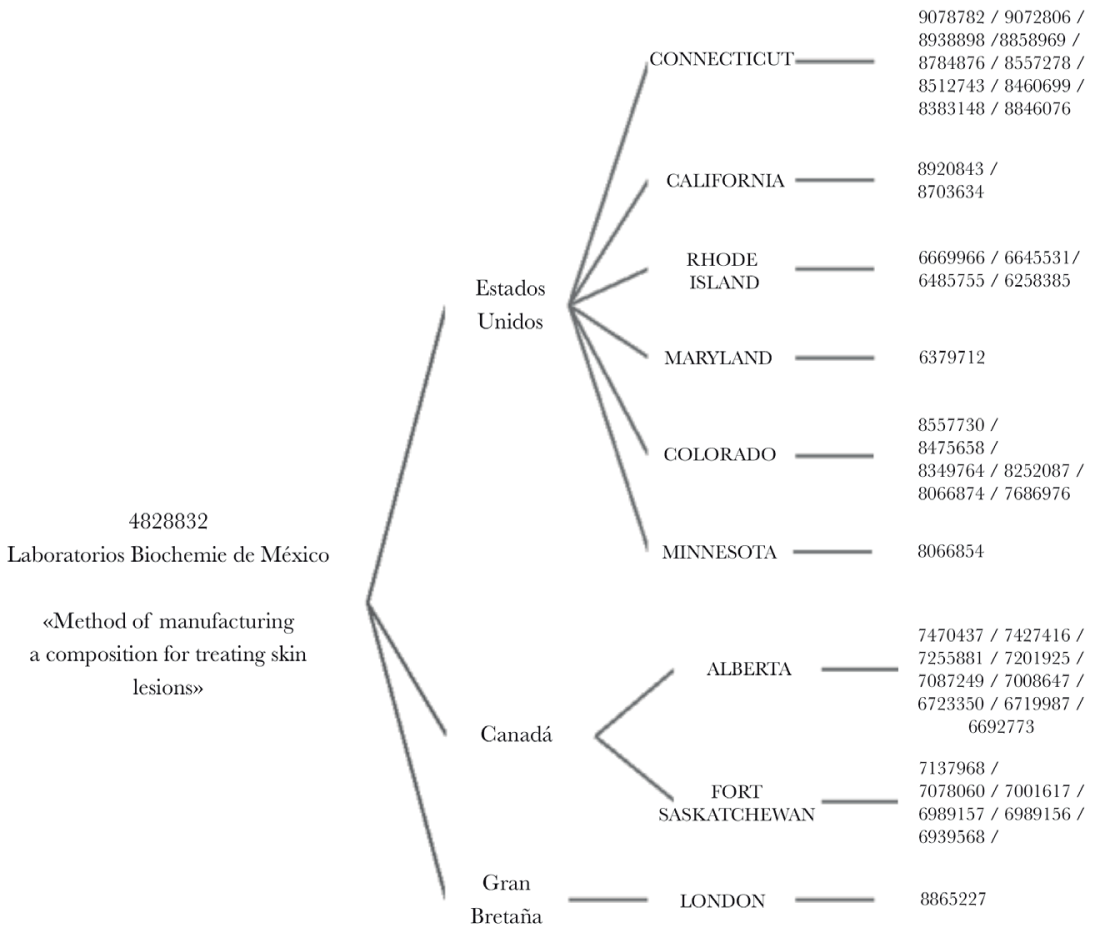

FUENTE: elaboración propia con base en USPTO, clases 514 y/o 424, y 800 y/o 435. 
Esta obra forma parte del acervo de la Biblioteca Jurídica Virtual del Instituto de Investigaciones Jurídicas de la UNAM

\section{GRÁFICO 9 \\ PATENTE DE BRASIL GONCEDIDA POR USPTO MAYOR CITADA POR PAÍSES Y NÚMERO DE LAS PATENTES QUE CITAN}

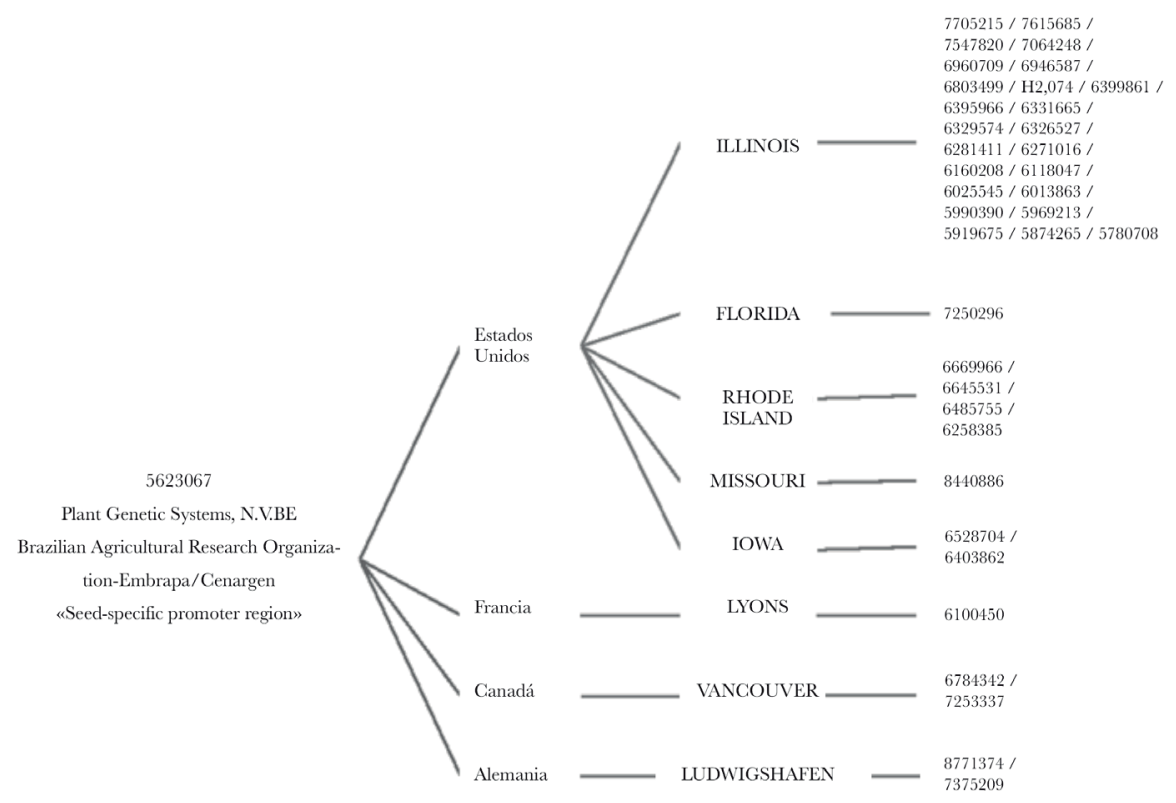

FUENTE: elaboración propia con base en USPTO, clases 514 y/o 424, y 800 y/o 435.

\section{Metodología}

Para estimar la difusión del conocimiento tecnológico generado en el sector biofarmacéutico de Brasil y México se consideraron los datos de patentes concedidas por la USPTO. La hipótesis inicial que se formuló es: considerando la cita de patentes hacia adelante (forward patent citation) como una variable proxy de la difusión de las innovaciones de mayor valor tecnológico, se espera que esta mayor difusión en el área biofarmacéutica de Brasil y México se asocie positivamente con las siguientes variables: innovación radical, número de reivindicaciones (claims), invenciones patentadas en varias oficinas (patentes PCT), la cooperación tecnológica (co-patentes), el tamaño del equipo de los inventores, la movilidad de los inventores (presencia de inventores extranjeros), la relación con el sector académico (número de citas de artículos científicos), el esfuerzo del sector estatal (institucional) en la innovación en el campo biofarmacéutico (número de patentes por universida- 
Esta obra forma parte del acervo de la Biblioteca Jurídica Virtual del Instituto de Investigaciones Jurídicas de la UNAM

des e institutos de investigación en biopharma), la participación de empresas (patentes de empresas), el menor tiempo con el que las patentes de América Latina son citadas (forward patent citation).

Sin embargo, después de probar con las diferentes variables en los modelos propuestos, se eliminaron las siguientes variables que no cumplían las pruebas estadísticas: la movilidad de los inventores (presencia de inventores extranjeros), el esfuerzo del sector institucional (patentes de universidades o instituciones en el área biofarmacéutica), la participación de empresas (patentes de empresas), la innovación radical o incremental, la innovación de proceso o de producto. Se esperaba que estas variables tuvieran una influencia en la difusión porque normalmente en países industrializados éstas tienen un gran impacto en la generación y difusión del conocimiento patentado. Muy probablemente el hecho de que México y Brasil tengan una reducida y errática actividad inventiva, asociado a la naturaleza de la actividad inventiva, repercute en que no pueda evaluarse el efecto de estas variables.

Finalmente, la hipótesis que en esta investigación se suscribe es la siguiente: se espera que la mayor difusión de las novedades de Brasil y México en el área biofarmacéutica se halle asociada positivamente con las siguientes variables: la amplitud tecnológica, el número de reivindicaciones, los registros de patentes en otras oficinas, la colaboración tecnológica (co-patentes), el tamaño de los equipos de investigación, la velocidad con la que se difunden las novedades y al conocimiento previo acumulado.

A fin de probar la hipótesis se propone un modelo de tipo Poisson y se establece la siguiente ecuación de difusión de los nuevos conocimientos tecnológicos, considerando como variable proxy de la difusión el número de citas hacia adelante de las patentes en el sector biofarmacéutico mundial en dos países de América Latina (Brasil y México), en función del conjunto de variables explicativas señaladas $(\mathrm{X}=\mathrm{xi})$ :

$$
\operatorname{DifBiof}_{B, M}=E\left[y_{i} / x_{i}\right]=\exp \left(x_{i}, \beta\right)
$$

$$
\operatorname{DifBiof}_{B, M}=E\left[y_{i} / x_{i}\right]=\exp \left(x_{i}, \beta\right)
$$

Donde:

DifBiof $_{B r, M x}=$ difusión de los nuevos conocimientos tecnológicos patentados en el área biofarmacéutica de Brasil y México. Se toma como variable proxy al número de citas a patentes de México $(\mathrm{Mx})$ y Brasil $(\mathrm{Br})$ concedidas en el área biofarmacéutica (FwPatCit — patentes hacia delante-).

El conjunto $\mathrm{X}$ se compone de las siguientes variables explicativas $x_{i}$ y sus respectivas hipótesis: 
Esta obra forma parte del acervo de la Biblioteca Jurídica Virtual del Instituto de Investigaciones Jurídicas de la UNAM

NATURALEZA DE LA DIFUSIÓN DEL CONOGIMIENTO TEGNOLÓGICO...

TABLA 2

VARIABLES DEL MODELO ECONOMÉTRICO

\begin{tabular}{|l|l|l|}
\hline & \multicolumn{1}{|c|}{ Variable proxy } & \multicolumn{1}{|c|}{ Hipótesis } \\
\hline TechPatCit & $\begin{array}{l}\text { Amplitud tecnológica. Es una } \\
\text { variable numérica que indica el } \\
\text { número de clases tecnológicas en } \\
\text { las que fueron citadas las patentes } \\
\text { de Ar, Bry Mx. }\end{array}$ & $\begin{array}{l}\text { Entre mayores sean las clases } \\
\text { tecnológicas de las patentes que } \\
\text { citan (FwPatCit), mayor la pro- } \\
\text { pensión a la difusión. }{ }^{19}\end{array}$ \\
\hline Cl & $\begin{array}{l}\text { Es el número de reivindicaciones } \\
\text { de novedad (claims). }\end{array}$ & $\begin{array}{l}\text { Al tener una patente mayor número } \\
\text { de reivindicaciones, son más las no- } \\
\text { vedades que se le reconocen a la } \\
\text { invención, entonces habrá mayor } \\
\text { propensión para su difusión.20 }\end{array}$ \\
\hline PCT & $\begin{array}{l}\text { Patentes concedidas en WIPO. Es } \\
\text { una variable dummy, donde 1= la } \\
\text { patente tiene registro PCT, y 0 = } \\
\text { la patente no tiene PCT. }\end{array}$ & $\begin{array}{l}\text { Una mayor propensión de difusión } \\
\text { cuando una patente sea PCT, } \\
\text { debido a que éstas pueden solicitar } \\
\text { su registro en 148 países. }\end{array}$ \\
\hline CoopTec & $\begin{array}{l}\text { Cooperación tecnológica. La titu- } \\
\text { laridad de la patente compartida } \\
\text { (co-patente) es una variable proxy } \\
\text { de la cooperación tecnológica } \\
\text { entre diferentes agentes. Es una } \\
\text { variable dummy, donde 1 = hay } \\
\text { cooperación tecnológica, y 0 no no } \\
\text { hay cooperación tecnológica. }\end{array}$ & $\begin{array}{l}\text { Una difusión cuando se trate } \\
\text { de co-patentes, bajo el supuesto de } \\
\text { que éstas son resultado de la coo- } \\
\text { peración entre agentes en la I+D. }{ }^{21}\end{array}$ \\
\hline
\end{tabular}

19 Alcácer, J. y Gittelman, M., "Patent Citations as a Measure of Knowledge Flows: The Influence of Examiner Citations", Review of Economics and Statistics, vol. 88, núm. 4, 2006.

20 Tong, X. y Frame, J. D., "Measuring National Technological Performance with Patent Claims Data", Research Policy, vol. 23, núm. 2, 1994; Lanjouw, J. O. y Schankerman, M., Patent Suits: Do They Distort Research Incentives?, CEPR, documento de trabajo, núm. 2042, 2000; Lanjouw, J. O. y Schankerman, M., "Patent Quality and Research Productivity: Measuring Innovation with Multiple Indicators", The Economic Fournal, vol. 114, núm. 495, 2004.

21 OCDE, Manual de estadísticas de patentes de la OCDE, OCDE, 2002. 
Esta obra forma parte del acervo de la Biblioteca Jurídica Virtual del Instituto de Investigaciones Jurídicas de la UNAM www.juridicas.unam.mx

\begin{tabular}{|c|c|c|}
\hline & Variable proxy & Hipótesis \\
\hline & & Se espera que: \\
\hline InvTSize & $\begin{array}{l}\text { Tamaño de los equipos de in- } \\
\text { vestigación. Es el número de } \\
\text { inventores involucrados en la ge- } \\
\text { neración de la patente. }\end{array}$ & $\begin{array}{l}\text { A mayor número de inventores } \\
\text { en la generación de la patente, las } \\
\text { redes tienden a crecer y, por tanto, } \\
\text { sea mayor la propensión de su } \\
\text { difusión. }{ }^{22}\end{array}$ \\
\hline LagPatCit & $\begin{array}{l}\text { Rezago temporal en que se cita a } \\
\text { una patente de Brasil y México. Es } \\
\text { una variable proxy de la velocidad } \\
\text { de difusión que considera el nú- } \\
\text { mero de años en que la patente es } \\
\text { citada, por fechas de solicitud de la } \\
\text { patente que cita y la citada. }\end{array}$ & $\begin{array}{l}\text { Entre menor sea el tiempo en que } \\
\text { la patente se cite mayor será la } \\
\text { propensión de su difusión e incluso } \\
\text { su valor. }{ }^{23}\end{array}$ \\
\hline BkPatCit & $\begin{array}{l}\text { Conocimiento previo acumulado } \\
\text { en este sector. Se toma como } \\
\text { variable proxy el número de citas } \\
\text { que contiene una patente asignada } \\
\text { en biofarmacéutica de otras pa- } \\
\text { tentes. }\end{array}$ & $\begin{array}{l}\text { Entre mayor sea el número de citas } \\
\text { que contiene una patente asignada } \\
\text { en el sector de biofarmacéutica } \\
\text { de otras patentes, mayor será la } \\
\text { propensión de la difusión del nuevo } \\
\text { conocimiento generado en este } \\
\text { sector tecnológico. }\end{array}$ \\
\hline
\end{tabular}

Posteriormente, se propusieron tres modelos más (binomial negativo, otro Poisson, y uno más binomial negativo) con la finalidad de encontrar aquel que permitiera una mejor distribución de los datos y sus resultados tuvieran confiabilidad para poder interpretarlos de manera adecuada.

\section{ANÁlisis DE LOS RESULTADOS}

Conforme a las estimaciones realizadas, se encontró que aun cuando los parámetros de las variables resultaron estadísticamente significativos (menores a 0.05), con excepción de la velocidad de difusión - LagPatCit - (con p-valeu de 0.08923$)$, la bondad de ajuste del modelo no resultó adecuada, debido a

22 Newman, M., "The Structure and Function of Complex Networks", SIAM Review, vol. 45, núm. 2, 2003.

23 Gay, C. et al., "The Determinants of Patent Citations: An Empirical Analysis of French and British Patents in the US", Economics of Innovation and New Technology, vol. 14, núm. 5, 2005. 
Esta obra forma parte del acervo de la Biblioteca Jurídica Virtual del Instituto de Investigaciones Jurídicas de la UNAM

que la R-cuadrada de McFadden es igual a 0.51. Los resultados del modelo 1 Poisson utilizado también presentan problemas de sobredispersión de los errores. Al ser la prueba de contraste Chi-cuadrada elevada (40.78) y el p-valeu de 0 , se debe rechazar la hipótesis nula que establece que no hay sobredispersión. Adicionalmente, el modelo presenta problemas de distribución anormal de los errores. El valor del estadístico de prueba Chi-cuadrada es elevado (92.62) y el $p$-valeu muy cercano a 0 , por lo que se debe rechazar la hipótesis nula que establece que los errores se distribuyen en forma normal.

Considerando los problemas de los resultados del modelo 1 Poisson, se estimó un segundo modelo de tipo binomial negativo considerando las mismas variables. Los resultados obtenidos en el modelo 2 fueron los siguientes: la prueba alpha resultó significativa con un valor positivo de 1.36 y un p-valeu de 0.00001, lo cual indica que los datos se representan mejor con la distribución binomial negativa. Sin embargo, no todos los valores de los estimadores resultaron significativos. Los estimadores de PCT e Inv TSize resultaron no significativos con un p-valeu de 0.14 y 0.76 , respectivamente. A su vez, los parámetros estimados de las variables $\mathrm{Cl}$ y BkPatCit muestran una significancia límite con un p-valeu de 0.05884 y 0.05272 , por lo que podrían ser considerados en los resultados.

En la búsqueda de mejorar las estimaciones se consideró un tercer modelo nuevamente de tipo Poisson, manteniendo las variables del primer y segundo modelos. Los resultados del modelo 3 fueron los siguientes: todos los coeficientes de las variables resultaron significativos, excepto el de la variable LagPatCit, con un p-valeu de 0.05745, en el límite de significancia. No obstante, en este modelo se presentan nuevamente problemas de sobredispersión, debido a que la prueba de contraste Chi-cuadrada presenta un valor elevado de 40.17 y un p-valeu de 0 , lo cual indica que se debe rechazar la hipótesis nula que establece que no hay sobredispersión de los errores.

Frente al problema de sobredispersión que presentó el tercer modelo de tipo Poisson, se estimó un cuarto modelo de tipo binomial negativo, considerando las mismas variables del tercer modelo de tipo Poisson. Pese a que este modelo 4 no cumple el supuesto de distribución de los errores, es el que mejor explica la influencia de las diferentes variables independientes en la variable dependiente. El parámetro de la prueba alpha fue de 1.45, con un p-valeu de 0.00001 , lo cual indica que la naturaleza de los datos se ajusta mejor a una distribución binomial negativa.

Los resultados de los dos últimos modelos se presentan en la tabla 3. En relación con el modelo 4, las variables: amplitud tecnológica, número de reivindicaciones de novedad, cooperación tecnológica, rezago temporal en que se cita a la patente y conocimiento previo acumulado en este sector 
Esta obra forma parte del acervo de la Biblioteca Jurídica Virtual del Instituto de Investigaciones Jurídicas de la UNAM www.juridicas.unam.mx

resultaron estadísticamente significativas. En cambio, las variables: patentes concedidas en WIPO y tamaño de los equipos de investigación no resultaron significativas, con un $p$-valeu de 0.21 y 0.77 , respectivamente.

TABLA 3

Resultados De los MODElOS POISSON Y BINOMIAL NEGATIVO

\begin{tabular}{|c|c|c|c|c|}
\hline \multicolumn{5}{|c|}{ México y Brasil } \\
\hline \multirow{2}{*}{ Variable } & \multicolumn{2}{|c|}{ Modelo 3 de tipo Poisson } & \multicolumn{2}{|c|}{$\begin{array}{c}\text { Modelo } 4 \text { de tipo binomial } \\
\text { negativo }\end{array}$} \\
\hline & Coeficiente & Valor $p$ & Coeficiente & Valor $p$ \\
\hline TechPatCit & 0.491302 & 0.00001 & 1.05086 & 0.00001 \\
\hline $\mathrm{Cl}$ & -0.00969425 & 0.03184 & -0.0245216 & 0.03485 \\
\hline PCT & -1.05708 & 0.00001 & -0.425596 & 0.21398 \\
\hline Cooptec & 0.640233 & 0.00001 & 0.665576 & 0.05557 \\
\hline InvTSize & 0.10037 & 0.00035 & 0.0217776 & 0.77418 \\
\hline LagPatCit & 0.00213288 & 0.05745 & 0.00887625 & 0.00634 \\
\hline BkPatCit & 0.0115382 & 0.00041 & 0.0183901 & 0.04997 \\
\hline \multirow{2}{*}{$\begin{array}{l}\text { R-cuadrado de } \\
\text { McFadden }\end{array}$} & & & \multicolumn{2}{|l|}{ Normalidad } \\
\hline & & 0.498388 & Errores & \\
\hline \multirow[t]{3}{*}{$\begin{array}{l}\text { Contraste de } \\
\text { sobredispersión }\end{array}$} & & & 15008.1 & 0.00000 \\
\hline & 40.1725 & 0.0000 & & \\
\hline & & & Alpha: 1.58095 & 0.00001 \\
\hline
\end{tabular}

FUENTE: estimación propia. 
Esta obra forma parte del acervo de la Biblioteca Jurídica Virtual del Instituto de Investigaciones Jurídicas de la UNAM

Interpretación de los resultados del modelo binomial negativo

Con la finalidad de analizar la magnitud de la influencia de cada variable independiente del modelo en la variable dependiente, difusión de los nuevos conocimientos tecnológicos patentados en el área biofarmacéutica de Brasil y México (cuya variable proxy es el número de citas recibidas por las patentes de Brasil y México), se estiman los efectos marginales de cada una de las variables con significancia estadística: amplitud tecnológica (TechPatCit), número de reivindicaciones de novedad $(C l)$, cooperación tecnológica $($ Coop Tec), rezago temporal en que se cita a la patente (LagPatCit) y conocimiento previo acumulado en este sector (BkPatCit). Dicho de otra manera, los efectos marginales o elasticidades dan cuenta de cuál es el grado de respuesta de la difusión de los nuevos conocimientos tecnológicos patentados en el área biofarmacéutica de Brasil y México (variable dependiente) frente a cambios de una unidad de cada una de las variables independientes. Así, la tasa de cambio del valor medio estimado (2.6) de la variable dependiente (DifBiof), respecto al cambio en una unidad de la variable independiente, es igual al valor del coeficiente estimado de la variable independiente por el valor medio estimado de la variable dependiente, y se expresa:

$$
\frac{\partial \mu}{\partial X_{i}}=C_{i} \mu
$$

GRÁFICO 10

EFEGTOS MARGINALES DE LAS VARIABLES DEPENDIENTES EN LA DIFUSIÓN DE LOS NUEVOS CONOGIMIENTOS TEGNOLÓGICOS PATENTADOS EN EL ÁREA BIOFARMACÉUTICA DE BRASIL Y MÉXICO

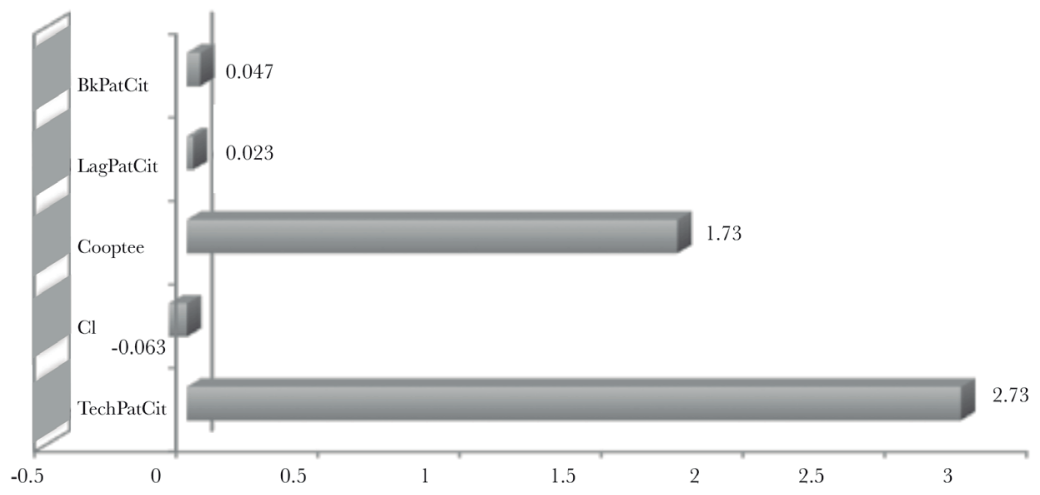

FUENTE: estimación propia con base en resultados del modelo binomial negativo. 
Esta obra forma parte del acervo de la Biblioteca Jurídica Virtual del Instituto de Investigaciones Jurídicas de la UNAM

De las cinco variables, cuatro tienen efectos positivos en la difusión de nuevos conocimientos patentados por Brasil y México en el área estudiada. La variable que tiene mayor efecto marginal es la amplitud tecnológica $\left(T_{e}-\right.$ chPatCit); al aumentar ésta en una unidad, el número de citas promedio recibidas puede ser de 2.73. Es decir, cuando una patente de Brasil y México del área de biofarmacéutica también es reconocida en otras clases tecnológicas, la amplitud tecnológica es mayor y, por tanto, una clase tecnológica adicional aumenta la propensión de ser citada o difundida en 2.73 veces. Este resultado sugiere que una medida política para favorecer la difusión de las invenciones de los dos países latinoamericanos es desarrollar invenciones cuyo impacto tenga una mayor amplitud en varias clases tecnológicas.

En segundo lugar, la variable colaboración tecnológica (CoopTec) tiene una elasticidad de 1.73. Es decir, cuando incrementa en una unidad esta variable, que se representa por una co-patente, la propensión de citas de patentes recibidas es de 1.73 veces en promedio. La colaboración de agentes en la generación de conocimiento influye positivamente en la difusión del nuevo conocimiento patentado en este sector. En muchos países se ha reconocido que la colaboración tecnológica tiene varios efectos positivos en la actividad innovativa. En particular, la lectura que se desprende de este resultado es que debe fomentarse la colaboración en la $\mathrm{I}+\mathrm{D}$ que se traduzca en co-patentes porque en este proceso se desarrollan redes de conocimientos, derramas de conocimiento tecnológico y, en consecuencia, mayores probabilidades de difusión.

Las otras dos variables con efectos positivos, pero muy marginales, son: rezago temporal de cita (LagPatCit) y conocimiento previo acumulado en este sector (BkPatCit). Así, al aumentar en un año el rezago en que una patente es citada (LagPatCit), la propensión de recibir citas será de 0.023 veces en promedio. Es decir, una unidad adicional en la velocidad de difusión del nuevo conocimiento generado en este sector tecnológico tiene un efecto positivo, pero magro. En términos netos, la difusión se ve limitada. Esta variable se asocia a factores como la cercanía tecnológica y geográfica con otros países. Si bien es cierto que México tiene cercanía geográfica con Estados Unidos, líder de la industria biofarmacéutica, países del este de Asia tienen una mayor cercanía geográfica. ${ }^{24}$

Finalmente, en el caso de la variable número de reivindicaciones $(C l)$, la elasticidad es negativa. A medida en que aumenta en una unidad el número de reivindicaciones de una patente, la propensión de citas recibidas promedio es de -0.063. Es decir, contrariamente a lo esperado, se registra un efecto negativo sobre la difusión del nuevo conocimiento generado en este sector.

24 Guzmán, A. y Gómez, H., "Patterns of Knowledge...", op. cit. 
Esta obra forma parte del acervo de la Biblioteca Jurídica Virtual del Instituto de Investigaciones Jurídicas de la UNAM

\section{CONCLUSIONES}

El estudio de la difusión internacional de las innovaciones tecnológicas y los factores que la determinan tiene una enorme relevancia para la comprensión de la naturaleza de la innovación de los países. En general, los estudios de la difusión tecnológica se centran en países industrializados. En particular, cómo se difunden las innovaciones en los países que las generan. En países en desarrollo o emergentes, la difusión de novedades de países industrializados ocurre mediante la transferencia tecnológica. Poco se ha abordado la difusión internacional de las invenciones patentadas en países emergentes.

Retomando las contribuciones de varios economistas sobre metodologías que se basan en la información contenida en los documentos de patentes, propusimos varios modelos hasta encontrar aquel que permitiera identificar las variables explicativas de la difusión de las novedades generadas en el sector biofarmacéutico de países latinoamericanos (Brasil y México).

El modelo que estima la propensión de difusión del conocimiento tecnológico, tomando como variable proxy la cita posterior que se hace a las patentes, la cual sugiere la importancia de la invención, así como de los factores que influyen, se enfrentó a problemas econométricos que están asociados al reducido número de patentes y la especificación de las variables dummy en lugar de numéricas.

La hipótesis inicial tuvo que ser ajustada cuando se hizo la propuesta de modelo en la medida en que algunas variables no satisficieron las pruebas necesarias para su modelación. Así, fueron descartadas variables que considerábamos esenciales para explicar la propensión a difusión de las novedades patentadas de la industria farmacéutica de Brasil y México: participación de firmas (patentes de firmas), participación de institutos (patentes de universidades e institutos) y vinculación con la academia (citas a artículos científicos).

$\mathrm{Al}$ estar en condiciones de escalar a nivel industrial las invenciones, las firmas están en mejores condiciones de difundir sus nuevas aportaciones tecnológicas. Aun cuando son las firmas las que poseen mayores recursos para establecer redes internacionales que contribuyan a una mayor difusión de sus innovaciones, el hecho de que las firmas de Brasil y México en el sector farmacéutico no dominen la actividad inventiva, como ocurre en otros países industrializados, no es posible apreciar la influencia en la propensión a difundir internacionalmente.

Así también, la actividad inventiva generada en las instituciones tiene mayor probabilidad de ser difundida cuando hay vinculación con empresas. 
Esta obra forma parte del acervo de la Biblioteca Jurídica Virtual del Instituto de Investigaciones Jurídicas de la UNAM

Los vínculos entre universidades/institutos aún son débiles, lo cual no abona a la difusión tecnológica.

No obstante las dificultades, nuestras estimaciones permiten corroborar parcialmente la hipótesis propuesta. Se confirma que la amplitud tecnológica, el número de reivindicaciones de novedad y la cooperación tecnológica, el rezago temporal en que se cita a la patente y el conocimiento previo acumulado en este sector son variables que afectan positivamente la propensión de la difusión de los nuevos conocimientos patentados en el área biofarmacéutica. Sin embargo, las patentes PCT (WIPO) y el tamaño de los equipos de investigación no reportan una influencia significativa en esta propensión.

Los resultados anteriores permiten hacer propuestas de política para lograr mayor difusión de las novedades patentadas de Brasil y México, especialmente aquellas orientadas a fomentar la invención con mayor amplitud tecnológica y la colaboración tecnológica.

La interacción entre universidades/institutos debe fomentarse en mayor grado, así también la integración de equipos de mayor tamaño, pasando por procesos de movilidad de los inventores. Un mayor esfuerzo institucional debe incluir un mayor esfuerzo en I+D y en la formación de capital humano especializado en el área biofarmacéutica, además de la cooperación tecnológica entre agentes de cada país. En este entorno virtuoso se incrementarán las capacidades de absorción del nuevo conocimiento tecnológico y se mejorará la eficiencia del sector biofarmacéutico de innovación. La probabilidad de difusión de los tres países tendrá un terreno fértil.

En cambio, estos dos países aún no han logrado generar las condiciones para tener equipos de investigadores de mayor tamaño, con los efectos de derrame asociados. En países industrializados, el número de los inventores tiende a ser mayor e incluso con presencia de inventores extranjeros debido a convenios de colaboración con otras empresas y universidades e institutos. La movilidad de inventores parece favorecer una mayor probabilidad de difusión tecnológica.

\section{REFERENGIAS BIBLIOGRÁFICAS}

Aghion, P. y HowitT, P., A Model of Growth through Creative Destruction, National Bureau of Economic Research, documento núm. 3223, 1990.

ALBUQUERQUE et al., Global Interactions Between Firms and Universities: Global Innovation Networks as First Steps Towards a Global Innovation System, Cedeplar, documento de trabajo, núm. 419, 2011. 
Esta obra forma parte del acervo de la Biblioteca Jurídica Virtual del Instituto de Investigaciones Jurídicas de la UNAM

Alcácer, J. y Gittelman, M., "Patent Citations as a Measure of Knowledge Flows: The Influence of Examiner Citations", Review of Economics and Statistics, vol. 88, núm. 4, 2006.

Cockburn, Iain y Henderson, Rebecca, "Scale and Scope in Drug Development: Unpacking the Advantages of Size in Pharmaceutical Research", fournal of Health Economics, vol. XX, núm. 6, 2001.

CRISCUOlO, P. et al., Measuring Knowledge Flows Among European and American Multinationals: A Patent Citation Analysis, Países Bajos, Eindhoven University of Technology, documento presentado en The Future of Innovation Studies Conference, septiembre de 2001.

GAY, G. et al., "The Determinants of Patent Citations: An Empirical Analysis of French and British Patents in the US", Economics of Innovation and New Technology, vol. 14, núm. 5, 2005.

Gomulka, S., The Theory of Technological Change and Economic Growth, Londres, Routledge, 1990.

GRANDSTRAND, Ove et al., Technology Management and International Business, Wiley \& Sons, 1992.

GriLICHes, Z., RED, Patents, and Productivity, Chicago-Londres, The University of Chicago Press, 1984.

GuZmán, A., Propiedad intelectual y capacidades de innovación en la industria farmacéutica de Argentina, Brasil y México, México, Gedisa-UAM, 2014.

Guzmán, A. y Gómez, H., "Patterns of Knowledge Flows from Industrialized to Emerging Countries. The Evidence of the Pharmaceutical Industry's Use of Patent Citation", Contaduria y Administración, vol. 60, 2015.

HaLl, B. et al., Market Value and Patent Citations: A First Look, Berkeley, Universidad de California, Departamento de Economía, documento de trabajo, núm. E01-304, 2001.

HALL, B. et al., NBER Patent Citations Data File: Lessons, Insights and Methodological Tools, National Bureau of Economic Research, documento núm. 8498, 2001.

Henderson, Rebecca et al., "Universities as a Source of Commercial Technology: A Detailed Analysis of University Patenting, 1965-1988", Review of Economics and Statistics, vol. 80, núm. 1, 1998.

HU, A. G. Z. y Jaffe, A., "Patent Citations and International Knowledge Flow: The Cases of Korea and Taiwan", International fournal of Industrial Organization, vol. 21, núm. 6, 2003.

Jaffe, A. y Trajtenberg, M., Patent, Citations and Innovations, CambridgeLondres, The MIT Press, 2002. 
Esta obra forma parte del acervo de la Biblioteca Jurídica Virtual del Instituto de Investigaciones Jurídicas de la UNAM

Lanjouw, J. O. y Schankerman, M., "Patent Quality and Research Productivity: Measuring Innovation with Multiple Indicators", The Economic fournal, vol. 114, núm. 495, 2004.

Lanjouw, J. O. y Schankerman, M., Patent Suits: Do They Distort Research Incentives?, GEPR, documento de trabajo, núm. 2042, 2000.

LEVIN, Richard et al., "Appropriating the Returns from Industrial Research and Development", Brookings Papers on Economic Activity, vol. 3, 1987.

LundvalL, B. A., National Systems of Innovation: An Analytical Framework, Londres, Pinter, 1992.

MASKUs, K., Intellectual Property Rights in the Global Economy, Washington, Institute for International Economics Press, 2000.

Newman, M., "The Structure and Function of Complex Networks", SIAM Review, vol. 45, núm. 2, 2003.

OCDE, La Mondialisation Industrielle. Quatre Études de Cas: Pièces Automobiles, Produits Chimiques, Construction y Semi-Conducteurs, París, 1992.

OCDE, La mondialisation de l'industrie, París, 1996.

OCDE, Manual de estadísticas de patentes de la OCDE, 2002.

OCDE, Symposium on Assessing the Economic Impact of Nanotechnology, Synthesis Report, OECD-NNI, 2013.

Rogers, M., Knowledge, Technological Catch-Up and Economic Growth, Cheltenham-Northampton, Edward Elgar, 2003.

Romer, P., "Endogenous Technological Change", Fournal of Political Economy, núm. 98, 1990.

Rosenberg, N., Inside the Black Box: Technology and Economics, Cambridge University Press, 1982.

Scherer, F. M., Patents, Economics, Policy and Measurement, Cheltenham-Northampton, Edward Elgar, 2005.

Schmookler, J., "Economic Sources of Inventive Activity", The Gournal of Economic History, vol. 22, núm. 1, 1962.

Tong, X. y Frame, J. D., "Measuring National Technological Performance with Patent Claims Data", Research Policy, vol. 23, núm 2, 1994.

Veugelers, Reinhilde y Cassiman, Bruno, "Make and Buy in Innovation Strategies: Evidence from Belgian Manufacturing Firms", Research Policy, vol. 28, núm. 1, 1999. 
Esta obra forma parte del acervo de la Biblioteca Jurídica Virtual del Instituto de Investigaciones Jurídicas de la UNAM

\section{ANEXO}

\begin{tabular}{|c|c|c|c|c|}
\hline \multicolumn{2}{|c|}{ Clasificación / pais } & Brasil & México & Total \\
\hline \multicolumn{2}{|c|}{ Número de patentes } & 127 & 72 & 199 \\
\hline \multirow{2}{*}{ Tipo de invención } & Incremental & 97 & 65 & 162 \\
\hline & Radical & 30 & 7 & 41 \\
\hline \multirow{3}{*}{ Tipo de invención } & Proceso & 29 & 19 & 48 \\
\hline & Producto & 83 & 30 & 113 \\
\hline & Ambos & 15 & 23 & 38 \\
\hline \multirow{5}{*}{ Número de claims } & $1-5$ claims & 46 & 12 & 58 \\
\hline & 6-10 claims & 30 & 19 & 49 \\
\hline & $11-20$ claims & 25 & 28 & 53 \\
\hline & 21-30 claims & 18 & 10 & 28 \\
\hline & 31 o más claims & 8 & 3 & 11 \\
\hline \multirow{8}{*}{ Tipo de titular } & Empresa & 72 & 27 & 99 \\
\hline & Individual & 2 & 7 & 9 \\
\hline & \begin{tabular}{|l|} 
Instituto \\
\end{tabular} & 30 & 18 & 48 \\
\hline & Universidad & 11 & 18 & 29 \\
\hline & Empresa-instituto & 3 & 0 & 3 \\
\hline & Individual-empresa & 0 & 0 & 0 \\
\hline & Universidad-empresa & 5 & 1 & 6 \\
\hline & Universidad-instituto & 4 & 1 & 5 \\
\hline \multirow{2}{*}{ Nacionalidad de los inventores } & Sólo nacionales & 108 & 60 & 168 \\
\hline & Con extranjeros & 19 & 12 & 31 \\
\hline \multirow{3}{*}{ Tamaño del equipo } & 1 inventor & 20 & 12 & 32 \\
\hline & 2-4 inventores & 66 & 44 & 110 \\
\hline & 5-11 inventores & 41 & 16 & 57 \\
\hline
\end{tabular}


Esta obra forma parte del acervo de la Biblioteca Jurídica Virtual del Instituto de Investigaciones Jurídicas de la UNAM www.juridicas.unam.mx

\begin{tabular}{|l|l|c|c|c|}
\hline \multirow{4}{*}{ Citas Bw } & Núm. citas atrás & 873 & 825 & 1698 \\
\cline { 2 - 5 } & Participación & $51 \%$ & $49 \%$ & $100 \%$ \\
\cline { 2 - 5 } & Promedio & 6.9 & 11.5 & 8.5 \\
\hline \multirow{4}{*}{ Citas Fw } & Núm. citas adelante & 235 & 287 & 522 \\
\cline { 2 - 5 } & Participación & $45 \%$ & $55 \%$ & $100 \%$ \\
\cline { 2 - 5 } & Promedio & 1.9 & 4.0 & 2.6 \\
\hline \multirow{3}{*}{ Referencias bibliográficas } & No & 29 & 6 & 35 \\
\cline { 2 - 5 } & Sí & 98 & 66 & 164 \\
\hline
\end{tabular}

FUENTE: USPTO, clases 514 y/o 424, y 800 y/o 435. 
Esta obra forma parte del acervo de la Biblioteca Jurídica Virtual del Instituto de Investigaciones Jurídicas de la UNAM

\title{
THE GENERICS PATHWAY IN THE USA: THE AMERICAN EXPERIENCE, A MODEL FOR THE WORLD?
}

\author{
Frederick M. AвBOTT*
}

SUMMARY: I. Some patent and market exclusivity basics for the USA.

II. The ANDA process. III. Paragraph IV settlements, reverse payments, etc.

IV. Assessment of the US system. V. A model for the world?

The United States experience is unique in terms of the pricing and availability of medicines. On one side, originator patented medicines are sold in volumes and at prices exceeding those for the rest of the world - it is the most highly valued market for the originator companies - ${ }^{1}$ On the other side, prices for generic medicines are likely the lowest among OECD countries, ${ }^{2}$ and perhaps for almost all countries. US consumers use large quantities of generic medicines.

There are characteristics of the USA pharmaceuticals market that warn against oversimplification. The government is a large-scale purchaser and insurance provider for drugs. Private distribution of drugs in the United States is under the control of a relative handful of large-scale distribution companies that use their distribution networks and purchasing power to bargain for low prices from manufacturers, and typically prefer to purchase across a range of products. It is not a market that is easy to enter profitably.

* Edward Ball Eminent Scholar Professor of International Law, Florida State University College of Law, USA. This paper was initially prepared for and presented at the ALIFAR/ ANAFAM Annual Meeting (Foro Latinoamericano - Mexico), May 15, 2012, Mexico City. It has been updated for this publication.

1 The Global Use of Medicines: Outlook Through 2015, Report by the IMS Institute for Healthcare Informatics, e.g., slides 3-5, May 2011.

2 U.S. Department of Commerce, International Trade Administration, Pharmaceutical Price Controls in OECD Countries, Implications for U.S. Consumers, Pricing, Research and Development, and Innovation, Wash., DC, December 2004, at 21-24 (hereinafter "DOC Pricing and R\&D"). 
Esta obra forma parte del acervo de la Biblioteca Jurídica Virtual del Instituto de Investigaciones Jurídicas de la UNAM

The regulatory environment is complex and strict, and companies face a continuing threat of tort-based liability lawsuits from end-users.

The generics pathway is fiercely competitive. Only at the early stages of patent expiration may generics companies enjoy a relatively high profit margin. The "gold cup" of the generics manufacturer is the 180 day market exclusivity period that may be earned through a paragraph IV certification challenge under the Hatch-Waxman Act. Today, the typical generics company pursuing a paragraph IV challenge is likely to be tempted by a lucrative settlement offer. As a result of a Court of Appeals for the Federal Circuit statutory interpretation, the-180 day market exclusivity period may now be shared among several generics producers.

There are serious issues confronting the USA in terms of its approach to providing access to healthcare broadly, and medicines specifically. There are issue areas surrounding the Hatch-Waxman Act, including refinement of the analysis by which courts weigh the anticompetitive impact of "reverse payment" settlement agreements, ${ }^{3}$ and continued "gaming" of the system by the originators. But, on the whole, the generics pathway in the USA produces a reasonably good result in terms of getting generic drugs onto the market in a reasonable period of time. I will suggest, however, that the elements necessary to make this system work in the USA are not present in most other countries, and that the temptation to transpose the USA system to other countries should be approached with caution.

\section{SOME PATENT AND MARKET EXCLUSIVITY BASICS FOR THE USA}

The generics pathway in the USA is the counter-balance to the system for the patenting of medicines. In the USA, the patent term is generally 20 years from the filing date of the application, but for medicines an extension for up to five years may be secured based on the length of the regulatory approval process. The five-year period is calculated by taking one-half the duration of clinical testing under an investigational new drug application (INDA), plus the time following submission of the New Drug Application (NDA). One may assume that with minor variation, the NCE/NME drug product enjoys a patent term of 25 years from the filing of the application. But, an extension

3 In June 2013 the US Supreme Court decided that buyout settlements of generic producer patent challenges by patent owners are subject to "rule of reason" assessment under the antitrust laws. Federal Trade Commission (FTC) v. Actavis, U.S. Sup. Ct., 526 U. S. 756 (2013). 
Esta obra forma parte del acervo de la Biblioteca Jurídica Virtual del Instituto de Investigaciones Jurídicas de la UNAM

can only be granted with respect to the first commercial marketing of a drug, not for variations of the "same" drug."

Many of the complications along the generic pathway are introduced by the possibility to obtain patents for things other than a new chemical entity or new molecular entity. The US PTO will grant patents for minor variations in molecular structure, for new uses of known compounds (such as for second, third, etc. medical indications), for new methods of delivery (including differences in dosages), for new target populations (for example, by age group), and for other variations.

When a new drug application (NDA) is submitted to the US Food and Drug Administration, the applicant provides information concerning the patents relevant to that drug. Those patents are listed in the so-called Orange Book. The NDA applicant, after the grant of marketing approval, may update Orange Book listings, including adding patents for new uses, etc., that may have been secured subsequent to the initial request for approval, and must provide information concerning approved uses under specific patents. ${ }^{5}$ The FDA does not screen or evaluate substance of these Orange Book submissions.

In the United States, the period of marketing exclusivity following approval of a new chemical entity-based drug is relatively brief, five years. The architects of the Hatch-Waxman Act deliberately kept the exclusivity term short, and assumed that it would not typically outlast the term of a patent covering the same drug. There are possibilities for additional 3-year market exclusivity terms based on new clinical investigations, and 6-month extensions for pediatric formulations.

Marketing exclusivity in respect to new biologics drugs approved by the FDA under legislation adopted in 2009 extends for 12 years, ${ }^{6}$ and the FDA continues to refine its rules for approval of biosimilar products. The decision by Congress to authorize 12 years of marketing exclusivity for biologics was (and remains) controversial, and the United States has proposed to incorporate this standard in the Trans Pacific Partnership (TPP) agreement under negotiation.

435 USC §156; US PTO Manual of Patent Examining Procedures, §1.720.

5 See Caraco Pharmaceutical Laboratories v. Novo Nordisk, US Sup. Ct., 132 S.Ct. 1670 (2012).

6 Biologics Price Competition and Innovation Act of 2009, Pub. L. No. 111-148, $\S \S$ 7001-7003, 124 Stat. 804 (2010) [hereinafter BPCI] (Title VII, Subtitle A of PPACA). 
Esta obra forma parte del acervo de la Biblioteca Jurídica Virtual del Instituto de Investigaciones Jurídicas de la UNAM

\section{THE ANDA PROCESS}

The originator company first seeking approval from the FDA for a new drug, or subsequently seeking approval for a new indication, must submit detailed information concerning the conduct of clinical trials and results, and information concerning the manufacturing process for the drug. ${ }^{7}$ This is all part of the new drug application or NDA process. The generic applicant submits an abbreviated new drug application, or ANDA, which requires the applicant to demonstrate that its chemical compound is bio- equivalent to the originator compound, along with information concerning manufacturing. ${ }^{8}$ The ANDA applicant is not required to submit data concerning clinical trials. It is permitted to rely upon the approval secured by the originator-holder of the commercial marketing approval.

The generic producer may submit an ANDA requesting that marketing approval be effective upon the expiration of the applicable patents of the originator. It may submit an ANDA indicating that there is no relevant patent (or that any patents have expired). Or, it may indicate that there is a patent that covers the drug or applicable use, but that the patent is invalid, or that the applicant will not infringe any relevant patent. The last route is referred to as a paragraph IV certification deriving from the relevant statutory citation. ${ }^{9}$ The originator holder of the patent identified in a paragraph IV certification may (and usually does) respond by initiating a patent infringement lawsuit against the ANDA applicant in federal court. This results in an automatic 30-month stay of the requested FDA approval for the generic, which time may be shorter based on a decision of the federal court.

In order to encourage challenges to originator patents, the Hatch-Waxman Act provides that the first challenger under paragraph IV is entitled to a 180-day period of market exclusivity following approval of the ANDA. As one might imagine, being the only generic supplier during a six-month period would be an extremely valuable prize for a generic producer. But, nothing is so simple.

7 US Food and Drug Administration, New Drug Applications (NDA), <http://wrew.fda. gov/Drugs/DevelopmentApprovalProcess/HowDrugsareDevelopedandApproved/ApprovalApplications/ NewDrugApplicationNDA/default.htm $>$.

8 US Food and Drug Administration, Generic Drugs: Information for Industry<http://wewre. fda.gov/Drugs/DevelopmentApprovalProcess/HowDrugsareDevelopedandApproved/ApprovalApplications/AbbreviatedNewDrugApplicationANDAGenerics/ucm142112.htm >.

921 U.S.C. $§ 355(\mathrm{j})(2)(\mathrm{A})(\mathrm{vii})(\mathrm{IV})$. 
Esta obra forma parte del acervo de la Biblioteca Jurídica Virtual del Instituto de Investigaciones Jurídicas de la UNAM

The FDA initially interpreted the Hatch-Waxman Act to provide that the 180-day marketing exclusivity period would be awarded to the first successful generic challenger of a patent under paragraph IV. However, this interpretation was rejected by the Court of Appeals for the Federal Circuit, which said that the language referred to the first party to submit a paragraph IV certification to the FDA. Initially, the FDA was then prepared to award the 180-day market exclusivity period to the first generic company that submitted an ANDA with a paragraph IV certification (and whose ANDA application was approved). The consequence was a chaotic race to file the first application, the formation of a tent city in the parking lot of the FDA for weeks prior to the first available date for filing an ANDA, and violence or threat of violence among those sent to file the application. ${ }^{10}$ The FDA feared for the safety of its personnel. This led to a change in the rule such that any application received on the same "first day" would be eligible for the 180-day marketing exclusivity. The exclusivity might now be shared.

The FDA has suggested that the possibility for a complete overlap of shared exclusivity is limited since ANDA applicants are not likely to receive marketing approval at the same time, and that in any case this provides an incentive to complete the application and approval process. It has from time to time hinted at the consideration of a new rule, but so far without taking action. Data compiled by the US Federal Trade Commission suggests that the foreseeability of shared exclusivity has not significantly deterred generics companies from filing paragraph IV certification challenges. ${ }^{11}$

10 See US FDA (CDER) Guidance for Industry 180-Day Exclusivity When Multiple ANDAs Are Submitted on the Same Day, July 2003; and US Federal Trade Commission, Authorized Generic Drugs: Short-Term Effects and Long-Term Impact, Aug. 2011, at 134 (hereinafter "FTC Authorized Generics").

11 FTG Authorized Generics, at 133-137. 
Esta obra forma parte del acervo de la Biblioteca Jurídica Virtual del Instituto de Investigaciones Jurídicas de la UNAM www.juridicas.unam.mx

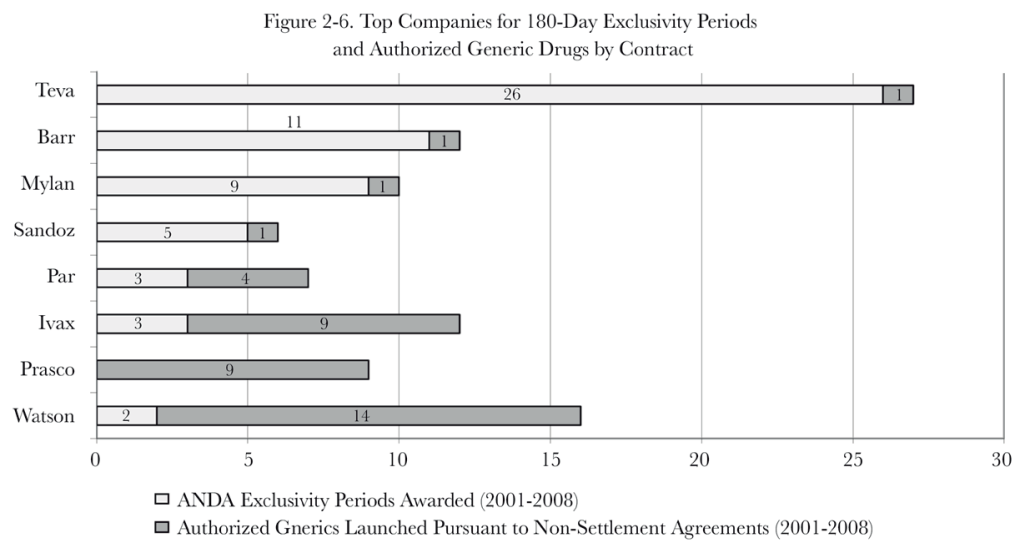

SOURCE: US Federal Trade Commission, Authorized Generic Drugs: Short-Term Effects and LongTerm Impact, Aug. 2011, at 25.

In a substantial number of cases, it is possible for potential ANDA applicants to determine what is the "first day" for submitting an application, which is one year prior to the expiration of the five-year market exclusivity period for the originator product. The products eligible for market exclusivity are limited to the first recipient of commercial approval for a new entity, and a limited number of other products for which additional clinical research has been conducted, so that shared exclusivity will be relevant only in some cases.

Figure 7-5. NCE Drugs with a Paragraph IV Certification Filed on the First Possible Day

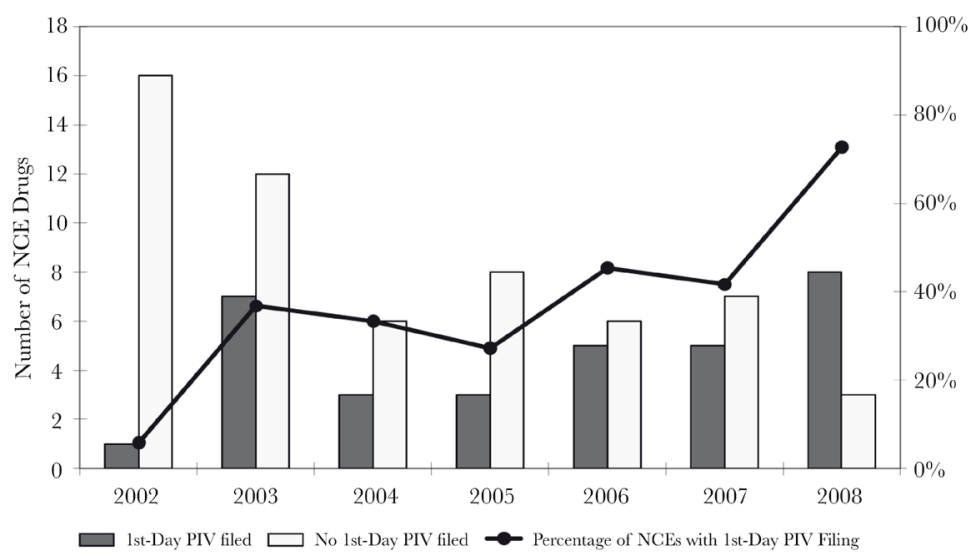

SOURCE: US Federal Trade Commission, Authorized Generic Drugs: Short-Term Effects and LongTerm Impact, Aug. 2011, at 135. 
Esta obra forma parte del acervo de la Biblioteca Jurídica Virtual del Instituto de Investigaciones Jurídicas de la UNAM

Much of the complexity of the Hatch-Waxman system arises from the fact that the FDA approves drugs for specific uses. A compound is directed to the treatment of a disease, or a number of diseases or conditions. These are the "approved uses." Physicians may prescribe the same compound to treat conditions that are not included among the approved ones for the drug on the theory that this is an exercise in medical professional discretion. But, the originator companies (and generic companies) are not permitted to market their drugs for "unapproved uses." 12 As the courts have acknowledged, the highest volume of sales for some drugs are for unapproved uses.

An ANDA applicant may not ordinarily seek approval for marketing for an unapproved use. But, ANDA applicants may file paragraph IV certifications with respect to approved uses where the originator believes that the generic company is intending to market for unapproved uses. Or, generic ANDA applicants may seek to market for uses as to which patents have expired, but for which the originators continue to hold use patents that have not expired. Again, the originators may believe that ANDA applicants are intending to market for uses that are covered by approved use patents.

This is, of course, an interesting problem. One can readily argue that the US PTO should not be granting a proliferation of patents for the same product, and that generic producers are justified in gaming the system to circumvent those patents, allowing doctors to determine the conditions for which drugs are prescribed. The originators conversely argue that their incentives to seek approval for new uses are diminished if the generic producers can readily cross over into the new territory.

\section{PARAGRAPH IV SETTLEMENTS, REVERSE PAYMENTS, ETC.}

In recent years, the biggest threat to the successful operation of the HatchWaxman paragraph IV mechanism has been the use of patent settlements by originator and generic companies. The originator companies have a major financial incentive to prevent the early marketing of generic versions of their products. Rather than risk invalidation (or a determination of non-infringement) of their patents, they prefer to pay paragraph IV ANDA certifiers to

12 See, e.g., Peter Loftus and Brent Kendall, Abbott to Pay \$1.6 Billion, Wall St. J., May 7 , 2012 (updated): "Abbott Laboratories agreed to pay $\$ 1.6$ billion and to plead guilty to a criminal misdemeanor violation of a federal drug law following allegations that the company improperly promoted antiseizure drug Depakote for unauthorized uses." 
Esta obra forma parte del acervo de la Biblioteca Jurídica Virtual del Instituto de Investigaciones Jurídicas de la UNAM

settle their patent infringement claims. These settlements may involve offering distribution licenses for the products covered by the patent or other products, licensing of technologies, and/or direct cash payments. If the originator can settle with each of the companies that is potentially entitled to a 180 day market exclusivity period, it will have eliminated most of the incentive for generic companies to pursue patent invalidity (or non-infringement) litigation which is quite expensive.

The US Federal Trade Commission has been extremely unhappy about the use of patent litigation settlements to prevent the early entry of generics. In 2013 the U.S. Supreme Court acted largely in favor of the FTC to resolve a split among federal circuit courts that had been somewhat unreceptive to the FTC's position, holding that so-called "reverse payment" settlements were not immunized from antitrust scrutiny even if they were within the legitimate zone of patent protection. ${ }^{13}$ Instead, the Supreme Court held that patent law and antitrust law function side-by-side with different policy objectives, and that large unexplained payments from patent owners to generic challengers are suspect under the antitrust laws. The Court said:

An unexplained large reverse payment itself would normally suggest that the patentee has serious doubts about the patent's survival. And that fact, in turn, suggests that the payment's objective is to maintain supracompetitive prices to be shared among the patentee and the challenger rather than face what might have been a competitive market - the very anti-competitive consequence that underlies the claim of antitrust unlawfulness. ${ }^{14}$

The Court noted that both the patent owner and the generic challenger may benefit from a reverse payment settlement - the patent owner maintaining its monopoly (and pricing power) and the generic producer receiving valuable consideration (i.e. a share of those monopoly profits) - but that consumers lose because of the delay in initiation of generic competition. The Supreme Court's decision re-invigorated the FTC's challenge to reverse payment settlements, but questions remain to be resolved regarding the standards by which courts assess whether there is a large unexplained payment from patent owner to generic challenger. ${ }^{15}$ Another complication

13 Federal Trade Commission (FTC) v. Actavis, U.S. Sup. Ct., 526 U. S. 756 (2013).

14 Idem.

15 See, e.g., In re Lipitor Antitrust Litig., 2014 U.S. Dist. LEXIS 127877 (D.N.J. 2014); In re Effexor XR Antitrust Litig, 2014 U.S. Dist. LEXIS 142206 (D.N.J. 2014). Silber, Seth et al., "«Good Luck» Post-Actavis: Current State of Play on «Pay-for-Delay» Settlements", CPI Antitrust Chronicle, No. 2, Nov. 2014. 
Esta obra forma parte del acervo de la Biblioteca Jurídica Virtual del Instituto de Investigaciones Jurídicas de la UNAM

with the Hatch-Waxman Act system involves the practice of originator companies to introduce "authorized generics" during the 180-day market exclusivity period (if and when it is earned by a generic producer or producers). Rather than ceding the generics market to third companies, the originator introduces a generic version of its product, going into competition with the holder of the 180-day exclusivity. While the US FTC has been critical of this practice on the theory that it may undermine the incentives for thirdparty generic producers to challenge patents, a recent FTC study concluded that, on one hand, potential competition from the originator did not appear to inhibit generic patent challenges (though it did reduce the profitability of the 180 day marketing exclusivity period). On the other hand, the FTC expressed considerable concern that originators were using their potential to introduce authorized generics as a way to induce generic challengers to patent settlements. ${ }^{16}$

\section{ASSESSMENT OF THE US SYSTEM}

The foregoing overview of the US system should highlight at least one of its features. It is the best thing that ever happened to patent litigators and FDA regulatory lawyers. It is an extremely complex system that is largely impenetrable to all but a handful of legal and regulatory experts. It is expensive to participate in as a player. Yet, as a US citizen my assessment is not so critical, on the whole. Though there are problems, generic products enter the market in the USA promptly after patent expiration. And, there is substantial financial incentive to challenge the patents held by originators.

16 FTC Authorized Generics, at, e.g., vi-vii. 
Esta obra forma parte del acervo de la Biblioteca Jurídica Virtual del Instituto de Investigaciones Jurídicas de la UNAM www.juridicas.unam.mx

Figure K-1. Years of Brand Patent Protection

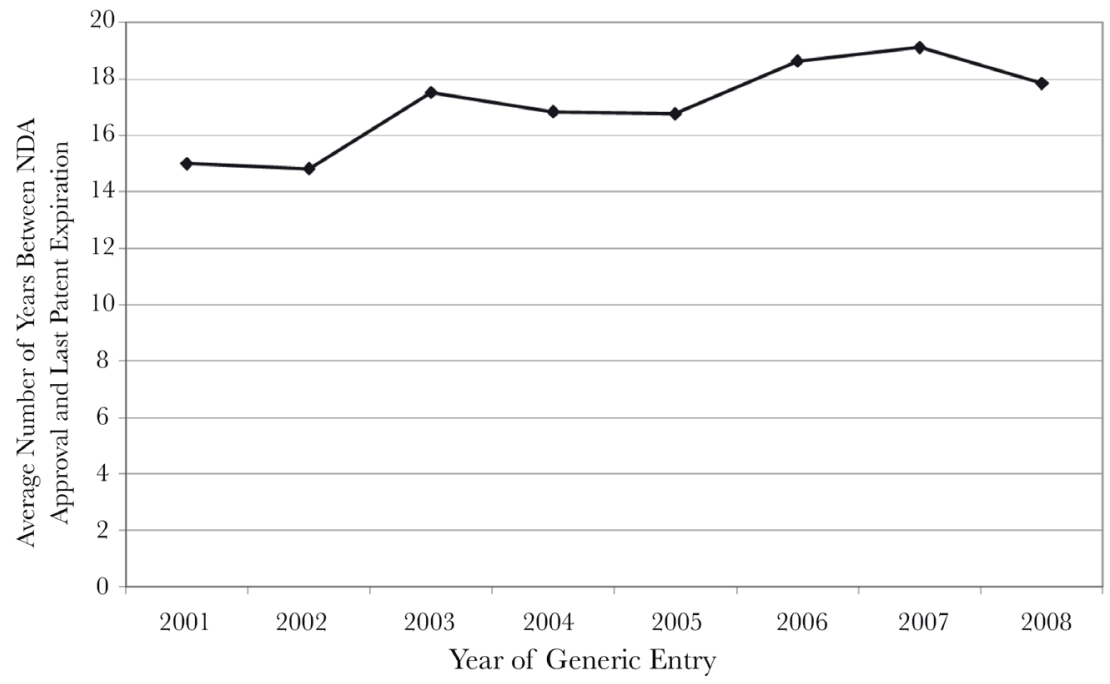

SOURCE: US Federal Trade Commission, Authorized Generic Drugs: Short-Term Effects and LongTerm Impact, Aug. 2011, at K-1.

Figure K-2. Years of Generic Entered Before Brand Patent Expiration

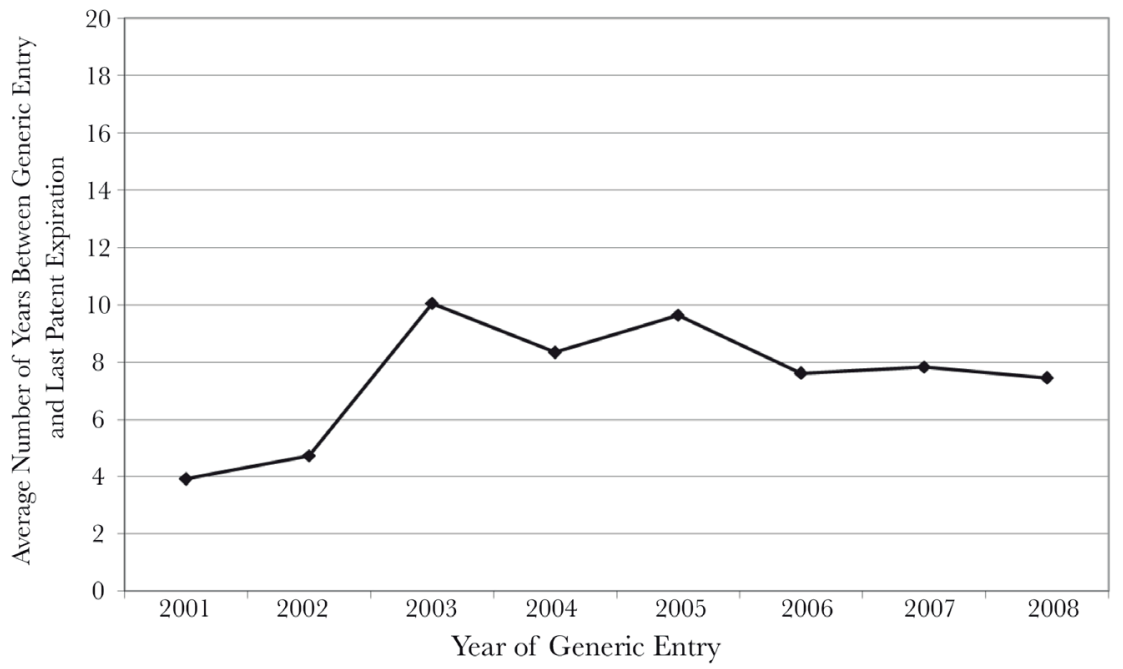

Source: US Federal Trade Commission, Authorized Generic Drugs: Short-Term Effects and LongTerm Impact, Aug. 2011, at K-2. 
Esta obra forma parte del acervo de la Biblioteca Jurídica Virtual del Instituto de Investigaciones Jurídicas de la UNAM

Figure K-3. Years of Brand Excluivity

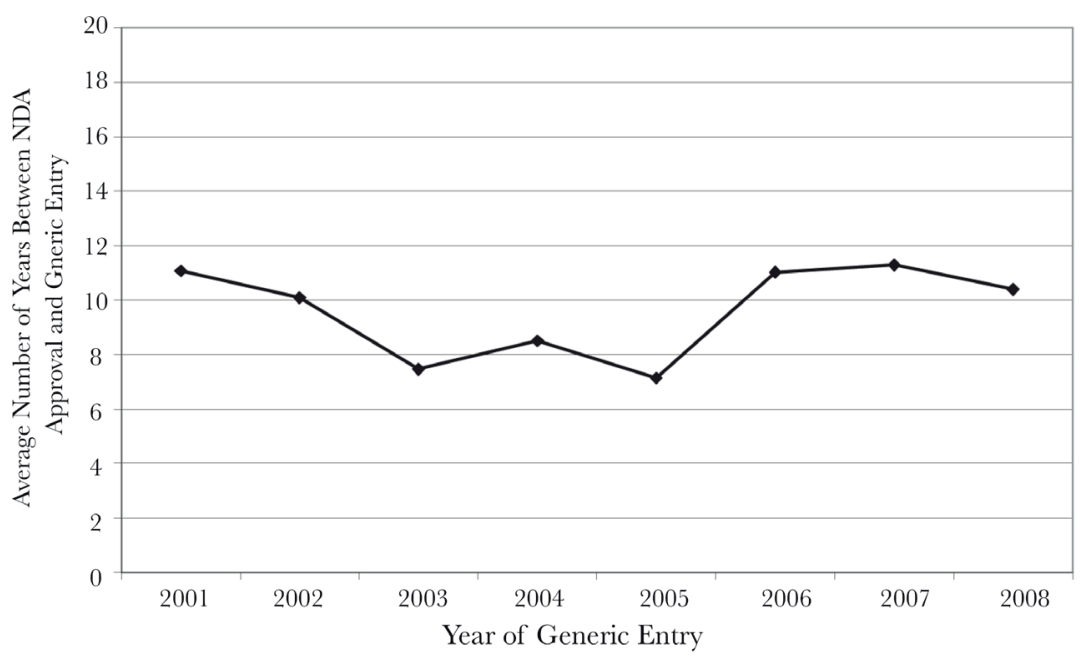

The main problem with the USA system as it is currently implemented is the very broad interpretation of patentable subject matter (including through interpretation of the criteria of patentability) applied by the US PTO and Court of Appeals for the Federal Circuit, allowing patenting of minor modifications, new dosages, patient populations, etc., which effectively permits patent flooding by the originator companies. That is not so much a question of the generic pathway, but of the scope of protection of pharmaceutical products by patent. This creates burdens on the pathway because it means that there are more patents that must be challenged, but that is not necessarily the same thing as a problem with the pathway design.

In terms of the generic pathway, it would be nice to simplify the system, but the development, testing and marketing of a new drug is inherently complex; patents are complex; and there is only so much simplification that can be done.

But, the USA system only works because of several critical factors.

First, there is a very significant financial incentive for generic producers to enter the USA market. This is based on a combination of factors, including the potential for securing a 180-day market exclusivity period, and more generally the high volume of potential generic sales in the US market. Generic producers are willing to pay lawyers and experts substantial sums of money (in the millions of dollars) to challenge the patents of the originators in court. 
Esta obra forma parte del acervo de la Biblioteca Jurídica Virtual del Instituto de Investigaciones Jurídicas de la UNAM

Second, there are governmental institutions, including the Federal Trade Commission, the Department of Justice, the State Attorneys General, and others that are paying attention to the pricing and practices of both the originators and the generic producers, and that are willing to intervene to make the system work for the benefit of the patient/consumers. This includes initiating actions under the antitrust (or competition) laws, as well as under the antifraud laws when these mechanisms are used to take unfair advantage of government drug reimbursement programs.

Third, there is a competent independent judiciary that referees the activity. While the tendency of the Court of Appeals for the Federal Circuit has been to support the interests of originators and to protect patents, the US Supreme Court over the past several years has intervened to control this over-protective tendency. The US courts have developed a sophisticated patent and health regulatory law jurisprudence that accounts for nuance. This entire judicial apparatus is expensive to operate.

Fourth, pharmaceutical prescription plan operators are increasingly sensitive to pricing issues and are encouraging use of generic products. While the originators continued to lobby for strong IP protection and high prices, there is a significant counter lobby involving consumer groups, state government health officials, and others constrained by budgetary limitations.

\section{A MODEL FOR THE WORLD?}

The USA has incorporated elements of the US Patent Act and the HatchWaxman generic regulatory pathway in a number of bilateral and regional free trade agreements, including those negotiated with countries of Latin America. The specific elements have varied. Several of the elements initially Incorporated in the FTAs with Colombia, Panama and Peru were modified in favor of the generic industry subsequent to the initial signing of the agreements based on US congressional intervention. The recent US-South Korea FTA, on the other hand, shows a strong form of USA demands regarding the pharmaceutical sector.

Draft provisions proposed by USTR in connection with the Trans-Pacific Partnership (TPP) negotiations appear intended to transpose the US patent and regulatory pathway into the law of its Pacific trading partners. On the subject matter patentability, USTR has proposed: 
Esta obra forma parte del acervo de la Biblioteca Jurídica Virtual del Instituto de Investigaciones Jurídicas de la UNAM

Article 8.1 (Patents) ...the Parties confirm that: patents shall be available for any new forms, uses, or methods of using a known product; and a new form, use, or method of using a known product may satisfy the criteria for patentability, even if such invention does not result in the enhancement of the known efficacy of that product. (USTR Proposal of Feb. 10, 2011.)

This new provision not only would imply coverage for the many types of secondary patents granted by the US PTO, but it is specifically designed to reject the approach taken by the India Patent Act, section 3(d), requiring an enhancement in efficacy as a condition of approving new forms of the same substance.

The provisions proposed regarding the term of marketing exclusivity for new entities, and for follow-on approvals based on submission of clinical information, attempt to mirror the requirements of US law (although they are probably more generous to the patent/exclusivity owner then US law) (see USTR Proposal of September 2011). Just as under the Hatch-Waxman regulatory pathway, a system would be put in place so that patent holders would be notified and would have the opportunity to initiate infringement litigation prior to any regulatory approval, there would be an automatic stay put in place, and the patent holder would have the opportunity to request preliminary and permanent injunctions. The draft suggests that a successful generic challenger to a patent should receive a reward for doing so, and a footnote is dropped to cover the fact that US law provides a reward to multiple same day paragraph IV certifiers. USTR's proposal would require that originators seeking to take advantage of these protective provisions should request marketing approval within the host territory within some prescribed timeframe, and USTR has suggested that this is a major incentive for countries to adopt the proposals.

It is also useful to note that USTR has incorporated provisions regarding the Doha Declaration on the TRIPS Agreement and Public Health, but true to form it has revised the text of the Doha Declaration to reflect its preferred negotiating stance, rather than the actual text of the Declaration.

Let us assume for the sake of argument that the TPP required the parties to mirror the US Patent Act and the Hatch-Waxman Act (including the regulatory pathway) in their national laws. As I have previously suggested, there is almost certainly a problem with the expanded scope of pharmaceutical patent subject matter that is bound to lead to excessive patenting. Already today patent examiners in many developing countries are willing to accept determinations of patentability previously made by the US PTO and/or the European Patent Office (including under the PCT), and there is 
Esta obra forma parte del acervo de la Biblioteca Jurídica Virtual del Instituto de Investigaciones Jurídicas de la UNAM

little reason to suspect that this would change with the introduction of patent law standards more compatible with those of the USA.

These patents can be used to block drug regulatory authorities from granting marketing approval to generic drugs, unless and until the patents are successfully challenged in court. Recall that because of the rule of independence of the international patent system, the invalidation of a patent in the USA would not invalidate the patent in another TPP party, and a determination of non-infringement in the USA would not be effective abroad. Essentially, the generic industry in each TPP party would be "on its own" in seeking to challenge patents. And, recall that the originator companies are prepared to invest millions of dollars in defending attempts to invalidate patents (or defending attempts to have them found not infringed).

I would suggest that adoption of a system such as that proposed by the TPP, modeled on the US Patent Act and Hatch-Waxman system, would operate heavily in favor of the originator pharmaceutical industry, and make it significantly more difficult for generic producers to enter national markets.

What would be the justification for this from the standpoint of parties to the TPP other than the USA? The argument from USTR and the originator industry is that this would increase profitability for the originators, which in turn would invest more in $\mathrm{R} \& \mathrm{D}$, which in turn would yield new and better medicines, which in turn would be supplied to those other parties. ${ }^{17}$

There is probably some truth in that line of argument. If the originator companies are more profitable they will probably invest more in $\mathrm{R} \& \mathrm{D}$ and that may lead to new and better medicines. (This does not require us to be naïve as to how pharmaceutical revenues are spent. Even taking into account wasteful practices, some money does find its way into actual R\&D.) The question is whether from the standpoint of countries other than the United States the preferred way to enhance pharmaceutical R\&D is to send money to the USA in the form of higher pharmaceutical prices paid to USA-based multinationals. It seems more likely that countries in Latin America might prefer to redirect $\mathrm{R} \& \mathrm{D}$ toward domestic institutions and industry, though this is not necessarily an easy process.

Adoption by countries of Latin America of the USA model will almost certainly result in delay to the introduction of generics in Latin America, which will impose a price on public health systems and consumers. Public health systems and consumers will absorb the cost.

A proposal to make the FTAs work better for trading partners of the USA would be to add a provision that to the effect that any patent invali-

17 This line of argument is clearly made in DOC Pricing and R\&D, supra note 2. 
Esta obra forma parte del acervo de la Biblioteca Jurídica Virtual del Instituto de Investigaciones Jurídicas de la UNAM

dated (or found not infringed) in the country of the originator would be presumed to be invalid (or not infringed) in all countries party to the FTA. Though the details of such a system could take a variety of forms, the essential idea is to eliminate the requirement that generic producers in other FTA countries must replicate court proceedings to invalidate (or obtain determinations of non-infringement of) patents. Without such a provision, it is possible that products for which there are generic substitutes on the market in the USA will still be exclusively provided by originator patent holders in its FTA partners. This type of provision would challenge the traditional idea of independence of patents under the Paris Convention on the Protection of Industrial Property (Incorporated by reference in the WTO TRIPS Agreement), but it is consistent with the "extraterritorial" approach taken by the USA with respect to data exclusivity. In other words, FTA partners are not permitted to rely on regulatory approvals granted in the USA even if no regulatory data is submitted in their territories. However, one would need to be careful to avoid linking this to a provision that patents granted in the country of the originator would similarly be granted in the FTA partner.

If trading partners of the USA conclude is in their better interest - as the price of concluding a TPP - to move toward US standards in respect to patents and regulatory exclusivity, it will be critical that they enhance their attention to implementation and enforcement of competition law. International rules allow a substantial degree of flexibility in the application of competition law, and there are public health-friendly approaches that can be used. In addition to reverse payment issues, there is the possibility to address excessive pricing, sham patent litigation and other restrictive practices that can be used to inhibit competition. The United Nations Development Program (UNDP) has, for example, recently published a guide book in this area. ${ }^{18}$

In the end, whether one concludes that the generic pathway in the USA is a model for the world depends on one's worldview. The USA model works reasonably well for the USA, and reasonably well for its originator and generic industries. It should work for the mercantile benefit of the USA if it is adopted in other countries. It may provide some additional new drugs for introduction into other countries, assuming that R\&D in the USA is successful. At the same time, it will slow down the introduction of generics.

18 Abbott, Frederick M. et al., UNDP, Using Competition Law to Promote Access to Health Technologies: A Guidebook for Low- and Middle-Income Countries (May 19, 2014). United Nations Development Program (ed. F. M. Abbott)(2014). Available at SSRN: http://ssrn.com/abs tract $=2439416$. 
Esta obra forma parte del acervo de la Biblioteca Jurídica Virtual del Instituto de Investigaciones Jurídicas de la UNAM

\title{
ALGUNAS REFLEXIONES \\ SOBRE JUDICIALIZAGIÓN Y ACGESO \\ A MEDICAMENTOS: EL CASO DE BRASIL \\ Y MÉXICO
}

José Luis CÁRDEnas T.*

\begin{abstract}
SUMARIO: I. Introducción. II. Sobre la existencia de Etesa y su evaluación. III. Sobre la racionalidad económica de la litigación. IV. Conclusiones. V. Bibliografia.
\end{abstract}

\section{INTRODUCGIÓN}

Mucho tiempo llevamos escuchando acerca de la creciente judicialización en temas relacionados con la salud y, especialmente, aquella vinculada con el acceso a medicamentos. ${ }^{1}$ Ella no es sino el resultado, en parte, del reconocimiento y consagración del derecho a la salud a nivel constitucional y de tratados

* Abogado (Universidad de Chile), LL.M. \& Ph.D. (Universidad de Friburgo, Alemania), Académico de la Facultad de Derecho de la Universidad de Chile, Sr. Director Government Affairs, Growth Markets, TEVA Group. Las opiniones expresadas en el presente trabajo son de exclusiva responsabilidad de su autor.

1 Véanse, entre otros, Guimarães, Reinaldo, "Technological Incorporation in the Unified Health System (SUS): The Problem and Ensuing Challenges", Ciência Ẽ Saúde Coletiva, vol. 19, núm. 12, 2014, pp. 4899-4908; Liang Wang, Daniel Wei, Courts As Healthcare PolicyMakers: The Problem, the Responses to the Problem and Problems in the Responses, Direito GV Research Paper Series, Legal Studies Paper, núm. 75, 2013; Manfredi, Christopher P. y Maioni, Antonia, "Courts and Health Policy: Judicial Policy Making and Publicly Funded Health Care in Canada", Fournal of Health Politics, Policy and Law, vol. 27, núm. 2, 2002, pp. 213-240; Rechnitzer, Adrián E., "Análisis de la judicialización en la gestión de medicamentos. Caso de estudio del Trastuzumab en el tratamiento del cáncer de mama en Costa Rica", Cuadernos Ibero-Americanos de Direito Sanitário, vol. 3, núm. 2, 2014; Yamin, Alicia y Norheim, Ole F., "Taking Equality Seriously: Applying Human Rights Frameworks to Priority Setting in Health", Human Rights Quarterly, vol. 36, núm. 2, 2014, pp. 296-324. 
Esta obra forma parte del acervo de la Biblioteca Jurídica Virtual del Instituto de Investigaciones Jurídicas de la UNAM www.juridicas.unam.mx

internacionales sobre derechos humanos/sociales, así como la disponibilidad de acciones constitucionales de naturaleza cautelar, además de la creciente conciencia de la efectividad de dicho mecanismo, en términos de lograr el acceso pretendido. ${ }^{2}$

Sobre ella se ha planteado que

[d]iversos factores pueden contribuir a la explicación del fenómeno: primero, el interés público ha cambiado: los usuarios poco a poco han venido demandando atención médica oportuna, de alta calidad y con vocación de servicio. Segundo, las Constituciones y las nociones de Estado han también cambiado, creando un campo fértil para las demandas de los ciudadanos. Tercero, existe un activismo judicial en que un interés renovado por el interés público encuentra simpatía de las cortes por el estudio de esas demandas. Cuarto, los sistemas de salud en la región mantienen procesos para la priorización y distribución de recursos que no son suficientemente validados técnicamente, con transparencia, participación y rendición de cuentas. Finalmente, las transiciones demográficas y epidemiológicas están conformando las necesidades clínicas de la población, mientras que las tecnologías disponibles para satisfacer esas necesidades son más amplias y costosas. ${ }^{3}$

Respecto de la judicialización, se critica en específico la tensión que ésta trae aparejada consigo, no sólo desde el punto de vista del aumento de los costos para el sistema de salud, ${ }^{4}$ sino también por contradecir decisiones técnico-políticas (por ejemplo, otorgando coberturas/reembolso a medicamentos que la fármaco-economía, ${ }^{5}$ o la evaluación de tecnologías sani-

2 Entre otros, la Declaración Universal de Derechos Humanos, artículo 25, párrafo 1; en el Sistema Interamericano de Derechos Humanos, en especial, el artículo 12 del Pacto Internacional de Derechos Económicos, Sociales y Culturales.

3 Funsalud, "Universalidad de los servicios de salud en México", Salud Pública de México, vol. 55, 2013, p. 28.

4 A modo de ejemplo: “[e]n Brasil, el gasto del Ministerio de Salud fue 3,2 veces mayor en 2007 comparado con el de 2002, mientras que el gasto en medicamentos pasó de $5,4 \%$ en 2002 a 10,7\% en 2007, con una gran influencia de los correspondientes al Programa de Medicamentos de Dispensación Excepcional (PMDE), cuyo incremento entre 2003 y 2007 ascendió a 252\%", así en Reveiz, Ludovic et al., "Litigios por derecho a la salud en tres países de América Latina: revisión sistemática de la literatura", Revista Panamericana de Salud Pública, vol. 33, núm. 3, 2013, p. 214.

5 Pearson, Alan et al., "The JBI Model of Evidence-Based Health Care", International Fournal of Evidence-Based Health Care, vol. 3, núm. 8, 2005, pp. 207-216. 
Esta obra forma parte del acervo de la Biblioteca Jurídica Virtual del Instituto de Investigaciones Jurídicas de la UNAM www.juridicas.unam. $m x$

tarias [Etesa] ${ }^{6}$ descartó), y de justicia distributiva, de recursos esencialmente escasos. $^{7}$

En este contexto, cabe tener presente que el término judicialización proviene de "judicializar", que se define según el Diccionario de la Lengua Española como "llevar por vía judicial un asunto que podría conducirse por otra vía, generalmente política". Es decir, ésta implica que quien tiene un determinado conflicto considera que resolverlo litigando en tribunales es más eficaz o eficiente que otras alternativas. Ahora, si no existen otras alternativas sólo debiera llegarse a la solución de litigar, si esa hipótesis genera un mayor beneficio/menor costo para el demandante-paciente que la hipótesis de no litigar, asumiendo siempre que el beneficio/menor costo es sólo una simple probabilidad. Dicho de otra forma, y desde una perspectiva de la racionalidad económica, sólo se litiga si:

$$
\left(B_{1} * P_{1}\right)-C_{1}>C
$$

\section{Donde,}

$B_{l}$ es el beneficio de litigar (i.e. mayor cobertura/reembolso de medicamento/menor copago);

$P_{l}$ representa la probabilidad de ganar el litigio;

$C_{l}$ el costo de litigar, y

$C_{0}$ el costo que debiese afrontarse si no se litiga (i.e. no tener cobertura/ reembolso de medicamento/copago muy alto).

Ahora, el efecto de la judicialización, como se insinuó, no sólo tiene potenciales efectos privados (mayor beneficio/menor costo), sino que externalidades, tanto positivas como negativas ${ }^{8}$ (véase figura 1): la ampliación de

6 “[E]s una disciplina que integra los aspectos clínicos, sociales, económicos, éticos y organizacionales que influyen en la incorporación de una tecnología. Los cuales son analizados siguiendo un proceso sistemático y riguroso de evaluación". Kuhn-Barrientos, Lucy, "Evaluación de tecnologías sanitarias: marco conceptual y perspectiva global", Revista Médica de Chile, vol. 142(S1), 2014, pp. 11.

7 Adler, Matthew D., "QALYs and Policy Evaluation: A New Perspective", Yale fournal of Health Policy, Law, and Ethics, vol. 6, 2006; Funsalud, "Universalidad...", op. cit., p. 28; Guimarães, Reinaldo, “Technological...”, op. cit., p. 4903; Liang Wang, Daniel Wei, Courts..., cit., p. 1 .

$8 \mathrm{Al}$ respecto, véase Shavell, Steven, "The Level of Litigation: Private Versus Social Optimality of Suit and Settlement", International Review of Law and Economics, vol. 19, 1999, pp. 99-115; Shavell, Steven, "The Fundamental Divergence Between the Private and the Social Motive to Use the Legal System", fournal of Legal Studies, vol. 24, núm. 4, 1997. 
Esta obra forma parte del acervo de la Biblioteca Jurídica Virtual del Instituto de Investigaciones Jurídicas de la UNAM www.juridicas.unam.mx

coberturas/reembolso a medicamentos, que no han sido priorizados según parámetros de ETESA, por medio de acciones judiciales, genera, por un lado, nuevos costos para el sistema de salud que no se encuentran internalizados por el demandante-paciente (externalidad negativa) y, por otro, habitualmente, en forma directa o indirecta, ${ }^{9}$ la extensión de dichas nuevas coberturas/reembolsos a terceros que se encuentren en similar situación que el demandante-paciente (externalidad positiva). ${ }^{10}$

\section{FIGURA 1}

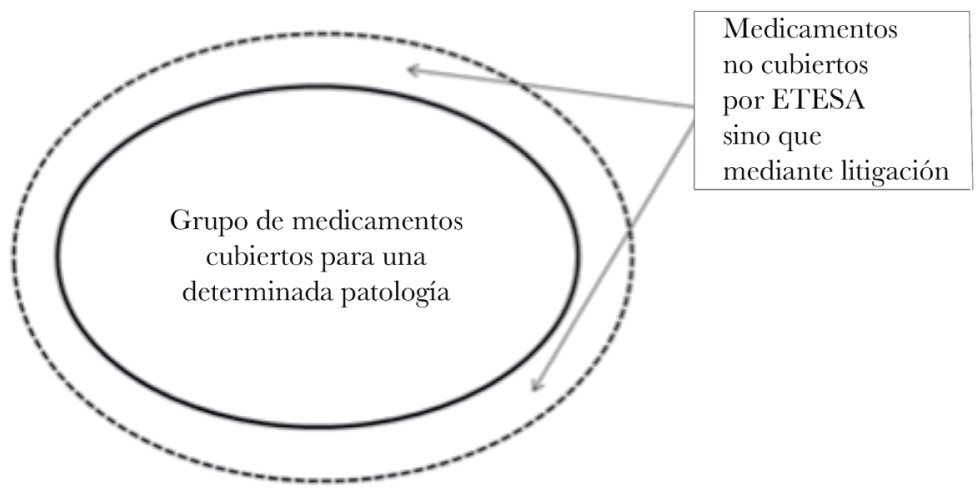

FUENTE: Elaboración propia.

Otra posible mirada del problema la aporta Siri Gloppen, ${ }^{11}$ quien enfatiza el rol que la judicialización puede jugar en las modificaciones de polí-

9 Ya sea que esos terceros deban demandar con base en la jurisprudencia generada por el primer caso que logró la cobertura/reembolso; o que, tras el primer caso, el sistema directamente extienda dichas nuevas coberturas/reembolso a todo tercero en similar situación (efecto erga omnes).

10 Gloppen, Siri, "Litigation As a Strategy to Hold Governments Accountable for Implementing the Right to Health", Health and Human Rights, vol. 10, núm. 2, 2008, pp. 24 y 25. Este autor sugiere un concepto más amplio de éxito del litigio: no sólo en el sentido que el tribunal acoja la acción judicial, sino que también su éxito social, el que se puede alcanzar ya sea ganando o perdiendo el caso, si es que genera visibilidad a un problema específico que pueda llevar al cambio de políticas públicas.

11 Gloppen, Siri, "Courts and Social Transformation: An Analytical Framework", en Gargarella, Domingo P. y Roux, T. (eds.), Courts and Social Transformation in New Democracies: An Institutional Voice for the Poor?, Aldershot, Ashgate, 2006, pp. 153-168; Gloppen, Siri, "Public Interest Litigation, Social Rights and Social Policy", en Dani, Anis A. y Haan, Arjan de (eds.), Inclusive States: Social Policy and Structural Inequalities, Washington, Word Bank Publications, 2008; Gloppen, Siri, "Litigation...", op. cit., pp. 21-36. 
Esta obra forma parte del acervo de la Biblioteca Jurídica Virtual del Instituto de Investigaciones Jurídicas de la UNAM

ticas públicas, al catalizar debates de orden político, pero también reconoce que, por sí sola, ésta no es la solución: en la medida que ese "envión" no sea correctamente utilizado en la redefinición de nuevas políticas públicas, con mayor aceptación social y viables en el tiempo, el problema que subyace no será solucionado, y la judicialización será sólo costo social con eventuales ganancias privadas, es decir, sin beneficios sociales evidentes.

Dentro de este contexto, es bastante pacífico afirmar que los tribunales no son los llamados per se a elaborar políticas públicas, ${ }^{12}$ como aquellas relacionadas con la priorización del gasto en coberturas/reembolso a medicamentos, especialmente porque no utilizan una mira sistémica (i.e. efecto agregado que puede generar una determinada línea jurisprudencial), sino que resuelven el caso concreto. Por otro lado, tampoco es realmente controversial indicar que no existen políticas públicas perfectas, óptimas, ni inmutables, ${ }^{13}$ que no requieran de continuos ajustes o de mejores niveles de consenso social, ${ }^{14}$ y puede que la judicialización señalice una necesidad de ajustes necesarios.

Etesa debiese tender a un nivel óptimo de cobertura para una sociedad dada (en adelante, el "nivel óptimo de cobertura"), maximizando su bienestar. ${ }^{15}$ Ahora bien, en el caso de Etesa, no existe una sola posible metodología a utilizar para determinar si procede la cobertura/reembolso a medicamentos, sino que múltiples, las que además pueden ser interpretadas de diversas formas. Ello lleva a que los resultados de esa evaluación técnica no se encuentren, necesariamente, carentes de elementos subjetivos

12 Véase, entre otros, García, José Francisco y Verdugo, Sergio, Activismo judicial en Chile, ¿Hacia el gobierno de los jueces?, Libertad y Desarrollo, 2013; Moses, Margaret L., "Beyond Judicial Activism: When the Supreme Court is No Longer a Court", U. Pa. Fournal of Constitutional Law, vol. 14, núm. 161, 2011; Roach, Kent, "The Myths of Judicial Activism", Supreme Court Law Review (2nd), vol. 14, 2001, pp. 297-330; Sowell, Thomas, "Judicial Activism Reconsidered", Essays in Public Policy, núm. 13, 1989.

13 Fotaki, Marianna, "Why Do Public Policies Fail so Often? Exploring Health PolicyMaking As an Imaginary and Symbolic Construction", Organization, vol. 17, núm. 6, 2010, pp. 703-720; McConnell, Allan, "Policy Success, Policy Failure and Grey Areas In-Between", Fournal of Public Policy, vol. 30, núm. 3, 2010, pp. 345-362.

14 La falta de consenso social de una política es una causal de falla de ésta. Al respecto, Carrow, M. M. et al. (eds.), Democracy, Social Values, and Public Policy, Westport, 1998.

15 European Observatory on Health Systems and Policies, "Ensuring Value for Money in Health Care: The Role of Health Technology Assessment in the European Union", Observatory Studies Series, núm. 11, 2008; World Health Organization, Making Fair Choices on the Path to Universal Health Coverage, 2014, disponible en: http://apps.who.int/iris/bitstre am/10665/112671/1/9789241507158_eng.pdf?ua=1. 
Esta obra forma parte del acervo de la Biblioteca Jurídica Virtual del Instituto de Investigaciones Jurídicas de la UNAM

que puedan alterar los resultados supuestamente anticipables, ${ }^{16}$ y el nivel óptimo de cobertura.

En ese sentido, puede ser deseable un cierto nivel de tensión entre las políticas públicas existentes, por ejemplo sobre priorización del gasto en coberturas/reembolso a medicamentos, y la potencial revisión judicial, que hagan que un sistema dado tienda al nivel óptimo de cobertura. Ello permite a) que quienes las diseñen consideren el riesgo de revisión judicial, y tomen los resguardos para minimizarlos (e.g. evitando discriminaciones que sean arbitrarias en coberturas/reembolso a medicamentos, exclusiones injustificadas, entre otros), realizando una labor de profilaxis; b) forzar correcciones u optimizaciones a las políticas públicas existentes, incorporando nuevas coberturas/reembolso a medicamentos, de ser necesario, y c) aumentar el consenso social.

Con base en lo planteado, el presente trabajo se enfocará, brevemente, en la situación en Brasil y México, por ser dos países de relevancia continental (aproximadamente 200 millones y 120 millones de habitantes, respectivamente), con sistemas formales y establecidos de Etesa.

Se revisará, como primer paso, si existe legalmente un proceso de Etesa en dichos países y cuál ha sido la evaluación existente hasta el momento, ello a fin de determinar si la política pública intervenida por la judicialización es robusta o todavía en etapa de desarrollo (si tiende al nivel óptimo de cobertura); en otras palabras, si lo afectado es una buena herramienta de priorización del gasto en medicamentos y de justicia distributiva o si es, en el extremo, tan arbitraria como el resultado de la judicialización (se aleja del nivel óptimo de cobertura).

Posteriormente, y como segundo paso, se revisarán los elementos de la racionalidad económica de la litigación: 1) si $B_{l}$ (beneficio esperado de litigar) es alto, el que definiremos como la obtención de mayor cobertura/reembolso de medicamento/menor copago, que la hipótesis de no litigar; 2) si $P_{l}$ (la probabilidad de ganar el litigio) es alta, digamos, mayor al 50\%; 3) $C_{l}$ (costo de litigar) es relevante o bajo, y 4 ) si $C_{0}$ (costo que debiese afrontarse si no se litiga) es mayor a la hipótesis de no litigar. Ello busca determinar si el incentivo a litigar es alto o bajo en los dos países.

El diagnóstico, tanto del proceso de Etesa en Brasil y México, como de los elementos que inciden sobre la racionalidad económica del litigio, relacionado con el acceso a medicamentos en los referidos países, servirán para

16 Stephens, Jennifer M. et al., "International Survey of Methods Used in Health Technology Assessment (HTA): Does Practice Meet the Principles Proposed for Good Research?”, Comparative Effectiveness Research, núm. 2, 2012, pp. 29-44. 
Esta obra forma parte del acervo de la Biblioteca Jurídica Virtual del Instituto de Investigaciones Jurídicas de la UNAM www.juridicas.unam. $m x$

aventurar una opinión sobre el sistema en su conjunto (Etesa tensionado por la judicialización).

\section{SOBRE LA EXISTENCIA DE ETESA \\ Y SU EVALUACIÓN}

\section{Brasil}

En Brasil, Etesa se encuentra radicada en la Comissão Nacional de Incorporação de Tecnologias no SUS (Conitec), ${ }^{17}$ establecida en 2011, y regulada en la ley, ${ }^{18}$ modificada por la Ley 12.401/201 1, ${ }^{19}$ y los decretos 7.508/2011 ${ }^{20}$ y 7.646/2011,,$^{21}$ entre otros.

Conitec es parte del SUS, que es el Sistema Único de Saúde, creado por los artículos 198 y siguientes de la Constitución Federal brasileña de 1988, ${ }^{22}$ que busca, precisamente, garantizar el derecho a la salud consagrado en el artículo $196^{23}$ de la referida ley fundamental.

Conitec fue creada para asesorar al Ministerio de Salud de Brasil sobre la incorporación, exclusión o modificación de nuevos medicamentos o protocolos clínicos o directrices terapéuticas, ${ }^{24}$ habiéndose incorporado hasta

17 Visible en: http://conitec.gov.br/.

18 "Dispõe sobre as condições para a promoção, proteção e recuperação da saúde, a organização e o funcionamento dos serviços correspondentes e dá outras providências".

19 "Altera a Lei no 8.080, de 19 de setembro de 1990, para dispor sobre a assistência terapêutica e a incorporação de tecnologia em saúde no âmbito do Sistema Único de SaúdeSUS".

20 "Regulamenta a Lei no 8.080, de 19 de setembro de 1990, para dispor sobre a organização do Sistema Único de Saúde-SUS, o planejamento da saúde, a assistência à saúde e a articulação interfederativa, e dá outras providências".

21 "Dispõe sobre a Comissão Nacional de Incorporação de Tecnologias no Sistema Único de Saúde e sobre o processo administrativo para incorporação, exclusão e alteração de tecnologias em saúde pelo Sistema Único de Saúde - SUS, e dá outras providências".

22 Regulado en las leyes orgánicas de salud 8080/90 y 8.142/90. Véase, entre otros, Tolentino S., Marcus, "Sistema único de salud: la experiencia brasileña en la universalización del acceso a la salud", Revista Peruana de Medicina Experimental y Salud Pública, vol. 26, núm. 2, 2009, pp. 251-257.

23 Norma que indica: "[a] saúde é direito de todos e dever do Estado, garantido mediante políticas sociais e econômicas que visem à redução do risco de doença e de outros agravos e ao acesso universal e igualitário às ações e serviços para sua promoção, proteção e recuperação".

24 Conitec, Balanço Conitec: 2012-2014, Brasília, Ministério da Saúde, Comissão Nacional de Incorporação de Tecnologias no SUS, 2014, p. 11. 
Esta obra forma parte del acervo de la Biblioteca Jurídica Virtual del Instituto de Investigaciones Jurídicas de la UNAM www.juridicas.unam.mx

el 2014, cerca de 114 nuevas tecnologías. ${ }^{25}$ Para ello, Conitec analiza la eficacia, seguridad, costo-efectividad y beneficio clínico del nuevo medicamento evaluado, el que, además, debe ser aplicable en el contexto brasileño y sustentable en el largo plazo. ${ }^{26}$

Para la Etesa, Conitec sigue el flujo siguiente (figura 2):27

\section{FIGURA 2}

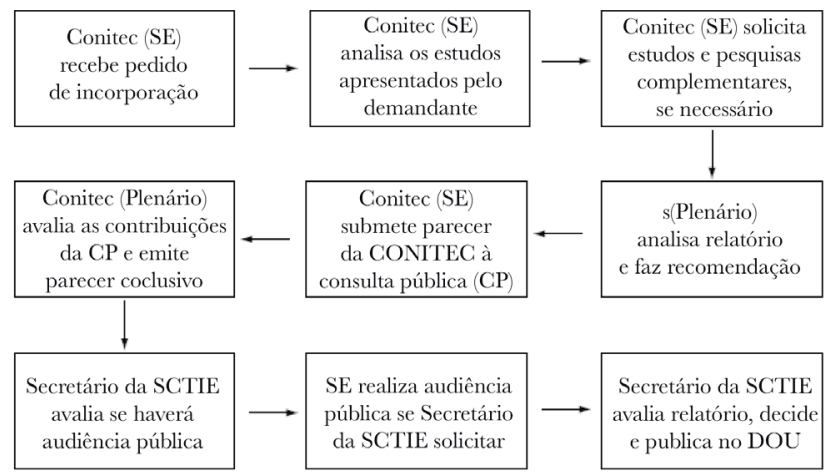

Conitec: Comissão Nacional de Incorporação de Tecnologias no Sistema Único de Saúde SE: Secretaria Executiva

SCTIE: Secretaria de Ciência, Tecnologia e Insumos Estratégicos do Ministério da Saúde DOU: Diario Oficial da União

Fonte: Ministério da Saúde. Disponível em: http://portal.saude.gov.br/portal/arquivos/pdf/FluxosimplificadoCONIOTC.pdf. Acessado em 15.Jan 2012.

Ahora, en cuanto a su resultado, se ha criticado, con data de 2013, que la mayor parte de las tecnologías incorporadas son "internas" (de laboratorios públicos), los que tienen una tasa de incorporación superior al $51 \%$, mientras que las "externas" (de laboratorios privados) en torno al 10\% (véase figura 3). ${ }^{28}$ Eso ha sido interpretado, de alguna forma, como un cierto

25 Ibidem, p. 6.

26 Ibidem, p. 7. Véanse, además, los artículos 19-O de la Ley 8.080/1990 y 18 del Decreto 7.646/2011. Asimismo, Guimarães, Reinaldo, “Technological...”, op. cit., y Kuhn-Barrientos, Lucy, "Evaluación...", op. cit., p. 13.

27 En Silva, Hudson P. et al., "Avanços e desafios da Política Nacional de Gestão de Tecnologias em Saúde”, Revista de Saúde Pública, vol. 46 (supl.), 2012, pp. 83-90.

28 Interfarma, Ciclo de Debates Interfarma: Políticas Relacionadas à Saúde, 2014, disponible en: http://gusaude.fgv.br/sites/gusaude.fgv.br/files/Revista_Final.pdf. Véase, también, sesión 0741/14 de la Câmara Dos Deputados: Debate sobre o acesso a medicamentos não comercializados no Brasil pela ausência de autorização da Agência Nacional de Vigilância Sanitária, disponible en: http://wrere.camara.leg.br/internet/sitaqweb/textoHTML.asp?etapa=11 $\mathrm{G}$ nuSessao $=0741 / 14$ EnuQuarto $=0$ EnuOrador $=0$ EnnInsercao $=0$ Ed t Horario Quarto $=11: 00$ EsgFase 
Esta obra forma parte del acervo de la Biblioteca Jurídica Virtual del Instituto de Investigaciones Jurídicas de la UNAM www.juridicas.unam.mx

sesgo en favor de las solicitudes de incorporación "internas", en desmedro de las "externas".

\section{FIGURA 3}

Tabela 1 - Panorama dos processos para incorporação de tecnologia no SUS Conitec até 21 de maio de 2013

\begin{tabular}{|c|c|c|c|c|}
\hline Medicamento & $\begin{array}{c}\mathrm{N}^{\circ} \text { submissões } \\
125\end{array}$ & $\begin{array}{c}\mathrm{N}^{\circ} \text { submissões } \\
73,5 \%\end{array}$ & $\begin{array}{c}\mathrm{N}^{\circ} \text { incorporações } \\
32\end{array}$ & $\begin{array}{c}\mathrm{N}^{\circ} \text { incorporações } \\
80,0 \%\end{array}$ \\
\hline Procediemiento & 21 & $12,4 \%$ & 5 & $12,5 \%$ \\
\hline Producto & 24 & $14,1 \%$ & 3 & $7,5 \%$ \\
\hline Total & 170 & $100 \%$ & 40 & $100,0 \%$ \\
\hline Origem & $\mathrm{N}^{\mathrm{o}}$ submissões & $\begin{array}{c}\mathrm{N}^{\circ} \text { incorporações } \\
\text { deferidas }\end{array}$ & $\begin{array}{c}\mathrm{N}^{\circ} \text { incorporações } \\
\text { deferidas }\end{array}$ & $\begin{array}{l}\text { Outros } \\
\text { status }\end{array}$ \\
\hline Externa & 116 & 12 & 22 & 82 \\
\hline Interna & 54 & 28 & 1 & 25 \\
\hline Total & 170 & 40 & 23 & 107 \\
\hline
\end{tabular}

Fonte: Conitec. Actualizada até 21 de maio de 2013

Ello se ha acentuado en favor de los laboratorios públicos, dado que a enero de 2015 la tasa media de incorporación es de 40\%, pero desagregada, muestra que esta tasa para la "demanda interna" es de $90 \%$, mientras que la "externa" de $20 \% .{ }^{29}$

Por otro lado, en el reporte de 2013 de la consultora Charles River Associates, se indica sobre la labor de Conitec que:

While the reforms have resulted in a more open and transparent process, concerns still exist regarding the potential for conflict of interests, the method of prioritisation and process. First, CONITEC is part of the Ministry of Health, which means that the assessments are conducted by parties with a vested interested in the outcome. Second, it is still not clear how CONITEC prioritises the assessments that they choose to review and evidence suggests that most of the reviews were commissioned by the SUS or other public stakeholders. Finally, there is no process that manufacturers can use to appeal the decisions made. ${ }^{30}$

Sessao $=$ EDData $=28 / 5 / 2014 \mathcal{E}^{\circ} \mathrm{t} x$ A pelido $=$ DEFESA $\% 20$ DO $\% 20$ CONSUMIDORE't $x$ FaseSess $a 0=$ Audi $\%$ C3\%AAncia $\% 20 P \%$ C3\%BAblica\%20Extraordin \%C3\%A1ria\%20-\%20Conjunta\%20das\%20 Comiss $\%$ C3\%B5es\%20CDC\%20e\%20CSSFEt $x$ TipoSessao $=$ Ed $d$ tHoraQuarto $=11: 00$ Et txEtapa $=$ (fecha de consulta: 22 de septiembre de 2015).

29 Disponible en: http://wrere.interfarma.org. $\mathrm{br} /$ guia2015/site $/$ guia $/$ index.php?val $=45$ Etitulo $=$ Comiss\%C3\%A30\%20Nacional\%20de\%20Incorpora\%C3\%A7\%C3\%A30\%20de\%20Tecnologias\%20(CONITEC) (fecha de consulta: 30 de septiembre de 2015).

30 Charles River Associates, A Comparative Analysis of the Role and Impact of Health Technology Assessment: 2013 Final Report, 2013, p. 54, disponible en: http://wrere.efpia.eu/uploads/documents/ cra-comparative-analysis.pdf. 
Esta obra forma parte del acervo de la Biblioteca Jurídica Virtual del Instituto de Investigaciones Jurídicas de la UNAM www.juridicas.unam.mx

Asimismo, se indica en dicho reporte que:

...the updated guidelines, which set out a range of possible methodologies, are not clear on which is the preferred methodology. It is also unclear how the system deals with uncertainty. According to CONITEC guidelines, molecules should be compared with products used to treat the same indication, which are funded by the SUS. Indirect costs can be considered when undertaking HTA, however; none of the case studies included in our assessment introduced them in the calculations. ${ }^{31}$

Si bien es cierto que el establecimiento de Conitec ha traído consigo avances relevantes en términos de trasparencia y de criterios de Etesa más anticipables, no lo es menos que su diseño todavía no garantiza completamente una necesaria autonomía del Ministerio de Salud, por lo que otros factores adicionales a Etesa podrían jugar un rol en las decisiones de incorporación, ${ }^{32}$ lo que afecta las coberturas/reembolso a medicamentos (no tendería al nivel óptimo de cobertura).

\section{México}

El Consejo de Salubridad General (CSG) ${ }^{33}$ que es una de las autoridades sanitarias mexicanas, regulada en los artículos 4o., 15 a 17, entre otros, de la Ley General de Salud, es la que emite las regulaciones basadas en Etesa; siendo el Centro Nacional de Excelencia Tecnológica (Cenetec) ${ }^{34}$ la agencia nacional de Etesa desde 2003 para dicho país.

Ahora, los medicamentos a ser incluidos también son evaluados con base en criterios de Etesa por cada uno de los seguros públicos que integran el Sistema Nacional de Salud de México (SNS), regulado en el título segundo de la Ley General de Salud, que cubren a la mayoría de la

31 Idem.

32 Al respecto, Alessandro Cirrincione ha sostenido que "[f]inally in the public sector the funding is limited, so even if you have a cost-effective drug it doesn't mean you're going to have public funding. The probability of success will depend on the political will to cover a product, to what extent it is seen as a national health priority. And of course there is the key question about the budget impact that it will have on the healthcare system". IMS Pharma Pricing E̊ Reimbursement, vol. 20, núm. 1, 2015, p. 14.

33 Puede consultarse en: http://wrere.csg.gob. $m x /$. Para Etesa, el CSG utiliza la denominada "Guía de evaluación de insumos para la salud", disponible en: http://wrere.csg.gob.mx/ descargas/pdfs/2015/GEI_2015.pdf.

34 Puede consultarse en: http://rerere.cenetec.salud.gob.mx/. Además, Kuhn-Barrientos, Lucy, "Evaluación...”, op. cit., p. 14. 
Esta obra forma parte del acervo de la Biblioteca Jurídica Virtual del Instituto de Investigaciones Jurídicas de la UNAM www.juridicas.unam.mx

población mexicana: ${ }^{35}$ IMSS (Instituto Mexicano del Seguro Social), ${ }^{36}$ ISSSTE (Instituto de Seguridad y Servicios Sociales de los Trabajadores del Estado), ${ }^{37}$ DIF (Desarrollo Integral de la Familia), ${ }^{38}$ Sedena (Secretaría de la Defensa Nacional), ${ }^{39}$ Semar (Secretaría de Marina) ${ }^{40}$ y Pemex (Petróleos Mexicanos). ${ }^{41}$ Ahora, todas estas instituciones conforman la Comisión Interinstitucional del Cuadro Básico y Catálogo de Insumos del Sector Salud, que se regula por el Reglamento Interior de la Comisión Interinstitucional del Cuadro Básico y Catálogo de Insumos del Sector Salud.

Cabe recalcar que el SNS de México precisamente busca garantizar el derecho a la protección de la salud, consagrado en el párrafo 4 del artículo 4o. de la Constitución Política de los Estados Unidos Mexicanos. ${ }^{42}$

\section{FIGURA 4}

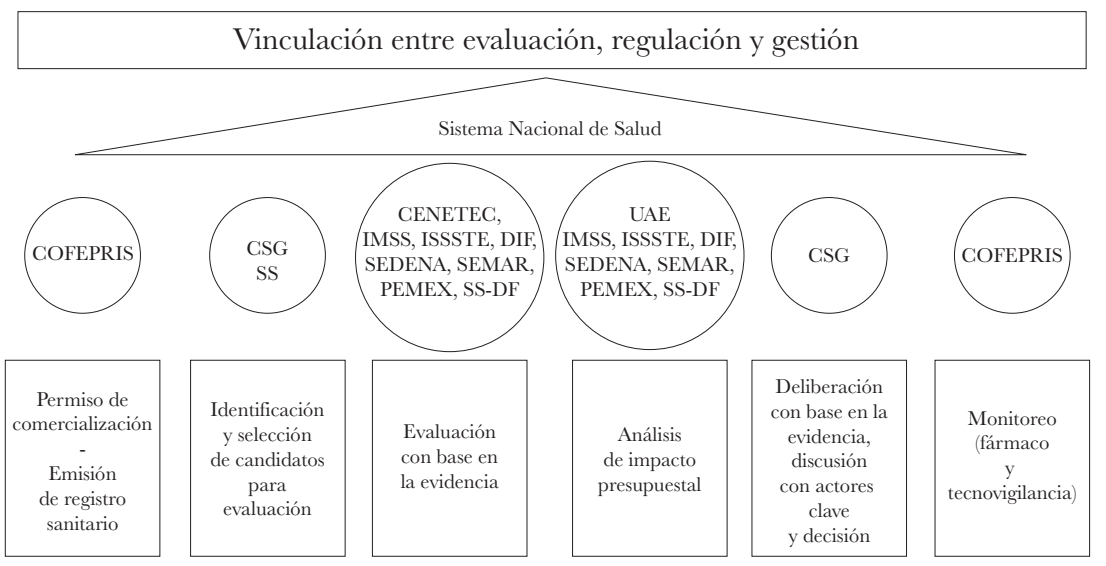

Fuente: Elaboración propia CENETEC, Modificado de Banco Interamericano del Desarrollo, 2012.

35 Cenetec, La cobertura universal de salud y el rol de la evaluación de tecnologías para la salud (ETES), disponible en: http://wrere.cenetec.salud.gob.mx/descargas/presentaciones-foro2014/La_cobertura_univer_salud_rol_evalu_tecno_salud_ETES.pdf. La Comisión Federal para la Protección contra Riesgos Sanitarios (Cofepris) es la agencia de medicamentos de México, puede consultarse en: http://wrwre.cofepris.gob.mx/Paginas/Inicio.aspx.

36 Disponible en: http://wrw.imss.gob.mx/.

37 Disponible en: http://wrere.issste.gob. $m x /$.

38 Disponible en: http://sn.dif.gob. $m x /$.

39 Disponible en: http://wrere.sedena.gob.mx/inicio.

40 Disponible en: http://wrwresemar.gob. $m x /$.

41 Disponible en: http://wrwe.pemex.com/Paginas/default.aspx.

42 "Toda persona tiene derecho a la protección de la salud. La ley definirá las bases y modalidades para el acceso a los servicios de salud y establecerá la concurrencia de la Federación y las entidades federativas en materia de salubridad general, conforme a lo que dispone la fracción XVI del artículo 73 de esta Constitución”. 
Esta obra forma parte del acervo de la Biblioteca Jurídica Virtual del Instituto de Investigaciones Jurídicas de la UNAM www.juridicas.unam.mx

Sobre el sistema mexicano, el informe de la consultora IMS Health, de $2013,{ }^{43}$ demuestra una constante baja de las incorporaciones dentro del SNS, tanto en el IMSS (véase figura 5) como en el ISSSTE (véase figura 6), lo que, entre otros, ha generado una baja cobertura de nuevas moléculas (véase figura 7). Asimismo, se constata que en el principal seguro público mexicano, el IMSS, la tasa de rechazo de incorporaciones de medicamentos es notablemente alta $(71 \%)$ (véase figura 8$)$. En general, la tasa de rechazo de incorporación mexicana es alta, comparada con la realidad de Australia, Canadá, Escocia y Reino Unido (véase figura 9).

\section{FIGURA 5}

\section{Inclusiones}

Las inclusiones del IMSS son irregulares; sin embargo en los últimos 3 años la inclusión de nuevas claves ha decrecido de manera constante

Inclusión al IMSS entre el 2008 al $2013^{1}$

Número de claves incluidas

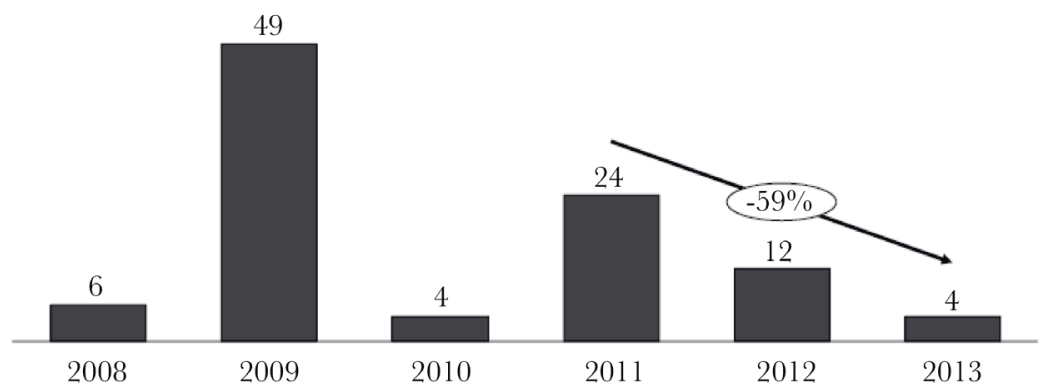

(1) Aprobadas por la Dirección de Prestaciones Médicas del IMSS

Resultados principales • Marzo 2014

18 Fuente: IMSS; Análisis de equipo

imshealth

43 IMS Health, Áreas de oportunidad en el proceso de acceso de medicamentos al paciente con el objetivo de mejorar los resultados de salud de México, 2014, disponible en: http://wrwreamïf.org/descarga. $p d f$. 
Esta obra forma parte del acervo de la Biblioteca Jurídica Virtual del Instituto de Investigaciones Jurídicas de la UNAM www.juridicas.unam.mx

\section{FIGURA 6}

Inclusiones

Mientras que en el ISSSTE han ido decreciendo significativamente desde el 2008; solo l genérico en 2012 y ninguna en este año

Inclusión de nuevas claves al ISSSTE de enero 2008 a sept 2013

Número de claves incluidas

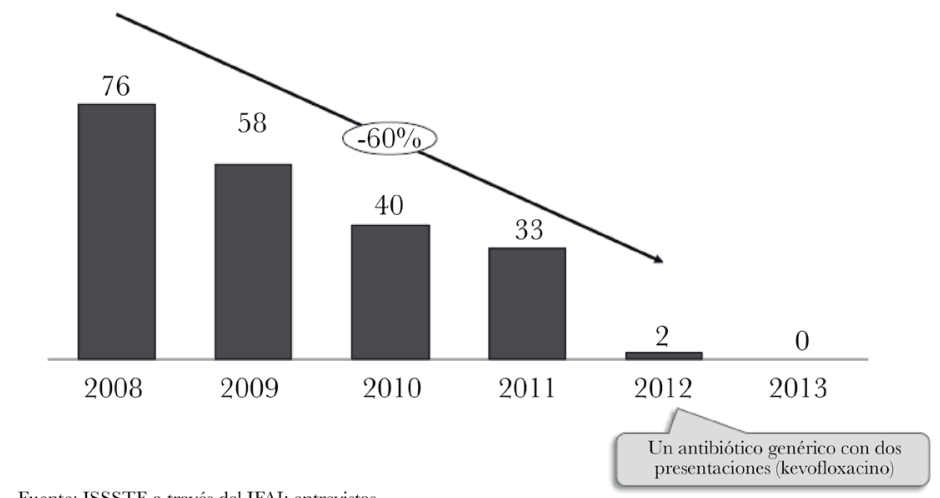

Fuente: ISSSTE a través del IFAI; entrevistas

Resultados principales Marzo 2014

19 Fuente: IMSS; Análisis de equipo

(1) No incluye exclusiones

imshealth

\section{FIGURA 7}

Inclusiones

...mientras que en nuevas moléculas, el sistema público mexicano tiene baja cobertura

Análisis del número de nuevas moléculas cubiertas por las Instituciones de las enfermedades analizadas

Cobertura de nuevas moléculas

Número de moléculas
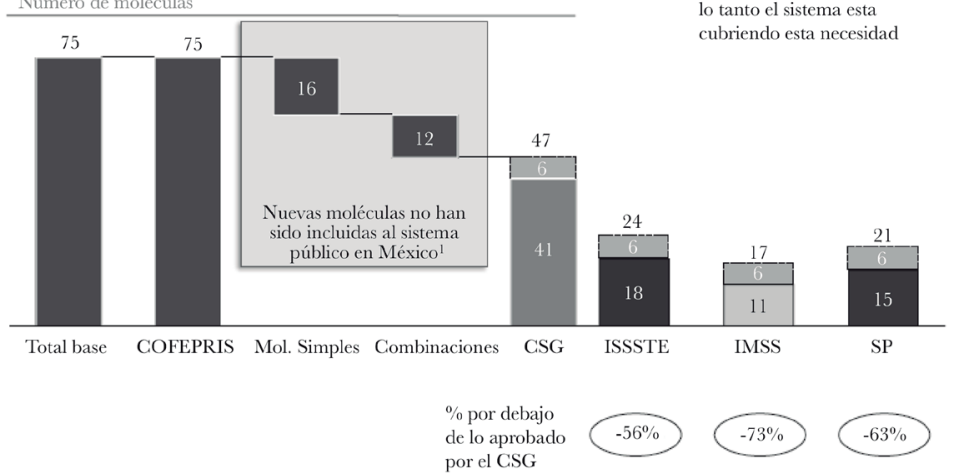

(1) Por rechazo de parte del CSG o por falta de interés en el sector por parte del fabricante

21 Fuente: COFEPRIS; CSG; IMSS; ISSSTE; Análisis de equipo 
Esta obra forma parte del acervo de la Biblioteca Jurídica Virtual del Instituto de Investigaciones Jurídicas de la UNAM www.juridicas.unam.mx

\section{FIGURA 8}

Razones de rechazo

De la muestra seleccionada se observa que la tasa de rechazo en el IMSS es muy alta

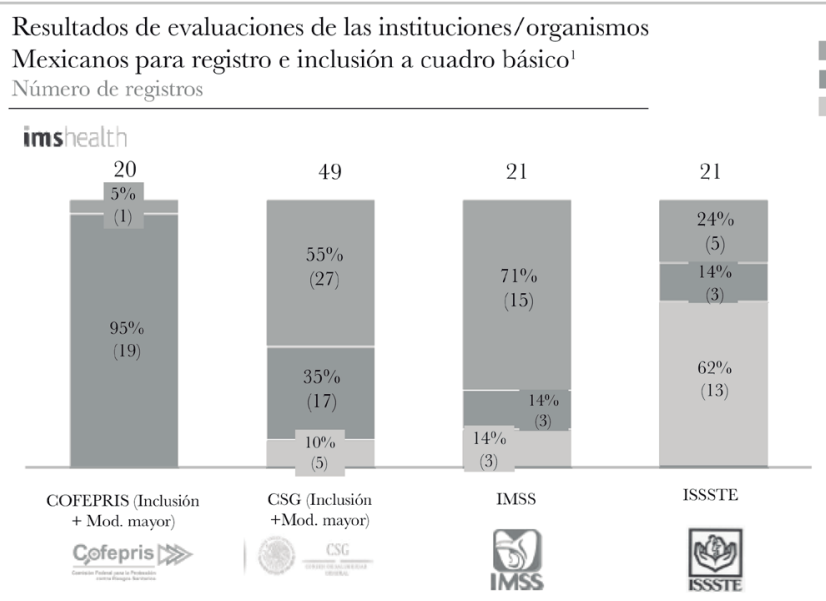

(1) Cuestionario muestra información del 80\% de los miembros de la AMIF. Moléculas evaluadas en el período enero 2011 - mayo 2013

Resultados principales $\bullet$ Marzo 2014

${ }^{22}$ Fuente: COFEPRIS; CSG; Cuestionario AMIIF; Análisis de equipo

\section{FIGURA 9}

Razones de rechazo

Observamos que en los diferentes pasos del proceso, en México es más difícil obtener acceso a nivel nacional comparado con otras ETSs ${ }^{1}$

Resultados de evaluaciones de organizaciones Internacionales para inclusión a cuadro básico

Número de reportes en 2011; México Enero 2011 a Diciembre 2013

Rechazo

Accptación

Sin respuesta

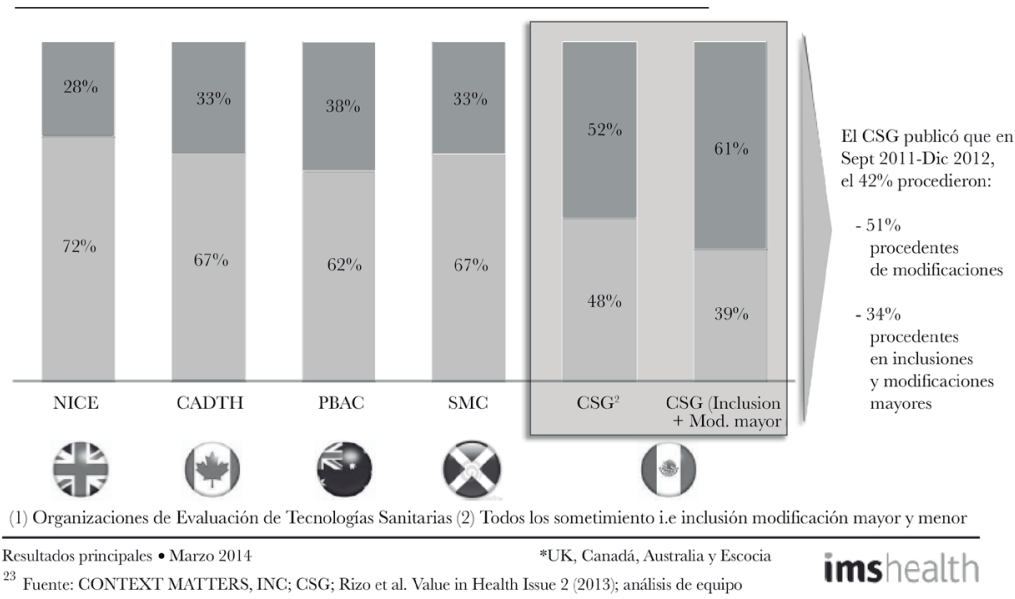


Esta obra forma parte del acervo de la Biblioteca Jurídica Virtual del Instituto de Investigaciones Jurídicas de la UNAM

Además, sobre el caso mexicano, Charles River Associates ha sostenido que:

However, it is unclear how in practice the reports are used in the decisionmaking process as the CSG only makes public the result of the assessments and it does not provide a detailed analysis of the appraisal process. Pharmaceutical companies receive some feedback when their technologies are rejected or accepted with conditions. Although a formal appeal process does not exist, companies can resubmit their applications addressing the requests of the CSG. Since mid-2013, this can be done on a rolling basis. ${ }^{44}$

De igual manera, se indica por parte de Charles River Associates que:

The CSG does not have a direct impact in reimbursement decisions, as the inclusion in each benefit plan is decided by each public payer (there are multiple benefit plans, for example, IMSS or ISSTE). Generally, public payers only include technologies that have been approved by the CSG and they are not obliged to include all of them. In order to decide which ones they ultimately include, they may develop additional assessments, including institutional budget impact analysis. ${ }^{45}$

Siguiendo con el análisis, se puntualiza sobre el sistema mexicano que:

In terms of the process, there remains considerable room for improvement if the Mexican system is to apply best practice principles. First, the current system does not include key stakeholder groups at any part of the process and does not have any official appeals process. Second, the completed assessments are not publicly available and only limited information is provided. Manufacturers often receive minimal feedback. ${ }^{46}$

En resumen, si bien en el sistema mexicano existe un proceso formal de Etesa, este se encuentra fragmentado (CSG, Cenetec, IMSS, ISSSTE, etcétera) y los criterios de decisión no son del todo claros, lo que ha llevado, en general, a un bajo nivel de incorporación, afectando el nivel óptimo de cobertura.

\footnotetext{
44 Charles River Associates, A Comparative Analysis..., cit., p. 45.

45 Idem.

46 Ibidem, p. 47.
} 
Esta obra forma parte del acervo de la Biblioteca Jurídica Virtual del Instituto de Investigaciones Jurídicas de la UNAM

\section{SOBRE LA RAGIONALIDAD ECONÓMICA DE LA LITIGACIÓN}

\section{Brasil}

En el trabajo de Reveiz et al. de $2013^{47}$ se realiza una búsqueda sistemática de la literatura existente sobre judicialización en temas de salud, incluido medicamentos, revisándose el caso de Brasil (véanse las figuras 10 y 11).

De ello se puede evidenciar que $B_{l}$ (beneficio esperado de litigar) es alto, dado que mediante esta vía se logra una mayor cobertura/reembolso de medicamento/menor copago, que la hipótesis de no litigar, ${ }^{48}$ y con una $P_{l}$ (la probabilidad de ganar el litigio) alta, ya que se sitúa entre $70 \%$ y $100 \%$.

Pareciera ser que el $C_{l}$ (costo de litigar) es bajo, dado que aquellas personas de escasos recursos en Brasil tienen derecho a asesoría legal gratuita, o son apoyadas por ONGs. ${ }^{49}$

47 Reveiz, Ludovic et al., "Litigios...", op. cit., pp. 217 y 218.

48 "En el caso de Brasil, una proporción de pacientes recurrió a la vía judicial, obviando la vía administrativa establecida para obtener medicamentos especiales (por ejemplo, por presentar documentación incompleta, o no cumplir los criterios) o disminuir los tiempos de espera. En otros casos, los medicamentos no estaban disponibles en las farmacias por deficiencias en la gestión, o se reclamaban todos los medicamentos prescritos al paciente, sin discriminar si ya estaban incluidos en el plan de beneficios", ibidem, p. 215. Gran parte de la judicialización en Brasil surgió en torno a medicamentos para el VIH: "Brazilian policy for HIV included the provision of drugs free of charge, albeit not the then more modern treatments that patients were willing to use in the place of, or in combination with, those already provided. Therefore, some HIV patients went to courts claiming that their right to health was being violated because the treatments available in the public health system were no longer effective for them and thus, they needed the most modern drugs. And because courts were deciding in favour of patients, these first cases were followed by more litigation with the same claim", Liang Wang, Daniel Wei, Courts..., cit., p. 8. El éxito de estos casos llevó a expandir esta tendencia a otras patologías: "The HIV patients successful litigation in all levels of the judicial branch has become an example for patients suffering from other diseases. Nowadays, the variety of diseases to which treatments are demanded is huge and ranges from very rare diseases (e.g., Gaucher's disease, Duchenne muscular dystrophy, epidermolysis bullosa) to diseases that affect a large sector of the population. Currently, research shows that most lawsuits demand drugs for chronic diseases, such as diabetes, cancer, arthritis, hepatitis $\mathrm{C}$ and arterial hypertension, alongside other health problems related to the digestive system and metabolism, the cardiovascular system and the nervous system", idem. La mayor parte de los juicios se refieren a medicamentos no incluidos: "The percentage of cases in which claimants demanded drugs not included in the public health system's pharmaceutical policy is high $-80.6 \%$ in the State of Rio de Janeiro, $92.5 \%$ in the City of Rio de Janeiro and $66.2 \%$ in the Federal District", idem.

49 "They found that more than $20 \%$ of litigants received free legal assistance provided by NGOs, which covered all the litigation costs... Sant'Anna (2009) also analyzed a small number of cases (27) in depth and found that $50 \%$ of the patients represented by private lawyers were sponsored by an NGO. Messeder et al. (2005) found that some of the private law firms 
Esta obra forma parte del acervo de la Biblioteca Jurídica Virtual del Instituto de Investigaciones Jurídicas de la UNAM

Como puede apreciarse, los elementos de la racionalidad económica de litigar en Brasil incentivan la presentación de acciones judiciales para lograr una mayor cobertura/reembolso de medicamento/menor copago.

Precisamente por el propicio escenario para la litigación relacionada con medicamentos, indicado previamente, en 2011 se presentaron $240 \mathrm{mil}$ acciones judiciales, las que en 2014 se incrementaron a 392 mil, es decir, un aumento de $62 \%$ en tres años. ${ }^{50}$

Ahora, es pacífico sostener que el caso brasileño es extremo, dado que este gran número de casos no sólo se refiere a medicamentos no incorporados por Conitec, sino que incluso aquellos que ni siquiera cuentan con registro sanitario de la Agência Nacional de Vigilância Sanitária (Anvisa). ${ }^{51}$

El Supremo Tribunal Federal (STF) ha indicado que

[e]ntre proteger a inviolabilidade do direito à vida, que se qualifica como direito subjetivo inalienável assegurado pela própria Constituição da República (art. $5^{\circ}$, caput), ou fazer prevalecer, contra essa prerrogativa fundamental, um interesse financeiro e secundário do Estado, entendo - uma vez configurado esse dilema - que razões de ordem ético-jurídica impõem ao julgador uma só e possível opção: o respeito indeclinável à vida. ${ }^{52}$

Esta línea jurisprudencial ha llevado a que el impacto en el presupuesto federal de salud para poder solventar medicamentos que se ha ordenado cubrir por sentencias judiciales ha ido de ${ }^{53} \mathrm{R} \$ 2,5$ millones (USD 235.000) en 2005, a R \$266 millones (USD 67 millones) en 2010. Entre 2003 y 2011 , el monto agregado alcanzó $\mathrm{R} \$ 588$ millones (USD 150 millones). ${ }^{54} \mathrm{~A}$ ello todavía debe sumarse el gasto a nivel estadual y municipal, que también es muy relevante..$^{55}$

representing litigants claiming treatments from the public health system have connections with patients' NGOs", ibidem, pp. 14 y 15.

50 Interfarma, "Saúde, 25 Anos Depois", Revista 25 Anos-Interfarma, 2014, p. 40.

51 Disponible en: http://portal.anvisa.gov.br/. Véase en Liang Wang, Daniel Wei, Courts..., cit., p. 10 .

52 STF: medida cautelar na petição: Pet 1246 SC. En similar sentido, véase STF: recurso extraordinário: RE 198263 RS. Esta línea jurisprudencial se ha intentado morigerar mediante iniciativas del Conselho Nacional de Justiça (http://wrerr.cnj.jus.br/), como del STF, pero sin real éxito, ibidem, pp. 30-40. "In conclusion, the criteria established by the STF still allow the adjudication of the right to health as an individual right and ignores issues that should be central in any health policy: opportunity costs, cost-effectiveness analysis, priority setting, robust scientific evidence and reasonable principles of distributive justice", ibidem, p. 35.

53 Al tipo de cambio de octubre de 2015.

54 Liang Wang, Daniel Wei, Courts..., cit., pp. 26-29.

55 Idem. 


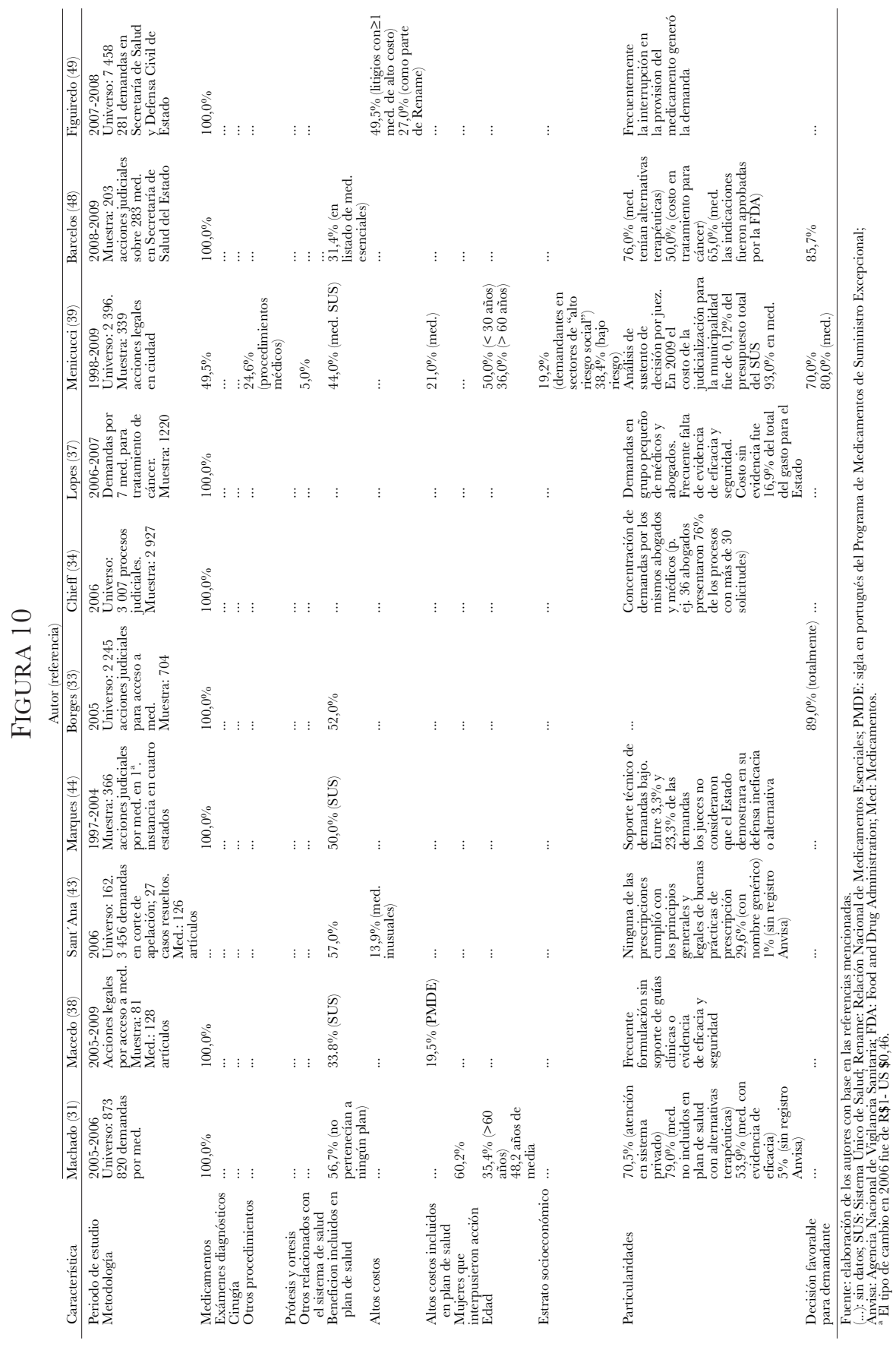




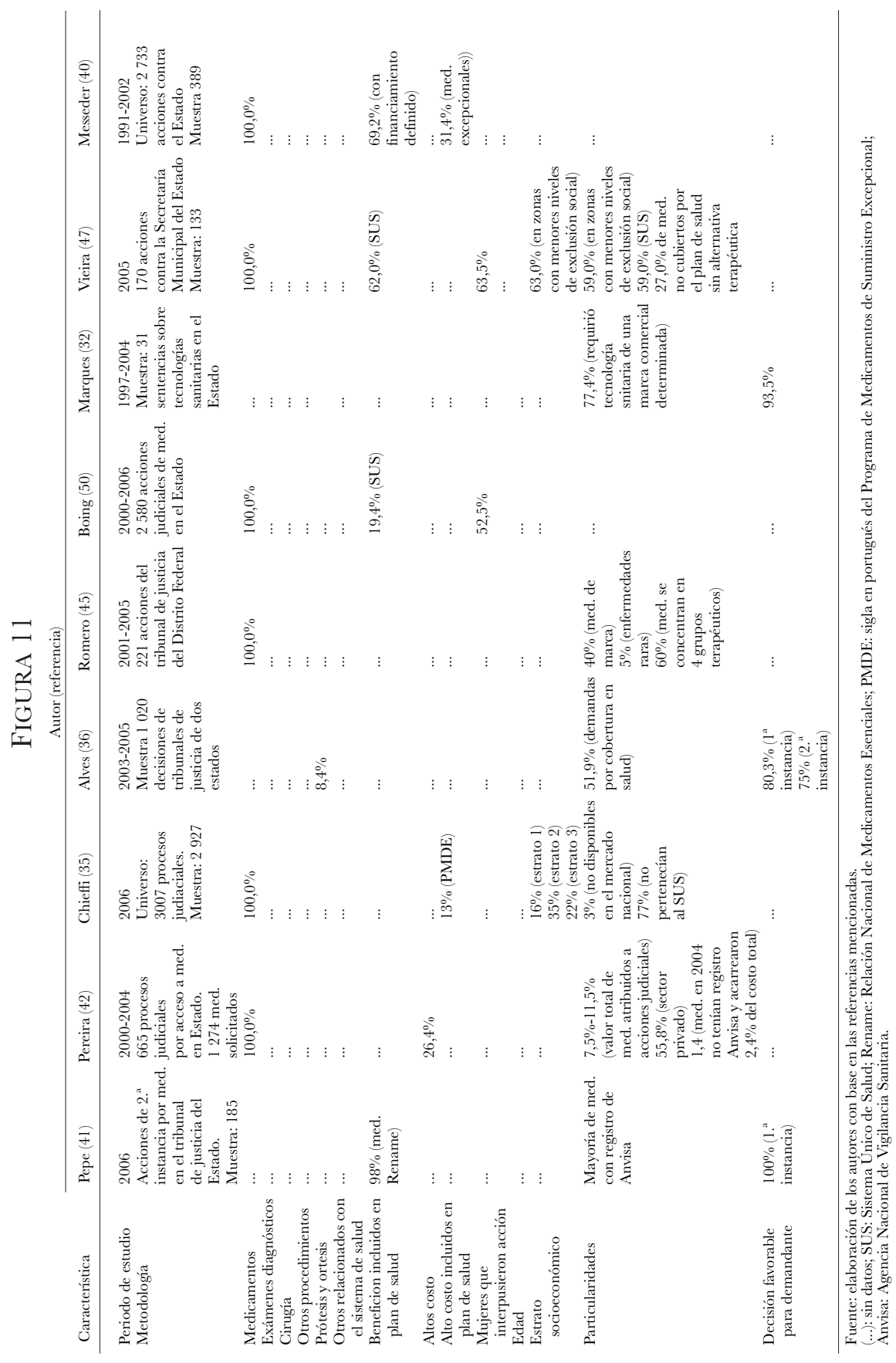


Esta obra forma parte del acervo de la Biblioteca Jurídica Virtual del Instituto de Investigaciones Jurídicas de la UNAM

A modo de conclusión parcial se puede indicar que si bien el sistema de Etesa de Brasil todavía no funciona todo lo bien que debiera (su diseño no garantiza completamente una necesaria autonomía del Ministerio de Salud, por lo que otros factores adicionales a Etesa podrían jugar un rol en las decisiones de incorporación, no tendiendo al nivel óptimo de cobertura), la respuesta de la judicialización ha sido extrema, tanto por el número de litigios como por el gran impacto económico para el presupuesto de salud (incluso ordenando la cobertura de medicamentos sin registros sanitarios), lo que también puede afectar la meta de lograr un nivel óptimo de cobertura.

\section{México}

El fenómeno de la judicialización vinculado con medicamentos en México es sustancialmente menor a lo indicado para Brasil. Prácticamente no existen estudios que realcen este fenómeno como uno relevante en México, tanto por el número de litigios como por el gasto adicional que debiera realizarse por órdenes judiciales.

Ello aparentemente se debería a: a) la dificultad técnica para iniciar juicios de amparo, especialmente previo a la reforma de 2011,56 debido a los requisitos de procedibilidad de la acción actualmente establecidos en el artículo 107, fracción I, de la Constitución Política de los Estados Unidos Mexicanos, y en el artículo 61, fracción XII, de la Ley de Amparo, referidos a la obligación de acreditar intereses jurídicos o legítimos del quejoso, lo que se erige como una relevante "barrera de entrada" a la litigación; ${ }^{57}$ o b) por los

56 Ortiz Hernández, Cristina, El interés legítimo dentro del juicio de amparo, 2015, disponible en: http://wrwre.letrasjuridicas.com/Volumenes/32/A07.

57 "En un trabajo reciente del magistrado Jean Claude Tron (2012) se hace un amplio recuento de la doctrina, tanto internacional como nacional, en torno al tema del interés jurídico y el interés legítimo. Allí se puede observar que las definiciones y explicaciones sobre estos conceptos son sumamente problemáticas... Uno de los problemas recurrentes consiste en aceptar que el interés jurídico es equivalente a (o implica) un derecho subjetivo, en el sentido técnico o estricto que usó Kelsen, mismo que consiste en tener una acción judicial para reclamar el cumplimiento de un deber. Tener entonces un interés legítimo para que proceda el recurso de amparo equivale a tener un poder jurídico (acción) para poder reclamar ante un juez la imposición de un deber de otra persona. Lo absurdo de esta noción cuando se usa para determinar si procede o no el juicio de amparo es que supone que tal poder jurídico o acción (derecho subjetivo en sentido técnico) es una acción procesal distinta de la acción de amparo, de modo que para tener acceso a una acción procesal (el amparo) se debía comprobar que se tenía otra acción procesal diferente del amparo (Cruz, 2007, pp. 175 y ss.). Este absurdo surgió precisamente por combinar la definición de derecho subjetivo de Ihering con la de Kelsen y particularmente por definir la noción de interés jurídico en términos de de- 
Esta obra forma parte del acervo de la Biblioteca Jurídica Virtual del Instituto de Investigaciones Jurídicas de la UNAM www.juridicas.unam.mx

criterios judiciales asentados por la Suprema Corte de Justicia de la Nación (SCJN), como el que se explicará a continuación.

En una reciente sentencia, ${ }^{58}$ referida al medicamento eculizumab ${ }^{59}$ (Soliris ${ }^{\circledR}$; en adelante "caso Soliris $\left.{ }^{\circledR} "\right)$, la SCJN sostuvo que:

Debe considerarse que la salud es un derecho humano de máximo orden, previsto en el artículo 4o., párrafo cuarto, de la Constitución Política de los Estados Unidos Mexicanos, donde se reconoce el derecho que tiene toda persona a la protección a la salud y se prevé que la ley definirá las bases y modalidades para el acceso a los servicios de salud. ${ }^{60}$

Asimismo, se indica que:

La Ley General de Salud, reglamentaria del artículo 4 de la Constitución Política de los Estados Unidos Mexicanos, define a la salud como el estado de completo bienestar físico, mental y social, y no solamente la ausencia de afecciones o enfermedades (artículo 1 bis); establece el Sistema Nacional de Salud, cuyo objetivo primario es proporcionar servicios de salud a toda la población y mejorar la calidad de los mismos (artículos 5 y 6); define a los servicios de salud como aquellas acciones realizadas en beneficio del individuo y de la sociedad en general, dirigidas a proteger, promover y restaurar la salud de la persona y de la colectividad (artículo 23); clasifica a los servicios de salud en de atención médica, de salud pública y de asistencia social (artículo 24); señala que

recho subjetivo", Cruz Parcero, Juan Antonio, "El concepto de interés legítimo y su relación con los derechos humanos. Observaciones críticas a Ulises Schmill y Carlos de Silva", Isonomía, núm. 39, 2013; "[u]na reciente investigación cuantitativa sobre la justicia constitucional en México en el periodo 2005-2007, demuestra que de los amparos resueltos por los juzgados de distrito, el 69,2\% no llegó al estudio y resolución de fondo, mientras que el restante 30,8\% sí lo hizo, es decir, de cada diez amparos indirectos resueltos por juzgados federales, siete no se resuelven de fondo (se desechan, sobreseen, etcétera) y únicamente tres sí lo hacen (se conceden o niegan). Además, del total de amparos indirectos resueltos $(30.8 \%=100 \%$ ), el $58,8 \%$ se concede y el remanente $31,2 \%$ se niega... Similar situación ocurre en relación con los amparos directos competencia de los tribunales colegiados. Véase la obra de Bustillos, Julio, La justicia constitucional en México. Análisis cuantitativo de las resoluciones judiciales en materia constitucional, México, UNAM, Instituto de Investigaciones Jurídicas, 2009, pp. 21-20 y 39", Montoya Camarena, Ramsés Samael, "Interés legítimo en amparo. Un instrumento procesal «comunitarista»", Revista Mexicana de Derecho Constitucional, núm. 30, 2014, p. 152.

58 Amparo en revisión 932/2014.

59 Soliris ${ }^{\circledR}$ está indicado en adultos y niños para el tratamiento de pacientes con: hemoglobinuria paroxística nocturna (HPN) y síndrome hemolítico urémico atípico (SHUa); puede consultarse en: http://wrwe.ema.europa.eu/docs/es_ES/document_library/EPAR__Product_ Information/human/000791/WC500054208.pdf, p. 2.

60 Ibidem, p. 28. 
Esta obra forma parte del acervo de la Biblioteca Jurídica Virtual del Instituto de Investigaciones Jurídicas de la UNAM www.juridicas.unam. $m x$

la disponibilidad de medicamentos y otros insumos esenciales para la salud constituye un servicio básico de salud (artículo 27, fracción VIII). ${ }^{61}$

Acto seguido, la SCJN aclara que:

Por otra parte, para efectos del derecho a la protección de la salud y los servicios básicos de salud, habrá un Cuadro Básico de Insumos para el primer nivel de atención médica y un Catálogo de Insumos para el segundo y tercer nivel, elaborados por el Consejo de Salubridad General, a los cuales se ajustarán las instituciones públicas del Sistema Nacional de Salud, y en los que se agruparán, caracterizarán y codificarán los insumos para la salud (artículo 28). ${ }^{62}$

Fruto de lo reflexionado, la SCJN manifiesta que:

Todo lo anterior permite afirmar que el de la salud es un derecho humano integral, que se manifiesta de diversas maneras; una de ellas vincula al Estado a procurar la disponibilidad de medicamentos e insumos para la salud, como servicio básico de salud, en cuyo caso las autoridades sanitarias estarán obligadas a procurar esa disponibilidad conforme a las bases y modalidades previstas en la ley, tal como lo indica expresamente la Constitución Federal (artículo 4, párrafo cuarto), y en relación con el caso en estudio, la Ley General de Salud y el Reglamento Interior de la Comisión Interinstitucional del Cuadro Básico y Catálogo de Insumos del Sector Salud, prevén incluir los fármacos que han probado su eficacia, seguridad y eficiencia, en el Cuadro Básico de Insumos o en el Catálogo de Insumos. ${ }^{63}$

Concluye la SCJN que: “...el derecho a la salud significa, entre otras, la obligación del Estado de determinar la lista de medicamentos y otros insumos esenciales para la salud, y garantizar su existencia permanente y disponibilidad a la población que los requiera, en coordinación con las autoridades competentes". ${ }^{64}$

Respecto del sistema mexicano, la SCJN puntualiza que:

Para elaborar y mantener actualizado el Cuadro Básico y Catálogo de Insumos, el Consejo de Salubridad General cuenta con la Comisión Interinstitucional del Cuadro Básico y Catálogo de Insumos del Sector Salud, la cual está integrada por los representantes de la Secretaría de Salud, del Instituto Mexi-

\footnotetext{
61 Idem.

62 Idem.

63 Ibidem, p. 29 (énfasis añadido).

64 Idem.
} 
Esta obra forma parte del acervo de la Biblioteca Jurídica Virtual del Instituto de Investigaciones Jurídicas de la UNAM

cano del Seguro Social, del Instituto de Seguridad y Servicios Sociales de los Trabajadores del Estado, del Sistema Nacional para el Desarrollo Integral de la Familia, de la Secretaría de la Defensa Nacional, de la Secretaría de Marina, de Petróleos Mexicanos y de la Secretaría de Salud del Distrito Federal. ${ }^{65}$

En el mismo sentido, se aclara que "la Comisión tiene por objeto elaborar el Cuadro Básico y el Catálogo de Insumos y mantenerlos actualizados para fomentar, mediante un proceso transparente y eficiente, la calidad y el uso racional de los insumos en las instituciones públicas del Sistema Nacional de Salud, de acuerdo con los avances de la ciencia y la tecnología en medicina". ${ }^{66}$

La SCJN enfatiza que:

...el Estado decide la inclusión de un medicamento en el Cuadro Básico o Catálogo de Insumos del Sector Salud, por conducto de la Comisión Interinstitucional respectiva, no sólo garantiza que el insumo correspondiente ha probado su eficiencia, seguridad y eficacia terapéutica, sino además, a partir de esa determinación, cumple con una de las obligaciones que involucran el derecho a la salud, la de procurar la disponibilidad de medicamentos que curen y alivien las enfermedades que aquejan a las personas, o que mejoren su estado de salud y calidad de vida. ${ }^{67}$

\section{Circunscribiendo la cuestión a decidir, la SCJN resalta que}

...la quejosa pretende acreditar que las autoridades responsables han violentado su derecho al más alto nivel de salud posible, por el hecho de que se han negado a suministrarle el medicamento eculizumab soliris, para tratar el padecimiento de $* * * * * * * * * * * *$, resulta claro que el punto a dilucidar en el juicio constitucional es si el mencionado fármaco es más eficiente, seguro y conveniente para la quejosa. ${ }^{68}$

\section{$\mathrm{Al}$ respecto, se concluye que}

...si las máximas autoridades sanitarias del país no han comprobado la seguridad, eficacia terapéutica y eficiencia del medicamento eculizumab soliris, a través del procedimiento relativo a su inclusión en el cuadro básico del sector salud, no puede concluirse que ese fármaco es seguro, eficaz y eficiente; conforme a la opinión de los expertos, el trabajo que realiza el Comité Específico de Medicamentos de la Comisión Interinstitucional del Cuadro Básico y Catálogo

\footnotetext{
65 Ibidem, p. 32.

66 Ibidem, p. 33 (énfasis añadido).

67 Ibidem, p. 44.

68 Idem.
} 
Esta obra forma parte del acervo de la Biblioteca Jurídica Virtual del Instituto de Investigaciones Jurídicas de la UNAM www.juridicas.unam. $m x$

de Insumos del Sector Salud, de acuerdo a los lineamientos indicados en las normas jurídicas que lo rigen. ${ }^{69}$

\section{Resolviendo la cuestión controvertida, la SCJN indica que}

En consecuencia, como la quejosa no acreditó de manera contundente y plena una mayor seguridad, eficacia terapéutica y eficiencia del medicamento eculizumab soliris, entonces no demostró la violación al derecho del nivel más alto de salud; ya que, incluso, tampoco demostró que el tratamiento que recibe de las autoridades no haya sido seguro, eficaz y eficiente. ${ }^{70}$

\section{A juicio de la SCJN,}

Resulta relevante insistir que la negativa de otorgar el citado medicamento no contraviene el derecho a la salud que está protegido a nivel constitucional, porque si este derecho humano implica para el Estado garantizar la disponibilidad de medicamentos que resulten eficientes, seguros y eficaces; entonces, este derecho se protege de igual manera, en sentido negativo, cuando no se suministra un medicamento que no ha comprobado su eficacia, seguridad y eficiencia, pues de lo contrario se estaría poniendo en riesgo la salud de las personas y, de esa manera, violentado el derecho humano a la salud..$^{71}$

La SCJN recalca que el derecho a la salud:

...es un derecho humano integral que se manifiesta de diversas maneras; una de ellas vincula al Estado a procurar la disponibilidad de medicamentos e insumos para la salud, catalogándolos en el Cuadro Básico de Insumos o en el Catálogo de Insumos. Es decir, el derecho a la salud significa, entre otras, la obligación del Estado de determinar la lista de medicamentos esenciales para la salud, y garantizar su eficiencia, seguridad y eficacia, así como su existencia permanente y disponibilidad a la población que los requiera, ya que como ha quedado señalado, el artículo 4, párrafo cuarto, de la Constitución federal, establece que los servicios de salud se proporcionarán conforme a las bases y modalidades previstas en la ley y, en el caso concreto, como se ha apuntado, la Ley General de Salud y el Reglamento Interior de la Comisión Interinstitucional del Cuadro Básico y Catálogo de Insumos del Sector Salud, ordenan incluir los medicamentos que han probado su eficacia, seguridad y eficiencia, en el Cuadro Básico de Insumos o en el Catálogo de Insumos. ${ }^{72}$

\footnotetext{
69 Ibidem, p. 45 (énfasis añadido).

70 Idem.

71 Ibidem, pp. 45 y 46 (énfasis añadido).

72 Ibidem, p. 46.
} 
Esta obra forma parte del acervo de la Biblioteca Jurídica Virtual del Instituto de Investigaciones Jurídicas de la UNAM

En buenas cuentas, en el caso Soliris ${ }^{\circledR}$, la SGJN sienta las bases de la deferencia judicial ${ }^{73}$ respecto a la labor de Etesa desarrollada por la Comisión Interinstitucional del Cuadro Básico y Catálogo de Insumos del Sector Salud. Es decir, la línea argumental utilizada por la SCJN lleva en forma casi definitiva a que medicamentos no incorporados al Cuadro Básico y Catálogo de Insumos del Sector Salud no puedan ser cubiertos compulsivamente por medio de una orden judicial. En otras palabras, entrega un voto de confianza al órgano administrativo.

Dadas las críticas que se han esbozado en torno al sistema de Etesa de México, ${ }^{74}$ es razonable preguntarse si la posición adoptada por la SCJN es la más razonable, especialmente por el bajo nivel de incorporación de medicamentos en los últimos años y la poca claridad de los criterios aplicados. El alto nivel de deferencia fijado por la SCJN asume, implícitamente, un alto nivel de infalibilidad del sistema de Etesa mexicano, supuesto que, como se indicó, no pareciera darse todavía en la realidad.

Bajo el marco actual fijado por el caso Soliris ${ }^{\circledR}$, se renuncia a la necesaria tensión entre las políticas públicas sobre priorización de gasto en coberturas/reembolso a medicamentos, y la potencial revisión judicial, la que, como se indicó, permite (i) que quienes las diseñen consideren el riesgo de revisión judicial, y tomen los resguardos para minimizarlos (e.g. evitando discriminaciones que sean arbitrarias en coberturas/reembolso a medicamentos, exclusiones injustificadas, entre otros), realizando una labor de profilaxis; (ii) forzar correcciones u optimizaciones a las políticas públicas existentes, incorporando nuevas coberturas/reembolso a medicamentos, y (iii) aumentar el consenso social.

Ahora, desde la perspectiva de la racionalidad económica de la litigación, evidentemente el caso Soliris ${ }^{\circledR}$ lleva a que $P_{l}$ (la probabilidad de ganar el litigio) sea extremadamente baja, por lo que incluso con un $B_{l}$ (beneficio esperado de litigar) alto y $C_{l}$ (costo de litigar) bajo, no pareciera ser razonable judicializar potenciales negativas a incorporación, lo que puede afectar el nivel óptimo de coberturas/reembolso a medicamentos.

73 "...judicial review is concerned with the question about the weight of administrative agencies' determinations in the judicial review process, or in other words, the scope of deference accorded by the court to these determinations... The scope of deference will normally depend on the standard of review applied by the court when assessing the decision of the initial administrative decision-maker". Bernatt, Maciej, Transatlantic Perspective on Fudicial Deference in Administrative Law, Loyola University Chicago, Institute for Consumer Antitrust Studies, documento de trabajo, 2015; Murphy, Richard W., "Judicial Deference, Agency Commitment, and Force of Law", Ohio State Law Fournal, vol. 66, 2005, pp. 1013-1074.

74 Véase II.2 supra. 
Esta obra forma parte del acervo de la Biblioteca Jurídica Virtual del Instituto de Investigaciones Jurídicas de la UNAM

Lo anterior se ve acentuado por los requisitos de procedibilidad del juicio de amparo sobre la existencia de intereses jurídicos o legítimos del quejoso, como se indicó previamente.

De esta forma, el sistema mexicano presenta un doble desincentivo a la litigación sobre coberturas/reembolso a medicamentos, lo que puede incidir en el nivel óptimo de cobertura, ya que no existe la debida tensión entre el sistema de Etesa y la potencial revisión judicial.

\section{CONCLUSIONES}

Con base en lo señalado en este trabajo, se puede concluir que:

1) Es deseable un cierto nivel de tensión entre las políticas públicas sobre priorización del gasto en coberturas/reembolso a medicamentos, y la potencial revisión judicial, que hagan que un sistema dado tienda al nivel óptimo de cobertura.

2) En Brasil, Conitec ha traído consigo avances relevantes en términos de trasparencia y de criterios de Etesa más anticipables, pero su actual diseño todavía no garantiza, completamente, una necesaria autonomía del Ministerio de Salud, por lo que otros factores adicionales a Etesa podrían jugar un rol en las decisiones de incorporación, lo que afecta las coberturas/reembolso a medicamentos (no tendería al nivel óptimo de cobertura).

3) En México, existe un proceso formal de Etesa, pero se encuentra fragmentado y los criterios de decisión no son del todo claros, lo que ha llevado, en general, a un bajo nivel de incorporación, afectando el nivel óptimo de cobertura.

4) En Brasil, la respuesta de la judicialización al sistema de Etesa ha sido extrema, tanto por el número de litigios como por el gran impacto económico para el presupuesto de salud (incluso ordenando la cobertura de medicamentos sin registro sanitario), lo que también puede afectar la meta de lograr un nivel óptimo de cobertura.

5) México presenta un doble desincentivo a la litigación sobre coberturas/reembolso a medicamentos (requisitos de procedibilidad del juicio de amparo y la línea jurisprudencial derivada del caso Soliris $\left.{ }^{\circledR}\right)$, lo que puede incidir en el nivel óptimo de cobertura, ya que no existe la debida tensión entre el sistema de Etesa y la judicialización.

6) Ni el sistema brasileño ni el mexicano pareciera que hayan alcanzado un balance entre la decisión técnica que deriva de Etesa y la legítima revisión judicial, lo que llevaría a resultados sub-óptimos. 
Esta obra forma parte del acervo de la Biblioteca Jurídica Virtual del Instituto de Investigaciones Jurídicas de la UNAM

\section{BIBLIOGRAFÍA}

ADLER, Matthew D., "QALYs and Policy Evaluation: A New Perspective", Yale Fournal of Health Policy, Law, and Ethics, vol. 6, 2006.

BernatT, Maciej, Transatlantic Perspective on Fudicial Deference in Administrative Law, Loyola University Chicago, Institute for Consumer Antitrust Studies, documento de trabajo, 2015.

Carrow, M. M. et al. (eds.), Democracy, Social Values, and Public Policy, Westport, 1998.

Charles River Associates, A Comparative Analysis of the Role and Impact of Health Technology Assessment: 2013 Final Report, 2013, disponible en: http:// wrere.efpia.eu/uploads/documents/cra-comparative-analysis.pdf.

Conitec, Balanço Conitec: 2012-2014, Brasília, Ministério da Saúde, Comissão Nacional de Incorporação de Tecnologias no SUS, 2014.

CRUZ PARCERO, Juan Antonio, "El concepto de interés legítimo y su relación con los derechos humanos. Observaciones críticas a Ulises Schmill y Carlos de Silva", Isonomía, núm. 39, 2013.

European Observatory on Health Systems and Policies, "Ensuring Value for Money in Health Care: The Role of Health Technology Assessment in the European Union", Observatory Studies Series, núm. 11, 2008.

FOTAKI, Marianna, "Why Do Public Policies Fail so Often? Exploring Health Policy-Making as an Imaginary and Symbolic Construction", Organization, vol. 17, núm. 6, 2010.

Funsalud, "Universalidad de los servicios de salud en México", Salud Pública de México, vol. 55, 2013.

García, José Francisco y Verdugo, Sergio, "Activismo judicial en Chile, ¿Hacia el gobierno de los jueces?”, Libertady Desarrollo, 2013.

Gloppen, Siri, "Courts and Social Transformation: An Analytical Framework", en Gargarella, Domingo P. y Roux, T. (eds.), Courts and Social Ttransformation in New Democracies: An Institutional Voice for the Poor?, Aldershot, Ashgate, 2006.

GLOPPEN, Siri, "Litigation as a Strategy to Hold Governments Accountable for Implementing the Right to Health", Health and Human Rights, vol. 10, núm. 2, 2008.

Gloppen, Siri, "Public Interest Litigation, Social Rights and Social Policy", en Dani, Anis A. y HaAn, Arjan de (eds.), Inclusive States: Social Policy and Structural Inequalities, Washington D. G., Word Bank Publications, 2008. 
Esta obra forma parte del acervo de la Biblioteca Jurídica Virtual del Instituto de Investigaciones Jurídicas de la UNAM

GUIMARÃES, Reinaldo, "Technological Incorporation in the Unified Health System (SUS): The Problem and Ensuing Challenges", Ciência E̊ Saúde Coletiva, vol. 19, núm. 12, 2014.

IMS HeALTH, Áreas de oportunidad en el proceso de acceso de medicamentos al paciente con el objetivo de mejorar los resultados de salud de México, 2014, disponible en: http://wrere.amïf.org/descarga.pdf.

Interfarma, Ciclo de Debates Interfarma: Políticas Relacionadas à Saúde, 2014, disponible en: http://gusaude.fgr.br/sites/gusaude.fgr.br/files/Revista_Final.pdf.

Interfarma, "Saúde, 25 Anos Depois", Revista 25 Anos-Interfarma, 2014.

KUHN-BARRIENTOS, Lucy, "Evaluación de tecnologías sanitarias: marco conceptual y perspectiva global", Revista Médica de Chile, vol. 142(S1), 2014.

Liang Wang, Daniel Wei, Courts As Healthcare Policy-Makers: The Problem, the Responses to the Problem and Problems in the Responses, Direito GV Research Paper Series, Legal Studies Paper, núm. 75, 2013.

Manfredi, Christopher P. y MAioni, Antonia, "Courts and Health Policy: Judicial Policy Making and Publicly Funded Health Care in Canada", Fournal of Health Politics, Policy and Law, vol. 27, núm. 2, 2002.

Mcconnelu, Allan, "Policy Success, Policy Failure and Grey Areas In-Between", Fournal of Public Policy, vol. 30, núm. 3, 2010.

Montoya Camarena, Ramsés Samael, "Interés legítimo en amparo. Un instrumento procesal «comunitarista»", Revista Mexicana de Derecho Constitucional, núm. 30, 2014.

Moses, Margaret L., "Beyond Judicial Activism: When the Supreme Court is No Longer A Court", U. Pa. Fournal of Constitutional Lare, vol. 14, núm. 161, 2011.

MurPHY, Richard W., "Judicial Deference, Agency Commitment, and Force of Law", Ohio State Law Fournal, vol. 66, 2005.

OrTiz Hernández, Cristina, El interés legítimo dentro del juicio de amparo, 2015, disponible en: http://wrere.letrasjuridicas.com/Volumenes/32/A07.pdf.

Pearson, Alan et al., "The JBI Model of Evidence-Based Health Care", International Fournal of Evidence-Based Health Care, vol. 3, núm. 8, 2005.

Rechnitzer, Adrián E., "Análisis de la judicialización en la gestión de medicamentos. Caso de estudio del Trastuzumab en el tratamiento del cáncer de mama en Costa Rica", Cuadernos Ibero-Americanos de Direito Sanitário, vol. 3, núm. 2, 2014.

REveIz, Ludovic et al., "Litigios por derecho a la salud en tres países de América Latina: revisión sistemática de la literatura", Revista Panamericana de Salud Pública, vol. 33, núm. 3, 2013. 
Esta obra forma parte del acervo de la Biblioteca Jurídica Virtual del Instituto de Investigaciones Jurídicas de la UNAM

ROACH, Kent, "The Myths of Judicial Activism", Supreme Court Law Review (2nd), vol. 14, 2001.

Shavelt, Steven, "The Fundamental Divergence Between the Private and the Social Motive to Use the Legal System", Fournal of Legal Studies, vol. 24, núm. 4, 1997.

SHAVELL, Steven, "The Level of Litigation: Private Versus Social Optimality of Suit and Settlement", International Review of Law and Economics, vol. 19, 1999.

Silva, Hudson P. et al., "Avanços e desafios da Política Nacional de Gestão de Tecnologias em Saúde”, Revista de Saúde Pública, vol. 46 (supl.), 2012.

Sowell, Thomas, "Judicial Activism Reconsidered", Essays in Public Policy, núm. 13, 1989.

Stephens, Jennifer M. et al., "International Survey of Methods Used in Health Technology Assessment (HTA): Does Practice Meet the Principles Proposed for Good Research?", Comparative Effectiveness Research, núm. 2, 2012.

TOLEnTino S., Marcus, "Sistema único de salud: la experiencia brasileña en la universalización del acceso a la salud", Revista Peruana de Medicina Experimentaly Salud Pública, vol. 26, núm. 2, 2009.

World Health Organization, Making Fair Choices on the Path to Universal Health Coverage, 2014, disponible en: http://apps.who.int/iris/bitstre am/10665/112671/1/9789241507158_eng.pdf?ua=1.

YAmin, Alicia y NorheIM, Ole F., "Taking Equality Seriously: Applying Human Rights Frameworks to Priority Setting in Health", Human Rights Quarterly, vol. 36, núm. 2, 2014. 
Esta obra forma parte del acervo de la Biblioteca Jurídica Virtual del Instituto de Investigaciones Jurídicas de la UNAM

\title{
EL ACUERDO DE ASOGIAGIÓN TRANSPACÍFICO (TPP) A LA LUZ DE LA CONVENGIÓN DE VIENA SOBRE EL DEREGHO DE LOS TRATADOS
}

\author{
Manuel BEGERRA RAMÍREZ*
}

\begin{abstract}
SumARIO: I. Introducción. II. Concepto de tratado. III. La naturaleza expansiva del TPP. IV. La maraña de TLCs y la cláusula de coexistencia. V. El TPP es ambiguo y vago. Los objetivos del TPP, normas que guían la interpretación del Tratado. VI. ¿Es posible la reserva del TPP? VII. La cláusula federal. VIII. Conclusiones. IX. Bibliografia.
\end{abstract}

\section{INTRODUGGIÓN}

El 5 de octubre de 2015, después de varios años de negociación en secreto en diferentes ciudades del Pacífico, doce países participantes en el Acuerdo de Asociación TransPacífico (TPP por sus siglas en inglés: Trans-Pacific Partnership) anunciaron la conclusión de sus negociaciones, y más tarde, el 3 de febrero de 2016, sus participantes firmaron el Tratado en Nueva Zelanda: Australia, Brunei Darussalam, Canadá, Chile, Estados Unidos, Japón, Malasia, México, Nueva Zelanda, Perú, Singapur y Vietnam, países con diferente nivel de desarrollo.

Sin embargo, cuando el TPP se envió para su aprobación a los órganos legislativos internos, la presidencia de Donald Trump retiró a los Estados Unidos de su proceso de aprobación y ratificación. Esto no causó sorpresa, pues había sido una promesa de campaña del ahora nuevo presidente estadounidense. La salida de la potencia de América del Norte hace imposible la continuación del proceso de adopción del Tratado, pues éste requiere para su entrada en vigor que lo ratifiquen seis de los doce Estados, y que además representen por lo menos el $85 \%$ del producto nacional bruto de

* Investigador en el Instituto de Investigaciones Jurídicas de la UNAM. 
Esta obra forma parte del acervo de la Biblioteca Jurídica Virtual del Instituto de Investigaciones Jurídicas de la UNAM

todos los miembros. Se trata de un candado a favor de Estados Unidos y Japón, que juntos significan el 79\% del PIB.

No obstante la "muerte súbita" del TPP, su análisis es importante, pues existe la propuesta de algunos de los Estados miembros para abrirlo nuevamente a la negociación sólo para quitarle el candado, o bien tomar lo negociado para nuevos tratados, o bien la adecuación de la legislación interna a los nuevos estándares negociados en el TPP. Esto último es posible en el caso de la propiedad intelectual que aquí nos interesa.

El TPP es un tratado muy ambicioso, compuesto de un preámbulo y 30 capítulos, su impacto sería fuerte en la economía de los firmantes, como en otro momento lo tuvo el Tratado de Libre Comercio de América del Norte (TLCAN) o el Tratado de Marrakech (Marruecos) mediante el cual se da por terminada la Ronda Uruguay del GATT y se firma el Acuerdo por el que se establece la Organización Mundial del Comercio (OMG).

El TPP es un tratado de carácter multilateral que en materia de propiedad intelectual (PI), a lo que se refiere este trabajo, sigue las tendencias de los que se denominan como TRIPs o ADPIC plus, pues toma como punto de partida ese código-tratado en materia de PI, de gran envergadura, que es el ADPIC, y va más allá en la protección de sus titulares. En efecto, los tratados de libre comercio posteriores al TLCAN y TRIPs, entre ellos con Costa Rica, Marruecos, Chile, Jordania, Singapur, etcétera, contienen normas que aumentan la protección obtenida anteriormente. En ese sentido, tienen una tendencia progresiva.

Pero a fin de cuentas, el TPP es un tratado internacional que está sujeto a las normas del derecho internacional y del derecho interno en su momento de recepción. Por lo tanto, son aplicables a él: la Convención de Viena sobre el Derecho de los Tratados de 1969 y, en el ámbito interno mexicano, las normas de recepción del derecho convencional internacional, es decir, la Constitución Política de los Estados Unidos Mexicanos y dos leyes concretas, que son las leyes de tratados de 1992 y 2005.

En consecuencia, por la trascendencia del tema, en este trabajo hacemos una descripción de las normas internas e internacionales que se aplican al TPP desde su firma hasta la entrada en vigor, haciendo hincapié en la problemática que pudiera presentarse a lo largo del proceso.

\section{GONCEPTO DE TRATADO}

Hablar del TPP como tratado parecería ocioso si no es que su concepto es un punto de partida para determinar la naturaleza jurídica de las partes que lo 
Esta obra forma parte del acervo de la Biblioteca Jurídica Virtual del Instituto de Investigaciones Jurídicas de la UNAM

componen. El TPP es un tratado en los términos que señalan tanto la Convención de Viena de 1969 sobre el Derecho de los Tratados (Viena 69) como la Ley sobre la Celebración de Tratados (LST) de 1992, ${ }^{1}$ que es claro que se inspira en la primera. De acuerdo con Viena 69, se entiende por tratado: "un acuerdo internacional celebrado por escrito entre Estados y regido por el derecho internacional, ya conste en un instrumento único o en dos o más instrumentos conexos y cualquiera que sea su denominación particular" (artículo 2o.).

Esta última definición es más precisa, dado que establece los límites del tratado a "un instrumento único o en dos o más instrumentos conexos..." y "cualquiera que sea su denominación particular". Estas expresiones son importantes, pues desafortunadamente en la práctica de los Estados en algunas ocasiones los gobiernos se escudan en una denominación diferente a la de "tratado" o "convención" para evadir la función de los órganos internos de control a quienes les corresponde la aprobación del tratado; por ejemplo, se habla de "acuerdo político". En este caso, Viena 69 se limita, más que al título o la forma, al contenido.

Otro caso patológico que suele suceder es que fuera de las negociaciones oficiales, y por personas no autorizadas para suscribir el tratado final, se suelen negociar acuerdos que obligan a los políticos (con recursos del Estado, por supuesto) pero no son oficiales, así sucedió en el caso de "las cartas paralelas" que se celebraron en la negociación del TLCAN. ${ }^{2}$

El TPP podemos calificarlo como un tratado "multilateral", por la serie de Estados negociadores, y además no es simple, es complejo y de naturaleza "expansiva".

\section{LA NATURALEZA EXPANSIVA DEL TPP}

El TPP tiene una tendencia - que tienen los tratados TRIPs-plus - expansiva o aglutinadora de otros tratados. Su carácter expansivo se puede ver desde dos perspectivas. La primera es que los negociadores acuerdan que

1 "El Convenio regido por el derecho internacional público, celebrado por escrito entre el gobierno de los Estados Unidos Mexicanos y uno o varios sujetos de derecho internacional público, ya sea que para su aplicación requiera o no la celebración de acuerdos en materias específicas, cualquiera que sea su denominación, mediante el cual los Estados Unidos Mexicanos asumen compromisos".

2 Cruz Miramontes, Rodolfo, "El Tratado de Libre Comercio de América del Norte y las denominadas «cartas paralelas»", Anuario Mexicano de Derecho Internacional, México, vol. I, 2001, pp. 121-164. 
Esta obra forma parte del acervo de la Biblioteca Jurídica Virtual del Instituto de Investigaciones Jurídicas de la UNAM

los miembros del tratado que se negocia deben además adherirse a otros tratados, lo cual, así de simple, aumenta las obligaciones para ellos. Lo que trae por consecuencia que los órganos de recepción interna del tratado (por ejemplo, en el caso de México, el Senado) deban medir con cuidado el impacto de las obligaciones contraídas al aceptar los otros tratados que vienen en "paquete". Así, no sólo los negociadores, sino también el órgano interno de aprobación del tratado, deben contar con un equipo especializado en PI que sepa medir el impacto de la adhesión a otros tratados.

Así, por ejemplo, el TPP establece en su artículo 18.7:

Artículo 18.7: Acuerdos internacionales

1. Cada parte afirma que ha ratificado o se ha adherido a los siguientes acuerdos:

(a) Tratado de Cooperación en materia de Patentes, enmendado el 28 de septiembre de 1979;

(b) Convenio de París, y

(c) Convenio de Berna.

2. Cada parte deberá ratificar o adherirse a cada uno de los siguientes acuerdos, en caso de no haberlo hecho todavía, a la fecha de entrada en vigor de este Acuerdo para dicha parte:

(a) Protocolo de Madrid;

(b) Tratado de Budapest;

(c) Tratado de Singapur [1]; 3

(d) UPOV 1991 [2];

(e) TODA, y

(f) TOIEF. ${ }^{4}$

Notas:

[1] Una parte podrá satisfacer las obligaciones en el párrafo 2(a) y 2(c) ratificando o adhiriéndose ya sea al Protocolo de Madrid o al Tratado de Singapur.

[2] El Anexo 18-A se aplica a este subpárrafo.

Esto obliga a que el análisis del TPP en el Senado deba ampliarse al de los tratados en los cuales nuestro país no sea parte y al impacto económico para los involucrados. Por ejemplo, el caso de México, quien es parte de UPOV 1979 a partir de la suscripción del TLCAN, pero si ratifica el nuevo

3 El 27 de marzo de 2006 fue adoptado por 147 Estados miembros de la OMPI el Tratado de Singapur sobre el Derecho de Marcas, que viene a ser una revisión del Tratado sobre el Derecho de Marcas de 1994.

4 Tratado de Budapest sobre el Reconocimiento Internacional del Depósito de Microorganismos a los fines del Procedimiento en Materia de Patentes, adoptado en 1977. 
Esta obra forma parte del acervo de la Biblioteca Jurídica Virtual del Instituto de Investigaciones Jurídicas de la UNAM

tratado tiene que cambiar de perspectiva y adherirse a UPOV 1991. ¿Cuál es la consecuencia? Pérez Miranda con acierto lo nota en varios de sus trabajos. En principio, el optar por UPOV 1991 significa dar doble protección a las variedades vegetales, ya que permite además su patentamiento, con lo cual se trata de satisfacer lo que "es una demanda de las empresas comercializadoras de plantas (semillas) y animales transgénicos". ${ }^{5}$ Pero además, hay un cambio muy trascendente, pues la adhesión a UPOV 1991 significa "autorizar el patentamiento o protección de los descubrimientos", lo cual “...implicaría autorizar la apropiación por particulares, nacionales o extranjeros, de la mayor parte de la diversidad biológica mexicana" ${ }^{6} \mathrm{Y}$ aún más, confirma la tendencia de que el movimiento de protección de la PI gradualmente rebasa los límites entre invención (que es susceptible de apropiación) y descubrimiento, que no es susceptible de comercialización. ${ }^{7}$

Aparte de ese tipo de expansión, en el TPP hay también otra que es una expansión a áreas no estrictamente de PI, tales como "nombres de dominio", ${ }^{8}$ los proveedores de servicios de Internet, ${ }^{9} \mathrm{o}$ bien la regulación del dominio público. ${ }^{10}$ En ese sentido, tiene el tratado un expansionismo ambicioso a áreas que en otro momento eran manejadas por la sociedad civil. Por ejemplo, hace veinte años era un bastión de la sociedad civil el Internet y su contenido, en una idea de autorregulación. Sin embargo, los gobiernos, concretamente los desarrollados, han empezado a incursionar en el gobierno del Internet y es precisamente el TPP un ejemplo concreto.

\section{LA MARAÑA DE TLCS Y LA CLÁUSULA}

DE GOEXISTENCIA

A esta característica expansiva del TPP es posible agregar otra: la sobrepoblación de tratados de libre comercio celebrados por México, que crea una maraña normativa que hay que seguirle la hebra. En efecto, México tiene un

5 Pérez Miranda, Rafael J., "Temas actuales en materia de propiedad intelectual en las negociaciones internacionales", en Negro, Sandra (coord.), Tendencias actuales en propiedad intelectual, Argentina, AbeledoPerrot-UBA, Facultad de Derecho, 2013, p. 145.

6 Pérez Miranda, Rafael J., Derecho de la propiedad industrial. Patentes, marcas, obtentores de vegetales, informática. Un enfoque de derecho económico, México, Porrúa, 2006, p. 222.

7 En efecto, esta tendencia ya ha sido observada en la doctrina de la PI; véase Bergel, Salvador D., "Los rumbos cambiantes del derecho de la propiedad industrial", en Negro, Sandra (coord.), Tendencias actuales en propiedad intelectual, cit., p. 13.

8 Artículo 18.28 del TPP.

9 Sección J, Proveedores de servicio de Internet, artículos 18.81 en adelante.

10 Artículo 18.15 del TPP. 
Esta obra forma parte del acervo de la Biblioteca Jurídica Virtual del Instituto de Investigaciones Jurídicas de la UNAM www.juridicas.unam.mx

número muy grande de tratados de libre comercio (véase tabla) a partir del TLCAN y el ADPIC que, como sabemos, en materia de PI, desde su vigencia, ha constituido el nuevo estándar mínimo sobre la materia.

\section{TABLA DE TRATADOS DE LIBRE COMERCIO CELEBRADOS POR MÉXICO}

- TLC México-Colombia

- TLC México-Costa Rica

- APP México-Uruguay

- TLG México-Triángulo Norte

- APP México-Paraguay química

- ACE México-Brasil

- TLC México-Nicaragua

- APP México-Paraguay fonográfica

- ALADI México-Ecuador-Paraguay

- TLG México-Perú

- ACE México-Bolivia

- ALADI México-Brasil

- APP México Panamá

- TLG México-Israel

- TLG México-Ghile

- TLC México-Uruguay

- APP México-Uruguay electrónica

- ALADI México-Argentina-Brasil-Cuba-Ecuador-Paraguay-Uruguay

- ALADI México-Ecuador

- TLC México-Países miembros de la UE

- ACE México-Mercosur

- TLG México-Costa Rica-Salvador-Guatemala-Honduras-Nicaragua

- TLG México-AELG

- ALADI México-Paraguay

- ALADI México-Argentina

- ALADI México-Uruguay

- ACE México-Cuba

- APP México-Uruguay fonográfica

- Culturales-ALADI 
Esta obra forma parte del acervo de la Biblioteca Jurídica Virtual del Instituto de Investigaciones Jurídicas de la UNAM

Pero precisamente este universo de tratados es perceptible a tal nivel que la doctrina ha acuñado el concepto de noodle bowl, ya que el fenómeno es muy marcado en Asia e inexcusablemente, toda esa maraña de tratados de libre comercio que existe en los Estados asiáticos puede ser complicada en términos de interpretación y aplicación, ya que las obligaciones se pueden contradecir o sobreponer.

Es por ello que los Estados negociadores del TPP, conscientes de tal situación, adoptaron una fórmula a la que denominan cláusula de coexistencia:

Artículo 1.2: Relación con otros tratados.

1. Reconociendo la intención de las partes del presente Tratado para coexistir con sus tratados internacionales existentes, cada parte confirma, (a) en relación con los tratados internacionales existentes en los que todas las partes son parte, incluyendo el Acuerdo OMC, sus derechos y obligaciones existentes entre ellas; y (b) en relación con los tratados internacionales en los que dicha parte y al menos otra parte sean parte, sus derechos y obligaciones existentes con respecto a la otra parte o partes, según sea el caso.

2. Si una parte considera que una disposición del presente Tratado es incompatible con una disposición de otro tratado en el que ésta y al menos otra parte sean parte, a solicitud de las partes relevantes del otro tratado consultarán con miras a alcanzar una solución mutuamente satisfactoria. Este párrafo es sin perjuicio de los derechos y obligaciones de una parte de conformidad con el Capítulo 28 (Solución de Controversias) (énfasis añadido).

En realidad, la cláusula de coexistencia lo único que hace es remitir al sistema de solución de controversias, pero aquí está el problema: ¿qué normas se pueden aplicar en la interpretación de los tratados? La respuesta es inmediata: Viena 69. En principio, la idea o la obligación para todas las partes en un tratado es que se cumpla de buena fe, además de que el cumplimiento se prefiera al de una norma de derecho interno; ${ }^{11}$ sin embargo, lógicamente pueden existir contradicciones en los tratados, en cuyo caso hay que decidir cuál norma se puede aplicar.

En el sistema jurídico nacional, en caso de contradicción se debe preferir, en primer lugar, la norma constitucional y después la de los tratados.

11 Viena 69 establece: "Observancia de los tratados.

Artículo 26. Pacta sunt servanda. Todo tratado en vigor obliga a las partes y debe ser cumplido por ellas de buena fe.

Artículo 27. El derecho interno y la observancia de los tratados. Una parte no podrá invocar las disposiciones de su derecho interno como justificación del incumplimiento de un tratado. Esta norma se entenderá sin perjuicio de lo dispuesto en el artículo 46”. 
Esta obra forma parte del acervo de la Biblioteca Jurídica Virtual del Instituto de Investigaciones Jurídicas de la UNAM www.juridicas.unam.mx

Si se prefiere, como debe de ser, la aplicación de la norma constitucional en detrimento de la internacional sabemos, de acuerdo con Viena 69, que entrará el Estado en responsabilidad internacional. Por lo tanto, lo ideal es que no exista esa contradicción desde los inicios, es decir desde la negociación del TPP o en el momento de expresar la ratificación del tratado. Por eso es claro que la negociación de un tratado de tal magnitud como el TPP debe ser siempre acompañada de los órganos encargados de la aprobación interna para prever o vigilar que sea constitucional ab initio.

Pero supongamos que haya contradicción entre los tratados y no se solucione por mutuo acuerdo, entonces se tendrá que recurrir a los sistemas de solución de controversias, y en tal caso quien resuelva tendrá que aplicar el sistema de interpretación de los tratados que contiene Viena 69, la cual contiene normas en materia de sucesión de tratados:

Artículo 30. Aplicación de tratados sucesivos concernientes a la misma materia.

1. Sin perjuicio de lo dispuesto en el artículo 103 de la Carta de las Naciones Unidas, ${ }^{12}$ los derechos y las obligaciones de los Estados partes en tratados sucesivos concernientes a la misma materia se determinarán conforme a los párrafos siguientes.

2. Cuando un tratado especifique que está subordinado a un tratado anterior o posterior o que no debe ser considerado incompatible con ese otro tratado prevalecerán las disposiciones de este último.

3. Cuando todas las partes en el tratado anterior sean también partes en el tratado posterior, pero el tratado anterior no quede terminado ni su aplicación suspendida conforme al artículo 59, el tratado anterior se aplicará únicamente en la medida en que sus disposiciones sean compatibles con las del tratado posterior.

4. Cuando las partes en el tratado anterior no sean todas ellas partes en el tratado posterior:

a) en las relaciones entre los Estados partes en ambos tratados se aplicará la norma enunciada en el párrafo 3.

b) en las relaciones entre un Estado que sea parte en ambos tratados y un Estado que sólo lo sea en uno de ellos, los derechos y obligaciones recíprocos se regirán por el tratado en el que los dos Estados sean partes.

5. El párrafo 4 se aplicará sin perjuicio de lo dispuesto en el artículo 41 y no prejuzgará ninguna cuestión de terminación o suspensión de la aplicación de un tratado conforme al artículo 60 ni ninguna cuestión de responsabilidad en que pueda incurrir un Estado por la celebración o aplicación de un tratado

12 El artículo 103 se refiere a la supremacía, en caso de contradicción con otro tratado, de la Carta de San Francisco. 
Esta obra forma parte del acervo de la Biblioteca Jurídica Virtual del Instituto de Investigaciones Jurídicas de la UNAM

cuyas disposiciones sean incompatibles con las obligaciones contraídas con respecto a otro Estado en virtud de otro tratado.

En términos generales, lo que guía la solución de controversias es el principio general del derecho: una norma posterior prevalece frente a la anterior. Ese mismo principio, en esencia, está contenido en el artículo 59, de Viena 69. ${ }^{13}$

Ahora bien, el TPP, ante el mar de tratados de libre comercio que México tiene celebrados, definitivamente puede tener contradicciones. Tomemos, por ejemplo, el caso de las patentes de segundo uso. El artículo 27 del ADPIC establece:

Materia patentable

1. Sin perjuicio de lo dispuesto en los párrafos 2 y 3 , las patentes podrán obtenerse por todas las invenciones, sean de productos o de procedimientos, en todos los campos de la tecnología, siempre que sean nuevas, entrañen una actividad inventiva y sean susceptibles de aplicación industrial...

Como vemos, en ningún caso se refiere a los segundos usos; en cambio, el TPP primero reconoce los elementos clásicos que deben reunir los inventos para ser considerados como patentables, pero además agrega:

\section{Artículo 18.37: Materia patentable}

1. Sujeto a los párrafos 3 y 4, cada parte pondrá a disposición patentes para cualquier invención, ya sea un producto o un proceso, en cualquier campo de la tecnología, siempre que dicha invención sea nueva, conlleve una actividad inventiva y sea susceptible de aplicación industrial.

2. Sujeto a los párrafos 3 y 4 y de conformidad con el párrafo 1, cada parte confirma que las patentes están disponibles para invenciones que se reivindiquen como al menos uno de los siguientes: nuevos usos de un producto conocido, nuevos métodos de usar un producto conocido, o nuevos procesos de uso de un producto

13 "Artículo 59. Terminación de un tratado o suspensión de su aplicación implícitas como consecuencia de la celebración de un tratado posterior.

1. Se considerará que un tratado ha terminado si todas las partes en él, celebran ulteriormente un tratado sobre la misma materia y:

a) se desprende del tratado posterior o consta de otro modo que ha sido intención de las partes que la materia se rija por ese tratado; o

b) las disposiciones del tratado posterior son hasta tal punto incompatibles con las del tratado anterior que los dos tratados no pueden aplicarse simultáneamente.

2. Se considerará que la aplicación del tratado anterior ha quedado únicamente suspendida si se desprende del tratado posterior o consta de otro modo que tal ha sido la intención de las partes". 
Esta obra forma parte del acervo de la Biblioteca Jurídica Virtual del Instituto de Investigaciones Jurídicas de la UNAM www.juridicas.unam. $m x$

conocido. Una parte puede limitar dichos procesos a aquellos que no reivindiquen el uso del producto como tal (énfasis añadido).

Pero además agrega inmediatamente lo que se ha denominado "cláusula moral", que permite excluir en algunos casos la patentabilidad:

3. Una parte puede excluir la patentabilidad de invenciones de las cuales la prevención de la explotación en su territorio sea necesaria para proteger el orden público o la moralidad, incluyendo la protección de la vida o la salud humana, animal o vegetal, o para evitar un perjuicio serio al medio ambiente, siempre que dicha exclusión no se lleve a cabo meramente porque su explotación esté prohibida por la ley de dicha parte. Una parte puede excluir también de patentabilidad:

(a) métodos de diagnóstico, terapéuticos o quirúrgicos para el tratamiento de humanos o animales;

(b) animales que no sean microorganismos, y procesos esencialmente biológicos para la producción de plantas o animales, que no sean procesos no biológicos o microbiológicos.

4. Una parte también puede excluir de patentabilidad plantas que no sean microorganismos. Sin embargo, de conformidad con el párrafo 1 y con sujeción al párrafo 3 , cada parte confirma que las patentes estarán disponibles al menos para invenciones derivadas de plantas (énfasis añadido).

Como vemos, las partes novedosas en el TPP son relativas a las patentes de segundo uso y "las patentes para invenciones derivadas de plantas".

En ese sentido, el estándar que inclusive adopta nuestra ley se debe modificar. En efecto, la Ley de Propiedad Industrial mexicana establece:

Artículo 19. No se considerarán invenciones para los efectos de esta Ley:

I. Los principios teóricos o científicos;

II. Los descubrimientos que consistan en dar a conocer o revelar algo que ya existía en la naturaleza, aun cuando anteriormente fuera desconocido para el hombre;

III. Los esquemas, planes, reglas y métodos para realizar actos mentales, juegos o negocios y los métodos matemáticos;

IV. Los programas de computación;

V. Las formas de presentación de información;

VI. Las creaciones estéticas y las obras artísticas o literarias;

VII. Los métodos de tratamiento quirúrgico, terapéutico o de diagnóstico aplicables al cuerpo humano y los relativos a animales, y

VIII. La yuxtaposición de invenciones conocidas o mezclas de productos conocidos, su variación de uso, de forma, de dimensiones o de materiales, salvo que en realidad se trate de su combinación o fusión de tal manera que 
Esta obra forma parte del acervo de la Biblioteca Jurídica Virtual del Instituto de Investigaciones Jurídicas de la UNAM

no puedan funcionar separadamente o que las cualidades o funciones características de las mismas sean modificadas para obtener un resultado industrial o un uso no obvio para un técnico en la materia.

Como se ve, tanto para el TLCAN como para la legislación mexicana no son patentables los segundos usos, pues carecen de los requisitos de patentabilidad: novedad y actividad inventiva, ${ }^{14}$ además de que, en algunos casos, se pueden considerar como descubrimientos y sabemos bien que no son patentables, caen en el dominio público puesto que son la base del desarrollo científico. Aparte del gran impacto económico que significa para los bolsillos de los consumidores el extender las patentes.

Pues bien, no obstante las muchas razones técnicas y económicas (desde la perspectiva de los consumidores y de la salud pública) que se pueden dar para no patentar los segundos usos, el TPP da un giro de 180 grados. En realidad, ésta es una muestra de que con la segunda generación de derechos de la PI, ligados a los tratados de libre comercio, de manera creciente se "invade" el campo del conocimiento científico para entrar al campo del conocimiento de la propiedad intelectual que, como sabemos, no es libre y está sujeto al comercio.

Pero volviendo a nuestro tema, la existencia de dos tratados con contenido contrapuesto: el TLCAN con la ley interna (la Ley de Propiedad Industrial) vs. el TPP, vigentes ambos en el mismo espacio geográfico, ¿cuál de los dos prevalece? De acuerdo con la cláusula de coexistencia y de interpretación, a la luz de Viena 69, prevalecerían las normas del TPP.

Sin embargo, el asunto no queda ahí, pues la adopción de las patentes de segundo uso tiene un impacto a la salud (simplemente porque su acceso se complica o se imposibilita para la población de bajos recursos económicos) y, en consecuencia, una afectación del derecho humano a la salud, con lo cual el análisis jurídico tiene una perspectiva diferente, pues tiene que ver, en el caso de México, con el mismo control de convencionalidad que hay que hacer de conformidad con los artículos 1o., 15 y 133 de la Constitución. Simplemente veamos que el artículo 15 establece:

Artículo 15. No se autoriza la celebración de tratados para la extradición de reos políticos, ni para la de aquellos delincuentes del orden común que hayan tenido en el país donde cometieron el delito, la condición de esclavos; ni de

14 Minutti Pérez, Karla Fiorella, Patentes de segundo uso en el sector farmacéutico, ¿exclusividad justificada o abuso del derecho de patentes?', México, UNAM, Facultad de Derecho, tesis de especialidad en derecho de la propiedad intelectual, 2015. 
Esta obra forma parte del acervo de la Biblioteca Jurídica Virtual del Instituto de Investigaciones Jurídicas de la UNAM

convenios o tratados en virtud de los que se alteren los derechos humanos reconocidos por esta Constitución y en los tratados internacionales de los que el Estado mexicano sea parte (énfasis añadido).

En efecto, México, junto a más de cien Estados, es parte ${ }^{15}$ del Pacto Internacional de Derechos Económicos, Sociales y Culturales (PIDESC), ${ }^{16}$ que consagra el acceso a los medicamentos como sección del derecho a la salud; ${ }^{17}$ capítulo indudable de los derechos humanos, es una positivización y codificación del derecho humano a la salud contenido en la Declaración Universal de los Derechos Humanos de 1948.18 Precisamente, la doctrina reconoce que el derecho al acceso de los medicamentos es un derecho humano que se desprende del derecho a la salud. ${ }^{19}$

Así, el artículo 12 del PIDESC establece:

1. Los Estados partes en el presente Pacto reconocen el derecho de toda persona al disfrute del más alto nivel posible de salud física y mental.

2. Entre las medidas que deberán adoptar los Estados partes en el Pacto a fin de asegurar la plena efectividad de este derecho, figurarán las necesarias para:

a) La reducción de la mortinatalidad y de la mortalidad infantil, y el sano desarrollo de los niños.

b) El mejoramiento en todos sus aspectos de la higiene del trabajo y del medio ambiente.

15 México se adhirió el 23 de marzo de 1981; fue publicado en el Diario Oficial de la Federación del 12 de mayo de 1981 .

16 Adoptado y abierto a la firma, ratificación y adhesión por la Asamblea General en su resolución 2200 A (XXI), del 16 de diciembre de 1966. Entró en vigor el 3 de enero de 1976.

17 Hestermeyer, Holger, Human Rights and the WTO. The Case of Patents and Access to Medicine, Reino Unido, Oxford University Press, 2007, p. 102.

$18 \mathrm{El}$ artículo 3o. de la Declaración establece: "Todo individuo tiene derecho a la vida, a la libertad y a la seguridad de su persona", y más adelante, el artículo 25 de la Declaración establece:

"1. Toda persona tiene derecho a un nivel de vida adecuado que le asegure, así como a su familia, la salud y el bienestar, y en especial la alimentación, el vestido, la vivienda, la asistencia médica y los servicios sociales necesarios; tiene asimismo derecho a los seguros en caso de desempleo, enfermedad, invalidez, viudez, vejez u otros casos de pérdida de sus medios de subsistencia por circunstancias independientes de su voluntad.

2. La maternidad y la infancia tienen derecho a cuidados y asistencia especiales. Todos los niños, nacidos de matrimonio o fuera de matrimonio, tienen derecho a igual protección social".

19 Bergel, Salvador Darío, "El acceso a los medicamentos como derecho humano: reconocimiento y limitaciones", en Becerra Ramírez, Manuel (coord.), Propiedad intelectual y farmacéutica. Hacia una política de Estado, México, ANAFAM-UNAM, Instituto de Investigaciones Jurídicas, 2013, pp. 80-84. 
Esta obra forma parte del acervo de la Biblioteca Jurídica Virtual del Instituto de Investigaciones Jurídicas de la UNAM

c) La prevención y el tratamiento de las enfermedades epidémicas, endémicas, profesionales y de otra índole, y la lucha contra ellas.

d) La creación de condiciones que aseguren a todos asistencia médica y servicios médicos en caso de enfermedad.

Independientemente de lo anterior, el aceptar las patentes de segundo uso violaría también el principio de progresividad que está reconocido en el artículo 1o. de la Constitución Política de los Estados Unidos Mescianos, ya que haría nugatorio un derecho antes reconocido. También se podría alegar que los derechos de autor y del inventor son derechos humanos. Si ello es así, entonces nos encontraríamos ante una colisión entre dos derechos humanos, lo cual se resolvería con la aplicación del principio pro homine.

La recepción en derecho interno con solidez y claridad del derecho internacional de los derechos humanos es un dique al abuso del derecho de la propiedad intelectual, que avanza en protección sin tomar en cuenta el impacto a la población, en este caso a la salud.

Ahora bien, surge la cuestión de si procede el control de convencionalidad. Recordemos que el control de convencionalidad es una obligación para los poderes de la Federación y no puede ser de otra manera, pues el incumplimiento de cualquier órgano del Estado puede causar una responsabilidad internacional.

\section{EL TPP ES AMBiguO Y VAGO. LOS OBJETIVOS DEL TPP, NORMAS QUE GUÍAN LA INTERPRETACIÓN DEL TRATADO}

Una de las características del TPP es que está redactado con un lenguaje ambiguo y vago, lo cual hay que tener en cuenta desde su análisis en el órgano de control interno encargado de su aprobación (el Senado en México), y en caso de que sea ratificado, en el momento de su aplicación y su reglamentación por las leyes que sean necesarias. Ejemplo de la vaguedad la tenemos en muchas de sus disposiciones, como:

\section{Artículo 18.17: Solicitud de cooperación}

Las actividades e iniciativas en materia de cooperación llevadas a cabo en términos del presente capítulo estarán sujetas a la disponibilidad de recursos, y se realizarán previa solicitud. Asimismo, se sujetarán a los términos y condiciones acordados mutuamente por las partes interesadas.

Aquí la vaguedad estriba en dejar el cumplimiento de una serie de disposiciones en materia de cooperación a la "disponibilidad de recursos"; al 
Esta obra forma parte del acervo de la Biblioteca Jurídica Virtual del Instituto de Investigaciones Jurídicas de la UNAM

fin de cuentas, la cooperación internacional queda sujeta a la voluntad de los Estados.

Otro ejemplo y grave de la vaguedad del TPP es cuando se refiere a esa parte nueva que alude a la extensión del término de duración de las patentes. En efecto, el artículo 18.46 está lleno de vaguedades: ${ }^{20}$ "retrasos irrazonables en el otorgamiento de patentes", "retrasos que no sean directamente atribuibles a la autoridad otorgante".

Además, Pedro Roffe pone el acento en cierta desventaja que tiene México respecto a otros dos países latinoamericanos miembros del TPP, Chile y Perú:

Cabe mencionar que con respecto a la extensión de la duración de las patentes por atrasos administrativos, el texto final del TPP no innova hacia un modo maximalista como se desprendía de la posición original de EE. UU. En este sentido, los países de la región, particularmente Chile y Perú, defendieron exitosamente lo ya previsto en sus respectivos TLC con el país norteamericano. El cambio, sin embargo, sí puede considerarse más importante para

20 Artículo 18.46: Ajuste de la duración de la patente por retrasos en la oficina de patentes

1. Cada parte hará todo lo posible para procesar las solicitudes de patentes de una manera eficiente y puntual, a fin de evitar retrasos innecesarios o irrazonables.

2. Una parte podrá disponer procedimientos para que los solicitantes de patentes soliciten la aceleración del examen de sus solicitudes de patente.

3. Si se dan retrasos irrazonables en el otorgamiento de patentes por una parte, esa parte dispondrá los medios para que, a petición del propietario de la patente, se deba ajustar el periodo de la patente para compensar dichos retrasos.

4. Para los efectos de este artículo, un retraso irrazonable incluye, al menos, un retraso en el otorgamiento de una patente de más de cinco años desde la fecha de presentación de la solicitud en el territorio de la parte, o tres años después de que se haya hecho la solicitud de examen, lo que ocurra en fecha más tardía. Una parte puede excluir de la determinación de dichos retrasos, los periodos de tiempo que no ocurran durante la tramitación o el examen de la solicitud de la patente por la autoridad otorgante; los periodos de tiempo que no sean directamente atribuibles a la autoridad otorgante; así como los periodos que sean atribuibles al solicitante de la patente.

El anexo 18-D se aplica a este párrafo.

Para los efectos de este párrafo, una parte podrá interpretar que la tramitación significa la tramitación administrativa inicial y la tramitación administrativa al momento del otorgamiento.

Una parte podrá tratar los "retrasos que no sean directamente atribuibles a la autoridad otorgante" como retrasos que están fuera de la dirección o el control de la autoridad otorgante.

Sin perjuicio del artículo 18.10 (aplicación del capítulo a materia existente y actos previos), este artículo aplicará a todas las solicitudes de patentes presentadas después de la fecha de entrada en vigor de este Acuerdo para una parte, o la fecha de dos años posterior a la firma de este Acuerdo, lo que ocurra en fecha más tardía. 
Esta obra forma parte del acervo de la Biblioteca Jurídica Virtual del Instituto de Investigaciones Jurídicas de la UNAM

México, puesto que el TLCAN no reguló estas materias con el nivel de detalle y exigencia que se encuentra en los acuerdos comerciales de Chile y Perú. ${ }^{21}$

Entonces, aquí nos encontramos con la necesidad de aplicar las normas de interpretación de los tratados contenidas en Viena 69.

En efecto, los artículos 31 y 32 de Viena 69 contienen reglas concretas de interpretación:

1. Un tratado deberá interpretarse de buena fe conforme al sentido corriente que haya de atribuirse a los términos del tratado en el contexto de éstos y teniendo en cuenta su objeto y fin.

2. Para los efectos de la interpretación de un tratado, el contexto comprenderá, además del texto, incluidos su preámbulo y anexos:

a) todo acuerdo que se refiera al tratado y haya sido concertado entre todas las partes con motivo de la celebración del tratado:

b) todo instrumento formulado por una o más partes con motivo de la celebración del tratado y aceptado por las demás como instrumento referente al tratado;

3. Juntamente con el contexto, habrá de tenerse en cuenta:

a) todo acuerdo ulterior entre las partes acerca de la interpretación del tratado o de la aplicación de sus disposiciones;

b) toda práctica ulteriormente seguida en la aplicación del tratado por la cual conste el acuerdo de las partes acerca de la interpretación del tratado;

c) toda forma pertinente de derecho internacional aplicable en las relaciones entre las partes.

4. Se dará a un término un sentido especial si consta que tal fue la intención de las partes.

Además hay medios de interpretación complementarios:

En particular a los trabajos preparatorios del tratado y a las circunstancias de su celebración, para confirmar el sentido resultante de la aplicación del artículo 31, o para determinar el sentido cuando la interpretación dada de conformidad con el artículo 31:

a) deje ambiguo u oscuro el sentido; o

b) conduzca a un resultado manifiestamente absurdo o irrazonable.

El caso es que además de su opacidad en la negociación del TPP, pues como sabemos se negoció en forma secreta, al parecer no existen "trabajos preparatorios", que es un elemento fundamental en la interpretación de todo tratado. Lo cual acentúa la opacidad.

21 Roffe, Pedro et al., "El TPP y la propiedad intelectual: viejos conocidos y nuevos desafíos", Intellectual Property, vol. 16, núm. 8, 29 de octubre de 2015. 
Esta obra forma parte del acervo de la Biblioteca Jurídica Virtual del Instituto de Investigaciones Jurídicas de la UNAM

Ahora bien, como se dijo anteriormente, "un tratado deberá interpretarse de buena fe conforme al sentido corriente que haya de atribuirse a los términos del tratado en el contexto de éstos y teniendo en cuenta su objeto y fin". La interpretación de buena fe es un principio general del derecho y por otra parte hay que tomar como punto de referencia el objeto y fin del tratado. Esto es muy importante, pues como veremos en este trabajo, también se toma como punto de partida para ver si proceden o no las reservas o cuáles son los límites de las reservas, en caso de que procedan.

Entonces, veámos si el TPP tiene objetivos concretos:

Artículo 18.2: Objetivos

La protección y observancia de los derechos de propiedad intelectual deberán contribuir al fomento de la innovación tecnológica, y a la transferencia y difusión de tecnología, para el beneficio mutuo de productores y usuarios del conocimiento tecnológico, y en forma tal que contribuya al bienestar social y económico, así como a un equilibrio de derechos y obligaciones.

Y principios:

Artículo 18.3: Principios

1. Una parte podrá, al redactar o reformar sus leyes y reglamentaciones, adoptar las medidas necesarias para proteger la salud pública y la nutrición de la población, así como promover el interés público en sectores que sean de vital importancia para su desarrollo socioeconómico y tecnológico, siempre que dichas medidas sean acordes con las disposiciones de este capítulo.

2. Se podrán requerir medidas pertinentes, a efecto de prevenir el abuso de los derechos de propiedad intelectual por parte de los titulares de derechos, o el uso de prácticas que de manera injustificada restrinjan el comercio o afecten de manera adversa el intercambio internacional de tecnología, siempre que sean acordes con las disposiciones de este capítulo.

En consecuencia, la vaguedad del TPP debe afrontarse con las reglas de Viena 69 que a su vez remiten al mismo tratado, que proclama, entre otros, "...bienestar social y económico, así como a un equilibrio de derechos y obligaciones", “...proteger la salud pública y la nutrición de la población” y "prevenir el abuso de los derechos de la propiedad intelectual". Lo cual permitiría, en dado caso, al legislador hacer un esfuerzo para adoptar una legislación no sólo protectora de las empresas trasnacionales, sino también de la salud pública. Pero ¿hasta dónde puede llegar esa libertad? No creemos que muy lejos, pues al final el artículo 18.3 ataja: "... siempre que sean acordes con las disposiciones de este capítulo". 
Esta obra forma parte del acervo de la Biblioteca Jurídica Virtual del Instituto de Investigaciones Jurídicas de la UNAM

Desde esa perspectiva, con miras a que el TPP sirva como un real motor de desarrollo tecnológico y garante de la salud pública, el Estado debe recurrir a otras figuras que tiene el mismo derecho de los tratados, como las reservas y la cláusula federal.

\section{VI. ¿ES POSIBLE LA RESERVA DEL TPP?}

Algo que hasta el momento no se ha explorado en el TPP es la interposición de reservas. El artículo 2.d) de Viena 69 entiende por "reserva": "una declaración unilateral, cualquiera que sea su enunciado o denominación, hecha por un Estado al firmar, ratificar, aceptar o aprobar un tratado o al adherirse a él, con objeto de excluir o modificar los efectos jurídicos de ciertas disposiciones del tratado en su aplicación a ese Estado". Como sabemos, el objetivo de las reservas en los tratados multilaterales es permitir que el Estado pueda ser parte de un tratado evadiendo los aspectos de éste que puedan violar su régimen interno, o bien haciendo una interpretación de alguna disposición del tratado en los términos que el Estado lo entiende.

La posibilidad de que un tratado pueda ser sujeto de reservas, en principio, depende del texto mismo del tratado, si lo permite o no, y en dado caso qué es posible reservase y qué no. Si el tratado es omiso, como es el caso del TPP, entonces se aplican las reglas de Viena 69 sobre reservas. Hay que mencionar que el tiempo u oportunidad para formular una reserva es el "momento de firmar, ratificar, aceptar o aprobar un tratado o de adherirse al mismo".

En el caso concreto de México, después de la aprobación del Senado o de la ratificación que haga el Poder Ejecutivo se podría formular una reserva. Las reglas de las reservas están contenidas en Viena 69, pero una regla básica que también tiene naturaleza consuetudinaria es la concordancia de la reserva con el objeto y fin del tratado. Como lo determinó la Corte Internacional de Justicia: "Es, pues, la compatibilidad de la reserva con el objeto y fin de la Convención el criterio que debe determinar la actitud del Estado que hace la reserva y la del Estado que objeta a ella". ${ }^{22}$

Si el TPP no prohíbe las reservas, en un ejercicio soberano, el Estado puede formular reservas respecto de muchas disposiciones que claramente violan los derechos humanos, o bien porque no tienen claridad, por lo cual debe interponerse un criterio de interpretación. Siempre viendo el interés nacional.

22 Corte Internacional de Justicia, Reserva a la Convención para la Prevención y la Sanción del Delito de Genocidio, opinión consultiva del 28 de mayo de 1951. 
Esta obra forma parte del acervo de la Biblioteca Jurídica Virtual del Instituto de Investigaciones Jurídicas de la UNAM

\section{LA CLÁUSULA FEDERAL}

Viena 69 prevé la adopción de tratados por los Estados federales; en aras de respetar la soberanía de los estados federados permite que en el momento de la negociación se pueda interponer la cláusula federal, que establecería que el Estado reserva su aprobación a los estados federados. En efecto, el artículo 29 de Viena 69 establece: "Ámbito territorial de los tratados. Un tratado será obligatorio para cada una de las partes por lo que respecta a la totalidad de su territorio, salvo que una intención diferente se desprenda de él o conste de otro modo".

Esta facultad que tienen los Estados federales no ha sido explorada por los negociadores mexicanos, no obstante que hay en la doctrina algunas críticas $^{23}$ que hablan de que vía el TLCAN hay una invasión de la soberanía de los estados que componen la República mexicana, dado que la Federación compromete a las entidades federativas en competencias que les corresponden a ellas.

\section{CONCLUSIONES}

El TPP es un nuevo instrumento normativo de una gran trascendencia dado el impacto que traerá, si se ratifica, a la economía y al marco jurídico interno de los Estados partes. Es por eso que proponemos aquí un ejercicio de aplicación del derecho de los tratados. Lo cual deberá hacerse por parte del órgano de control interno, que en el caso mexicano es el Senado.

En ese sentido, hasta que no se ratifique por parte del Ejecutivo Federal el tratado, técnicamente está sujeto a análisis y adecuación a la Constitución Política de los Estados Unidos Mexicanos y, a final de cuentas, a las necesidades de desarrollo del país y bienestar de su población. Dada su importancia y sus características (su carácter expansivo tan amplio y que toca áreas inéditas para un tratado en materia de PI y de su vaguedad) es aconsejable un análisis cuidadoso y, en dado caso, la utilización de ciertas figuras o herramientas que permite el derecho internacional de los tratados, como las reservas o la cláusula federal.

23 Muriá Tuñón, Arnau, "Crítica a las resoluciones de la Corte con respecto a la jerarquía constitucional de los tratados internacionales", Anuario Mexicano de Derecho Internacional, México, vol. VIII, 2008, pp. 553-585. 
Esta obra forma parte del acervo de la Biblioteca Jurídica Virtual del Instituto de Investigaciones Jurídicas de la UNAM

\section{BIBLIOGRAFÍA}

Bergel, Salvador Darío, "El acceso a los medicamentos como derecho humano: reconocimiento y limitaciones", en BECERRA RAMíREz, Manuel (coord.), Propiedad intelectual y farmacéutica. Hacia una política de Estado, México, ANAFAM-UNAM, Instituto de Investigaciones Jurídicas, 2013.

Bergel, Salvador Darío, "Los rumbos cambiantes del derecho de la propiedad industrial", en Negro, Sandra (coord.), Tendencias actuales en propiedad intelectual, Argentina, AbeledoPerrot-UBA, Facultad de Derecho, 2013.

Cruz Miramontes, Rodolfo, "El Tratado de Libre Comercio de América del Norte y las denominadas "cartas paralelas»", Anuario Mexicano de Derecho Internacional, México, vol. I, 2001.

Hestermeyer, Holger, Human Rights and the WTO. The Case of Patents and Access to Medicine, Reino Unido, Oxford University Press, 2007.

Minutti PéRez, Karla Fiorella, Patentes de segundo uso en el sector farmacéutico, ¿exclusividad justificada o abuso del derecho de patentes?, México, UNAM, Facultad de Derecho, tesis de especialidad en derecho de la propiedad intelectual, 2015.

Murí́ Tuñón, Arnau, "Crítica a las resoluciones de la Corte con respecto a la jerarquía constitucional de los tratados internacionales", Anuario Mexicano de Derecho Internacional, México, vol. VIII, 2008.

Negro, Sandra (coord.), Tendencias actuales en propiedad intelectual, Argentina, AbeledoPerrot-UBA, Facultad de Derecho, 2013.

PÉRez Miranda, Rafael J., Derecho de la propiedad industrial. Patentes, marcas, obtentores de vegetales, informática. Un enfoque de derecho económico, México, Porrúa, 2006.

PÉREZ MirandA, Rafael J., "Temas actuales en materia de propiedad intelectual en las negociaciones internacionales", en NEGRO, Sandra (coord.), Tendencias actuales en propiedad intelectual, Argentina, Abeledo Perrot-UBA, Facultad de Derecho, 2013.

ROFFE, Pedro et al., "El TPP y la propiedad intelectual: viejos conocidos y nuevos desafios", Intellectual Property, vol. 16, núm. 8, 29 de octubre de 2015. 
Esta obra forma parte del acervo de la Biblioteca Jurídica Virtual del Instituto de Investigaciones Jurídicas de la UNAM

\title{
EL USO ESTRATÉGICO DE LAS PATENTES SEGUNDARIAS Y OTROS INSTRUMENTOS EN EL SEGTOR FARMACÉUTICO: LA EXPERIENCIA MEXICANA
}

\author{
Hedwig LINDNER LÓPEZ* \\ Manuel MORANTE SORIA**
}

\begin{abstract}
SumARIO: I. Introducción. II. Estrategias dilatorias. III. Abuso de las disposiciones normativas de tratados sobre protección de datos "clinicos". IV. Acuerdo TransPacifico de Asociación. V. Conclusiones. VI. Bibliografia.
\end{abstract}

\section{INTRODUCGIÓN}

Durante los últimos veinte años el mercado de los productos farmacéuticos ha crecido considerablemente debido a una serie de cambios legislativos y regulatorios que han permitido que la industria farmacéutica trasnacional se desarrolle vertiginosamente en nuestro país. Lamentablemente, esto ha implicado también la aparición de obstáculos reales y presentes al ingreso de medicamentos genéricos al mercado mexicano. Lo anterior ha traído como consecuencia que el acceso sustancial a medicamentos seguros y eficaces no sea una realidad para un buen porcentaje de la población. Las patentes secundarias, junto con otras estrategias y mecanismos, impiden el florecimiento de una competencia real en el mercado farmacéutico y evitan que los pacientes tengan acceso a medicamentos esenciales para su salud, dignidad y bienestar.

La Ley de la Propiedad Industrial no hace una distinción expresa entre patentes primarias y secundarias. Estos términos son comúnmente usados por aquellas personas que se dedican a la materia, particularmente en el campo de las patentes farmacéuticas.

* Profesora en la Facultad de Derecho de la Universidad Panamericana.

** Profesor en la Facultad de Derecho de la Universidad Panamericana.

Los autores agradecen a John Murphy su valioso apoyo durante la investigación. 
Esta obra forma parte del acervo de la Biblioteca Jurídica Virtual del Instituto de Investigaciones Jurídicas de la UNAM

Generalmente, el uso del término "patente primaria" hace referencia a las patentes otorgadas a los nuevos ingredientes o principios activos (nuevas moléculas), y el término "patente secundaria" se refiere a patentes otorgadas a variantes de la materia protegida en "patentes primarias" o a materia existente, como diversas formas de los principios activos ya patentados (diferentes sales, ésteres, éteres, polimorfos, metabolitos, isómeros, etcétera); nuevos usos; regímenes de dosificación o tratamiento; diversas composiciones farmacéuticas, caracterizadas, por ejemplo, por la forma farmacéutica, la vía de administración, los excipientes, la cantidad de principio activo, la forma de liberación (inmediata, prolongada, controlada, etcétera); cambios en los procesos de fabricación, síntesis o purificación, entre otras. ${ }^{1}$

Cada vez son más las patentes secundarias que se tramitan para proteger una misma molécula o principio activo. Si bien, en teoría, su existencia no debería obstaculizar la concurrencia de competidores genéricos (y biocomparables) una vez que la patente primaria ha caducado, la complejidad de la normativa involucrada, acompañada de las estrategias litigiosas de las compañías farmacéuticas trasnacionales, ${ }^{2}$ favorece un ambiente de incertidumbre jurídica que las beneficia, al retrasar el ingreso de medicamentos genéricos al mercado.

Este fenómeno sin duda trasciende al acceso a los insumos para la salud a los que la población tiene derecho por mandato constitucional. ${ }^{3}$ En países como el nuestro, donde el sistema de salud no ha logrado la universalidad, la adecuada y armónica regulación, acompañada de políticas públicas consistentes con la realidad socioeconómica y perfil epidemiológico y demográfico de la población mexicana, constituye un imperativo impostergable.

\section{El sistema de salud de México}

La población en México es de más de 121 millones de habitantes, ${ }^{4}$ de los cuáles el $78.5 \%$ cuenta con algún tipo de cobertura sanitaria. ${ }^{5} \mathrm{Si}$ bien

1 Kapczynski, Amy et al., "Polymorphs and Prodrugs and Salts (Oh My!): An Empirical Analysis of «Secondary» Pharmaceutical Patents”, PloS ONE, núm 7, diciembre de 2012, p. 1.

2 En lo sucesivo se les identificará como "compañías innovadoras", como generalmente se les distingue.

3 Constitución Política de los Estados Unidos Mexicanos, artículo 4o., párrafo 4.

4 Instituto Nacional de Estadística y Geografía, "Proyecciones de la población total a mitad de año según sexo y grandes grupos de edad", Anuario estadístico y geográfico de los Estados Unidos Mexicanos 2015, México, INEGI, serie anual de 2010 a 2016, cuadro 2.1, 2015.

5 Organización para la Cooperación y el Desarrollo Económicos, OECD Reviewes of Health Systems: Mexico, París, OCDE, 2016, p. 55. 
Esta obra forma parte del acervo de la Biblioteca Jurídica Virtual del Instituto de Investigaciones Jurídicas de la UNAM

esta cifra supone un incremento considerable, comparada con la de 2005, en el que solamente la mitad de la población estaba asegurada, ${ }^{6}$ las diferentes coberturas siguen siendo insuficientes, tanto en el tipo de insumos que comprenden como en su cantidad, que frecuentemente reporta condiciones de escasez.

Existen numerosos obstáculos para superar tal reto: altas tasas de pobreza extrema $(9.5 \%)^{7}$ y de trabajo informal $(57.5 \%),{ }^{8}$ marcada desigualdad de los ingresos, ${ }^{9}$ disparidades regionales en el desarrollo económico, ${ }^{10}$ acceso desigual a los servicios públicos, ${ }^{11}$ y una población con un ritmo rápido de envejecimiento. ${ }^{12}$

Mientras que la inversión pública en salud ha aumentado del $2.4 \%$ al $3.2 \%$ del producto interno bruto (PIB) entre 2003 y 2013, ${ }^{13}$ México aún gasta un pequeña porción de su PIB en servicios sanitarios financiados públicamente comparado con cualquier otro país de la Organización de Cooperación y Desarrollo Económicos, ${ }^{14}$ y no hay claridad si los aumentos modestos en el gasto durante la última década mejoraron en general la calidad del cuidado de la salud. ${ }^{15}$

Ante un escenario así, preocupa el recorte presupuestal a la Secretaría de Salud. En la propuesta de Presupuesto de Egresos de la Federación para 2016 se incluía una posible disminución del 6.6\% respecto al presupuesto de 2015. ${ }^{16} \mathrm{Al}$ final, hay que señalar que para 2016 el gobierno federal sí tuvo

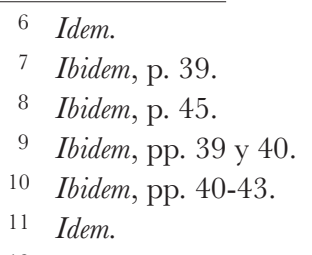

12 Ibidem, p. 47. Según la OCDE, el sector de la población mexicana mayor de 65 años aumentó un 10\% en 2010. Ese mismo sector tendrá un incremento del 21\% para el 2050. Cabe destacar que el número de personas en edad laboral en México que cumplirá 65 años será el que más crezca respecto al resto de América Latina. Según estadísticas de 2015, 901 millones de personas poseen una edad de 60 o más años, lo que representa el 12\% de la población mundial. Ese sector de la población tiene un crecimiento anual del 3.26\%. Se calcula que para 2030, 1,400 millones de personas serán mayores de 60 años; para 2050 serán 2,100 millones, y para 2,100 serán 3,200 millones. Véase United Nations, World Population Prospects: The 2015 Revision, Key Findings and Advance Tables, Nueva York-Ginebra, United Nations, Department of Economic and Social Affairs, Population Division, ESA/P/WP.241, 2015, p. 7.

13 Ibidem, p. 13.

14 Ibidem, p. 23.

15 Ibidem, p. 11.

16 Cfr. Secretaría de Hacienda y Crédito Público, Proyecto de Presupuesto de Egresos de la Federación 2016, México, Secretaría de Hacienda y Crédito Público, versión ciudadana, 2015, 
Esta obra forma parte del acervo de la Biblioteca Jurídica Virtual del Instituto de Investigaciones Jurídicas de la UNAM www.juridicas.unam.mx

que realizar un recorte presupuestal importante en su gasto debido a los bajos precios internacionales del petróleo y a la volatilidad cambiaria del peso frente al dólar estadounidense. Lamentablemente, el sistema de salud sí fue afectado por dicho recorte. Así, la Secretaría de Salud tuvo una disminución del $5.12 \%$ y el seguro popular del $2.21 \%$. Esto mantendrá la inversión en salud en un nivel bajo con respecto al promedio de los países miembros de la OCDE. ${ }^{17}$

México cuenta con la expectativa de vida más baja entre los miembros de la OCDE (74.6 años), ${ }^{18}$ y a pesar de la cobertura sanitara ampliada, ${ }^{19}$ los mexicanos costean una cantidad mayor de los gastos de salud de sus bolsillos $(45 \%)$ que los demás ciudadanos de otros países de la OCDE. ${ }^{20}$

Según el estudio de la OCDE, la ineficiencia del sistema se debe parcialmente a su estructura vertical, fragmentación y falta de coordinación entre los subsistemas. Los subsistemas más grandes e importantes son:

a) Instituto Mexicano del Seguro Social (IMSS), que abarca alrededor de 42 millones de derechohabientes e incluye trabajadores asalariados y sus familias, pensionados y estudiantes. ${ }^{21}$

b) Instituto de Seguridad y Servicios Sociales de los Trabajadores del Estado (ISSSTE), que abarca alrededor de seis millones de trabajadores al servicio del Estado (en los niveles federal, estatal y municipal), junto con sus familias y los pensionados. ${ }^{22}$

c) Seguro popular, que ofrece cobertura sanitaria subsidiada básica ${ }^{23}$ a 52 millones de personas que no se encuentran protegidas en los otros

disponible en: http://wrwertransparenciapresupuestaria.gob.mx/work/models/PTP/Presupuesto/Presu puestacion/ppef2016.pdf (fecha de última consulta: 1o. de abril de 2016).

17 Díaz Echeverría, Daniela, "Los recortes en salud para el 2016”, El Universal, México, disponible en: http://wrwreluniversal.com.mx/blogs/fundar/2015/11/28/los-recortes-en-saludpara-el-2016 (fecha de última consulta: 31 de marzo de 2016).

18 Organización para la Cooperación y el Desarrollo Económicos, OECD Reviewes..., cit., p. 13. "While life expectancy increased by three years on average across OECD countries between 2000 and 2013 (rising from 77.1 years to 80.4 years), it increased by only 1.3 years in Mexico (from 73.3 to 74.6 years)".

19 Ibidem, p. 14.

20 Ibidem, p. 121. El cuadro 4.2. Por otro lado, los consumidores de los Estados Unidos pagan de sus bolsillos sólo el 12\% de sus gastos en salud. El promedio de la OCDE es del 19\%.

21 Bonilla-Chacín, M. E. y Aguilera, Nelly, México. El sistema de protección social en salud, Washington, Banco Mundial, 2013, p. 2.

22 Idem.

23 El seguro popular, que es como se conoce al sistema de protección social en salud, tiene como objetivo garantizar el acceso efectivo, oportuno, de calidad, sin desembolso al momento de su utilización y sin discriminación, a los servicios médico-quirúrgicos, farmacéuticos y 
Esta obra forma parte del acervo de la Biblioteca Jurídica Virtual del Instituto de Investigaciones Jurídicas de la UNAM

dos esquemas, y que están desempleadas, autoempleadas o en la economía informal. ${ }^{24}$

Otros esquemas de cobertura de seguridad social están manejados por la Secretaría de la Defensa Nacional (Sedena), la Secretaría de Marina (Semar), y Petróleos Mexicanos (Pemex). Cabe destacar que sólo alrededor del $6.9 \%$ de los mexicanos cuenta con seguros privados de salud. ${ }^{25}$

\section{El proceso gubernamental de compras}

El gobierno federal es probablemente el comprador más grande de productos farmacéuticos del país. La compra de los insumos para la salud que pueden ser adquiridos por las instituciones de salud está determinado por una Comisión intersecretarial subordinada al Consejo de Salubridad General (CSG), ${ }^{26}$ con representantes de la Secretaría de Salud, la Secretaría de Salud de la Ciudad de México, del IMSS, ISSSTE, Sedena, Semar, Pemex y del DIF (Sistema Nacional para el Desarrollo Integral de la Familia).27

El objeto principal de la Comisión es elaborar, actualizar y difundir el "Cuadro básico y catálogo de insumos del sector salud" "“Cuadro Básico"). Dicho de manera sencilla, se puede concluir que ninguna de las instituciones públicas del sistema nacional de salud adquirirá insumos que no se encuentren incluidos en el Cuadro Básico. ${ }^{28}$

hospitalarios que satisfagan de manera integral las necesidades de salud, mediante la combinación de intervenciones de promoción de la salud, prevención, diagnóstico, tratamiento y de rehabilitación, seleccionadas en forma prioritaria según criterios de seguridad, eficacia, costo, efectividad, adherencia a normas éticas profesionales y aceptabilidad social. Como mínimo se deben contemplar los servicios de consulta externa en el primer nivel de atención, así como de consulta externa y hospitalización para las especialidades básicas de: medicina interna, cirugía general, ginecoobstetricia, pediatría y geriatría, en el segundo nivel de atención. Véase Ley General de Salud, artículo 77 bis 1, segundo párrafo y "seguro popular", Comisión Nacional de Protección Social en Salud: Seguro popular ¿qué es?, http://wrwre.seguro-popular.salud.gob. $m x /$ index.php/conocenos/seguro-popular-1 (fecha de última consulta: 4 de abril de 2016).

24 Bonilla-Chacín, M. E. y Aguilera, Nelly, op. cit., p. 2.

25 Organización para la Cooperación y el Desarrollo Económicos, OECD Reviews..., cit., p. 62.

26 Comisión Intersecretarial del Cuadro Básico y Catálogo de Insumos del Sector Salud.

27 Reglamento Interior de la Comisión Intersecretarial del Cuadro Básico y Catálogo de Insumos del Sector Salud, artículo 4.

28 El "Cuadro básico y catálogo de insumos del sector salud" es el documento en el que se agrupan, caracterizan y codifican todos los medicamentos, el material de curación, el instrumental, el equipo médico y los auxiliares de diagnóstico empleados por las instituciones públicas del sistema nacional de salud para otorgar servicios de salud a la población. 
Esta obra forma parte del acervo de la Biblioteca Jurídica Virtual del Instituto de Investigaciones Jurídicas de la UNAM

En general, la legislación mexicana establece que el gobierno federal debe adquirir los productos y servicios que requiere a través de licitaciones públicas. ${ }^{29}$ Los medicamentos patentados incluidos en el Cuadro Básico se someten a un régimen de excepción. ${ }^{30}$ Esto constituye un incentivo suficiente para solicitar múltiples patentes secundarias y tratar de adaptar las inclusiones y modificaciones al Cuadro Básico con descripciones que empaten con la materia patentada y que se ajusten sucesivamente a las patentes secundarias y modificaciones a los registros innovadores o de referencia.

En 2012, el gobierno federal centralizó la compra de medicamentos, entre otros insumos para la salud, para poder negociar así precios más bajos con los productores. ${ }^{31}$ En 2015, el gobierno federal gastó 48 mil millones de pesos en más de 1,760 tipos de medicamentos e insumos médicos. ${ }^{32}$ Este esquema es manejado por el IMSS, y el gobierno federal afirma que se han logrado ahorros por más de 10 mil 800 millones de pesos desde que se implementó. ${ }^{33}$

No obstante, la consolidación de las compras públicas de medicamentos ha tenido efectos no deseados. Desde que las compras gubernamentales se han consolidado, es más tentador para las compañías farmacéuticas innovadoras excluir a los competidores del mercado.

\section{Patentes farmacéuticas en México}

Hace veinticinco años los problemas que se abordan en este documento no existían, ya que la legislación de patentes no permitía el patentamiento de productos farmacéuticos. ${ }^{34}$ Esto cambió en 1991 con la entrada en vi-

El cuadro básico de insumos aplica en el primer nivel de atención y el catálogo de insumos en el segundo y tercer nivel. Tiene por objeto colaborar en la optimización de los recursos públicos destinados a la atención de los problemas de salud del país, mediante el empleo de insumos que han probado su seguridad, eficacia terapéutica y eficiencia. Adicionalmente, es un instrumento de referencia sobre los insumos para la salud que sirve para informar y colaborar en la actualización de los profesionales de la salud. Ibidem, artículo 2o.

29 Ley de Adquisiciones, Arrendamientos y Servicios del Sector Público, artículo 26.

30 Ibidem, artículo 41.

31 Presidencia de la República, El gobierno de la República cuenta con una estrategia de contratación pública: EPN, boletín de prensa, 8 de julio de 2013.

32 Instituto Mexicano del Seguro Social, Transparencia, competencia y certidumbre generan importantes ahorros al sector salud en compra consolidada de medicamentos, vacunas y material de curación, boletín de prensa, 12 de enero de 2016.

33 Idem.

34 Ley de Invenciones y Marcas, artículo 10, fracción IV. 
Esta obra forma parte del acervo de la Biblioteca Jurídica Virtual del Instituto de Investigaciones Jurídicas de la UNAM www.juridicas.unam.mx

gor de la Ley de Fomento y Protección de la Propiedad Industrial (que fue renombrada como Ley de la Propiedad Industrial en 1994). ${ }^{35} \mathrm{El}$ artículo décimo segundo transtorio de esta nueva Ley constituyó un claro presagio de lo que estaba por venir y que habría de afectar prioritariamente a los fabricantes de medicamentos genéricos. ${ }^{36}$

La mayoría de las patentes otorgadas por el Instituto Mexicano de la Propiedad Industrial (IMPI) corresponde a titulares extranjeros. Por ejemplo, en 2015 sólo 410 de las 9,338 patentes otorgadas (4.4\%) pertenecen a mexicanos. Así, México se ubicó en el sexto lugar en la lista de los países de origen de los titulares de patentes, detrás de Estados Unidos (46\%), Alemania $(9 \%)$, Japón $(6.4 \%)$, Suiza $(5.8 \%)$ y Francia $(4.6 \%)$. La siguiente tabla sintetiza la información entre 1993 y 2015:37

\begin{tabular}{|c|c|c|c|c|c|c|c|c|c|}
\hline \multicolumn{10}{|c|}{ Patentes otorgadas por nacionalidad del titular } \\
\hline Año & Total & México & Alemania & EUA & Francia & Fapón & $\begin{array}{c}\text { Reino } \\
\text { Unido }\end{array}$ & Suiza & $\begin{array}{c}\text { Otros } \\
\text { países }\end{array}$ \\
\hline 1993 & 6,183 & 343 & 458 & 3,714 & 251 & 220 & 206 & 256 & 735 \\
\hline 1994 & 4,367 & 288 & 395 & 2,367 & 210 & 175 & 175 & 228 & 529 \\
\hline 1995 & 3,538 & 148 & 205 & 2,198 & 162 & 123 & 136 & 109 & 457 \\
\hline 1996 & 3,186 & 116 & 214 & 2,084 & 108 & 101 & 70 & 101 & 392 \\
\hline 1997 & 3,944 & 112 & 227 & 2,873 & 120 & 98 & 90 & 112 & 312 \\
\hline
\end{tabular}

35 Ley de la Propiedad Industrial, artículos 16 y 19.

36 El artículo décimo segundo transitorio de la Ley de la Propiedad Industrial restauró las patentes farmacéuticas y algunas otras patentes más para otro tipo de invenciones que no eran patentables bajo la Ley de 1976. Si una compañía extranjera había presentado la solicitud de patente en otro país miembro del Tratado de Cooperación de Patentes (PCT, por sus siglas en inglés), se permitía solicitar la patente en México dentro del plazo de un año a partir de la entrada en vigor de la Ley de 1991, manteniendo la fecha de prioridad PCT, aunque la invención no fuese patentable en nuestro país a la fecha de la prioridad presentada originalmente. Varias compañías mexicanas que estaban en un proceso de desarrollo de medicamentos genéricos cuando entró en vigor la Ley de 1991 tuvieron que abandonar sus planes de negocios y asumir las pérdidas. Más aún, algunas compañías innovadoras, aprovechando el lenguaje ambiguo del artículo décimo segundo transitorio, argumentaron que las patentes otorgadas bajo dicha norma tenían el derecho a extender la vigencia de la patente mexicana cuando la vigencia de la prioridad base hubiera sido extendida con sustento en la normativa aplicable al país de origen. Los tribunales eventualmente rechazaron las peticiones, pero a costa de varios años de litigio durante los cuales los titulares lograron mantener "vigentes" patentes que legalmente ya habían caducado.

37 Instituto Mexicano de la Propiedad Industrial, IMPI en cifras 2016, México, IMPI, 2016, p. 9. 
Esta obra forma parte del acervo de la Biblioteca Jurídica Virtual del Instituto de Investigaciones Jurídicas de la UNAM

LINDNER LÓPEZ / MORANTE SORIA

\begin{tabular}{|c|c|c|c|c|c|c|c|c|c|}
\hline \multicolumn{9}{|c|}{ Patentes otorgadas por nacionalidad del titular } \\
\hline Año & Total & México & Alemania & EUA & Francia & Fapón & $\begin{array}{c}\text { Reino } \\
\text { Unido }\end{array}$ & Suiza & $\begin{array}{c}\text { Otros } \\
\text { países }\end{array}$ \\
\hline 1998 & 3,219 & 141 & 215 & 2,060 & 117 & 102 & 114 & 101 & 369 \\
\hline 1999 & 3,899 & 120 & 351 & 2,324 & 209 & 134 & 124 & 152 & 485 \\
\hline 2000 & 5,519 & 118 & 525 & 3,158 & 333 & 243 & 167 & 228 & 747 \\
\hline 2001 & 5,479 & 118 & 480 & 3,237 & 298 & 218 & 167 & 181 & 780 \\
\hline 2002 & 6,611 & 139 & 736 & 3,706 & 335 & 256 & 197 & 246 & 996 \\
\hline 2003 & 6,008 & 121 & 610 & 3,368 & 337 & 197 & 156 & 241 & 978 \\
\hline 2004 & 6,838 & 162 & 726 & 3,552 & 522 & 234 & 181 & 315 & 1,146 \\
\hline 2005 & 8,098 & 131 & 806 & 4,338 & 558 & 284 & 234 & 386 & 1,361 \\
\hline 2006 & 9,632 & 132 & 877 & 5,180 & 711 & 378 & 265 & 506 & 1,583 \\
\hline 2007 & 9,957 & 199 & 885 & 5,094 & 745 & 418 & 272 & 506 & 1,838 \\
\hline 2008 & 10,440 & 197 & 899 & 5,483 & 682 & 407 & 252 & 538 & 1,982 \\
\hline 2009 & 9,629 & 213 & 786 & 4,831 & 592 & 399 & 266 & 553 & 1,989 \\
\hline 2010 & 9,399 & 229 & 712 & 4,769 & 439 & 401 & 206 & 585 & 2,058 \\
\hline 2011 & 11,485 & 245 & 960 & 5,612 & 551 & 579 & 302 & 775 & 2,461 \\
\hline 2012 & 12,330 & 281 & 1,027 & 5,924 & 568 & 794 & 305 & 753 & 2,678 \\
\hline 2013 & 10,343 & 302 & 939 & 4,792 & 500 & 665 & 257 & 630 & 2,258 \\
\hline 2014 & 9,819 & 305 & 886 & 4,514 & 398 & 709 & 243 & 570 & 2,194 \\
\hline 2015 & 9,338 & 410 & 805 & 4,270 & 432 & 601 & 237 & 532 & 2,051 \\
\hline
\end{tabular}

La estrategia recurrente de las compañías innovadoras comienza con la obtención de una patente primaria para la sustancia activa de un nuevo medicamento (o, inclusive, una familia completa de compuestos químicos), seguido del trámite de varias patentes secundarias que abarcan nuevas formas, dosis, usos, etcétera, según se señaló previamente.

Esto puede ilustrarse a partir del siguiente planteamiento hipotético.

Supongamos que en 1996, SOCI Corporation presentó en México la solicitud de patente primaria sobre un grupo de compuestos químicos útiles para el tratamiento de enfermedades cardiovasculares, entre los cuales se encuentra el principio activo " $\mathrm{X}$ ". Imaginemos que esta patente primaria se concedió en junio de 2000 y venció en enero de 2015.

Posteriormente, SOCI Corporation presenta en México una solicitud de patente secundaria sobre un nuevo uso del principio activo "X", que 
Esta obra forma parte del acervo de la Biblioteca Jurídica Virtual del Instituto de Investigaciones Jurídicas de la UNAM

durante el trámite divide en dos solicitudes que amparan dos usos del principio activo "X". Ambas patentes se conceden en febrero de 2003 y vencen en julio de 2016.

Después, SOCI Corporation presenta en México otra solicitud de patente secundaria, pero ahora sobre una composición farmacéutica oral que comprende un rango amplio del principio activo "X". La patente correspondiente supongamos que se concede en octubre de 2004 y vence en abril de 2020.

Un año después de presentarse la solicitud de patente sobre la composición farmacéutica oral que comprende un rango amplio del principio activo "X", SOCI Corporation presenta en México dos nuevas solicitudes de patentes secundarias. En la primera solicitud reclama la forma del principio activo "X" caracterizado por el tamaño de partícula, y en la segunda solicitud reclama una composición farmacéutica conteniendo el fármaco libre junto con excipientes particulares.

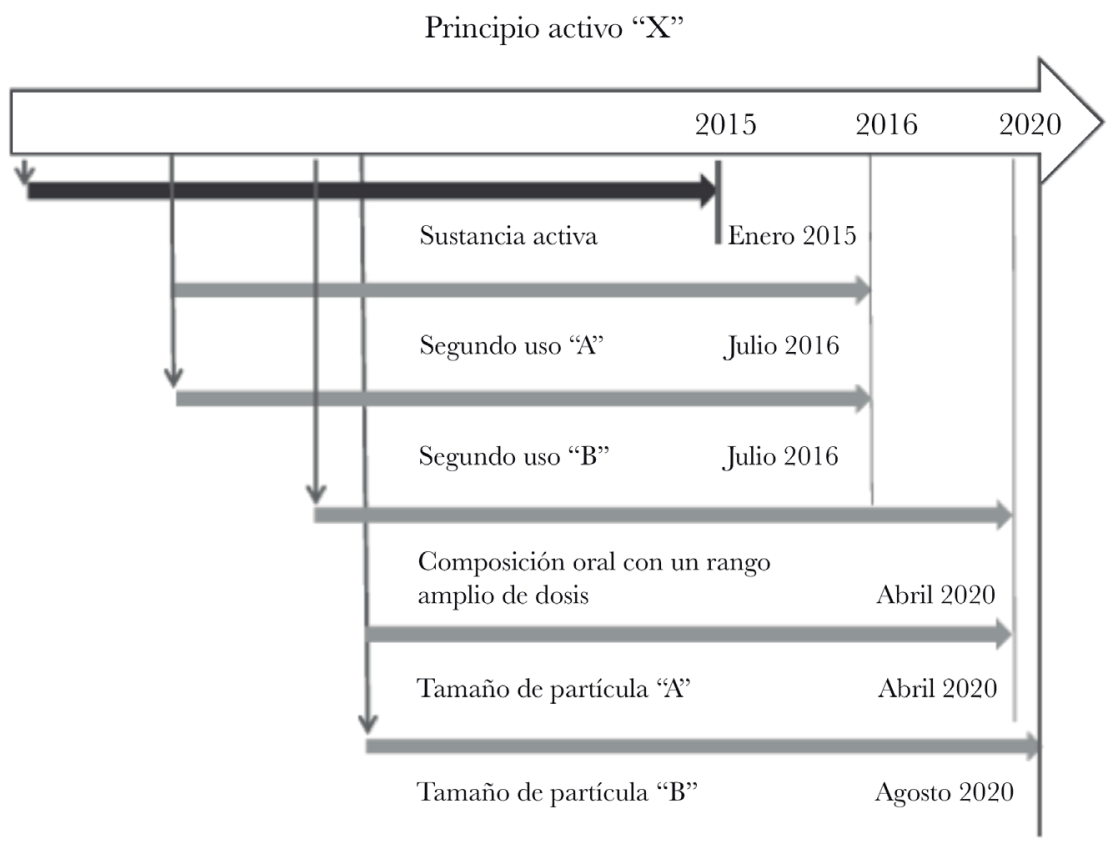

Supongamos ahora que en diciembre de 2003 SOCI Corporation lanza al mercado un medicamento en forma de tableta que contiene el principio activo " $\mathrm{X}$ " en una cantidad específica seleccionada del rango amplio 
Esta obra forma parte del acervo de la Biblioteca Jurídica Virtual del Instituto de Investigaciones Jurídicas de la UNAM

previamente patentado. Antes de hacer este lanzamiento, también podría haber presentado una nueva solicitud de patente alegando "efectos inesperados", "menores efectos secundarios" u otras "ventajas", indicado para el tratamiento previamente patentado ("patente de selección"), y de ser así, la patente expiraría en 2023.

En teoría, las patentes secundarias de SOCI Corporation no deberían impedir a un competidor ingresar al mercado con versiones genéricas del medicamento que contiene el principio activo " $\mathrm{X}$ ", una vez que la patente primaria haya vencido. Sin embargo, la realidad es muy distinta.

Independientemente de que la validez de la mayoría de las patentes secundarias sea cuestionable, y aun cuando la patente primaria hubiera vencido en enero de 2015, subsisten múltiples patentes con vencimientos sucesivos que pueden generar confusión y retrasos en la autorización e ingreso de medicamentos genéricos al mercado, como se ejemplificó en el modelo anterior. Esto muestra que las compañías innovadoras han sabido explotar las debilidades del sistema para retrasar o evitar la competencia de los medicamentos genéricos, en perjuicio de los pacientes, los consumidores y el erario público.

\section{ESTRATEGIAS DILATORIAS}

\section{Antecedentes}

Hasta hace poco, los consumidores mexicanos consideraban a los medicamentos genéricos como inferiores en comparación con los productos innovadores; incluso se percibían como peligrosos. Los pacientes en el mercado privado evitaban los medicamentos genéricos y no exigían a los médicos que se los prescribieran.

Esta percepción ha cambiado. Por ejemplo, en 2012 los medicamentos genéricos representaban el $90.1 \%$ del valor de los medicamentos vendidos al sector privado, y el $98.2 \%$ por unidad de venta. Igualmente, los genéricos representaron el 61.3\% del valor de las compras gubernamentales de medicamentos, y el $99.1 \%$ por unidad de venta. ${ }^{38}$ Este cambio se debe a factores económicos y a campañas publicitarias que han presentado a los medicamentos genéricos como seguros, eficaces y de igual calidad respecto a los "medicamentos de patente". ${ }^{39}$

38 Fundación Mexicana para la Salud, Descripción del sector farmacéutico en México 2013, México, Funsalud, 2013.

39 Comisión Europea, Executive Summary of the Pharmaceutical Sector Inquiry Report, 2009, p. 24. 
Esta obra forma parte del acervo de la Biblioteca Jurídica Virtual del Instituto de Investigaciones Jurídicas de la UNAM

Mientras que los medicamentos genéricos han ganado una aceptación amplia, los medicamentos biocomparables no lo han logrado aún. ${ }^{40}$ Fabricantes de biocomparables enfrentan retrasos injustificados para obtener los registros sanitarios de la Comisión Federal para la Protección contra Riesgos Sanitarios (Cofepris) ${ }^{41}$ y las compañías innovadoras atacan los registros sanitarios otorgados bajo el régimen anterior a la incorporación de la figura de medicamentos biocomparables ${ }^{42}$ con argumentos poco sostenibles, no obstante su probada seguridad y eficacia por varios años de comercialización y suministro. ${ }^{43}$

40 Reglamento de Insumos para la Salud, artículo 20.: "Para efectos del presente Reglamento, se entenderá por: ...XIII Bis 1. Medicamento biotecnológico biocomparable, al medicamento biotecnológico no innovador que demuestre ser biocomparable en términos de seguridad, calidad y eficacia al medicamento biotecnológico de referencia a través de las pruebas que establezca la Ley, este Reglamento y demás disposiciones aplicables".

41 Conforme a la Ley General de Salud, artículo 17 bis, corresponde a la Cofepris ejercer las atribuciones de regulación, control y fomento sanitario; el control y vigilancia de los establecimientos de salud; la prevención y el control de los efectos nocivos de los factores ambientales en la salud del hombre; la salud ocupacional y el saneamiento básico; el control sanitario de productos, servicios y de su importación y exportación, y de los establecimientos dedicados al proceso de los productos; el control sanitario del proceso, uso, mantenimiento, importación, exportación y disposición final de equipos médicos, prótesis, órtesis, ayudas funcionales, agentes de diagnóstico, insumos de uso odontológico, materiales quirúrgicos, de curación y productos higiénicos, y de los establecimientos dedicados al proceso de los productos; el control sanitario de la publicidad de las actividades, productos y servicios; el control sanitario de la disposición de órganos, tejidos y sus componentes, células de seres humanos; la sanidad internacional, y el control sanitario de las donaciones y trasplantes de órganos, tejidos, células de seres humanos.

42 La incorporación de los medicamentos biocomparables a la normativa nacional se da con la adición del artículo 222 bis a la Ley General de Salud (Diario Oficial de la Federación del 11 de junio de 2009). No obstante, es hasta octubre de 2011 cuando se integran al Reglamento de Insumos para la Salud disposiciones relativas a las características que distinguen a los medicamentos biotecnológicos innovadores, de referencia y biocomparables; donde se fijan las nomenclaturas respectivas; los parámetros para las pruebas requeridas para obtener su autorización, entre otros, aclarándose que los trámites de solicitudes de registro que se encontraran pendientes se resolverían conforme a la normatividad vigente al momento de su presentación (Diario Oficial de la Federación del 19 de octubre de 2011). Asimismo, es hasta febrero de 2012 cuando se determina la integración y funcionamiento del Comité de Moléculas Nuevas, así como del Subcomité de Evaluación de Productos Biotecnológicos en el Reglamento Interior del Comité de Moléculas Nuevas (Diario Oficial de la Federación del 23 de febrero de 2012), después de lo cual se han seguido publicando más disposiciones o reformas a lineamientos y normas oficiales mexicanas.

43 En un caso reciente, la actora, una compañía innovadora, impugnó el registro sanitario otorgado a un medicamento biotecnológico para tratar ciertos tipos de cáncer, del único competidor. Este medicamento había demostrado, cuando menos por cuatro años, su seguridad y eficacia. Hay que añadir que después de que el medicamento competidor salió 
Esta obra forma parte del acervo de la Biblioteca Jurídica Virtual del Instituto de Investigaciones Jurídicas de la UNAM www.juridicas.unam.mx

\section{Estrategias de patentamiento}

Es común encontrar en el sector farmacéutico patentes amplias y múltiples solicitudes de patentes para abarcar un mismo medicamento. Esto es especialmente cierto en los medicamentos de alto impacto (blockbuster), ya que los incentivos para mantener a los competidores fuera del mercado son sensiblemente mayores. La misma existencia de numerosas solicitudes de patentes para un medicamento genera incertidumbre jurídica e inhibe el lanzamiento de productos competidores, que disminuyen los precios, en ocasiones, sustancialmente. ${ }^{44}$

La proliferación de patentes secundarias es una clara evidencia de su uso estratégico para generar incertidumbre y contar con un buen arsenal para atacar y bloquear a la competencia. Para ello basta con analizar las diversas ediciones de la Gaceta de patentes vigentes de medicamentos, donde se aprecia el incremento de patentes secundarias y de patentes que, aunque se definen como patentes de principio activo, en realidad no constituyen nuevas moléculas sino formas diversas de los mismos principios activos. ${ }^{45}$

Por ejemplo, en la edición de la Gaceta de medicamentos de febrero de 2016 se publicaron un total de 678 patentes. De éstas, se identificaron como patentes de principio activo 289; como patentes que amparan composiciones farmacéuticas $353(52.06 \%)$; como patentes de uso 31 (4.57\%), y como patentes de proceso $5(0.74 \%)$. Sin embargo, si se analizan las patentes de principio activo, al menos 112 de éstas (16.52\%) no corresponden en realidad a nuevas moléculas, sino a formas diversas de principios activos cono-

al mercado, el precio pagado por el gobierno federal por una dosis de $500 \mathrm{mg}$ del producto de referencia bajó de $\$ 20,852.47$ a $\$ 5,329.00$. Se trata de una reducción del 75\%. La actora argumentó que el registro sanitario del competidor debía revocarse porque éste no cumplía con las disposiciones reglamentarias en materia de biocomparables y que, por tanto, no era seguro ni eficaz, aun y cuando dichas normas no existían cuando el registro fue tramitado.

44 Según Cofepris, la política de genéricos del gobierno de la República ha generado un ahorro de $\$ 21,148$ millones de pesos hasta marzo de 2015. Asimismo, ha permitido una reducción promedio del $61 \%$ en los precios de los medicamentos, lo que ha representado un ahorro promedio de $\$ 1,047$ pesos para el consumidor, pasando de $\$ 1,652$ pesos a $\$ 605$ pesos, en promedio. Disponible en: http://wrwrecofepris.gob.mx/Documents/NotasPrincipa les/26032015_2.pdf (fecha de última consulta: 1o. de abril de 2016).

45 En la Gaceta de Medicamentos se clasifican como "patentes de principio activo", no sólo las que corresponden a una nueva entidad química reivindicada en forma particular, sino también las que abarcan (generalmente primero) familias completas en forma genérica (Markush); las que reivindican el principio activo en forma particular (como una "invención de selección”) y, adicionalmente, variantes de éste, como: sales específicas, profármacos, metabolitos, hidratos, solvatos, isómeros (enantiómeros), formas cristalinas, formas pseudocristalinas y formas amorfas. 
Esta obra forma parte del acervo de la Biblioteca Jurídica Virtual del Instituto de Investigaciones Jurídicas de la UNAM

cidos que pueden ser calificadas dentro del rubro de patentes secundarias. Esto da por resultado que de las patentes publicadas en este ejemplar sólo el $26.11 \%$ corresponde a patentes primarias de principio activo propiamente dichas. La obtención de este último tipo de patentes generalmente obedece a la misma motivación estratégica que las patentes secundarias en general.

La incertidumbre se agrava debido al hecho de que los expedientes de las solicitudes son confidenciales hasta que las patentes son otorgadas.

Otra estrategia frecuentemente utilizada es la presentación de solicitudes de patente que abarcan materia amplia y que durante el trámite de fondo se dividen en una o más solicitudes adicionales (divisionales). Lamentablemente, la Ley de la Propiedad Industrial exime la publicación de las solicitudes divisionales, y los terceros que se puedan ver perjudicados con su otorgamiento no pueden conocer de su existencia sino hasta que las patentes divisionales sean otorgadas. De nuevo, la proliferación de solicitudes divisionales no publicadas crea inseguridad jurídica.

Finalmente, la ausencia de un verdadero sistema de oposición ${ }^{46}$ aumenta el número de patentes otorgadas de baja calidad. Estas patentes permanecen vigentes hasta que expiran o hasta que sean declaradas nulas a solicitud de un tercero, y después de entre tres y cinco años de litigio. Estas patentes no sólo crean incertidumbre jurídica, sino que interfieren con los procedimientos administrativos que las compañías competidoras inician para obtener los registros sanitarios respectivos.

\section{Vinculación de patentes y registros sanitarios}

Cualquier medicamento comercializado o utilizado en México debe ser autorizado por la Cofepris. La misión de este órgano no es la protección de derechos de propiedad industrial, sino asegurar que los medicamentos son seguros, eficaces y de calidad. A pesar de ello, el procedimiento para la obtención de un registro sanitario está "vinculado" al sistema de patentes, con resultados perversos.

En 2003, México siguió el camino de los Estados Unidos y creó una "vinculación" entre las patentes farmacéuticas y los registros sanitarios. La

46 La Ley de la Propiedad Industrial, en su artículo 52 bis, establece que cualquier tercero podrá presentar información sobre el incumplimiento a los requisitos de patentabilidad de las solicitudes de patente dentro de los seis meses posteriores a su publicación en la Gaceta de la Propiedad Industrial. El IMPI podrá considerar los documentos o información presentados como documentos de apoyo técnico, pero sin entablarse un procedimiento de oposición propiamente dicho. 
Esta obra forma parte del acervo de la Biblioteca Jurídica Virtual del Instituto de Investigaciones Jurídicas de la UNAM

idea general es que la Cofepris no autorice la comercialización de un medicamento si éste puede infringir una patente. La justificación que se ha esgrimido es que la vinculación "garantiza el respeto de los derechos de propiedad industrial...". ${ }^{47}$

El fundamento legal del sistema de vinculación es el artículo 167 bis del Reglamento de Insumos para la Salud. ${ }^{48}$

Conforme a este precepto, el solicitante de un registro sanitario cuenta con dos opciones: a) demostrar que es titular de la patente sobre la sustancia activa o que cuenta con la licencia de la misma, o b) manifestar, bajo protesta de decir verdad, que cumple con las disposiciones aplicables en materia de patentes respecto a la sustancia o ingrediente activo objeto de la solicitud. En este último supuesto, la Cofepris no considera a cabalidad lo manifestado por el solicitante para justificar que el medicamento sometido a registro no infringe las patentes referidas en dicho precepto. Más bien, utiliza un formato estandarizado para requerir al IMPI una opinión para determinar si el solicitante infringe alguna patente. Dicha opinión tiene que emitirse en un plazo de diez días laborales.

El artículo 167 bis hace referencia a otra disposición, al artículo 47 bis del Reglamento de la Ley de la Propiedad Industrial, que requiere que el

47 Valencia Hernández, Armando, Sistema de vinculación-regulación sanitariay la propiedad industrial, disponible en: http://wrwe.amegi.com.mx/pdf/curso_practico/vinculacion_cofepris_impi_2014. $p d f$.

48 "Artículo 167 bis. El solicitante del registro de un medicamento alopático deberá anexar a la solicitud la documentación que demuestre que es el titular de la patente de la sustancia o ingrediente activo o que cuenta con la licencia correspondiente, ambas inscritas en el IMPI.

Alternativamente, y de acuerdo con el listado de productos establecidos en el artículo 47 bis del Reglamento de la Ley de la Propiedad Industrial, podrá manifestar, bajo protesta de decir verdad, que cumple con las disposiciones aplicables en materia de patentes respecto a la sustancia o ingrediente activo objeto de la solicitud. En este supuesto, la Secretaría pedirá de inmediato la cooperación técnica del Instituto Mexicano de la Propiedad Industrial para que, dentro del ámbito de su competencia, éste determine a más tardar dentro de los diez días hábiles posteriores a la recepción de la petición, si se invaden derechos de patente vigentes. En caso de que el Instituto Mexicano de la Propiedad Industrial concluya que existen patentes vigentes sobre la sustancia o ingrediente activo de las que el solicitante no sea titular o licenciatario, lo informará a la Secretaría para que ésta prevenga al solicitante con el objeto de que demuestre que es titular de la patente o que cuenta con la licencia respectiva, dentro del plazo que determine la Secretaría y que no podrá ser menor a cinco días hábiles contados a partir de que haya surtido efectos la notificación. En el supuesto de que el solicitante no subsane la omisión, la Secretaría desechará la solicitud e informará al solicitante los motivos de esta determinación para que, en su caso, los dirima ante la autoridad competente. La falta de respuesta del Instituto Mexicano de la Propiedad Industrial dentro del plazo señalado se entenderá en sentido favorable al solicitante...". 
Esta obra forma parte del acervo de la Biblioteca Jurídica Virtual del Instituto de Investigaciones Jurídicas de la UNAM

IMPI publique una lista "de productos que deban ser objeto de protección industrial de acuerdo con la sustancia o ingrediente activo, el cual precisará la vigencia de la patente respectiva". La lista se publica en la Gaceta de patentes vigentes de medicamentos y es actualizada dos veces al año.

Originalmente, la Gaceta incluía únicamente patentes de sustancias activas, como lo señala la letra del artículo 167 bis del Reglamento de Insumos para la Salud. Esto cambió en 2010, cuando la Segunda Sala de la Suprema Corte de Justicia de la Nación resolvió que todas las patentes otorgadas a medicamentos alopáticos debían ser listadas, excepto aquellas patentes de fabricación o de procesos de formulación. ${ }^{49}$ Como resultado de lo anterior, la publicación se ha vuelto incontrolable - el grosor de la Gaceta ha aumentado considerablemente, de 56 páginas en noviembre de 2003 a 436 en febrero de 2016 - y la obtención de registros sanitarios para medicamentos genéricos se ha tornado sumamente compleja, incierta, tardada y onerosa.

A ello se suma que el solicitante no recibe copia alguna de la consulta o de la respuesta del IMPI, es decir, no tiene acceso al procedimiento de consulta Cofepris-IMPI, ni se le permite participar en el proceso para justificar errores en la identificación de patentes que se estime puedan ser infringidas ni en la argumentación sobre la ausencia de infracción. Adicionalmente, la búsqueda del IMPI no se limita a lo establecido en el artículo 167 bis del Reglamento de Insumos para la Salud. Para empezar, la búsqueda no sólo incluye a la Gaceta de patentes vigentes de medicamentos, sino a toda su base de datos de patentes. Esto favorece que el resultado de la búsqueda pueda arrojar falsos positivos (patentes secundarias que mencionan la sustancia activa pero que no necesariamente implican la infracción de alguna de ellas), sin posibilidad del solicitante de detectarlos y salvarlos.

Es poco probable que el IMPI cuente con los elementos suficientes para hacer análisis meticulosos en todos los casos, dada la corta duración del plazo que tiene para responder, porque no tiene acceso al expediente de la solicitud de registro sanitario, sino exclusivamente a la información que Cofepris decida incluir en el formato de consulta, ${ }^{50}$ y porque carece de recursos humanos suficientes para satisfacer las crecientes consultas derivadas del sistema de vinculación.

En resumen, el artículo 167 bis no garantiza a los solicitantes de registros sanitarios el derecho al debido proceso. Bajo este artículo, la única

49 Tesis 2a/J. 7/2010, Semanario Fudicial de la Federación y su Gaceta, Novena Época, t. XXXI, febrero de 2010, p. 1092.

50 Ocasionalmente, el IMPI solicita información complementaria a la Cofepris, pero no tiene obligación legal de hacerlo. 
Esta obra forma parte del acervo de la Biblioteca Jurídica Virtual del Instituto de Investigaciones Jurídicas de la UNAM

forma en que un solicitante puede superar el desechamiento de un registro sanitario cuando existe alguna patente (primaria o secundaria, relativa al mismo principio activo) es presentando pruebas que acrediten que es el titular o licenciatario de la patente o patentes citadas por el IMPI, lo cual resulta imposible y absurdo si no existe invasión.

Una vez que la Cofepris emite un desechamiento o denegación final del registro sanitario, el solicitante puede impugnarlo a través de procesos costosos, complejos y lentos que concluyen en un promedio de tres años. Esto genera que a los consumidores y pacientes se les niegue el acceso a medicamentos genéricos seguros, eficaces y de bajo costo.

\section{Abuso de los litigios}

En México, como en otras jurisdicciones, las compañías innovadoras usan el sistema legal para crear obstáculos a los fabricantes de medicamentos genéricos que buscan colocar en el mercado productos competidores. Así, "en ciertas circunstancias, las compañías originadoras pueden considerar iniciar un litigio no tanto porque existan fundamentos reales, sino para postergar el ingreso de genéricos". ${ }^{51}$ Por ejemplo:

1) Las compañías innovadoras utilizan la Ley Federal de Transparencia y Acceso a la Información Pública Gubernamental para obtener información sobre las solicitudes de registro sanitario de medicamentos genéricos. Aunque la información en el expediente de la solicitud es confidencial, la presentación de la misma no lo es. Armadas con dicha información, las compañías presentan demandas de nulidad (juicio contencioso administrativo) ante la sala especializada en materia de propiedad intelectual (SEPI) o inclusive amparos indirectos en contra de la Cofepris. El objetivo principal es obtener una medida cautelar para evitar la emisión de cualquier registro sanitario relacionado con el producto de referencia.

2) Si un registro sanitario es expedido, el titular de la patente suele iniciar un juicio de nulidad en contra de la Cofepris para solicitar que dicho registro sea anulado. Normalmente, el titular de la patente solicita una medida cautelar con el fin de suspender los efectos del registro sanitario mientras el juicio es resuelto.

3) Finalmente, los titulares de patentes pueden iniciar procedimientos de declaración administrativa de infracción ante el IMPI, en los que

51 Comisión Europea, Executive Summary..., cit., p. 11. 
Esta obra forma parte del acervo de la Biblioteca Jurídica Virtual del Instituto de Investigaciones Jurídicas de la UNAM

solicitan la imposición de medidas precautorias que impidan la fabricación, comercialización, etcétera, del medicamento genérico. Aunque ésta debería ser la única opción viable dada la naturaleza de los reclamos (supuesta infracción a una patente), es cada vez la menos utilizada por los titulares de patentes, como se explicará posteriormente.

Desde la perspectiva de un titular de patente, un juicio de nulidad en contra de Cofepris (las primeras dos opciones) es preferible a un procedimiento de infracción en contra de un fabricante de un medicamento genérico (tercera opción). Para empezar, el juicio de nulidad contra la Cofepris es más simple, menos caro y desarrollado con menos vigor. Más aún, el actor en un procedimiento de infracción tiene el riesgo de que el demandado inicie en reconvención un procedimiento de declaración de nulidad de la patente base de la acción. En los juicios de nulidad, el titular de la patente puede demandar a Cofepris sin poner en riesgo sus patentes.

Hay que añadir que el fin principal de la mayoría de los actores es simplemente obtener la medida cautelar que detendrá el ingreso al mercado o subsistencia en éste de productos competidores. El fondo del asunto es de importancia secundaria. El demandado en un procedimiento de infracción de patente puede presentar una contrafianza y levantar así la medida precautoria. ${ }^{52}$

Es importante destacar la falta de salvaguardas procesales en contra de medidas precautorias o cautelares abusivas. En Estados Unidos, por ejemplo, la parte que solicite las medidas precautorias debe demostrar que existe una probabilidad de éxito del litigio principal, una amenaza de daño irreparable si la medida no es emitida y la proporcionalidad entre la medida y el daño que se pueda causar de no obsequiarse. La solicitud de medidas debe ser apoyada por declaraciones juradas, testimonios escritos u orales. El demandado debe ser notificado de la solicitud de las medidas para poder contrarrestar lo presentado por el actor.

Ninguna de estas salvaguardas existen en los procedimientos ante el IMPI y la SEPI. El actor simplemente solicita una medida precautoria, y si existe una patente vigente (independientemente de su validez) se otorga sin notificar previamente al demandado.

En casos en los que el fabricante de medicamentos genéricos sea demandado, las compañías innovadoras presentan fianzas extremadamente

52 En los procedimientos de infracción de patente ante el IMPI, el monto legal de la contrafianza es de un 140\% del valor de la fianza presentada por el actor (Ley de la Propiedad Industrial, artículo 199 bis 1). En los juicios contenciosos administrativos y en los amparos, éstas varían. 
Esta obra forma parte del acervo de la Biblioteca Jurídica Virtual del Instituto de Investigaciones Jurídicas de la UNAM www.juridicas.unam. $m x$

altas para que la demandada (usualmente una compañía mucho más pequeña) no tenga la capacidad económica para sufragar el gasto y la contingencia que involucra la contrafianza. El IMPI y los tribunales raramente rechazan las fianzas de montos excesivos.

Hay que agregar que generalmente toma varios días tramitar la contrafianza y obtener así de un tribunal o del IMPI el levantamiento de la medida precautoria o cautelar. Mientras tanto, el demandado puede incurrir en contingencias adicionales. Por ejemplo, si un titular de patente obtiene una medida precautoria poco antes del plazo para la presentación de ofertas en las licitaciones públicas, y si el demandado no alcanza a levantarlas antes de este proceso, el fabricante de medicamentos genéricos puede quedar impedido para presentar su oferta, teniendo que esperar un año para participar en nuevas licitaciones.

Finalmente, el sistema legal mexicano no impone castigo alguno a litigantes abusivos. Mientras que en un juicio civil el demandado que es absuelto puede reclamar gastos y costas, el demandado en un procedimiento administrativo debe asumir los costos de su propia defensa, aun en los casos de demandas frívolas.

\section{ABUSO DE LAS DISPOSICIONES NORMATIVAS DE TRATADOS SOBRE PROTECCIÓN DE DATOS "CLÍNICOS"}

Un fabricante que solicite la autorización de un nuevo medicamento que no hubiere sido previamente registrado ante la Cofepris, debe presentar los datos clínicos que demuestren que el producto es seguro y eficaz. En general, este requisito no es aplicable a los fabricantes de medicamentos genéricos. ${ }^{53}$ Éstos tienen que acreditar, entre otras cosas, la intercambiabilidad ${ }^{54}$ de sus productos en relación con el medicamento innovador o de referencia que ya ha demostrado que es seguro y eficaz.

53 Reglamento de Insumos para la Salud, artículo 2o., fracción XIV: "Medicamento genérico, a la especialidad farmacéutica con el mismo fármaco o sustancia activa y forma farmacéutica, con igual concentración o potencia, que utiliza la misma vía de administración y que mediante las pruebas reglamentarias requeridas, ha comprobado que sus especificaciones farmacopéicas, perfiles de disolución o su biodisponibilidad u otros parámetros, según sea el caso, son equivalentes a las del medicamento de referencia".

54 Reglamento de Insumos para la Salud, artículo 72. "Para efectos de lo dispuesto en el artículo 376 bis, fracción I de la Ley, los medicamentos destinados al mercado de genéricos serán únicamente las especialidades farmacéuticas que, en términos del presente Reglamento, sean intercambiables". 
Esta obra forma parte del acervo de la Biblioteca Jurídica Virtual del Instituto de Investigaciones Jurídicas de la UNAM

No sorprende, sin embargo, que las compañías innovadoras busquen impedir que los fabricantes de medicamentos genéricos se basen en sus datos clínicos. El fundamento legal de la protección de datos clínicos se encuentra en los artículos 39.3 del Acuerdo sobre los Aspectos de los Derechos de Propiedad Intelectual Relacionados con el Comercio (ADPIC) y 1711.5 del Tratado de Libre Comercio de América del Norte (TLCAN). ${ }^{55}$ Ambos artículos requieren que las partes protejan, contra actos de competencia desleal, a aquellos datos de prueba ("datos o estudios clínicos") que acrediten la seguridad y la eficacia de nuevos componentes o entidades químicas, que no hayan sido divulgados y cuya generación implique un esfuerzo considerable. Estas disposiciones se aplican sólo a los medicamentos de síntesis química y no a los medicamentos biotecnológicos. ${ }^{56}$

A pesar de estas limitaciones, los innovadores han obtenido medidas cautelares en contra de Cofepris para impedirle el otorgamiento de cualquier registro sanitario "basado" en el medicamento innovador o de referencia. En algunos casos, la SEPI ha otorgado las medidas precautorias aun cuando hubieran transcurrido más de cinco años desde el otorgamiento del registro sanitario del medicamento innovador. Igualmente, la SEPI ha concedido medidas precautorias en casos relacionados con productos biotecnológicos, ya que el actor omite indicar que las disposiciones sobre protección de datos del ADPIC y del TLCAN sólo son aplicables a medicamentos de síntesis química. Como los solicitantes de registros sanitarios para medicamentos genéricos nunca son llamados como terceros interesados a participar en los litigios que entablan los innovadores contra la Cofepris (no obstante que las medidas cautelares les deparan perjuicios directos), éstos capitalizan sustancialmente la ventaja que supone la ausencia de los argumentos que sin duda podrían aportar el o los terceros interesados. La autorización de medicamentos genéricos puede ser retrasada por un año o más, aun cuando la demanda sea desechada y las medidas precautorias levantadas.

55 Estos artículos fueron incorporados a través de los artículos 86 bis de la Ley de la Propiedad Industrial y 167 bis del Reglamento de Insumos para la Salud, que estipulan que la confidencialidad de los datos relacionados con la seguridad y eficacia de productos farmacéuticos y agroquímicos debe ser mantenida, de acuerdo con lo dispuesto por los acuerdos internacionales de los que México es parte.

56 En 2012, la Cofepris emitió unos lineamientos sobre el uso de datos no divulgados presentados para demostrar que un producto farmacéutico que contiene una "nueva entidad química" es seguro y eficaz. 
Esta obra forma parte del acervo de la Biblioteca Jurídica Virtual del Instituto de Investigaciones Jurídicas de la UNAM

\section{AGuerdo TransPacífico de Asociación}

El Acuerdo TransPacífico de Asociación (TPP, por sus siglas en inglés) tendrá efectos de gran calado en el derecho y práctica jurídica de nuestro país. En el área de las patentes farmacéuticas los cambios más relevantes serán, entre otros, que habrá periodos de vigencia más largos para las patentes y una protección reforzada de los datos clínicos, lo que sin duda judicializará aún más los temas farmacéuticos e impactará negativamente en los tiempos de otorgamiento de registros sanitarios de medicamentos genéricos y medicamentos biociomparables, afectando el acceso a medicamentos asequibles.

\section{Extensión de vigencia de patentes}

Actualmente, el periodo de vigencia de las patentes en México es de veinte años improrrogables, contados a partir de la presentación de la solicitud. ${ }^{57}$

Por las obligaciones establecidas en el TPP, el IMPI tendrá que extender la vigencia de las patentes cuando: a) se retrase injustificadamente en el otorgamiento de la patente, ${ }^{58} \mathrm{o}$ b) cuando Cofepris se demore injustificadamente en emitir el registro sanitario de un medicamento patentado. ${ }^{59}$ Sin duda, esta figura hará que sea más difícil para los fabricantes de medicamentos genéricos y biocomparables la obtención de autorizaciones de sus productos por parte de la Cofepris. Si no se legisla adecuadamente esta figura, los titulares de las patentes podrán manipular los tiempos en los que solicitarán dichas extensiones en forma estratégica para inhibir la competencia y ampliar sus monopolios. En cualquier caso, la inseguridad jurídica que crearán las extensiones podrá adquirir dimensiones mayúsculas.

\section{Protección extendida de los datos clínicos}

El TPP extenderá la protección de los datos clínicos contenida en el TLCAN y ADPIC. Por ejemplo, las disposiciones de ambos tratados limitan la protección de datos clínicos a los medicamentos de síntesis química, mien-

57 Ley de la Propiedad Industrial, artículo 23.

58 TPP, artículo 18.45. Esta obligación surtirá efectos en cuanto el Tratado entre en vigor (TPP, artículo 30.5).

59 TPP, artículo 18.48. México cuenta con un periodo de transición de 4.5 años a partir de la entrada en vigor del TPP para implementar dicho artículo (TPP, artículo 18.83.4.c.iii). 
Esta obra forma parte del acervo de la Biblioteca Jurídica Virtual del Instituto de Investigaciones Jurídicas de la UNAM

tras que el TPP incluye la protección a cierto tipo de medicamentos biotecnológicos. ${ }^{60} \mathrm{El}$ lenguaje de las disposiciones es deliberadamente vago y con certeza fomentará litigios. ${ }^{61} \mathrm{El}$ potencial de litigios abusivos aumentará, a menos que el régimen legal doméstico de implementación logre aclarar el lenguaje y la redacción.

\section{CONCLUSIONES}

Este trabajo no es un alegato en contra del derecho de patentes o la industria farmacéutica de innovación. Las compañías innovadoras tienen derecho a un justo retorno económico por sus inversiones en materia de investigación y desarrollo. Sin embargo, debe recordarse que el monopolio creado por una patente es limitado y temporal, y debe estar plenamente justificado a la luz de los requisitos sustantivos impuestos en la Ley de la Propiedad Industrial.

Así como una protección insuficiente puede eventualmente desincentivar la investigación y desarrollo (aunque existen estudios serios que controvierten esta premisa), la sobreprotección de derechos de patente puede frenar la competencia legítima y limitar el acceso de los pacientes a medicamentos genéricos y biocomparables seguros, eficaces y a precios asequibles.

Las limitaciones presupuestales que suelen enfrentar las instituciones públicas de salud hacen indispensable un análisis holístico para aportar soluciones a corto, mediano y largo plazo que favorezcan la definición pertinente de las coberturas y el acceso universal de los pacientes a la salud, independientemente del régimen de atención al que estén o no afiliados.

Una exploración holística no puede omitir la normativa y prácticas relacionadas con la propiedad industrial y en especial con los temas aquí tratados (patentes, protección de datos clínicos, vinculación, etcétera). La realidad atestigua puntualmente cómo es cada vez más usada esta materia para favorecer escenarios con el principal propósito de crear barreras adicionales a la competencia. Lamentablemente, estos alcances son escasamente dimensionados por los decisores políticos, e incluso, por las autoridades jurisdiccionales competentes.

Es hora de desmitificar o al menos desmenuzar los discursos que acompañan a las compañías innovadoras, que difunden cifras millonarias supuestamente aplicadas a la investigación y desarrollo de sus productos, justifica-

60 TPP, artículo 18.52.

61 Un claro ejemplo de esta aseveración es, entre otros, el artículo 18.52 relativo a productos biológicos. 
Esta obra forma parte del acervo de la Biblioteca Jurídica Virtual del Instituto de Investigaciones Jurídicas de la UNAM

ción central en el incesante cabildeo para reforzar la propiedad industrial e inventar nuevos mecanismos de bloqueo.

Si la justificación a la sobreprotección de los derechos de propiedad industrial en materia farmacéutica es la inversión que requiere su generación, parecería justo y honesto exigir que se transparente la supuesta inversión que se realiza en el rubro de investigación y desarrollo para el descubrimiento de cada molécula nueva (incluidos los supuestos intentos fallidos debidamente documentados); la inversión que subyace a cada patente secundaria; la que sufraga (directamente) la empresa que se beneficia de la exclusividad de datos para la realización de los estudios clínicos que acreditan la seguridad y eficacia de cada medicamento innovador, etcétera. Inversiones todas ellas desglosadas y separadas de los demás gastos que suelen velarse en aquellas cifras multimillonarias, como, por ejemplo, los de publicidad y promoción médica, que nada tienen que ver con la razón que supuestamente justifica el escalamiento de la protección de los diversos regímenes de exclusividad que favorecen prioritariamente a la industria farmacéutica innovadora, no obstante las repercusiones en el costo y el acceso de los pacientes a insumos vitales.

Sin un honesto análisis, el sistema de patentes (y ahora también las exclusividades de otro tipo, como la protección o exclusividad de datos) se habrá convertido justamente en lo que se buscó evitar cuando se gestó el sistema de patentes a nivel internacional, y en el caso mexicano se insertó en el artículo 28 constitucional con un carácter excepcional y por tanto limitado.

El descubrimiento de nuevas moléculas ha decrecido. Las razones pueden ser varias. Las estrategias mencionadas que permiten extender la vida de los monopolios y exclusividades, difiriendo la necesidad de abrir nuevas líneas de investigación que conduzcan a innovaciones sustanciales, pueden ser sin duda una de ellas.

Las patentes secundarias que no protejan verdaderas innovaciones juegan un papel inevitablemente negativo. Desaceleran la innovación del titular de la patente primaria, que puede obtener réditos sobre variantes de la misma innovación primaria por periodos de tiempo más prolongados, sin necesidad de incurrir en gastos ni riesgos mayores; desincentivan la inversión e innovación de competidores; atentan contra el más esencial y valioso de los principios que sostiene el sistema de patentes a nivel mundial: el otorgamiento por parte del Estado de un monopolio temporal a cambio de la aportación y divulgación del conocimiento innovador, no obvio y útil en beneficio de la sociedad. Una patente superflua o dudosa simplemente no aporta nada a la sociedad y, sin embargo, sí le traslada el costo resultante del monopolio. 
Esta obra forma parte del acervo de la Biblioteca Jurídica Virtual del Instituto de Investigaciones Jurídicas de la UNAM

\section{BIBLIOGRAFÍA}

Bonilla-Chacín, M. E. y Aguilera, Nelly, México. El sistema de protección social en salud, Washington D. C., Banco Mundial, 2013.

Comisión Europea, Executive Summary of the Pharmaceutical Sector Inquiry Report, 2009.

COMISIÓn Federal PARA LA PROTEGGión CONTRA RiEsgos SANITARIOS, Política de genéricos del gobierno de la República, marzo de 2015, disponible en: http://wrere.cofepris.gob.mx/Documents/NotasPrincipales/26032015_2.pdf.

DíAz EcheverríA, Daniela, "Los recortes en salud para el 2016", El Universal, México, disponible en: http://wrere.eluniversal.com.mx/blogs/fundar/ 2015/11/28/los-recortes-en-salud-para-el-2016.

Fundación MeXicana PaRa la SALud, Descripción del sector farmacéutico en México 2013, México, Funsalud, 2013.

Instituto MEXicano DE LA PROPIEDAD INDUSTRIAL, IMPI en cifras 2016 , México, IMPI, 2016.

Instituto Mexicano Del Seguro Social, Transparencia, competencia y certidumbre generan importantes ahorros al sector salud en compra consolidada de medicamentos, vacunas y material de curación, boletín de prensa, 12 de enero de 2016.

Instituto Nacional de Estadística y GeOgRAFía, Anuario estadístico y geográfico de los Estados Unidos Mexicanos 2015, México, INEGI, 2015.

KAPCZYNSKI, Amy et al., "Polymorphs and Prodrugs and Salts (Oh My!): An Empirical Analysis of «Secondary» Pharmaceutical Patents", PloS ONE, núm. 7, diciembre de 2012.

Organización Mundial de la Propiedad InTelectual, Organización Mundial de la Propiedad Intelectual, indicadores 2015, Ginebra, OMPI, 2015.

ORGANIZACIÓN PARA LA COOPERAGiÓN Y EL DESARROLLO ECONÓMICOS, OECD Reviewes of Health Systems: Mexico, París, OCDE, 2016.

PRESIDENCIA DE LA REPÚBLICA, El gobierno de la República cuenta con una estrategia de contratación pública: EPN, boletín de prensa, 8 de julio de 2013.

Secretaría de Hacienda y Crédito Público, Proyecto de Presupuesto de Egresos de la Federación 2016, México, Secretaría de Hacienda y Crédito Público, versión ciudadana, 2015, disponible en: http://wrerc.transpa renciapresupuestaria.gob.mx/work/models/PTP/Presupuesto/Presupuestacion/ ppef2016.pdf. 
United Nations, World Population Prospects: The 2015 Revision, Key Findings and Advance Tables, Nueva York-Ginebra, United Nations, Department of Economic and Social Affairs, Population Division, ESA/P/WP.241., 2015.

VALENCIA HeRnÁNDEZ, Armando, Sistema de vinculación-regulación sanitaria y la propiedad industrial, disponible en: http://revere.amegi.com.mx/pdf/curso_practico/ vinculacion_cofepris_impi_2014.pdf. 
Industria farmacéutica, derecho a la salud y propiedad intelectual: el reto del equilibrio, editado por el Instituto de Investigaciones Jurídicas de la UNAM, se terminó de imprimir el 28 de febrero de 2018 en los talleres de Desarrollo Gráfico Editorial, S. A. de C. V., Municipio Libre 175-A, colonia Portales, delegación Benito Juárez, 03300 Ciudad de México, tel. 5601 0796. Se utilizó tipo Baskerville en 9, 10 y 11 puntos. En esta edición se empleó papel cream book 70 x 95 de 60 gramos para los interiores y cartulina couché de 250 gramos para los forros. Consta de 1,000 ejemplares (impresión offset). 


\section{Este libro se refiere a uno de los temas más importan-}

tes no sólo para la academia sino para las políticas públicas de los Estados: el acceso de la población a la salud. Con el cambio de paradigma, en la década de los años noventa, en la protección de la propiedad intelectual que incluye a las patentes farmacéuticas, los Estados, como México, sufrieron un fuerte impacto en varias áreas de su economía. En principio, en el precio de los farmacéuticos y, por supuesto, en el acceso a la salud; después en lo que toca a la industria nacional de farmacéuticos, que tiene que ver también con el tema anterior de acceso a los medicamentos y con el desarrollo de una soberanía de la salud del Estado mexicano.

Por otra parte, es evidente la tendencia en los tratados intemacionales en materia de libre comercio la protección de las invenciones farmacéuticas, vía el reforzamiento de la normatividad en materia de propiedad intelectual. Con lo cual convergen tres temas fundamentales: industria farmacéutica, derecho a la salud y propiedad intelectual, que se colocan en el centro de la preocupación del Estado contemporáneo.

En este libro se incluyen las reflexiones de varios expertos, de gran prestigio, en propiedad intelectual de nuestro continente. 